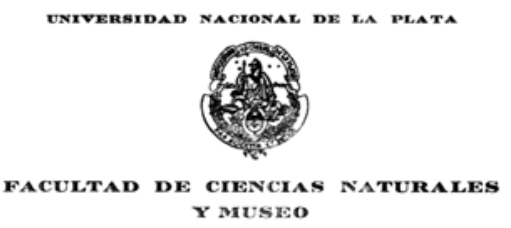

Zooarqueología del Sur de los Valles Calchaquíes: Estudio de conjuntos faunísticos del Período Formativo.

Andrés Darío Izeta

Tesis para optar al grado académico de

Doctor en Ciencias Naturales

Directora de Tesis:

Dra. Laura Lucía Miotti 
Esta Tesis está especialmente dedicada a las dos personas más importantes de mi vida, las que compartieron todo el proceso en las buenas y en las malas. Roxana, mi esposa y Mercedes nuestra hija. 
Índice

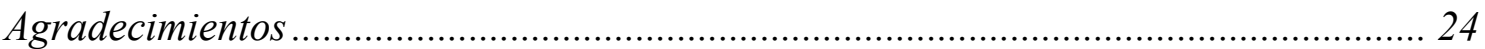

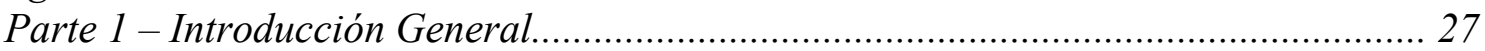

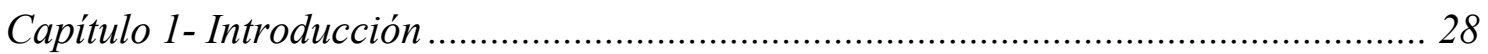

1.1. Antecedentes arqueológicos del área y de estudios faunísticos en el noroeste

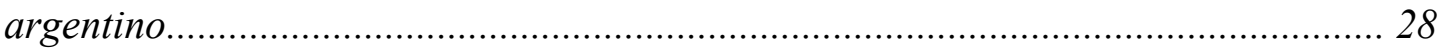

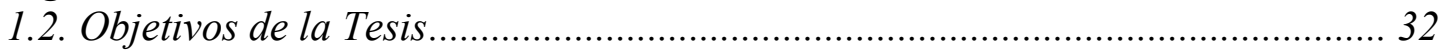

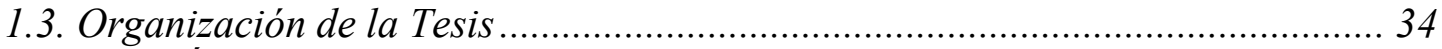

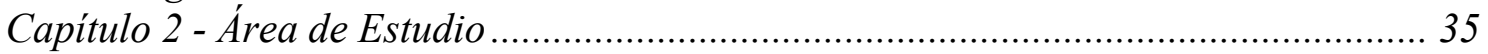

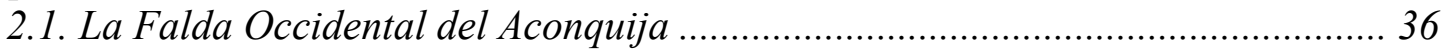

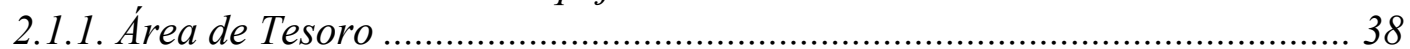

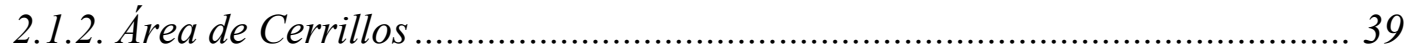

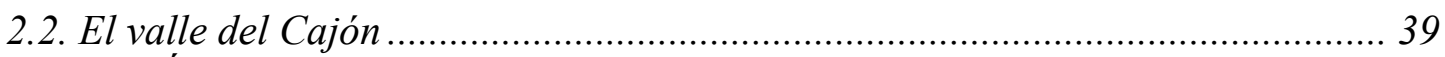

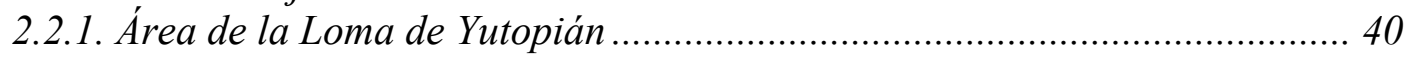

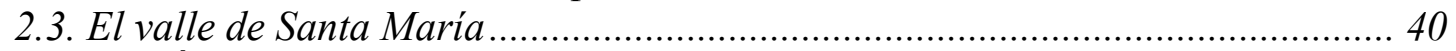

2.3.1. Área de El Bañado.................................................................................... 41

2.3.2. Área de Pajanguillo................................................................................. 41

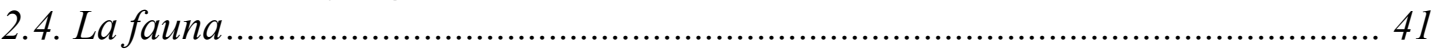

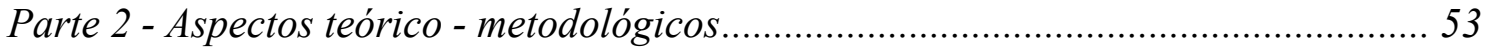

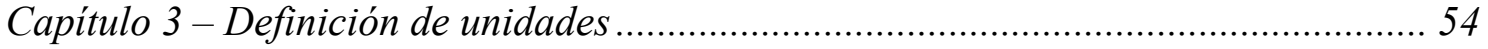

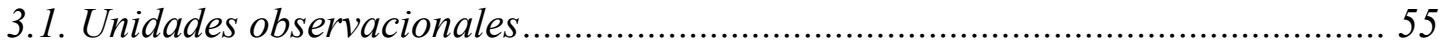

3.1.1. Identificación y registro del material óseo a nivel elemento........................ 55

3.1.2. Identificación y registro del material óseo de camélidos a nivel taxonómico

3.1.3. Identificación interespecífica por medio de las falanges proximales ........... 56

3.1.4. Identificación interespecífica de elementos postcraneales de camélidos. ... 57

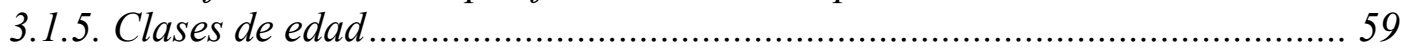

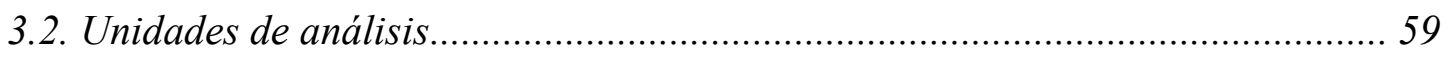

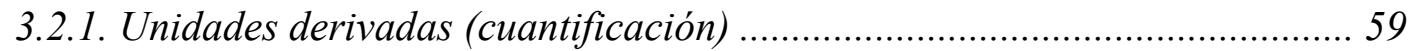

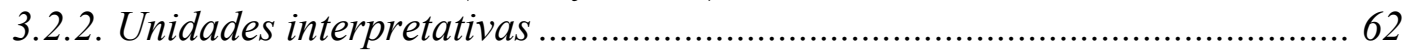

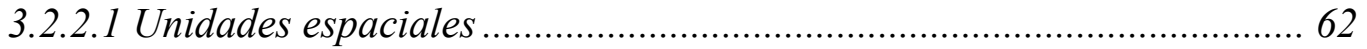

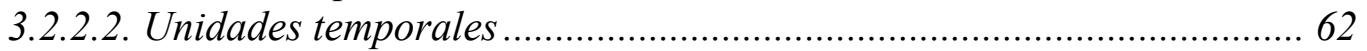

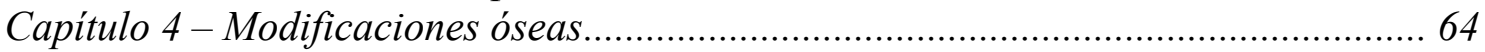

4.1. Aproximación tafonómica-modificaciones naturales ...................................... 64

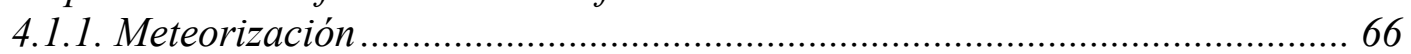

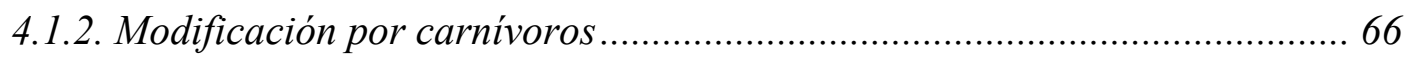

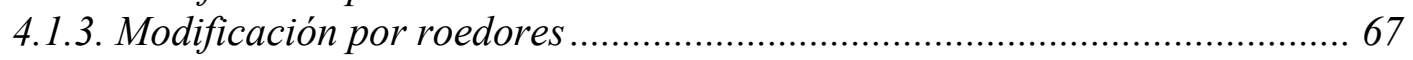

4.1.4. Supervivencia del material óseo mediada por la densidad ósea ................. 67

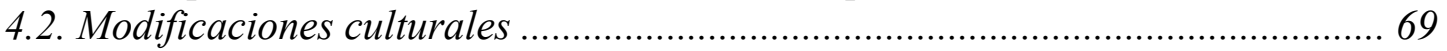

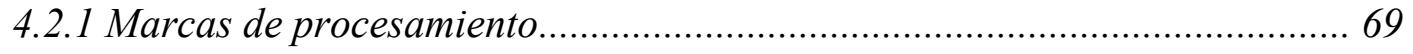

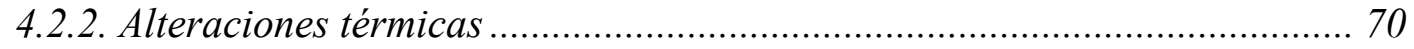

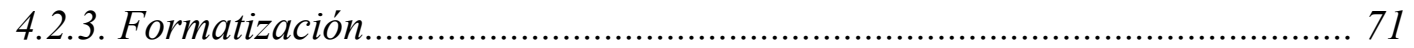

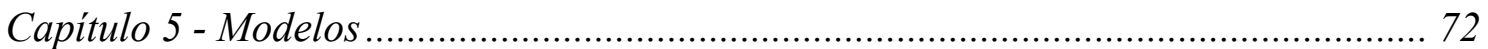

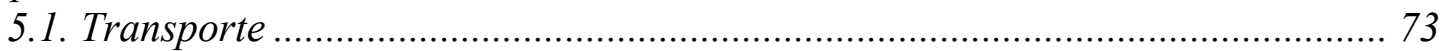

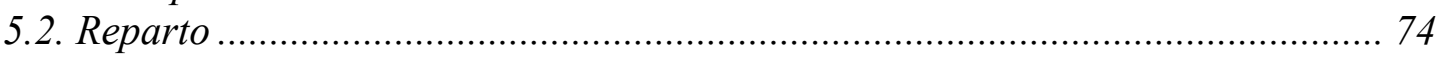

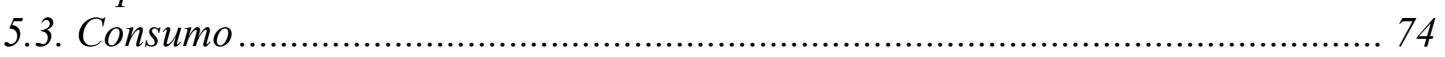

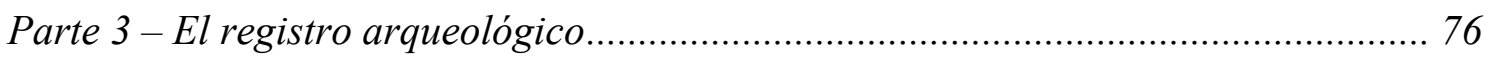

Capítulo 6 - Sitios arqueológicos del sur de los valles Calchaquíes ............................ 77 


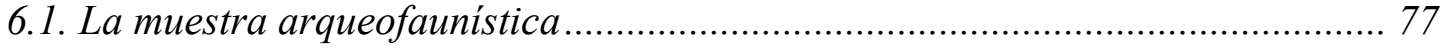

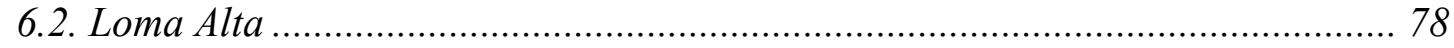

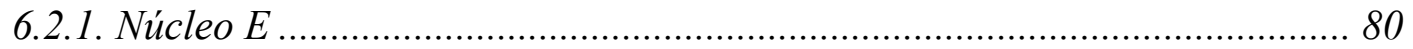

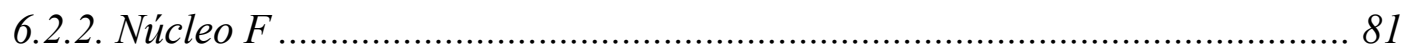

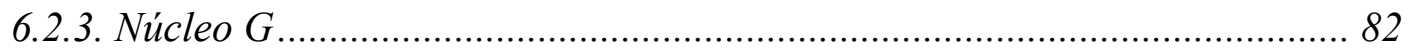

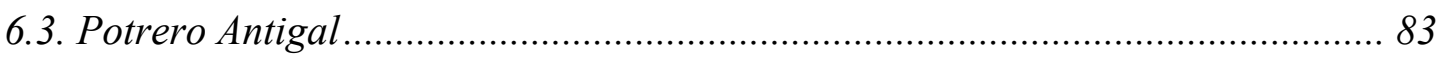

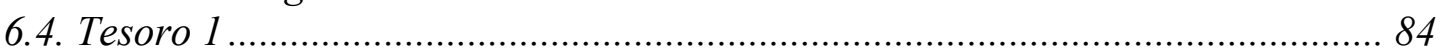

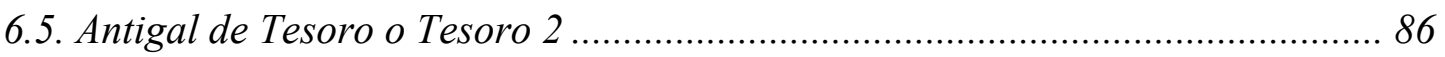

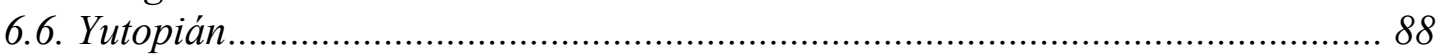

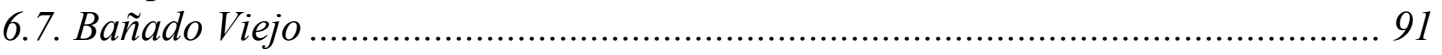

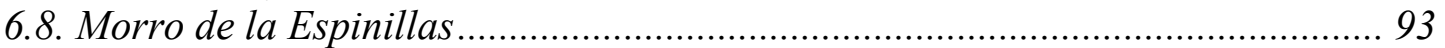

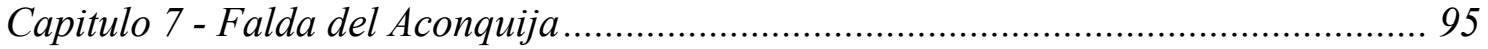

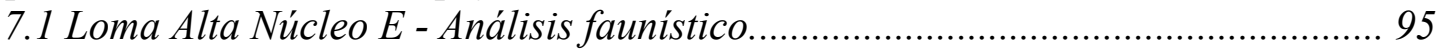

7.1.1. Análisis del subconjunto de camélidos..................................................... 101

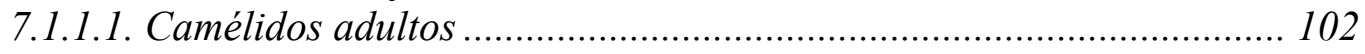

7.1.1.1.a. Supervivencia del material óseo mediada por la densidad ósea.. 103

7.1.1.1.b. Número Mínimo de Elementos (MNE) ......................................... 103

7.1.1.1.c. Número Mínimo de Individuos (MNI) ...................................... 114

7.1.1.1.d. Unidades anatómicas representadas (MAU) ........................... 115

7.1.1.1.e. Fragmentación del subconjunto .............................................. 117

7.1.1.1.f. Utilización de las carcasas........................................................ 120

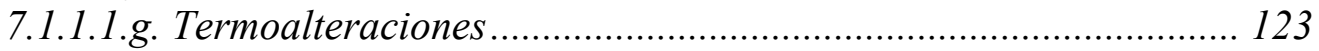

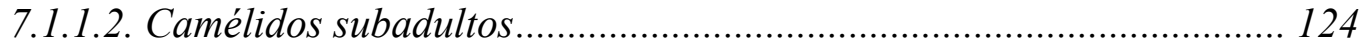

7.1.1.2.a. Supervivencia del material óseo mediada por la densidad ósea.. 125

7.1.1.2.b. Número Mínimo de Elementos (MNE) ........................................ 125

7.1.1.2.c. Número Mínimo de Individuos (MNI) ....................................... 130

7.1.1.2.d. Unidades anatómicas representadas (MAU) ............................ 131

7.1.1.2.e. Fragmentación del subconjunto .............................................. 133

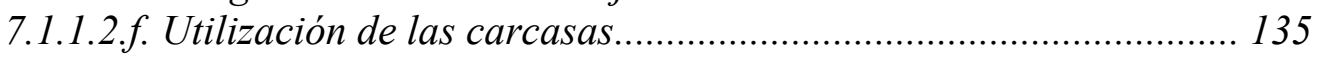

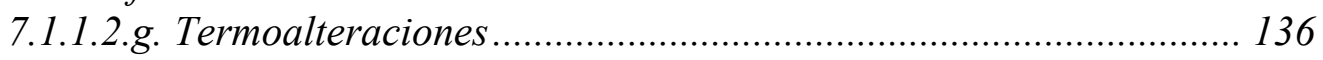

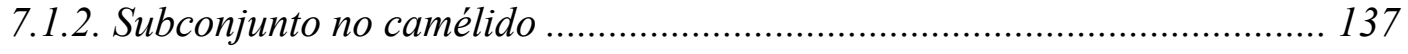

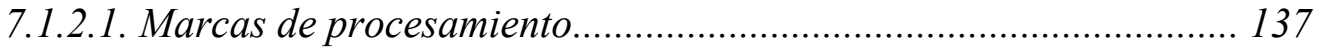

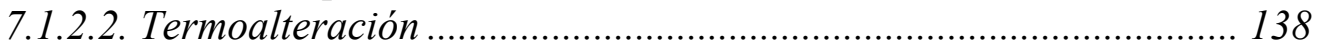

7.1.2.3. Fragmentación del subconjunto de no camélidos. ......................... 139

7.2. Loma Alta Núcleo F-Análisis faunístico........................................................ 141

7.2.1. Análisis del subconjunto de camélidos.................................................. 144

7.2.1.1. Camélidos adultos ........................................................................... 145

7.2.1.1.a. Supervivencia del material óseo mediada por la densidad ósea.. 145

7.2.1.1.b. Número Mínimo de Elementos (MNE) ......................................... 145

7.2.1.1.c. Número Mínimo de Individuos (MNI) ....................................... 152

7.2.1.1.d. Unidades anatómicas representadas (MAU) ............................ 152

7.2.1.1.e. Fragmentación del subconjunto .............................................. 154

7.2.1.1.f. Utilización de las carcasas.......................................................... 156

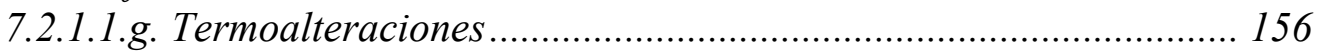

7.2.1.2. Camélidos subadultos....................................................................... 157

7.2.1.2.a. Supervivencia del material óseo mediada por la densidad ósea.. 157

7.2.1.2.b. Número Mínimo de Elementos (MNE) ...................................... 158

7.2.1.2.c. Número Mínimo de Individuos (MNI) ........................................ 159

7.2.1.2.d. Unidades anatómicas representadas (MAU) ............................. 159

7.2.1.2.e. Fragmentación del subconjunto ............................................... 159 
7.2.1.2.f. Utilización de las carcasas............................................................ 160

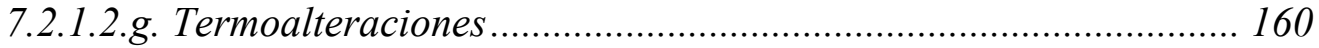

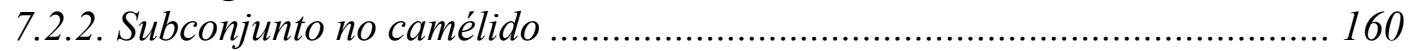

7.2.2.1. Marcas de procesamiento y relacionadas con el uso de huesos como

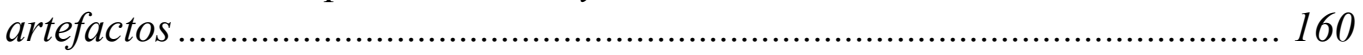

7.2.2.3. Fragmentación del subconjunto de no camélido............................... 161

7.3 Loma Alta Núcleo G-Análisis faunístico....................................................... 163

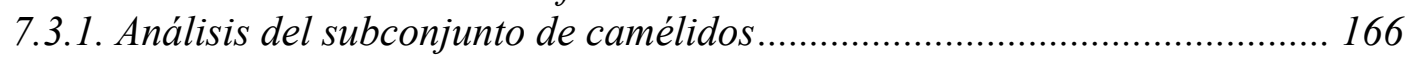

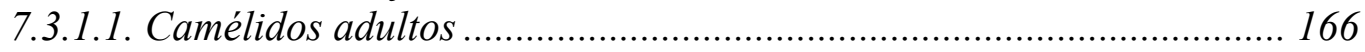

7.3.1.1.a. Supervivencia del material óseo mediada por la densidad ósea.. 166

7.3.1.1.b. Número Mínimo de Elementos (MNE) ........................................ 167

7.3.1.1.c. Número Mínimo de Individuos (MNI) ....................................... 169

7.3.1.1.d. Unidades anatómicas representadas (MAU) ............................ 169

7.3.1.1.e. Fragmentación del subconjunto ................................................... 169

7.3.1.1.f. Termoalteraciones........................................................................ 170

7.3.1.2. Camélidos subadultos....................................................................... 171

7.3.1.2.a. Supervivencia del material óseo mediada por la densidad ósea.. 171

7.3.1.2.b. Número Mínimo de Elementos (MNE) ...................................... 171

7.3.1.2.c. Número Mínimo de Individuos (MNI) ...................................... 173

7.3.1.2.d. Fragmentación del subconjunto ............................................... 173

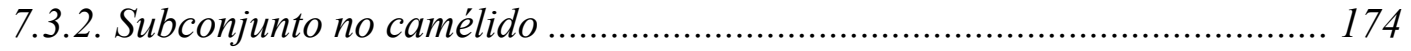

7.3.2.1. Marcas de procesamiento primario y secundario (Impactos) ........... 174

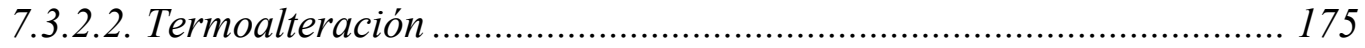

7.3.2.3. Fragmentación del subconjunto de no camélidos. ............................. 175

7.4. Potrero Antigal - Análisis faunístico .......................................................... 177

7.4.1. Análisis del subconjunto Tamaño Corporal 4...................................... 178

7.4.1.1. Fragmentación del conjunto.............................................................. 179

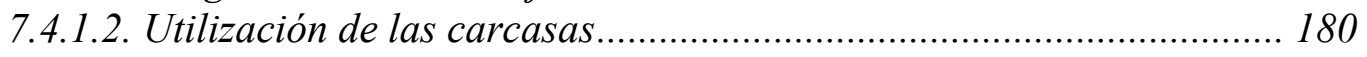

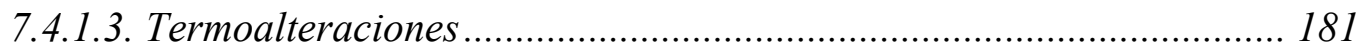

7.4.2. Subconjunto no camélido (otros tamaños corporales)............................ 181

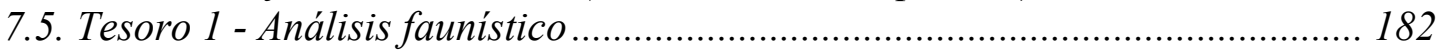

7.6. Antigal de Tesoro o Tesoro 2 - Análisis faunístico ........................................ 183

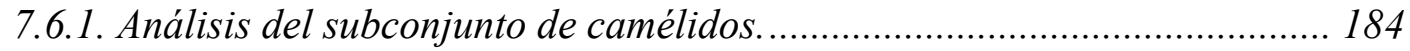

7.6.1.1. Camélidos adultos ............................................................................ 184

7.6.1.1.a. Supervivencia del material óseo mediada por la densidad ósea.. 184

7.6.1.1.b. Número Mínimo de Elementos (MNE) ....................................... 185

7.6.1.1.c. Número Mínimo de Individuos (MNI) ...................................... 186

7.6.1.1.d. Unidades anatómicas representadas (MAU) ............................ 186

7.6.1.1.e. Fragmentación del subconjunto .............................................. 187

7.6.1.1.f. Utilización de las carcasas y Termoalteraciones......................... 188

7.6.1.2. Camélidos subadultos.................................................................. 188

7.6.1.2.a. Supervivencia del material óseo mediada por la densidad ósea.. 188

7.6.1.2.b. Número Mínimo de Elementos (MNE) ........................................ 189

7.6.1.2.c. Número Mínimo de Individuos (MNI) ........................................ 189

7.6.1.2.d. Fragmentación del subconjunto ................................................. 189

7.6.1.2.e. Utilización de las carcasas y termoalteración ............................ 190

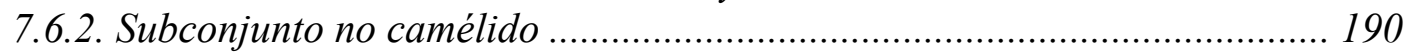

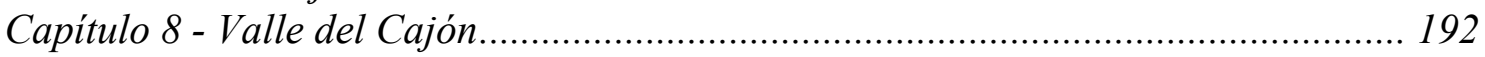

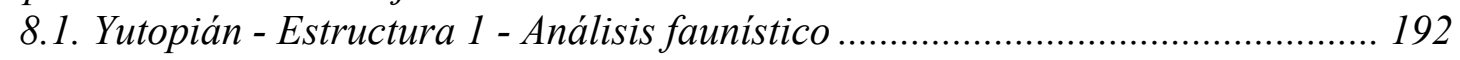

8.1.1. Análisis del Subconjunto Camelidae .................................................... 194 


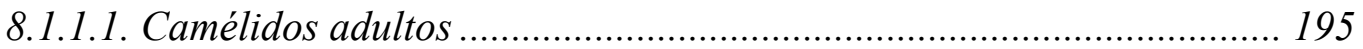

8.1.1.1.a. Supervivencia del material óseo mediada por la densidad ósea.. 195

8.1.1.1.b. Número Mínimo de Elementos (MNE) ........................................ 196

8.1.1.1.c. Número Mínimo de Individuos (MNI) ........................................ 204

8.1.1.1.d. Unidades anatómicas representadas (MAU) .............................. 204

8.1.1.1.e. Fragmentación del subconjunto ................................................. 206

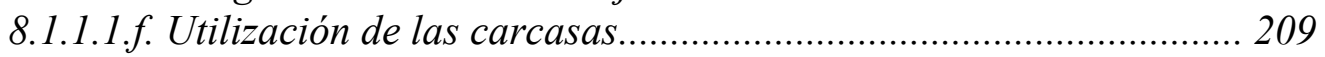

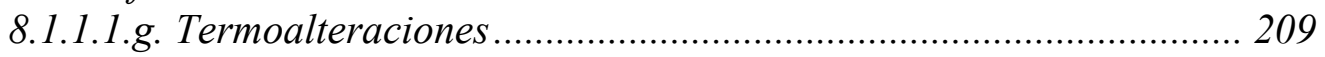

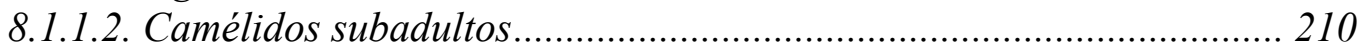

8.1.1.2.a. Supervivencia del material óseo mediada por la densidad ósea.. 210

8.1.1.2.b. Número Mínimo de Elementos (MNE) ........................................ 210

8.1.1.2.c. Número Mínimo de Individuos (MNI) ......................................... 213

8.1.1.2.d. Unidades anatómicas representadas (MAU) ............................ 213

8.1.1.2.e. Fragmentación del subconjunto ................................................... 214

8.1.1.2.f. Utilización de las carcasas........................................................ 214

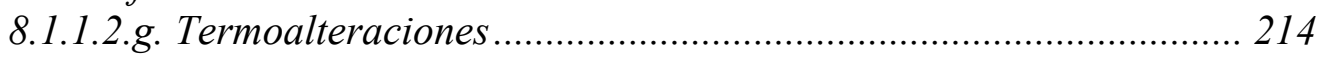

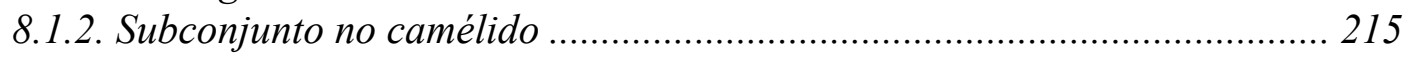

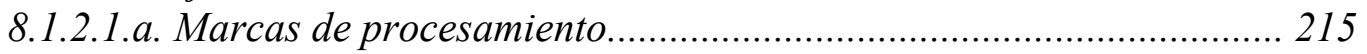

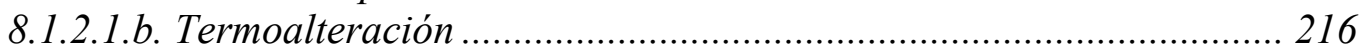

8.1.2.1.c. Fragmentación del conjunto no camélido ...................................... 216

8.2. Yutopián - Patio de Núcleo 1 - Análisis faunístico.......................................... 218

8.2.1. Análisis del Subconjunto Camelidae .................................................... 219

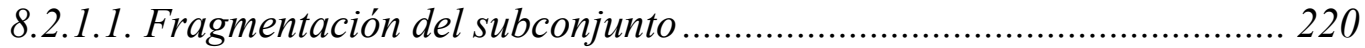

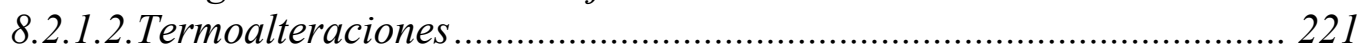

8.2.2. Subconjunto no camélido (otros tamaños corporales)............................... 221

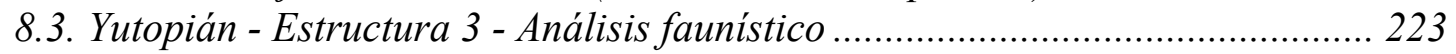

8.3.1. Análisis del subconjunto de camélidos.................................................. 225

8.3.1.1. Camélidos adultos ........................................................................... 226

8.3.1.1.a. Supervivencia del material óseo mediada por la densidad ósea.. 226

8.3.1.1.b. Número Mínimo de Elementos (MNE) ..................................... 226

8.3.1.1.c. Número Mínimo de Individuos (MNI) .......................................... 233

8.3.1.1.d. Unidades anatómicas representadas (MAU) ............................ 233

8.3.1.1. e. Fragmentación del subconjunto ............................................... 235

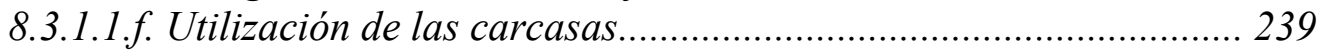

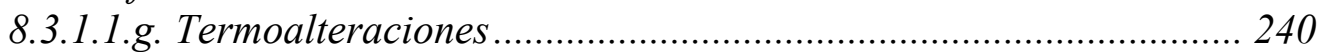

8.3.1.2. Camélidos subadultos...................................................................... 240

8.3.1.2.a. Supervivencia del material óseo mediada por la densidad ósea.. 240

8.3.1.2.b. Número Mínimo de Elementos (MNE) ........................................ 241

8.3.1.2.c. Número Mínimo de Individuos (MNI) ........................................ 243

8.3.1.2.d. Unidades anatómicas representadas (MAU) ............................. 243

8.3.1.2. e. Fragmentación del subconjunto ............................................... 244

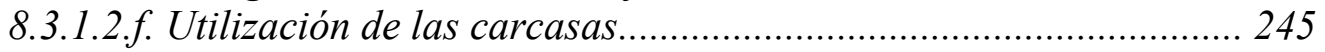

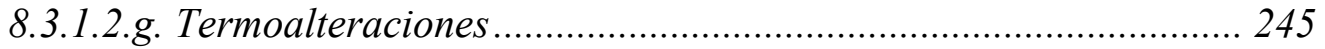

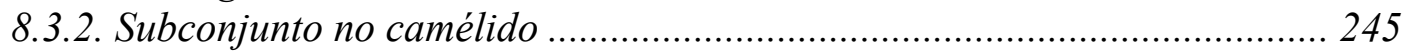

8.3.2.1. Marcas de procesamiento................................................................... 246

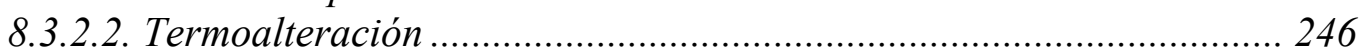

8.3.2.3. Fragmentación del conjunto no camélido ......................................... 247

8.4. Yutopián - Estructura 4-Ocupación Superior - Análisis faunístico .................. 248

8.4.1. Análisis del subconjunto de camélidos................................................. 250

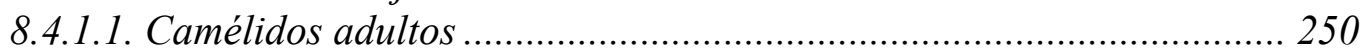


8.4.1.1.a. Supervivencia del material óseo mediada por la densidad ósea.. 250

8.4.1.1.b. Número Mínimo de Elementos (MNE) ..................................... 251

8.4.1.1.c. Número Mínimo de Individuos (MNI) ....................................... 259

8.4.1.1.d. Unidades anatómicas representadas (MAU) ............................. 259

8.4.1.1.d. Fragmentación del subconjunto ............................................... 261

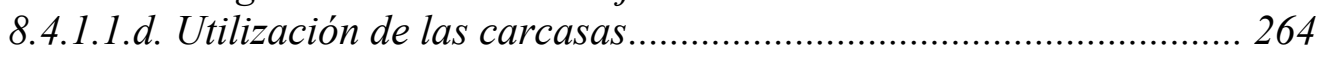

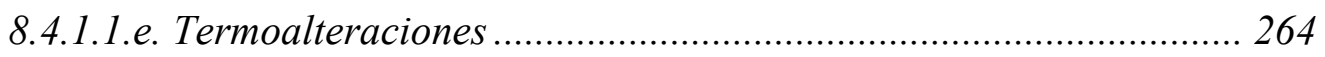

8.4.1.2. Camélidos subadultos.......................................................................... 265

8.4.1.2.a. Supervivencia del material óseo mediada por la densidad ósea.. 265

8.4.1.2.b. Número Mínimo de Elementos (MNE) ...................................... 265

8.4.1.2.b. Número Mínimo de Individuos (MNI) ......................................... 268

8.4.1.2.c. Unidades anatómicas representadas (MAU)............................... 268

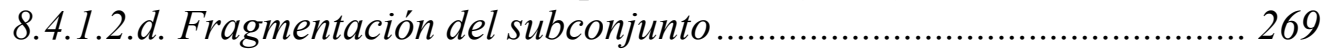

8.4.1.2.e. Utilización de las carcasas ........................................................... 269

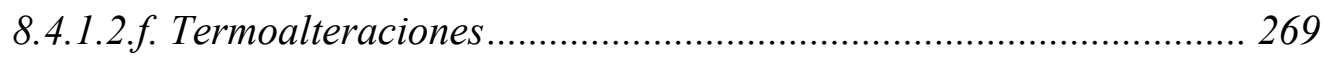

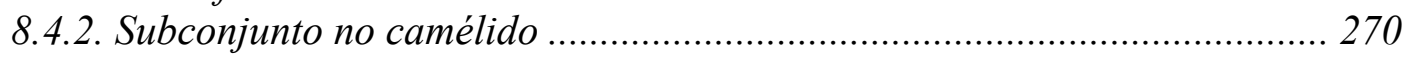

8.4.2.1. Marcas de procesamiento............................................................. 270

8.4.2.1. Termoalteración ................................................................................ 270

8.4.2.2. .Fragmentación del conjunto no camélido ...................................... 271

8.5. Estructura 4 - Ocupación Inferior - Análisis faunístico................................. 272

8.5.1. Análisis del subconjunto de camélidos.................................................. 273

8.5.1.1. Número Mínimo de Elementos (MNE) .......................................... 273

8.5.1.2. Numero Mínimo de Individuos (MNI) ............................................ 274

8.5.1.3. Unidades anatómicas representadas (MAU) ..................................... 274

8.5.1.4. Fragmentación del subconjunto ...................................................... 275

8.5.1.5. Utilización de las carcasas.............................................................. 275

8.5.1.6. Termoalteraciones ............................................................................ 275

8.5.2. Subconjunto no camélido (otros tamaños corporales)............................. 275

8.6. Yutopián - Estructura 5 - Análisis faunístico .............................................. 277

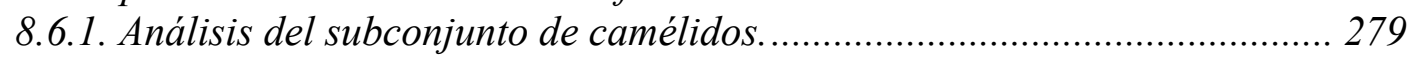

8.6.1.1. Camélidos adultos ............................................................................. 280

8.6.1.1.a. Supervivencia del material óseo mediada por la densidad ósea.. 280

8.6.1.1.b. Número Mínimo de Elementos (MNE) ........................................ 280

8.6.1.1.c. Número Mínimo de Individuos (MNI) ......................................... 285

8.6.1.1.d. Unidades anatómicas representadas (MAU) ............................. 285

8.6.1.1.e. Fragmentación del subconjunto ............................................... 287

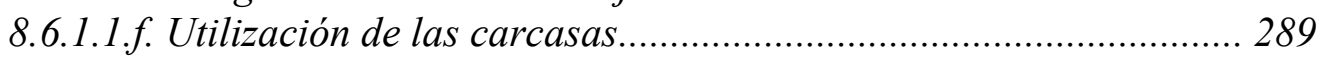

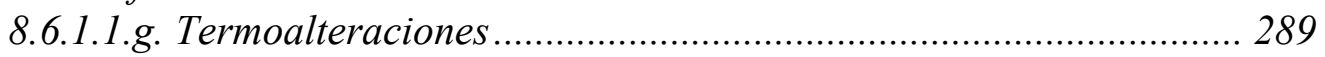

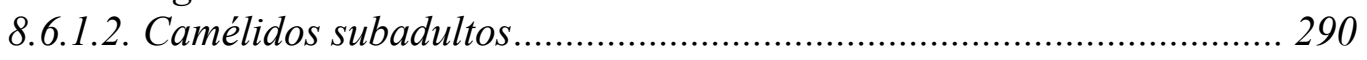

8.6.1.2.a. Supervivencia del material óseo mediada por la densidad ósea.. 290

8.6.1.2.b. Número Mínimo de Elementos (MNE) ........................................ 291

8.6.1.2.c. Número Mínimo de Individuos (MNI) .......................................... 293

8.6.1.2.d. Unidades anatómicas representadas (MAU) ............................. 293

8.6.1.2.e. Fragmentación del subconjunto .................................................. 294

8.6.1.2.f. Utilización de las carcasas y termoalteraciones.......................... 294

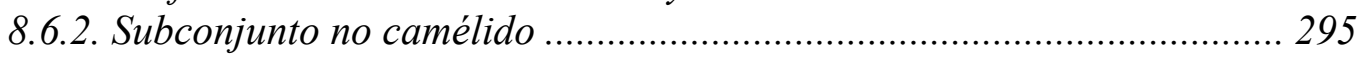

8.6.2.1. Marcas de procesamiento.................................................................. 295

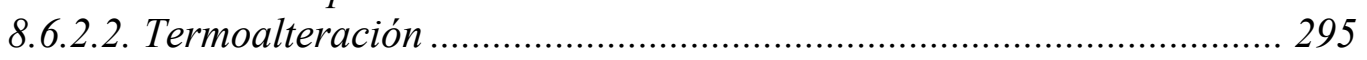

8.6.2.3. Fragmentación del conjunto no camélido ........................................ 296

8.7. Yutopián - Estructura 11 - Análisis faunístico ............................................... 297 


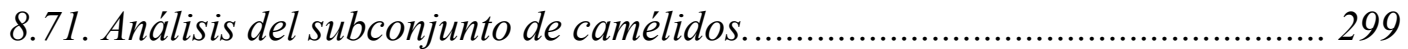

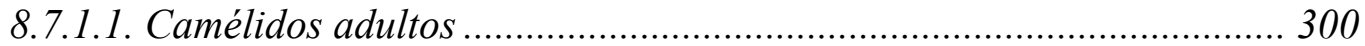

8.7.1.1.a. Supervivencia del material óseo mediada por la densidad ósea.. 300

8.7.1.1.b. Número Mínimo de Elementos (MNE) ......................................... 301

8.7.1.1.c. Número Mínimo de Individuos (MNI) ......................................... 308

8.7.1.1.d. Unidades anatómicas representadas (MAU) ............................. 308

8.7.1.1.e. Fragmentación del subconjunto ............................................... 310

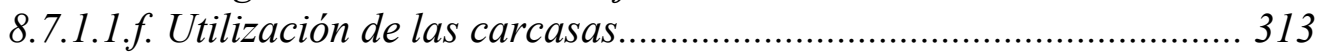

8.7.1.1.g. Termoalteraciones................................................................... 313

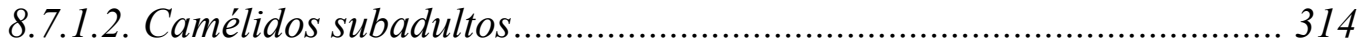

8.7.1.2.a. Supervivencia del material óseo mediada por la densidad ósea.. 314

8.7.1.2.b. Número Mínimo de Elementos (MNE) ........................................ 315

8.7.1.2.c. Número Mínimo de Individuos (MNI) ...................................... 318

8.7.1.2.d. Unidades anatómicas representadas (MAU) ............................. 318

8.5.1.2.e. Fragmentación del subconjunto ................................................... 319

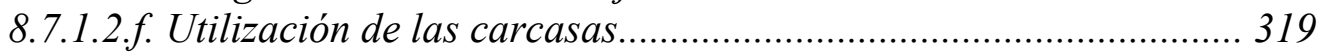

8.7.1.2.g. Termoalteraciones .................................................................... 319

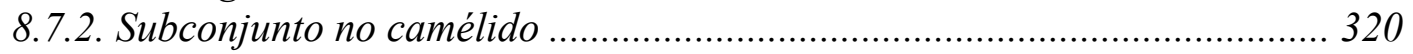

8.7.2.1. Marcas de procesamiento................................................................. 320

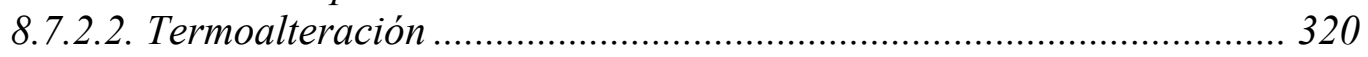

8.7.2.3. Fragmentación del conjunto no camélido ........................................ 321

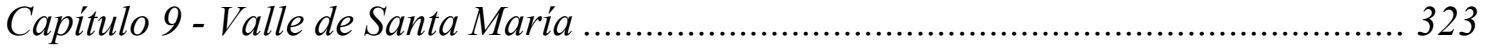

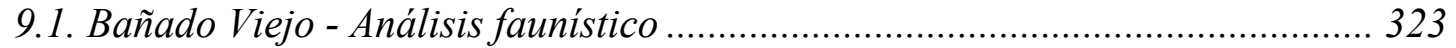

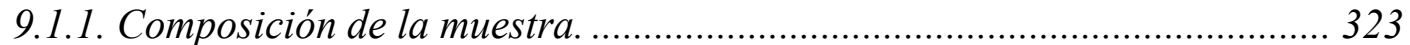

9.1.2. Aspectos tafonómicos por Depósito ........................................................ 324

9.1.3. Marcas de corte, impacto e instrumentos................................................. 325

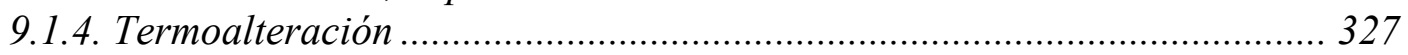

9.2. Morro de las Espinillas - Análisis faunístico ................................................. 328

9.2.1. Subconjunto de tamaño corporal 4 ........................................................ 328

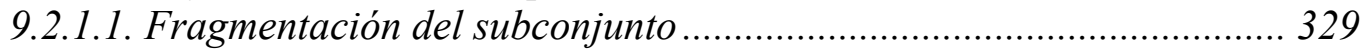

9.2.1.2. Utilización de las carcasas y termoalteraciones................................ 329

9.2.2. Subconjunto no camélido (otros tamaños corporales).............................. 329

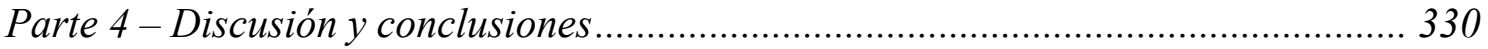

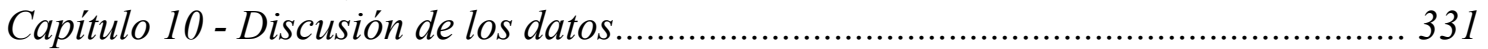

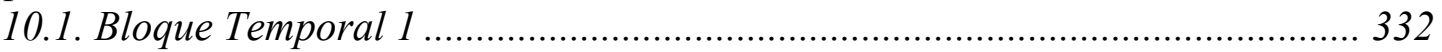

10.1.1. Yutopián Estructura 11...................................................................... 332

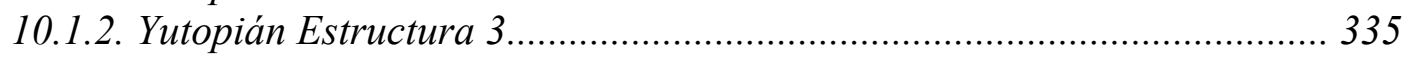

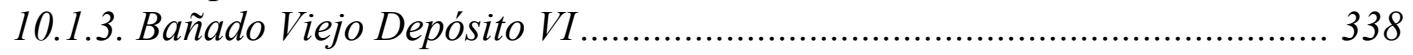

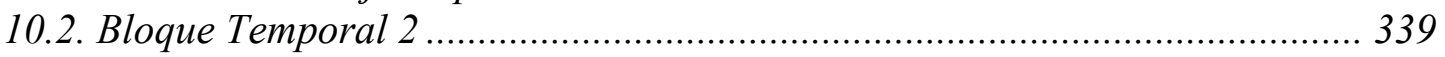

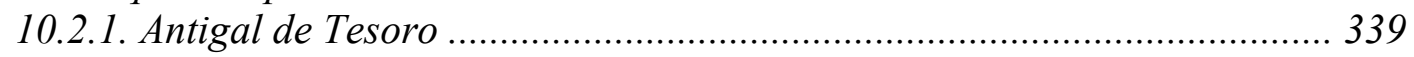

10.2.2. Yutopián Estructura 4 - Ocupación inferior .......................................... 340

10.2.3. Yutopián Estructura 4 - Ocupación superior ........................................ 341

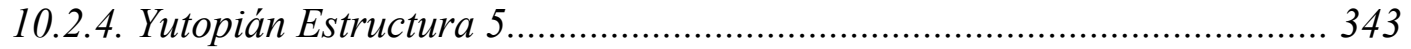

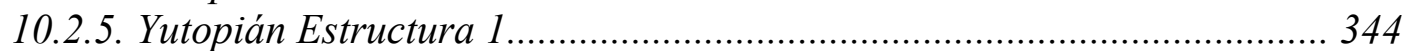

10.2.6. Yutopián Estructura Patio Núcleo1......................................................... 346

10.2.7. Loma Alta Núcleo E......................................................................... 347

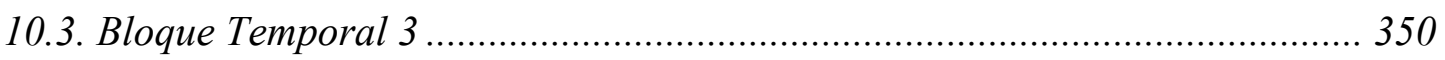

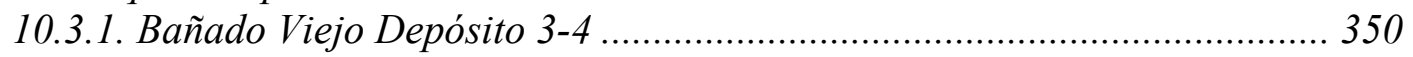

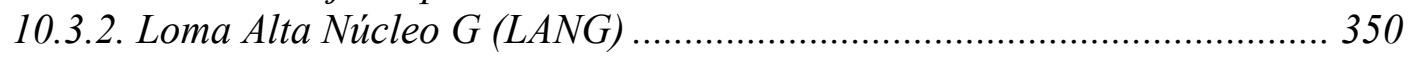

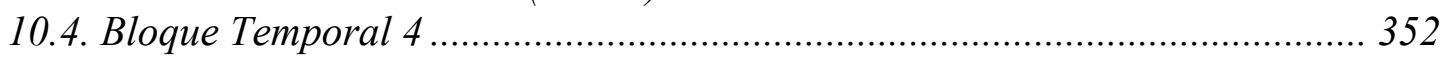




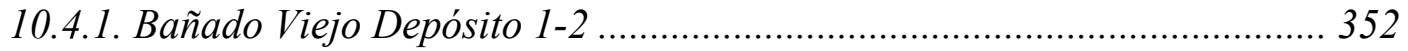

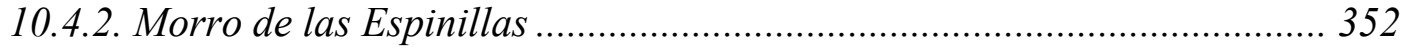

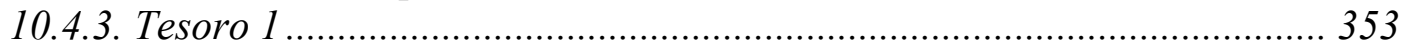

10.4.4. Loma Alta Núcleo F.............................................................................. 354

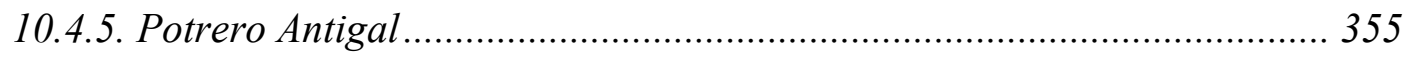

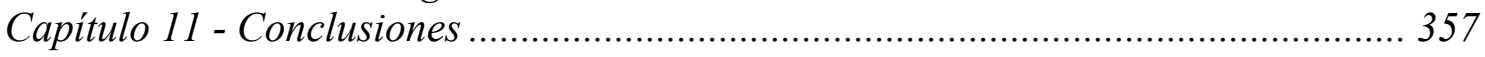

11.1 Resultados obtenidos en relación con aspectos metodológicos ...................... 357

11.1.1. Reevaluación comparativa de las muestras disponibles para establecer la relación componente de caza vs. pastoreo con el objeto de establecer las diferencias

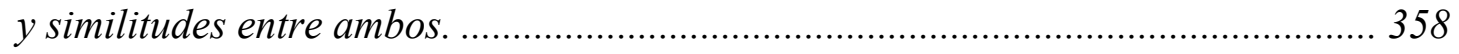

11.1.2. Profundización en el conocimiento de los patrones de fracturas. ............... 358

11.1.3. Características de los cortes y marcas, con especial interés en la determinación de patrones. ................................................................................ 359

11.1.4. Resultados de la aplicación del software de GIS para la cuantificación de elementos óseos versus métodos tradicionales....................................................... 359

11.2. Resultados obtenidos en relación con el análisis de la arqueofauna. .............. 361

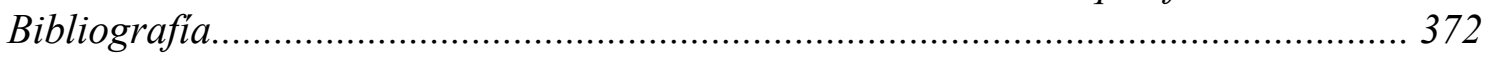

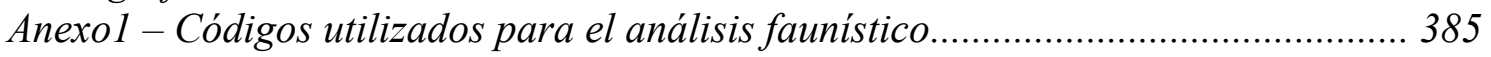

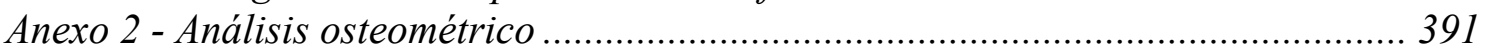

Códigos utilizados en el análisis osteométrico................................................ 430 


\section{Índice de Tablas}

Tabla 3.1. Listado tamaños corporales y de animales más frecuentes en la región en estudio.

Tabla 5.1. Resumen de procesos a los que estaría sometido un elemento óseo. Tomado

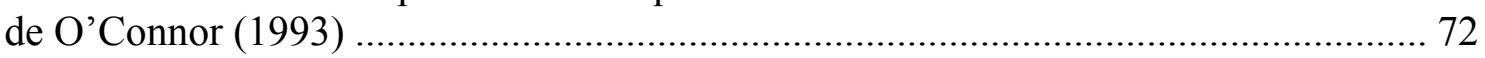

Tabla 6.1. Fechados radiocarbónicos Loma Alta Recinto 47 (Scattolin 2001).............. 80

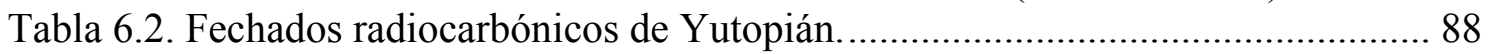

Tabla 6.3. Fechados radiocarbónicos Bañado Viejo. Tomado de Izeta y Scattolin 2001.

Tabla 7.2. Composición del conjunto faunístico del Recinto 44....................................96

Tabla 7.3. Composición del conjunto faunístico del Recinto 46....................................97

Tabla 7.4. Composición del conjunto faunístico del Recinto 47................................... 98

Tabla 7.5. Meteorización del conjunto faunístico del Núcleo E. Loma Alta ................. 99

Tabla 7.6. Modificaciones por agentes naturales. Núcleo E, Loma Alta. ..................... 100

Tabla 7.7. Camelidae, huesos del esqueleto axial y apendicular. Núcleo E, Loma Alta.

Tabla 7.8. Correlación entre el \%MAU y la densidad ósea. ....................................... 103

Tabla 7.9. Abundancia relativa de partes esqueletarias expresadas como NISP, MNE comprehensivo, MNI, MAU y \%MAU. Loma Alta, Núcleo E................................... 113

Tabla 7.10. Marcas en hueso de camélidos adultos expresado en NISP ..................... 121

Tabla 7.11. Termoalteración del conjunto de camélidos adultos. ............................... 123

Tabla 7.12. Relación entre tipo de termoalteración y tipo de fractura del conjunto de camélidos adultos. Loma Alta, Núcleo E. .................................................................... 124

Tabla 7.13. Correlación entre el \%MAU y la densidad ósea. .................................... 125

Tabla 7.14. Abundancia relativa de partes esqueletarias expresadas como NISP, MNE

comprehensivo, MAU y \%MAU. D = derecho, $\mathrm{I}=$ izquierdo, $\mathrm{S} / \mathrm{D}=$ axial o sin datos 130

Tabla 7.15. Marcas en huesos de camélido subadulto expresado en NISP................ 135

En general las huellas de procesamiento se presentan en frecuencias bajas y todas

referirían a etapas de procesamiento primario (de extracción de carne) o secundarios (de

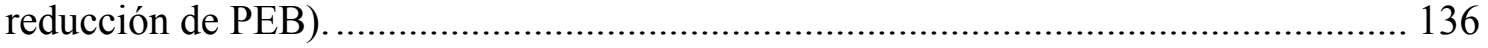

Tabla 7.16. Termoalteración del conjunto de camélidos subadultos............................ 136

Tabla 7.17. Relación entre el tipo de termoalteración y tipo de fractura del conjunto de

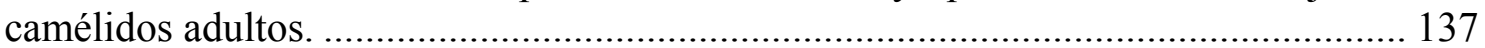

Tabla 7.18. Marcas en huesos del conjunto no camélido expresado en NISP. ............ 137

Tabla 7.19. Termoalteración del conjunto de no camélido. ....................................... 139

Tabla 7.20. Composición del conjunto faunístico del Recinto 63A.............................. 141

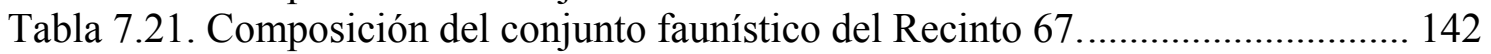

Tabla 7.22. Meteorización del conjunto faunístico del Núcleo F. Loma Alta .............. 143

Tabla 7.23. Modificaciones por roedores y carnívoros. Núcleo F. Loma Alta ............. 144

Tabla 7.24. Composición del conjunto total de camélidos. Núcleo F. Loma Alta....... 144

Tabla 7.25. Correlación entre el \%MAU y la densidad ósea. .................................... 145

Tabla 7.26. Abundancia relativa de partes esqueletarias expresadas como NISP, MNE

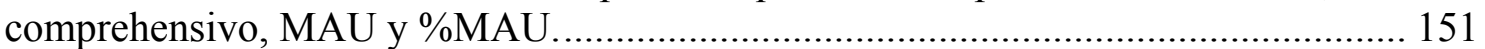

Tabla 7.27. Termoalteración del conjunto de camélidos adultos................................ 157

Tabla 7.28. Relación entre tipo de termoalteración y tipo de fractura del conjunto de

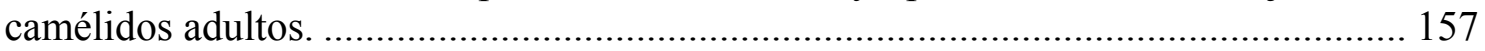

Tabla 7.29. Correlación entre el \%MAU y la densidad ósea. ..................................... 158 
Tabla 7.30. Abundancia relativa de partes esqueletarias expresadas como NISP, MNE

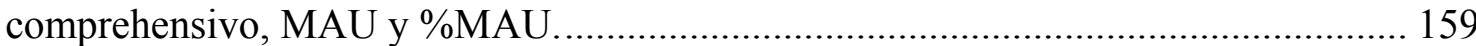

Tabla 7.31. Marcas en huesos del conjunto no camélido expresado en NISP. ........... 160

Tabla 7.32. Termoalteración del conjunto de no camélido. .......................................... 161

Tabla 7.33. Composición del conjunto faunístico del Recinto 87.................................. 163

Tabla 7.34 Composición del conjunto faunístico del Recinto 88................................. 164

Tabla 7.35. Composición del conjunto faunístico del Recinto 89................................ 164

Tabla 7.36. Meteorización del conjunto faunístico del Núcleo G. Loma Alta.............. 165

Tabla 7.37 Modificaciones por agentes naturales . Núcleo G. Loma Alta................... 165

Tabla 7.38. Camelidae, huesos del esqueleto axial y apendicular. Núcleo G, Loma Alta.

Tabla 7.39. Correlación entre el \%MAU y la densidad ósea. ...................................... 167

Tabla 7.40. Abundancia relativa de partes esqueletarias.............................................. 168

Tabla 7.41. Termoalteración del conjunto de camélidos adultos. ................................ 170

Tabla 7.42. Correlación entre el \%MAU y la densidad ósea. ...................................... 171

Tabla 7.43. Abundancia relativa de partes esqueletarias expresadas como NISP, MNE

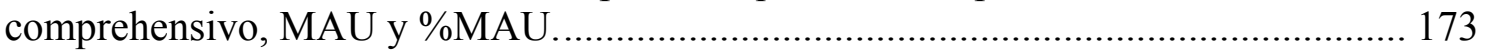

Tabla 7.44. Marcas en huesos del conjunto no camélido expresado en NISP. ............. 175

Tabla 7.45. Termoalteración del conjunto "no camélidos"........................................ 175

Tabla 7.46. Composición de la muestra. Potrero Antigal............................................ 177

Tabla 7.47. Meteorización del conjunto faunístico de Potrero Antigal........................ 177

Tabla 7.48. Modificaciones por agentes naturales del conjunto faunístico Potrero

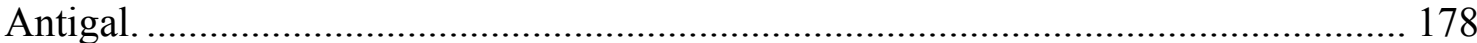

Tabla 7.49. Tamaño Corporal 4, huesos del esqueleto axial y apendicular. Potrero

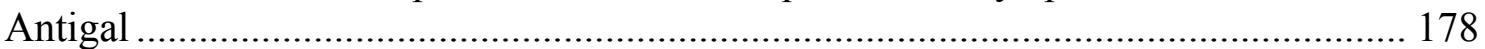

Tabla 7.50. Marcas en huesos de tamaño corporal 4 expresado en NISP.................... 181

Tabla 7.51. Termoalteración del conjunto de tamaño corporal 4................................. 181

Tabla 7.52. Relación entre tipo de termoalteración y tipo de fractura del conjunto de

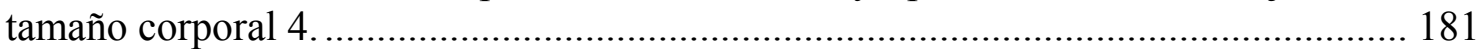

Tabla 7.53. Composición de la muestra. Tesoro 1..................................................... 182

Tabla 7.54. Composición de la muestra. Antigal de Tesoro o Tesoro 2. ..................... 183

Tabla 7.55. Meteorización del conjunto faunístico de R19. Antigal de Tesoro ............ 183

Tabla 7.56. Correlación entre el \%MAU y la densidad ósea. ..................................... 185

Tabla 7.57. Abundancia relativa de partes esqueletarias expresadas como NISP, MNE

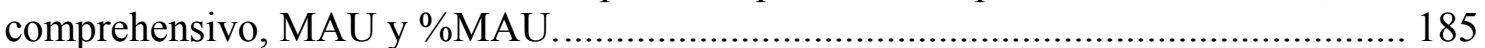

Tabla 7.58. Termoalteración del conjunto de camélidos adultos. ................................ 188

Tabla 7.59. Relación entre tipo de termoalteración y tipo de fractura del conjunto de

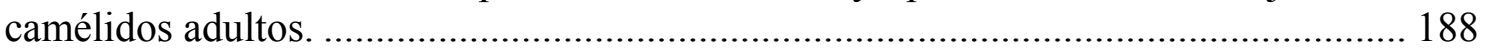

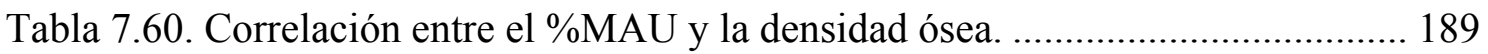

Tabla 7.61. Abundancia relativa de partes esqueletarias............................................. 189

Tabla 7.62. Termoalteración del conjunto de camélidos adultos. ................................ 190

Tabla 7.63. Termoalteración del conjunto de no camélido. ....................................... 190

Tabla 8.1. Composición del conjunto faunístico de la Estructura 1............................. 192

Tabla 8.2. Meteorización del conjunto faunístico de la Estructura 1. Yutopián ........... 193

Tabla 8.3 Modificaciones por agentes naturales del conjunto faunístico de la Estructura

1. Yutopián

Tabla 8.4. Camelidae, huesos del esqueleto axial y apendicular. Estructura 1, Yutopián.

Tabla 8.5. Correlación entre el \%MAU y la densidad ósea. ...................................... 196 
Tabla 8.6. Abundancia relativa de partes esqueletarias expresadas como NISP, MNE

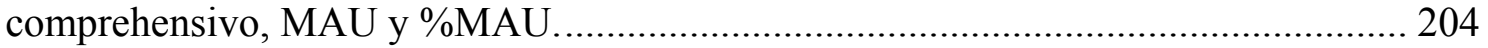

Tabla 8.7. Marcas en hueso de camélidos adultos expresado en NISP ....................... 209

Tabla 8.8. Termoalteración del conjunto de camélidos adultos. .................................. 209

Tabla 8.9. Relación entre tipo de termoalteración y tipo de fractura del conjunto de

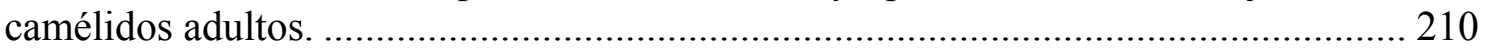

Tabla 8.10. Correlación entre el \%MAU y la densidad ósea. .................................... 210

Tabla 8.11. Abundancia relativa de partes esqueletarias expresadas como NISP, MNE

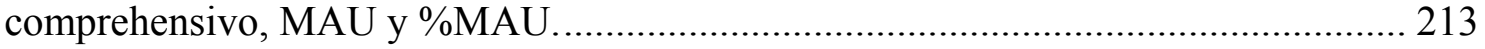

Tabla 8.12. Marcas en huesos del conjunto no camélido expresado en NISP. ............ 214

Tabla 8.13. Termoalteración del conjunto de camélidos subadultos............................ 215

Tabla 8.14. Relación entre el tipo de termoalteración y tipo de fractura del conjunto de

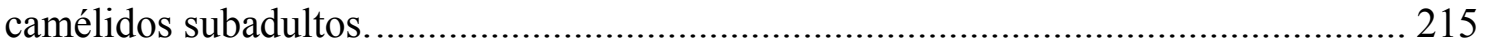

Tabla 8.15. Marcas en huesos del conjunto no camélido expresado en NISP. ............ 215

Tabla 8.16. Termoalteración del conjunto no camélido................................................ 216

Tabla 8.17. Composición del conjunto faunístico del Patio Núcleo 1......................... 218

Tabla 8.18. Meteorización del conjunto faunístico del Patio Núcleo 1. Yutopián........ 218

Tabla 8.19. Modificaciones por agentes naturales del conjunto faunístico del Patio

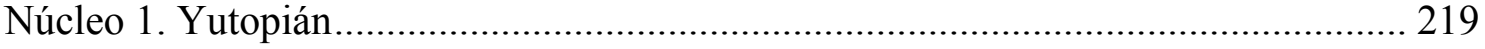

Tabla 8.20. Camelidae, huesos del esqueleto axial y apendicular. Patio Núcleo 1,

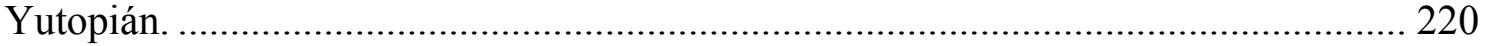

Tabla 8.21. Termoalteración. Patio Núcleo 1. Yutopián............................................. 221

Tabla 8.22. Relación entre tipo de termoalteración y tipo de fractura. Patio Núcleo 1.

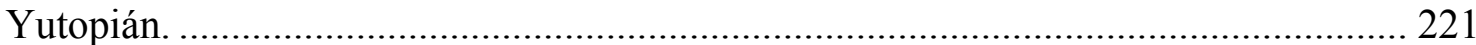

Tabla 8.23. Composición del conjunto faunístico de la Estructura 3........................... 223

Tabla 8.24. Meteorización del conjunto faunístico de la Estructura 3. Yutopián ........ 224

Tabla 8.25. Modificaciones por agentes naturales del conjunto faunístico de la

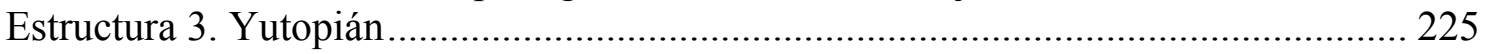

Tabla 8.26. Camelidae, huesos del esqueleto axial y apendicular. Estructura 3,

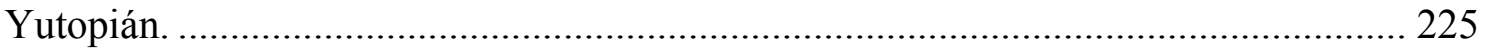

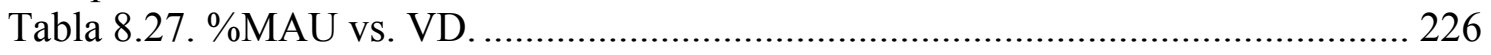

Tabla 8.28. Abundancia relativa de partes esqueletarias expresadas como NISP, MNE

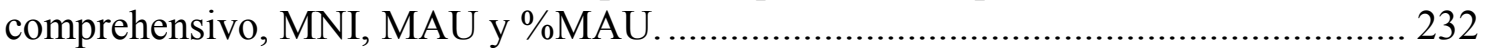

Tabla 8.29. Marcas en hueso de camélidos adultos expresado en NISP .................... 239

Tabla 8.30. Termoalteración del conjunto de camélidos adultos. ................................ 240

Tabla 8.31. Relación entre tipo de termoalteración y tipo de fractura del conjunto de

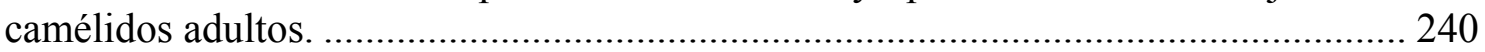

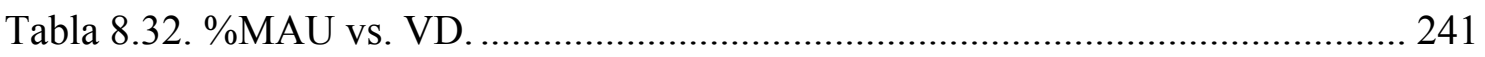

Tabla 8.33. Abundancia relativa de partes esqueletarias expresadas como NISP, MNE

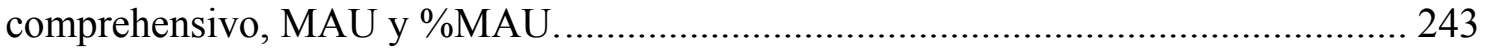

Tabla 8.34. Marcas en hueso de camélidos subadultos expresado en NISP ................ 245

Tabla 8.35 Termoalteración del conjunto de camélidos subadultos............................ 245

Tabla 8.36. Relación entre tipo de termoalteración y tipo de fractura del conjunto de

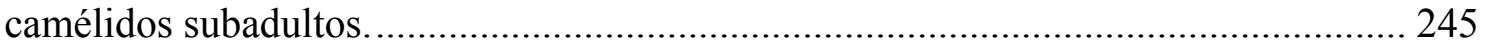

Tabla 8.37. Marcas en huesos del conjunto no camélido expresado en NISP. ............ 246

Tabla 8.38. Termoalteración del conjunto de no camélido. ......................................... 246

Tabla 8.39. Composición del conjunto faunístico de la Estructura 4 - Ocupación

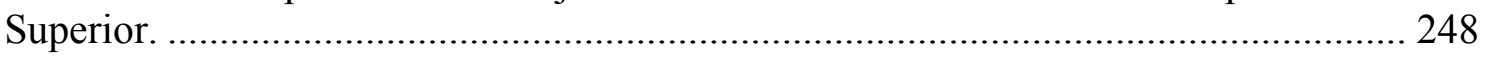

Tabla 8.40. Meteorización del conjunto faunístico de la Estructura 4 - Ocupación

Superior. Yutopián 
Tabla 8.41. Modificaciones por agentes naturales del conjunto faunístico de la

Estructura 4 - Ocupación Superior. Yutopián

Tabla 8.42. Camelidae, huesos del esqueleto axial y apendicular. Estructura 4 -

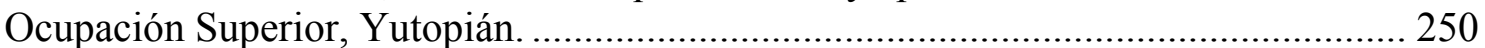

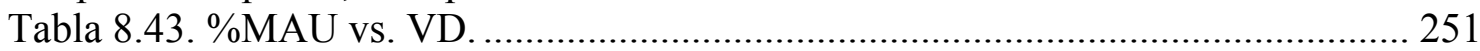

Tabla 8.44. Abundancia relativa de partes esqueletarias expresadas como NISP, MNE

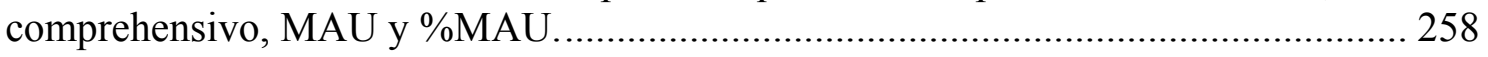

Tabla 8.45. Marcas en hueso de camélidos adultos expresado en NISP ..................... 264

Tabla 8.46. Termo alteración del conjunto de camélidos adultos. ............................... 264

Tabla 8.47. Relación entre tipo de termoalteración y tipo de fractura del conjunto de

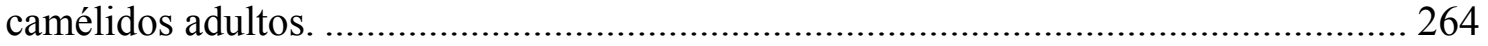

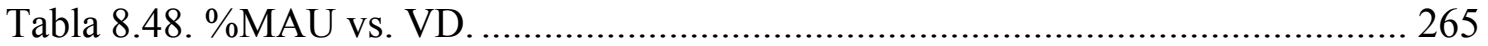

Tabla 8.49. Abundancia relativa de partes esqueletarias expresadas como NISP, MNE

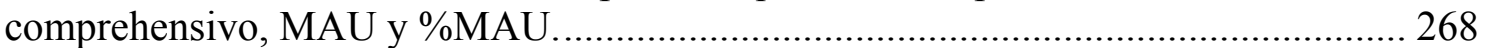

Tabla 8.50 Marcas en huesos del conjunto no camélido expresado en NISP. ............. 269

Tabla 8.51. Termoalteración del conjunto de camélidos subadultos............................ 269

Tabla 8.52. Marcas en hueso de camélidos adultos expresado en NISP ..................... 270

Tabla 8.53. Termoalteración del conjunto no camélido............................................ 270

Tabla 8.54. Composición del conjunto faunístico de la Estructura 4 - Ocupación

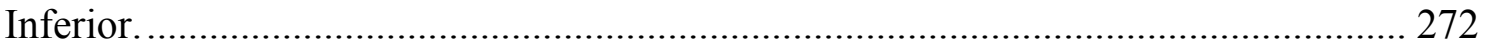

Tabla 8.55. Meteorización del conjunto faunístico de la Estructura 4 - Ocupación

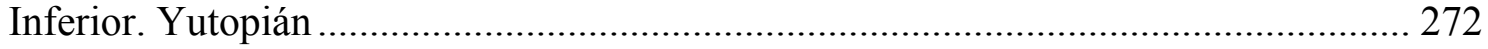

Tabla 8.56. Camelidae, huesos del esqueleto axial y apendicular. Estructura 4 -

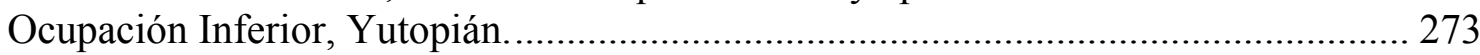

Tabla 8.57. Abundancia relativa de partes esqueletarias expresadas como NISP, MNE

comprehensivo, MAU y \%MAU.......................................................................... 274

Tabla 8.58. Termoalteración del conjunto de camélidos.......................................... 275

Tabla 8.59. Composición del conjunto faunístico de la Estructura 5......................... 277

Tabla 8.60. Meteorización del conjunto faunístico de la Estructura 5. Yutopián ........ 278

Tabla 8.61. Modificaciones por agentes naturales del conjunto faunístico de la

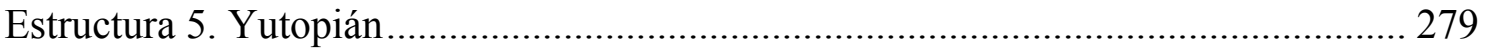

Tabla 8.62. Camelidae, huesos del esqueleto axial y apendicular. Estructura 5,

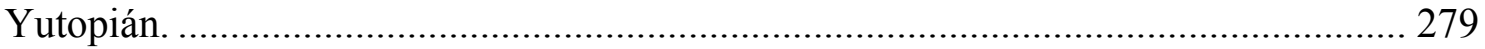

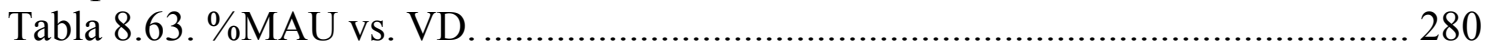

Tabla 8.64. Abundancia relativa de partes esqueletarias expresadas como NISP, MNE

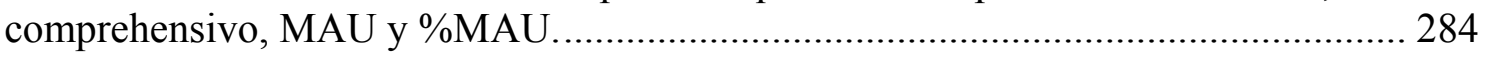

Tabla 8.65. Marcas en hueso de camélidos adultos expresado en NISP ..................... 289

Tabla 8.66. Termoalteración del conjunto de camélidos adultos. ................................ 290

Tabla 8.67. Relación entre tipo de termoalteración y tipo de fractura del conjunto de

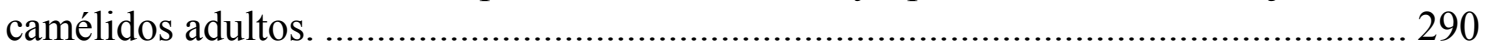

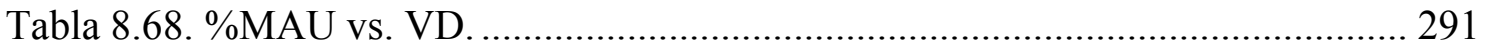

Tabla 8.69. Abundancia relativa de partes esqueletarias expresadas como NISP, MNE

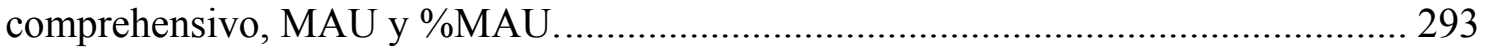

Tabla 8.70. Marcas en huesos del conjunto no camélido expresado en NISP. ............ 295

Tabla 8.71. Termoalteración del conjunto no camélido............................................... 295

Tabla 8.72. Composición del conjunto faunístico de la Estructura 11......................... 297

Tabla 8.73. Meteorización del conjunto faunístico de la Estructura 11. Yutopián ....... 298

Tabla 8.74. Modificaciones por agentes naturales del conjunto faunístico de la

Estructura 11. Yutopián. 
Tabla 8.75. Camelidae, huesos del esqueleto axial y apendicular. Estructura 11, Yutopián.

Tabla 8.76. \%MAU vs. VD.

Tabla 8.77. Abundancia relativa de partes esqueletarias expresadas como NISP, MNE comprehensivo, MAU y \%MAU.

Tabla 8.78. Marcas en hueso de camélidos adultos expresado en NISP ...................... 313

Tabla 8.79. Termoalteración del conjunto de camélidos adultos................................. 314

Tabla 8.80. Relación entre tipo de termoalteración y tipo de fractura del conjunto de camélidos adultos.

Tabla 8.81. \%MAU vs. VD.

Tabla 8.82. Abundancia relativa de partes esqueletarias expresadas como NISP, MNE

comprehensivo, MAU y \%MAU.

Tabla 8.83. Marcas en hueso de camélidos subadultos expresado en NISP ................ 319

Tabla 8.84. Termoalteración del conjunto de camélidos subadultos.............................. 319

Tabla 8.85. Marcas en huesos del conjunto no camélido expresado en NISP. ............. 320

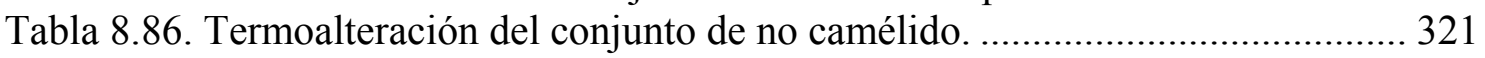

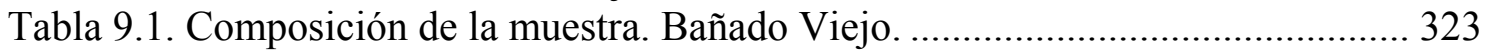

Tabla 9.2. Modificaciones observadas en el material de Bañado Viejo....................... 326

Tabla 9.3. Composición de la muestra. Morro de las Espinillas .................................. 328

Tabla 9.4. Tamaño corporal 4, huesos del esqueleto axial y apendicular. ................... 328

Tabla 9.5. Termoalteración del conjunto de tamaño corporal 4. Morro de las Espinillas 


\section{Índice de Figuras}

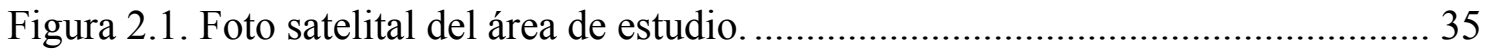

Figura 2.2. Falda Occidental del Aconquija (adaptado de Fauque y Strecker 1987).... 37

Figura 2.3. Foto aérea del área de Tesoro (Colección Scattolin). ................................. 38

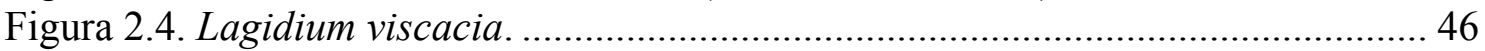

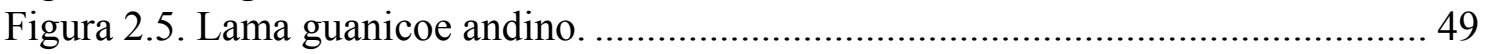

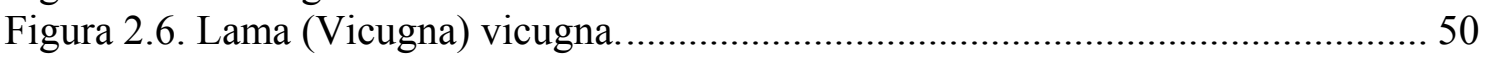

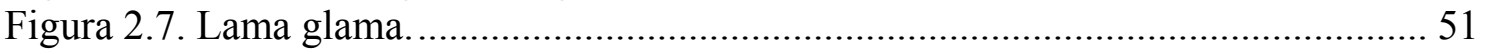

Figura 6.1. Foto aérea del sitio Loma Alta. (Foto colección Scattolin) ......................... 79

Figura 6.2. Vista general del sitio Loma Alta. (Foto colección Scattolin) ..................... 79

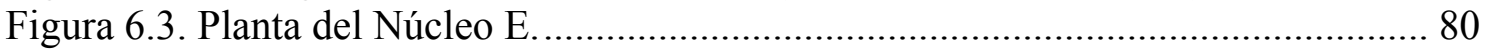

Figura 6.4. Nivel de Ocupación del R47. (Foto colección Scattolin)............................. 81

Figura 6.5. Núcleo F. Se observa la superficie excavada en el Recinto 63A y 67........ 82

Figura 6.6 Vista de las excavaciones realizadas en el R63A. (Foto colección Scattolin)

Figura 6.7. Núcleo G. Se observa la superficie excavada (S4, S5 y S7) ....................... 83

Figura 6.8. Vista de las excavaciones realizadas en el R87. (Foto colección Scattolin) 83

Figura 6.9. Vista general de Potrero Antigal. (Foto colección Scattolin) ...................... 84

Figura 6.10. Vista de la excavación realizada en Potrero Antigal. (Foto colección

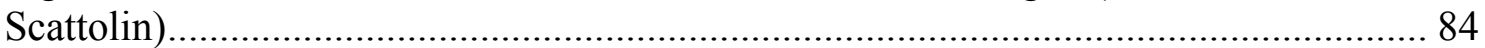

Figura 6.11. Vista general del sitio Tesoro 1. (Foto colección Scattolin) ...................... 85

Figura 6.12. Excavación en el sitio Tesoro 1. (Foto colección Scattolin)....................... 85

Figura 6.13. Corral moderno ocupado con ejemplares de Lama glama. Cerca de Tesoro

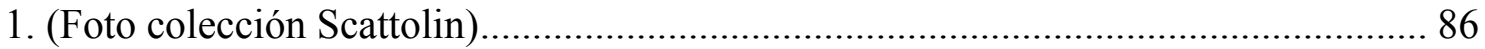

Figura 6.14. Planta del Recinto 19, Antigal de Tesoro. Tomado de Scattolin (2001).... 86

Figura 6.15. Vista de la vega (centro de la fotografía) desde Antigal de Tesoro. (Foto

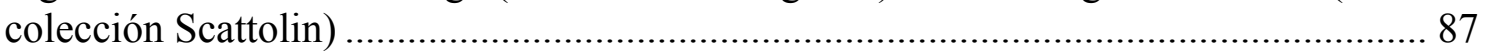

Figura 6.16. Vista general del ambiente de Antigal de Tesoro. (Foto colección Scattolin)

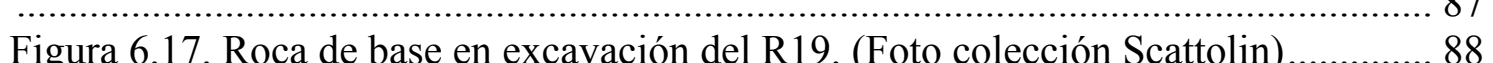

Figura 6.18. Planta del sitio Yutopián. Tomado de Gero y Scattolin (2002).................. 89

Figura 6.19. Estructura 1 y Estructura 3, Yutopián. (Foto colección Gero-Scattolin) ... 90

Figura 6.20. a) Estructura 4 y 5, b) Detalle de los fogones hallados en Estructura 4.

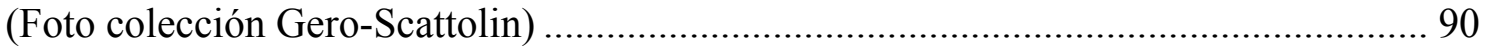

Figura 6.21. Estructura 11. Yutopián. (Foto colección Gero-Scattolin)......................... 91

Figura 6.22. Acumulación discreta de cerámica presantamariana y Sondeo 1. Bañado

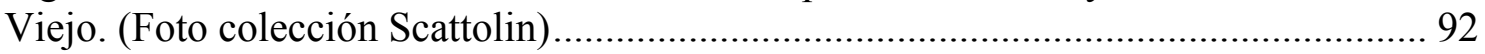

Figura 6.23. Perfil Sur esquemático de la Cuadrícula 1 de Bañado Viejo (Izeta y

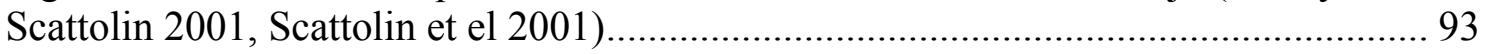

Figura 6.24 Vista de la Cuadrícula 1 de Bañado Viejo. (Foto colección Scattolin)....... 93

Figura 6.25. Vista general de Morro de las Espinillas y Sondeo 3. (Fotos colección

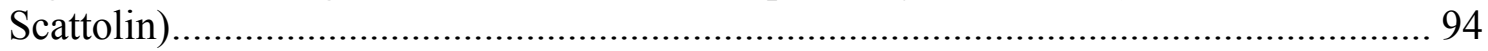

Figura 6.26. Plano de Morro de las Espinillas mostrando la ubicación de los sondeos.

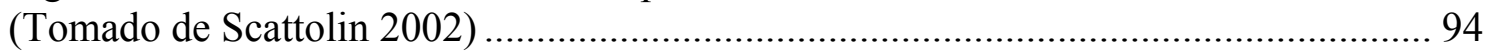

Figura 7.1. Estadios de meteorización según tamaño corporal. Núcleo E, Loma Alta 100 Figura 7.2. Núcleo E. R46 y R47. Distribución espacial de restos de tamaño corporal 4.

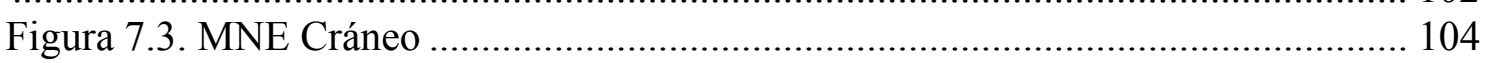

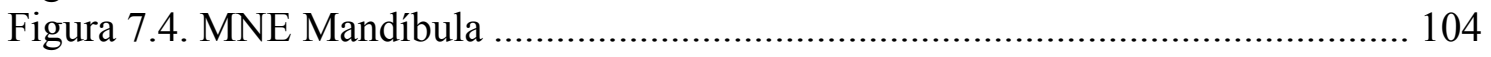




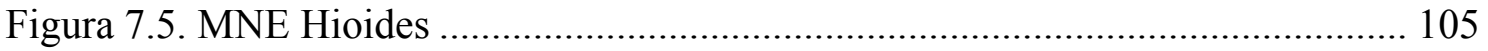

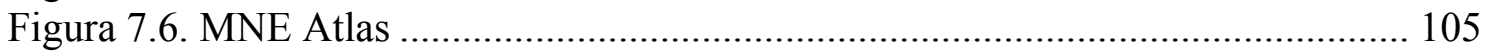

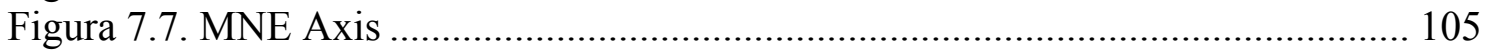

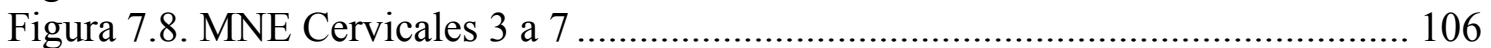

Figura 7.9. MNE Escápula izquierda y derecha …………………………………...... 106

Figura 7.10. MNE Húmero izquierdo y derecho ..................................................... 107

Figura 7.11. MNE Radioulna izquierda y derecha ………………………………........ 107

Figura 7.12. MNE Metacarpo izquierdo y derecho ................................................... 108

Figura 7.13. MNE Falange proximal delantera ....................................................... 109

Figura 7.14. MNE Innominado izquierdo y derecho................................................... 109

Figura 7.15. MNE Fémur izquierdo y derecho......................................................... 109

Figura 7.16. MNE Tibia izquierda y derecha ......................................................... 110

Figura 7.17. MNE Astrágalo izquierdo y derecho ………………………………...... 110

Figura 7.18. MNE Calcáneo izquierdo y derecho ..................................................... 111

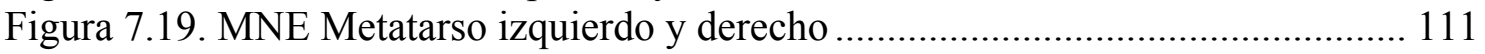

Figura 7.20. MNE Falange proximal trasera …………………………………....... 112

Figura 7.21. MNE Metapodio general................................................................... 112

Figura 7.22. MNE Falange proximal general ......................................................... 112

Figura 7.23. MNE Falange medial ...................................................................... 113

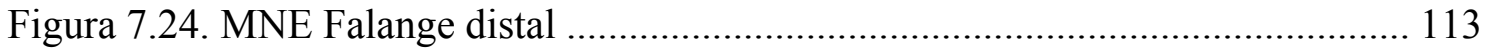

Figura 7.25. Abundancia relativa de elementos esqueletarios..................................... 115

Figura 7.26. a) Relación \%MAU VS FUI huesos "no-largos"; b) Relación \%MAU VS

FUI huesos "largos"; c) Relación \%MAU VS Cavidad Medular. ................................ 116

Figura 7.27. Módulos de tamaño expresado en NISP para especímenes y elementos del subconjunto adulto de camélidos............................................................................... 117

Figura 7.28. Fragmentación de elementos del esqueleto axial.................................... 118

Figura 7.29. Fragmentación esqueleto apendicular delantero (izquierdo y derecho)... 119

Figura 7.30. Fragmentación esqueleto apendicular trasero (izquierdo y derecho)....... 119

Figura 7.31. Cantidad (NISP) de especímenes y elementos del subconjunto adulto de camélidos según tipo de fractura. Loma Alta, Núcleo E.............................................. 120

Figura 7.32. a) esqueleto apendicular delantero; b) esqueleto apendicular trasero...... 122

Figura 7.33. Mapa de contorno del Núcleo E mostrando las densidades de hueso quemado de camélidos adultos (izquierda) y no quemados con fractura seca (derecha).

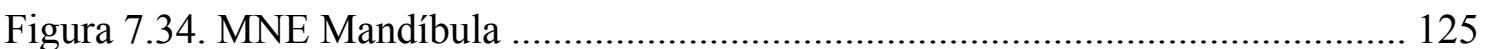

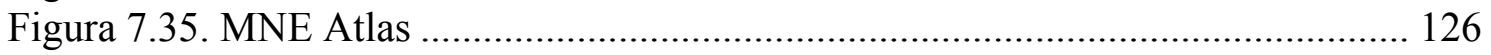

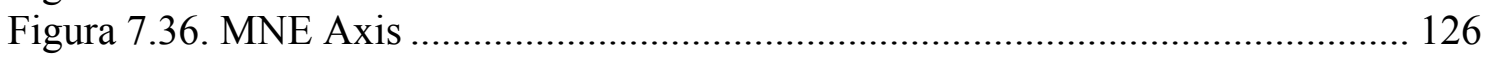

Figura 7.37. MNE Cervicales 3-7......................................................................... 126

Figura 7.38. MNE Húmero izquierdo y derecho ........................................................ 127

Figura 7.39. MNE Radioulna izquierda y derecha …………...................................... 127

Figura 7.40. MNE Fémur izquierdo y derecho........................................................ 128

Figura 7.41. MNE Tibia izquierda y derecha ........................................................ 128

Figura 7.42. MNE Calcáneo izquierdo y derecho ....................................................... 128

Figura 7.43. MNE Metatarso izquierdo y derecho ……………………….................. 129

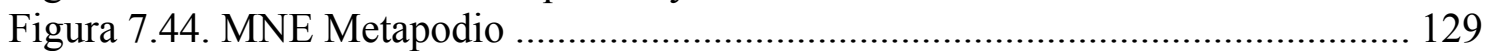

Figura 7.45. MNE Falange proximal................................................................... 129

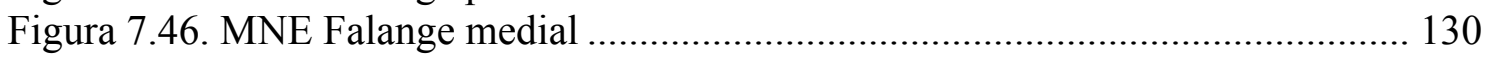

Figura 7.47. Abundancia relativa de elementos esqueletarios...................................... 131

Figura 7.48. a) Relación \%MAU VS FUI huesos "no-largos"; b) Relación \%MAU VS

FUI huesos "largos"; c) Relación \%MAU VS Cavidad Medular. ................................. 132 
Figura 7.49. Módulos de tamaño expresado en NISP para especímenes y elementos del

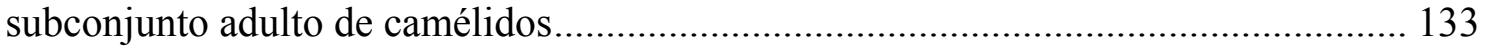

Figura 7.50. Fragmentación de elementos del esqueleto axial................................... 133

Figura 7.51. Fragmentación esqueleto apendicular delantero (izquierdo y derecho)... 134

Figura 7.52. Fragmentación esqueleto apendicular trasero (izquierdo y derecho)....... 134

Figura 7.53. Cantidad (NISP) de especímenes y elementos del subconjunto adulto de

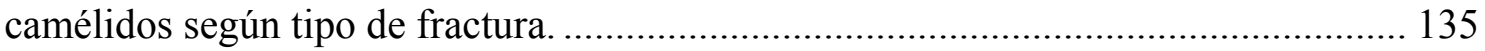

Figura 7.54. Utilización de las carcasas. a) Pata delantera y b) Pata trasera................. 136

Figura 7.55. Fragmentación del conjunto no camélido expresado en NSP. a) Tamaño

corporal 1, b) Tamaño corporal 2 y c) Tamaño corporal 4 ......................................... 140

Figura 7.56. Estadios de meteorización según tamaño corporal. Núcleo F. Loma Alta

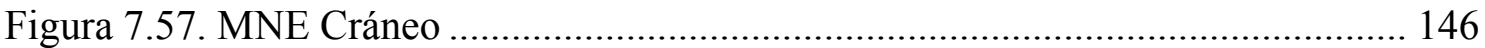

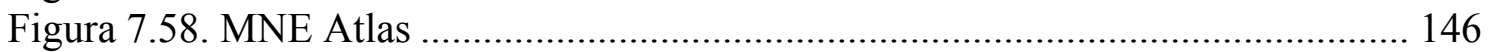

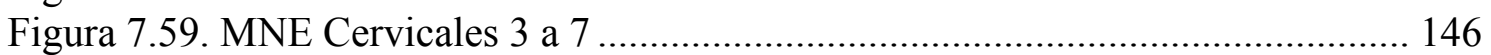

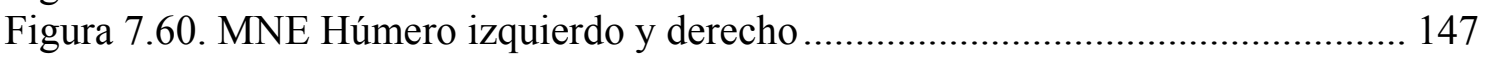

Figura 7.61. MNE Radioulna izquierda y derecha ................................................. 147

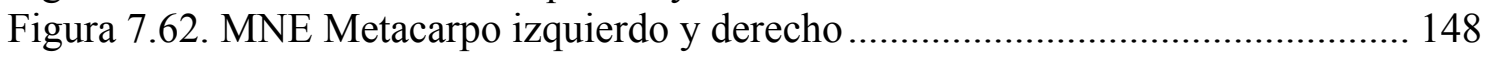

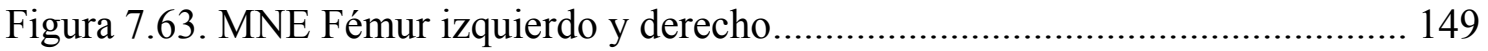

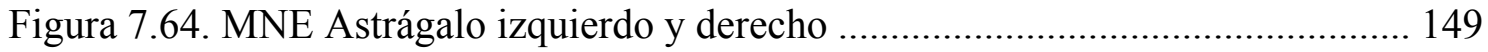

Figura 7.65. MNE Calcáneo izquierdo y derecho ....................................................... 149

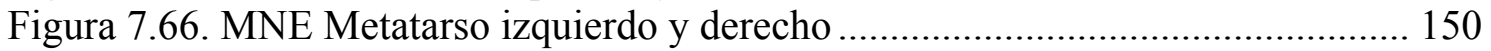

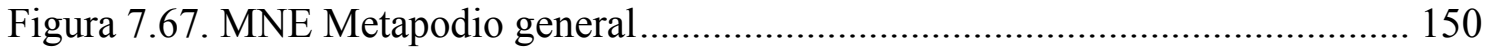

Figura 7.68. MNE Falange proximal general ............................................................... 150

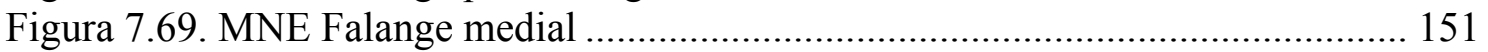

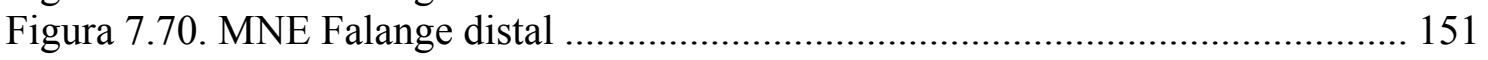

Figura 7.71. Abundancia relativa de elementos esqueletarios................................... 152

Figura 7.72. a) Relación \%MAU VS FUI huesos "no-largos"; b) Relación \%MAU VS

FUI huesos "largos"; c) Relación \%MAU VS Cavidad Medular. ............................... 153

Figura 7.73. Módulos de tamaño expresado en NISP para especímenes y elementos del

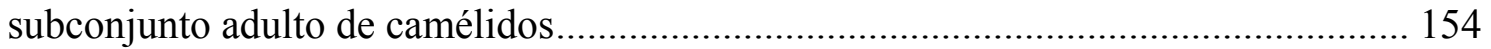

Figura 7.74. Fragmentación de elementos del esqueleto axial................................... 155

Figura 7.75. Fragmentación esqueleto apendicular delantero (izquierdo y derecho)... 155

Figura 7.76. Fragmentación esqueleto apendicular trasero (izquierdo y derecho)........ 156

Figura 7.77. Cantidad (NISP) de especímenes y elementos del subconjunto adulto de

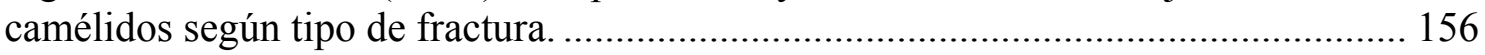

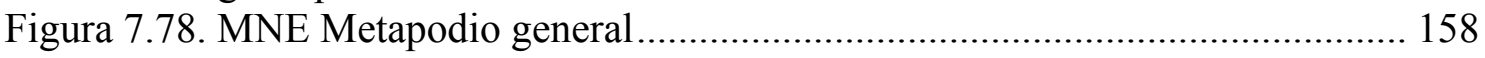

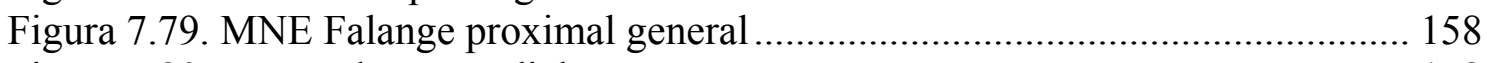

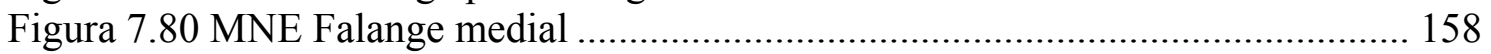

Figura 7.81. Abundancia relativa de elementos esqueletarios..................................... 159

Figura 7.82. Fragmentación del conjunto no camélido expresado en NSP. a) Tamaño

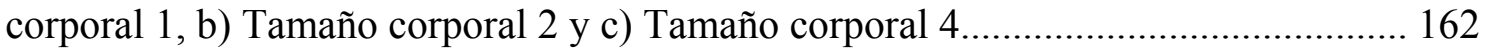

Figura 7.83. Estadios de meteorización según tamaño corporal. Núcleo G, Loma Alta

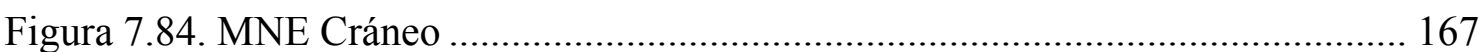

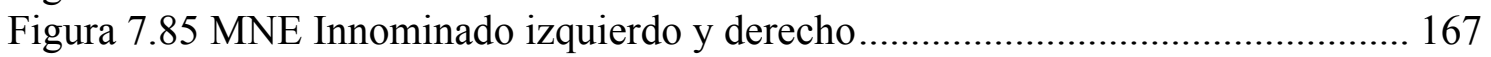

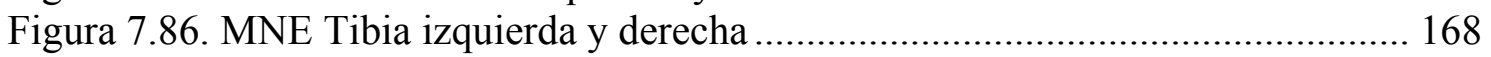

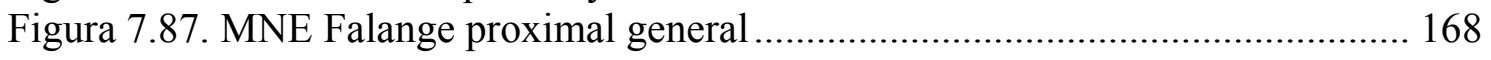

Figura 7.88. Abundancia relativa de elementos esqueletarios................................... 169 
Figura 7.89. Módulos de tamaño expresado en NISP para especímenes y elementos del

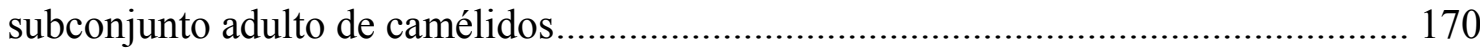
Figura 7.90. Cantidad (NISP) de especímenes y elementos del subconjunto adulto de

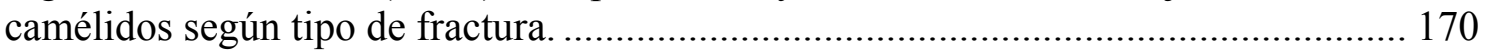

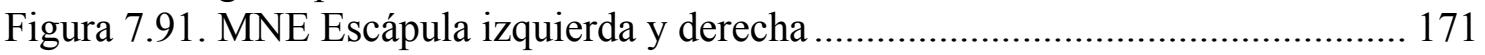

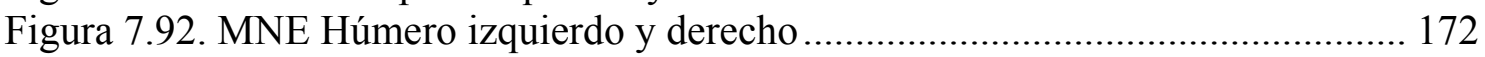

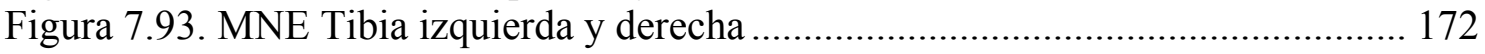

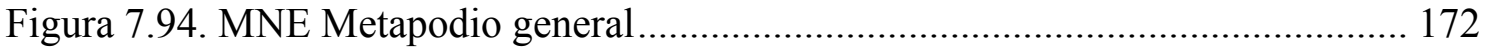

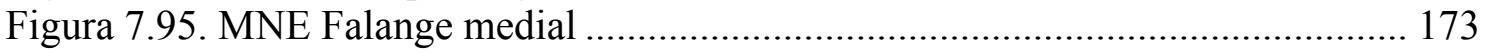

Figura 7.96. Módulos de tamaño expresado en NISP para especímenes y elementos del

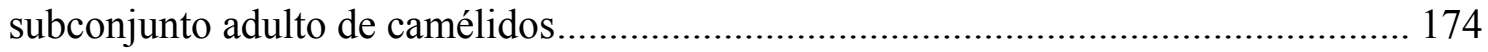
Figura 7.97. Cantidad (NISP) de especímenes y elementos del subconjunto subadulto de

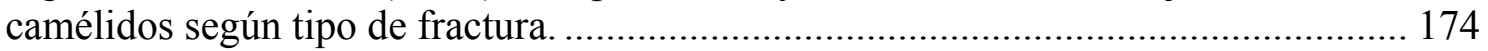
Figura 7.98. Fragmentación del conjunto "no camélido" expresado en NSP. a) Tamaño

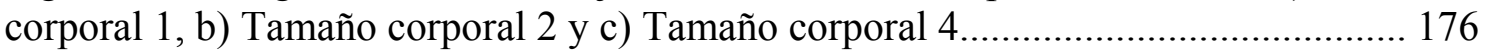
Figura 7.99. Estadios de meteorización según tamaño corporal. Potrero Antigal........ 178 Figura 7.100. Representación de clases de edad. ..................................................... 179 Figura 7.101. Módulos de tamaño expresado en NISP para especímenes y elementos de tamaño corporal 4............................................................................................ 180 Figura 7.102. Cantidad (NISP) de especímenes y elementos de tamaño corporal 4 según

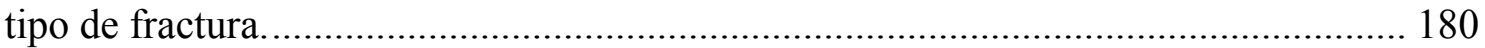
Figura 7.103. Estadios de meteorización según tamaño corporal. Antigal de Tesoro. 184 Figura 7.104. Abundancia relativa de elementos esqueletarios................................. 186 Figura 7.105. a) Relación \%MAU VS FUI huesos "no-largos"; b) Relación \%MAU VS FUI huesos "largos"; c) Relación \%MAU VS Cavidad Medular. ................................ 187 Figura 7.106. Módulos de tamaño expresado en NISP para especímenes y elementos del subconjunto adulto de camélidos............................................................................... 187 Figura 7.107. Módulos de tamaño expresado en NISP para especímenes y elementos del subconjunto subadulto de camélidos ............................................................................ 190 Figura 7.108. Fragmentación del conjunto no camélido expresado en NSP. a) Tamaño corporal 1, b) Tamaño corporal 2 y c) Tamaño corporal 4.......................................... 191 Figura 8.1. Estadios de meteorización según tamaño corporal. Estructura 1, Yutopián.

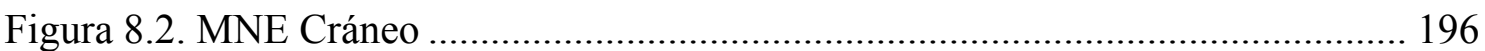

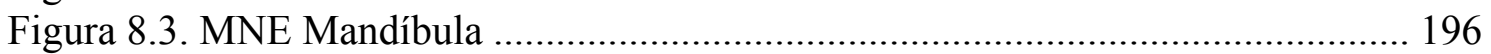

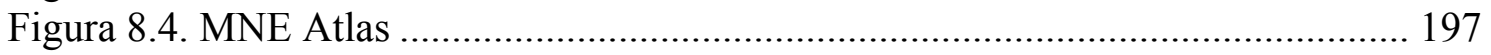

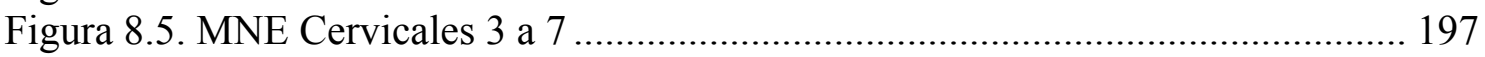

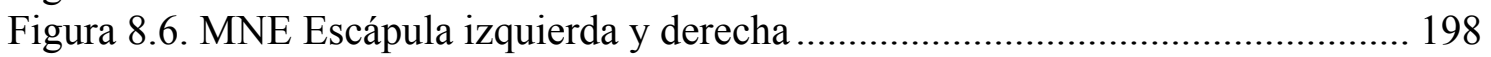

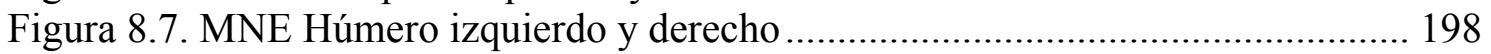

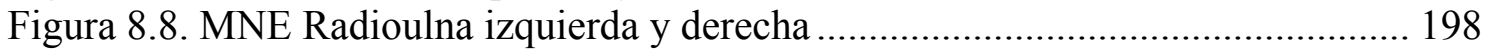

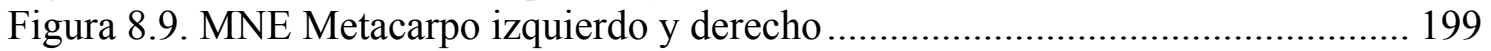

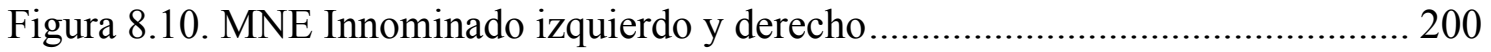

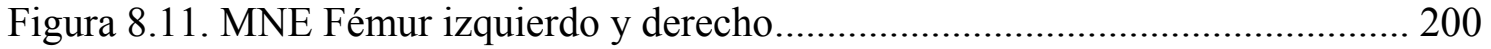

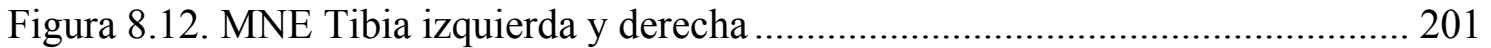

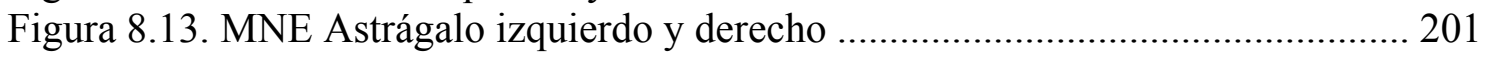

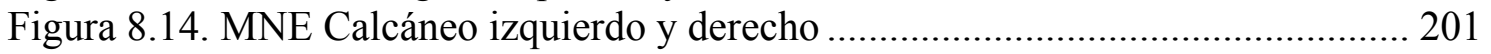

Figura 8.15. MNE Metatarso izquierdo y derecho ..................................................... 202

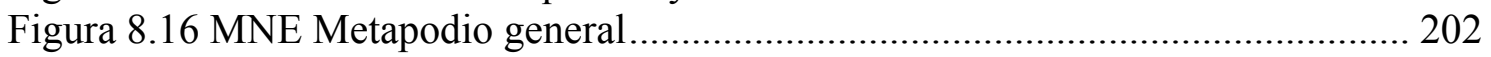

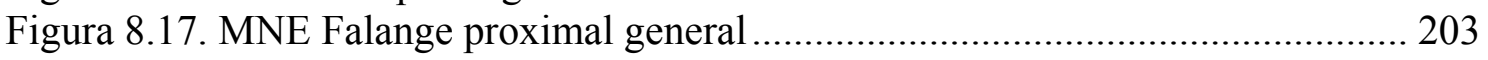

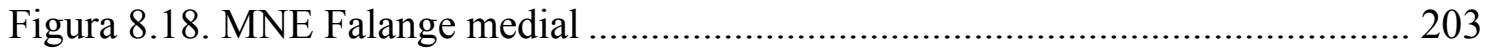




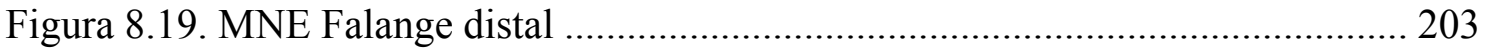

Figura 8.20. Abundancia relativa de elementos esqueletarios..................................... 205

Figura 8.21. a) Relación \%MAU VS FUI huesos "no-largos"; b) Relación \%MAU VS

FUI huesos "largos"; c) Relación \%MAU VS Cavidad Medular. ............................... 206

Figura 8.22. Módulos de tamaño expresado en NISP para especímenes y elementos del

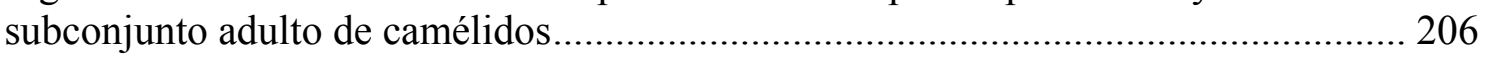

Figura 8.23. Fragmentación de elementos del esqueleto axial.................................. 207

Figura 8.24. Fragmentación esqueleto apendicular delantero (izquierdo y derecho)... 208

Figura 8.25. Fragmentación esqueleto apendicular trasero (izquierdo y derecho)....... 208

Figura 8.26. Cantidad (NISP) de especímenes y elementos del subconjunto adulto de

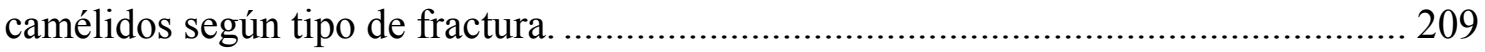

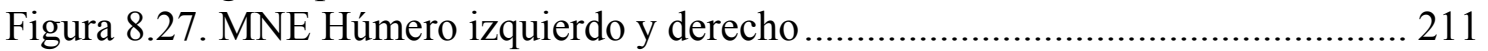

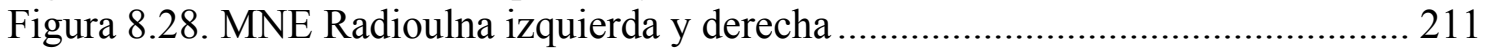

Figura 8.29. MNE Fémur izquierdo y derecho............................................................... 212

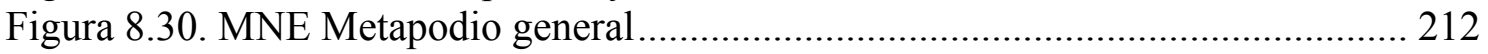

Figura 8.31. MNE Falange proximal general .......................................................... 212

Figura 8.32. MNE Falange medial ..................................................................... 212

Figura 8.33. Abundancia relativa de elementos esqueletarios.................................... 213

Figura 8.34.a) Módulos de tamaño expresado en NISP para especímenes y elementos del subconjunto subadulto de camélidos, b) Cantidad (NISP) de especímenes y

elementos del subconjunto subadulto de camélidos según tipo de fractura. ................. 214

Figura 8.35. Fragmentación del conjunto no camélido expresado en NSP. a) Tamaño

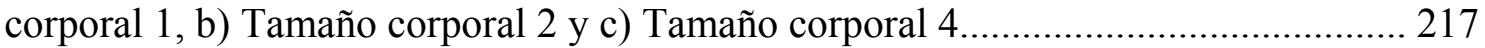

Figura 8.36. Estadios de meteorización según tamaño corporal. Patio Núcleo 1,

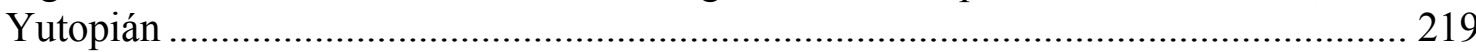

Figura 8.37. Módulos de tamaño expresado en NISP para especímenes y elementos del

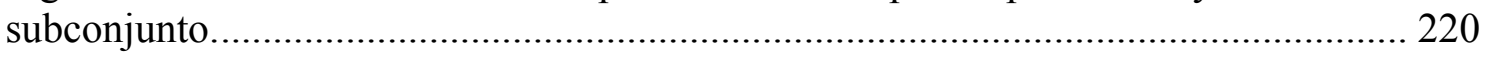

Figura 8.38. Estadios de meteorización según tamaño corporal. Estructura 3, Yutopián

Figura 8 39. MNE Cráneo ....

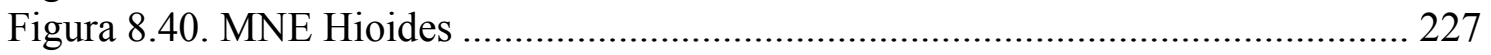

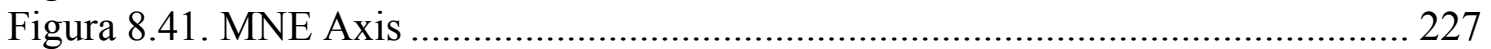

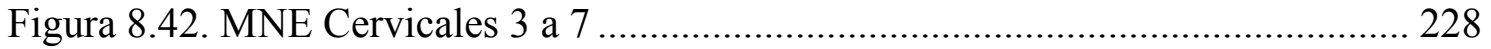

Figura 8.43. MNE Húmero izquierdo y derecho ........................................................ 228

Figura 8.44. MNE Radioulna izquierda y derecha ................................................. 229

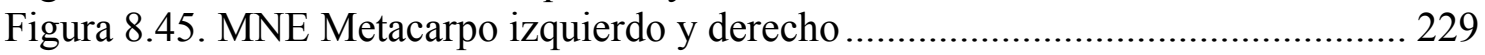

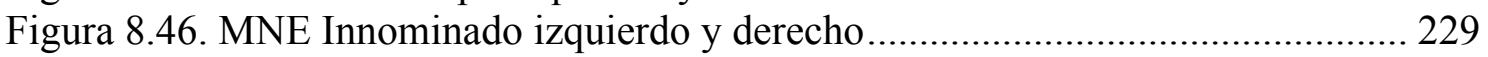

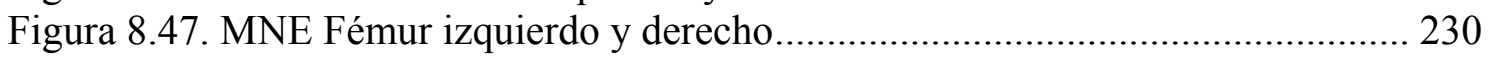

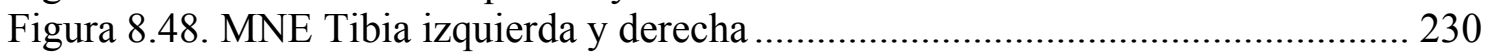

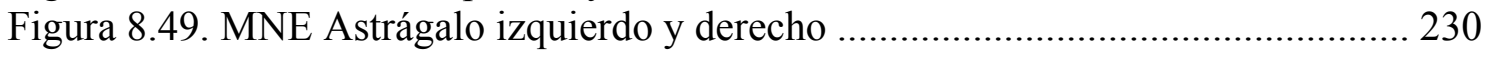

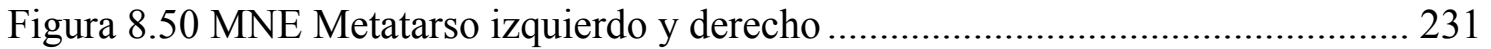

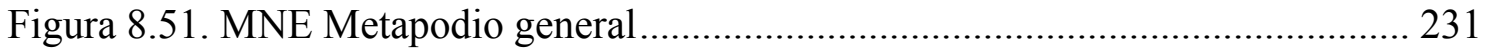

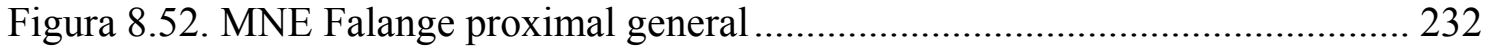

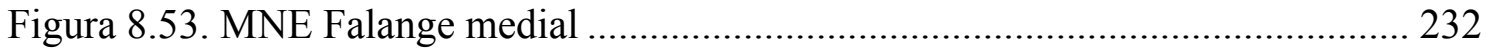

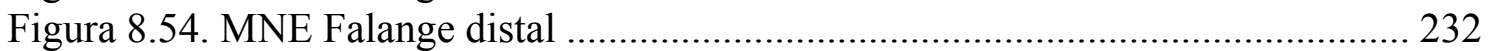

Figura 8.55. Abundancia relativa de elementos esqueletarios.................................... 234

Figura 8.56. a) Relación \%MAU VS FUI huesos "no-largos"; b) Relación \%MAU VS

FUI huesos "largos"; c) Relación \%MAU VS Cavidad Medular. .............................. 235

Figura 8.57. Módulos de tamaño expresado en NISP para especímenes y elementos del

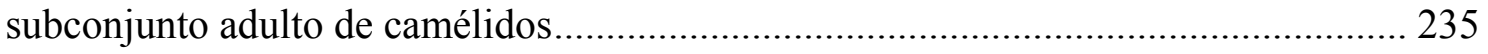


Figura8.58. Fragmentación de elementos del esqueleto axial.................................... 236

Figura 8.59. Fragmentación esqueleto apendicular delantero (izquierdo y derecho)... 237

Figura 8.60. Fragmentación esqueleto apendicular trasero (izquierdo y derecho)....... 238

Figura 8.61. Cantidad (NISP) de especímenes y elementos del subconjunto adulto de

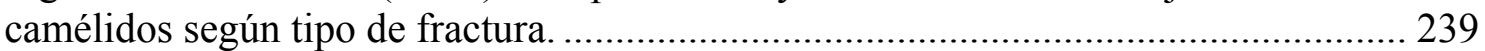

Figura 8.62. a) esqueleto apendicular delantero; b) esqueleto apendicular trasero...... 239

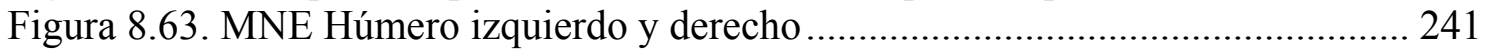

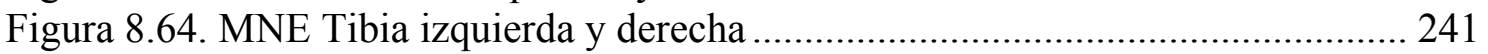

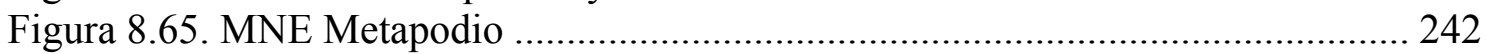

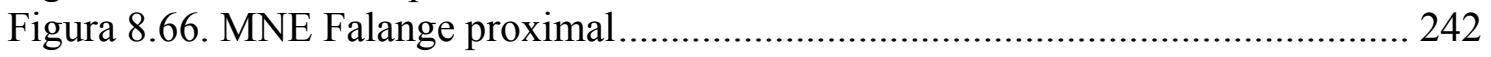

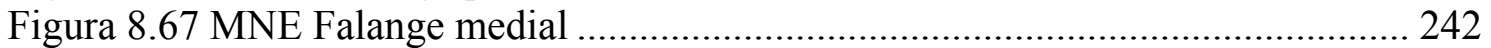

Figura 8.68. Abundancia relativa de elementos esqueletarios..................................... 243

Figura 8.69. a) módulos de tamaño, b) especímenes y elementos del subconjunto subadulto de camélidos según tipo de fractura................................................................ 244

Figura 8.70. Fragmentación del conjunto no camélido expresado en NSP. a) Tamaño

corporal 1, b) Tamaño corporal 2 y c) Tamaño corporal 3-4 ..................................... 247

Figura 8.71. Estadios de meteorización según tamaño corporal. Estructura 4 -

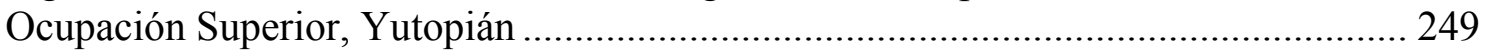

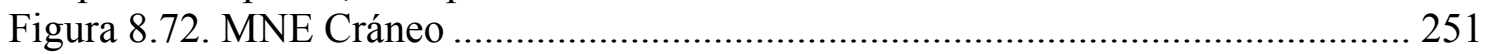

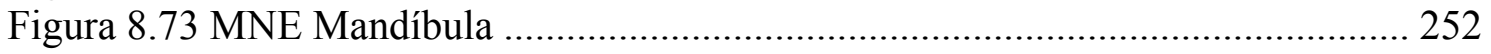

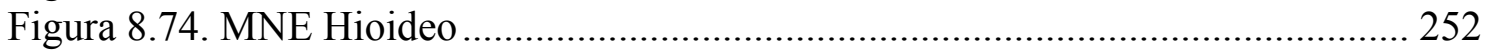

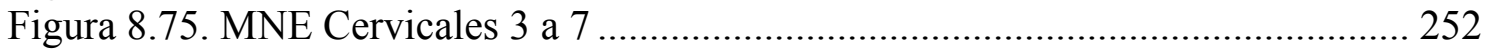

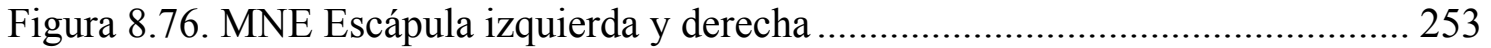

Figura 8.77. MNE Húmero izquierdo y derecho ............................................................ 253

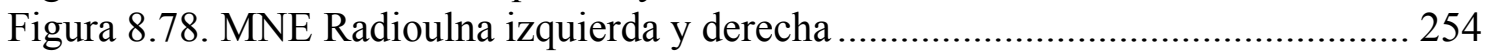

Figura 8.79. MNE Innominado izquierdo y derecho................................................. 255

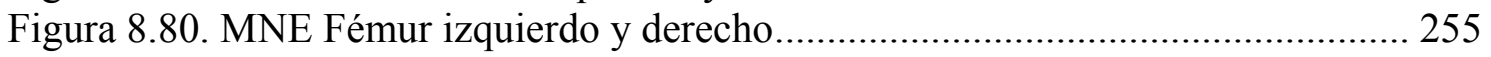

Figura 8.81. MNE Tibia izquierda y derecha ........................................................... 255

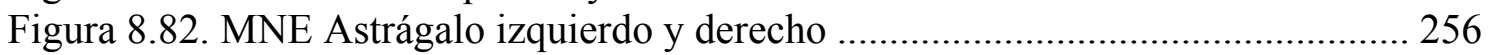

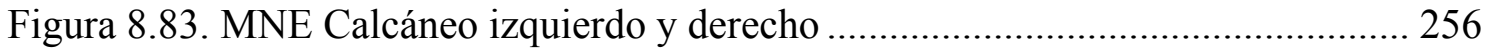

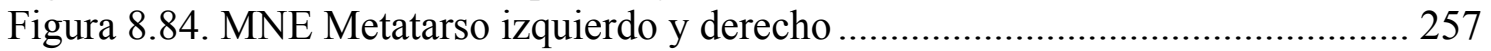

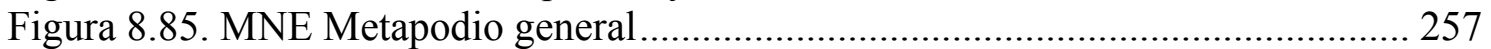

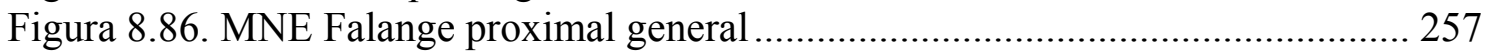

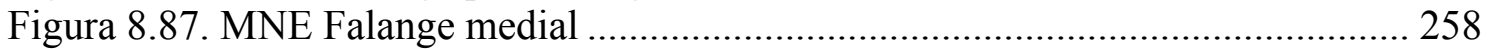

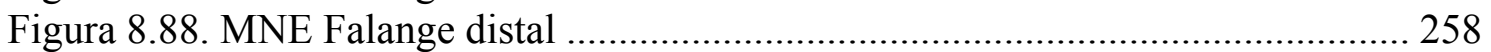

Figura 8.90. a) Relación \%MAU VS FUI huesos "no-largos"; b) Relación \%MAU VS

FUI huesos "largos”; c) Relación \%MAU VS Cavidad Medular. ................................ 261

Figura 8.91. Módulos de tamaño expresado en NISP para especímenes y elementos del

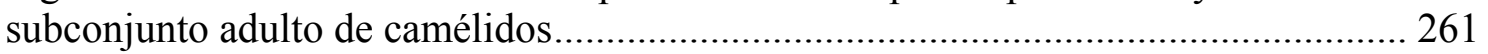

Figura 8.92. Fragmentación de elementos del esqueleto axial................................... 262

Figura 8.93. Fragmentación esqueleto apendicular delantero (izquierdo y derecho)... 262

Figura 8.94. Fragmentación esqueleto apendicular trasero (izquierdo y derecho)....... 263

Figura 8.95 Cantidad (NISP) de especímenes y elementos del subconjunto adulto de

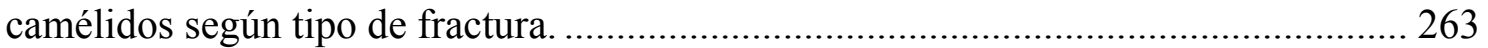

Figura 8.96. MNE Húmero izquierdo y derecho ......................................................... 265

Figura 8.97. MNE Radioulna izquierda y derecha .................................................. 266

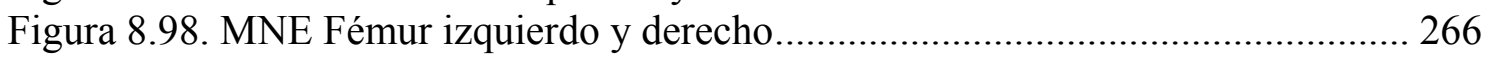

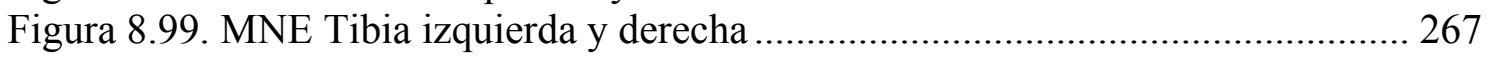

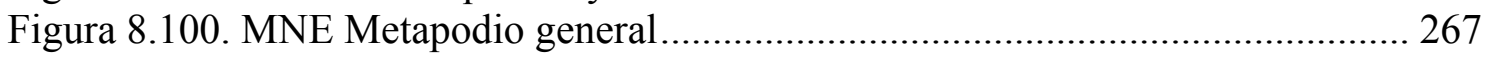

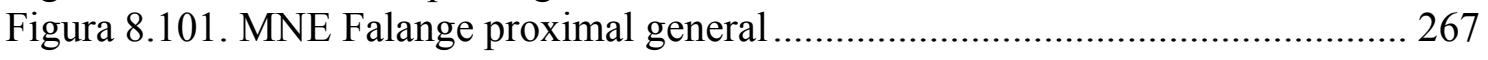




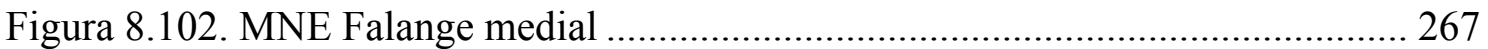

Figura 8.103. Abundancia relativa de elementos esqueletarios................................. 268

Figura 8.104. a) Módulos de tamaño expresado en NISP y b) tipo de fractura. .......... 269

Figura 8.105. Fragmentación del conjunto no camélido expresado en NSP. a) Tamaño

corporal 1, b) Tamaño corporal 2 y c) Tamaño corporal 4........................................ 271

Figura 8.106. Estadios de meteorización según tamaño corporal. Estructura 4 -

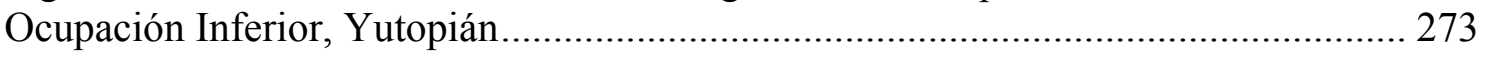

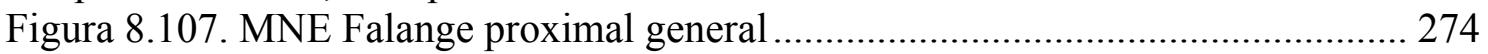

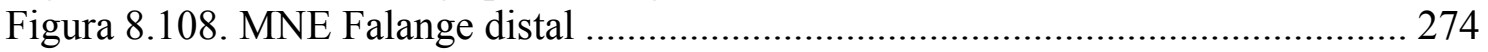

Figura 8.109. Módulos de tamaño expresado en NISP para especímenes y elementos del

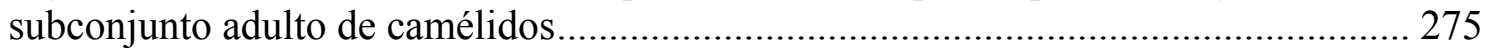

Figura 8.110. Estadios de meteorización según tamaño corporal. Estructura 5, Yutopián

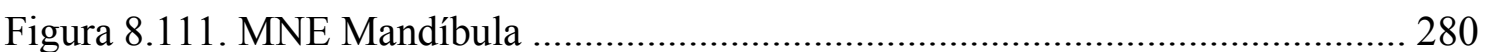

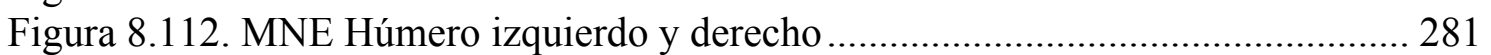

Figura 8.113. MNE Metacarpo izquierdo y derecho ................................................... 282

Figura 8.114. MNE Innominado izquierdo y derecho .............................................. 282

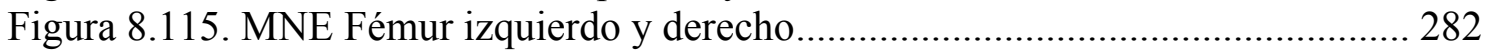

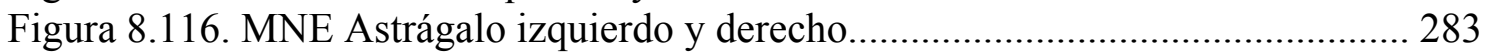

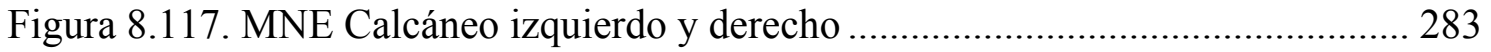

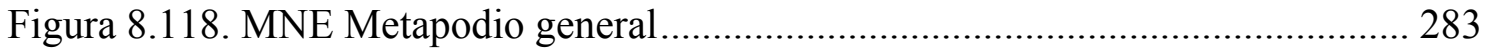

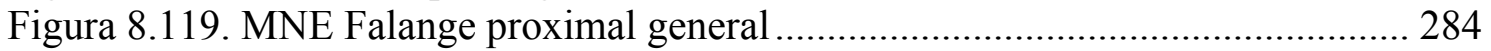

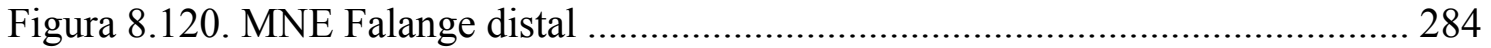

Figura 8.121. Abundancia relativa de elementos esqueletarios.................................... 286

Figura 8.122. a) Relación \%MAU VS FUI huesos “no-largos"; b) Relación \%MAU VS

FUI huesos "largos"; c) Relación \%MAU VS Cavidad Medular. ............................... 287

Figura 8.123. Módulos de tamaño expresado en NISP para especímenes y elementos del

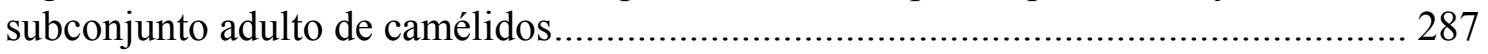

Figura 8.124. Fragmentación de elementos del esqueleto axial.................................. 288

Figura 8.125. Fragmentación esqueleto apendicular delantero (izquierdo y derecho). 288

Figura 8.126. Fragmentación esqueleto apendicular trasero (izquierdo y derecho).... 289

Figura 8.127. Cantidad (NISP) de especímenes y elementos del subconjunto adulto de

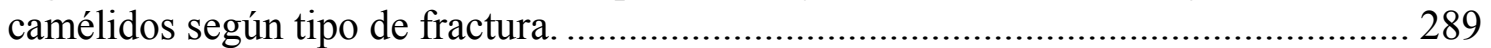

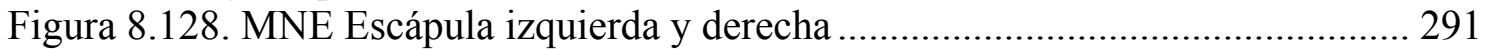

Figura 8.129. MNE Radioulna izquierda y derecha .................................................. 291

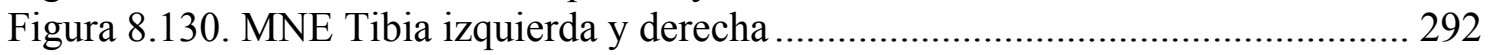

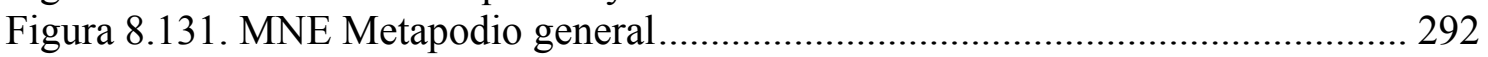

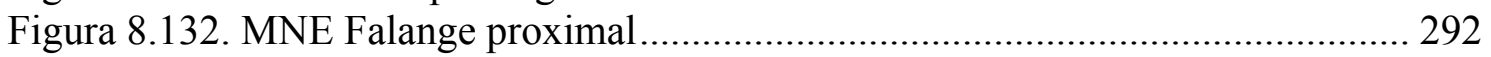

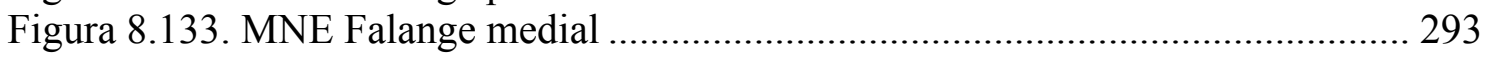

Figura 8.134. Abundancia relativa de elementos esqueletarios.................................... 294

Figura 8.135. Módulos de tamaño expresado en NISP para especímenes y elementos del subconjunto subadulto de camélidos ............................................................................ 294

Figura 8.136. Fragmentación del conjunto no camélido expresado en NSP. a) Tamaño

corporal 1, b) Tamaño corporal 2 y c) Tamaño corporal 4........................................ 296

Figura 8.138. Estadios de meteorización según tamaño corporal. Estructura 11,

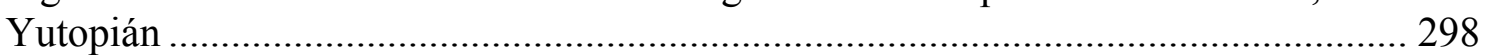

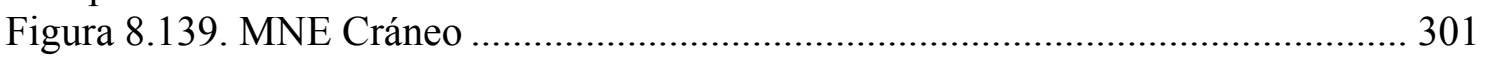

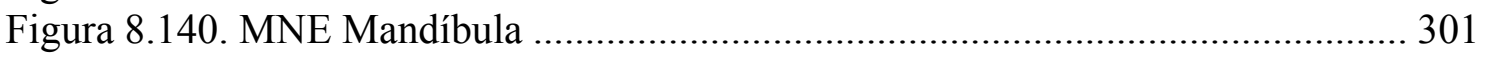

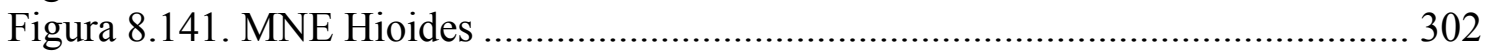

Figura 8.142. MNE Húmero izquierdo y derecho ................................................... 302 


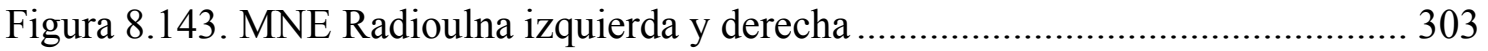

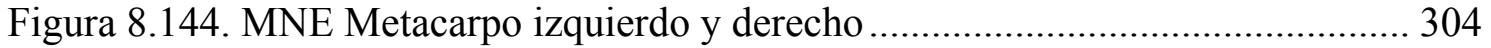

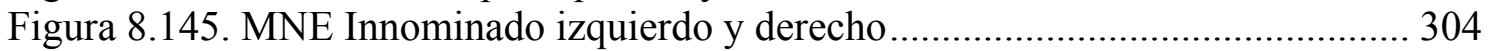

Figura 8.146. MNE Fémur izquierdo y derecho........................................................... 304

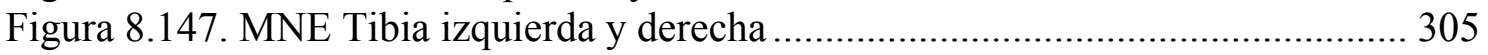

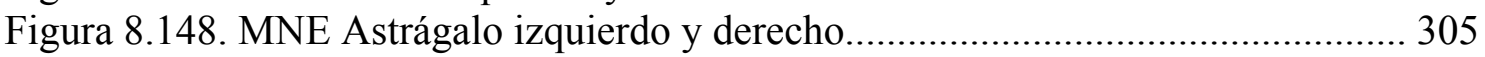

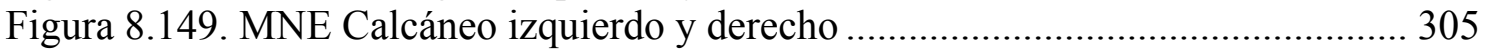

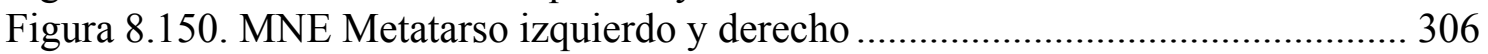

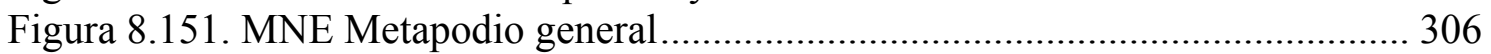

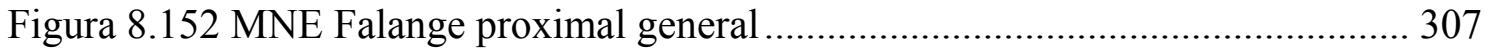

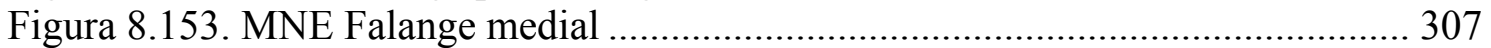

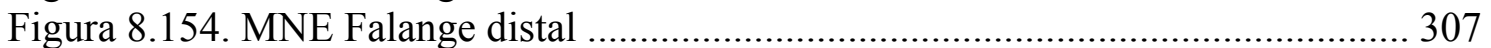

Figura 8.155. Abundancia relativa de elementos esqueletarios.................................. 309

Figura 8.156. a) Relación \%MAU VS FUI huesos "no-largos"; b) Relación \%MAU VS

FUI huesos "largos"; c) Relación \%MAU VS Cavidad Medular. ................................ 310

Figura 8.157. Módulos de tamaño expresado en NISP para especímenes y elementos del

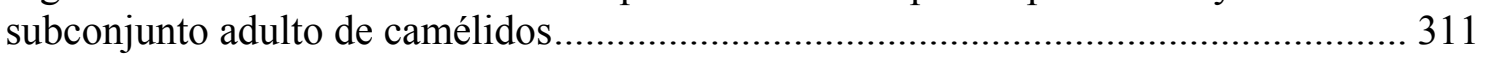

Figura 8.158. Fragmentación de elementos del esqueleto axial................................. 311

Figura 8.159. Fragmentación esqueleto apendicular delantero (izquierdo y derecho). 312

Figura 8.160. Fragmentación esqueleto apendicular trasero (izquierdo y derecho)..... 312

Figura 8.161. Cantidad (NISP) de especímenes y elementos del subconjunto adulto de

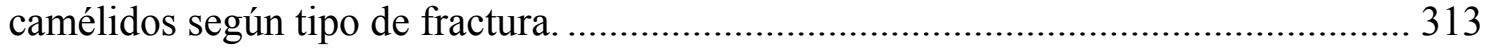

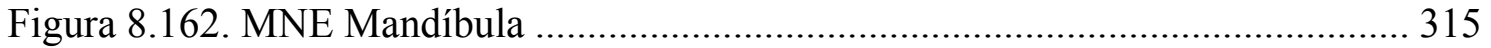

Figura 8.163. MNE Húmero izquierdo y derecho ......................................................... 315

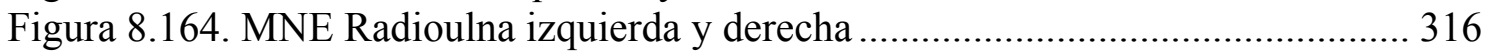

Figura 8.165. MNE Metacarpo izquierdo y derecho ................................................. 316

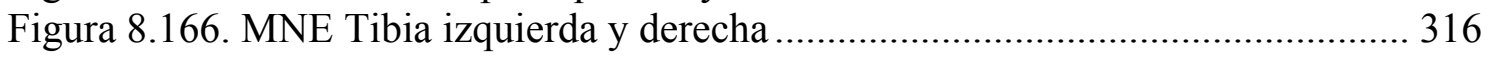

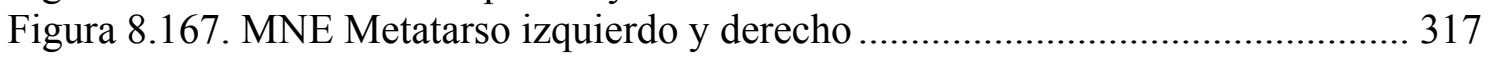

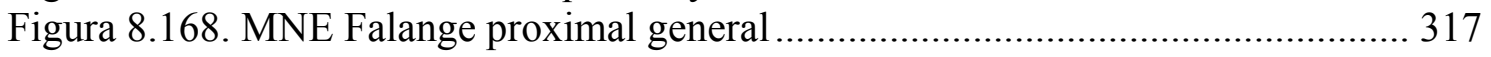

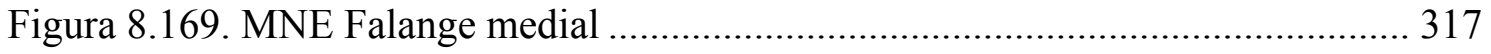

Figura 8.170. Abundancia relativa de elementos esqueletarios.................................. 318

Figura 8.171.a) Módulos de tamaño expresado en NISP para especímenes y elementos del subconjunto subadulto de camélidos, b) Cantidad (NISP) de especímenes y elementos del subconjunto subadulto de camélidos según tipo de fractura.

Figura 8.172. Fragmentación del conjunto no camélido expresado en NSP. a) Tamaño

corporal 1, b) Tamaño corporal 2 y c) Tamaño corporal 4 ......................................... 322

Figura 9.2. Meteorización de los conjuntos. a) Depósito I, b) Depósito II, c) Depósito

III, d) Depósito IV, e) Depósito V, f) Depósito VI. Bañado Viejo. .............................. 325

Figura 10.1. Distribución de especímenes en la Estructura 3. a) Tamaño corporal 1, b)

Tamaño corporal 2, c) Tamaño corporal 4 ............................................................ 338

Figura 10.2. Distribución de camélidos en la Estructura 3. a) Adultos, b) Subadultos.338

Figura 10.3. Remontajes de elementos. Estructura 4 ............................................. 342

Figura 10.4. Distribución de especímenes en la Estructura 4 Ocupación Superior. a)

Tamaño corporal 1, b) Tamaño corporal 2, c) Tamaño corporal 4............................ 343

Figura 10.5. Distribución de camélidos en la Estructura 4 Ocupación Superior. a)

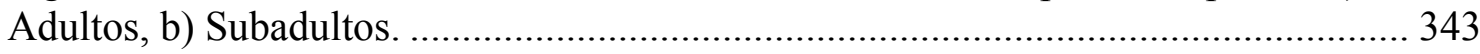

Figura 10.5 Distribución de especímenes en la Estructura 1. a) Tamaño corporal 1, b)

Tamaño corporal 2, c) Tamaño corporal 4. .......................................................... 345

Figura 10.6. Distribución de camélidos en la Estructura 1. a) Adultos, b) Subadultos.346

Figura 10.7. Distribución de camélidos en LANE. a) Adultos, b) Subadultos. ............ 348 
Figura 10.8. Distribución de especímenes en la Estructura 1. a) Llama 1, b) Guanaco, c)

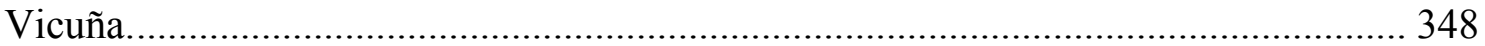

Figura 10.9. Representación diferencial de partes esqueletales básicas de camélidos. a)

Adultos y b) Subadultos 352

Figura 10.10. Distribución de especímenes de camélidos. LANF. a) Adultos, b)

Subadultos. 354

Figura 10.11. Representación diferencial de partes esqueletales básicas de camélidos. a) Adultos y b) Subadultos 355

Figura 11.1. Proporción de camélidos no identificados e identificados a nivel de especie. 363

Figura 11.8. Proporción de camélidos adultos y subadultos. 367

Figura 11.9. Índice de Artiodáctilos según Bloque Temporal....................................... 368

Figura 11.10.Proporción de especies de camélidos. 369 


\section{Agradecimientos}

Durante más de cuatro años la finalización de esta Tesis Doctoral fue un objetivo que comenzó siendo algo personal y que terminó siendo una cuestión familiar. Muchas cosas sucedieron en el camino y por suerte puedo escribir que éste no lo he recorrido solo.

Hay mucha gente a la que agradecer, no solo por su apoyo en el plano profesional sino también en momentos en que la moral no estaba lo suficientemente alta como para poner todas las ganas en lograr este objetivo. Espero sepan disculpar los olvidos que pudiera cometer.

En primer término deseo agradecer a las instituciones que me permitieron llegar a la conclusión de esta tesis: al CONICET por confiar en mis habilidades y antecedentes a través de una Beca de Formación de Postgrado para desarrollar un tema que estaba olvidado para la arqueología del noroeste argentino; al Museo Etnográfico "Juan B. Ambrosetti" de la Facultad de Filosofía y Letras de la Universidad de Buenos Aires, especialmente en la persona de su Director el Dr. José Antonio Pérez Gollán, por brindarme el espacio institucional para desarrollar mi trabajo; a la Fundación Antorchas por otorgarme un Subsidio de apoyo para la finalización de doctorado (Proyecto 1418857). Por último a los Doctores Robert Kelly y Marcel Kornfeld (como director del George C. Frison Institute of Archaeology and Anthropology) de la University of Wyoming, quienes me permitieron a través de una beca ingresar al estudio de las faunas de las grandes llanuras de Norte América y así comenzar mi especialización en el estudio de arqueofaunas.

Mucha gente me acompañó en estos años, principalmente mi guía y mentora en asuntos de arqueología del noroeste argentino, la Lic. M. Cristina Scattolin. Aun recuerdo cuando en el año 1998 me ofreció el material faunístico recolectado por ella en más de veinte años de campañas arqueológicas. Espero que esta tesis refleje de algún modo la calidad del trabajo realizada por ella en el campo. Por último no sólo me ayudó a comprender la importancia de lo que estaba haciendo sino que brindó su apoyo en todo momento. 
La ayuda y apoyo de mi directora de Tesis, la Dra. Laura Miotti, fue siempre estimulante logrando solucionar mis dudas y teniéndome actualizado en las últimas actividades de los colegas zooarqueólogos.

Durante mi estancia en Estados Unidos un grupo de personas hicieron que la identificación de un fragmento de hueso al mayor nivel posible se convirtiera en un juego. Estos fueron mis compañeros de laboratorio en el Edificio A1 en Laramie, Matt Hill, Dave Rapson y Laura Niven.

También quisiera agradecer a Oskar Burger, George y June Frison, Jonathan Kent, Edward Knell, Mary Lou Larson, Curtis Marean, Mike Peterson, Charles Chuck Reher, Audrey Shalinsky y Larry Todd, por compartir sus experiencias y conocimientos conmigo. Para completar la sección internacional deseo expresar mi agradecimiento nuevamente a Bob Kelly, a su esposa Lin Poyer, y sus hijos Matthew y Dycus quienes nos hicieron sentir como en casa en nuestra estancia en Laramie.

En la Argentina muchos colegas me ofrecieron su ayuda y conocimientos para avanzar en el estudio de faunas del noroeste argentino, estoy especialmente agradecido de la paciencia de Willie Mengoni Goñalons, Myriam Tarragó y Luis Borrero. Gracias a Salomón Hocsman por compartir información y bibliografía inédita. A Jorge Martínez por su constante preocupación por el desarrollo de esta Tesis.

Joan Gero, junto a Cristina Scattolin, me permitieron gentilmente acceder a la fauna del sitio Yutopián.

Quisiera agradecer a la UEP por estos años de compañerismo. Mariela Hernández tuvo que aguantar miles de disquisiciones sobre la tesis. Carlos "Charly" Romero, Matías Tolosa Chaneton, Federico Ferella y Rodrigo Velásquez Fuica me ayudaron a solucionar miles de problemas con las bases de datos y los programas de diseño y de GIS. Karina Beneventano y Luis Echeverría fueron mis compañeros “tesistas". Gerardo Tozzi brindo la paz mental y los tiempos que necesitaba para terminar esta tarea. Eleonora Levin me ayudo de mil maneras para que pudiera aprovechar los tiempos en la UEP, gracias Eleo. Pablo Velásquez Fuica compartió viajes y tareas. La Lic. Carolina Galcerán apoyó este trabajo de mil y una maneras, cubriendo los momentos en los que necesitaba concentrarme en escribir y eligiendo lugares cerca de La Plata en mis últimos viajes para que me quedara tiempo para finalizar esta tesis, gracias Caro. A Jorge Andrade quien a brindó el tiempo necesario para tomar cursos y capacitarme. A Sergio Etcheto. 
Al equipo: Fabiana Bugliani, Lucas Pereyra Domingorena, Marisa Lazzari, Leticia Martínez y Cecilia Fraga.

Un agradeciemientno muy especial les debo a Graciela Leguizamón y a la Lic. Fernanda Esnaola.

Mi familia ha participado en el desarrollo de esta carrera por lo cual agradezco a mis padres y hermanos por entender mis ausencias.

Por último quiero agradecer especialmente y desde lo profundo de mi corazón a Roxana, mi querida y paciente esposa. Gracias a su ayuda y durante la redacción de cada una de las partes de esta tesis, en las que tuvo mucho que ver, tuve el ánimo necesario para llegar a la meta. Sin ella nada tendría sentido.

A Mercedes que con su amor me ha permitido comprender lo maravilloso de esta vida. 
Parte 1 - Introducción General 
El carácter de la presente Tesis Doctoral surge en el marco de un proyecto mayor de estudios regionales sobre las sociedades agropastoriles prehispánicas del Sur de los Valles Calchaquíes, cuyo objetivo general es "determinar la naturaleza de los sistemas aldeanos del Período Formativo (Primer milenio A. D.), que sirvieron de base al desarrollo de los sistemas socioeconómicos más complejos de las sociedades semiurbanas del Período de Desarrollos Regionales en los valles del noroeste argentino". Tal proyecto investiga una dinámica y por tanto requiere considerar un lapso temporal que abarque la transformación mencionada, es así que enfoca la primera parte del mencionado desarrollo, esto es, las bases formativas (Scattolin 1990, 1994b, 2000).

Esta Tesis se orienta en particular al análisis de la composición de los conjuntos arqueofaunísticos de sitios arqueológicos del sur de los valles Calchaquíes (Valle de Santa María - Departamento de Santa María y Andalgalá, Provincia de Catamarca, Departamento de Tafí, Provincia de Tucumán y el Valle del Cajón - Departamento de Santa María, Provincia de Catamarca), en la región Valliserrana, asociados a sistemas aldeanos del Período Formativo. De esta manera se busca llenar un vacío de información fundamental acerca de la base de subsistencia de estas aldeas antiguas. Se trata asimismo de proveer un corpus de información que contribuya al conocimiento de la reproducción y economía doméstica en las comunidades aldeanas prehispánicas.

A través de la obtención de nuevos datos se pretende generar un modelo relacionado con el sistema de subsistencia (caza-pastoreo) de los habitantes de estas aldeas, a la vez que se intenta contribuir al conocimiento de la variabilidad general de recursos animales, a la diferenciación de especies domésticas y silvestres de camélidos y a la incidencia de la fauna menor en tal espectro de recursos. Se espera que finalmente provea una base de datos más precisa para comprender el rol que haya tenido la caza y el pastoreo en tales economías mixtas así como a un entendimiento del consumo y distribución diferencial de recursos en el Período Formativo.

1.1. Antecedentes arqueológicos del área y de estudios faunísticos en el noroeste argentino 
Las sociedades que trataremos en este trabajo han sido caracterizadas como comunidades aldeanas que vivieron desde unos 500 años a. $\mathrm{C}$ y durante el primer milenio A. D. Siguiendo a Scattolin (2002) se considerará:

“al Período Formativo en un sentido amplio, que "abarca las ocupaciones o componentes arqueológicos agroalfareros anteriores al Período Tardío o de los Desarrollos Regionales (de los poblados aglomerados y jefaturas establecidas y luego confederadas contra los españoles) cuyo comienzo se postula hacia 'fines del siglo IX" y que presentan cerámica de estilo santamariano' (Tarragó et al. 1997:224)"

De manera muy general, se trata de grupos que vivieron en la zona de la puna, pre-puna y en los piedemontes y fondos de los valles inter-montanos del noroeste argentino. Y están caracterizadas principalmente por: a) La presencia de cerámica, y otros bienes artesanales, b) Un sistema de subsistencia apoyado en la agricultura y el pastoreo y c) Un alto grado de sedentarización, con arquitectura remanente que muestra patrones de distribución dispersos o de escasa concentración (Scattolin 1994b), y que usualmente no muestra evidencias claras de intensificación del uso del espacio (Scattolin 1994a, 1994b)

Por el contrario, en áreas aledañas y muy cercanas a la tratada aquí se ha propuesto que estos sistemas socio-económicos sufrieron un proceso de complejización y de intensificación social y política creciente a lo largo del primer milenio A. D. que desembocaron en sistemas comparables a jefaturas o señoríos (Aguada) (Heredia et al. 1974, Pérez Gollán 1991, Tarragó 1984, 1994, Tarragó y Scattolin 1999).

En los últimos años el trabajo arqueológico sistemático realizado en el noroeste argentino se ha centrado en mayor parte en la excavación y posterior análisis de contextos domésticos, en los cuales no sólo se encuentran restos cerámicos, sino también conjuntos de instrumental lítico y óseo y restos de la base de subsistencia de estos grupos, es decir macro y micro restos vegetales y restos óseos de fauna (Pochettino y Scattolin 1991, Scattolin 1986). De la mano del análisis de estos contextos es que el estudio metódico de la fauna de los sitios arqueológicos comenzó a tomar importancia recién a partir de la década de 1970 (Raffino 1977, Raffino et al. 1977, Tonni y Laza 1977, Tarragó 1978, entre otros), lo cual es acorde al desarrollo de la 
disciplina tanto a nivel regional como mundial (para una historia de la zooarqueología se puede consultar: Lyman 1994b, Mengoni Goñalons 1988, Reitz y Wing 1999). Las primeras investigaciones presentan resultados de análisis de arqueofaunas provenientes de sitios arqueológicos de la Quebrada del Toro (Raffino et al. 1977, Tonni y Laza 1977) y del norte del valle Calchaquí (Tarragó 1978) y fueron los que sentaron las bases sobre las que se comenzó a discutir el problema de la identificación de las especies de importancia económica para los pueblos prehispánicos del noroeste argentino. Allí se pueden encontrar interpretaciones acerca de los perfiles etarios de las muestras y la aplicación de metodologías que permitieron identificar la presencia de animales domésticos y silvestres en los conjuntos arqueológicos.

Sobre dichos análisis se construyó una caracterización de la economía de las sociedades del Período Formativo y períodos posteriores, caracterizándose a estos pueblos como poseedores de una economía agro-pastoril, pero sin determinar qué componente correspondía al consumo o utilización de animales domésticos o el aporte de la caza dentro de su sistema.

Luego de estas publicaciones acerca de la fauna de sitios formativos el estudio de este tema se ve interrumpido por diversas causas. Los trabajos en los años siguientes no tienen al estudio de las faunas como tema central, hasta que a fines de la década de 1980 vuelve cierto interés en este tipo de temas. Esta vez la incorporación de la corriente teórica procesual traída por investigadores que ya la habían aplicado en faunas de otras regiones como la Patagonia argentina lleva a la búsqueda de datos de base en cuanto a la composición de los conjuntos arqueofaunísticos de los sitios del noroeste argentino, integrando a esta región en discusiones referentes a temas como la domesticación a nivel regional y supra regional (Yacobaccio 1988, entre otros). Además el interés se centró en el estudio de procesos tafonómicos, en la composición etaria de los conjuntos y se intentó utilizar por primera vez el uso de la osteometría con el fin de identificar el componente doméstico del silvestre. Es a partir de esta década que el volumen de publicaciones sobre estudios faunísticos comienza a cobrar gran importancia, centrándose en gran medida en sitios correspondientes en la Puna tanto de Catamarca como la de Jujuy.

Desde esa fecha se han efectuado grandes avances en lo referente a la metodología de estudio de conjuntos faunísticos. Gran parte de esos avances se han aplicado a la comprensión de los procesos de domesticación de camélidos durante épocas arcaicas en el noroeste argentino (Aschero et al. 1991, Elkin 1996, Olivera 
1992), el análisis de fibras de camélidos para su identificación específica (Reigadas 1994, 2001), análisis de la arqueofauna en contextos pastoriles (Madero 1992), estudios actualísticos tales como experiencias tafonómicas (Nasti 1991, 1994/95) y estudios etnoarqueológicos (Yacobaccio y Madero 1994).

Analizando los trabajos de esta época se puede advertir la presencia de datos relacionados con las proporciones de camélidos juveniles en relación con adultos denominados Perfiles de Edad. Este dato es de suma importancia ya que sobre ellos se han construido modelos de utilización del recurso camélido para las sociedades del formativo de las áreas puneñas. Además para los períodos anteriores esta medida ha contribuido sustancialmente a la comprensión del proceso de domesticación precedente. Por otra parte el conocimiento de las edades de muerte de los distintos animales es un dato muy informativo para conocer la utilización diferencial de la fauna en distintos contextos domésticos.

Hasta la fecha los modelos de subsistencia relacionados a los pueblos del Período Formativo del noroeste argentino han estado basados en los análisis propuestos para la Puna (Puna Jujuy - Yacobaccio et al. 1998, Madero 1992, Puna Atacama - Antofalla Olivera 1992, 1998, Elkin 1996, Haber 1999, López Campeny 1999). A diferencia de lo que ocurre en esa región, en el área Valliserrana del noroeste argentino existen escasos estudios intensivos de conjuntos faunísticos de sitios del Período Formativo por lo que proporcionalmente la intensidad de investigación detallada y de estudios arqueofaunísticos sofisticados para las aldeas Formativas en los valles es menor. Luego de los trabajos pioneros para la Quebrada del Toro (Raffino 1977, Raffino et al. 1977, Tonni y Laza 1977) se tardaron casi veinte años para que se volviera a centrar la atención en el estudio de las arqueofaunas de los valles con diversos intereses como la exploración de las faunas a nivel de sitio arqueológico, a nivel regional o el re-análisis de viejas colecciones (Bonnin 1997, Izeta y Scattolin 2001, Nasif y Gómez Cardozo 1999). Recién a finales de la década de 1990 comienzan a recobrar importancia los estudios de faunas de los valles mesotermales del noroeste argentino con temas de estudio tales como la arqueofauna de sitios ceremoniales (Olivera 2001, Nasif y Gómez Cardozo 1999) y de contextos domésticos y no domésticos (Ambato - Bonnin 1997, La Rioja - A. Rex González 1998, Santa María - Izeta y Scattolin 2001, Scattolin et al. 2001).

En los últimos años y en cuanto a aspectos metodológicos se ha avanzado en la aplicación de técnicas estadísticas multivariadas para identificar diferencias entre las 
especies de camélidos (Cartajena y Concha 1997, Yacobaccio et al. 1998, Izeta 2002) y en la creación de índices de utilidad a partir de camélidos domésticos (Mengoni Goñalons 1991, 1996, 2001, Olivera 2001) entre otras líneas de investigación.

Hoy en día los estudios de arqueofaunas siguen avanzando en la región de los valles mesotermales y se espera que esta Tesis Doctoral sea un aporte valioso para la comparación de los conjuntos de esta región con los ya estudiados en regiones aledañas.

\subsection{Objetivos de la Tesis}

Cuestiones como la relación caza/pastoreo y pastoreo/agricultura, en economías mixtas no intensivas como las propuestas para las sociedades formativas (Raffino 1977, Tarragó 1978), son capitales para interpretar los procesos aldeanos prehispánicos del noroeste argentino y para buscar respuestas explicativas a sus modalidades económicas. Por ello es de fundamental importancia abordar el análisis de la arqueofauna, realizado con la debida profundidad, integrándolo al resto de las interpretaciones de este pasado.

Por otro lado la mayor parte de nuestras inferencias se refieren a la esfera de obtención $\mathrm{y}$, eventualmente, a la de producción o reproducción de los recursos faunísticos (hatos de camélidos). No obstante, si no contamos siquiera con la información de base, se hace arduo avanzar en aquellos aspectos económicos de más difícil acceso pero que justamente atañen a las sociedades que tratamos. Uno de ellos son las condiciones de consumo y distribución o acumulación de tales recursos.

Varios de los modelos actuales del Período Formativo en el noroeste argentino plantean la hipótesis de que durante el primer milenio A. D. se producen procesos de complejización social que tienen que ver con la distribución desigual de bienes y recursos (Pérez Gollán 1991, Tartusi y Núñez Regueiro 1993). Lo precedente se ha planteado sobre la base del reconocimiento de patrones arquitectónicos particulares y de áreas de actividad doméstica, los cuales han sido ampliamente discutidos en la región y han aportado una gran cantidad de datos para el lapso considerado. Esto ha permitido, a su vez, afinar más la resolución de las cronologías y reconocer mejor las dispersiones de los estilos o de los acervos culturales particulares durante el tiempo considerado lo cual ha ayudado también a comprender las trayectorias temporales de los procesos de transformación de las comunidades aldeanas.

Tomando como punto de partida tales hipótesis, esta Tesis intenta contribuir, en última instancia, al debate que se está desarrollando en la actualidad referente a la 
distribución y consumo diferencial desde la perspectiva de la subsistencia. Asimismo a la expresión en los cambios hacia la intensificación de los recursos y su potenciación puesto que los restos de fauna han aportado menos a la discusión de los cambios en las trayectorias de estos sistemas en transición a la complejidad al menos en el sector Argentino-Chileno de los Andes Centro Sur y Meridionales. Por ello nos proponemos plantear por ejemplo si los cambios hacia la especialización que se observan en los conjuntos de bienes artesanales de cerámica y metal del Período Formativo se correlacionan o no con modificaciones en los conjuntos arqueofaunísticos asociados. Preguntas tales como: ¿hubo intensificación agropecuaria? o ¿diferenciación regional del manejo de los recursos? o ¿utilización divergente de conjuntos de recursos? pueden ser respondidas a través del estudio de los conjuntos arqueofaunísticos. Por otro lado y más allá del aporte -por lo demás inestimable- del conocimiento de la base de subsistencia aldeana ¿cómo podrían los innumerables huesos encontrados en tantos asentamientos colaborar en el entendimiento de las trayectorias de cambio socioeconómico del Formativo?

Entonces es que a través de la obtención de nuevos datos se pretende como objetivo general generar un modelo relacionado con el sistema de subsistencia (cazapastoreo) de los habitantes de las aldeas del Periodo Formativo del Sur de los Valles Calchaquíes, a la vez que se intenta contribuir al conocimiento de la composición de los conjuntos arqueofaunísticos provenientes de sitios arqueológicos de la región y con ello evaluar la información potencial de estos conjuntos en relación a las preguntas planteadas precedentemente.

Para cumplir con este objetivo general se plantearon los siguientes objetivos específicos:

1. Analizar de manera cualitativa las muestras de los sitios del Sur de los Valles Calchaquíes, con el objeto de establecer especies representadas.

2. Analizar de manera cuantitativa las muestras, con el objeto de establecer composición de partes esqueletarias, perfil etario, porcentajes de identificación, etc.

3. Evaluar comparativamente las muestras disponibles para establecer la relación componente de caza versus pastoreo con el objeto de establecer las diferencias y similitudes en la composición de partes esqueletarias y clases de edad entre ambos.

4. Comparar nuestros resultados con otros datos publicados para la misma región.

5. Proveer un corpus de información que contribuya al conocimiento de la reproducción y economía doméstica en las comunidades aldeanas prehispánicas. 
Finalmente los intereses perseguidos en esta Tesis a través del análisis cualicuantitativo de los conjuntos arqueofaunísticos del sur de los valles Calchaquíes pueden resumirse en:

1. la economía y tecnología prehistórica de las aldeas formativas del sur de los valles Calchaquíes, con particular referencia a la importancia de las especies faunísticas representadas en las muestras recuperadas, los patrones de marcas y de fracturas y, la formatización de elementos.

2. la identificación de las especies presentes en las muestras.

3. la posible significación de la fauna para la dieta de los antiguos pobladores de las aldeas Formativas.

4. los procesos de formación del registro arqueológico, con particular referencia a distinguir la incidencia de las variables naturales (procesos tafonómicos) respecto de las culturales (procesos antrópicos) a lo largo de la historia de un sitio arqueológico.

\subsection{Organización de la Tesis}

Por lo presentado más arriba como el estado de la cuestión es imprescindible el tratamiento intensivo de estudios arqueofaunísticos en contextos formativos del sur de los valles Calchaquíes, ya que su potencial para el estudio de, al menos, el cambio ambiental y socioeconómico ha sido planteado en otras partes del mundo y de este modo desarrollarlo orgánicamente en este sector del espacio. Formulado así, esta Tesis se presenta entonces en cuatro partes principales. En la Parte 1 se ofrece el marco ambiental y geográfico en el cual se centra el presente estudio. En la Parte 2 se presentan los aspectos teóricos metodológicos utilizados, a la vez que se plantean una serie de expectativas con respecto al registro arqueofaunístico basados principalmente en la utilización de distintos modelos de transporte, reparto y consumo. En la Parte 3 se tratan los conjuntos recuperados de los sitios analizados. Por último la Parte 4 presenta la discusión de los resultados obtenidos y las conclusiones surgidas de ella, a la vez que se presentan nuevas propuestas para investigaciones futuras. 
El sector delimitado para este estudio corresponde al área que se extiende desde aproximadamente los $65^{\circ}$ Longitud $\mathrm{W}$ hasta los $65^{\circ} 30^{\prime}$ Longitud $\mathrm{W}$ y desde los $26^{\circ}$ Latitud S hasta los $27^{\circ} 30^{\prime}$ Latitud S (Figura 2.1). Abarca varias unidades orográficas importantes: dos grandes valles (del Cajón y Santa María), una depresión tectónica (el Campo del Arenal) y al menos dos cadenas montañosas (la Sierra del Aconquija y Sierra del Cajón). Estos valles se ubican en la porción nor-occidental de la Provincia de Tucumán (Departamento de Tafí) y nor-oriental de la Provincia de Catamarca (Departamentos de Santa María y Andalgalá).

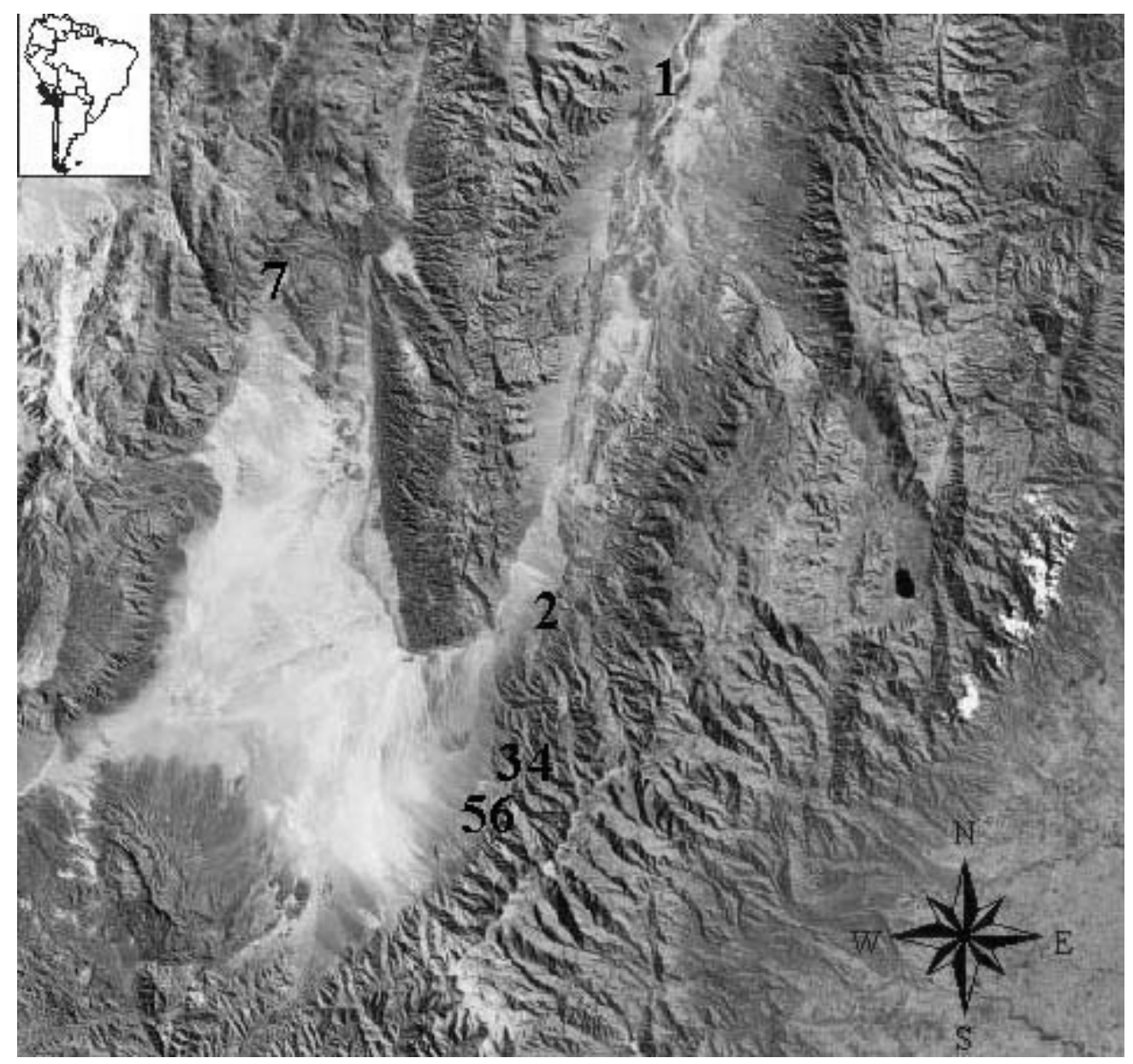

Figura 2.1. Foto satelital del área de estudio.

1: Bañado Viejo; 2: Morro de las Espinillas; 3: Tesoro 1; 4: Antigal de Tesoro; 5: Loma Alta; 6: Potrero Antigal; 7: Yutopián. 
Estos dos valles tienen una orientación norte-sur y se componen de formas topográficas negativas (depresiones como los fondos de valle) y elementos topográficos positivos (elevaciones) (Fauque y Strecker 1987, Galván 1981, Ruiz Huidobro 1972, Turner 1973).

Entre los primeros se encuentran las sierras que delimitan las depresiones. Estas son de Este a Oeste: Cumbres Calchaquíes y Sierra del Aconquija, Sierra del Cajón o de Quilmes y Sierra de las Cuevas y Chango Real. Estos cordones poseen orientaciones norte-sur ubicándose paralelamente entre si. Las elevaciones promedio van desde los $3000 \mathrm{msnm}$ a los $5500 \mathrm{msnm}$, presentando las cumbres más elevadas nieves eternas que alimentan los cauces de cursos de agua permanentes.

Las depresiones más claras son tres: el fondo del valle del Cajón, el Campo del Arenal y el fondo del valle de Santa María. Los dos fondos de valle se encuentran surcados por una única corriente de agua que en el valle del Cajón se denomina río Cerros Colorados y en el valle de Santa María se lo conoce como río Santa María. El primero de estos posee una orientación norte-sur y el segundo sur-norte. El Campo del Arenal es una depresión de origen tectónico compuesta principalmente por dunas de arena y es el lugar en el cual desaguan las corrientes permanentes originadas en la Falda Occidental del Aconquija.

Dentro de esta gran área se focalizó el trabajo en tres sectores principales: la Falda Occidental del Aconquija, el valle del Cajón y el valle de Santa María. Dentro de estos consideramos las siguientes localidades: Tesoro y Cerrillos para la Falda Occidental del Aconquija; La Quebrada para el valle del Cajón; y El Bañado y Pajanguillo para el valle de Santa María.

\subsection{La Falda Occidental del Aconquija}

La Falda Occidental del Aconquija se encuentra ubicada en la parte centro oriental de la Provincia de Catamarca, Departamentos de Santa María y Andalgalá. Scattolin (2001) define a este sector como:

"una faja de ancho variable que se extiende sobre el piedemonte de la Sierra de Aconquija desde los $27^{\circ} 5^{\prime}$ de Latitud S y $66^{\circ} 5^{\prime}$ de Longitud $\mathrm{W}$ a los $27^{\circ} 15^{\prime}$ de Latitud S y los $66^{\circ} 15^{\prime}$ de Longitud W. Dicha faja está ubicada entre las cotas de 2.500 y $3.100 \mathrm{msnm}$, limitando al norte con el extremo sur del valle de Santa María y por el sur con la Sierra de Capillitas y flanqueada por dos importantes 
unidades orográficas: la Sierra del Aconquija al Este Sud Este (ESE) y el Campo de Arenal al Oeste Nor Oeste (ONO)" (ver Figura 2.2)

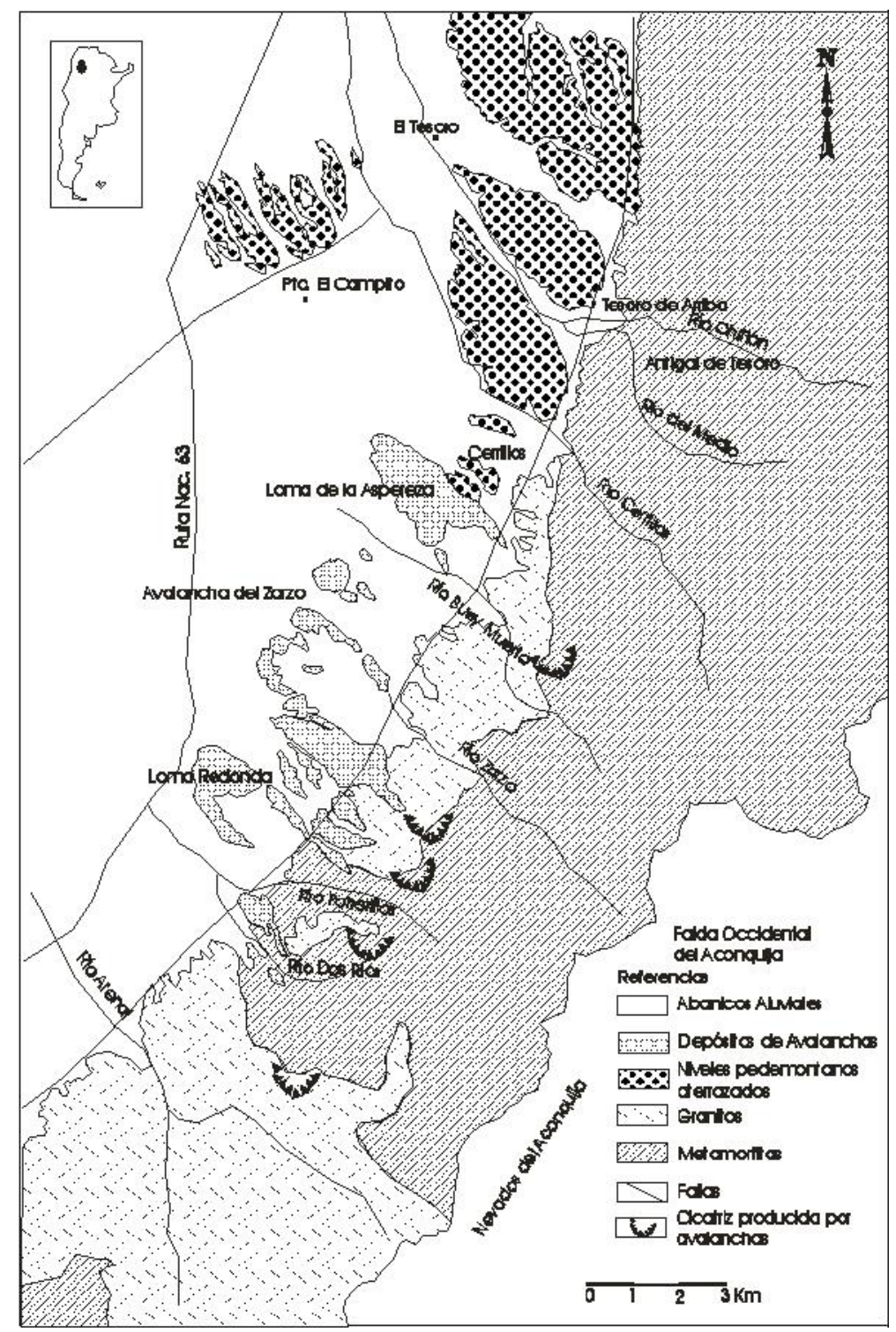

Figura 2.2. Falda Occidental del Aconquija (adaptado de Fauque y Strecker 1987)

La Falda Occidental del Aconquija se caracteriza por poseer un clima árido y seco en contraste con el sector oriental que es húmedo. Esta variación en los ambientes se produce por las grandes alturas $(5500 \mathrm{msnm})$ de la sierra del Aconquija (González Bonorino 1951, Scattolin y Korstanje 1994).

Al contrario de los sectores correspondientes a los valles (Santa María y del Cajón) este sector posee al menos once ríos principales que se nutren del agua producto del deshielo de los nevados permanentes ubicados en la Sierra del Aconquija. Estos son 
(de norte a sur): Tesoro, Del Medio, Cerrillos, Buey Muerto, Zarzo, Potrerillos, Dos Ríos, Arenal, Las Conchas, Mático y Blanco.

\subsection{1. Área de Tesoro}

Esta zona se encuentra surcada por el río homónimo, el cual es el que se ubica más al norte de todos los que componen la Falda Occidental del Aconquija. La zona de Tesoro esta dividida en tres secciones: Tesoro de Abajo, Tesoro de Arriba y el Antigal de Tesoro. La primera sección es la que se encuentra comprendida desde el borde del Campo del Arenal (2500 msnm) hasta los $2800 \mathrm{msnm}$ zona en la que se produce un encajonamiento del Río Tesoro a través de unos niveles pedemontanos aterrazados (Figura 2.2). La segunda comprende desde los $2800 \mathrm{msnm}$ hasta los $3200 \mathrm{msnm}$ y es la zona en la que se produce la unión de los ríos Chiflón y del Medio. Por último se encuentra la zona de Antigal de Tesoro que comprende desde los $3200 \mathrm{msnm}$ hasta los 3500 msnm donde comienza a apreciarse la zona de estepa arbustiva de transición. Son sobre estas dos últimas franjas en las cuales se localizan los sitios tratados en esta Tesis.

En general las franjas que no poseen acceso al agua suelen presentarse desprovistas de vegetación y el suelo suele ser arenoso. Por el contrario cuando el suelo es regado puede apreciarse un cambio notorio en la composición de la cubierta vegetal

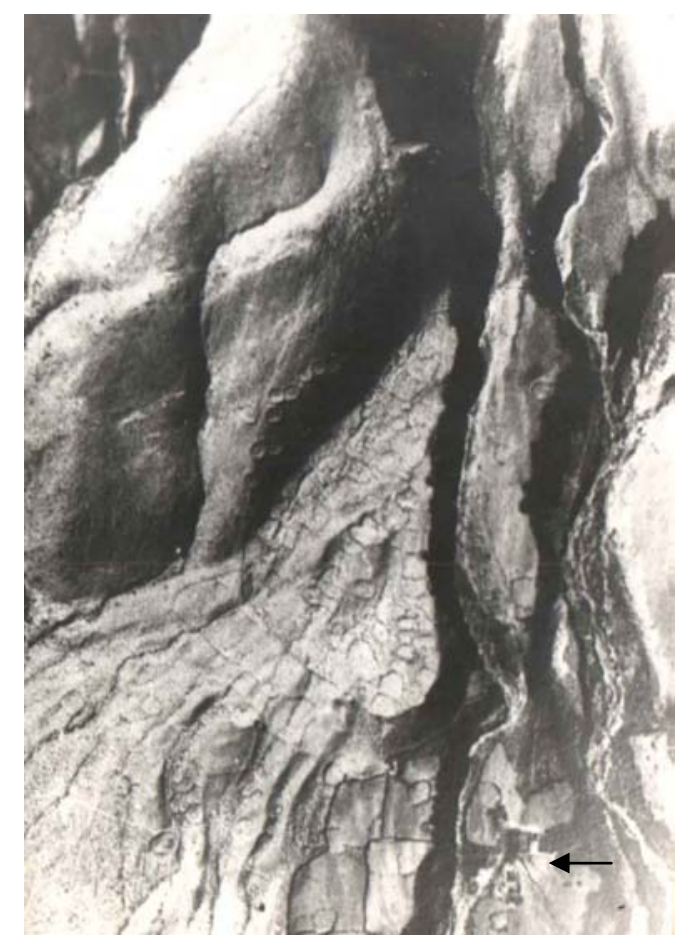

Figura 2.3. Foto aérea del área de Tesoro (Colección Scattolin). 
La franja que abarca Tesoro de Arriba esta compuesta por tres mesadas cortadas por los ríos Chiflón y del Medio lo que dificulta el paso de una mesada a otra (Figura 2.3). En la mesada ubicada más al norte es donde se encuentra el sitio Tesoro 1 y un puesto actual. En la mesada central se encuentra el sitio Antigal de Tesoro.

\subsection{2. Área de Cerrillos}

Esta zona se ubica alrededor del río Cerrillos y está comprendida entre la parte más austral de los niveles aterrazados de la zona de Tesoro y el depósito de avalancha denominado Loma de la Aspereza (Figura 2.2). El abanico aluvional que compone esta zona también esta compuesto por varias lomadas dentro de las cuales se encuentran dos sitios arqueológicos que serán tratados aquí. En una de las lomadas se encuentra el sitio Potrero Antigal, que se ubica en las cercanías de la estancia Cerrillos y la Escuela correspondiente a la localidad. Separada por la Quebradita de Lorohuasi se encuentra otra lomada en la cual se halla el sitio Loma Alta. La distancia entre una y otra es de aproximadamente $4 \mathrm{~km}$. Estas lomadas se encuentran en la cota de los $3000 \mathrm{msnm}$.

\subsection{El valle del Cajón}

El valle del Cajón posee una orientación Norte - Sur. Se encuentra delimitado al este por la Sierra del Cajón o de Quilmes y al oeste por un cordón compuesto por la Sierra de la Cuevas, Sierra Chango Real y los cerros Ciro, Laguna Piedrosa, Olla Quebrada, Ciénaga Redonda y Mollar (Turner 1973). Al sur se encuentra el Campo del Arenal.

La Sierra del Cajón posee alturas que van de los 2300 hasta los 3300 msnm decreciendo de norte a sur. Los cordones del Oeste poseen su altura máxima en el Cerro Mollar de $5.132 \mathrm{msnm}$. Los cerros nombrados anteriormente poseen alturas comprendidas entre los 4.000 y $4800 \mathrm{msnm}$. Cabe remarcar que al oeste del valle se presenta el borde sur-oriental de la Puna.

El valle del Cajón presenta varias corrientes de agua permanente. De norte a sur está el río Toroyaco que junto al río Ovejería conforman el río Cerro Colorado que desde la zona de Punta de Balasto pasa a denominarse río Santa María. El río presenta su cauce actual al pie de la Sierra del Cajón, es decir que sólo se ve favorecida por el agua la margen oriental del valle. Otro Cauce lo conforma el río La Quebrada que corre de norte a sur pero en el extremo occidental del valle. 
El fondo del valle se encuentra a una altura que va desde los $3200 \mathrm{msnm}$ al norte hasta los $2300 \mathrm{msnm}$ al sur. El largo del valle se estima en unos $65 \mathrm{Km}$. de largo y un ancho que varía entre $10 \mathrm{Km}$. al norte (a la altura de la localidad de La Hoyada) y unos $30 \mathrm{Km}$. en la zona en que el valle se une con el Campo del Arenal.

\subsection{1. Área de la Loma de Yutopián}

La Loma de Yutopián se ubica en la zona occidental del valle central. El área tal como fue definida "consiste en una mesada chata y elongada en dirección N-S que se extiende por aproximadamente $300 \mathrm{~m}$ de largo, con terrazas que descienden hacia los lados Gero y Scattolin (1994). En la actualidad existe una ocupación permanente cuyos habitantes se dedican al cultivo de vegetales y el pastoreo de animales.

\subsection{El valle de Santa María}

El valle de Santa María se ubica en el extremo nor-oriental de la Provincia de Catamarca (Departamento de Santa María) y el ángulo noroeste de la Provincia de Tucumán (Departamento Tafí). Tiene una longitud aproximada de $100 \mathrm{~km}$ y un ancho promedio de $20 \mathrm{~km}$. Este valle al igual que el del Cajón posee una orientación norte-sur. Al este lo limita la cadena montañosa del Aconquija y las Cumbres Calchaquíes (separadas por el Abra del Infiernillo). Al oeste se encuentra la sierra de Quilmes o el Cajón y al sur el Campo del Arenal. Las elevaciones principales se encuentran en la Sierra del Aconquija y van desde los 5000 msnm hasta los 3000 msnm en el Abra del Infiernillo. Las Cumbres Calchaquíes posen alturas máximas de 4700 msnm (Ruiz Huidobro 1972).

La corriente de agua más importante la conforma el río Santa María, que es la continuación del Río Cerros Colorados.

El valle presenta distintas unidades de paisaje: una es la compuesta por los abanicos aluvionales que presentan cursos de drenaje muy espaciados y cubiertos por estepa arbustiva, otro lo compone el fondo del valle con la planicie aluvial del Río Santa María que se encuentra bordeada por bosque marginal, otra lo componen los niveles aterrazados con quebradas transversales del este del valle y por último las altas laderas occidentales y orientales (Bolsi 1967: 125) 


\subsection{1. Área de El Bañado}

La zona del Bañado se ubica en la parte Central del valle de Santa María. El sector se caracteriza por estar compuesto por un terreno arenoso y ondulado, de superficie sin cubierta herbácea pero con vegetación arbórea y arbustiva en la que se presentan relictos del bosque de algarrobos (Scattolin et al. 2001).

\subsection{2. Área de Pajanguillo}

Esta es la localidad más meridional del valle de Santa María y se ubica en la confluencia del río Pajanguillo con el río Santa María. Actualmente ésta se localiza a unos 5 kilómetros al este de la actual localidad de Punta de Balasto (Scattolin 2002). La altura de la zona corresponde a una media de unos 2000 metros sobre el nivel del mar.

\subsection{La fauna}

La región en estudio presenta distintas unidades de paisaje que en la actualidad presentan una distribución diferencial de la fauna. Estos distintos tipos de paisajes no habrían cambiado sustancialmente en los últimos dos mil años (Grosjean et al. 2003, Olivera 2003 com. pers.) por lo cual planteamos a manera de hipótesis que la distribución en el pasado de la fauna local debería mostrar una disposición similar a la actual.

Con el fin de contrastar esta idea es que se procedió al análisis de tres tipos de fuentes de información. La primera se refiere a los documentos escritos por cronistas en los primeros siglos luego del contacto europeo con las poblaciones indígenas que habitaron el sur de los valles Calchaquíes. El segundo tipo de fuente proviene del registro etnográfico realizado en la zona. Por último se utilizaron descripciones actuales provenientes de estudios de distribución de especies en el área de estudio.

Según los registros etnohistóricos las especies animales registradas en el sur de los valles Calchaquíes no diferirían demasiado con las que pueden ser halladas en la actualidad. Por ejemplo en la "Descripción Corográfica del Gran Chaco Gualamba" del padre Pedro Lozano [1989 (1773)] se encuentran menciones acerca de la presencia de la taruca (Hippocamelus antisensis), la vicuña (Lama (Vicugna) vicugna), el guanaco (Lama guanicoe), la llama (Lama glama) y los quirquinchos (Chaetophractus vellerosus), entre otros, para la región en estudio y zonas aledañas. 
En cuanto a la presencia de la vicuña, Lama (Vicugna) vicugna, existen registros etnohistóricos que dan cuenta de su presencia en los Altos de Singuil (Pérez Gollán com. pers. 2003), ubicados al sur del área de estudio.

Con esta información podemos inferir que al menos la distribución de la vicuña sería más amplia que la actual y que no se circunscribiría tan solo a regiones de Puna como Laguna Blanca o Antofagasta de la Sierra, sino también a zonas más al este, abarcando el área en estudio.

En cuanto a la información suministrada por los habitantes de la zona rural del sur de los valles Calchaquíes, y en particular para la zona de Cerrillos se relevaron datos con respecto a la distribución de la fauna (datos relevados por la M. C. Scattolin 10/11/1987- en conversaciones con Don Jesús Franco, encargado de la finca Cerrillos).

De acuerdo a la definición dada por el informante los animales se dividen según el área en los que son hallados con mayor frecuencia. Por ello la primera división se refiere a los que "viven en el cerro" y los que lo hacen en "el campo", definiendo al "cerro" como la parte sobre la línea de "costa" y al "campo" como la parte inmediatamente inferior a la primera. La línea de "costa" se refiere en nuestro caso al límite entre la zona pedemontana y el "cerro" y que coincide en general con una cota superior a los 3300 metros sobre el nivel del mar.

Según el informante local la llama (Lama glama) "es del cerro pero no se cría por la cuestión del puma" (Felis concolor), de todos modos agrega que "en el campo también pueden vivir las llamas". Es decir que en la actualidad no se crían llamas ya que el puma ataca a los rebaños haciendo improductiva la cría de este animal. Sin embargo esto no sucede con el ganado caprino, ya que éste es uno de los que posee mayor cantidad de cabezas en toda la provincia (Mares et al. 1997). Por lo que estimamos que la cría del ganado caprino en desmedro de las llamas sería producto de cuestiones de mercado más que por el ataque de predadores actuales, ya que el puma ataca tanto a llamas como a cabras.

La taruca, Hippocamelus antisensis, "vive en el cerro". Suele verse conformando tropillitas que no bajan y solo viven en lo alto. Por el contrario el guanaco, Lama guanicoe, "baja hasta las casas". Esta diferencia en el comportamiento de estas dos especies hace presumir que la obtención de la taruca puede haber sido menos frecuente que la del guanaco debido a la baja probabilidad de la presencia de la primera frente al segundo. 
Con respecto a otros animales se menciona la presencia de quirquincho, Chaetophractus vellerosus ("en el campo"); el zorrino, Conepatus chinga ("en los potreros"); la vizcacha de la sierra, Lagidium viscacia ("en el cerro" y no suele moverse de sus colonias, una de las mas grandes se hallan en la zona de nominada la Aspereza, ver Figura 2.2).

El zorro, Pseudolapex sp habita tanto en "cerro" como en el "campo". El zorro gris (P. griseus) se encuentra mas en el "campo" y el zorro colorado (P. culpaeus) se lo halla con mayor frecuencia en el "cerro".

Los estudios actuales realizados por biólogos dan cuenta de la presencia una gran cantidad de especies animales para la región. Trabajos como los de Braun y Díaz (1999), Díaz et al (1997), Mares, Ojeda y Bárquez (1989) han tenido como objetivo el registro de la distribución de los mamíferos en el área. A partir de ellos se elaboró la lista sumaria que se detalla más abajo:

\section{MAMMALIA}

Orden Marsupalia

Familia Didelphidae (comadrejas)

Didelphys albiventris, Marmosa elegans, Marmosa pusilla,

Orden Xenarthra

Familia Dasypodidae (armadillos)

Chaetophractus vellerosus

Orden Rodentia

Familia Muridae

Akodon albiventer, Akodon andinus, Akodon boliviensis, Akodon varius, Andynomis edax, Auliscomys sublimis, Calomys laucha, Eligmodontia moreni, Eligmodontia puerulus, Graomys domorum, Graomys griseoflavus, Oryzomys longicaudatus, Oxymycterus paramensis, Phyllotis darwin.

\section{Familia Caviidae}

Galea musteloides, Microcavia australis, Microcavia shiptoni,

Familia Chinchillidae (vizcacha de la sierra, chinchillas)

Lagidium viscacia, Chinchilla brevicaudata

Familia Ctenomyidae (tuco-tucos u ocultos)

Ctenomys mendocinus, Ctenomys opimus, Ctenomys saltarius 
Familia Abrocomidae

Abrocoma cinerea

Familia Octodontidae

Octodontomys gliroides

Familia Cricetidae

Orden Carnivora

Familia Canidae (zorros)

Pseudolapex culpaeus, Pseudolapex griseus, Pseudolapex gimnocercus

Familia Mustelidae

Galictis cuja

Familia Mephitidae (zorrino)

Conepatus chinga

Familia Felidae

Felis colocolo, Felis concolor, Felis geoffroyi,

Orden Artyodactila

Familia Cervidae

Masama americana, Hippocamelus antisensis

Familia Camelidae (guanaco, vicuña)

Lama guanicoe, Lama (Vicugna) vicugna

A esta síntesis construida sobre la bibliografía disponible debe sumársele las especies autóctonas domésticas y las introducidas en momentos pos-contacto. Entre las especies domésticas de mamíferos podemos encontrar:

\author{
Orden Artyodactila \\ Familia Camelidae \\ Lama glama (llama, autóctona) \\ Familia Bovidae \\ Bos taurus (vaca, introducido) \\ Capra hircus (cabra, introducido) \\ Ovis aries (oveja, introducido) \\ Familia Equidae \\ Equus (caballo, introducido)
}


Además de los mamíferos citados con anterioridad se encuentran distribuidos en el área de estudio AVES (por ejemplo: Familia Furnariidae; Familia Rheidae, Pterocnemia pennata “suri”), reptiles (REPTILIA, en general representada por pequeñas lagartijas y serpientes) y moluscos (MOLLUSCA, GASTROPODA).

Los datos aportados por las distintas fuentes documentales utilizadas nos han brindado un panorama de que especies están presentes hoy en día y cuales lo estuvieron en el pasado del área contribuyendo de este modo a la construcción de una idea de la biodiversidad representada.

A partir de este listado sumario se procedió a realizar una breve síntesis de la corología y las características de los taxones presentes en el registro arqueológico del sur de los valles Calchaquíes.

MAMMALIA, Orden Rodentia, FAMILIA CTENOMYDAE, Ctenomys opimus, $C$. mendocinus, C. saltarius "oculto"

Esta familia se distribuye por todo el territorio de la República Argentina. Se conocen más de cincuenta especies (Palermo 1983). Para el área en estudio se conocen la presencia de las especies mencionadas más arriba. Son roedores de hábitos subterráneos y en general se encuentran activos durante la noche. Se alimentan de raíces, ramas, cortezas y hojas.

Los individuos pertenecientes a esta familia pesan entre 90 y 1000 gramos. Los pesos de los registrados por Mares et al. (1989) oscilan entre 200 y 400 gramos. Por ello se los incluyó dentro del Tamaño Corporal 1.

Restos de esta familia fueron encontrados en los sitios Loma Alta y Yutopián. Para los restantes sitios tratados en esta Tesis en general no fue posible realizar una asignación taxonómica debido a la ausencia de elementos diagnósticos (cráneos). Por ello no debe descartarse la presencia de esta familia en ellos dentro de los elementos determinados como "Rodentia Tamaño corporal 1".

MAMMALIA, Orden Rodentia, FAMILIA CHINCHILLIDAE, Lagidium viscacia, Molina 1782, "vizcacha de la sierra", Chinchilla brevicaudata "chinchilla" 


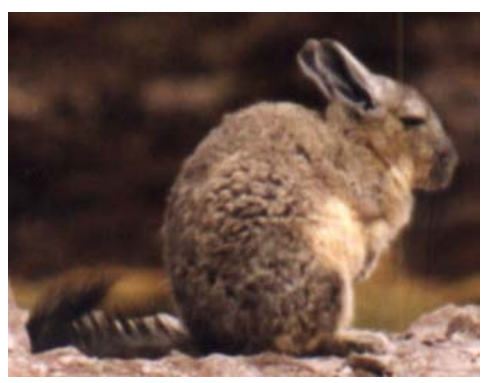

Figura 2.4. Lagidium viscacia.

Esta familia se distribuye en una amplia zona de la República Argentina. Las dos especies mencionadas aquí se hallan en las tierras altas de la Provincia de Catamarca.

La primera es común en las zonas de peñascos superiores a los 2000 metros sobre el nivel del mar. Son animales herbívoros que suelen vivir en extensas colonias. Su peso varía entre 900 a 3000 gramos (Mares et al.. 1989).

Según los habitantes de Cerrillos, y como se hizo notar más arriba, en La Aspereza, un roquedal cercano al sitio Loma Alta (ver Figura 2.2) se encuentra una gran colonia de estos animales.

La segunda especie comparte muchas de las características de la anterior. La chinchilla es muy apreciada por su piel y en la actualidad se la cría por ello. El peso promedio de esta especie para la región es de 500 gramos (Mares et al. 1989). Osteológicamente se diferencia de Lagidium viscacia por su tamaño apreciablemente menor (Elkin 1996).

Ejemplares de estas especies se han hallado en los sitios Loma Alta y Yutopián.

MAMMALIA, Orden Rodentia, FAMILIA CAVIIDAE, Microcavia australis, Galea musteloides.

Galea musteloides y Microcavia australis son roedores que suelen encontrarse en los pastizales de altura. Según Cabrera (1953) ambos se encuentran en la misma región.

Mediante el análisis osteológico comparativo solo pudo asignarse algunos elementos al género Microcavia. Ejemplares de esta familia se han hallado en los sitios Tesoro 1, Potrero Antigal, Loma Alta, Yutopián. 
MAMMALIA, Orden Rodentia, FAMILIA MURIDAE, Akodon albiventer, A. andinus, A. boliviensis

Son roedores de pequeño tamaño. Fueron asignados a tamaño corporal 1.

MAMMALIA, Orden Xenarthra, FAMILIA DASYPODIDAE, Chaetophractus vellerosus, Gray, 1865 "armadillo", "quirquincho"

Esta especie de armadillo es la más común para las regiones áridas de Catamarca y se encuentran a diferentes altitudes. Es de hábitos nocturnos y presenta su mayor actividad durante los meses cálidos (Greegor 1980a, 1980b, Mares et al. 1997). En general la identificación de este taxón se logró a través de los diseños de las placas ectodérmicas que componen el "caparazón” (Scillato Yané 1982)

Restos de armadillos fueron recuperados de los sitios Loma Alta, Potrero Antigal, Tesoro 1, Yutopián y Bañado Viejo. Es de notar que todos estos se ubican a alturas menores a 3000 metros sobre el nivel del mar.

MAMMALIA, Orden Carnivora, FAMILIA CANIDAE, Pseudalopex culpaeus, Pseudalopex griseus, Pseudalopex gimnocercus, Canis familiaris “zorro", "perro"

Esta familia esta representada en la Provincia de Catamarca por las cuatro especies nombradas mas arriba. Las tres primeras corresponden a zorros. Pseudalopex culpaeus solo se halla en tierras altas en tanto que los otros dos pueden ser encontrados en tierras altas o bajas indistintamente.

Canis familiaris es el perro doméstico. Su presencia ha sido registrada previamente en distintos contextos prehispánicos como por ejemplo en Santa Rosa de Tastil (Cigliano 1973) un sitio del Período de Desarrollos Regionales ubicado en la Provincia de Salta, Los Toldos Cueva Tres en la Provincia de Santa Cruz (Cardich et al 1977) o en la cueva L-1 de Lauricocha en Perú (Wheeler et al 1976) ambos en contextos cazadores recolectores, entre otros.

En los sitios tratados solo se identificaron los restos a nivel de familia para los sitios Loma Alta, Yutopián y Bañado Viejo. 
MAMMALIA, Orden Artiodactyla, FAMILIA CERVIDAE, Hippocamelus antisensis, d'Orbigni, 1834 "taruca"

Hippocamelus antisensis es un cérvido que se distribuye desde el norte de Perú hasta el norte de Chile y la Argentina. En este país se lo ha registrado en las Provincia de Catamarca, Jujuy, Salta, Tucumán y La Rioja, principalmente en la región de las Sierras Pampeanas a alturas superiores a los 3000 metros sobre el nivel del mar (Sielfeld et al. 1999, Mares et al. 1989, 1997). Para los pobladores actuales de la zona de Cerrillos la taruca es conocida como un "venado que vive en el cerro". Según los mismos informantes la taruca conforma tropillas que nunca bajan de la parte más alta de la Sierra del Aconquija.

Sus restos han sido hallados en los sitios Loma Alta y Yutopián.

\section{MAMMALIA, Orden Artiodactyla, FAMILIA CAMELIDAE}

Es conocido que los camélidos habitan Sudamérica desde el Plio-Pleistoceno. Desde ese momento hasta el presente se produjo una gran diversificación, lo que resultó en la aparición y extinción de variadas formas, de las cuales sólo unas pocas han convivido con el hombre durante al menos 10,000 a 12,000 años.

La familia Camelidae está compuesta actualmente por cuatro especies: Lama guanicoe Müller 1776 (guanaco), Lama glama Linnaeus 1758 (llama), Lama pacos Linnaeus 1758 (alpaca) y Vicugna vicugna o Lama (Vicugna) vicugna Molina 1782 (vicuña).

Además de estas especies contemporáneas, las poblaciones humanas también compartieron el territorio con otras que hoy en día se encuentran extinguidas. Este es el caso, entre otros, de Lama (Vicugna) gracilis Menegaz, Goin y Ortiz Jaureguizar (1989), que ha sido hallada en contextos arqueológicos y paleontológicos de la Patagonia y la Pampa de Argentina y Uruguay (Ubilla 1996).

Se ha propuesto para las especies vivientes de esta familia un gradiente de tamaño corporal que para el área andina corresponde con el siguiente orden, de mayor a menor: llama $>$ guanaco $>$ alpaca $>$ vicuña, lo que permitió a algunos investigadores utilizar las categorías "camélido grande" para las dos primeras y "camélido pequeño" para las últimas (Kent 1982, Yacobaccio y Madero 1992). 


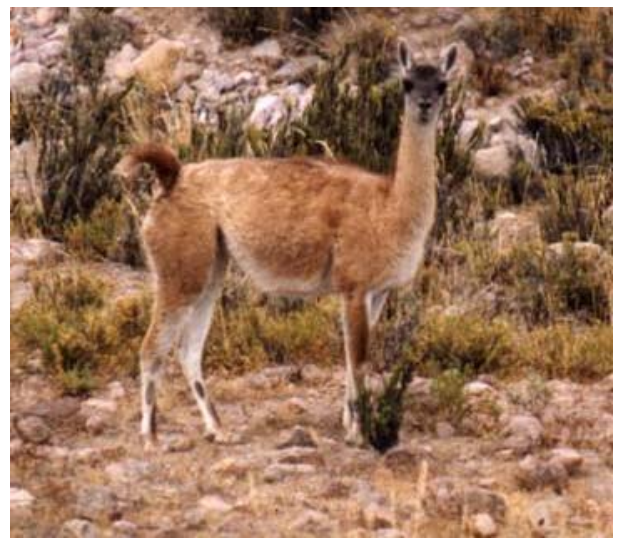

Figura 2.5. Lama guanicoe andino.

Lama guanicoe es una de las especies silvestres que componen la familia. Se distribuye por toda el área andina sudamericana, extendiéndose por la Pampa argentina y la Patagonia extra-andina, Tierra del Fuego y la isla Navarino. Se le encuentra a altitudes que van desde el nivel del mar hasta los $4250 \mathrm{msnm}$ (Franklin 1982). No obstante ello la presencia de animales a grandes alturas no es frecuente ya que los requerimientos energéticos debido a su gran tamaño son difíciles de alcanzar en el límite superior de su rango altitudinal (Lucherini 1995)

Para la zona andina su presencia se asocia a áreas de pastizales desérticos o semidesérticos y áreas de vegetación arbustiva.

Su tamaño corporal es variable ya que como dijo Franklin (1982) a medida que aumenta la latitud se agranda el tamaño corporal de los animales. Es decir que los guanacos de Tierra del Fuego son los de mayor tamaño y los del área andina central o centro sur serían los mas pequeños. Esta escala de tamaños cobra singular importancia a la hora de la diferenciación de especies de camélidos del área andina. Especialmente por que dentro de la escala de tamaños corporales de Camélidos para el área andina, el guanaco ocupa el segundo lugar después de la llama (Mengoni Goñalons y Elkin 1990). Entonces la utilización de muestras de referencia de guanacos patagónicos utilizadas para la identificación de camélidos del área andina central o centro sur es una cuestión que debe tenerse en cuenta ya que puede llevar a confundir llamas (domésticas) con guanacos (Izeta 2003, Yacobaccio et al. 1998)

Los guanacos de distinguen por ser generalistas en el consumo de su alimento. Según el área en la cual habiten su consumo de vegetales puede variar aunque en donde 
este disponible, los vegetales mas preciado por esta especie son los pastos (Saba 1987 y obras allí citadas)

También se caracteriza por poseer una estructura social más o menos estable basada en la defensa permanente o estacional del territorio, dependiendo de si son grupos migratorios o no migratorios. Estos rasgos son comunes a los camélidos silvestres del área andina. Ello permite una alta predictibilidad para los camélidos silvestres como recurso para la subsistencia.

Restos de guanaco se han recuperado de los sitios Bañado Viejo, Loma Alta y Yutopián.

Lama (Vicugna) vicugna o Vicugna vicugna Molina 1782 (CAMELIDAE, Artiodactyla) "vicuña"

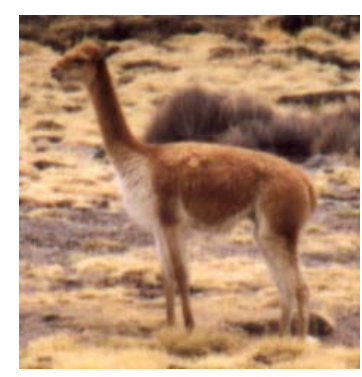

Figura 2.6. Lama (Vicugna) vicugna.

Lama (Vicugna) vicugna es el camélido silvestre de menor tamaño. Su distribución se restringe al área andina, desde Ecuador, Perú, oeste de Bolivia, el norte de Chile y noroeste de la Argentina. A diferencia del guanaco, la vicuña solo habita zonas de gran altitud, razón por la cual se ha propuesto que las diferencias geográficas y ecológicas entre estas dos especies se relacionan con las distintas adaptaciones a la altura de la vicuña (Franklin 1982). En general se ubica a la vicuña en ambientes de puna, con alturas superiores a 3700 metros sobre el nivel del mar hasta los $4800 \mathrm{msnm}$. Su presencia se asocia a áreas con pastizales de altura de tipo puna.

La organización social corresponde a grupos no migratorios. Igual que su pariente silvestre el guanaco, son territoriales y poseen áreas de alimentación y áreas de descanso basadas en circuitos anuales.

Sus hábitos de alimentación al contrario que el guanaco no son generalistas sino que se centra solo en el consumo de pastos. 
La lana, uno de sus productos secundarios, fue de crucial importancia para las sociedades andinas prehistóricas debido a que el pelo de la vicuña es uno de los más finos dentro de los camélidos sudamericanos (Haber 1999, Reigadas 1994, 2001).

Restos de esta especie fueron determinados para los sitios Bañado Viejo, Loma Alta y Yutopián.

Lama glama Linnaeus 1758 (CAMELIDAE, Artiodactyla) "llama"

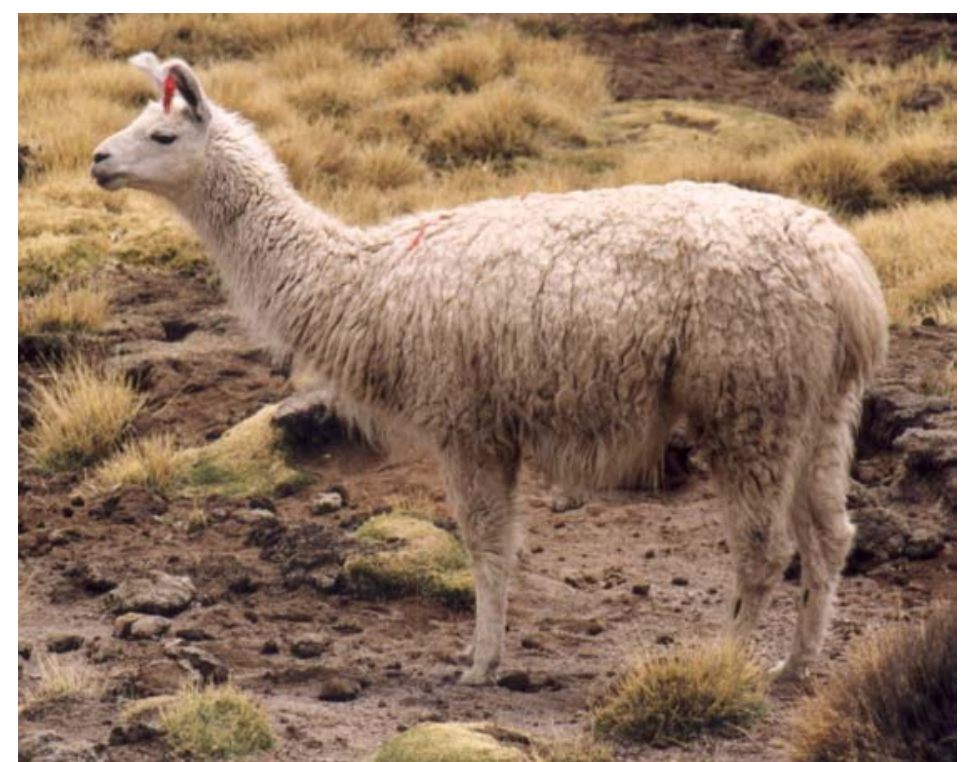

Figura 2.7. Lama glama.

Lama glama es el camélido doméstico de mayor tamaño. Su distribución se circunscribe al área andina y es una de las especies con mayor cantidad de ejemplares dentro de la familia (Franklin 1982).

Habita las zonas comprendidas entre 2300 y 4000 metros sobre el nivel del mar y se asocia con flora de tipo pastizal de altura y áreas de vegetación arbustiva. Es de hábitos generalistas en su alimentación.

$\mathrm{Su}$ estructura social está modificada por el manejo humano, pero por algunas conductas se sugiere una estructura poligínica basada en la territorialidad (Franklin 1982).

Restos de llama fueron identificados en los sitios Bañado Viejo, Loma Alta y Yutopián.

Lama pacos Linnaeus 1758 (CAMELIDAE, Artiodactyla) "alpaca" 
Lama pacos es la especie doméstica de menor tamaño. Su presencia en territorio argentino en tiempos prehispánicos debido a sus particulares requerimientos ambientales ha sido puesta en duda por varios autores (Elkin 1996, Yacobaccio et al 1997/1998), a la vez que otros citan su presencia en sitios arqueológicos (González 1998).

Esta especie no fue identificada en ninguno de los sitios arqueológicos del área.

AVES, FAMILIA RHEIDAE, Pterocnemia pennata "suri"

Restos de la familia Rheidae han sido hallados en sitios arqueológicos de regiones diversas, tales como la Pampa argentina, la Patagonia, la Puna chilena y los valles mesotermales del noroeste argentino (Cruz y Elkin 2003, González 1998, Miotti 1989, 1998, Salemme y Miotti 1998). Pero para grandes extensiones del noroeste argentino no se han registrado arqueológicamente elementos o especímenes asignables a este taxón (Elkin 1996). No obstante ello González da cuenta de grandes volúmenes de cáscara de huevo asignables a esta especie en las excavaciones realizadas en valles mesotermales de la misma región (González 1998).

En la actualidad esta especie se encuentra presente en el área y en algunas ocasiones, M. C. Scattolin (com. pers. 1998) ha observado grupos de "suris" en el fondo del Campo del Arenal. Sin embargo no se ha podido constatar su presencia en sitios arqueológicos a través de evidencia osteológica no obstante su alta representación como motivo decorativo en diversos estilos cerámicos.

Para los sitios arqueológicos tratados en esta Tesis solo se han encontrado fragmentos de cáscara de huevo posiblemente asignables a esta especie en Morro de las Espinillas y los Depósitos I y II de Bañado Viejo, los que han sido ubicados temporalmente hacia el final del período estudiado. 
Parte 2 - Aspectos teórico - metodológicos 
El análisis de los conjuntos arqueofaunísticos del sur de los valles Calchaquíes fue diseñado para extraer distintos tipos de información ya sea desde aspectos tafonómicos hasta explicaciones conductuales con el fin de evaluar distintos modelos de subsistencia propuestos para las comunidades agroalfareras del Período Formativo.

En este capítulo se definen las unidades con las que se trabajó y algunos procedimientos básicos desprendidos a partir de ello.

En general se adoptó un enfoque tafonómicamente orientado (Gifford-Gonzalez 1991, Hill 1994, 2001, Lyman 1994b, Marean 1995, Mengoni Goñalons 1999, Rapson y Todd 1999, Todd 1987, Todd y Rapson 1988). Cuestiones relativas a la historia tafonómica de los conjuntos se evaluaron a través de la articulación de marcos de referencia de rango medio (Elkin 1995, 1996, Stahl 1999, Yacobaccio y Madero 1994, Yacobaccio et al. 1998) y unidades de análisis desarrollados a través de la documentación sistemática de distintos atributos cuali-cuantitativos de cada uno de los elementos o especímenes recuperados de las excavaciones arqueológicas.

Partimos de la base de concebir a las unidades como categorías construidas por el investigador para observar, describir, analizar e interpretar entidades observables o conceptos. Todas las unidades requieren ser definidas y pueden ser creadas o pueden seleccionarse de unidades pre-existentes. Básicamente sirven para medir, estimar o calcular cualquiera de las propiedades o la variabilidad del registro arqueológico. Siguiendo a Ramenofsky y Steffen (1998: 6) una unidad es una herramienta que puede ser definida a diferentes escalas de inclusión y a diferentes escalas de medidas.

Operativamente las dividiremos en dos tipos: observacionales y de análisis (Lyman 1994a). La primera se refiere a las entidades físicas manifiestas con las que se trabaja y en la que pueden incluirse por ejemplo: espécimen, elemento, etc. La segunda toma las medidas observadas en conjuntos exigiendo de esta manera algún tipo de cómputo. Es decir que una unidad de análisis se halla relacionada con la cuantificación de las unidades observacionales. Las unidades de análisis poseen dos dimensiones que son la contemporaneidad y la asociación (relación física de las unidades observacionales). 
A continuación se definirán específicamente cada una de las unidades utilizadas a través del estudio de los conjuntos arqueológicos.

\subsection{Unidades observacionales}

La unidad mínima con la que se trabajó a través de esta Tesis es espécimen. Seguimos la definición propuesta por Salemme et al. (1988: 66) por la cual espécimen es “... todo fragmento óseo identificable o inidentificable...”. Esta definición es similar a la propuesta por Grayson (1984). Los especímenes pueden ser identificables o no identificables (inidentificables según lo expuesto mas arriba) dependiendo de la presencia de zonas diagnósticas denominadas "landmarks" (Berwick 1975, Morlan 1994, Todd y Rapson 1988, Hill 2001) y que corresponden a rasgos anatómicos discretos tales como tuberosidades, agujeros nutricios, zonas de inserción muscular, entre otros. A lo largo de esta Tesis la palabra espécimen puede ser reemplazada por fragmento con el fin de evitar excesivas repeticiones de la primera.

Elemento es otra de las unidades importantes en lo que refiere a la descripción de las entidades físicas observadas. Siguiendo también a Salemme et al. (1988) elemento se define como “... cualquier hueso o diente completo (unidad anatómica)...”.

Se deduce entonces que elemento es una categoría más inclusiva que espécimen y cualquier espécimen identificable puede ser referido al elemento al que pertenece.

Otras de las categorías utilizadas fueron porción y segmento. Una porción corresponde a zonas discretas de los elementos, esto es diáfisis y epífisis para huesos largos, cóndilo, etc. Por último, un segmento refiere a la ubicación espacial a la que corresponde determinado espécimen o elemento en relación con la posición del homólogo en el esqueleto de un individuo de referencia (ver Anexo 1).

\subsubsection{Identificación y registro del material óseo a nivel elemento}

La identificación de los especímenes y elementos óseos se realizó mediante la comparación con muestras de referencia y distintos atlas osteológicos (Altamirano 1983, Mares et al. 1989, Pacheco Torres et al. 1979).

Las muestras de referencia se componen de un ejemplar de hembra adulta de Lama glama proveniente de La Quebrada (Valle del Cajón), un ejemplar adulto de sexo indeterminado de Lama guanicoe de Tesoro de Arriba (Falda Occidental del Aconquija) 
y varios elementos craneales y post-craneales de diversas especies de roedores de la Falda Occidental del Aconquija.

La comparación morfológica tuvo en cuenta regiones diagnósticas (epífisis, agujeros nutricios, forámenes, tuberosidades, espesor del hueso compacto, etc.)

Las categorías usadas (elemento, porción y segmento) permitieron utilizar el sistema de codificación tripartita (Gifford y Crader 1977, Todd 1987) en la que la información se registra por medio de un sistema de información jerárquicamente detallada (se describe desde lo general a lo particular) para cada elemento o espécimen (Hill 2001: 21)

\subsubsection{Identificación y registro del material óseo de camélidos a nivel taxonómico}

Se utilizaron dos tipos de análisis: de tipo morfológico comparativo y análisis multivariados cuantitativos.

Aquellos del primer tipo se basan en las diferencias morfológicas de algunos elementos diagnósticos (principalmente dientes). Aquí se siguió la metodología planteada por Wheeler (1982) que permite la discriminación de $L$ ( $V$.) vicugna de $L$. glama y L. guanicoe.

En cuanto a los análisis multivariados utilizamos la metodología planteada por Menegaz et al. (1989), resumida en Cardich e Izeta (1999-2000) y la utilizada por Izeta (2003) En este caso se aplicaron distintos análisis estadísticos sobre las muestras de falanges y otros elementos óseos que permitieron la discriminación y la asignación más ajustada de cada uno de estos elementos a una especie de camélido en particular.

\subsubsection{Identificación interespecífica por medio de las falanges proximales}

La identificación ínter-especifica de restos de Camelidae para la región andina se ha realizado básicamente a partir de estudios osteométricos realizados sobre las primeras falanges (Kent 1982, Izeta 2002, Yacobaccio et al 1997/1998, Elkin 1996, Cartajena y Concha 1997).

Como primer paso las falanges se discriminaron en delanteras y traseras basándose en la caracterización morfológica propuesta por Kent (1982: 164-166). Seguidamente se obtuvieron los valores de las medidas de seis caracteres morfométricos continuos:

\#1: largo máximo, tomado en forma paralela al eje mayor utilizando como base la tangente formada por los cóndilos plantares proximales y el final en el punto más distal 
de la superficie articular distal (FP1V1 y BP1V177 de Kent 1982; Gl de von den Driesch 1976)

\#2: ancho de la superficie articular proximal (FP1V2 y BP1V178 de Kent 1982; BFp de von den Driesch 1976)

\#3: alto de la superficie articular proximal (FP1V3 y BP1V179 de Kent 1982)

\#4: ancho de la superficie articular distal (FP1V4 y BP1V180 de Kent 1982; Bd de von den Driesch 1976)

\#5: alto de la superficie articular distal (FP1V5 y BP1V181 de Kent 1982)

Todos los valores obtenidos corresponden a medidas absolutas en milímetros por lo que no fue necesario codificarlas. Esta información fue ingresada en una base de datos incluyendo observaciones provenientes de falanges arqueológicas del área analizada, así como mediciones efectuadas sobre material comparativo actual y paleontológico.

Siguiendo a Menegaz et al. $(1988,1989)$ la base fue tratada a través de varias técnicas: a) aplicación del Coeficiente de similitud "Manhattan Distance" o "City Block"; b) Análisis de agrupamiento UPGMA (Unweighted Pair Group using Arithmetical Averages); c) Análisis de los Componentes Principales. Las técnicas b) y c) se efectuaron con el fin de poder expresar gráficamente las relaciones de similitud entre las falanges.

Por otro lado, y siguiendo la metodología planteada por Kent (1982:172 y Apéndice IV.3), se procedió a la confección de gráficos de dispersión con las variables \#1 y \#2 a partir de los cuales separamos a las muestras según su agrupamiento en “camélidos grandes" o "pequeños”, para aplicar de esta manera análisis multivariados con el fin obtener grupos de tamaño más precisos y así segregar a cuál especie pertenece cada muestra.

En nuestro caso, además de las mediciones efectuadas en esqueletos de camélidos actuales de la región, se cuenta con las que proceden de la colección comparativa de la División Paleontología de Vertebrados del Museo de La Plata. De este conjunto se utilizaron las medidas obtenidas de falanges proximales de dos vicuñas (Lama (Vicugna) vicugna) del territorio altoandino de Perú.

\subsubsection{Identificación interespecífica de elementos postcraneales de camélidos.}


Si bien las falanges han sido los elementos más utilizados a la hora de diferenciar especies de camélidos, los demás elementos postcraneales pueden también ser utilizados para tal fin (Lavallée 1990, Izeta 2003).

Cada elemento analizado fue medido siguiendo los caracteres definidos por Hill (1996), Izeta (2003), Kent (1982), Morlan (1991) y Von den Driesch (1976) (ver Anexo 2).

Los resultados de estas mediciones fueron volcados en tablas que fueron luego tratadas estadísticamente. Para este estudio la determinación interespecífica se basó en procedimientos establecidos en el ámbito de la taxonomía numérica mediante la utilización del Análisis de Conglomerados Jerárquico utilizando el UPGMA con la aplicación del coeficiente de similitud Manhattan (Salemme et al. 1988).

Además se trabajó con otras técnicas con el fin de observar cómo se agrupaban los elementos arqueológicos con aquellos pertenecientes al material comparativo. Se hicieron diagramas de dispersión bivariados puesto que según Kent (1982) serían un medio para aproximarse a la discriminación entre camélidos grandes y pequeños. También se aplicó sobre la muestra el Análisis del Componente Principal (Menegaz et al. 1988, 1989).

Uno de las precauciones metodológicas más importantes a la hora de realizar la determinación interespecífica de los elementos postcraneales es la de tomar en cuenta las clases de edad de los elementos arqueológicos. Siguiendo a Kent (1982) los huesos post-craneales de los camélidos poseen distintos centros de osificación que pueden contarse desde uno hasta cinco según el elemento. Esto significa que los huesos de un mismo individuo adquirirán las características de un animal adulto a distintas edades. La maduración ósea, es entonces, el criterio que se toma para diferenciar a animales adultos de sub-adultos (juveniles, neonatos y nonatos). En general, a los 36 meses de edad los camélidos tienen la mayor parte de los huesos fusionados y por ello pueden ser considerados adultos (Kent 1982, Madero 1992, Yacobaccio et al 1998). Este es el criterio tomado en este trabajo para la discriminación entre adultos y sub-adultos.

Cuantos más centros de osificación haya en un hueso, mayor es la probabilidad de que la determinación por medio de estudios osteométricos sea más ajustada, ya que nos permitirá discriminar mejor a qué grupo de edad corresponde determinado elemento óseo. Para el caso de los elementos tarsales y carpales nos encontramos con un solo centro de osificación razón por la cual se hace más difícil la identificación por criterios osteométricos. No obstante ello se tomó como criterio que los elementos que se 
agruparan con aquellos pertenecientes al elemento óseo comparativo de Lama glama o los que presentaran valores mayores pertenecerían a llama. El resto correspondería a cualquiera de las dos especies silvestres o a algún animal doméstico juvenil razón por la cual la asignación a alguna de las especies no se podría realizar.

\subsubsection{Clases de edad}

La estimación de las clases de edad se ha basado en el estado de fusión epifisiaria para cada uno de los conjuntos (Kauffman 2002 e.p. para guanaco, Kent 1982 para alpaca y camélidos en general).

En la vida de un animal los elementos óseos pasan por una serie de estadios que macroscópicamente pueden diferenciarse a partir de la presencia de líneas de fusión. A medida que el animal crece estas líneas se van desdibujando. Por medio de esta aproximación se pueden distinguir huesos "no fusionados" y huesos "fusionados". Dentro de la primera categoría se distinguen los huesos que poseen: a) las epífisis totalmente separadas, b) las epífisis y diáfisis se encuentra fusionadas parcialmente ya que presentan marcadamente la línea de fusión y c) aquellas en la que esta línea se aprecia pero comienza a desdibujarse.

\subsection{Unidades de análisis}

Estas unidades se pueden clasificar en dos tipos: Unidades de Análisis Derivadas y Unidades de Análisis Interpretativas. Dentro de las primeras se ubican las que permiten efectuar algún tipo de cuantificación de las muestras. La segunda presenta las unidades espaciales o de agregación y las unidades temporales definidas.

\subsubsection{Unidades derivadas (cuantificación)}

Número de especímenes (NSP): Incluye aquellos huesos o partes de huesos identificables y no identificables (Grayson 1991)

Número de Especimenes Identificados o NISP (Number of Identified Specimens): Es el número de especímenes identificados por taxón (Klein y Cruz Uribe 1984)

Número Mínimo de Elementos o MNE (Minimum Number of Elements): En 1982 Bunn lo define como "el número mínimo de elementos identificados para un taxón en 
particular" (Bunn 1982 citado en Lyman 1994a). A partir de esa definición se ha avanzado en las técnicas de cuantificación llegándose a diferenciar varios tipos de cálculos del MNE: el MNE comprehensivo (MNE comprehensive, Bunn 1986, Bunn y Kroll 1986), la aproximación por suma de fracciones (Klein y Cruz Uribe 1984), MNE de zonas diagnósticas (Morlan 1994b, Hill 2001), la aproximación por solapamiento (Marean y Spencer 1991) y por último la aproximación por medio del análisis de imágenes a través de GIS software, procedimiento desarrollado por Marean y colaboradores (Marean et al 2001, Abe et al. 2002).

La aproximación mediante el registro de zonas diagnósticas implica el reconocimiento e identificación de especímenes que conserven al menos una parte de un “landmark" (Morlan 1991, Hill 2001). Esto permite incluir en la cuantificación a especímenes pertenecientes principalmente a la diáfisis, los cuales no habían sido tenidos en cuenta en aproximaciones anteriores. Marean et al. (2003) demostraron que el no tomar en cuenta a los fragmentos diafisiarios en el momento de la cuantificación causaría una sobrerrepresentación de las epífisis con el consiguiente error en las interpretaciones de los conjuntos faunísticos.

Sobre la base de estos criterios Marean et al (2001) procedieron a confeccionar una aplicación informática que permitiera ubicar a los especímenes dentro de una "plantilla" y de ese modo controlar la superposición de especímenes con el fin de ajustar la cuantificación. Esta es la denominada aproximación por medio del análisis de imágenes a través de programas informáticos de GIS.

Esta última metodología implica la utilización del criterio de zonas diagnósticas ya que sin la presencia de ellas no se podría ubicar al elemento dentro de la "plantilla" digital. La utilización de esta aproximación comprende la digitalización de los elementos de un ejemplar comparativo (Lama glama en nuestro caso) con el fin de utilizarlo para la confección de modelos en formato electrónico, así como de cada uno de los especímenes arqueológicos.

La ventaja de este método con respecto a la cuantificación tradicional es que permite utilizar el criterio de zonas diagnósticas y con ello ajustar mejor el MNE a la realidad de la muestra. Asimismo la representación gráfica permite observar patrones de fractura y procesamiento de manera más rápida.

Es por lo anteriormente nombrado que en esta Tesis se utilizará esta aproximación en conjunto con el MNE de zonas diagnósticas. 
Número Mínimo de Individuos o MNI (Minimum Number of Individuals): Es el número de animales individuales representado por cada elemento. Esto es, el MNI es el número mínimo de animales necesarios para conformar la muestra de todos los especímenes identificados de un determinado conjunto arqueofaunístico (Casteel y Grayson 1977).

Número Mínimo de Individuos de distinción máxima o mxMNI (maximum distinction Minimum Number of Individuals): Se construye igual al anterior (MNI) solo que se le agregan datos métricos y no-métricos, principalmente los provenientes del MNE comprehensivo, la osteometría y las clases de edad (Hill 2001, Todd 1987).

Unidades Anatómicas Mínimas o MAU (Minimum Anatomical Units): Es el resultado obtenido de la división del valor del MNE y la frecuencia de ese elemento en el esqueleto completo (Binford 1984)

Tamaño corporal: Se utilizó una escala adaptada a la fauna del noroeste argentino de tamaño corporal (BDSZ) basada en la clasificación propuesta por Brain (1981). Esta escala permitió la comparación de distintos atributos entre animales de porte pequeño y de porte grande con el fin de observar distintos patrones relacionados con la diferencia de tamaño de los elementos y especímenes óseos (ver Tabla 3.1).

Tabla 3.1. Listado tamaños corporales y de animales más frecuentes en la región en estudio.

\begin{tabular}{cllc}
\hline Tamaño corporal & Taxón o categoría & Nombre vulgar & Peso aproximado $(\mathrm{kg})$ \\
1 & Ctenomys sp & Oculto & 0.50 \\
1 & Rodentia & Roedores & $>0.50$ \\
2 & Lagidium sp & Vizcacha & 1.60 \\
3 & Pterocnemia pennata & Suri & 30.00 \\
4 & Hippocamelus antisensis & Taruca & 52.00 \\
4 & Lama (Vicugna) vicugna & Vicuña & 50.00 \\
4 & Lama glama & Llama & 120.00 \\
4 & Lama guanicoe & Guanaco & 70.00 \\
9 & No identificable & - & desconocido \\
\hline
\end{tabular}

Por otra parte para la asignación del tamaño corporal de especímenes que no pudieron ser clasificados taxonómicamente consideramos los siguientes atributos: largo máximo del espécimen y grosor del espécimen. 


\subsubsection{Unidades interpretativas}

Estas unidades se distinguen entre las que conciernen al espacio y las que se relacionan con la variable tiempo. Este es el último nivel de análisis con el que se trabajará en esta tesis y que corresponde a la instancia de integración de las unidades observacionales.

\subsubsection{Unidades espaciales}

Las unidades espaciales que se utilizaron estuvieron íntimamente relacionadas con las características de cada uno de los sitios. Se tomó como criterio la definición de tres unidades sobre las cuales se procedió a realizar el análisis faunístico. Estos son: Recintos o Estructuras, Depósitos o Capas en los que se encontraron Niveles de ocupación y Rasgos.

Recintos o Estructuras: Los recintos fueron definidos como unidades cerradas o abiertas circunscriptas por muros o líneas delimitantes que pueden estar constituidas por rocas $\mathrm{u}$ otro material.

Depósitos o Capas: Los recintos y estructuras fueron excavados siguiendo dos criterios: por medio de capas artificiales de $10 \mathrm{~cm}$. o siguiendo los depósitos naturales de sedimentación. En ambos casos se tomó para el presente estudio a aquellas capas o depósitos en los cuales se identificó a campo la presencia de niveles de ocupación. No integran las muestras aquellos depósitos que fueron considerados de "relleno".

Rasgos: Dentro de esta categoría se encuentran estructuras de combustión, pozos de almacenamiento, espacios diferenciados intra-recinto tales como pasillos, puertas, etc.

\subsubsection{Unidades temporales}

El lapso temporal estudiado supone un continuum en el cual se producen procesos que llevan a la complejización de las sociedades prehispánicas en estudio. Por ello y con el fin de acotar la contemporaneidad de los recintos y poder de esa manera compararlos se dividió a la muestra en cuatro bloques temporales definidos arbitrariamente a partir de los fechados radiocarbónicos disponibles para cada uno de 
los recintos. Además se tomó como criterio la comparación de estilos y composiciones de pastas de la cerámica de los sitios bajo estudio (Fraga 1999, Martínez 1999, Scattolin 1990). Por último y a modo de control se tomó como patrón a los resultados obtenidos en el sitio Bañando Viejo (Scattolin et al 2001, Bugliani y Pereyra Domingorena 2002, Izeta y Scattolin 2001) el cual presenta en su secuencia todo el rango temporal desarrollado en esta Tesis.

El primer bloque corresponde a los fechados ubicados entre los 1900 años a. p. y los 1700 años a. p. (Bañado Viejo Nivel 24, Yutopián Estructura 3, Estructura 11 y Antigal de Tesoro). El segundo bloque engloba a los fechados de 1600 años a. p. (Loma Alta Núcleo E y Yutopián Estructura 1 y Estructura 4). El tercer bloque a los fechados de 1400 y 1300 años a. p. (Bañado Viejo Nivel 10, Loma Alta Núcleo F). El último bloque incluye a los fechados de 1100 años a. p. y 1000 años a. p. (Tesoro 1, Morro de las Espinillas, Bañado Viejo Nivel 4, Loma Alta Núcleo G).

Uno de los objetivos al realizar estos bloques temporales arbitrarios es el de poder comparar la evolución del comportamiento de las muestras a lo largo del tiempo utilizando para ello un índice cuantitativo simple de abundancias relativas de vertebrados denominado Índice de Artiodáctilos (Broughton 1994). Este se calcula mediante la siguiente ecuación: Índice de Artiodáctilos $=\sum$ Artiodáctilos / $\left(\sum\right.$ Artiodáctilos $+\sum$ Vertebrados pequeños)

Este estimador de abundancia de artiodáctilos permite conocer la contribución de este tipo de animales dentro de un conjunto faunístico. Los valores que pueden obtenerse se encuentran entre 1.0 (representa frecuencias altas de artiodáctilos) y 0.0 (representa frecuencias de artiodáctilos bajas en relación con vertebrados más pequeños).

Con esto se intenta observar si existieron cambios o no en la composición de las faunas en relación con la variable temporal. 
Los conjuntos arqueofaunísticos se ven sometidos a una serie de procesos desde el momento en que pasan de un contexto de vida (biocenosis) a un contexto de muerte (tafocenosis), hasta que en última instancia es recuperado por los arqueólogos. Los procesos actuantes pueden ser tanto naturales como culturales y pueden afectar la composición de la muestra en términos de biodiversidad o simplemente en cuanto a partes anatómicas representadas. Por ello se ha adoptado en esta Tesis el estudio de estos factores en términos de las modificaciones halladas en los conjuntos. En la primera parte se tratará el conjunto de modificaciones naturales seguido de los criterios adoptados para la identificación de marcas de origen cultural.

\subsection{Aproximación tafonómica-modificaciones naturales}

Como parte de las tareas de reconstruir el contexto en el cual se ha conformado originalmente el registro arqueológico suelen utilizarse procedimientos que provienen de una disciplina denominada tafonomía. La utilización de estos métodos y técnicas permiten comprender los procesos naturales que llevan a la incorporación en la litosfera de elementos provenientes de la biosfera.

Para los arqueólogos el uso de la tafonomía es variable. En general se asocia a estudios de tipo faunístico ya que la gran mayoría de estos trabajos han sido llevados a cabo por zooarqueólogos, sin embargo es utilizada tanto para estudios zooarqueológicos como paleoecológicos. Los primeros tienden a identificar los procesos naturales actuantes con el fin de separarlos y de ese modo llegar al comportamiento de los humanos en el pasado, mientras que los segundos tratan de identificar las huellas tafonómicas con el fin de reconstruir los procesos que dieron como resultado el registro fósil.

Según Lyman (1994b) existen tres objetivos principales para la tafonomía:

1- eliminar las huellas tafonómicas del registro fósil con el fin de obtener una resolución ajustada de la conformación de la comunidad biótica del pasado,

2- identificar el carácter de las huellas tafonómicas con el fin de reconstruir los procesos precisos que dieron como resultado el registro fósil,

3- reconstruir la historia tafonómica. 
Según Marean (1995) existen dos aproximaciones: una actualística y una experimental. Para entender estas aproximaciones es necesario tener en cuenta algunos conceptos que ayudan a comprender la cadena analítica tal como fue definida por Gifford González (1991):

- rasgo (trace): es el atributo visible (ej: raspado en un hueso)

- agente causante (causal agency). es el causante físico del rasgo (ej: diente efectuando el raspado)

- effector: es el material que efectúa el rasgo (ej: diente)

- actor: es la fuente de fuerza o energía que crea el rasgo (la hiena mordiendo el hueso)

De acuerdo con Marean la aproximación actualística tiene un componente naturalístico y uno experimental. En el primero de ellos el analista observa los procesos que ocurren y los patrones resultantes. El analista no toma parte de este proceso ya que es un observador de lo que sucede en un contexto natural y no manipula los parámetros del proceso. Por supuesto no existen dudas acerca del actor que produce el rasgo. EJ: estudios de Blumenschine (1988) de consumo de carcasas por grandes carnívoros africanos. El componente experimental es similar al naturalístico pero la diferencia es que en este caso se tiene control de los parámetros. Por lo tanto se tiene control del proceso que une las trayectorias desde rasgo hasta actor, por ejemplo: estudios con hienas cautivas por Marean (1991) y Marean et al. (1992). Por otro lado la aproximación comparativa es diferente a la anterior ya que la trayectoria que va desde los rasgos hasta el actor no ha sido observada pero acerca de la cual se creen conocidas, por ejemplo: estudios de Behrensmeyer (1978) sobre meteorización.

Estos modos de aproximarse al registro arqueológico nos permiten tener los elementos necesarios para realizar una tafonomía en positivo, esto es sumar todos aquellos datos que aporta este tipo de enfoque para la reconstrucción de la historia tafonómica y no solo utilizarla para eliminar aquellos factores naturales que puedan estar "ocultando" la actividad humana.

Teniendo todo esto en cuenta es que se emplearon criterios tales como los efectos de la meteorización, la modificación producida por carnívoros, la modificación producto de la acción de roedores y el efecto de la densidad ósea como mediadora de la destrucción diferencial de los elementos óseos. 


\subsubsection{Meteorización}

Meteorización se define como "los procesos que producen la separación de los componentes de los huesos ya sea por medio de agentes físicos o químicos" (Behrensmeyer 1978). Los huesos expuestos a la acción de los agentes de meteorización sub-aéreos tienden a fraccionarse en partes cada vez más pequeñas. Behrensmeyer identificó para colecciones actualísticas del este africano seis etapas o estadios de meteorización medidas a través del análisis de la alteración de la superficie cortical del hueso. A su vez asoció a cada una de los estadios con el lapso temporal necesario para que el conjunto llegara a esa condición. Sin embargo estudios posteriores demostraron que para otras especies animales no se podía apreciar una relación lineal entre estadio de meteorización y tiempo.

Por otro lado Todd (1987) pudo observar en experimentos controlados que la alteración de las superficies articulares no siempre correspondía con las modificaciones de la superficie cortical. Por ello realizó una modificación a la escala propuesta por Behrensmeyer.

Esta escala modificada es la que se utiliza en esta Tesis (ver Anexo 1)

\subsubsection{Modificación por carnívoros}

Las modificaciones producidas por carnívoros fueron identificadas a partir de la descripción de los siguientes atributos: a) marcas de mordisqueo en huesos, b) localización de las marcas y c) frecuencia de marcas en los conjuntos.

El primer atributo toma en cuenta distintos tipos de marcas tales como impronta de dientes, hoyuelos, ahuecado y ranurado (Binford 1981).

La localización de las marcas deberían coincidir con las partes con valores de densidad global mas bajos, principalmente epífisis o en bordes de los huesos planos. Estas zonas son las que coincidirían en términos generales con aquellas que presentan tejido esponjoso y que por ello retendrían mas nutrientes internos como grasa ósea y que serían la zona de mas fácil acceso a la médula ósea para los carnívoros.

La frecuencia de estas marcas relacionadas con el tipo de elemento y la porción sobre la cual se registren permitirán evaluar el grado de acción de estos agentes en relación a patrones de destrucción, dispersión y modificación de los conjuntos arqueológicos. 


\subsubsection{Modificación por roedores}

Las modificaciones producidas por roedores fueron evaluadas a través de las improntas dejadas por los incisivos al roer. Siguiendo a Mengoni Goñalons (1999: 96) consideramos como huellas de roedor a aquellas que "se presentan como surcos cortos de fondo plano o redondeado y de a pares, a veces superpuestos o adyacentes unos a otros". La ubicación también sería un atributo a tener en cuenta ya que en general las huellas deberían presentarse "en las aristas y bordes de elementos con densidad global alta” (Mengoni Goñalons 1999: 97)

\subsubsection{Supervivencia del material óseo mediada por la densidad ósea}

En la década de 1980 Lyman (1984) sentó las bases para la realización de estudios sobre la acción diferencial de distintos agentes tafonómicos sobre elementos óseos y cuya destrucción depende, entre otros factores, de la densidad del contenido mineral de los huesos lo que se denomina destrucción mediada por la densidad ósea. Los primeros trabajos se basaron en los valores obtenidos por medio de estudios de densitometría ósea para una especie de cérvido (Odoicoelius virginianus). En ese trabajo y posteriores (ver Lyman 1994b y obras allí citadas) se propusieron lugares específicos de los huesos en los cuales deberían realizarse las lecturas de los valores de densidad ósea, ya que dentro de cada elemento anatómico el contenido mineral puede variar, particularmente debido a las espacios que contienen cavidades (medulares o tejido esponjoso por ejemplo) y al diseño anatómico particular de cada hueso. A estos lugares se los denominó "scan sites" o zonas de examen.

Con el fin de establecer el grado en que un conjunto se vio afectado por la destrucción mediada por la densidad ósea se analiza la relación entre las variables “densidad ósea" (VD o Volume Density) y el "\% MAU”. Esto se realiza en general a través de la utilización de análisis estadísticos de correlación bivariadas de orden jerárquico tales como el coeficiente de correlación de Spearman o Rho de Spearman o $r_{s}$ (Elkin 1995, Fernández 2001, Hill 2001, Morlan 1994).

En la Argentina los análisis de destrucción mediada por la densidad ósea han sido aplicados para conjuntos compuesto por camélidos utilizando los valores obtenidos por Elkin y Zanchetta (1991) y Elkin (1995) los cuales se basan en los resultados obtenidos mediante la medición del contenido de mineral óseo en un solo "scan site" 
por elemento (Elkin 1995, 1996). No obstante existe otro conjunto de mediciones efectuadas para camélidos, que no ha sido muy usado, que es el planteado por Stahl (1999). Este autor presenta valores para todos los "scan sites" propuestos por Lyman (1984) y agrega también valores para elementos no considerados en ese momento tales como los tarsianos y carpianos (para una discusión mas en detalle ver Stahl 1999).

Sin embargo los valores obtenidos por Stahl distan mucho de los valores promedio obtenidos por otros autores para las mismas especies u otras (Lyman 1994: Tabla 7.6). Esto se debe en general a que en este análisis Stahl logra eliminar de los cálculos aquellas áreas que no contienen mineral óseo. A esto lo denomina ajuste "a la forma" (shape adjustment). En un trabajo reciente Lam et al. (2003) realizaron un análisis comparativo de los estudios de densidad ósea en zooarqueología. Allí definen que estos se dividen en cuatro categorías según el grado de refinamiento metodológico por el cual se obtuvieron los valores. Para el caso de los camélidos se comparan dos conjuntos: el propuesto por Elkin y el propuesto por Stahl. Para el primero existen dos grupos de datos, uno calculado según la metodología planteada por Lyman (VD) y la otra calculando el volumen de la parte de hueso compacto por medio de desplazamiento de agua (BMD2). Para el segundo también hay dos grupos, uno siguiendo lo propuesto por Lyman (VD ld/bt) y un segundo realizado con el ajuste a la forma realizada mediante soporte electrónico (VDsa). Según Lam et al. (2003) dentro de la categorización propuesta los dos últimos conjuntos de cada uno de los autores serían los mas confiables, siendo el de Elkin el que representa mejor la realidad.

Puesto que los valores obtenidos por Stahl se correlacionan positivamente y son estadísticamente significativos respecto de los valores obtenidos por Elkin por medio del método del desplazamiento de agua y dado que los datos presentados por el primer autor presentan valores para todas los zonas diagnósticas de los huesos, en esta Tesis se optó por utilizar los valores obtenidos por Stahl para la estimación de la acción de agentes tafonómicos mediados por la densidad ósea.

En cuanto al uso de estos valores en estudios tafonómicos, Morlan (1994) plantea la utilización de las frecuencias dada por el MNE no solo de los elementos sino también de zonas diagnósticas o landmarks con el fin de observar la correlación entre frecuencias de estas zonas y la densidad ósea. Esto permite acceder a un perfil mas completo de la destrucción ósea mediada por la densidad que la que ofrece el análisis de elementos completos basados en mediciones de un solo "scan site". En esta Tesis por lo 
tanto se siguen los lineamientos planteados por Morlan (1994) para observar el grado de incidencia de la destrucción ósea mediada por factores tafonómicos.

Para ello se tomó el MNE de cada zona diagnóstica (MNE landmark sensu Hill 2001), se calculó el MAU y el \%MAU y se confeccionó una tabla. Una vez obtenidos los resultados se seleccionó para cada "scan site" el valor de \%MAU mas elevado y se obtuvo el coeficiente de correlación de Spearman para cada elemento.

El conjunto de indicadores descriptos anteriormente permiten realizar estudios tafonómicos intrasitio y a nivel regional. Para los estudios regionales además deben tenerse en cuenta aquellos mega-procesos tafonómicos que pudieran haber afectado alguna parte de una región borrando el registro de determinado período temporal, por ejemplo: remociones en masa, inundaciones, incendios, erupciones volcánicas, etc.

\subsection{Modificaciones culturales}

Los indicadores utilizados son: marcas de procesamiento (corte, señales de impactos, machacado, aserrado, fracturas), alteración térmica y formatización de huesos (instrumentos y adornos). Estas marcas son entendidas como resultado de un proceso de utilización y reutilización de los elementos óseos por parte de las poblaciones humanas del pasado. A su vez nos permiten advertir el grado de aprovechamiento y utilización de los productos animales en las economías prehispánicas puesto que sobre la presencia de este tipo de evidencias es que se construirán los modelos del uso de los recursos.

\subsubsection{Marcas de procesamiento}

Los tipos de fractura registrados en las muestras fueron descriptos siguiendo los criterios básicos fijados por Biddick y Tomenchuck (1975), Cardich y Laguens (1984), Johnson (1985) y Miotti (1990/1992). Además se tuvo en cuenta el contorno del fragmento, el ángulo y la textura de la superficie de fractura (Outram 2001, Borrero 2003). Se utilizaron, a su vez, los códigos empleados en la Universidad de Wyoming los cuales permiten registrar el estado de los huesos antes de ser fragmentados según las categorías fresca, seca, reciente e indeterminada (Hill 2001, entre otros). También se aplicaron categorías descriptivas como las propuestas por Saadek Kooros (1975) y otras resumidas en Mengoni (1999), Miotti (1990-92) y Outram (2001) entre otros. 
Las categorías morfológicas de las fracturas se definieron como:

a) Fractura en espiral, denominada helicoidal en otros trabajos (Miotti 1990/1992), esta sigue el diseño de aquellos huesos que presentan la torsión de una de sus epífisis respecto de la otra (por ejemplo el húmero).

b) Fractura transversa, siguiendo a Gifford González (1989) y Mengoni Goñalons (1999) es la que presenta "el largo del borde de la misma [la fractura] es menor al diámetro de la diáfisis del hueso".

c) Fractura longitudinal, típica de fractura en huesos largos como metapodios (Miotti 1990/1992).

d) Fractura escalonada, cuando el borde de la fractura se presenta irregular, en general en especímenes que presentan grietas longitudinales.

e) Cono de impacto, es el negativo que queda luego de un impacto en el hueso.

f) Fractura recientes por recolección, determinada por la diferencia de coloración entre la coloración general del hueso y la del borde. En general las fracturas recientes son mas “amarillentas" que aquellas fracturas arqueológicas (Outram 2001, Borrero 2003).

g) Fractura indeterminada. Categoría para ubicar a aquellos especímenes que no pueden situarse en ninguna de las categorías anteriores.

En cuanto al tipo de fractura según el estado en el que se encontraba el hueso al ser fracturado se registraron las categorías fresca, seca, indeterminada e intermedia.

Las marcas de impacto y de corte de los conjuntos fue abordado siguiendo los criterios sintetizados en Mengoni Goñalons (1999). El material se procesó de dos maneras: la primera se realizó a ojo desnudo y la segunda con lupa binocular de bajos aumentos. Se tuvo en cuenta la forma y la ubicación de los rasgos. Las categorías analizadas incluyen: impactos (simples y bipolares), marcas de corte, de raspado, de machacado y de aserrado.

\subsubsection{Alteraciones térmicas}

Se tuvo en cuenta el grado de alteración mediante la observación macroscópica. Se diferenciaron aquellos elementos o especímenes que presentaban las siguientes alteraciones: hueso carbonizado, hueso con oxidación incompleta y hueso calcinado. Estas categorías fueron basadas en el color que presentaron los elementos y especímenes analizados, variando desde el pardo oscuro, negro, azul hasta el blanco (Nicholson 1993). 
La asignación de la alteración térmica a agentes naturales o culturales fue dada a cada elemento y espécimen según el contexto en el que fue hallado, sobre todo se ha considerado su asociación a áreas de combustión o cubetas de vaciado de fogones, etc.

\subsubsection{Formatización}

Para los especímenes formatizados se utilizaron las categorías utilizadas por Casiraghi (1985) y Nasif y Gómez Cardozo (1999). Esto autores plantean la clasificación de las piezas en tres grupos "de acuerdo a su morfología y función: instrumentos, adornos personales y tallas".

Los instrumentos son aquellos que fueron realizados con fines utilitarios, los adornos con fines ornamentales y las tallas son confecciones cuyo fin puede haber sido artístico (Nasif y Gómez Cardozo 1999)

Los criterios utilizados para definir un espécimen como formatizado se basan en la presencia de rasgos tales como pulido de superficies, raspado producto de la utilización, presencia de extremos punzantes, asociación con piezas aserradas, entre otros. 
Siguiendo a O’Connor (1993) asumimos que las carcasas de los animales se van desmembrando a través del tiempo. Es así que se han distinguido una sucesión de estadios de procesamiento y utilización que pueden o no estar ligados a la obtención de productos primarios. Cada estadio involucra un producto o un desecho, esto es un conjunto óseo "producido" y otro conjunto óseo "desechado". Estos conjuntos, por cierto, deben ser definidos como tales a través del estudio de los contextos de los cuales se han recuperado y de estudios tafonómicos previos con el fin de observar que procesos anteriores han actuado sobre el conjunto.

O'Connor propone una serie de indicadores que podrían ayudar a la identificación de las distintas etapas, los productos y los desechos generados en este proceso.

Tabla 5.1. Resumen de procesos a los que estaría sometido un elemento óseo. Tomado de O’Connor (1993)

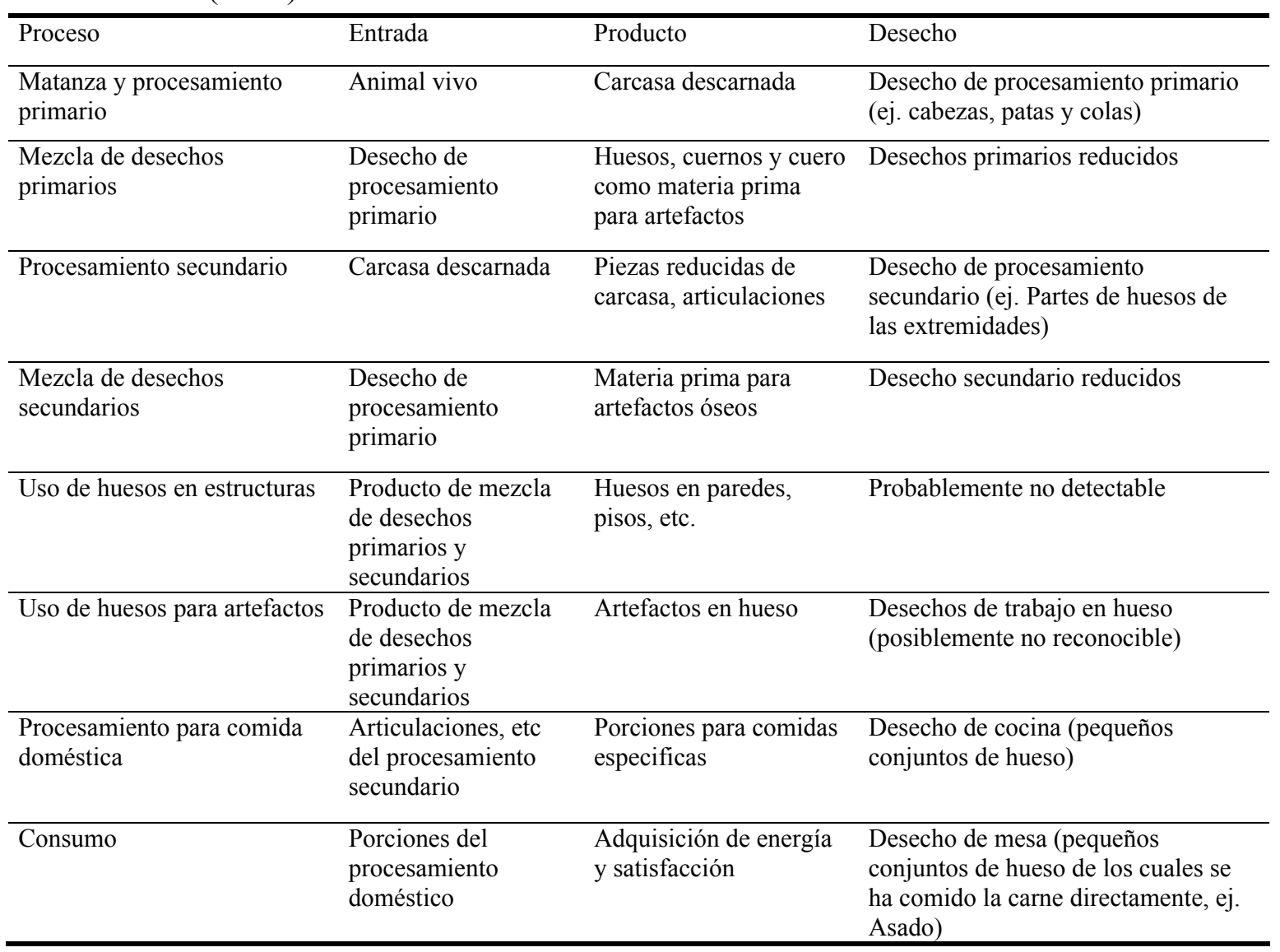


La identificación de estas etapas comienza, como se dijo más arriba, con análisis pormenorizados de aspectos tafonómicos y contextuales. Una vez resuelto ello, y si el conjunto lo permite, se realizan estimaciones en base a las proporciones de elementos o partes anatómicas presentes o ausentes, ya que una sobre-representación o una subrepresentación de determinada parte anatómica puede ser producto de la adición o sustracción intencional humana.

En esta Tesis se trabajó sobre la base de tres modelos teóricos ligados a la historia de los conjuntos arqueofaunísticos recuperados, desde su apropiación hasta su descarte. Los modelos están básicamente asociados a las acciones de transporte de unidades de trozamiento (desde el lugar de matanza hasta el de procesamiento primario), reparto de tales unidades a nivel intrasitio y su consumo.

Como los modelos se fundamentan en las frecuencias de elementos esqueletales calculadas es necesario aplicar sobre las muestras diversos controles tafonómicos, estudios de supervivencia mediadas por la densidad ósea (por ejemplo Hill 2001, Morlan 1994, Stahl 1999) y la relación con la anatomía económica (Grayson 1988, Lyman 1994, Marean y Frey 1997, Mengoni Goñalons 1991, 1996, 1999, Olivera 2001).

\subsection{Transporte}

La cuestión del transporte de las presas de caza o de animales domésticos desde el lugar de muerte hasta el de consumo es un tema central de la zooarqueología.

De manera general se ha estudiado esta cuestión a partir del análisis de la economía anatómica y otras investigaciones actualísticas.

Por ello a la hora de evaluar un conjunto arqueofaunístico con el fin de determinar si ha sido transportado y a qué modelo puede ser asociado, hay que tener en cuenta algunos factores condicionantes como la cantidad de animales, el tamaño de las presas, el número de portadores, la distancia a recorrer y los medios de locomoción. A su vez debe apreciarse que los costos de procesamiento en el campo y los costos de transporte se asocian íntimamente con el transporte selectivo.

En este sentido puede considerarse que no todos los modelos de transporte pueden ser utilizados por analogía con el registro arqueofaunístico. Por ello en esta Tesis se trabajará principalmente aunque no exclusivamente con los modelos propuestos para el área andina, con el fin de observar si los conjuntos del sur de los valles Calchaquíes se ajustan a alguno de ellos. 
Para el área andina se ha propuesto un modelo denominado "efecto ch'arki" derivado del denominado "schlepp effect" ("efecto arrastre") propuesto por Perkins y Daly (1968) basándose en las frecuencias de elementos esqueletales encontradas en sitios del neolítico de Turquía. Este modelo del "efecto ch'arki" fue presentado por Miller (1979) en base a estudios etnoarqueológicos en comunidades indígenas del Perú. Ejemplos de la aplicación de este modelo y sus críticas se encuentran en Miller y Burger (1995), Stahl (1999) y Valdez (2000).

Por otro lado se utilizarán los modelos de transporte generados para la Puna de Jujuy (Yacobaccio et al. 1998) y Antofagasta de la Sierra-Antofalla (Haber 1999, 2002, Haber et al. 1991).

\subsection{Reparto}

El reparto es otro de los temas que revisten gran importancia a la hora de estudiar un conjunto arqueofaunístico tanto entre grupos cazadores-recolector como entre agricultores-pastores (Hocket 1998, Zeder 1991, Zeder y Arter 1996, entre otros). En los últimos años y consecuentemente con el avance de los estudios arqueofaunísticos se han comenzado a realizar estudios sobre el reparto en sociedades complejas.

En general las cuestiones de reparto diferencial de los alimentos o los bienes se asocian, entre otros aspectos, con diferencias sociales (desigualdad) o con la adquisición de prestigio diferencial dentro de las comunidades. Esto se observa en los análisis efectuados en tumbas de gran número de sociedades (para un ejemplo del noroeste argentino ver Johansson 1996).

Estudios como los de Hocket (1998), Hudson (1990), Jackson y Scott (2003), Marshall (1994), Scott y Jackson (1989) y Zeder y Arter (1996), son los que se consideraron con el fin de examinar la presencia de reparto diferencial a nivel intrasitio de los elementos correspondientes a camélidos.

\subsection{Consumo}

Luego de la apropiación y el reparto de las unidades en las que se ha trozado el animal actúan una serie de factores relacionados con el consumo. Este lo entendemos en un sentido amplio, es decir no solo como aprovechamiento de los productos primarios y secundarios sino también la reutilización de los elementos óseos (por ejemplo como artefactos) 
El consumo esta condicionado por distintas variables, las cuales hay que tener en cuenta a la hora de aplicar los modelos. Estas variables corresponden a la toma de decisión (se incluyen las necesidades y preferencias), el modo de adquisición (ver transporte más arriba), el uso (modos, contextos de uso) y por último la disposición post-utilización (reutilización, reciclado y descarte).

Los modelos de consumo final de los recursos faunísticos se nutren de la experimentación y otros estudios actualísticos. Los modelos a considerar son los planteados por De Nigris (1999), Lupo y O’Connel (2002), Outram (2001), Yacobaccio, et al. (1998), en cuestiones tales como efectos del hervido, patrones de fractura, modos de procesamiento de las carcasas, efecto "Pot sizing", entre otros.

Para ello se partirá de la cuantificación y análisis de los tipos de fracturas, y los índices de supervivencia de cada elemento basados en el cálculo de las superficies relativas de cada espécimen mediante el uso de GIS (Izeta 2003), entre otras aproximaciones. 
Parte 3 -El registro arqueológico 
En los últimos años M .C. Scattolin ha procedido a ampliar el corpus de información obtenida con anterioridad en la Falda Occidental del Aconquija ampliándola tanto al vecino valle del Cajón como al valle de Santa María (Izeta y Scattolin 2001, Gero y Scattolin 2002, Scattolin 1982, 1990, 2002, Scattolin et al. 2001).

La arqueofauna analizada en esta Tesis proviene de distintos sitios ubicados en los tres sectores. Los sitios excavados con mayor intensidad corresponden a Loma Alta, con sus Núcleos habitacionales ocupando un período temporal de casi mil años, y a Yutopián que presenta un período de ocupación similar o aún mayor. A estos se suman una muestra de más de cinco sitios que están en proceso de excavación y que por el momento nos muestran sólo una parte de la variabilidad observada hasta el momento en el registro arqueológico de la región.

En el presente Capítulo se procederá a realizar una descripción de los contextos arqueológicos hallados. El criterio de agrupamiento para la descripción será el geográfico, tanto en este capítulo como el próximo con el fin de permitir de un modo mas sencillo ubicar espacialmente a cada uno de los sitios arqueológicos. Luego se tratarán los resultados en conjunto siguiendo el criterio de bloques temporales.

\subsection{La muestra arqueofaunística}

En esta Tesis se trabajó con la mayor parte del material arqueofaunístico recuperado durante las campañas arqueológicas realizadas en los últimos veinte años en la Falda Occidental del Aconquija, en el Valle de Santa María y el Valle del Cajón por el equipo dirigido por M. Cristina Scattolin.

Esta muestra comprende los restos óseos de los niveles de ocupación definidos para trece núcleos habitacionales y tres depósitos naturales de siete sitios arqueológicos del área de estudio.

El número de especímenes identificados para este conjunto supera los 16.000 . Sobre ello se analizaron 34 atributos lo cual da al menos unos 570.000 observaciones para el total de la muestra. 
Por otro lado se tomaron 2.055 medidas de 383 elementos (arqueológicos y modernos) con el fin de realizar análisis osteométricos.

Además se ingresaron esquemas de los contornos de 701 especímenes con el fin de realizar la cuantificación a través del uso de software de SIG (o GIS).

\subsection{Loma Alta}

Este sitio arqueológico ha sido excavado en sucesivas campañas por M. Cristina Scattolin desde el año 1983 hasta el año 1995. Durante ese período los esfuerzos se centraron en la recolección de datos y el análisis de los conjuntos cerámicos y líticos, además de la distribución espacial de los rasgos más conspicuos (Scattolin 1990, Lazzari, 1989, Martínez 1999, entre otros).

El sitio se encuentra en la localidad de Cerrillos, la cual se halla incluida en un gran conoide de deyección con evidencia arquitectónica superficial y una superficie total de 40 hectáreas (Figuras 6.1 y 6.2).

"El sitio Loma Alta se ubica sobre una lomada al sur del cono aluvial. Se trata de una angosta elevación aplanada cuyos límites, dados por dos pequeñas quebradas, la separan del gran conoide de Cerrillos. Presenta también un mejor estado de conservación y mayor visibilidad pues el terreno no se utiliza. Comprende unas 100 estructuras de formas y tamaños diversos. Las pircas tienden a ser curvas, adoptando formas irregulares, en general, subcirculares, de un diámetro de una a varias decenas de metros. Todo el sitio visto en planta da la apariencia de un retículo muy irregular en donde las zonas más abigarradas corresponden a los Núcleos Habitacionales (NH) que se encuentran intercalados entre los campos de cultivo y adosados a ellos. Hay 9 de estos NH, algunos de ellos ya excavados, y casi 50 recintos de cultivo (Scattolin 1990). La superficie se ha tomado por dentro del perímetro más externo que abarcan los recintos y dio 6 ha. Pero toda el área de la mesada abarca unas 9 ha" (Scattolin 1994)

Estos Núcleos Habitacionales se denominaron desde la "A" hasta la "I". Los analizados en esta tesis son los núcleos E, F y G.

En cuanto al registro cerámico encontrado en el sitio se observó la presencia de tipos similares a Río Diablo, La Manga, Ciénaga Inciso, Aconquija Inciso, Allpatauca, etc. asignables al Período Formativo Inferior y Medio (Scattolin 1990). 
En el año 1986 los Dres. E. Tonni y M. Salemme (Facultad de Ciencias Naturales y Museo de la UNLP) efectuaron un análisis preliminar de la fauna de este sitio. Esta muestra estaba compuesta por 126 elementos (no se incluyen especímenes). Si embargo y para dar una idea cerca del grado de fragmentación de la muestra se tomó registró el peso $(3,2 \mathrm{~kg})$ y se determinó que más de la mitad de esa cantidad comprendía fragmentos muy pequeños y/o no identificables incluyendo las piezas óseas determinables y los huesos con señales de uso. De este análisis sólo fue realizada una aproximación al MNI alcanzando un total de 21 individuos entre todas las especies analizadas (Tonni y Salemme en Scattolin 1986).

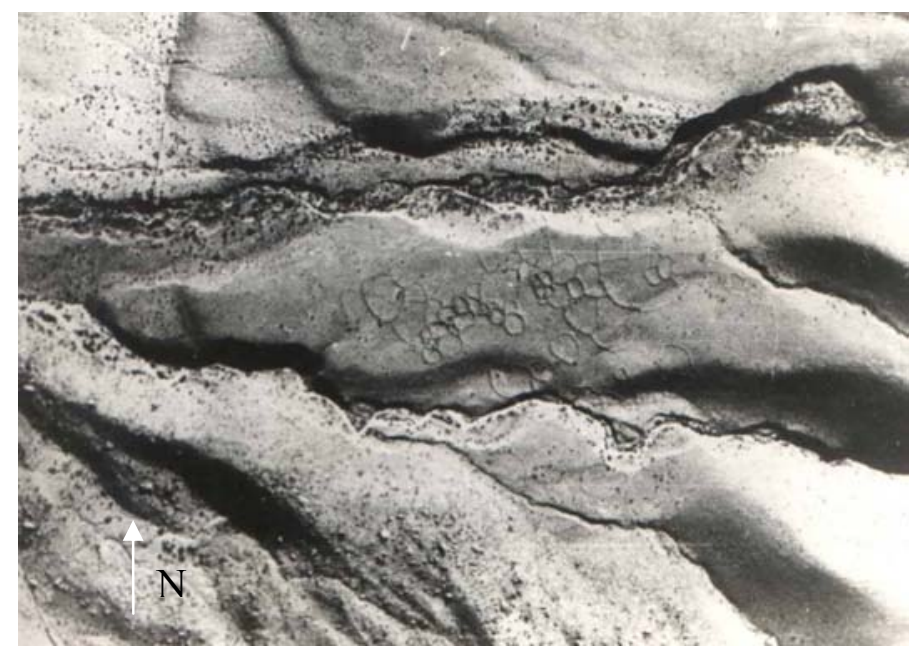

Figura 6.1. Foto aérea del sitio Loma Alta. (Foto colección Scattolin)

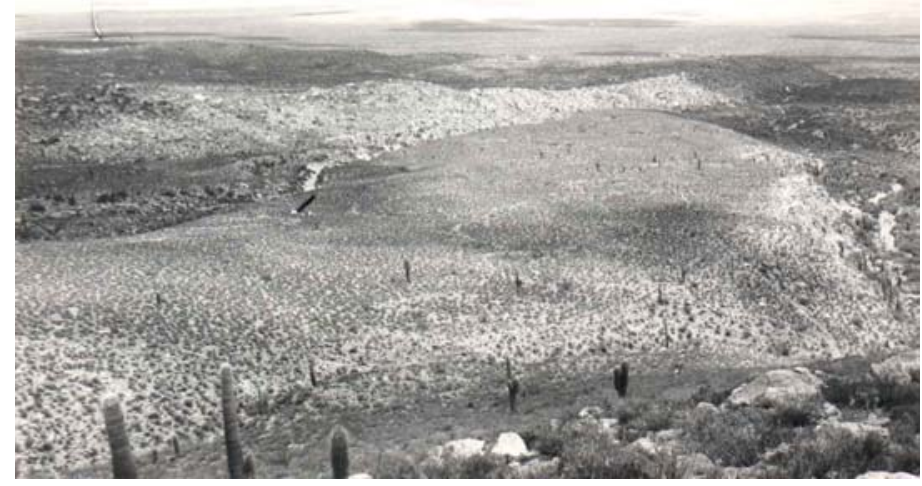

Figura 6.2. Vista general del sitio Loma Alta. (Foto colección Scattolin) 


\subsubsection{Núcleo $E$}

El núcleo $\mathrm{E}$ es el que ha sido excavado con más intensidad en toda la Falda Occidental del Aconquija. Este núcleo esta compuesto por los recintos R37, R41, R42, R43, R44, R45, R46, R47 y R48. De estos recintos los excavados son el R44, R46 y R47. Se conocen tres fechados radiocarbónicos (Scattolin 2001). Para esta Tesis se tomarán los presentados en la Tabla 6.1 que sitúan temporalmente a la ocupación del núcleo alrededor del 1550-1600 A. P. y en nuestro Bloque Temporal 2 y que son los que están directamente asociados con el nivel de ocupación.

Tabla 6.1. Fechados radiocarbónicos Loma Alta Recinto 47 (Scattolin 2001).

\begin{tabular}{lll}
\hline Laboratorio y código & Fechados A.P. & Procedencia (nivel) \\
GX21580 & $1600+/-120$ & L. Alta R47/C10/1 \\
GX21581 & $1560+/-130$ & L. Alta R47/C10/2 \\
\hline
\end{tabular}

Durante la excavación se identificaron cuatro depósitos (1, 2, 3 y 4). El depósito 4 es el inferior y resulto estéril en términos arqueológicos. El depósito 3 es en el cual se ha determinado un nivel de ocupación y se ubica sobre el depósito 4. Para esta Tesis se trabajó con los restos faunísticos hallados en este depósito (equivale a un tercio de la muestra total recuperada del sitio).

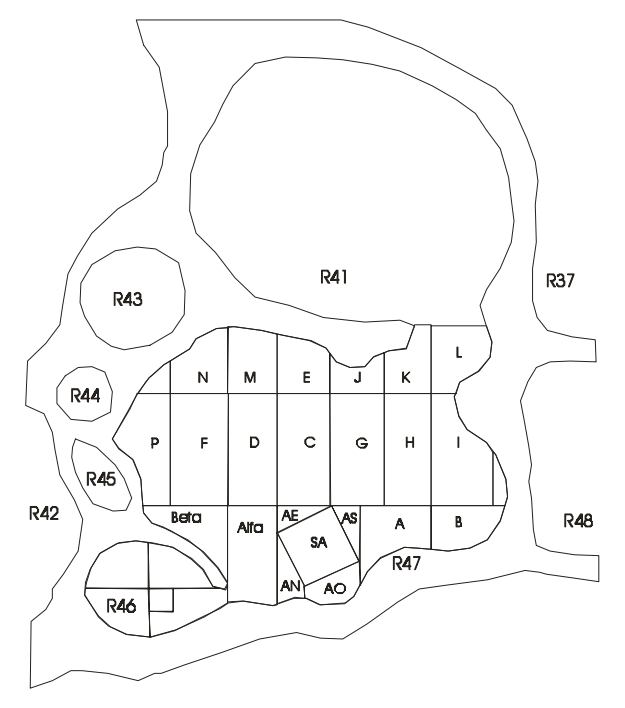

Figura 6.3. Planta del Núcleo E.

En el nivel de ocupación del R47 se hallaron distintos rasgos in situ (ver Scattolin 1990). Se puede remarcar la ubicación de distintas estructuras de combustión. En la cuadrícula AO y en su límite con SA (Figura 6.3) se identificó la presencia de dos fondos de vasija posiblemente utilizadas como fondos de fogones (Scattolin 1990). 
Asimismo y en el mismo nivel se halló en el sector Alfa una conana. Estos rasgos pueden observarse en la Figura 6.4, el fogón se ubica en el extremo inferior derecho junto a una gran roca, en tanto que la conana se puede ver en la parte izquierda de la figura.

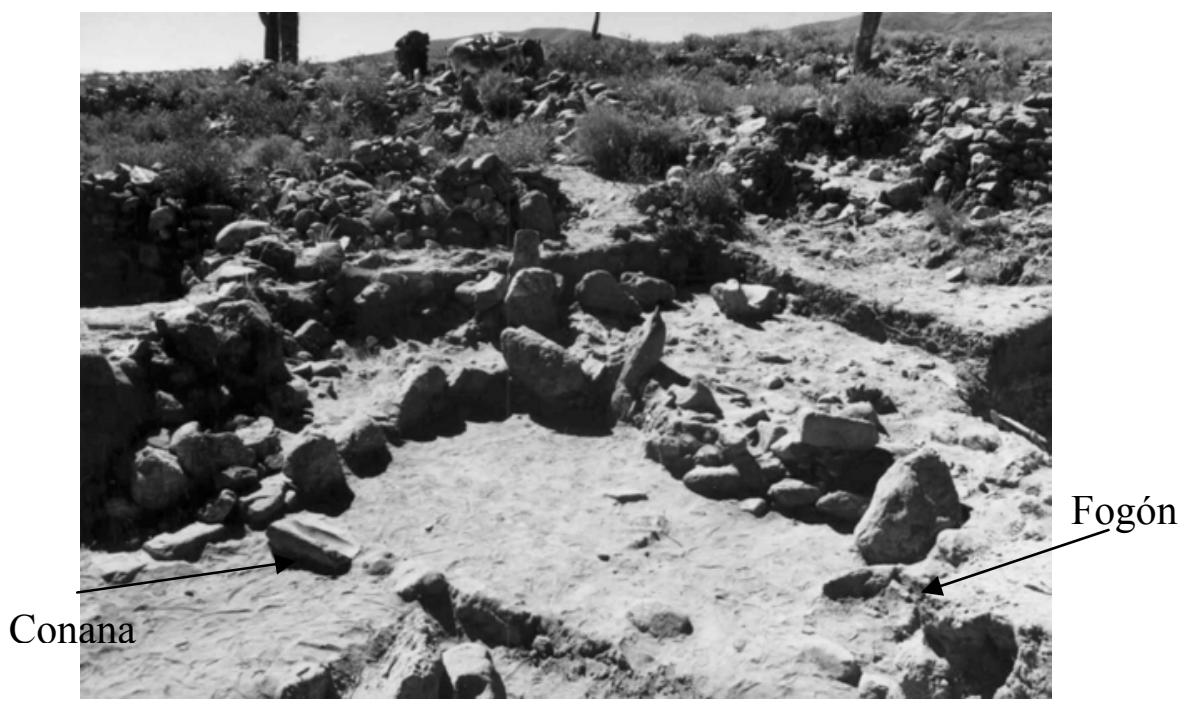

Figura 6.4. Nivel de Ocupación del R47. (Foto colección Scattolin)

La ubicación de distintos rasgos y diferencias en los tipos y estructuras de los sedimentos permitió identificar una estructuración del espacio y a partir de ello el planteamiento de distintas áreas de actividades. Como conclusión de ello se propuso que en este núcleo se han llevado a cabo distintas actividades tales como molienda de vegetales, preparación, cocción y uso de alimentos, trozamiento de animales y producción y uso de instrumentos líticos (Scattolin 1990).

El R46 no fue excavado en su totalidad. De todos modos en las partes excavadas se notó que la cantidad de restos arqueológicos hallado fue menor. La estratigrafía es similar a la hallada en el R47 (Scattolin 1990).

Por último el R44 fue excavado en su totalidad. Según Scattolin (1990: 89) este recinto "presenta una serie de lajas plantadas verticalmente formando un círculo de menos de $1 \mathrm{~m}$ de diámetro". Esta disposición en conjunto con otros datos contextuales llevó a la autora a proponer a este recinto la función de silo o depósito.

\subsubsection{Núcleo $F$}

Compuesto por los recintos R61, R 62, R63 A, R63B, R64, R65, R66 y R67 (Figura 6.5). Los dos únicos recintos excavados de este núcleo corresponden al R63A y 
el R67. Del primero se obtuvo un fechado radiocarbónico (LP-214 LAR67/3 700 +/- 50 A. P.) situando la ocupación de este núcleo en el final del último bloque temporal.

El R67 fue excavado en su totalidad durante el año 1983 y el R63A de manera parcial en al año 1995.

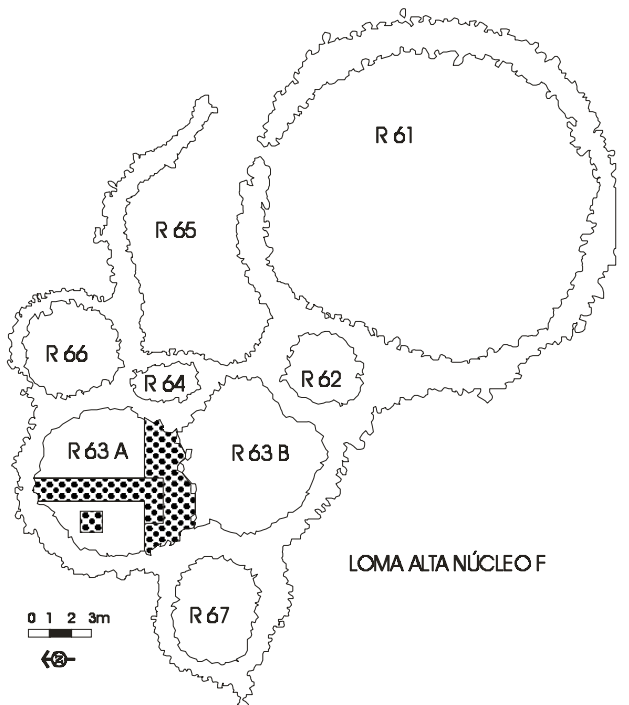

Figura 6.5. Núcleo F. Se observa la superficie excavada en el Recinto 63A y 67.

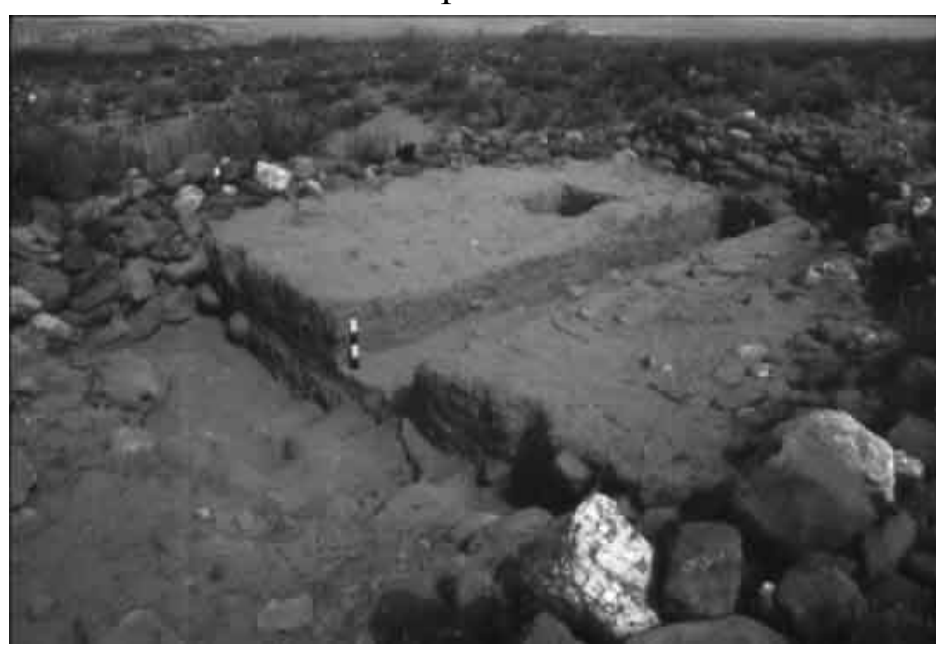

Figura 6.6 Vista de las excavaciones realizadas en el R63A. (Foto colección Scattolin)

\subsubsection{Núcleo $G$}

Compuesto por los recintos R87, R88 y R89. El recinto R87 fue excavado en su totalidad. En los otros dos recintos se procedió a la realización de sondeos (Figura 6.7 y $6.8)$.

La fecha de ocupación de estos recintos corresponde al 1,365 A.P. (GX21577 LAR88/S4/3 1,365 +/- 90 A. P.) (Scattolin com. pers. 2003) 
En el R88 se encontraron fragmentos de estilo Aguada.

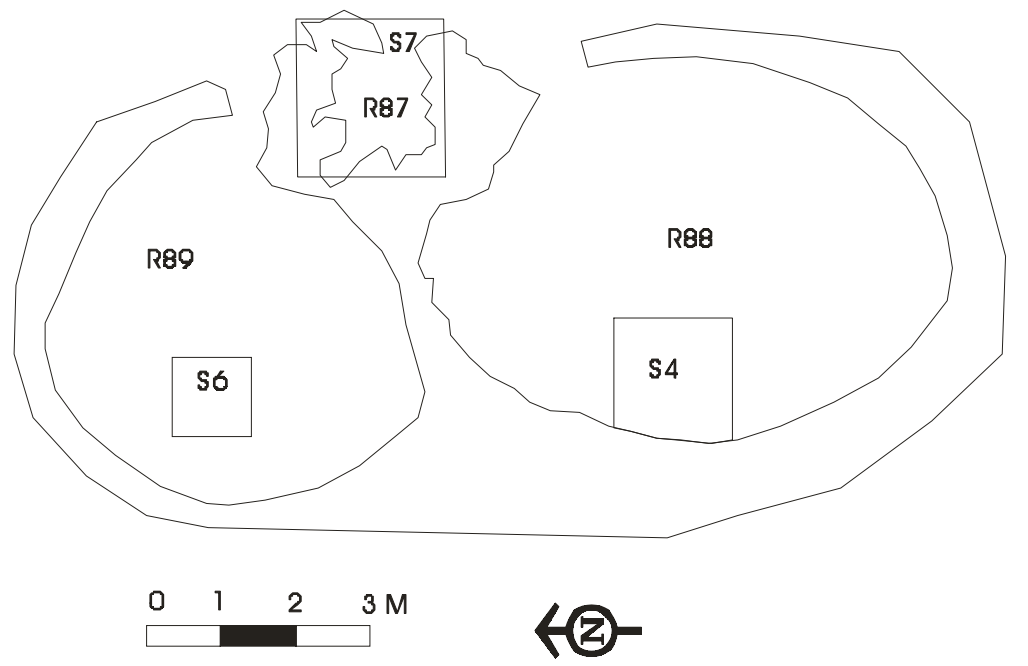

Figura 6.7. Núcleo G. Se observa la superficie excavada (S4, S5 y S7).

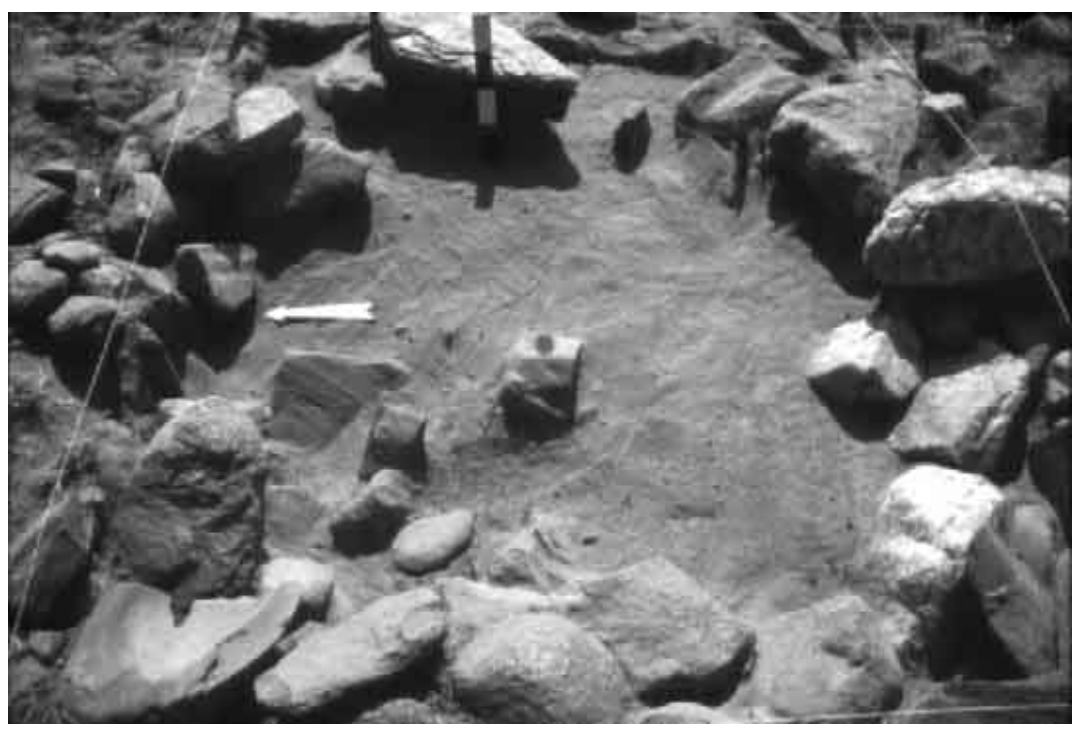

Figura 6.8. Vista de las excavaciones realizadas en el R87. (Foto colección Scattolin)

\subsection{Potrero Antigal}

El sitio se ubica en la Localidad de Cerrillos (ver Figura 2.2 y 6.9). En la actualidad se encuentra rodeado por estructuras modernas como el casco de la estancia Cerrillos y su Escuela, así como de otras estructuras accesorias. 
Durante abril de 1985 se realizó un sondeo de 1 metro de lado. Se excavaron 10 niveles artificiales. En el nivel 7 se ubicó un piso de ocupación (Figura 6.10). Aquí consideraré el nivel de ocupación abarcando desde el nivel inmediatamente superior (nivel 6) hasta el 10. Hay un fechado realizado en hueso que arrojó una fecha de 735 +/115 A. P. (GX-21583-G) (Scattolin com. pers. 2003) lo que lo ubica dentro de nuestro bloque temporal 4.

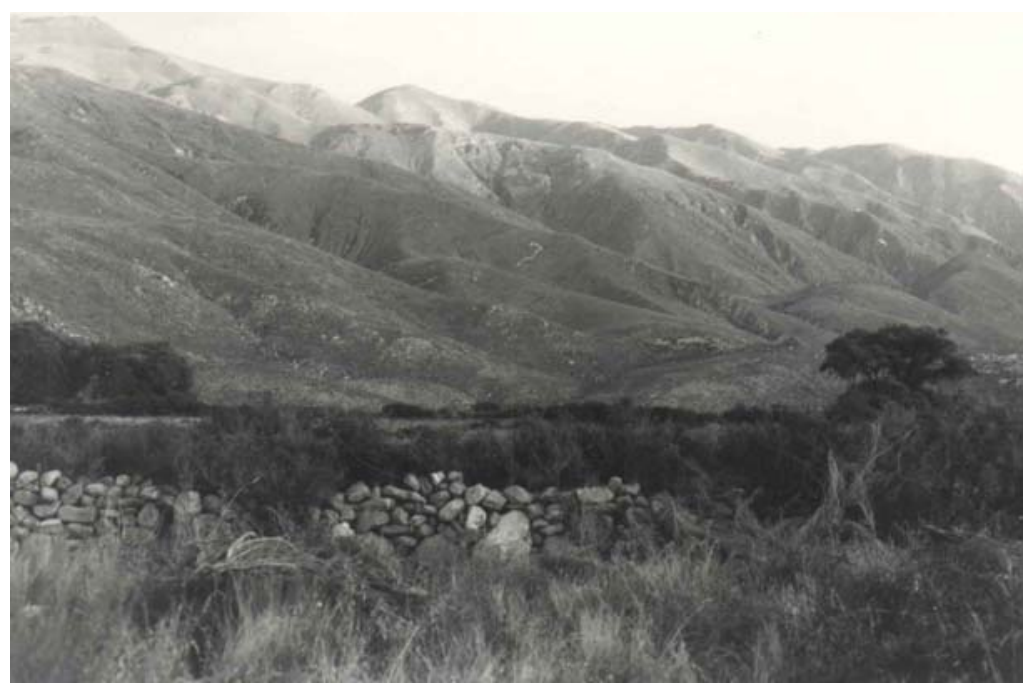

Figura 6.9. Vista general de Potrero Antigal. (Foto colección Scattolin)

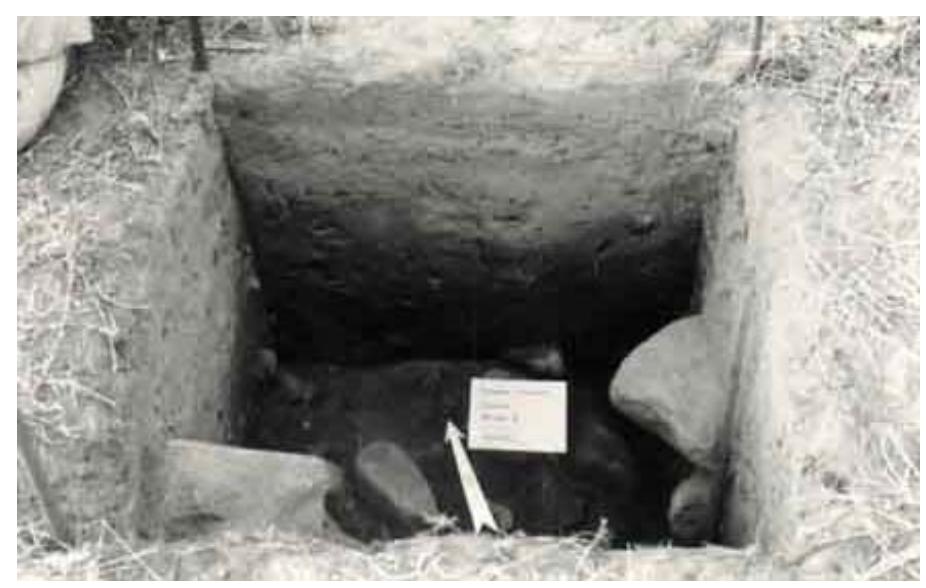

Figura 6.10. Vista de la excavación realizada en Potrero Antigal. (Foto colección Scattolin)

\subsection{Tesoro 1}

El sitio fue prospectado por primera vez en abril de 1983 (Scattolin y Albeck 1994). Durante la recolección de material de superficie del sitio se encontró gran 
cantidad de cerámica asignable a los estilos definidos para el Período Formativo del área principalmente cerámica gris-negra pulida.

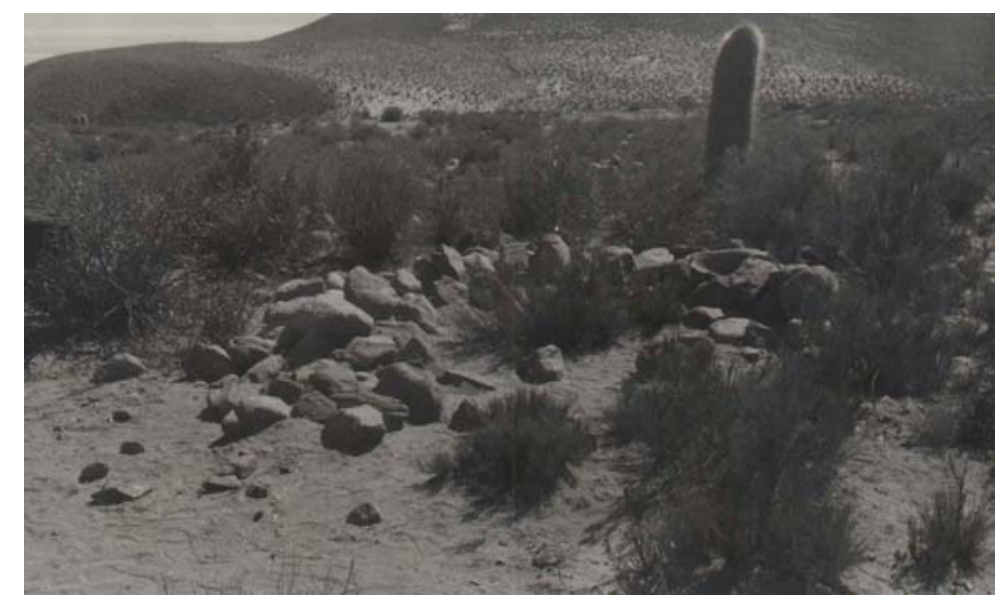

Figura 6.11. Vista general del sitio Tesoro 1. (Foto colección Scattolin)

Debido a ello se realizó un sondeo de 1,5 metros de lado en una de las estructuras del sitio (Recinto 7 del núcleo A). Se excavaron seis niveles artificiales de los cuales los tres últimos se asignaron a un nivel de ocupación, diferenciándolo de los niveles superiores. Para el nivel 4 se obtuvo un fechado radiocarbónico efectuado sobre hueso: 1,090 +/- 115 A. P. (GX-21582-G) (Scattolin com. pers. 2003)

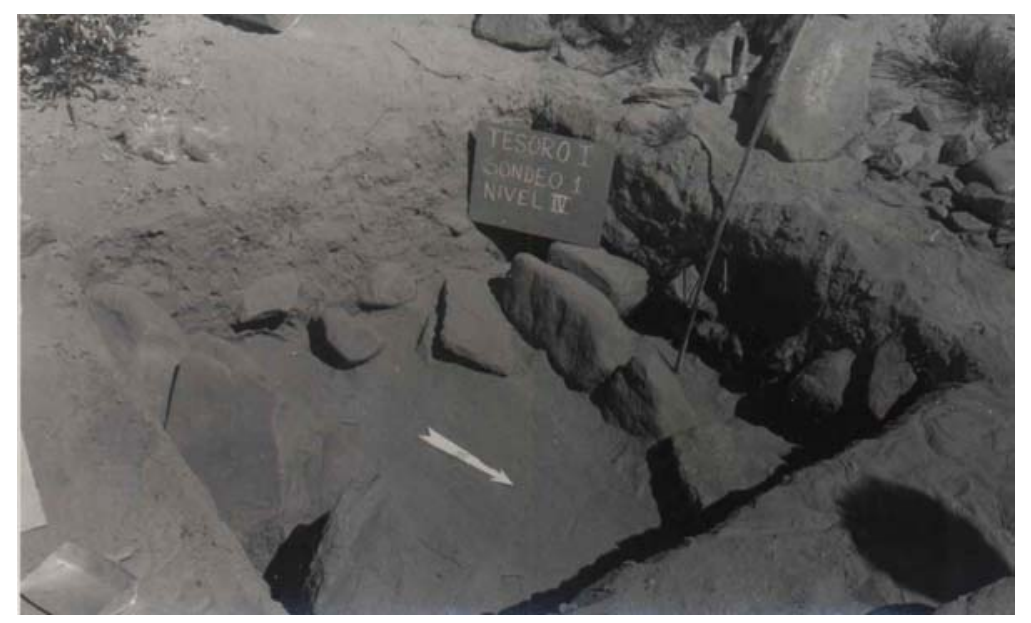

Figura 6.12. Excavación en el sitio Tesoro 1. (Foto colección Scattolin)

El sitio se compone de dos áreas diferenciadas. En la parte superior del sitio se encuentran estructuras de gran tamaño asignables a tareas de producción agrícola. En la 
"parte inferior de la ladera al noroeste se halla un grupo de recintos en arco" denominado "El Rosario" (Scattolin y Albeck 1994)

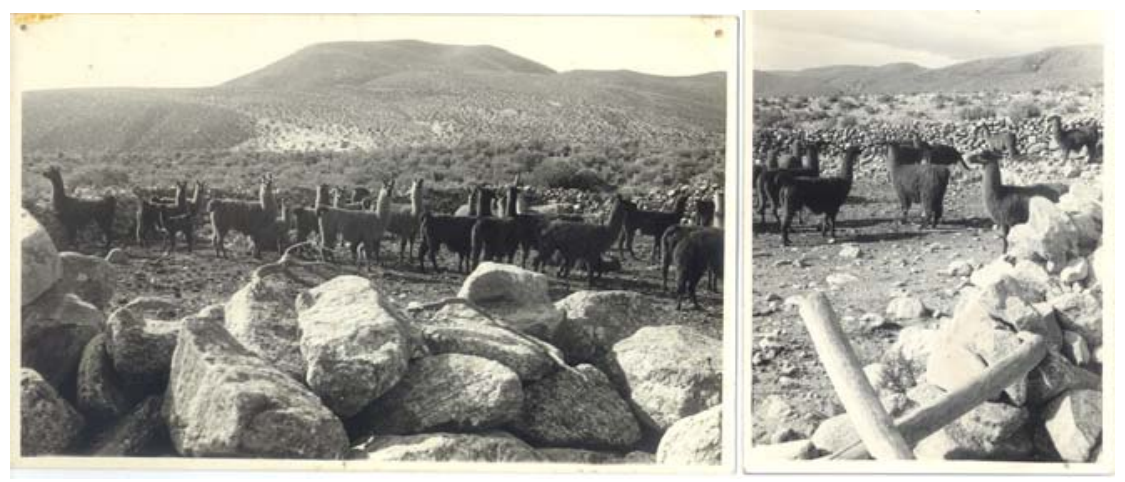

Figura 6.13. Corral moderno ocupado con ejemplares de Lama glama. Cerca de Tesoro 1. (Foto colección Scattolin)

\subsection{Antigal de Tesoro o Tesoro 2}

Este sitio fue descripto por primera vez por Scattolin y Korstanje (1994: 171). Durante el año 1995 fue vuelto a prospectar y en esa ocasión se realizó el mapa de las estructuras.

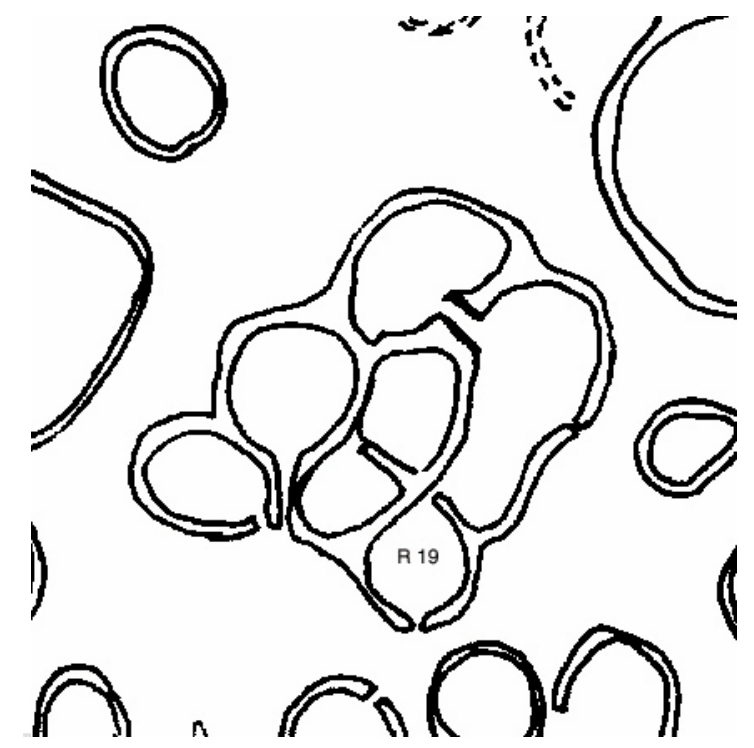

Figura 6.14. Planta del Recinto 19, Antigal de Tesoro. Tomado de Scattolin (2001)

La ubicación del sitio es al este de Tesoro 1 y a unos $3200 \mathrm{msnm}$. La presencia de una vega de altura hace del ambiente un lugar propicio para que los animales se alimenten allí en la actualidad. Creemos que en pasado puede haber actuado de la 
misma forma ya que el perfil observado en esta vega posee una gran potencia sedimentaria.

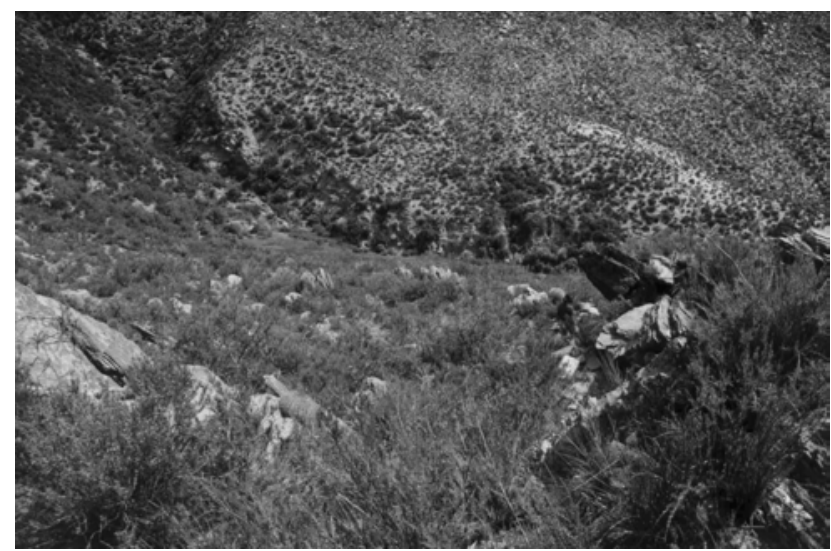

Figura 6.15. Vista de la vega (centro de la fotografía) desde Antigal de Tesoro. (Foto colección Scattolin)

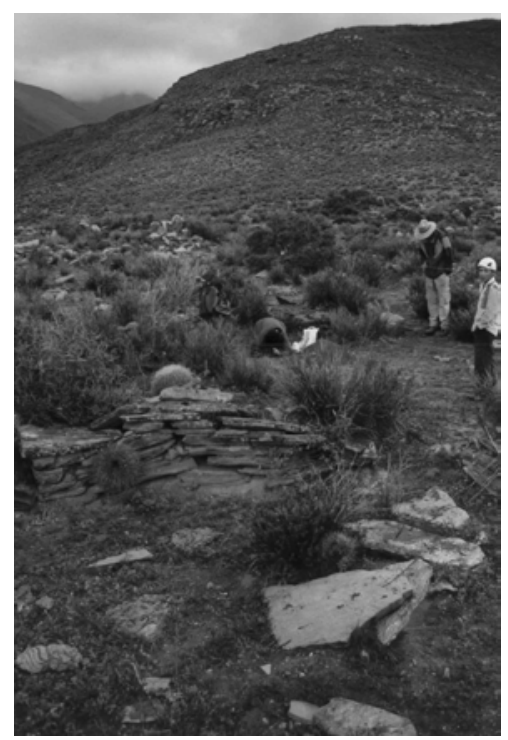

Figura 6.16. Vista general del ambiente de Antigal de Tesoro. (Foto colección Scattolin)

En el año 1999 se procedió a la excavación de un cuadrante del denominado Recinto 19 (Figura 6.14). Durante esa excavación se llegó a un piso de ocupación en el cual se logró extraer fragmentos de una vasija.

El fechado obtenido sobre carbón y realizado mediante AMS arrojó una fecha de 1536+-25 A. P. (AA53821 - TES 2 /Rec19) (Scattolin com. pers. 2003) 


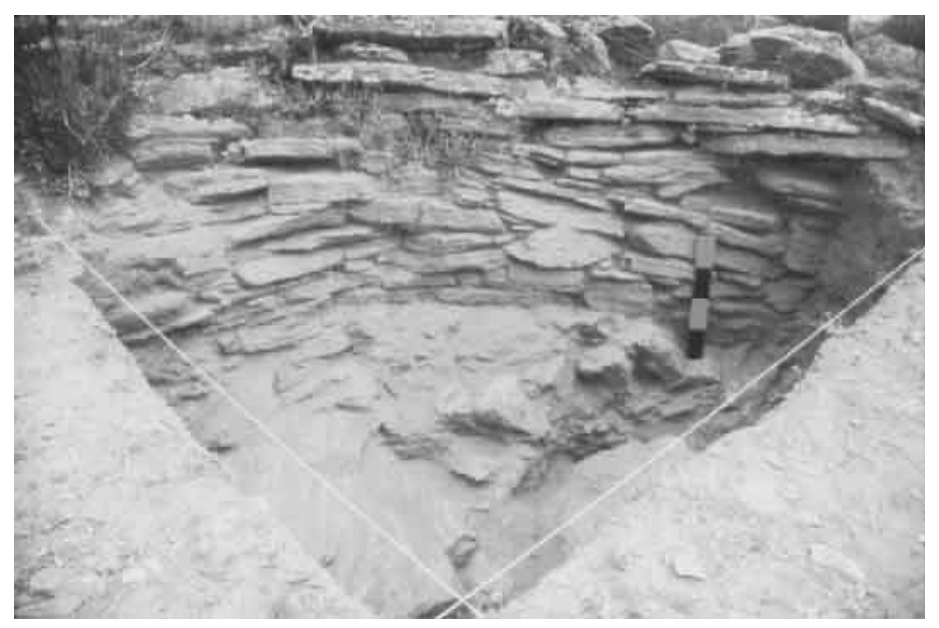

Figura 6.17. Roca de base en excavación del R19. (Foto colección Scattolin)

\subsection{Yutopián}

El sitio Yutopián ha sido excavado durante varias campañas por el equipo conformado por las arqueólogas M. Cristina Scattolin y Joan Gero.

Como resultado de estas investigaciones se han publicado varios artículos (Scattolin y Gero 1999, Gero y Scattolin 2000, Gero y Scattolin 2002) y ponencias en congresos (Scattolin y Gero 1994, Scattolin y Gero 1997, Gero y Scattolin 1999, Scattolin y Gero 1999, entre otros).

Desde 1994 a la fecha se han realizado excavaciones de estructuras completas y unos veinte pozos de prueba (Scattolin y Gero 1999). Del total de excavaciones realizadas en esta Tesis solo se toman las correspondientes a las estructuras 1, Patio de Núcleo 1, 3, 4, 5 y 11.

Sin embargo, y a pesar de lo avanzado en el análisis de los conjuntos tanto líticos como cerámicos, las muestras faunísticas no habían sido analizadas con profundidad. Es por ello que se encaró el estudio sistemático de toda la colección faunística recuperada hasta la fecha.

Los fechados radiocarbónicos obtenidos para el sitio corresponden a las estructuras 3, 4 y 11 (Tabla 6.2).

Tabla 6.2. Fechados radiocarbónicos de Yutopián.

\begin{tabular}{ccc}
\hline Laboratorio y código & Fechado A. P. & Procedencia (nivel) \\
Beta95610 & $1940+/-90$ & YutoE11/13-14 \\
Beta95609 & $1830+/-60$ & YutoE3/p1 \\
Beta95611 & $1630+/-60$ & YutoE4/331-2/5 \\
\hline
\end{tabular}




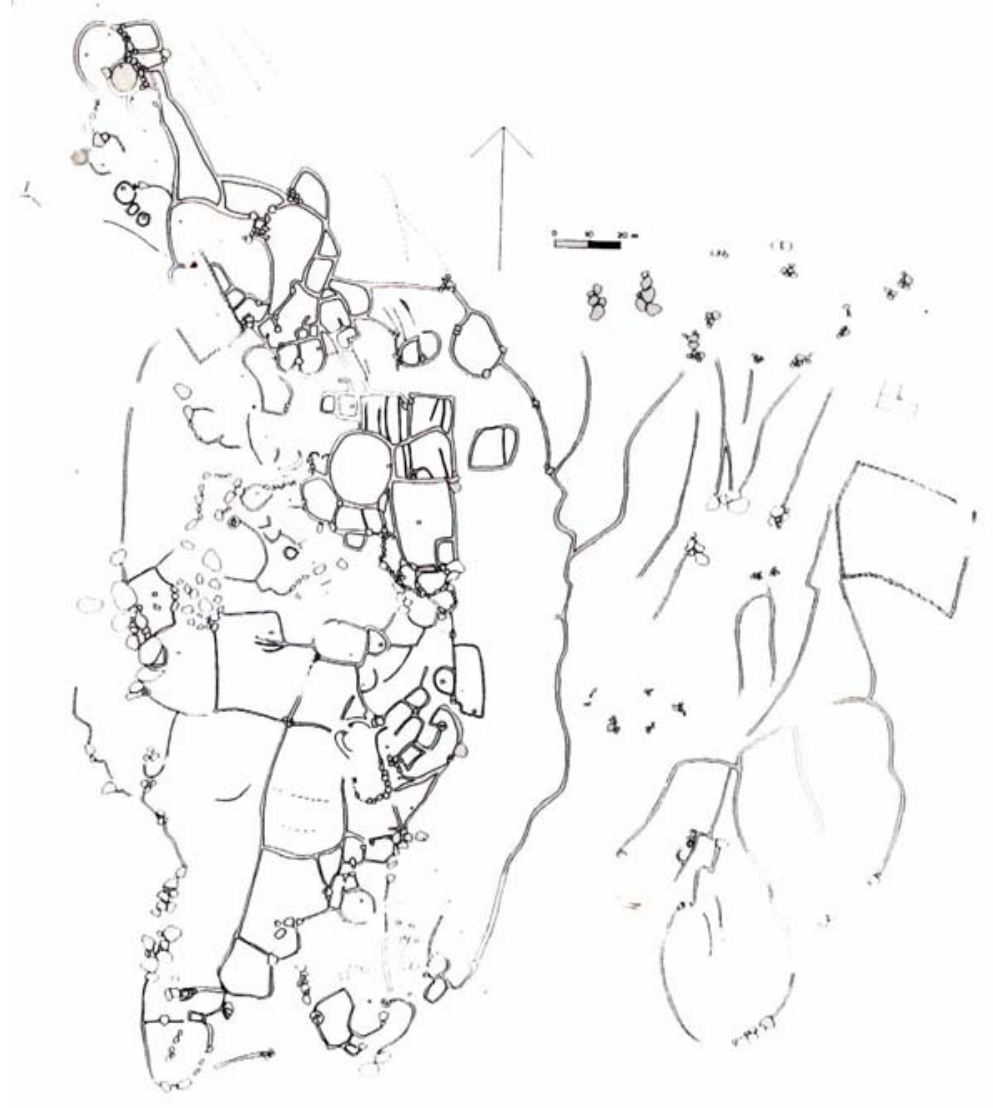

Figura 6.18. Planta del sitio Yutopián. Tomado de Gero y Scattolin (2002).

Las Estructuras 1, 2 y 3 (Núcleo 1) conforman una unidad en la porción norte del sitio. Los hallazgos realizados en la primera de ellas (particularmente el fogón) y los artefactos asociados, hacen suponer que aparte de las actividades domésticas allí están representadas etapas del proceso de producción de artefactos metálicos (Gero y Scattolin 1994, Scattolin y Gero 1999).

La Estructura 1 es una de las mejor conservadas en el sitio Yutopián. No posee fechados radiocarbónicos, pero por la estructuración del espacio, los conjuntos cerámicos y las proporciones de materiales líticos presentes se postula su contemporaneidad con la Estructura 4 (Gero y Scattolin 1999, 2002).

Para la estructura 3 "como evidencia remarcable se ha hallado una interesante asociación de cerámica tosca, gris pulido, gris inciso, fragmentos con decoración antropomorfa al pastillaje e incisa (Tafi-Candelaria) y Condorhuasi policromo" (Scattolin y Gero 1999: 353) 

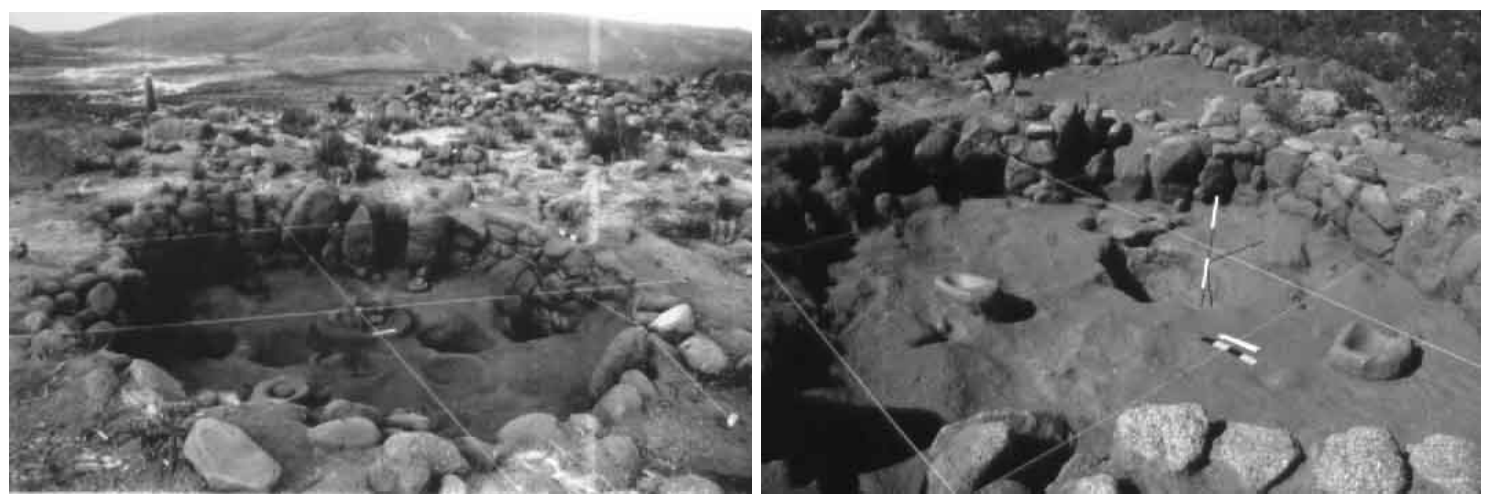

Figura 6.19. Estructura 1 y Estructura 3, Yutopián. (Foto colección Gero-Scattolin)

Las estructuras 4 y 5 se encuentran ubicadas cerca del Núcleo 1. Según Scattolin y Gero (1999: 355)

"Aquí se recuperaron muestras de restos vegetales carbonizados, tales como carozos de chañar. Además se recuperó un alambre de cobre, y varios fragmentos de alfarería de tamaño mediano y grande, con decoración al pastillaje e incisiones punteadas, que pueden ser remontados para formar vasijas semicompletas. Una vasija gris incisa se halló inmediatamente al lado y apoyada contra este fogón. Esta Estructura 4, carece hasta el momento de conanas, lo cual la diferencia de Estructura 1 y 3, y a la vez presenta el nivel de ocupación muy carbonizado, con varias piedras ahumadas lo que permitiría afirmar su uso como cocina".
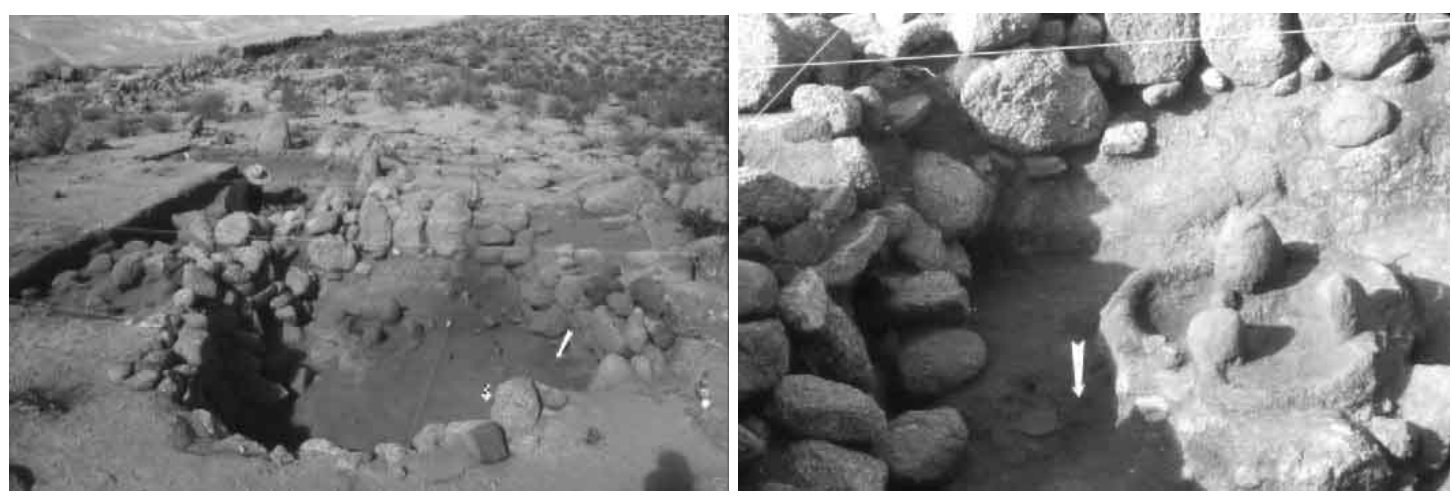

Figura 6.20. a) Estructura 4 y 5, b) Detalle de los fogones hallados en Estructura 4. (Foto colección Gero-Scattolin) 
La Estructura 11 está compuesta por dos componentes. Uno superior asignado al Período Tardío - Hispano Indígena y uno inferior asignado al Período Formativo (Scattolin y Gero 1999: 353). En este último componente se ha hallado un nivel de piso de ocupación en el cual se encontraron rasgos tales como un fogón, una puerta, conanas in situ y diversos pozos de almacenaje.

En las capas artificiales asignadas al componente formativo de esta estructura hasta su contacto con la roca de base se han hallado restos óseos, líticos, cerámicos y semillas carbonizadas. La cerámica abarca un conjunto ordinario y uno fino. "Este último está compuesto principalmente por alfarería gris pulida y unos pocos fragmentos Condorhuasi marrón pulido y Condorhuasi rojo sobre ante" (Scattolin y Gero 1999: 353).

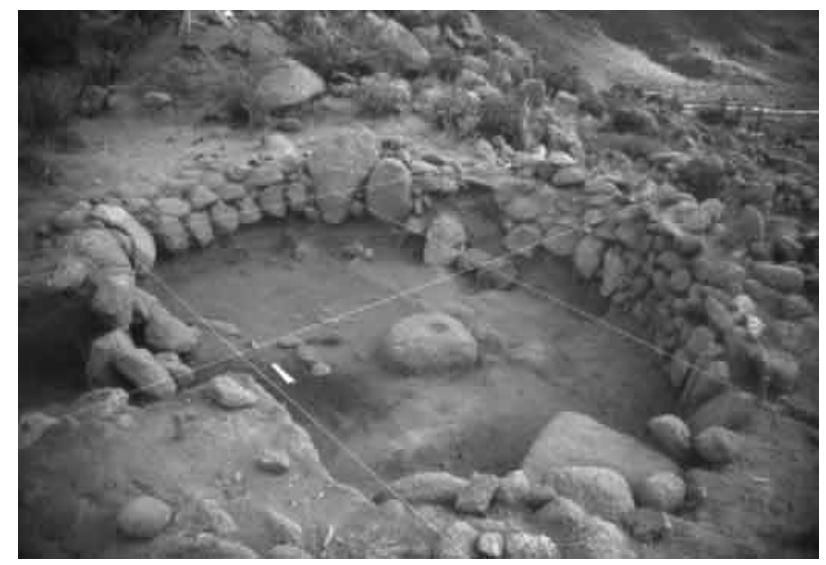

Figura 6.21. Estructura 11. Yutopián. (Foto colección Gero-Scattolin)

\subsection{Bañado Viejo}

Durante los años 1997 y 1998 Scattolin y colaboradores llevaron a cabo excavaciones en el sitio Bañado Viejo (Bugliani y Pereyra Domingorena 2001, Izeta y Scattolin 2001 y Scattolin et al. 2001).

Este se ubica a unos $8 \mathrm{~km}$ al noreste del sitio arqueológico Quilmes, en la Provincia de Tucumán.

Durante las "prospecciones se pudo localizar un sector particular denominado Bañado Viejo -unos 3,5 km al norte del poblado actual de El Bañado y 1,5 km al oeste del cauce del río Santa María- que fue seleccionado para su estudio por haberse determinado un área restringida que parecía ofrecer exclusivamente ocupaciones pretardías" (Izeta y Scattolin 2001: 386). 


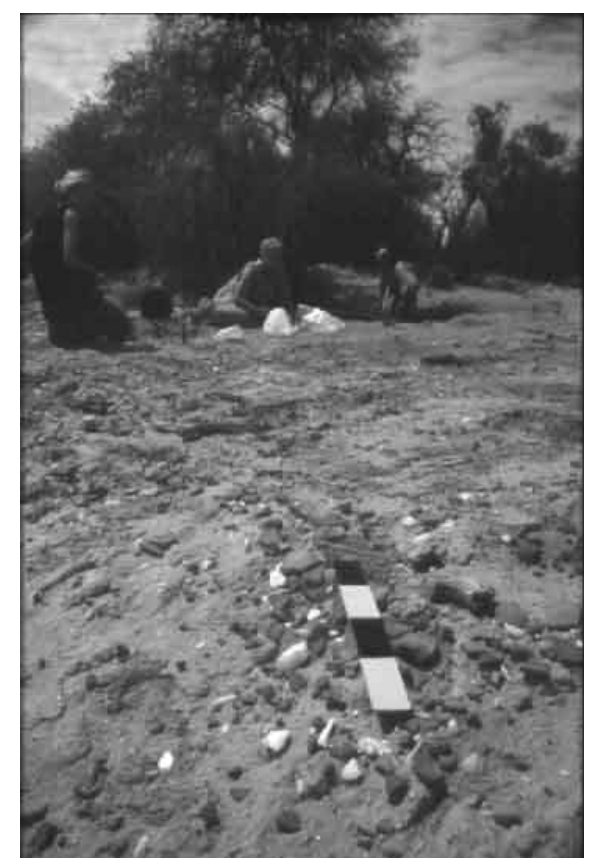

Figura 6.22. Acumulación discreta de cerámica presantamariana y Sondeo 1. Bañado Viejo. (Foto colección Scattolin)

En este lugar se realizo la excavación de un sondeo de 2 x $1 \mathrm{~m}$ (Cuadrícula 1) y cuya potencia sedimentaria alcanzó los 3,20 m con presencia de registro arqueológico durante toda la excavación.

De acuerdo a las características sedimentológicas se determinó la presencia de seis depósitos naturales los que varían en tamaño (Figura 6.23)

Para el sitio se cuenta con tres fechados radiocarbónicos, realizados en todos los casos en carbón (Tabla 6.3)

Tabla 6.3. Fechados radiocarbónicos Bañado Viejo. Tomado de Izeta y Scattolin 2001.

\begin{tabular}{lcll}
\hline Laboratorio y código & Fechados A. P. & Procedencia (nivel) & Procedencia (Depósito) \\
LP923 & $1170+/-40$ & Cuadrícula 1/Nivel 4 & Depósito II \\
LP940 & $1400+/-40$ & Cuadrícula 1/Nivel 10 & Depósito III \\
LP962 & $1760+/-100$ & Cuadrícula 1/Nivel 24 & Depósito VI \\
\hline
\end{tabular}




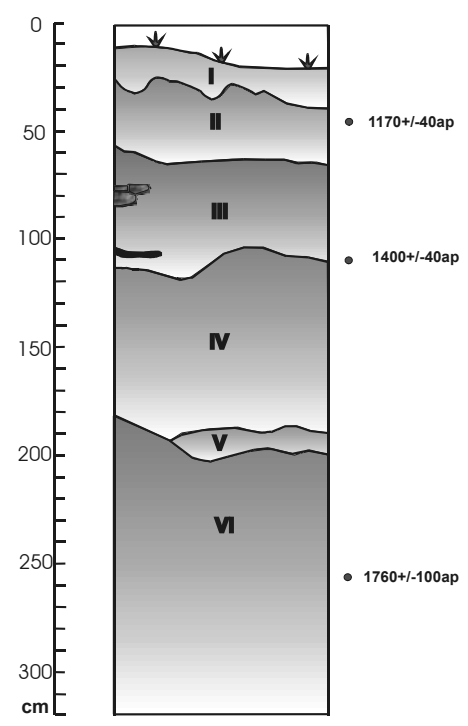

Figura 6.23. Perfil Sur esquemático de la Cuadrícula 1 de Bañado Viejo (Izeta y Scattolin 2001, Scattolin et el 2001)

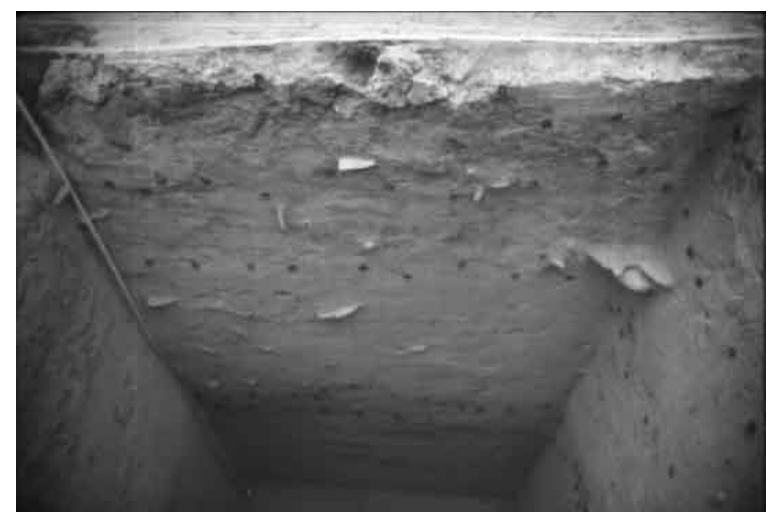

Figura 6.24 Vista de la Cuadrícula 1 de Bañado Viejo. (Foto colección Scattolin)

\subsection{Morro de la Espinillas}

Este sitio fue excavado en el año 1959 por Cigliano et al. (1960). En ese momento se excavaron cuatro habitaciones. Luego se produjo un abandono por cerca de cuarenta años hasta que en el año 1998 se volvieron a retomar las excavaciones (Scattolin 2002).

Este sitio presenta los restos faunísticos provenientes de tres sondeos dentro de los cuales se han recuperados lascas líticas de basalto, basandesitas, cuarzo y un caso de calcedonia. La cerámica hallada se caracteriza por la ausencia de material cerámico de estilo santamariano y la presencia de una combinación de alfarerías grises pulidas, grises incisas, ante pintadas en negro y rojo, y también en negro sobre rojizo, con diferentes motivos geométricos dentro del conjunto fino o vajilla de servicio, y una 
cantidad apreciable de cerámica ordinaria sin decoración, ya sea de cocción o almacenaje (Fraga 1999, Scattolin 2002).

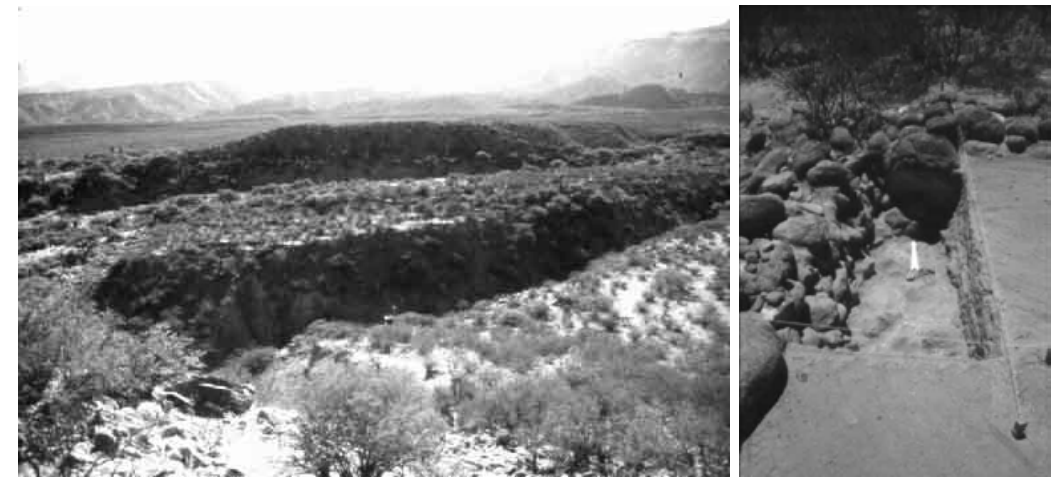

Figura 6.25. Vista general de Morro de las Espinillas y Sondeo 3. (Fotos colección Scattolin)

Una de las características de este sitio es "que presentaba la rara combinación de una arquitectura similar a la de los poblados conglomerados del período de Desarrollos Regionales con una cerámica tipológicamente atribuible a lo que en ese entonces se consideraba del período Medio o Temprano" (Scattolin 2002) como se puede observar en la Figura 6.26.

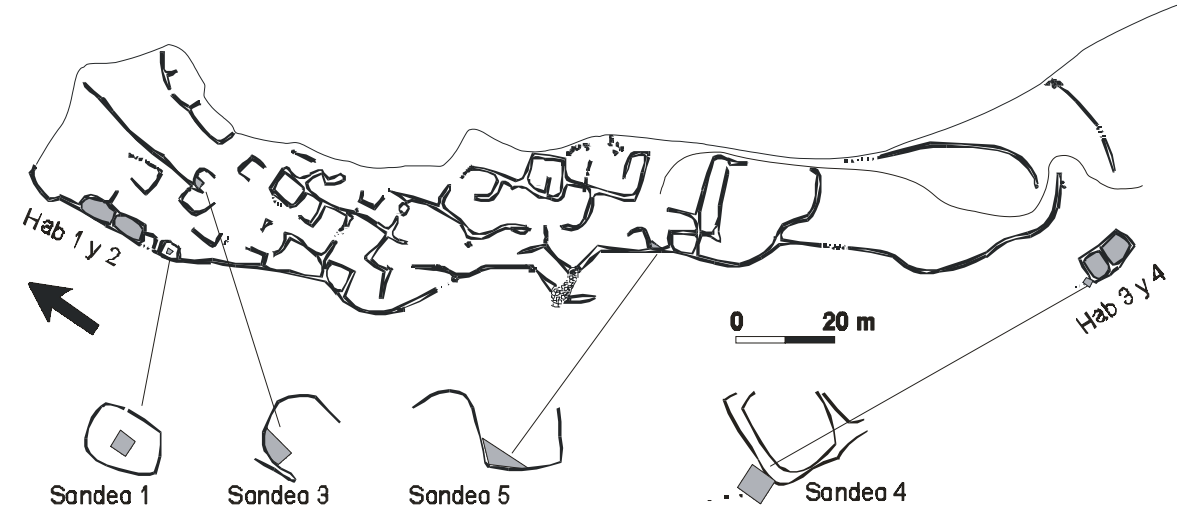

Figura 6.26. Plano de Morro de las Espinillas mostrando la ubicación de los sondeos. (Tomado de Scattolin 2002) 


\subsection{Loma Alta Núcleo E - Análisis faunístico.}

A la fecha se ha analizado todo el material correspondiente a los niveles de ocupación detectados en cada uno de los recintos excavados. Para todo el nivel de ocupación del Núcleo E se registró un NSP $=3892$ y un NISP $=2033$, resultando que los elementos y especímenes identificados a algún nivel taxonómico alcanzan al 52,23 $\%$ del conjunto.

Tabla 7.1. Composición de la muestra. Loma Alta Núcleo E.

\begin{tabular}{|c|c|c|}
\hline Taxón & $\begin{array}{c}\text { Tamaño Corporal } \\
1\end{array}$ & $\begin{array}{r}\text { Total NSP } \\
6\end{array}$ \\
\hline AVES & 2 & 1 \\
\hline Chaetophractus vellerosus & 2 & 85 \\
\hline Rodentia & 1 & 56 \\
\hline Rodentia & 2 & 74 \\
\hline Cricetidae & 1 & 4 \\
\hline Chinchillidae & 1 & 1 \\
\hline Chinchillidae & 2 & 2 \\
\hline Lagidium viscacia & 2 & 4 \\
\hline Ctenomys sp. & 1 & 25 \\
\hline Microcaviasp. & 1 & 6 \\
\hline Carnivora & 2 & 4 \\
\hline Carnivora & $2-3$ & 1 \\
\hline Artiodactyla & 4 & 1162 \\
\hline Lama sp. & 4 & 525 \\
\hline Lama guanicoe & 4 & 15 \\
\hline Lama glama & 4 & 41 \\
\hline Lama (V.) vicugna & 4 & 12 \\
\hline Hippocamelus antisensis & 4 & 9 \\
\hline Subtotal Identificados & & 2033 \\
\hline No identificable & 1 & 80 \\
\hline No identificable & $1-2$ & 3 \\
\hline No identificable & 2 & 42 \\
\hline No identificable & $2-3$ & 21 \\
\hline No identificable & $3-4$ & 463 \\
\hline No identificable & 4 & 499 \\
\hline No identificable & 9 & 751 \\
\hline Subtotal No Identificables & & 1859 \\
\hline & TOTAL & 3892 \\
\hline
\end{tabular}

Para este conjunto se identificaron quince taxones de los cuales tres presentan elementos o especímenes asignables a distintos tamaños corporales (AVES, Carnivora y 
Rodentia). Además se reconocieron seis categorías de tamaños corporales dentro de los no identificables taxonómicamente $(1,1-2,2,3,3-4,4)$.

A continuación se darán datos sumarios de cada uno de los recintos que componen el núcleo y luego se hará un análisis del conjunto global.

Recinto 44 (R44). Este es el recinto más pequeño de los tres excavados (Scattolin 1990). El volumen excavado es de aproximadamente $73 \mathrm{dm} 3$ con una densidad de restos faunísticos por decímetro cúbico de 2,32. Se identificó a nivel taxonómico el $38 \%$ de la muestra.

Tabla 7.2. Composición del conjunto faunístico del Recinto 44.

\begin{tabular}{lcr}
\hline \multicolumn{1}{c}{ Taxón } & Tamaño Corporal & Total NSP \\
Chaetophractus vellerosus & 2 & 5 \\
Rodentia & 1 & 1 \\
Cricetidae & 1 & 1 \\
Chinchillidae & 2 & 2 \\
Artiodactyla & 4 & 38 \\
Lama sp. & 4 & 18 \\
Lama glama & 4 & 1 \\
$\quad$ & & 66 \\
$\quad$ Subtotal Identificados & & \\
$\quad$ & 1 & 6 \\
No identificable & $2-3$ & 47 \\
No identificable & $3-4$ & 47 \\
No identificable & 4 & \\
No identificable & & 104 \\
$\quad$ Subtotal No identificables & & \\
& & \\
& &
\end{tabular}

Como puede observarse en la Tabla 7.2 los elementos o especímenes mas representados corresponden al tamaño corporal 4 (88\%), tanto para los identificados como en la categoría no identificable. La gran fragmentación del conjunto permitió que sólo el 11\% (NISP=19) de la muestra fuera asignada a Camelidae. Dentro de esta categoría se asignó un elemento a Lama glama mediante el uso de las variables largo (L), ancho (A) y profundidad (P) (Izeta 2002 y Anexo 2 de esta Tesis).

En este conjunto se identificaron siete taxones distintos y cuatro categorías de especímenes no identificables taxonómicamente (1, 2-3, 3-4 y 4). 
Recinto 46 (R46). El volumen excavado para el Depósito 3 del cuadrante SW del R46 es de $21 \mathrm{dm}^{3}$ con una densidad de restos faunísticos por decímetro cúbico de 7,14. Se identificó a nivel taxonómico el 76,6 \% de la muestra.

Tabla 7.3. Composición del conjunto faunístico del Recinto 46.

\begin{tabular}{lcr}
\hline \multicolumn{1}{c}{ Taxón } & Tamaño Corporal & Total NSP \\
Chaetophractus vellerosus & 2 & 2 \\
Canidae & $2-3$ & 1 \\
Artiodactyla & 4 & 76 \\
Lama sp. & 4 & 32 \\
Lama guanicoe & 4 & 1 \\
Lama glama & 4 & 3 \\
$\quad$ Subtotal Identificados & & 115 \\
No identificable & 1 & 2 \\
No identificable & 2 & 1 \\
No identificable & $3-4$ & 17 \\
No identificable & 4 & 11 \\
No identificable & 9 & 4 \\
$\quad$ Subtotal No identificable & & \\
& & \\
& & \\
& & \\
\end{tabular}

Como puede observarse en la Tabla 7.3 se identificaron seis taxones y cuatro categorías de tamaño corporal $(1,2,3-4$ y 4). Los elementos o especímenes mas representados corresponden al tamaño corporal 4 (93,33\%), tanto para los identificados como en la categoría no identificable.

La gran fragmentación del conjunto permitió que solo el 24 \% (36) de la muestra fuera asignada a Camelidae. Dentro de esta categoría se asignaron un elemento a Lama guanicoe y tres a Lama glama.

El elemento correspondiente a Lama guanicoe es una falange medial y para su asignación a esta especie se utilizaron las medidas de cinco variables, siendo éstas: \#6, \#7, \#8 \#9 y \#10 (Kent 1982).

La determinación de la presencia de Lama glama se efectuó mediante el análisis de: una falange medial (\#6, \#7, \#8 \#9 y \#10, Kent 1982) y un tarso cuarto (L, A y P, Izeta 2002)

Recinto 47 (R47). El volumen excavado para el Depósito 3 del Recinto 47 es de $5 \mathrm{~m} 3$ con una densidad de restos faunísticos por metro cúbico de 445 . Se identificó a nivel taxonómico el 76,6 \% de la muestra. 
Tabla 7.4. Composición del conjunto faunístico del Recinto 47.

\begin{tabular}{lcr}
\hline \multicolumn{1}{c}{ Taxón } & Tamaño Corporal & Total NSP \\
AVES & 1 & 2 \\
AVES & 2 & 1 \\
Chaetophractus vellerosus & 2 & 59 \\
Rodentia & 1 & 41 \\
Cricetidae & 1 & 3 \\
Chinchillidae & 1 & 1 \\
Lagidium sp. & 2 & 3 \\
Ctenomys sp. & 1 & 24 \\
Microcavia sp. & 1 & 5 \\
Canidae & 2 & 4 \\
Rodentia & 2 & 73 \\
Artiodactyla & 4 & 862 \\
Lama sp. & 4 & 386 \\
Lama guanicoe & 4 & 12 \\
Lama glama & 4 & 30 \\
Lama (V.) vicugna & 4 & 12 \\
Hippocamelus antisensis & 4 & 8 \\
\multicolumn{1}{c}{ Subtotal Identificados } & & \\
No identificable & & 1526 \\
No identificable & 1 & \\
No identificable & 2 & 55 \\
No identificable & $2-3$ & 40 \\
No identificable & $3-4$ & 10 \\
No identificable & 4 & 268 \\
& 9 & 604 \\
Subtotal No Identificables & & \\
& & \\
& & \\
& &
\end{tabular}

Como puede observarse en la Tabla 7.4 se identificaron quince taxones y cinco categorías de tamaño corporal. Los elementos o especímenes mas representados corresponden al tamaño corporal $4(64,60 \%)$, tanto para los identificados como en la categoría no identificable. La gran fragmentación del conjunto permitió que solo el $16,91 \%$ (442) de la muestra fuera asignada a Camelidae. Dentro de esta categoría se asignaron doce elementos a Lama guanicoe, doce a Lama (V.) vicugna y treinta a Lama glama.

Con respecto a los elementos que permitieron la asignación a cada una de las especies se presenta el siguiente detalle:

Lama guanicoe: Astrágalo con seis variables (Ll, Lm, Ap, AD, Pm y Pl según Izeta 2002), Calcáneo con siete variables (L, La, Lt, Ap, AD, Pp y Pd según Izeta 2002), Fémur con una variable \#117 de Kent (1982), Húmero con seis variables \#150, \#151, \#156, \#157, \#162 y \#163 de Kent (1982), Falange proximal con cinco variables \#1, \#2, 
\#3, \#4 y \#5 de Kent (1982) y por último una falange medial con cinco variables \#6, \#7, \#8 \#9 y \#10 de Kent (1982).

Lama glama: Astrágalo con seis variables (L1, Lm, Ap, AD, Pm y Pl según Izeta 2002; Calcáneo con siete variables (L, La, Lt, Ap, AD, Pp y Pd según Izeta 2002), Carpo intermedio, Carpo radial, Carpo tercero, Carpo Lunar, Maléolo lateral, Tarso central y Tarso Tercero con tres variables L, A y P (Izeta 2002), Falange proximal con cinco variables \#1, \#2, \#3, \#4 y \#5 de Kent (1982); falange medial con cinco variables \#6, \#7, \#8 \#9 y \#10 de Kent (1982); Falange distal con cuatro variables \#11, \#12, \#13 y \#14 de Kent (1982) y por último un Radioulna con las variables \#141, \#142, \#143 y \#144 de Kent (1982)

Lama (Vicugna) vicugna: Húmero con dos variables \#152 y \#155 de Kent (1982); Incisivos por caracteres morfológicos (Wheeler 1982, Lavallée 1990); Metacarpo con diez variables \#59, \#60, \#61, \#62, \#63, \#64, \#65, \#66, \#67 y \#68 de Kent (1982); Falange proximal con cinco variables \#1, \#2, \#3, \#4 y \#5 de Kent (1982); falange medial con cinco variables \#6, \#7, \#8 \#9 y \#10 de Kent (1982); Radioulna con cinco variables \#140, \#141, \#142, \#143 y \#144 de Kent (1982) y Tibia con veintiún variables \#86, \#87, \#88, \#89, \#90, \#91, \#92, \#93, \#94, \#95, \#96, \#97, \#102, \#103, \#104, \#105, \#106, \#107, \#108, \#109 y \#110 de Kent (1982).

Nivel de ocupación de los recintos $R 44, R 46$ y R47. Hasta el momento se vieron las composiciones de cada uno de los recintos que componen el núcleo E. Ahora veremos en que grado el conjunto ha sido afectado por factores tafonómicos.

Con respecto a la meteorización se puede observar en la Tabla 7.5 que se ha podido identificar algún estadio de meteorización en el 71,80 \% de la muestra. De esta sub-muestra se observa que el 92,73\% fueron asignados al estadio 1, el 7,07\% al estadio 2 y el $0,18 \%$ al estadio 3 . No se registraron especímenes ni elementos correspondientes a los estadios 4, 5 o 6 . El estadio 9 corresponde a los especímenes en los que no pudo registrase la meteorización.

Tabla 7.5. Meteorización del conjunto faunístico del Núcleo E. Loma Alta

\begin{tabular}{crrrrrrr}
\hline Tamaño Corporal & \multicolumn{9}{c}{ Meteorización } \\
& 1 & 2 & 3 & 4 & 5 & 9 & Total NSP \\
1 & 138 & 2 & - & - & - & 1 & 141 \\
2 & 179 & 1 & - & - & - & 10 & 190 \\
$2-3$ & 13 & - & - & - & - & 2 & 15 \\
\hline
\end{tabular}




\begin{tabular}{crrrrrrrr}
\hline $3-4$ & & 123 & 11 & - & - & - & 40 & 174 \\
4 & & 1318 & 116 & 3 & - & - & 368 & 1805 \\
9 & 182 & 19 & 1 & - & - & 406 & 608 \\
& TOTAL & 1953 & 149 & 4 & - & - & 827 & 2933 \\
\hline
\end{tabular}

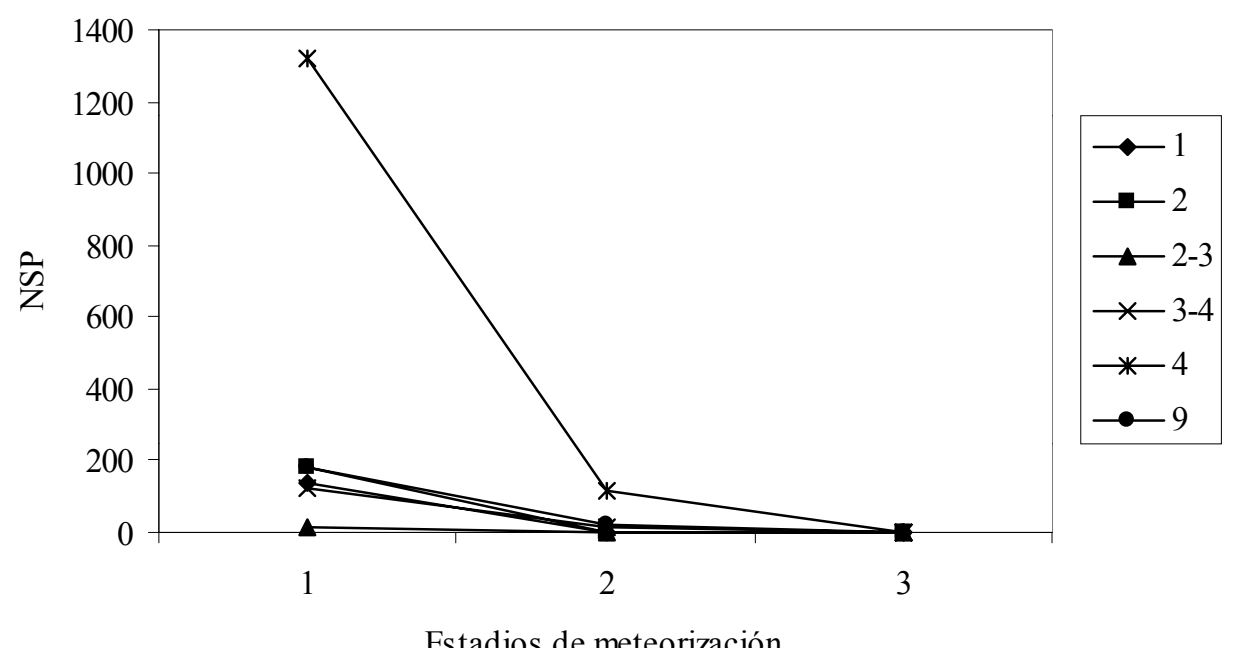

Estadios de meteorización

Figura 7.1. Estadios de meteorización según tamaño corporal. Núcleo E, Loma Alta

Como se puede observar tanto en la Tabla 7 como en la Figura 6 el grueso de los especímenes se ubican dentro de los estadios 1 y 2 (99,82\%), lo que implica una meteorización relativamente baja. Asimismo se puede observar que la mayoría de los tamaños corporales se comportan de manera similar, lo que contribuye a pensar que los restos se han depositado contemporáneamente. En cuanto a la modificación producida por roedores y carnívoros se puede observar en la Tabla 7.6 que el 96,96\% $(\mathrm{NSP}=2844)$ del conjunto no ha sido afectado por estos agentes.

Tabla 7.6. Modificaciones por agentes naturales. Núcleo E, Loma Alta.

\begin{tabular}{crccccr}
\hline Tamaño Corporal & $\begin{array}{c}\text { Sin } \\
\text { modificaciones }\end{array}$ & $\begin{array}{c}\text { Daño ligero } \\
\text { por roedor }\end{array}$ & $\begin{array}{c}\text { Daño } \\
\text { moderado/grave } \\
\text { por roedor }\end{array}$ & $\begin{array}{c}\text { Mordisqueo } \\
\text { de carnívoro }\end{array}$ & $\begin{array}{c}\text { Posible } \\
\text { mordisqueo } \\
\text { de carnívoro }\end{array}$ & $\begin{array}{c}\text { Total } \\
\text { general }\end{array}$ \\
1 & 140 & 1 & - & - & - & 141 \\
2 & 187 & 3 & - & - & - & 190 \\
$2-3$ & 15 & - & - & - & - & 15 \\
$3-4$ & 172 & 2 & - & - & - & 174 \\
4 & 1725 & 68 & 9 & 2 & 1 & 1805 \\
9 & 605 & 2 & 1 & - & - & 608 \\
Total & 2844 & 76 & 10 & 2 & 1 & 2933 \\
\hline
\end{tabular}

Tomando en cuenta ambos resultados es posible advertir el conjunto tiende a presentar valores bajos en relación a la acción de distintos agentes tafonómicos. Esto 
podría estar indicando que la muestra se habría acumulado sin sufrir grandes modificaciones pre o post-depositacionales.

\subsubsection{Análisis del subconjunto de camélidos.}

El subconjunto de camélidos esta compuesto por un NISP $=445$. Correspondiendo 386 a Lama sp., 34 a Lama glama, 13 a Lama guanicoe y 12 a Lama (V.) vicugna (Tabla 7.7)

Tabla 7.7. Camelidae, huesos del esqueleto axial y apendicular. Núcleo E, Loma Alta.

\begin{tabular}{|c|c|c|c|c|c|}
\hline $\begin{array}{l}\text { Elemento } \\
\text { CRN }\end{array}$ & $\begin{array}{l}\text { L. guanicoe } \\
\text { - }\end{array}$ & $\begin{array}{l}\text { L. glama } \\
\text { - }\end{array}$ & $\begin{array}{l}\text { Lama sp. } \\
17\end{array}$ & L. (V.) vicugna & $\begin{array}{l}\text { NISP } \\
17\end{array}$ \\
\hline MR & - & - & 7 & - & 7 \\
\hline HY & - & - & 9 & - & 9 \\
\hline TFR & - & - & 4 & - & 4 \\
\hline IC & - & - & 6 & 2 & 8 \\
\hline $\mathrm{CN}$ & - & - & 1 & - & 1 \\
\hline PMX & - & - & 1 & - & 1 \\
\hline MMX & - & - & 2 & - & 2 \\
\hline MUN & - & - & 5 & - & 5 \\
\hline AT & - & - & 7 & - & 7 \\
\hline $\mathrm{AX}$ & - & - & 6 & - & 6 \\
\hline CE 3-7 & - & - & 10 & - & 10 \\
\hline TH 1-14 & - & - & 15 & - & 15 \\
\hline $\mathrm{RB}$ & - & - & 22 & - & 22 \\
\hline SN & - & - & 2 & - & 2 \\
\hline LM & - & - & 3 & - & 3 \\
\hline SAC & - & - & 2 & - & 2 \\
\hline $\mathrm{CA}$ & - & - & 4 & - & 4 \\
\hline $\mathrm{SC}$ & - & - & 4 & - & 4 \\
\hline $\mathrm{HM}$ & 2 & - & 18 & 1 & 21 \\
\hline RDU & - & 1 & 21 & 2 & 24 \\
\hline CPU & - & 1 & 2 & - & 3 \\
\hline CPI & - & 2 & 2 & - & 4 \\
\hline CPR & - & 3 & 4 & - & 7 \\
\hline $\mathrm{CPT}$ & - & 1 & 1 & - & 2 \\
\hline $\mathrm{CPF}$ & - & - & 2 & - & 2 \\
\hline $\mathrm{MC}$ & - & - & 5 & 1 & 6 \\
\hline PHFD & - & - & 5 & - & 5 \\
\hline IM & - & - & 6 & - & 6 \\
\hline FM & 2 & - & 6 & - & 8 \\
\hline PT & - & - & 3 & - & 3 \\
\hline TA & - & - & 20 & 3 & 23 \\
\hline LTM & - & 2 & 2 & - & 4 \\
\hline $\mathrm{AS}$ & 1 & 1 & 9 & - & 11 \\
\hline $\mathrm{CL}$ & 1 & 1 & 9 & - & 11 \\
\hline TRC & - & 3 & 10 & - & 13 \\
\hline TRT & - & 5 & 3 & - & 8 \\
\hline
\end{tabular}




\begin{tabular}{llllll} 
& & & \multicolumn{2}{c}{ Continuación Tabla 7.7 } \\
\hline TR4 & - & - & 7 & - & 7 \\
MT & - & - & 5 & - & 5 \\
PHFT & - & - & 3 & - & 3 \\
& & & & & \\
MP & & 3 & 45 & - & 45 \\
PHF & 5 & 24 & 1 & 33 \\
PHS & 2 & 5 & 24 & 2 & 33 \\
PHT & - & 6 & 17 & - & 23 \\
SE & - & - & 6 & - & 6 \\
Total & 13 & 34 & 386 & 12 & 445 \\
\hline
\end{tabular}

La distribución espacial de los especímenes de camélidos del R47 es la que se observa en la Figura 7.2. Allí se puede observar que esta muestra forma dos conjuntos dentro de este recinto.

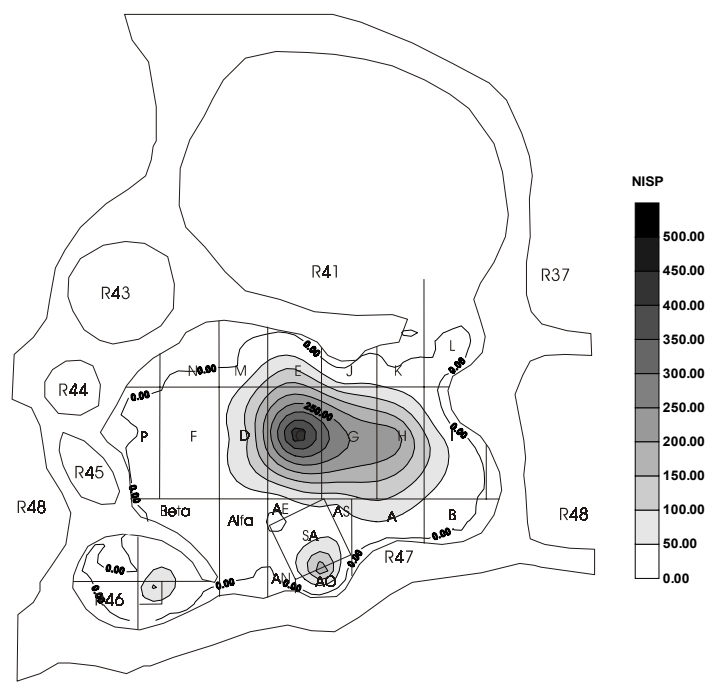

Figura 7.2. Núcleo E. R46 y R47. Distribución espacial de restos de tamaño corporal 4.

A los fines de realizar el análisis del este grupo se realizó una segregación de aquellos elementos o especímenes que por poseer rasgos diagnósticos pudieron ser asignados a una de las dos clases de edad definidas (adulto y subadulto o juvenil).

De aquí en más se presentarán los resultados de los análisis propuestos en los capítulos 3,4 y 5 .

\subsubsection{Camélidos adultos}

Este subconjunto esta compuesto por un NISP $=340$ (Tabla 7.9). Este número de especímenes identificados corresponde tanto a huesos del esqueleto axial como del apendicular. 


\subsubsection{1.a. Supervivencia del material óseo mediada por la densidad ósea}

El resultado de este análisis muestra que sobre los diez elementos considerados se efectuaron seis correlaciones positivas, dos negativas y dos no presentan correlación. El resultado general muestra una correlación positiva débil sin significación estadística lo que en general representaría para el conjunto una presencia mayor de "landmarks" con valores de densidad ósea elevados en relación con "landmarks" con densidades óseas bajas.

Esto indicaría la presencia de algún tipo de acción modificadora sobre el conjunto afectando la composición de este de manera diferencial en relación a la densidad ósea de los elementos.

\begin{tabular}{cccc} 
Tabla & \multicolumn{4}{c}{ 7.8. Correlación entre el \%MAU y la densidad ósea. } \\
\cline { 2 - 4 } \multicolumn{1}{c}{ Elemento } & Rank & $r_{s}$ & $p$ \\
Mandíbula (MR) & 8 &, 550 &, 078 \\
Escápula (SC) & 4 &,- 105 &, 447 \\
Húmero (HM) & 5 &, 461 &, 216 \\
Radioulna (RDU) & 6 &, 000 &, 500 \\
Metacarpo (MC) & 4 &,- 316 &, 683 \\
Innominado (IM) & 8 &, 032 &, 469 \\
Fémur (FM) & 5 &, 112 &, 429 \\
Tibia (TA) & 5 &, 000 &, 500 \\
Calcáneo (CL) & 4 &, 105 &, 447 \\
Metatarso (MT) & 4 &, 316 &, 342 \\
Arqueofauna & 29 &, 113 &, 148 \\
\hline
\end{tabular}

\subsubsection{1.b. Número Mínimo de Elementos (MNE)}

\section{Cráneo (CRN)}

Se identificaron 17 fragmentos pero ningún elemento completo. En general las zonas diagnósticas con mayor representación corresponden al petroso (indicado con un círculo en la Figura 7.3) seguido por el occipital, el temporal, el proceso yugal, porciones de la caja craneana (con suturas diagnósticas) y el meato acústico externo. En base al petroso se logró un MNE comprehensivo igual a 6 . 


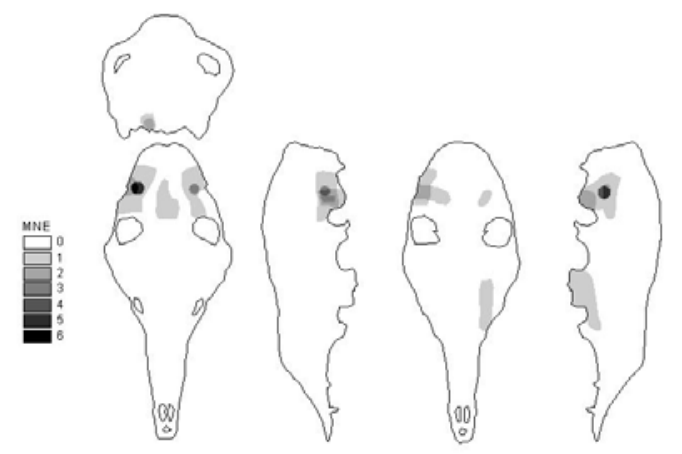

Figura 7.3. MNE Cráneo

Existen fragmentos de huesos planos que pueden corresponder a partes de la caja craneana, pero por no poseer suturas o zonas de inserción muscular, no se ha podido determinar su asignación a Camelidae.

El cráneo es uno de los elementos con mayor representación en el conjunto y su abundancia relativa es una de las mas altas $(\%$ MAU $=92,31)$. Su grado de fragmentación es alto y se puede observar en la Figura 7.3.

\section{Mandibula (MR)}

Este elemento se halla representado en el conjunto por las siguientes zonas diagnósticas: coronoides, angular y fragmentos de la rama horizontal (Figura 7.4). En base al angular se pudo componer un MNE igual a 3.

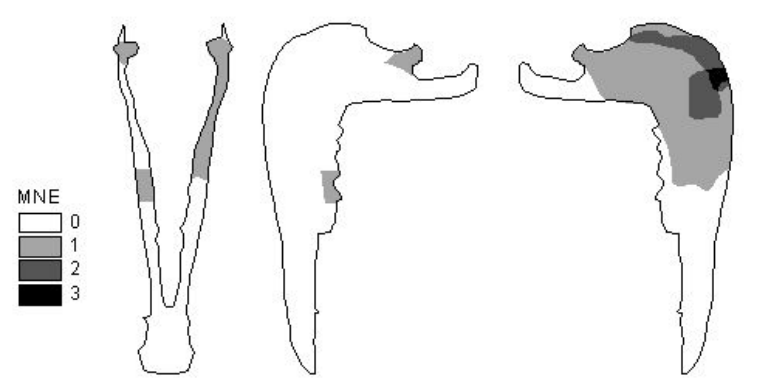

Figura 7.4. MNE Mandíbula

Hioides (HY)

Las zonas diagnósticas que se reconocieron en este elemento corresponden al cuerpo y la porción angular (proximal). Sobre los fragmentos del cuerpo se obtuvo un valor de MNE igual a 7 (Figura 7.5) 


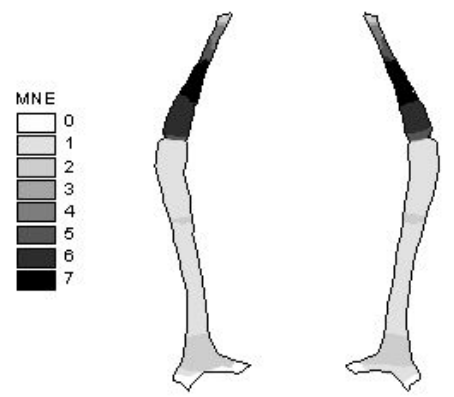

Figura 7.5. MNE Hioides

Dientes (TFR, IC, CN, PMX, MMX, MUN)

Se identificaron un total de 21 especímenes. Cuatro de ellos son restos de dientes que no han podido ser asignados a algún tipo en particular. Del resto se obtuvo un MNE igual a 8 para incisivos, un MNE igual a 1 para caninos, un MNE igual a 1 para premolares del maxilar, un MNE igual a 3 para molariformes, un MNE igual a 2 para molares del maxilar. En general el estado de los dientes es fragmentario.

$\operatorname{Atlas}(A T)$

Las zonas diagnósticas que representan a este elemento corresponden al tubérculo ventral, cavidades articulares craneales y caudales (Figura 7.6) El MNE es igual a 3.

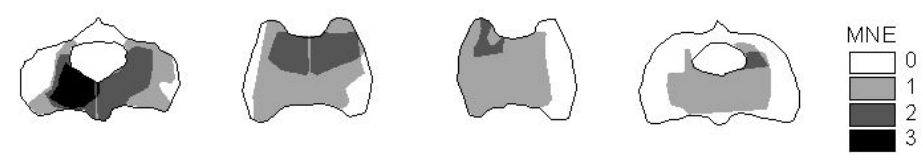

Figura 7.6. MNE Atlas

$\operatorname{Axis}(A X)$

De este elemento se hallaron dos fragmentos los cuales corresponden a una porción caudal del cuerpo vertebral y a una apófisis odontoides. El MNE calculado para este hueso corresponde a 1 (Figura 7.7)
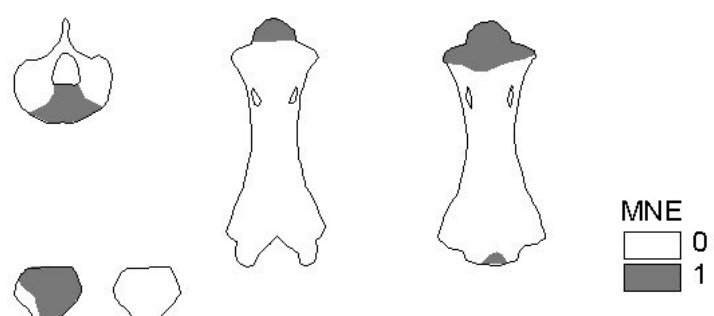

Figura 7.7. MNE Axis 
Cervicales 3-7(CE)

Para este elemento se identificaron las siguientes zonas diagnósticas: cuerpo vertebral, epífisis distal, proceso articular y arco neural. El MNE calculado es igual a 3 (Figura 7.8).

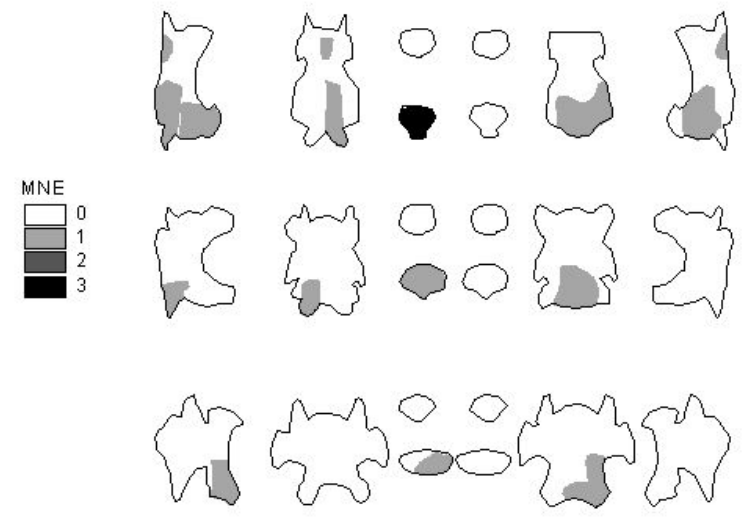

Figura 7.8. MNE Cervicales 3 a 7

Torácicas 1-14 (TH)

Fragmentos de estos elementos han sido identificados a partir de la presencia de cuerpos vertebrales, procesos espinosos, epífisis, apófisis y procesos transversos. El MNE calculado para este elemento asciende a 15.

\section{Escápula (SC)}

Este elemento esta representado por la presencia de tres especímenes cuyas zonas diagnósticas corresponden a la cavidad glenoidea. El MNE calculado para la escápula izquierda corresponde a 1 y para el elemento derecho el MNE es igual a 2 (Figura 7.9)
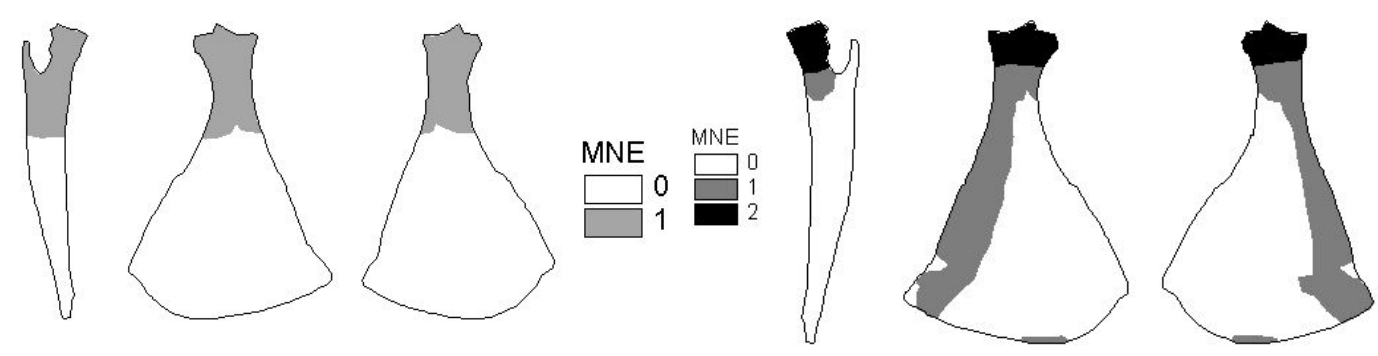

Figura 7.9. MNE Escápula izquierda y derecha

Húmero (HM)

Para este elemento se identificaron las siguientes zonas diagnósticas: teres mayor, foramen posterolateral, epicóndilo lateral, epicóndilo medial, cóndilo lateral y 
cóndilo medial. El cálculo del MNE se realizó en base a la lateralidad de los fragmentos identificados. Para el lado izquierdo se calculó un MNE igual a 2 y para el derecho un MNE igual a 3 (Figura 7.10), por lo tanto el MNE total es igual a 5.

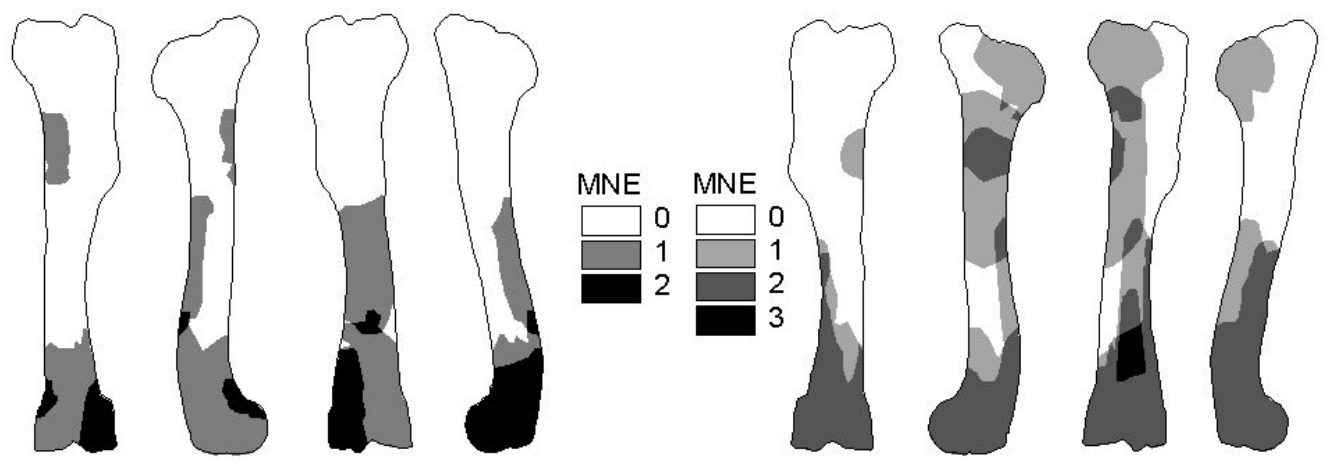

Figura 7.10. MNE Húmero izquierdo y derecho

Radioulna (RDU)

Las zonas diagnósticas que permitieron identificar a este elemento son: proceso olecraniano, proceso anconeal, facetas articulares, proceso estiloide de la ulna, cavidad glenoidea lateral, cavidad glenoidea medial, diáfisis postero-proximal, tuberosidad radial, foramen postero-lateral, faceta de articulación con el carpo intermedio, faceta de articulación con el carpo radial, diáfisis postero-medial, diáfisis antero-medial, diáfisis postero-distal y diáfisis antero-distal.

El MNE obtenido para el elemento izquierdo es 2 y para el derecho 5, lo cual hace un total de un mínimo de 7 elementos (Figura 7.11)
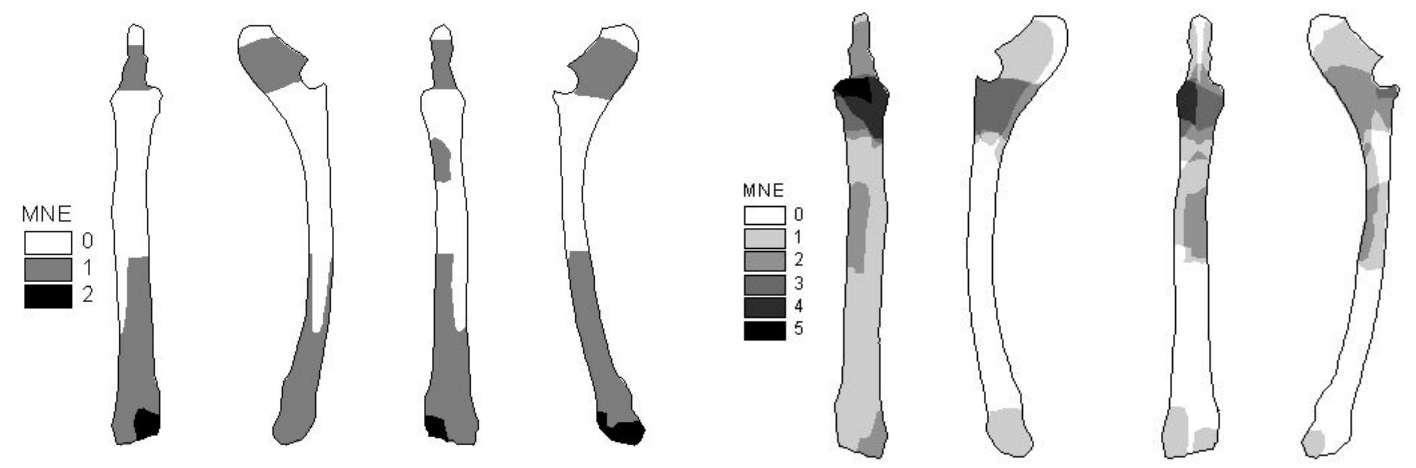

Figura 7.11. MNE Radioulna izquierda y derecha

Carpo Ulnar (CPU)

Se calculó un MNE igual a tres para este elemento, asignándose 1 al lado izquierdo y 2 al lado derecho. Este elemento se presenta en todos los casos de manera completa. 
Carpo intermedio (CPI)

Se calculó un MNE igual a 4 para este elemento, asignándose 1 al lado izquierdo y 3 al lado derecho. Este elemento se presenta en todos los casos de manera completa.

\section{Carpo radial (CPR)}

Se calculó un MNE igual a 7 para este elemento, asignándose 3 al lado izquierdo y 4 al lado derecho. Este elemento se presenta en todos los casos de manera completa.

Carpo tercero (CPT)

Se calculó un MNE igual a 2 para este elemento, asignándose 1 al lado izquierdo y 1 al lado derecho. Este elemento se presenta en todos los casos de manera completa.

\section{Carpo cuarto (CPF)}

Se calculó un MNE igual a 2 para este elemento, asignándose 1 al lado izquierdo y 1 al lado derecho. Este elemento se presenta en todos los casos de manera completa.

Metacarpo (MC)

Para este elemento las zonas diagnósticas utilizadas fueron epífisis proximal, diáfisis anterior y diáfisis posterior. El MNE comprehensivo para este elemento es de 2 para el derecho y 2 para el izquierdo haciendo un total de 4 elementos (Figura 7.12)
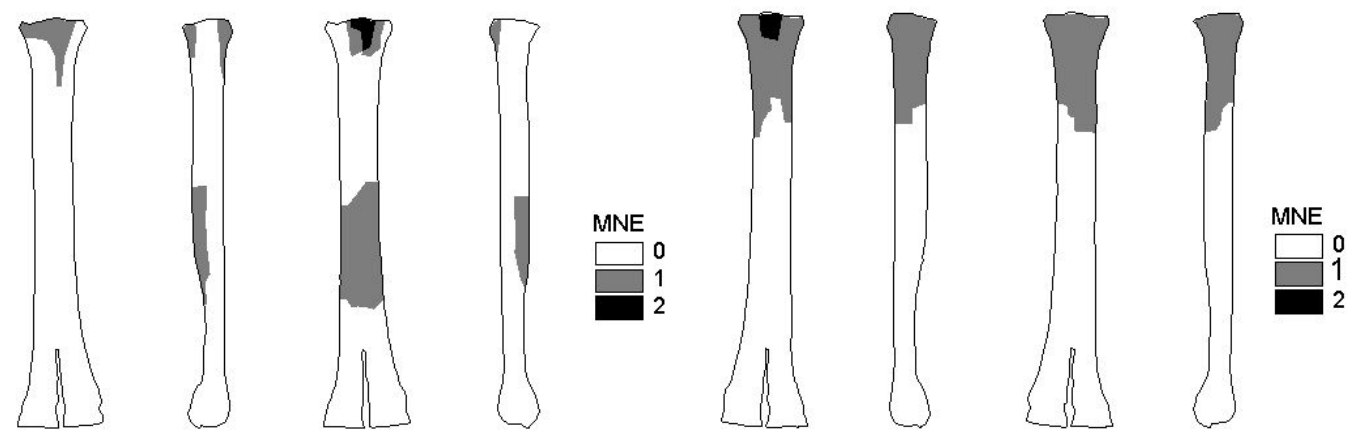

Figura 7.12. MNE Metacarpo izquierdo y derecho

Falange proximal delantera (PHFD)

Para este elemento las zonas diagnósticas utilizadas fueron la epífisis proximal, epífisis distal y diáfisis (Figura 7.13). El MNE obtenido es igual a 5. 


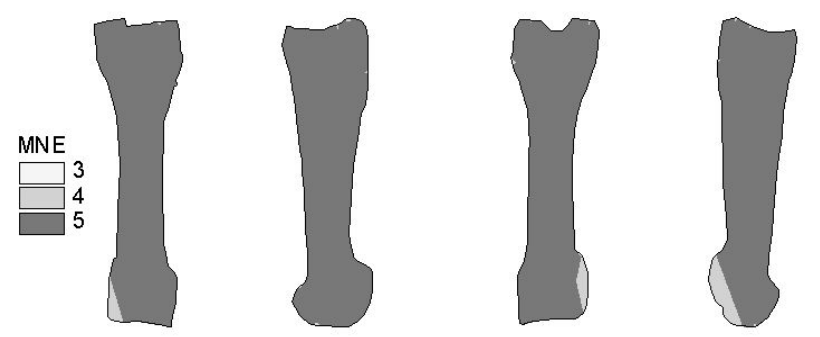

Figura 7.13. MNE Falange proximal delantera

Innominado (IM)

Las zonas diagnósticas reconocidas parta este elemento son la hoja del ilium, el acetábulo, la diáfisis del isquio y la diáfisis del pubis. Este elemento si bien es uno solo, para la cuantificación se lo dividió según su lateralidad (izquierda o derecha). Sobre la base de estas zonas se logró determinar un MNE igual a 2 para el elemento izquierdo y un MNE igual a 3 para el derecho. Esto es un total de 5 elementos (Figura 7.14). Es de notar que las porciones que se han conservado corresponden mayormente a la zona de unión entre este elemento y el fémur, y que a su vez, del fémur solo se ha conservado la parte proximal (la cabeza).
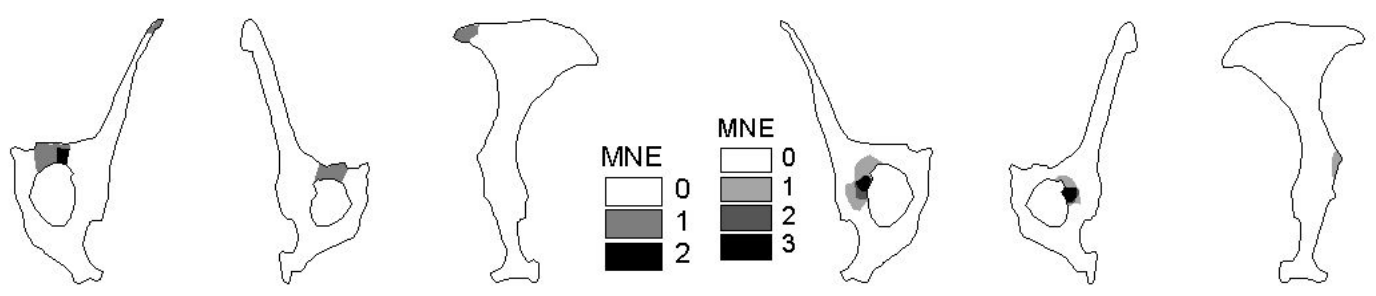

Figura 7.14. MNE Innominado izquierdo y derecho

Fémur (FM)

Sólo está representado por dos especímenes que corresponden a la cabeza y parte del trocánter mayor. El MNE alcanzado es igual a 2 elementos derechos (Figura 7.15)

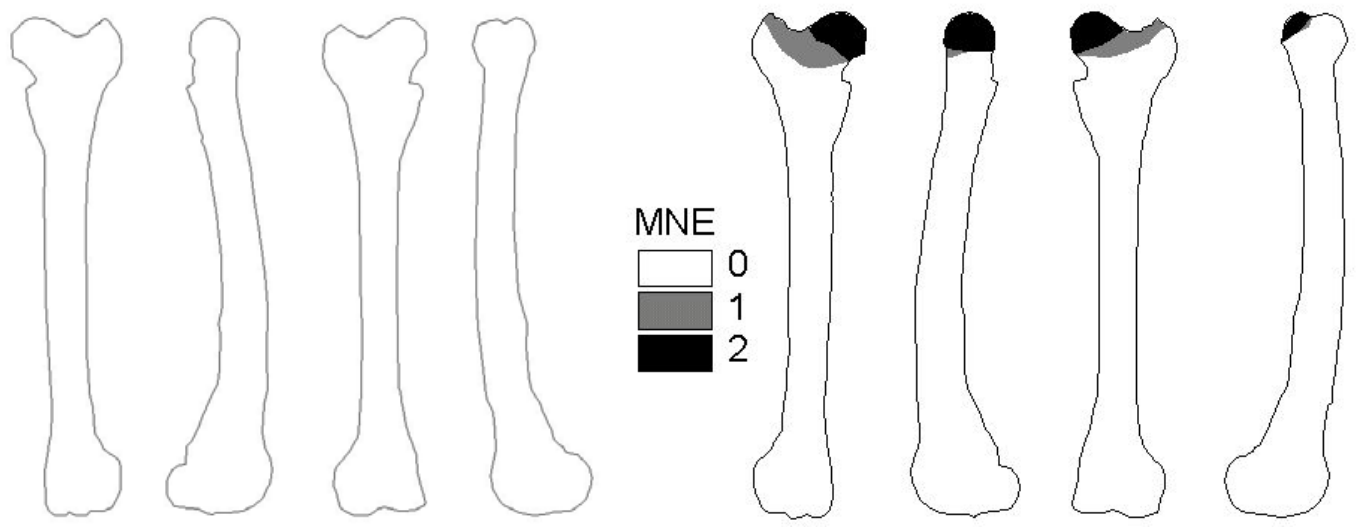

Figura 7.15. MNE Fémur izquierdo y derecho 
Patela o rótula $(P T)$

Se calculó un MNE igual a 3 para este elemento, asignándose 2 al lado izquierdo y 1 al lado derecho. Este elemento se presenta en todos los casos de manera completa.

Tibia (TA)

Las zonas diagnósticas utilizadas para identificar a los especímenes de este elemento corresponden al cóndilo lateral, el foramen posterolateral, a la diáfisis proximal posterior, a la diáfisis anterior distal y al surco medial.

Se calculó un MNE igual a 2 para el elemento izquierdo y de 5 para el derecho (Figura 20)
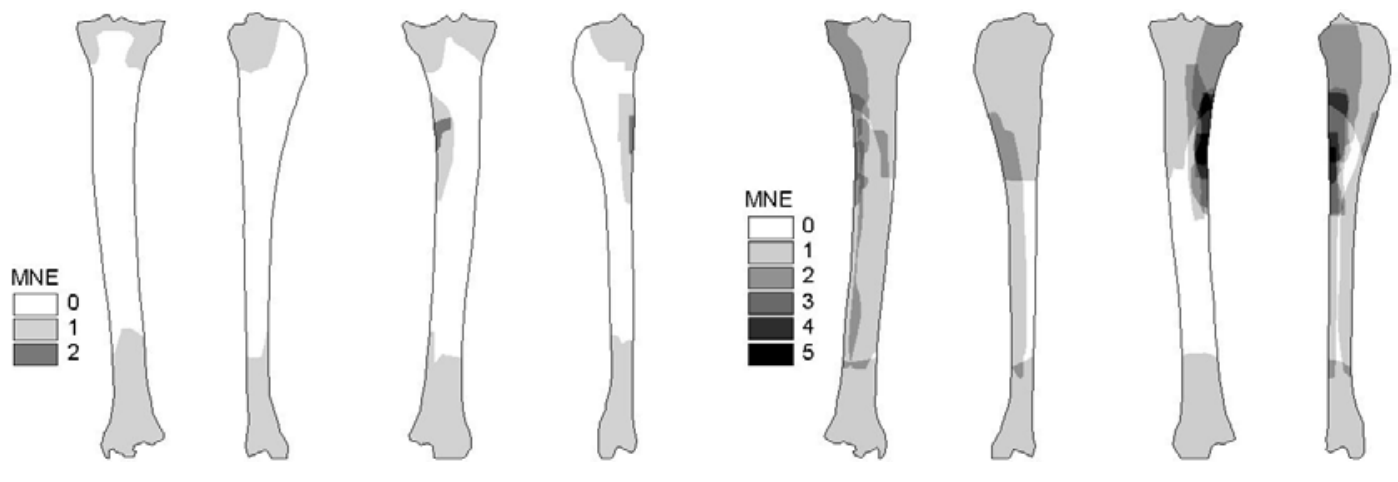

Figura 7.16. MNE Tibia izquierda y derecha

\section{Maléolo Lateral (LTM)}

Se calculó un MNE igual a cuatro para este elemento, asignándose 2 al lado izquierdo y 2 al lado derecho. Este elemento se presenta en todos los casos de manera completa.

\section{Astrágalo (AS)}

Este elemento se presenta en el mayor número de los casos de manera completa (Figura 7.17). Para el elemento izquierdo se calculó un MNE igual a 4 y para el derecho 6 , lo que hace un total de 10 elementos.
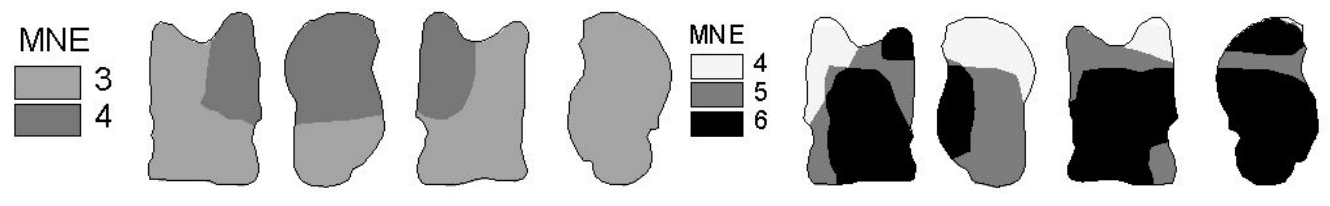

Figura 7.17. MNE Astrágalo izquierdo y derecho 


\section{Calcáneo $(C L)$}

Los especímenes asignados al elemento izquierdo se encontraron en mayor frecuencia que los asignados al elemento derecho (Figura 7.18). El MNE calculado para cada lado corresponde a 3 elementos para el izquierdo y 2 para el derecho.

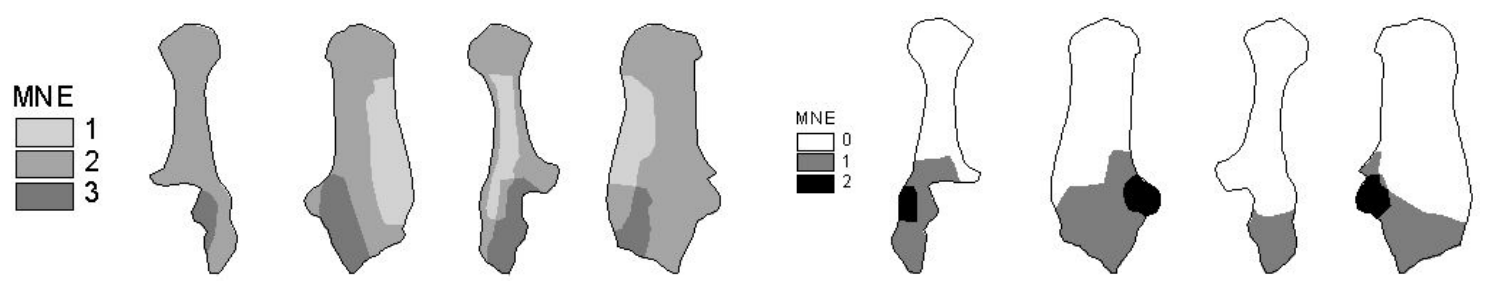

Figura 7.18. MNE Calcáneo izquierdo y derecho

Tarso central (TRC)

Se calculó un MNE igual a 13 para este elemento, asignándose 7 al lado izquierdo y 6 al lado derecho. Este elemento se presenta en todos los casos de manera completa.

\section{Tarso tercero (TRT)}

Se calculó un MNE igual a 5 para este elemento, asignándose todos al lado derecho. Este elemento se presenta en todos los casos de manera completa.

Tarso cuarto (TR4)

Se calculó un MNE igual a 3 para este elemento, asignándose todos al lado derecho. Este elemento se presenta en todos los casos de manera completa.

\section{Metatarso (MT)}

Este elemento presenta tres especímenes a partir de los cuales se pudo establecer un MNE igual a 1 para cada lado (Figura 7.19)
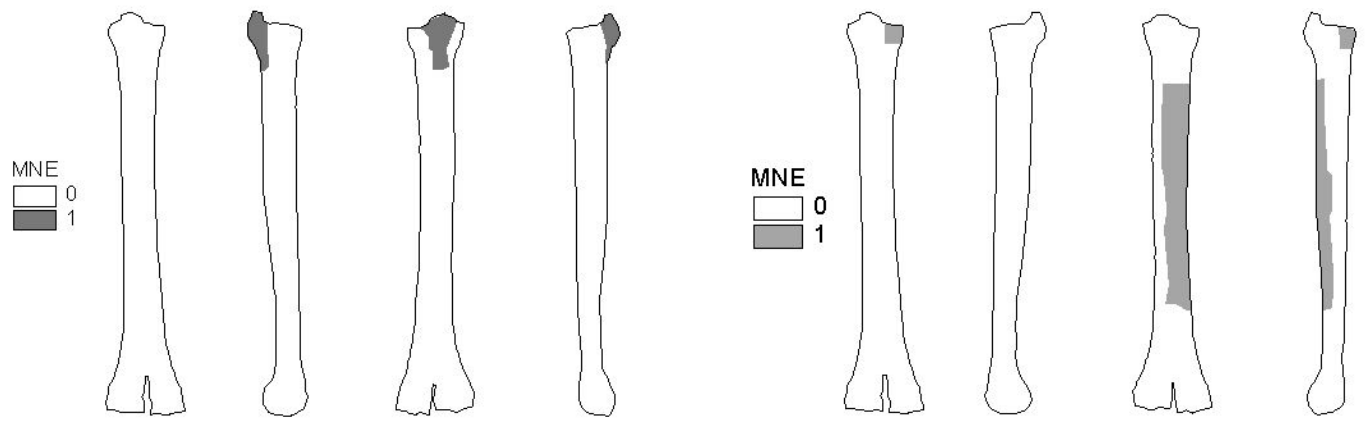

Figura 7.19. MNE Metatarso izquierdo y derecho 
Falange proximal trasera (PHFT)

Se identificaron tres elementos completos $(\mathrm{MNE}=3)$. Para este elemento las zonas diagnósticas utilizadas fueron la epífisis proximal, epífisis distal y diáfisis (Figura 7.20)

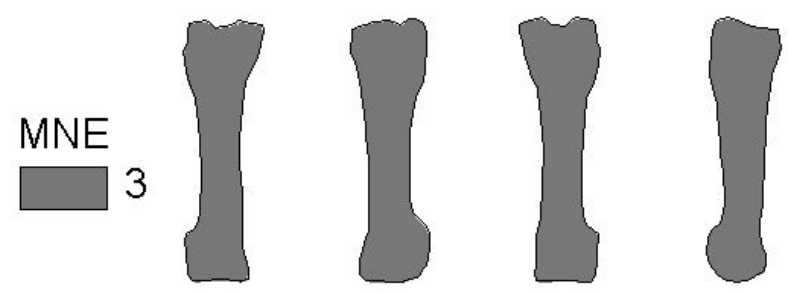

Figura 7.20. MNE Falange proximal trasera

Metapodio general (MP)

Los restos de metapodio que no pudieron ser asignados a metacarpo o metatarso se agruparon en una categoría denominada metapodio general. Se logró calcular sobre este conjunto de especímenes un MNE igual a 7 (Figura 7.21).

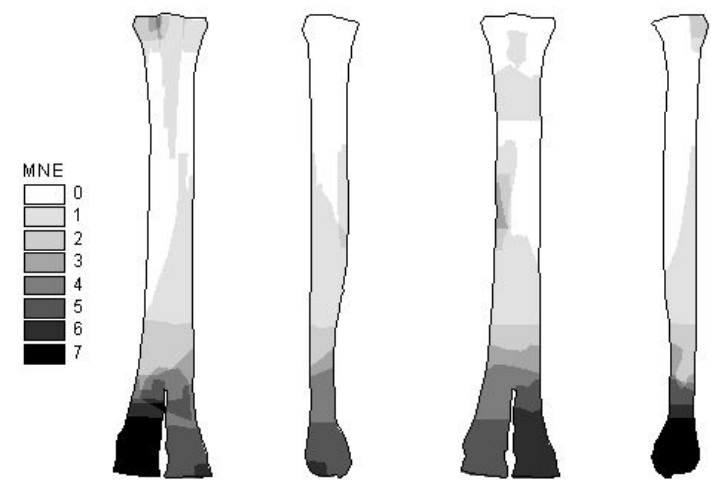

Figura 7.21. MNE Metapodio general

Falange proximal general (PHF)

Para este elemento las zonas diagnósticas utilizadas fueron la epífisis proximal, epífisis distal y diáfisis. Sobre los especímenes asignados a esta categoría se calculó un MNE igual a 12 elementos (Figura 7.22)
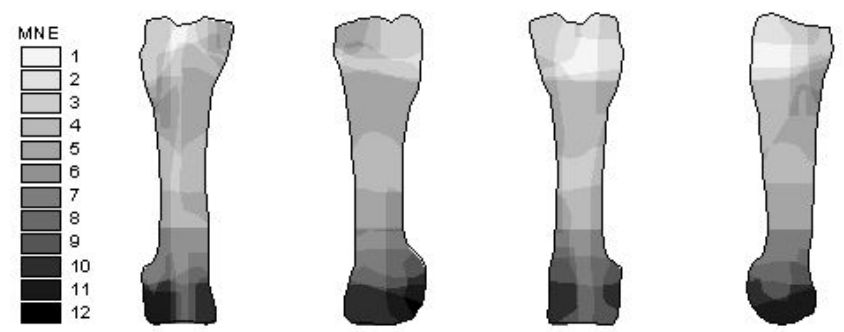

Figura 7.22. MNE Falange proximal general 


\section{Falange medial (PHS)}

Para este elemento, al igual que para el caso de todas las falanges, las zonas diagnósticas utilizadas fueron la epífisis proximal, epífisis distal y diáfisis. El cálculo del MNE arrojó una cantidad de 19 elementos (Figura 7.23)
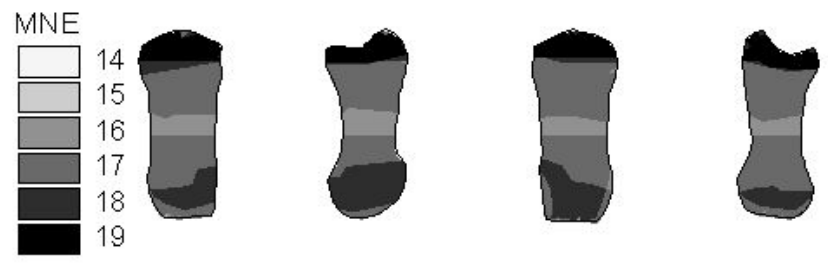

Figura 7.23. MNE Falange medial

Falange distal (PHT)

Para este elemento las zonas diagnósticas utilizadas fueron la epífisis proximal, epífisis distal y diáfisis (Figura 7.24) siendo el MNE calculado igual a 23.
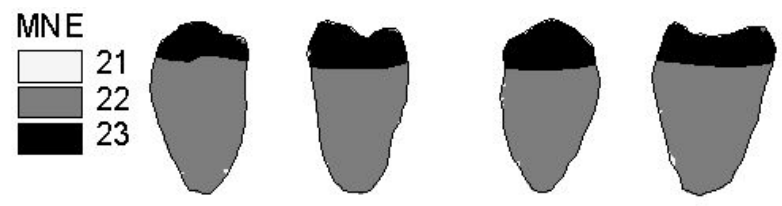

Figura 7.24. MNE Falange distal

Sesamoideos (SE)

Se identificaron seis elementos completos $(\mathrm{MNE}=6)$

Tomando los resultados obtenidos mediante este análisis se procedió a la confección de la Tabla 7.9. Allí se presentan los valores de NISP para cada elemento y el cálculo de estimadores como el MNE, MNI, MAU y \%MAU.

Tabla 7.9. Abundancia relativa de partes esqueletarias expresadas como NISP, MNE comprehensivo, MNI, MAU y \%MAU. Loma Alta, Núcleo E.

\begin{tabular}{lrrrrrrrr}
\hline Elemento & NISP & I $^{*}$ & D $^{*}$ & S/D* & MNE & MNI & MAU & \%MAU \\
CRN & 17 & - & - & 6 & 6 & 6 & 6.00 & 92.31 \\
MR & 4 & - & - & 3 & 3 & 3 & 3.00 & 46.15 \\
HY & 9 & - & - & 7 & 7 & 4 & 3.50 & 53.85 \\
TFR & 4 & - & - & - & - & - & - & - \\
IC & 8 & - & - & 8 & 8 & 2 & 2.00 & 30.77 \\
CN & 1 & - & - & 1 & 1 & 1 & 0.25 & 3.85 \\
PMX & 1 & - & - & 1 & 1 & 1 & 0.25 & 3.85 \\
MMX & 2 & - & - & 2 & 2 & 1 & 0.50 & 7.69 \\
MUN & 5 & - & - & 3 & 3 & 1 & 0.38 & 5.77 \\
AT & 5 & - & - & 3 & 3 & 3 & 3.00 & 46.15 \\
AX & 2 & - & - & 1 & 1 & 1 & 1.00 & 15.38 \\
CE 3-7 & 8 & - & - & 3 & 3 & 1 & 0.60 & 9.23 \\
\hline
\end{tabular}




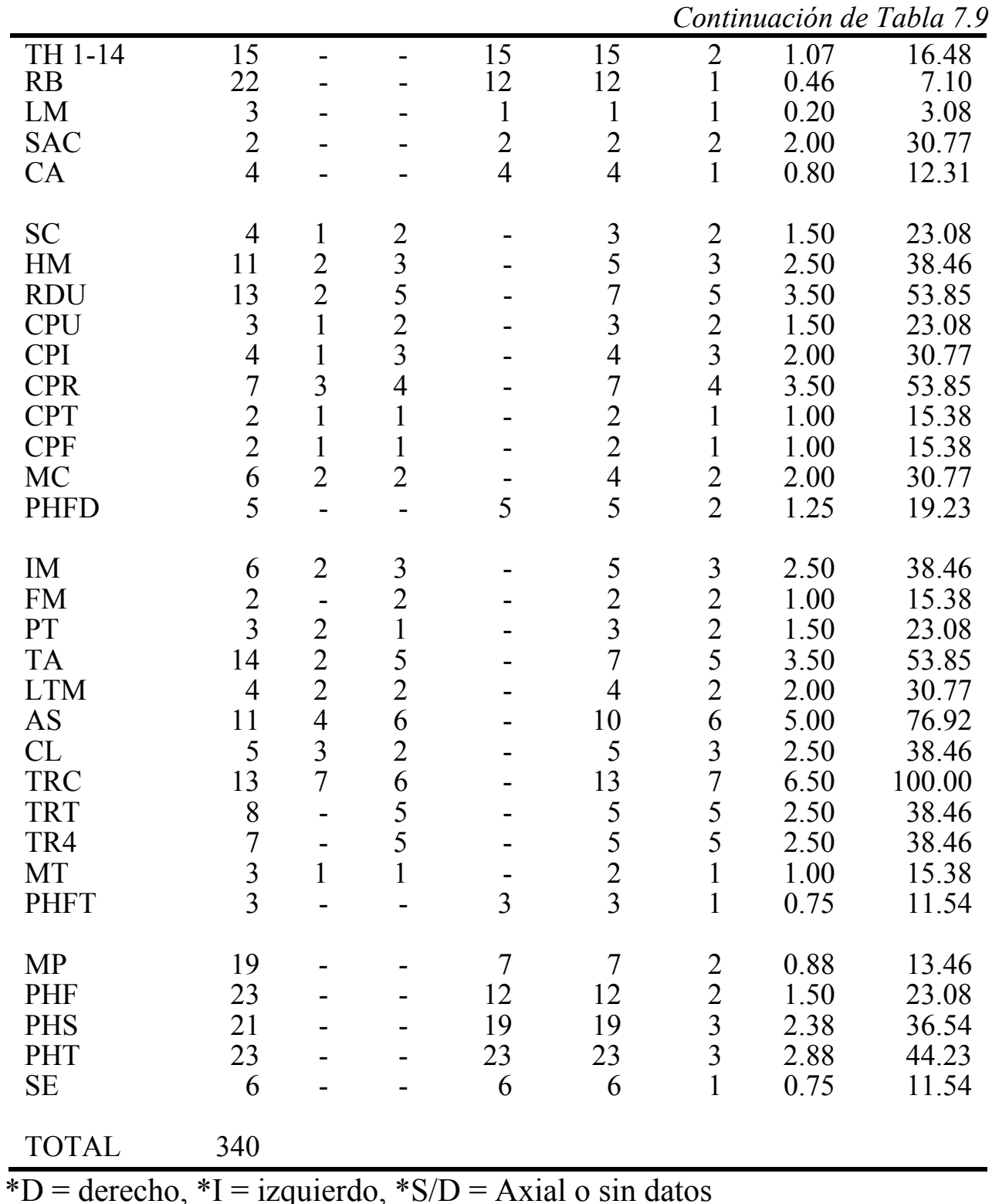

\subsubsection{1.c. Número Mínimo de Individuos (MNI)}

Según lo que puede observarse en la Tabla 7.9 a cada elemento se le asignó un valor de MNI. Para el subconjunto de camélidos adultos es el tarso central el que posee el valor más alto (7). No obstante ello si tenemos en cuenta otros atributos del conjunto como tamaño de los elementos (asociado a la identificación inter-específica en nuestro caso) el MNI, en este caso de distinción máxima, asciende al menos a 8 adultos correspondiendo 4 a Lama glama, 2 a Lama guanicoe y 2 a Lama (Vicugna) vicugna. 


\subsubsection{1.d. Unidades anatómicas representadas (MAU)}

En la Figura 7.25 puede observarse las unidades anatómicas representadas en este subconjunto expresado como el porcentual de MAU (\%MAU).

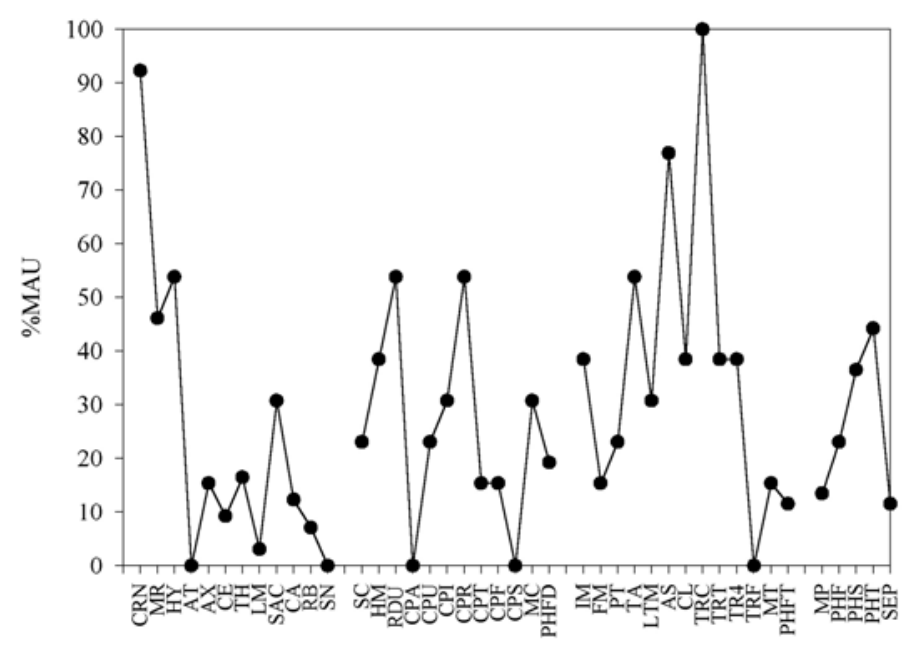

Figura 7.25. Abundancia relativa de elementos esqueletarios.

En términos generales los elementos menos representados corresponden al esqueleto axial desde el axis hacia la región caudal. El cráneo, la mandíbula, el hioides y las piezas dentales (todos elementos que componen la cabeza), así como el atlas están más representados que los elementos más posteriores del esqueleto axial.

Para el esqueleto apendicular los elementos más representados corresponden a los miembros posteriores. Se puede observar que las frecuencias más altas corresponden a los elementos más pequeños. Esto puede deberse tanto a la alta fragmentación a la que se vieron sujetos los elementos más grandes (ver más abajo).

A partir de la construcción de este índice de abundancia relativa se procedió a la comparación por medio de gráficos bivariados de estos valores con el índice utilidad de alimento (FUI, Food Utility Index) para llama adulta (Mengoni Goñalons 1991) y los valores de la cavidad medular de los huesos largos (Mengoni Goñalons 2001) con el fin de observar tendencias en cuanto a la utilización de las carcasas. Para esto se siguió lo planteado por Marean y Frey (1997) quienes proponen que los huesos largos sean tratados de manera independiente de los "no-largos", ya que esto puede confundir los resultados finales. 

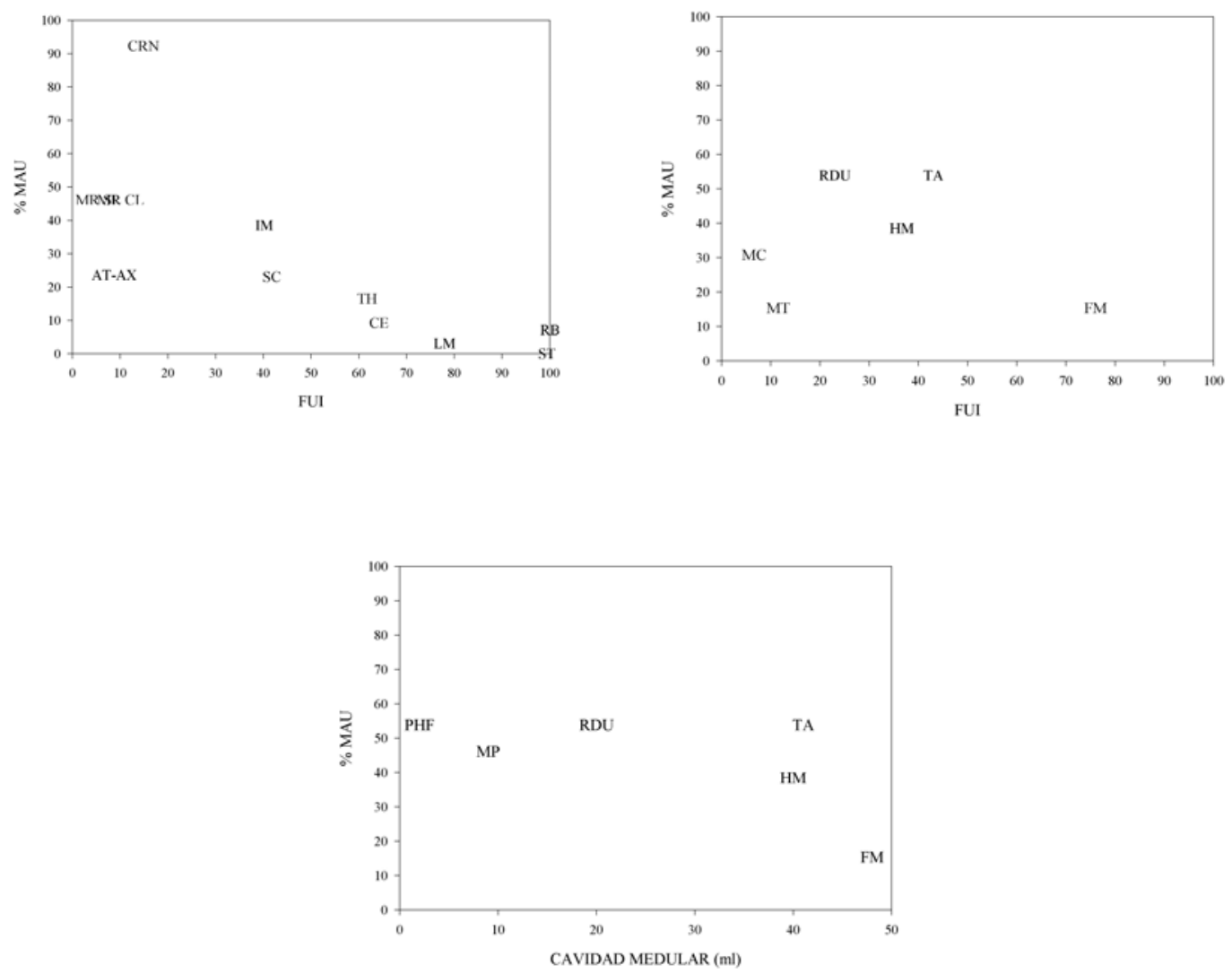

Figura 7.26. a) Relación \%MAU VS FUI huesos "no-largos"; b) Relación \%MAU VS FUI huesos "largos"; c) Relación \%MAU VS Cavidad Medular.

Como puede observarse en la Figura 7.26.a los elementos "no-largos" presentan una tendencia similar a la planteada para la curva de utilidad inversa (Reverse Utility Curve) (Binford 1978). Esto se nota al realizar la correlación de los valores cuyo resultado es una relación negativa estadísticamente significativa $\left(r_{s}-.875 \mathrm{p} .01\right)$. Esto nos muestra la alta proporción de elementos de bajo rendimiento como el cráneo. Sin embargo para los huesos largos esta relación es débilmente positiva y estadísticamente no significativa $\left(r_{s} .088 \mathrm{p}\right.$.434). Salvo el caso del fémur se puede observar que la disposición de los valores de los huesos largos se aproxima a la forma de la "estrategia imparcial" (Unbiased Strategy) (Binford 1978) en la cual se seleccionan las unidades de la carcasa en proporción directa a su utilidad económica (Thomas y Mayer 1983).

Con respecto a la relación entre el \%MAU y la cavidad medular se observa una relación negativa estadísticamente no significativa $\left(r_{s}-.5161 \mathrm{p} .147\right)$ 
Estos datos estarían representado un escenario en el cual los nutrientes internos (médula ósea) no serían los que mejor explicarían la conformación de este conjunto y que los elementos con mayor índice de utilidad no son los que se encuentran representados con mayor frecuencia. Este resultado coincide con el obtenido por Marean y Frey (1997) para el conjunto faunístico del sitio Ain Dara, proveniente de contextos domésticos de una habitación y patio de la edad del Hierro en Irán.

\subsubsection{1.e. Fragmentación del subconjunto}

Siguiendo a Outram (2001) se efectuó un análisis de la fragmentación del subconjunto de camélidos adultos sobre la base del NISP agrupado según módulos de tamaño para los que presentaban fracturas y aquellos que se encontraban completos (Figura 7.27).

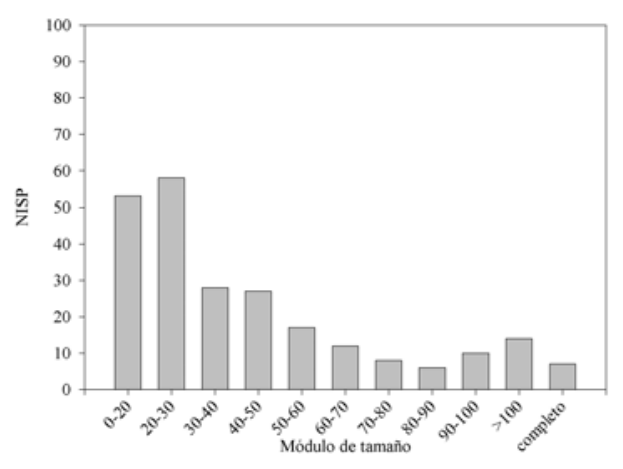

Figura 7.27. Módulos de tamaño expresado en NISP para especímenes y elementos del subconjunto adulto de camélidos

El resultado de esta exploración preliminar muestra que el conjunto en su gran mayoría se encuentra representado por fragmentos más que por elementos completos.

A partir de esta primera evaluación avanzaremos sobre cada región en particular. Para una mejor visualización se tratarán a los elementos según su pertenencia a categorías mayores como esqueleto axial, esqueleto apendicular delantero y esqueleto apendicular trasero (Partes Esqueletales Básicas o PEB siguiendo a Yacobaccio et al. 1998). Los gráficos se construyeron a partir del cálculo de la superficie relativa preservada de cada espécimen.

\section{Esqueleto axial}


Los elementos analizados muestran una alta tasa de fragmentación, ya que sólo dos de estos (hioides y atlas) presentan más del 50\% del área del elemento. Esto puede apreciarse particularmente en la Figura 7.28 en los cuales los especímenes con superficies mayores al $25 \%$ representado no superan el cinco por ciento de cada una de las muestras por elemento.

Estos valores relativos expresados según el largo máximo de cada espécimen no superan en general los $60 \mathrm{~mm}$.

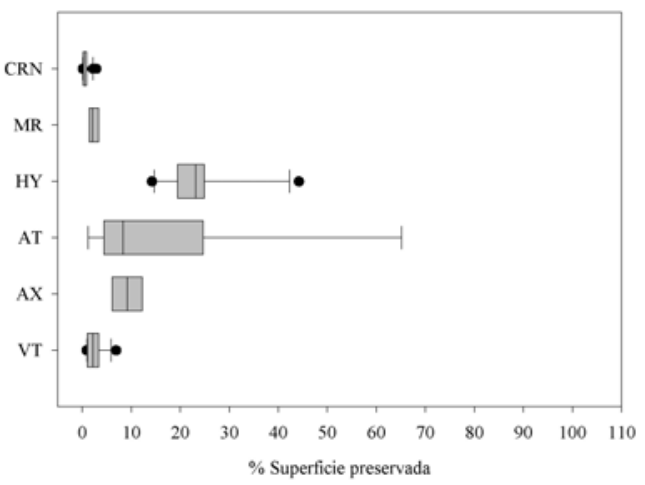

Figura 7.28. Fragmentación de elementos del esqueleto axial.

Esqueleto apendicular delantero

Como puede observarse en la Figura 7.29 existe un patrón de fragmentación basado en la cantidad de superficie total preservada para cada elemento y que se repite tanto para el lado izquierdo como para el derecho. A simple vista podría interpretarse como el producto de una posible estandarización del modo en que se fragmentó el conjunto.

Esto se puede observar asimismo en las figuras correspondientes al cálculo de MNE para cada elemento en dónde se observa que nos solo los tamaños son similares sino que las porciones preservadas son en general las mismas (Figuras 7.10 a 7.13). 

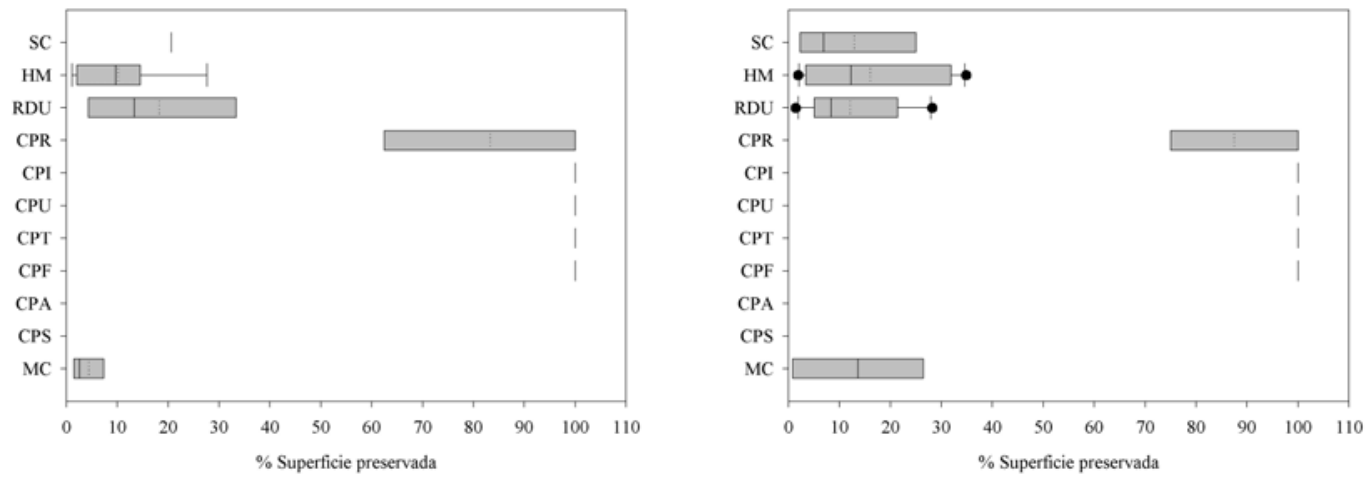

Figura 7.29. Fragmentación esqueleto apendicular delantero (izquierdo y derecho) Esqueleto apendicular trasero

En este caso se vuelve a producir un patrón que, aunque presenta pequeñas diferencias, se repite para ambos lados. Las diferencias en este caso corresponden a la fragmentación del calcáneo, el cual para el elemento derecho los fragmentos presentan menos del $25 \%$ de la superficie total del elemento, en tanto los del lado izquierdo comprenden valores superiores al $60 \%$. El fémur solo se encuentra presente para el lado derecho aunque su presencia se basa en el 7,88\% de la superficie total del elemento.
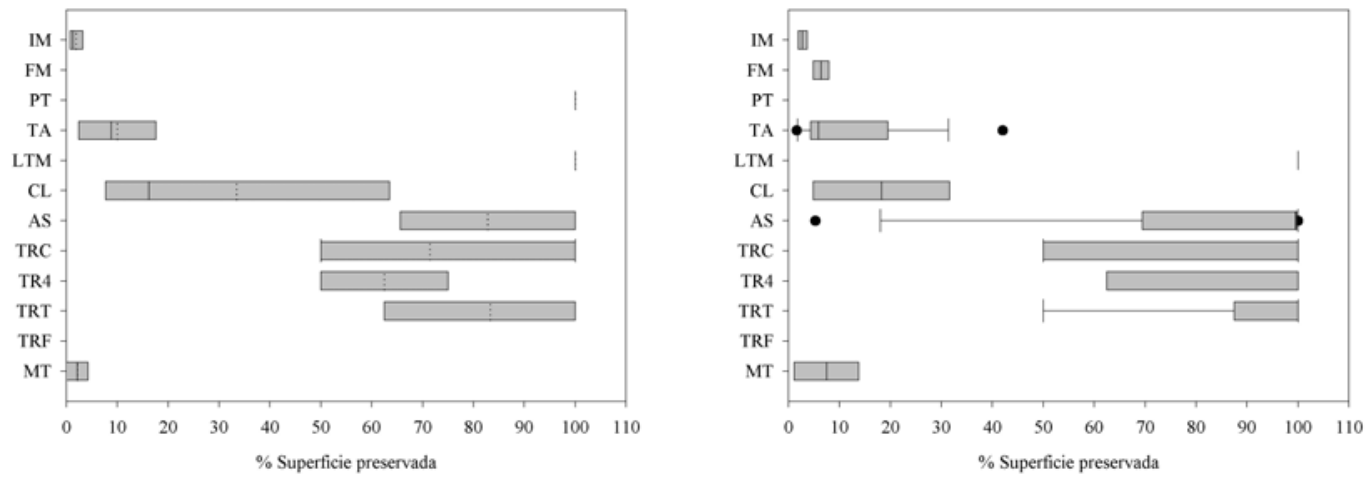

Figura 7.30. Fragmentación esqueleto apendicular trasero (izquierdo y derecho)

Hasta aquí se apreció que el conjunto presenta un alto grado de fragmentación. A su vez los tamaños de los especímenes son pequeños, ya sea expresado como largo máximo o como proporción de superficie preservada. Además a ésta aparente regularidad en los tamaños debe sumársele la recurrencia de las porciones representadas en el subconjunto. Por lo tanto es necesario un análisis más profundo a fin de indagar 
las causas por las que se habría producido este patrón. Para ello se aplicará a la muestra algunos criterios propuestos por Outram (2001) con el fin de contrastar el patrón reconocido con los posibles procesos actuantes para la conformación del mismo.

En la Figura 7.31 se presentan las frecuencias de tipos de fracturas presentes en el subconjunto. Como puede apreciarse, el tipo de fractura realizado en estado seco está representado en mayor cantidad, seguido por los fragmentos en los que no se pudo estimar el estado en el que se produjo la fragmentación, las fracturas realizadas en estado fresco y las fracturas intermedias.

Este resultado es interesante ya que las fracturas realizadas mientras el hueso aún estaba fresco no representan la mayor frecuencia lo que muestra que este conjunto posiblemente haya sido sometido a procesos posteriores que podrían haber enmascarado el procesamiento primario. Quizás esto se deba a la acción del calor, intencional o no, mediante el hervido o la acción directa del fuego. Más adelante continuaré con el desarrollo de esta discusión.

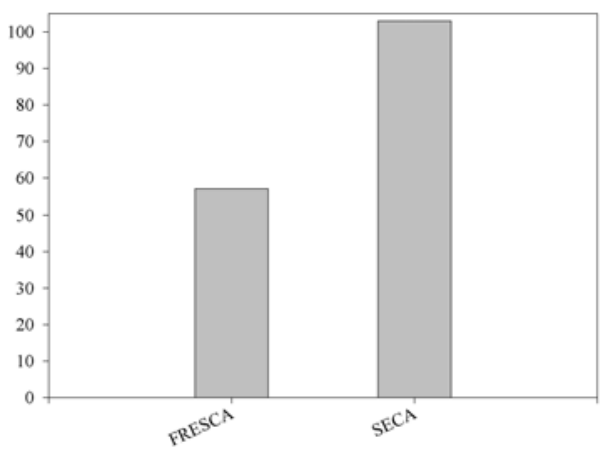

Figura 7.31. Cantidad (NISP) de especímenes y elementos del subconjunto adulto de camélidos según tipo de fractura. Loma Alta, Núcleo E.

\subsubsection{1.f. Utilización de las carcasas}

El uso al que fue sometido el conjunto de camélidos adultos se analizó también a través de las huellas dejadas en la superficie de los elementos óseos. Como puede observarse en la Tabla 7.10 se reconocieron marcas relacionadas con cinco tipos de actividades: aserrado, formatización, marcas de impactos y de corte, que se vinculan a distintas etapas en el procesamiento de las carcasas de los animales. 
Tabla 7.10. Marcas en hueso de camélidos adultos expresado en NISP

\begin{tabular}{|c|c|c|c|c|c|c|}
\hline Elemento & Porción & Aserrado & Formatización & Impacto & Marcas de corte & Total \\
\hline MR & ANG & - & - & - & 1 & 1 \\
\hline $\mathrm{TH}$ & PR & - & - & - & 1 & 1 \\
\hline $\mathrm{RB}$ & PR & - & - & - & 2 & 2 \\
\hline HM & DF & - & - & 2 & - & 2 \\
\hline HM & DS & - & - & 2 & 1 & 3 \\
\hline RDU & PR & - & - & - & 1 & 1 \\
\hline $\mathrm{MC}$ & DF & - & - & 1 & - & 1 \\
\hline IM & PB & - & - & - & 1 & 1 \\
\hline FM & PRS & 1 & - & - & - & 1 \\
\hline TA & PR & - & 1 & 1 & - & 2 \\
\hline TA & DF & - & - & 3 & - & 3 \\
\hline TA & DS & - & - & 2 & - & 2 \\
\hline TR4 & PR & - & - & - & 1 & 1 \\
\hline MT & DF & - & - & 1 & - & 1 \\
\hline MP & DS & 1 & - & 1 & - & 2 \\
\hline & Total & 2 & 1 & 13 & 8 & 24 \\
\hline
\end{tabular}

Marcas de procesamiento primario y secundario (Impactos y marcas de corte)

Con el fin de observar las tendencias en cuanto a estos atributos se analizará la muestra según su pertenencia al esqueleto axial o al apendicular.

\section{Esqueleto axial}

Para esta parte esqueletal básica (PEB) se identificaron solo marcas de corte, que se ubicaron en una mandíbula, en una vértebra torácica y en una costilla. En todos los casos se sitúan en las porciones proximales cerca de áreas correspondientes a articulaciones entre elementos, razón por lo cual se puede interpretar que estas marcas corresponden a la acción de reducción de las partes esqueletales básicas en unidades menores, es decir una etapa de procesamiento primario de las carcasas.

\section{Esqueleto apendicular}

El esqueleto apendicular parece más afectado por impactos y marcas de corte. Se pudo apreciar que todos los elementos del esqueleto apendicular delantero presentan algún tipo de marca asociada con el procesamiento primario de los elementos (Figura 7.32.a). Marcas de impacto pueden observarse con mayor frecuencia en el húmero, tanto en su parte proximal como distal, lo que quizás esté asociado con prácticas de 
extracción de la médula ósea. Presencia de impactos también se observaron en la diáfisis del metacarpo.

Marcas de corte se identificaron en el húmero distal y la radioulna proximal. La presencia de marcas de corte en porciones que se hallan contiguas nos hace suponer que se generaron en el mismo evento de desarticulación de estos elementos.

Los elementos del esqueleto apendicular trasero presentan marcas de impacto en la tibia en todas sus porciones (epífisis proximal, diáfisis y epífisis distal) y el metatarso en la diáfisis. Marcas de corte se identificaron en el pubis y el tarso cuarto. La interpretación de la ubicación de las marcas de corte corresponde, al igual que para los elementos del miembro anterior, a lugares de articulación intermembral (Figura 7.32 b)

Por último se halló un fragmento distal de un metapodio con un negativo de impacto repitiéndose en este caso el mismo patrón hallado para el metacarpo y el metatarso.

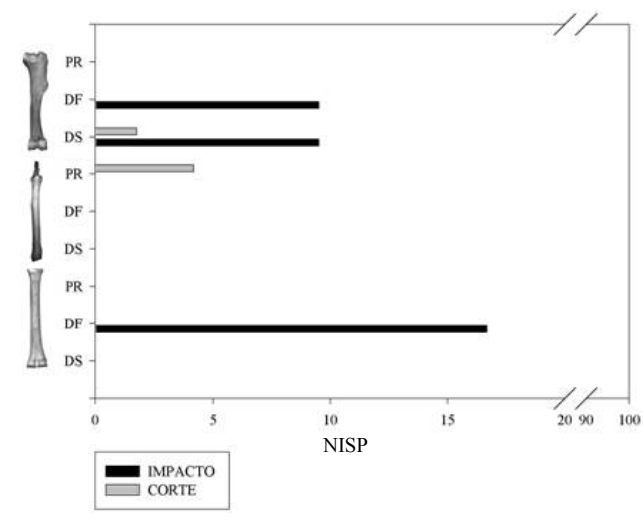

a

Figura 7.32. a) esqueleto apendicular delantero; b) esqueleto apendicular trasero.

\section{Marcas relacionadas con el uso de huesos como artefactos}

Marcas de este tipo solo fueron identificadas para dos elementos del esqueleto apendicular trasero y para un metapodio (Tabla 7.10). Dos de estos elementos (fémur proximal y metapodio distal) presentan sus diáfisis con marcas de haber sido aserrados. Un fragmento de diáfisis de tibia proximal presenta un extremo formatizado conformando lo que pudo haber constituido un punzón.

El conjunto en general presenta una muy baja frecuencia de preservación de marcas de acción antrópica. No obstante se encuentra representada una gran diversidad 
de formas y tipos. La preservación de marcas es mayor en el miembro posterior, el cual parecería haber sido procesado con mayor intensidad.

\subsubsection{1.g. Termoalteraciones}

La submuestra presentó en el 24,02\% $(\mathrm{n}=92)$ del total algún tipo de termoalteración.

Tabla 7.11. Termoalteración del conjunto de camélidos adultos.

\begin{tabular}{cccccc}
\hline & Sin alteración & $\begin{array}{c}\text { Oxidación } \\
\text { incompleta/carbonización } \\
\text { marrón claro-negro } \\
\text { (moteado) }\end{array}$ & Carbonizado & Calcinado & Total \\
Temperatura & - & $200{ }^{\circ} \mathrm{C}-300^{\circ} \mathrm{C}$ & $300{ }^{\circ} \mathrm{C}$ & $>500{ }^{\circ} \mathrm{C}$ & \\
NISP & 291 & 14 & 51 & 27 & 383 \\
\hline
\end{tabular}

El 70,65\% $(n=62)$ de elementos termoalterados presenta rastros de haber sido expuesto a temperaturas que rondan los 200 a $300{ }^{\circ} \mathrm{C}$. El otro $29,35(\mathrm{n}=27)$ presenta signos de haber sido expuesto a valores superiores a los $500{ }^{\circ} \mathrm{C}$. Esto puede deberse a la cercanía de estos restos respecto de las estructuras de combustión definidas para la ocupación (Figura 7.33)

Los restos de hueso quemado fueron hallados con mayor frecuencia precisamente en la unidades SA y AO, C, A, y H del R47, donde se determinaron varias estructuras de combustión (Scattolin 1990)
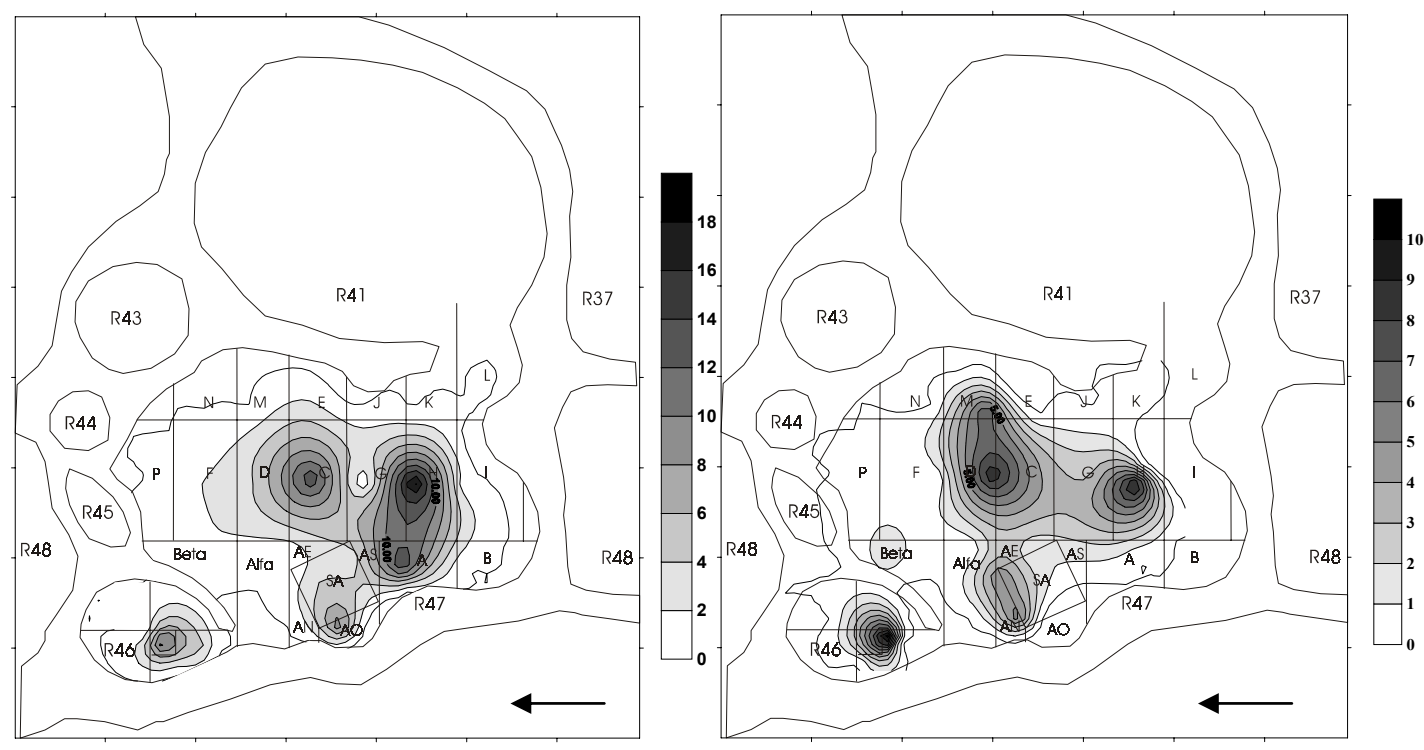

Figura 7.33. Mapa de contorno del Núcleo E mostrando las densidades de hueso quemado de camélidos adultos (izquierda) y no quemados con fractura seca (derecha). 
Examinamos la posibilidad de que algunos huesos estuvieran más termoalterados que otros, lo que denominamos selectividad. Para el esqueleto axial no presentan alteración térmica ni el axis, ni el atlas así como tampoco los fragmentos de dientes. Para el esqueleto apendicular no se registro alteración por calor en el metatarso, ni en el carpo cuarto, carpo radial y carpo ulnar. El resto de los elementos se vio afectado por acción del calor. Por ello podría plantearse que no existiría un patrón de selectividad con respecto a la acción de las alteraciones térmicas ya que la mayoría de los elementos presentan en algún grado al menos un fragmento con rastros de acción del calor.

Con respecto a los restos que no presentan signos de acción directa del calor se los relacionó con el tipo de fractura ya que la convección indirecta de calor puede formar patrones de fragmentación similares al tipo de fractura seca.

Tabla 7.12. Relación entre tipo de termoalteración y tipo de fractura del conjunto de camélidos adultos. Loma Alta, Núcleo E.

\begin{tabular}{ccccc}
\hline Tipo de alteración & Fresca & Intermedia & Seca & Total \\
Sin Alteración & 47 & 1 & 63 & 111 \\
Oxidación incompleta & 1 & - & 8 & 9 \\
Carbonizado & 5 & 1 & 20 & 26 \\
Calcinado & 4 & - & 12 & 16 \\
Total & 57 & 2 & 103 & 162 \\
\hline
\end{tabular}

Como se puede observar en la Tabla 7.12, el 56,75\% $(\mathrm{n}=63)$ de los especímenes sin termoalteración presentan fractura de tipo seca, la que podría asociarse tanto a rastros producidos por termoalteraciones como cocción en horno o por hervido (Outram 2001).

En cuanto a la distribución espacial de estos restos en particular se puede observar en la Figura 7.33 que estos se encuentran en general mas alejados de las estructuras de combustión e incluso dentro del área de la habitación del R46. Por esto es que creemos que posiblemente este tipo de fractura este más relacionado con factores atribuibles a la meteorización que a la alteración térmica. No obstante sería de interés desarrollar una línea de investigación que permita resolver este tipo de problemas.

\subsubsection{Camélidos subadultos}

Este subconjunto esta compuesto por un NISP $=105$ (Tabla 7.14). Este número de especímenes identificados corresponde tanto a huesos del esqueleto axial como del apendicular. 


\subsubsection{2.a. Supervivencia del material óseo mediada por la densidad ósea}

Para los siete elementos analizados en esta categoría de edad las correlaciones efectuadas presentan cinco resultados positivos y dos negativos. El resultado para toda la fauna muestra una correlación negativa débil sin significación estadística, lo que en general representaría para el conjunto una presencia mayor de landmarks con valores de densidad ósea bajas en relación con landmarks con densidades óseas elevadas. Esto caso presenta el resultado inverso al calculado para el conjunto de camélidos adultos de este mismo Núcleo.

Tabla 7.13. Correlación entre el \%MAU y la densidad ósea.

\begin{tabular}{cccc}
\hline Elemento & Rank & $r_{s}$ & $p$ \\
Mandíbula (MR) & 8 & .300 & .235 \\
Húmero (HM) & 5 & .632 & .184 \\
Radioulna (RDU) & 6 & .088 & .434 \\
Fémur (FM) & 5 & .105 & .447 \\
Tibia (TA) & 5 & -.707 & .091 \\
Calcáneo (CL) & 4 & -.400 & .300 \\
Metatarso (MT) & 4 & .258 & .371 \\
Arqueofauna & 29 & -.134 & .103 \\
\hline
\end{tabular}

7.1.1.2.b. Número Mínimo de Elementos (MNE)

\section{Mandibula (MR)}

Este elemento se halla representado en el conjunto por las siguientes zonas diagnósticas: coronoides, angular y fragmentos de la rama horizontal (Figura 7.34), por lo tanto se logró el cálculo de un MNE igual a 1.

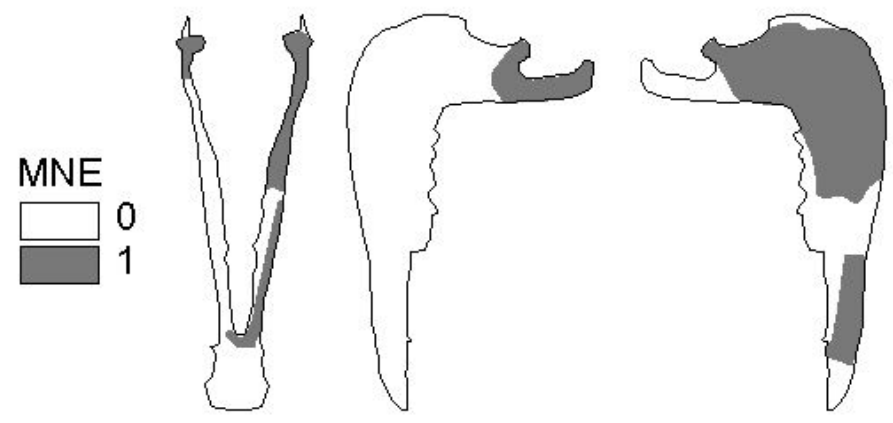

Figura 7.34. MNE Mandíbula

Atlas

Las zonas diagnósticas que representan a este elemento corresponden al tubérculo ventral, cavidades articulares craneales y caudales (Figura 7.35) El MNE comprehensivo es igual a 2 . 


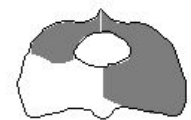

Figura 7.35. MNE Atlas

Axis

De este elemento se hallaron cuatro fragmentos los cuales corresponden a dos apófisis odontoides y dos fragmentos del cuerpo vertebral anteriores. El MNE calculado para este hueso corresponde a 2 (Figura 7.36)

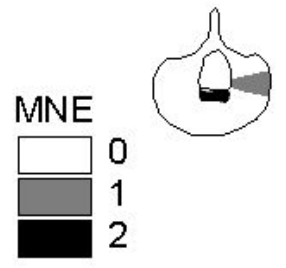

Figura 7.36. MNE Axis

Cervicales 3-7

Para este elemento se identificaron las siguientes zonas diagnósticas: cuerpo vertebral, epífisis proximal, epífisis distal y proceso articular. El MNE calculado es igual a 1 .

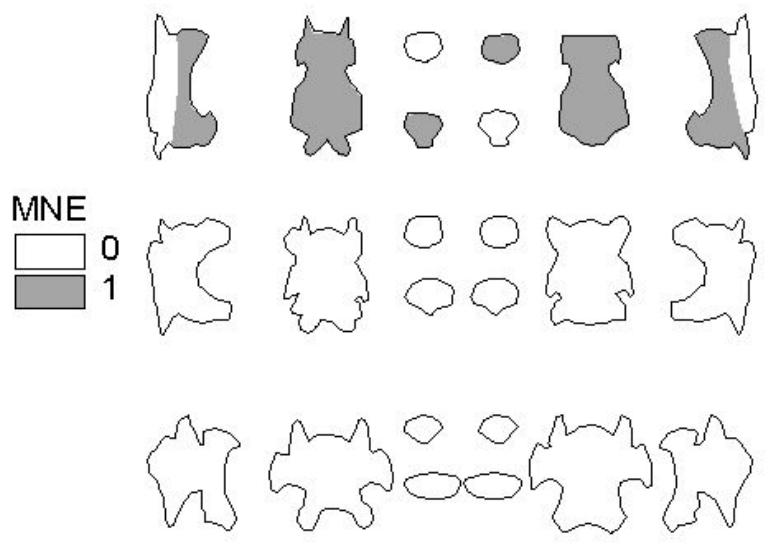

Figura 7.37. MNE Cervicales 3-7

Esternón

Se identificaron dos elementos esternales con un MNE igual a 2. 


\section{Húmero}

Para este elemento se identificaron las siguientes zonas diagnósticas: teres mayor, foramen posterolateral, epicóndilo lateral, epicóndilo medial, cóndilo lateral y cóndilo medial. El cálculo del MNE se realizó en base a la lateralidad de los fragmentos identificados. Para el lado izquierdo se calculó un MNE igual a 5 y para el derecho un MNE igual a 3 (Figura 7.38). El MNE total para este elemento es igual a 8.
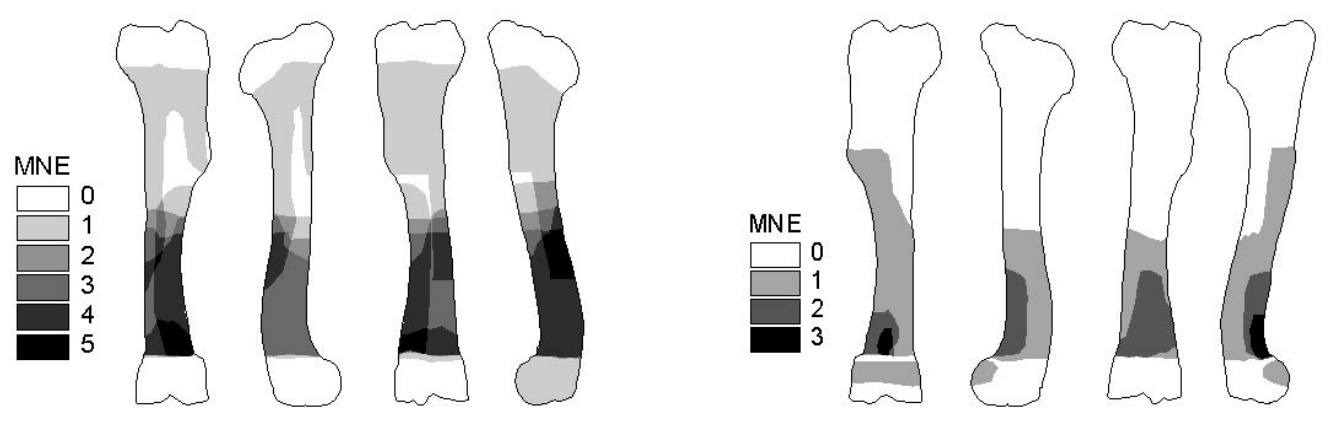

Figura 7.38. MNE Húmero izquierdo y derecho

\section{Radioulna}

Las zonas diagnósticas que permitieron identificar a este elemento son: proceso olecraniano, proceso anconeal, facetas articulares, proceso estiloide de la ulna, cavidad glenoidea lateral, cavidad glenoidea medial, diáfisis postero-proximal, tuberosidad radial, faceta de articulación con el carpo intermedio y faceta de articulación con el carpo radial. El MNE obtenido arrojó como resultado para el elemento izquierdo un valor igual a 6 y para el derecho a 1 , lo cual hace un total de un mínimo de 7 elementos (Figura 7.39)
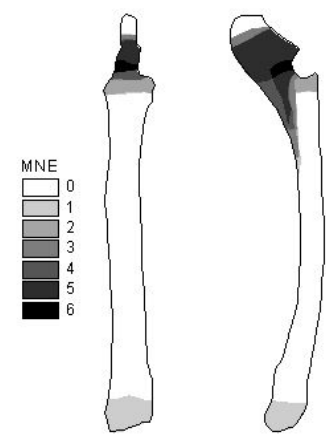
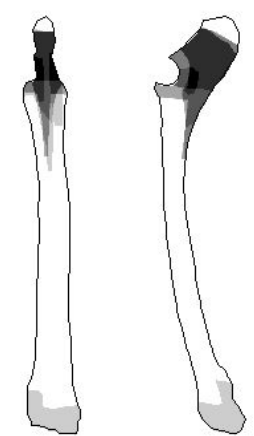
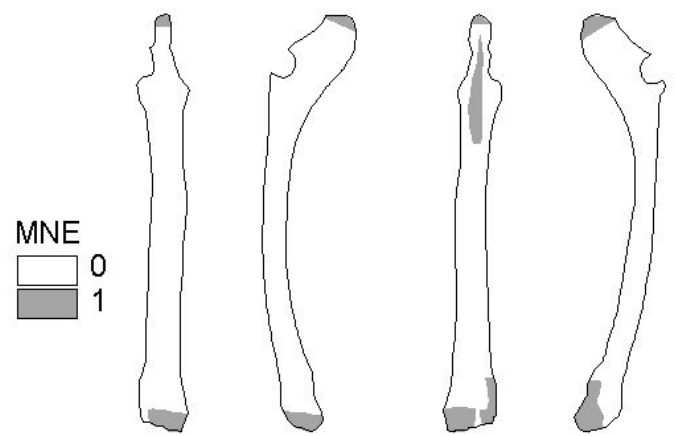

Figura 7.39. MNE Radioulna izquierda y derecha

Fémur

Se identificaron como zona diagnósticas: la cabeza, el trocánter mayor y la tróclea. El MNE alcanzado es igual a un elemento izquierdo y dos elementos derechos (Figura 7.40) totalizando un MNE igual a 3. 


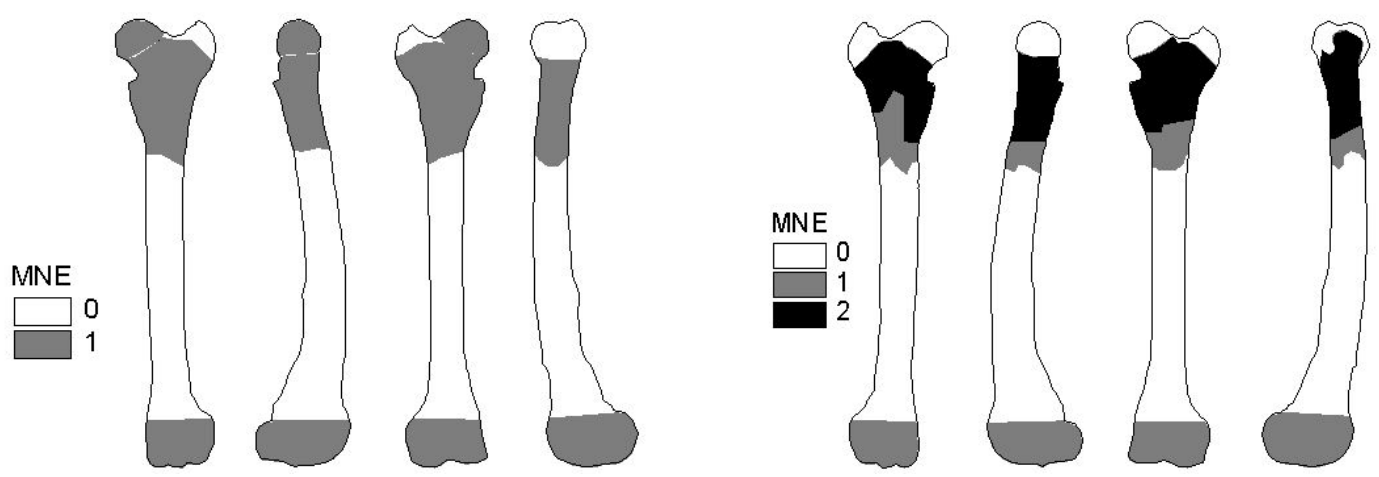

Figura 7.40. MNE Fémur izquierdo y derecho

Tibia

Las zonas diagnósticas utilizadas la identificación de este elemento corresponden al cóndilo lateral, a la diáfisis proximal posterior, a la diáfisis anterior distal, al surco medial y al surco lateral. Se calculó un MNE igual a 1 para el elemento izquierdo y de 5 para el derecho (Figura 7.41)
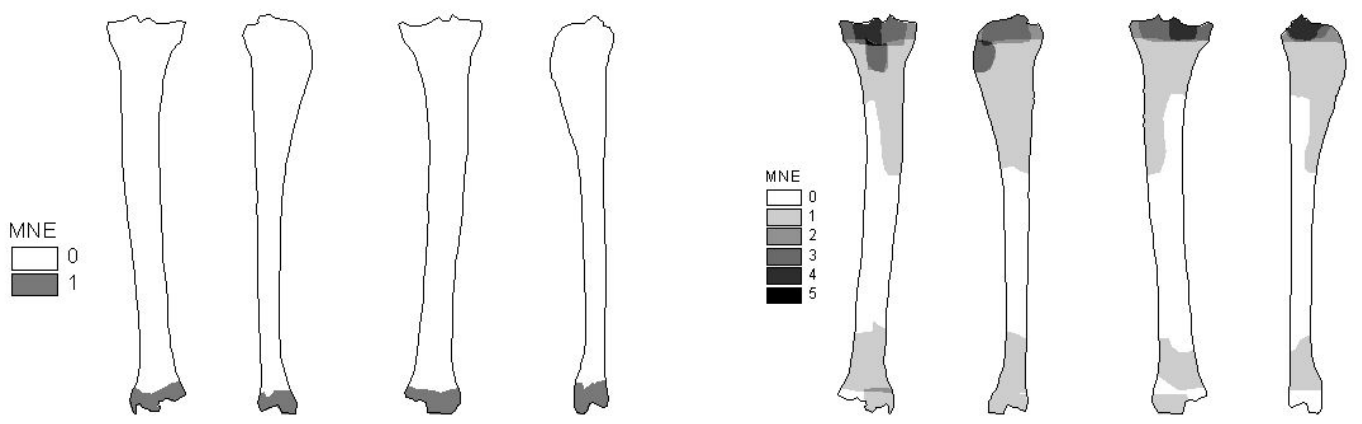

Figura 7.41. MNE Tibia izquierda y derecha

Calcáneo

El MNE calculado para cada lado corresponde a 1 elemento para el lado izquierdo y 5 para el derecho, ofreciendo un total de 6 elementos.

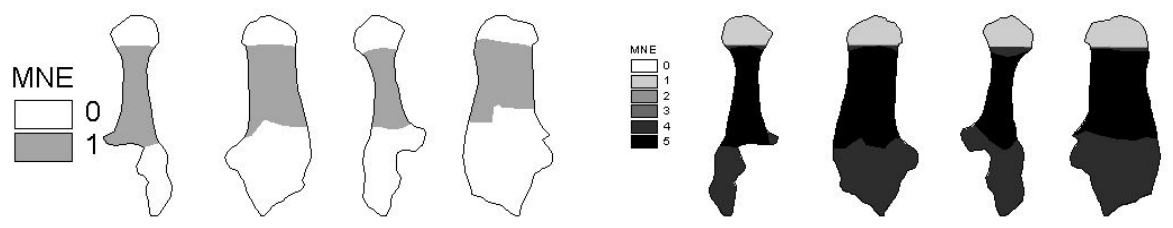

Figura 7.42. MNE Calcáneo izquierdo y derecho

\section{Metatarso}

Este elemento presenta dos especímenes a partir de los cuales se pudo establecer un MNE igual a 1 para cada lado (Figura 7.43) 

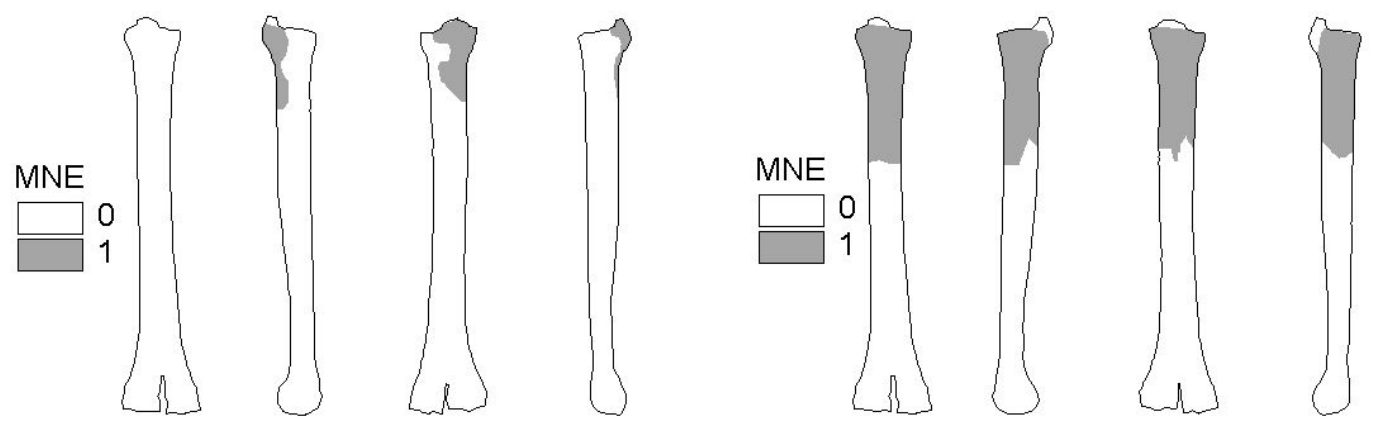

Figura 7.43. MNE Metatarso izquierdo y derecho

\section{Metapodio}

Lo mismo que en el caso de los adultos, los restos de metapodio que no pudieron ser asignados a metacarpo o metatarso se agruparon en una categoría denominada metapodio general. Se logró calcular sobre este conjunto de especímenes un MNE igual a 14 (Figura 7.44).
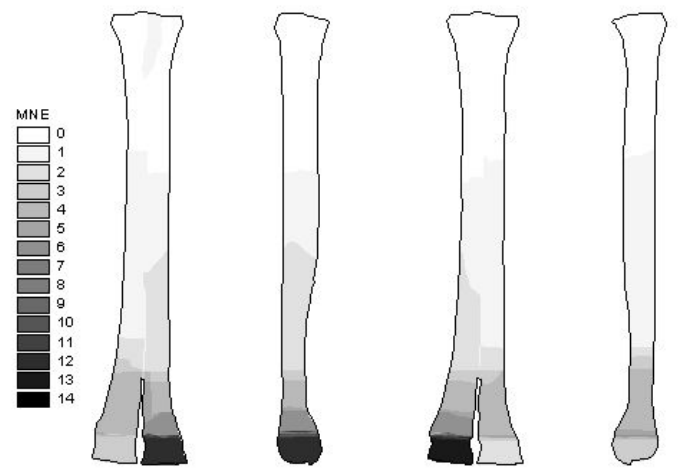

Figura 7.44. MNE Metapodio

\section{Falange proximal}

Para este elemento las zonas diagnósticas utilizadas fueron la epífisis proximal, epífisis distal y diáfisis. Sobre los especímenes asignados a esta categoría se calculó un MNE igual a 8 elementos (Figura 7.45)
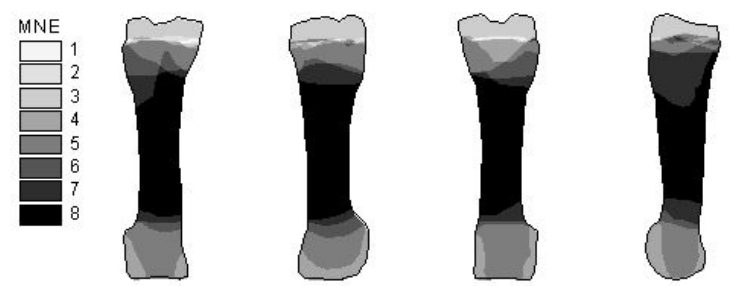

Figura 7.45. MNE Falange proximal

Falange medial 
Para este elemento, al igual que para el caso de todas las falanges, las zonas diagnósticas utilizadas fueron la epífisis proximal, epífisis distal y diáfisis. El cálculo del MNE arrojó una cantidad de 7 elementos (Figura 7.46)
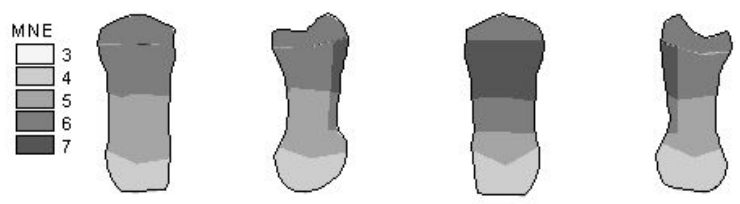

Figura 7.46. MNE Falange medial

Al igual que lo ya realizado para el subconjunto de camélidos adultos se ofrece a continuación un resumen de los datos obtenidos hasta el momento. A partir del NISP y el MNE se calcularon el MNI, MAU y \%MAU los cuales se encuentran expresados en la Tabla 7.14.

Tabla 7.14. Abundancia relativa de partes esqueletarias expresadas como NISP, MNE comprehensivo, MAU y \%MAU. $\mathrm{D}=$ derecho, $\mathrm{I}=$ izquierdo, $\mathrm{S} / \mathrm{D}=$ axial o sin datos

\begin{tabular}{lcccccccc}
\hline \multicolumn{1}{c}{ Elemento } & NISP & I & D & S/D & MNE & MNI & MAU & $\%$ MAU \\
Mandíbula & 3 & - & - & 1 & 1 & 1 & 1.00 & 25.00 \\
Atlas & 2 & - & 2 & - & 2 & 2 & 2.00 & 50.00 \\
Axis & 4 & - & - & 2 & 2 & 2 & 2.00 & 50.00 \\
Vértebra cervical & 2 & - & - & 1 & 1 & 1 & 0.25 & 6.25 \\
Elemento esternal & 2 & - & - & 2 & 2 & 1 & 0.29 & 7.14 \\
& & & & & & & & \\
Húmero & 10 & 5 & 3 & - & 8 & 5 & 4.00 & 100.00 \\
Radioulna & 11 & 6 & 1 & - & 7 & 6 & 3.50 & 87.50 \\
Fémur & & & & & & & & \\
Tibia & 6 & 1 & 2 & - & 3 & 2 & 1.50 & 37.50 \\
Calcáneo & 9 & 1 & 5 & - & 6 & 5 & 3.00 & 75.00 \\
Metatarso & 6 & 1 & 5 & - & 6 & 5 & 3.00 & 75.00 \\
& 2 & 1 & 1 & - & 2 & 1 & 1.00 & 25.00 \\
Metapodio & & & & & & & & \\
Primera falange & 26 & - & - & 14 & 14 & 4 & 1.00 & 25.00 \\
Segunda falange & 10 & - & - & 8 & 8 & 1 & 1.00 & 25.00 \\
& 12 & - & - & 7 & 7 & 1 & 0.88 & 21.88 \\
& & & & & & & & \\
\hline
\end{tabular}

\subsubsection{2.c. Número Mínimo de Individuos (MNI)}

Para el subconjunto de camélidos subadultos es la radioulna izquierda la que posee el valor más alto (6), y la que nos estaría indicando la cantidad mínima de animales que integran la submuestra.

Se estableció la probable presencia de un guanaco subadulto en este subconjunto. Esto fue posible a partir de la identificación interespecífica de una falange 
proximal con estadio de fusión ósea 2 lo que expresaría una edad de aproximadamente 32 meses.

\subsubsection{2.d. Unidades anatómicas representadas (MAU)}

Partiendo de las identificaciones efectuadas y los cálculos de NISP y MNE se construyó un perfil de unidades anatómicas representadas y se lo graficó a partir de la estandarización de este índice (\%MAU)

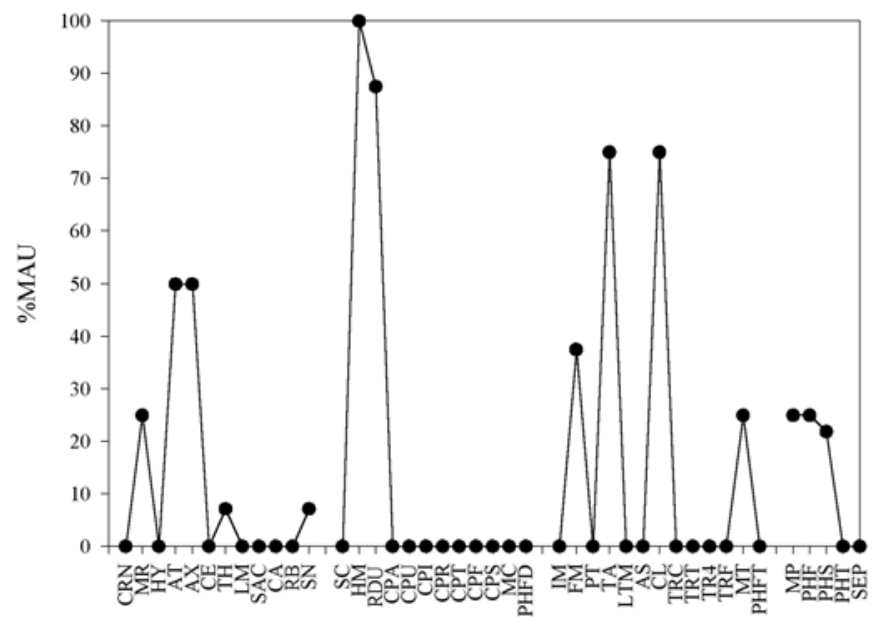

Figura 7.47. Abundancia relativa de elementos esqueletarios.

Como se observa en el gráfico los elementos del esqueleto apendicular tanto delantero como trasero estarían más representados que aquellos pertenecientes al esqueleto axial. Tanto en el esqueleto axial como en el apendicular estarían representados elementos de elevado rendimiento económico. Pero para avanzar más en este perfil anatómico se procedió a la comparación por medio de gráficos bivariados de los valores de MAU estandarizados (\%MAU) con el índice utilidad de alimento (FUI, Food Utility Index) para llama subadulta (Olivera 2001) y los valores de la cavidad medular de los huesos largos (Mengoni Goñalons 2001) con el fin de observar tendencias en cuanto a la utilización de las carcasas. 

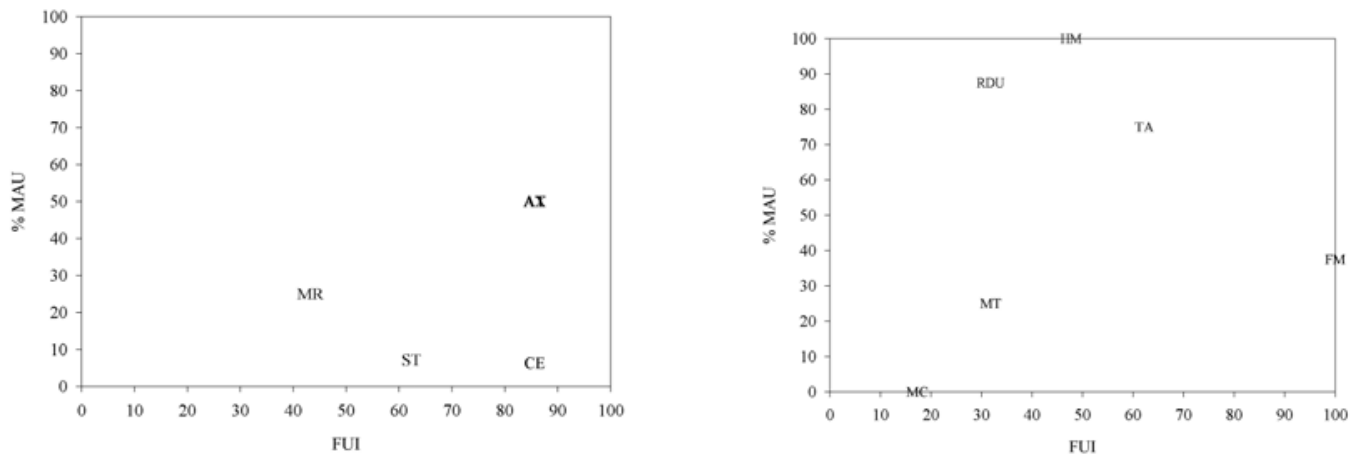

a

$\mathrm{b}$

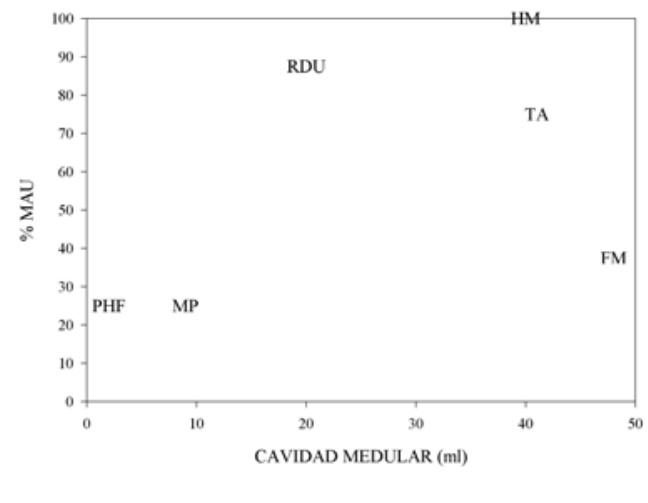

Figura 7.48. a) Relación \%MAU VS FUI huesos "no-largos"; b) Relación \%MAU VS FUI huesos "largos"; c) Relación \%MAU VS Cavidad Medular.

Como puede observarse en la Figura 7.48.a los elementos "no-largos" presentan una mayor proporción de huesos con utilidad económica alta (atlas y axis) respecto del resto de los elementos identificados.

Los huesos largos muestran una tendencia similar, aunque la mayor frecuencia se aprecia en elementos con valores de utilidad media (Figura 7.48.b). Por último se puede observar en la Figura 7.48.c que se encuentran representados en mayor cantidad los huesos que poseen un volumen de la cavidad ósea más grande.

Por los resultados obtenidos para este subconjunto se puede interpretar a partir de las partes esqueletarias registradas que su conformación podría estar asociada a la extracción de productos primarios como carne y medula ósea, tanto para el esqueleto axial como para el apendicular. Compárese con los resultados obtenidos para el subconjunto de camélidos adultos de este mismo Núcleo. 


\subsubsection{2.e. Fragmentación del subconjunto}

Al igual que para el conjunto de camélidos adultos se realizó una estimación del número de fragmentos por módulo de tamaño. Lo que se puede observar (Figura 7.49) es que para este subconjunto no se encuentra ningún elemento completo y que los módulos de tamaño más pequeños son los que presentan mayor cantidad de fragmentos. Esto es lo esperable por otra parte ya que el tamaño general de los huesos de animales juveniles son de por sí menores a los esperados para animales adultos. No obstante la fragmentación del subconjunto es relativamente alta.

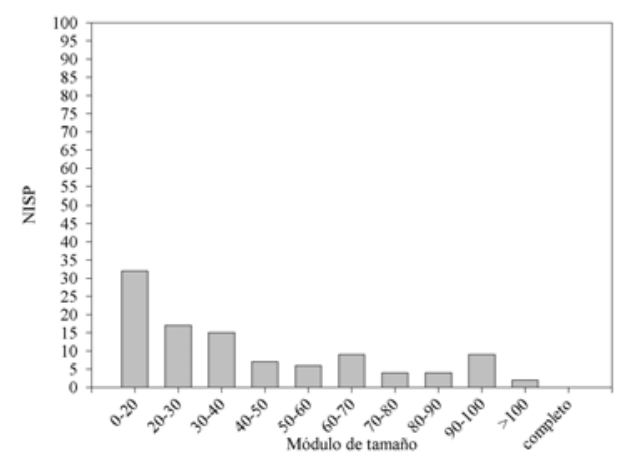

Figura 7.49. Módulos de tamaño expresado en NISP para especímenes y elementos del subconjunto adulto de camélidos

\section{Esqueleto axial}

Con respecto a la fragmentación por elemento dentro de cada parte esqueletaria básica se pudo observar que se repite un patrón similar al de los animales adultos, siendo el atlas el que preserva una mayor cantidad de superficie relativa.

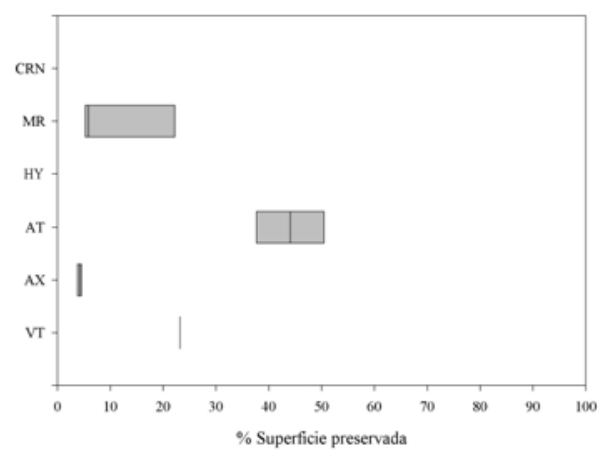

Figura 7.50. Fragmentación de elementos del esqueleto axial. 
Esqueleto apendicular delantero

El patrón de fragmentación para los elementos del miembro delantero se repite para ambos lados. Los elementos representados presentan aproximadamente la misma distribución, siendo los fragmentos del húmero los que presentan mayor superficie. Los valores calculados para el lado izquierdo son menores al $40 \%$ del total de la superficie de los elementos mientras que para el lado derecho estos son aún más pequeños ya que no superan el $30 \%$.
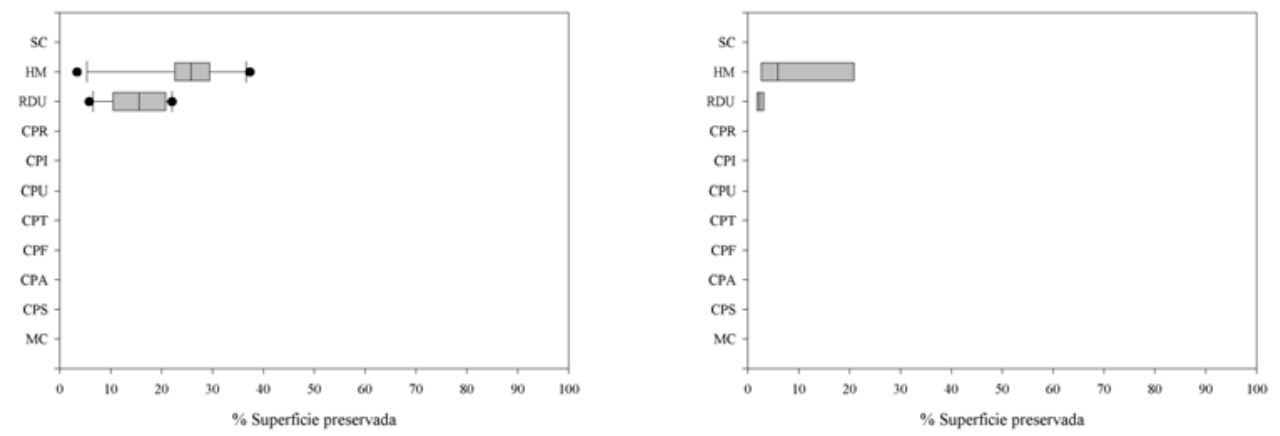

Figura 7.51. Fragmentación esqueleto apendicular delantero (izquierdo y derecho)

Esqueleto apendicular trasero

Aquí se vuelve a repetir en términos generales el mismo patrón. Los valores para ambos lados del fémur son prácticamente iguales. Para la tibia izquierda solo hay un fragmento que coincide con los valores calculados para la mediana del elemento derecho. Para el calcáneo existen diferencias ya que el lado izquierdo esta representado por fragmentos menores al 50\% del elemento en tanto que el derecho observa superficies mayores al 45\%. Por último para el metacarpo si bien existen diferencias, la superficie total representada no supera el 35\% del total del área.
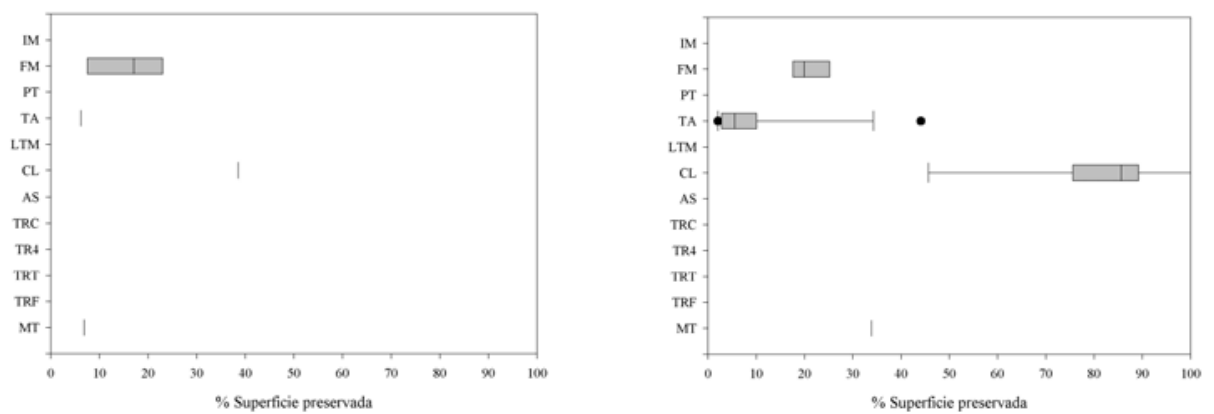

Figura 7.52. Fragmentación esqueleto apendicular trasero (izquierdo y derecho) 
Con respecto a los atributos referidos al estado en el cual se produjo la fragmentación del conjunto se puede ver en la Figura 7.53 que las fracturas en estado fresco y en seco presentan las mismas frecuencias.

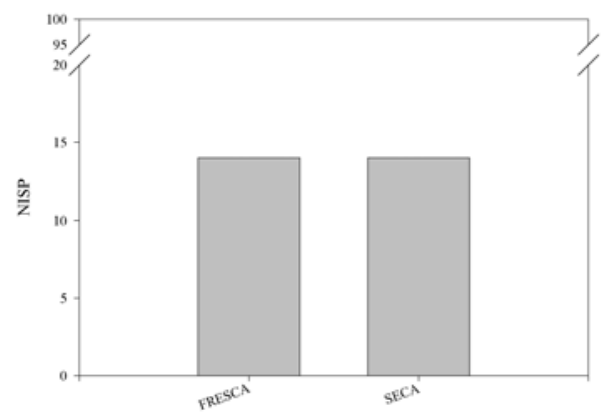

Figura 7.53. Cantidad (NISP) de especímenes y elementos del subconjunto adulto de camélidos según tipo de fractura.

\subsubsection{2.f. Utilización de las carcasas}

En el conjunto de camélidos subadultos se observaron principalmente marcas de corte y de impacto, no registrándose otros tipos de huellas de acción antrópica. Con respecto a su localización podemos ver en la Tabla 7.15 y Figura 7.54 que se distribuyen tanto en elementos del esqueleto axial como del apendicular. Para los elementos del esqueleto axial es la mandíbula el único que presenta marcas de corte. Esta se ubica en la porción del angular. Por el otro lado el esqueleto apendicular delantero muestra tanto marcas de impacto como de corte. Ambas fueron reconocidas en la porción distal de la diáfisis. Por último para el esqueleto axial trasero se registraron los negativos de un impacto bipolar en la porción proximal de la diáfisis del fémur.

Tabla 7.15. Marcas en huesos de camélido subadulto expresado en NISP.

\begin{tabular}{|c|c|c|c|c|}
\hline $\begin{array}{l}\text { Elemento } \\
\text { MR }\end{array}$ & $\begin{array}{l}\text { Porción } \\
\text { ANG }\end{array}$ & $\begin{array}{c}\text { Impacto } \\
-\end{array}$ & $\begin{array}{c}\text { Marcas de corte } \\
1\end{array}$ & $\begin{array}{r}\text { Total } \\
1\end{array}$ \\
\hline HM & DSS & 1 & 1 & 2 \\
\hline FM & PRS & 1 & - & 1 \\
\hline PHF & $\mathrm{SH}$ & - & 1 & 1 \\
\hline Total & & 2 & 3 & 5 \\
\hline
\end{tabular}




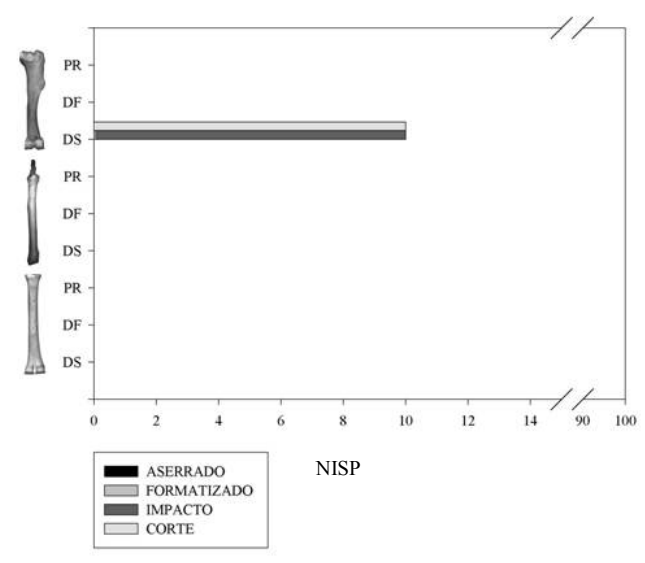

a

Figura 7.54. Utilización de las carcasas. a) Pata delantera y b) Pata trasera.

En general las huellas de procesamiento se presentan en frecuencias bajas y todas referirían a etapas de procesamiento primario (de extracción de carne) o secundarios (de reducción de PEB).

\subsubsection{2.g. Termoalteraciones}

Del total de 105 especímenes 12 mostraron rastros de alteración térmica en distinto grado lo que representa un $11 \%$ del total. Dentro de esta pequeña muestra 8 presentan signos de haber sido sometido a temperaturas menores a los $300^{\circ} \mathrm{C}$, lo que implicaría que su exposición al calor ha sido por poco tiempo o su ubicación sería periférica al lugar con mayor poder calórico del fogón.

Tabla 7.16. Termoalteración del conjunto de camélidos subadultos.

\begin{tabular}{|c|c|c|c|c|c|}
\hline Descripción & Sin & Oxidación & Carbonizado & Calcinado & Total \\
\hline Color & $\begin{array}{c}\text { alteración } \\
-\end{array}$ & $\begin{array}{l}\text { incompleta/carbonización } \\
\text { marrón claro-negro } \\
\text { (moteado) }\end{array}$ & negro & gris-blanco & \\
\hline Temperatura & $<200^{\circ} \mathrm{C}$ & $200^{\circ} \mathrm{C}-300^{\circ} \mathrm{C}$ & $300^{\circ} \mathrm{C}$ & $>500{ }^{\circ} \mathrm{C}$ & \\
\hline NISP & 93 & 3 & 5 & 4 & 105 \\
\hline
\end{tabular}

Respecto a los elementos que presentan estas alteraciones por calor se identificaron mayormente a aquellos pertenecientes al esqueleto apendicular como metapodios, falanges mediales, radioulna y tibia, en tanto que para el esqueleto axial solo una esternebra presento indicios de modificaciones térmicas.

Por último y considerando la relación tipo de estado de la fractura y tipo de alteración térmica (Tabla 7.17) se observó que la muestra termoalterada en solo tres de 
los doce casos presenta asociada algún tipo de fractura. Dos de ellas presentan características de fractura realizada en estado fresco y la tercera en estado seco. Sin embargo el tamaño de esta muestra es muy pequeño por lo cual no se realizará ninguna apreciación sobre este punto.

Tabla 7.17. Relación entre el tipo de termoalteración y tipo de fractura del conjunto de camélidos adultos.

\begin{tabular}{cccr}
\hline Tipo de alteración & Fresca & Seca & Total \\
Sin alteración & 12 & 14 & 26 \\
Oxidación incompleta & - & - & - \\
Carbonizado & - & 1 & 1 \\
Calcinado & 2 & - & 2 \\
Total & 14 & 15 & 29 \\
\hline
\end{tabular}

\subsubsection{Subconjunto no camélido}

La muestra se compone por un NISP $=2488$ e incluye a taxones de tamaños corporales 1, 2, 2-3 y 4. Para este último tamaño corporal se toman en cuenta los cérvidos y los artiodáctilos no identificados como camélidos.

\subsubsection{Marcas de procesamiento}

Para el conjunto correspondiente a los taxones que no se identificaron como camélidos se observaron huellas de procesamiento primario, secundario y de formatización. Dentro de estas categorías se hallaron especímenes que presentan cinco tipos de huellas: marcas de corte, impactos, marcado perimetral, aserrado y formatización (Tabla 7.18)

Tabla 7.18. Marcas en huesos del conjunto no camélido expresado en NISP.

\begin{tabular}{|c|c|c|c|c|c|c|c|c|c|}
\hline Taxón & $\begin{array}{l}\text { Tamaño } \\
\text { corporal }\end{array}$ & Elemento & Porción & Aserrado & Formatización & Impacto & $\begin{array}{l}\text { Impacto - } \\
\text { marca } \\
\text { perimetral }\end{array}$ & $\begin{array}{c}\text { Marcas } \\
\text { de } \\
\text { corte }\end{array}$ & $\begin{array}{l}\text { Total } \\
\text { NISP }\end{array}$ \\
\hline \multirow[t]{2}{*}{ Rodentia } & 2 & LB & $\mathrm{CO}$ & - & - & - & - & 1 & 1 \\
\hline & & LB & $\mathrm{SH}$ & 1 & - & - & - & - & 1 \\
\hline \multirow[t]{7}{*}{ Artiodactyla } & 4 & $\mathrm{CL}$ & PRS & - & - & - & - & 1 & 1 \\
\hline & & FB & US & - & 1 & - & - & - & 1 \\
\hline & & HM & FK & - & - & 1 & - & - & 1 \\
\hline & & LB & AST & - & 2 & 1 & - & - & 3 \\
\hline & & LB & FK & - & - & 20 & 1 & 1 & 22 \\
\hline & & LB & IFK & - & - & 3 & - & - & 3 \\
\hline & & $\mathrm{RB}$ & $\mathrm{BL}$ & - & - & - & - & 1 & 1 \\
\hline \multirow{2}{*}{$\begin{array}{c}\text { No } \\
\text { identificable }\end{array}$} & 1 & LB & AST & - & 1 & - & - & - & 1 \\
\hline & $3-4$ & US & US & - & 1 & - & - & - & 1 \\
\hline Total & & & & 1 & 5 & 25 & 1 & 4 & 36 \\
\hline
\end{tabular}


Especímenes y elementos pertenecientes a dos tamaños corporales distintos presentan marcas asociadas al procesamiento primario y secundario.

Un hueso largo de roedor presentó marcas de corte. Este se asignó al tamaño corporal 2, el cual incluye a Lagidium sp, un taxón cuyo consumo por parte de poblaciones prehispánicas ha sido registrado para otros sitios arqueológicos de la zona y regiones aledañas (Elkin 1996 y obras allí citadas).

La mayor parte de las marcas han sido registradas en especímenes asignados a la categoría artiodáctilos de tamaño corporal 4 , los cuales posiblemente correspondan a camélidos en general. Salvo un fragmento de costilla, el resto de las huellas se han identificado en restos de huesos largos, replicando de alguna manera el patrón hallado tanto en el conjunto de camélidos adultos como el de subadultos. La mayor frecuencia corresponde a negativos de impactos seguido por lascas óseas. Las marcas de corte solo se presentan en tres especímenes y el marcado perimetral en un fragmento de hueso largo.

Respecto a las marcas relacionadas con el uso de huesos como artefactos la mayor cantidad de huellas se han asignado a especímenes de artiodáctilos de tamaño corporal 4. En todos los casos las evidencias de formatización parecerían haber sido confeccionadas con el fin de utilizarlo como artefactos. Para el roedor de tamaño corporal 2 un espécimen presenta evidencias de haber sido sometido a un proceso de aserrado. Por último un espécimen no identificable asignado a tamaño corporal 1 presentó signos de formatización.

\subsubsection{Termoalteración}

El 21,72\% de la muestra presentó algún grado de termoalteración. La mayor parte de los especímenes termoalterados corresponden a artiodáctilos o no identificables de tamaño corporal 4 (67\% de los elementos termoalterados). El resto se divide en elementos quemados de Carnivora, H. antisensis, Chaetophractus vellerosus, Rodentia y diversos especímenes no identificables de todos los tamaños corporales. 
Tabla 7.19. Termoalteración del conjunto de no camélido.

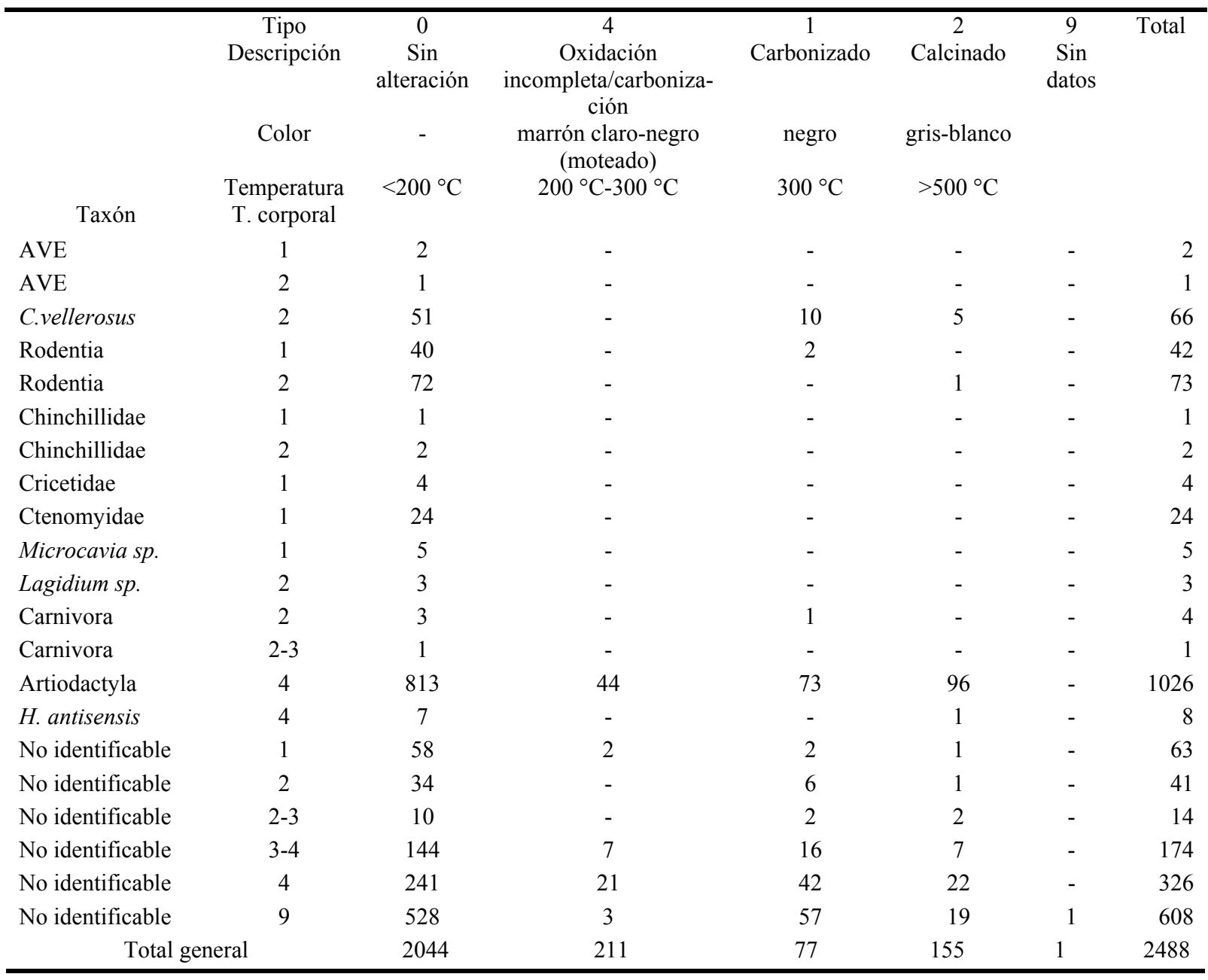

\subsubsection{Fragmentación del subconjunto de no camélidos.}

En la Figura 7.55a, b, y c, se observan los patrones de fragmentación de la muestra ósea de no camélidos. Cada uno de los gráficos corresponde a un tamaño corporal comenzando por el 1, pasando por el 2 y finalizando en el 4.

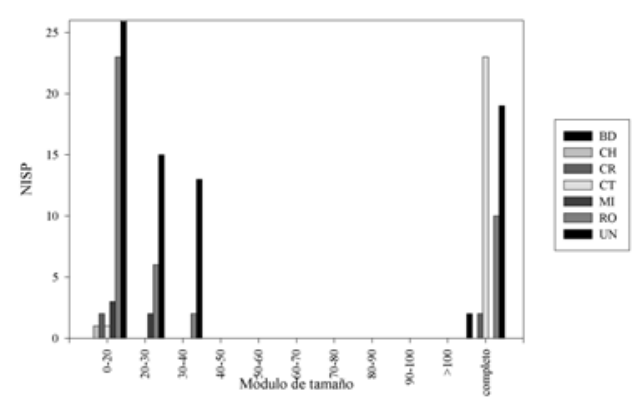

a

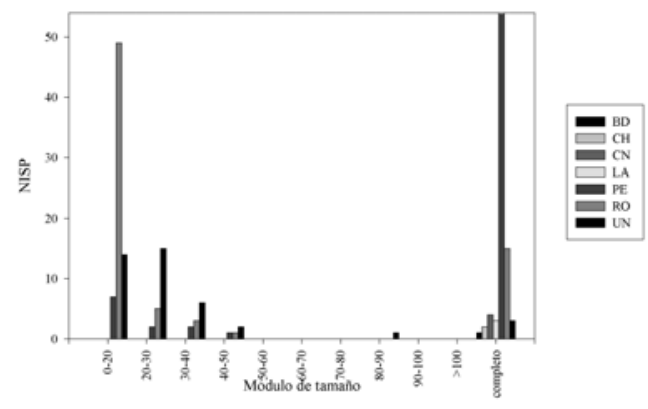

b 


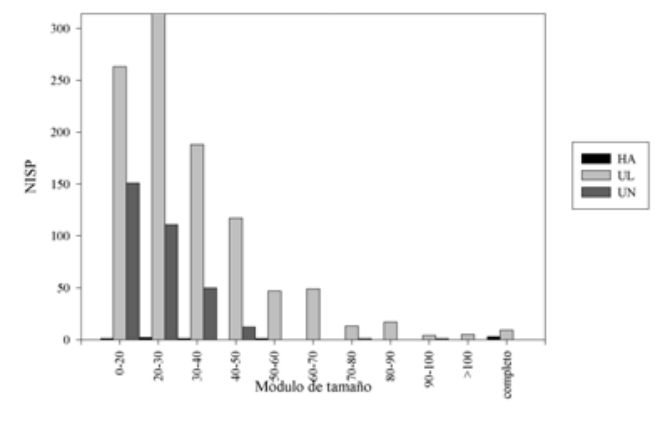

Figura 7.55. Fragmentación del conjunto no camélido expresado en NSP. a) Tamaño corporal 1, b) Tamaño corporal 2 y c) Tamaño corporal 4.

Para el tamaño corporal 1 se puede observar que el grado de fragmentación nos muestra una alta tasa de rotura de los huesos especialmente para Microcavia sp y Chinchillidae, Rodentia y "no identificables". En tanto que AVES y Ctenomyidae muestran básicamente los huesos completos.

El caso de los huesos del tamaño corporal 2 se advirtió que Rodentia y no identificables presentaron huesos fragmentados, en tanto el resto de los taxones lo hicieron completos.

Por último para el tamaño corporal 4 se vuelve a observar el mismo patrón que para el conjunto de camélidos con una gran mayoría de fragmentos en los primeros módulos de tamaño y una baja frecuencia de elementos completos. Los patrones de fragmentación, la alteración térmica y las huellas halladas para este tamaño corporal se comportan del mismo modo que los dos subconjuntos de camélidos de este Núcleo. 


\subsection{Loma Alta Núcleo F-Análisis faunístico}

La muestra total recuperada fue de un NSP $=506$, lográndose identificar a nivel taxonómico un 44,26\% del total de la muestra. El volumen excavado para el conjunto es de $1,2 \mathrm{~m}^{3}$ resultando en una densidad de huesos de 421 fragmentos $/ \mathrm{m}^{3}$. A continuación se presentará la composición taxonómica general de cada recinto excavado y luego se tratará el conjunto en su totalidad.

Recinto $63 A$ (R63A). Para este recinto se excavaron un sondeo, una trinchera y tres cuadriculas las que en total cubrieron una superficie de aproximadamente $15 \mathrm{~m}^{2}$. En esta unidad se observaron dos depósitos correspondiendo el inferior al nivel de ocupación. Del total de este conjunto se identificó a nivel taxonómico a un 47,02\%. En estas unidades de excavación se hallaron elementos o especímenes correspondientes a nueve taxones diferentes de los cuales la frecuencia mayor fue asignada a artiodáctilos y camélidos (Tabla 7.20) correspondiendo a este último taxón un $29,76 \%$ de especímenes identificados.

Tabla 7.20. Composición del conjunto faunístico del Recinto 63A.

\begin{tabular}{lcr}
\hline \multicolumn{1}{c}{ Taxón } & Tamaño corporal & Total NSP \\
AVE & 1 & 2 \\
Chaetophractus vellerosus & 2 & 3 \\
Rodentia & 1 & 7 \\
Lagidium sp. & 2 & 1 \\
Artiodactyla & 4 & 110 \\
Lama sp. & 4 & 30 \\
Lama guanicoe & 4 & 1 \\
Lama glama & 4 & 3 \\
H. antisensis & 4 & 1 \\
$\quad$ Subtotal Identificados & & \\
$\quad$ No identificable & 1 & 158 \\
$\quad$ No identificable & $1-2$ & 2 \\
$\quad$ No identificable & $3-4$ & 10 \\
$\quad$ No identificable & 4 & 26 \\
$\quad$ No identificable & 9 & 138 \\
$\quad$ Subtotal No identificables & & \\
$\quad$ & & 336 \\
\hline
\end{tabular}


Se identificaron ocho taxones y cuatro categorías de tamaño corporal. Los elementos o especímenes representados en mayor frecuencia son los correspondientes al tamaño corporal 4 (identificados o no identificables)

Cuatro elementos de camélidos fueron determinados taxonómicamente a nivel de especie. El elemento especificado como Lama guanicoe corresponde a una falange proximal y para su asignación se utilizaron las siguientes variables osteométricas: \#1, \#2, \#3, \#4 y \#5 de Kent (1982). Los elementos correspondientes a Lama glama son una falange proximal, una falange medial y una falange distal definidas mediante las siguientes medidas: \#1, \#2, \#3, \#4 y \#5 para la primera \#6, \#7, \#8, \#9, \#10 para la segunda y \#11, \#12, \#13, \#14 para la tercera (todas las medidas corresponden a Kent 1982)

Recinto 67 (R67).Este recinto fue excavado completamente computándose un $\mathrm{NSP}=170$. De este total se identificó a nivel taxonómico al 38,82\% de la muestra. Como Camelidae se identificó al 10,58\% lográndose reconocer un elemento perteneciente a Lama guanicoe y dos a Lama glama. El primero corresponde a un calcáneo completo y su identificación se logró a partir de las medidas correspondientes a las variables 201,202, 203, 204, 209 y 214 de Kent (1982). Como Lama glama se registraron un carpo ulnar (CPU) y un carpo primero (CPF) con las medidas L, A y $\mathrm{P}$ (Izeta 2002 y Anexo 2 de esta Tesis).

\begin{tabular}{lcr} 
Tabla 7.21. Composición del conjunto faunístico del Recinto 67. \\
\hline \multicolumn{1}{c}{ Taxón } & Tamaño Corporal & Total NSP \\
AVE & 1 & 1 \\
Chaetophractus vellerosus & 2 & 12 \\
Rodentia & 2 & 1 \\
Ctenomys sp. & 1 & 1 \\
Microcavia sp. & 1 & 1 \\
Artiodactyla & 4 & 32 \\
Lama sp. & 4 & 15 \\
Lama guanicoe & 4 & 1 \\
Lama glama & 4 & 2 \\
$\quad$ Subtotal Identificados & & 66 \\
$\quad$ No identificable & 1 & 2 \\
$\quad$ No identificable & $3-4$ & 3 \\
$\quad$ No identificable & 4 & 94 \\
No identificable & 9 & 5 \\
Subtotal No identificables & & 104 \\
& &
\end{tabular}


La biodiversidad observada es prácticamente la misma que para el recinto 63A; aquí solo se agrega la presencia de un ave. El conjunto de artiodáctilos junto con el de camélidos es el que esta representado en mayor proporción. Específicamente el conjunto de camélidos abarca el 10,58\% de la muestra.

Nivel de ocupación de los recintos $R 63 A$ y $R 67$. Con respecto a la meteorización observada en el conjunto se puede apreciar en la Tabla 7.22 y la Figura 7.56 que son los estadios más bajos ( 1 y 2 ) los que se presentan en mayor proporción, y que todos los tamaños corporales se comportan de un modo similar. Portes pequeños y grandes se encuentran, en general, igualmente meteorizados, por lo que podría haberse depositado penecontemporáneamente o con poca diferencia temporal en su ingreso al registro arqueológico

Tabla 7.22. Meteorización del conjunto faunístico del Núcleo F. Loma Alta

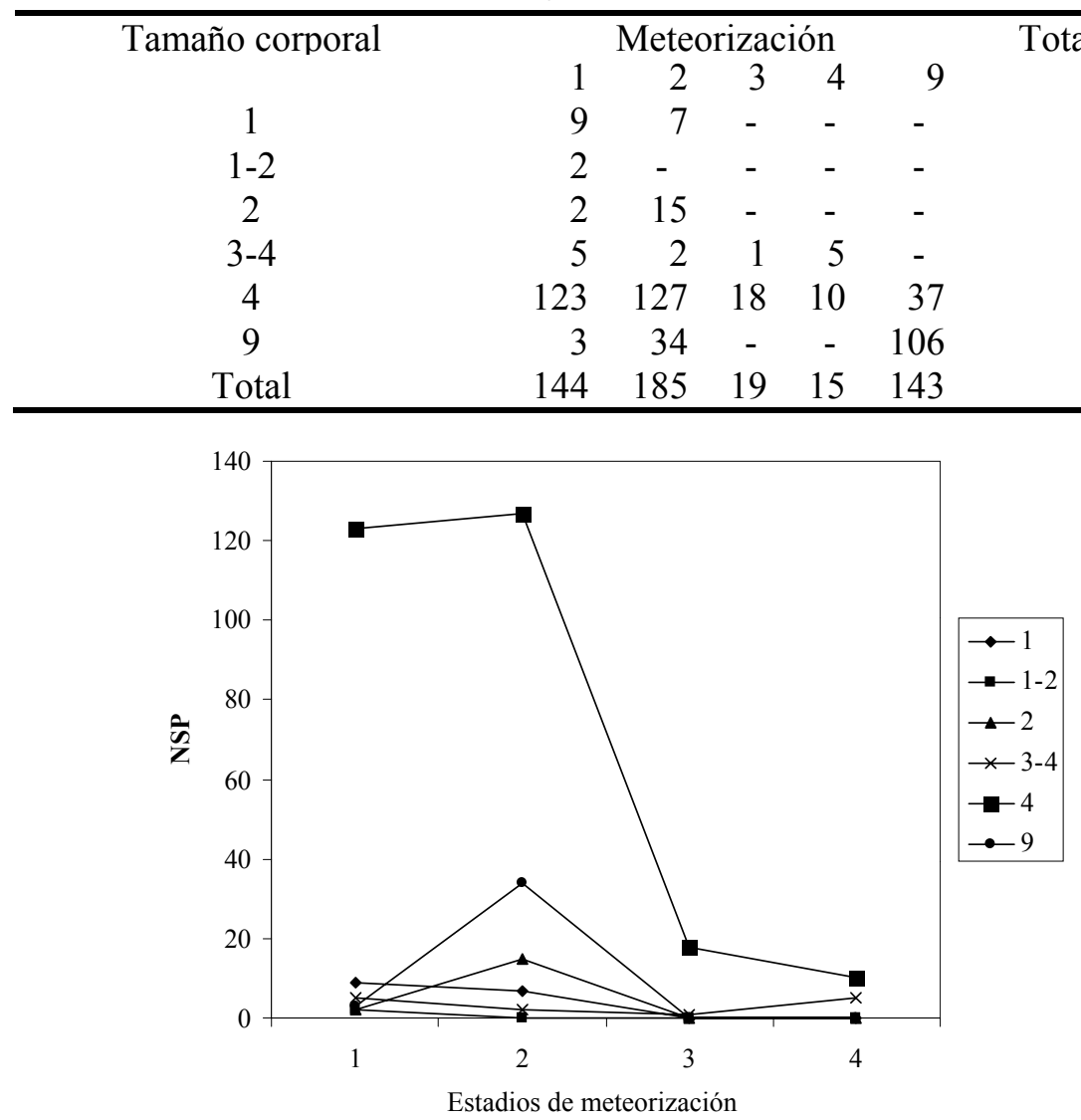

Figura 7.56. Estadios de meteorización según tamaño corporal. Núcleo F. Loma Alta 
En cuanto a la acción de carnívoros y roedores sobre el conjunto se observa en la Tabla 7.23 que solo un $2,17 \%$ de la muestra ofrece señales de haber sido afectado por ellos, razón por la cual pensamos que su acción habría sido mínima.

Tabla 7.23. Modificaciones por roedores y carnívoros. Núcleo F. Loma Alta

\begin{tabular}{cccccr}
\hline $\begin{array}{c}\text { Tamaño } \\
\text { corporal }\end{array}$ & $\begin{array}{c}\text { Sin } \\
\text { modificaciones }\end{array}$ & $\begin{array}{c}\text { Daño } \\
\text { ligero por } \\
\text { roedor }\end{array}$ & $\begin{array}{c}\text { Mordisqueo de } \\
\text { carnívoro }\end{array}$ & $\begin{array}{c}\text { Posible mordisqueo } \\
\text { de carnívoro }\end{array}$ & $\begin{array}{l}\text { Total } \\
\text { general }\end{array}$ \\
1 & 15 & 1 & - & - & 16 \\
$1-2$ & 2 & - & - & - & 2 \\
2 & 17 & - & - & - & 17 \\
$3-4$ & 13 & - & - & - & 13 \\
4 & 305 & 8 & 1 & - & 315 \\
9 & 143 & - & - & 1 & 506 \\
Total general & 495 & 9 & 1 & - & 506 \\
\hline
\end{tabular}

En conjunción, estos dos análisis, sugieren que la integridad de los desechos óseos, desde el momento de su depositación hasta su recuperación arqueológica, se ha mantenido sin demasiadas alteraciones.

\subsubsection{Análisis del subconjunto de camélidos.}

El subconjunto de Camelidae de los niveles de ocupación de R63A y R67 está compuesto por un NISP $=52$, correspondiendo 45 a Lama sp., 2 a Lama guanicoe y 5 a Lama glama (Tabla 7.24).

Tabla 7.24. Composición del conjunto total de camélidos. Núcleo F. Loma Alta

\begin{tabular}{ccccc}
\hline Elemento & L. guanicoe & L. glama & Lama sp. & NISP \\
CRN & - & - & 3 & 3 \\
TFR & - & - & 8 & 8 \\
AT & - & - & 1 & 1 \\
CE & - & - & 1 & 1 \\
TH & - & - & 1 & 1 \\
VT & - & - & 1 & 1 \\
SN & - & - & 1 & 1 \\
& & - & & \\
HM & - & - & 3 & 3 \\
RDU & - & - & 2 & 2 \\
CPA & - & - & 1 & 1 \\
CPF & - & 1 & 1 & 2 \\
CPS & - & - & 1 & 1 \\
CPT & - & - & 1 & 1 \\
CPU & - & 1 & - & 1 \\
MC & - & - & 1 & 1 \\
FM & - & - & 1 & 1 \\
\hline
\end{tabular}




\begin{tabular}{lllcr} 
& & \multicolumn{3}{c}{ Continuación de Tabla 7.24} \\
\hline MT & - & - & 1 & 1 \\
AS & - & - & 1 & 1 \\
CL & 1 & - & - & 1 \\
& & - & 5 & 5 \\
MP & - & 1 & 7 & 9 \\
PHF & 1 & 1 & 3 & 4 \\
PHS & - & 1 & 1 & 2 \\
PHT & - & 5 & 45 & 52 \\
Total & 2 & &
\end{tabular}

\subsubsection{Camélidos adultos}

Este subconjunto está compuesto por un NISP $=46$ (Tabla 7.26) lo que representa un $88,5 \%$ del total de la muestra de camélidos.

\subsubsection{1.a. Supervivencia del material óseo mediada por la densidad ósea}

Podemos observar en los resultados de este análisis que tres elementos presentan correlaciones positivas, uno presenta correlación positiva y uno no presenta correlación. El elemento radioulna es el único que presenta una correlación positiva estadísticamente significativa aunque dado el contexto y la asociación con otros elementos óseos que no presentan esta característica podría explicarse más por una cuestión de patrones de explotación o de descarte de este hueso que por la acción diferencial de la densidad ósea. En tanto para el total de la muestra no existiría correlación entre la densidad ósea y las unidades anatómicas representadas. Para este conjunto la densidad ósea en general no sería un factor para su conformación.

Tabla 7.25. Correlación entre el \%MAU y la densidad ósea.

\begin{tabular}{cccc}
\hline Elemento & Rank & $r_{\mathrm{s}}$ & $p$ \\
Húmero & 5 &, 632 &, 126 \\
Radioulna & 6 &, 828 &, $021^{*}$ \\
Metacarpo & 4 &,- 774 &, 113 \\
Fémur & 5 &, 000 &, 500 \\
Metatarso & 4 &, 774 &, 113 \\
Arqueofauna & 29 &, 000 &, 499 \\
\hline \multicolumn{4}{r}{$*$ Significativa $\mathrm{p}>0.05$}
\end{tabular}

\subsubsection{1.b. Número Mínimo de Elementos (MNE)}

\section{Cráneo (CRN)}


No se halló ningún elemento completo identificándose las siguientes zonas diagnósticas: arco zigomático y petroso del temporal. Sobre el arco zigomático se construyó el MNE obteniéndose un número mínimo de elementos igual a 2.

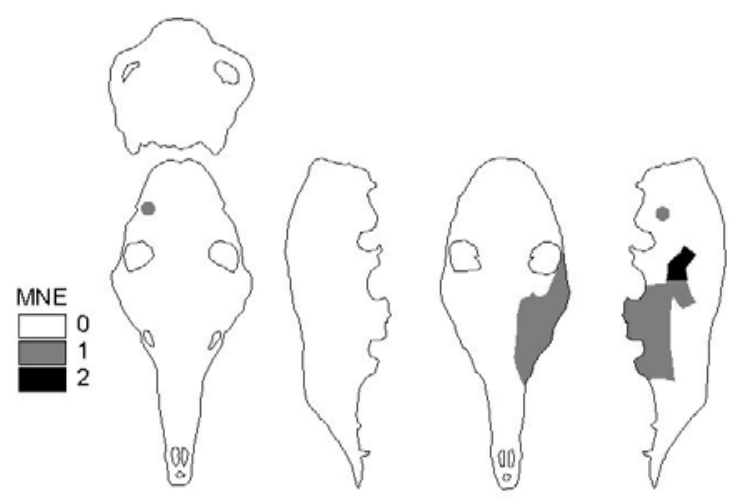

Figura 7.57. MNE Cráneo

Atlas (AT)

Las zonas diagnósticas identificadas para este elemento corresponden a una cavidad articular caudal ofreciendo un valor de MNE igual a 1.

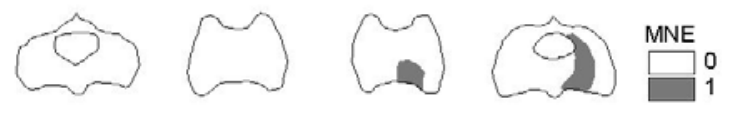

Figura 7.58. MNE Atlas

Cervicales 3 a 7 (CE 3-7)

Sólo pudo identificarse un espécimen a esta categoría anatómica a través de la descripción de una porción distal del cuerpo vertebral. Por ello el MNE obtenido corresponde a 1 elemento.

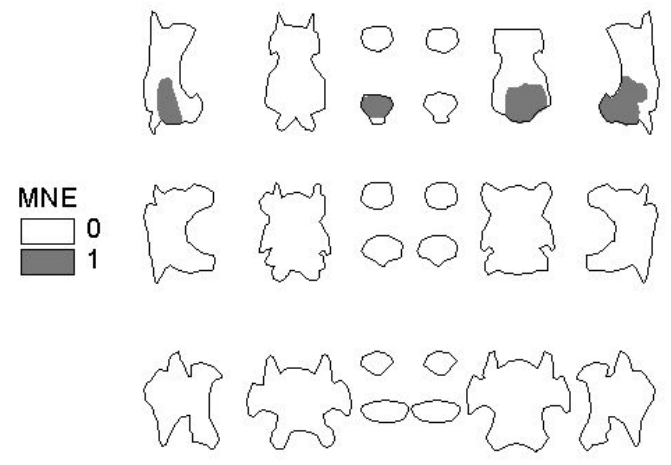

Figura 7.59. MNE Cervicales 3 a 7

Torácicas 1-14 (TH 1-14)

Representadas por un solo fragmento lo que arroja un MNE igual a 1. 


\section{Esternón $(S N)$}

Al igual que las vértebras torácicas sólo se pudo identificar un solo espécimen asignable al esternón, obteniéndose un MNE igual a 1.

\section{Húmero (HM)}

Este elemento se encuentra representado por dos fragmentos de epífisis distal y un agujero nutricio posterolateral. Una de las epífisis distales fue determinada para el lado izquierdo en tanto que para el derecho lo fueron los otros dos especímenes. Esto nos ofrece como resultado 1 elemento para cada lado y 2 en total.

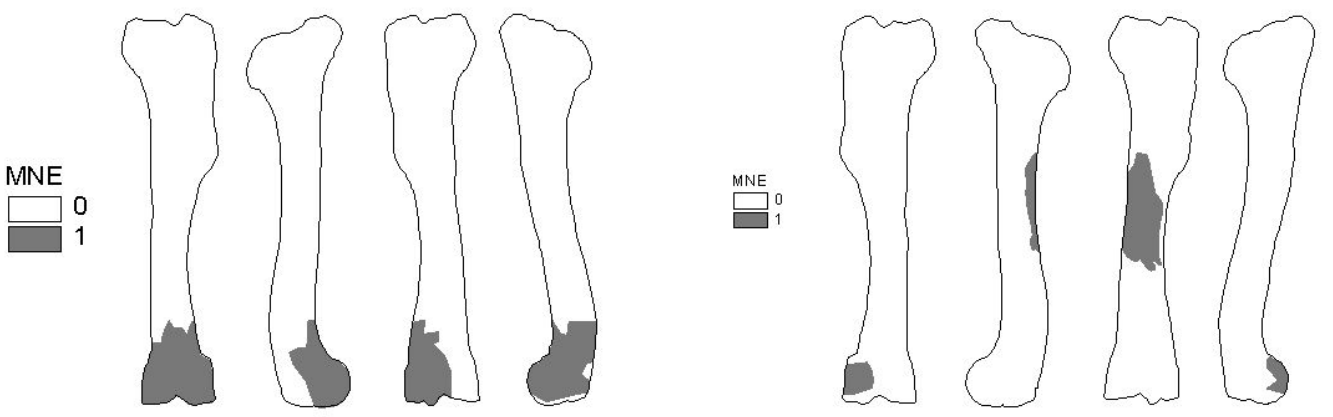

Figura 7.60. MNE Húmero izquierdo y derecho

Radioulna (RDU)

Se identificaron dos especímenes correspondientes al elemento derecho. Las zonas diagnósticas localizadas fueron un fragmento del proceso anconeal y un fragmento de diáfisis posterolateral. La suma de estos dos especímenes da un MNE total igual a 1 elemento.
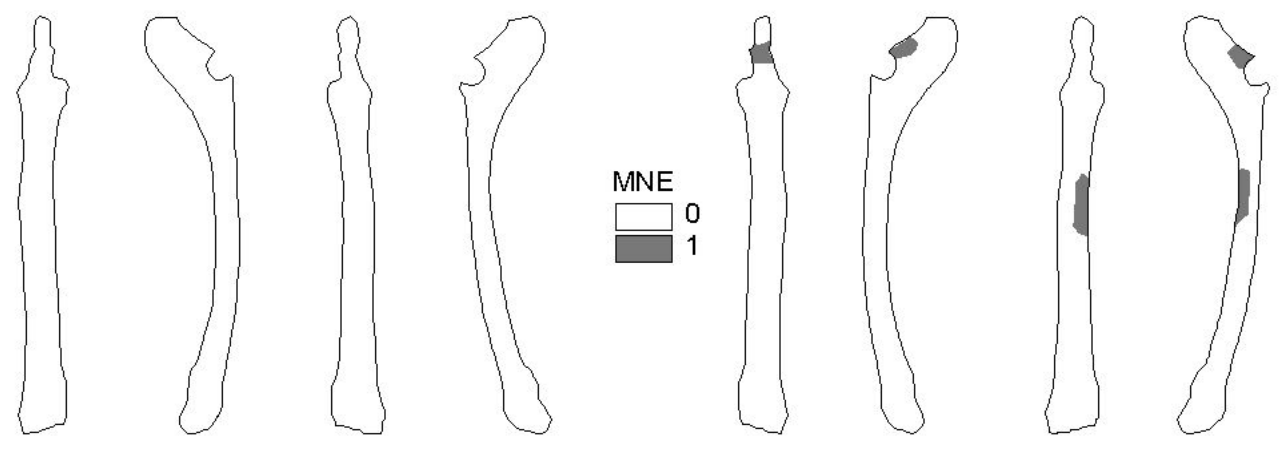

Figura 7.61. MNE Radioulna izquierda y derecha

\section{Carpo accesorio (CPA)}

Se asignó un elemento al lado izquierdo. Este es el único de los carpianos que se presentó fragmentado. El MNE es igual a 1. 
Carpo cuarto (CPF)

Se identificaron dos elementos correspondiendo un elemento a cada lado. El MNE entonces es de 1 elemento para el lado izquierdo y 1 para el lado derecho. Ambos se hallaron completos.

Carpo segundo (CPS)

Se asignó un elemento al lado izquierdo. El MNE es igual a 1. Hallado completo.

Carpo tercero (CPT)

Se asignó un elemento al lado derecho. El MNE es igual a 1. Recuperado completo.

Carpo Ulnar (CPU)

Se asignó un elemento al lado derecho. El MNE es igual a 1. Recuperado completo.

Metacarpo $(M C)$

Para este elemento sólo se asignó un espécimen al lado derecho correspondiendo a la porción medial de la epífisis proximal. El MNE calculado para el elemento derecho es igual a 1.
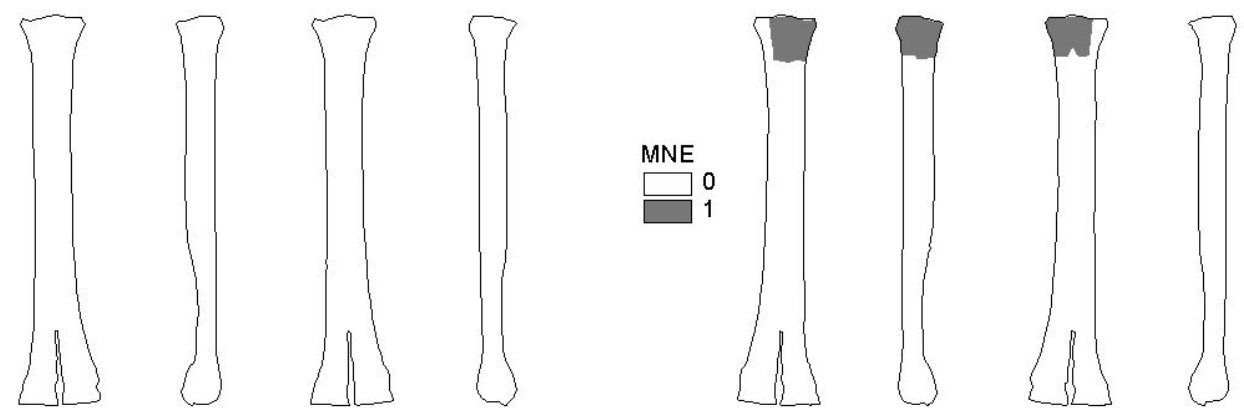

Figura 7.62. MNE Metacarpo izquierdo y derecho

Fémur (FM)

La zona diagnóstica identificada para el único fragmento de fémur hallado corresponde al agujero nutricio posterolateral del elemento izquierdo, calculándose a partir de él un MNE igual a 1. 


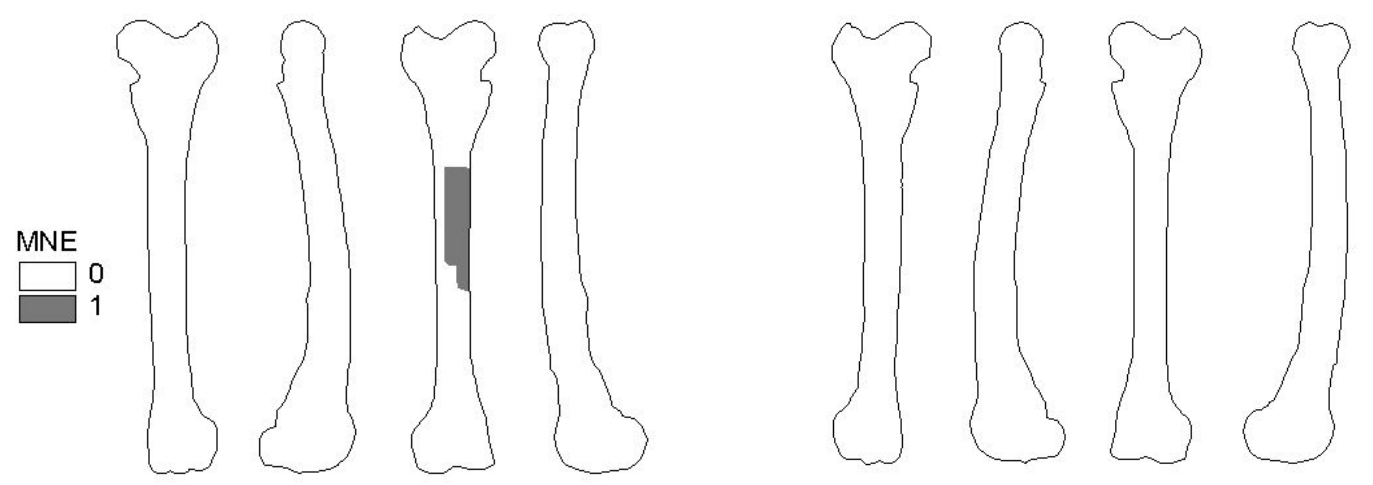

Figura 7.63. MNE Fémur izquierdo y derecho

Astrágalo (AS)

Se determinó un espécimen perteneciente a la porción medial de un elemento izquierdo. MNE igual a 1.
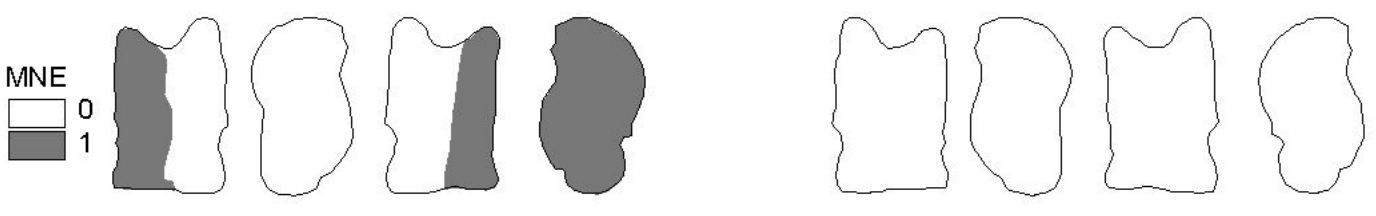

Figura 7.64. MNE Astrágalo izquierdo y derecho

\section{Calcáneo (CL)}

Se halló completo un calcáneo derecho, en tanto que no se identificó la presencia de ningún fragmento del elemento izquierdo. Esto resulta en un MNE igual a 1 para el elemento derecho.
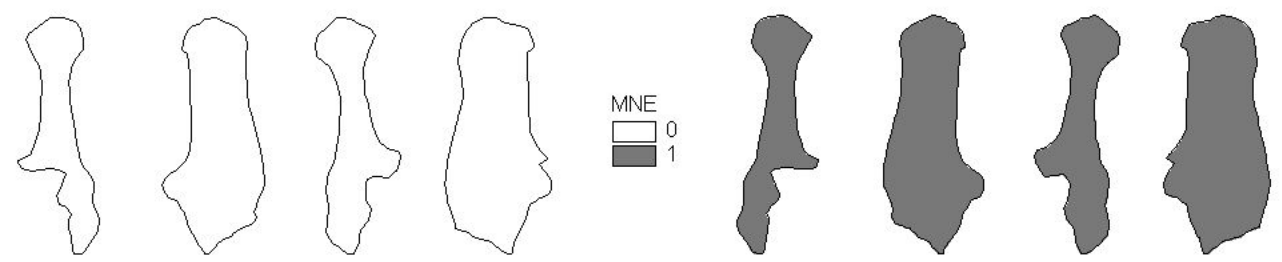

Figura 7.65. MNE Calcáneo izquierdo y derecho

Metatarso (MT)

El elemento derecho presenta un solo espécimen correspondiente a la porción caudal de la epífisis proximal, obteniéndose un MNE igual a 1. 


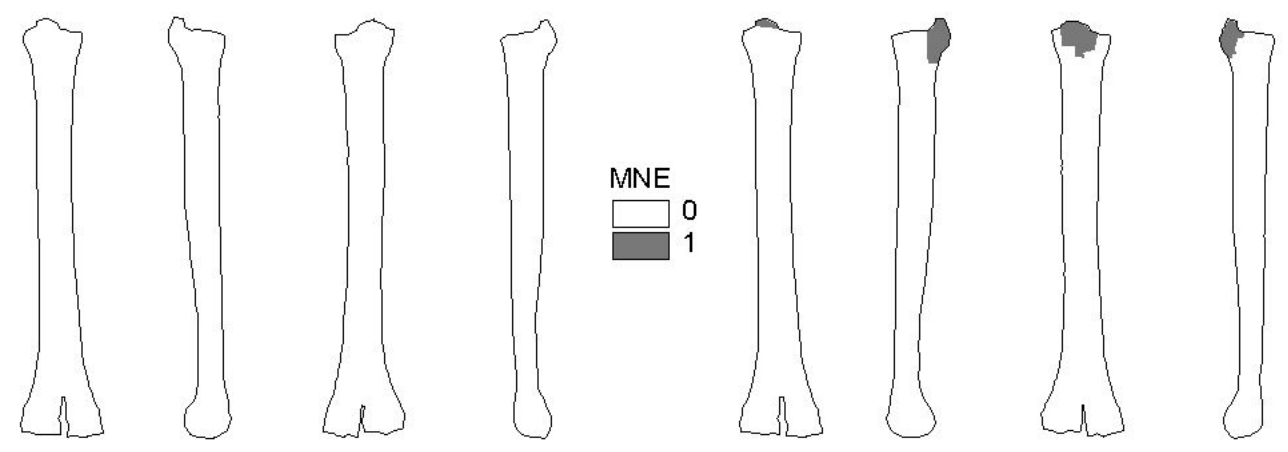

Figura 7.66. MNE Metatarso izquierdo y derecho

\section{Metapodio (MP)}

El MNE para este elemento es igual a 1 y se calculó mediante la identificación de una porción de un cóndilo distal y de un fragmento de diáfisis anterior.

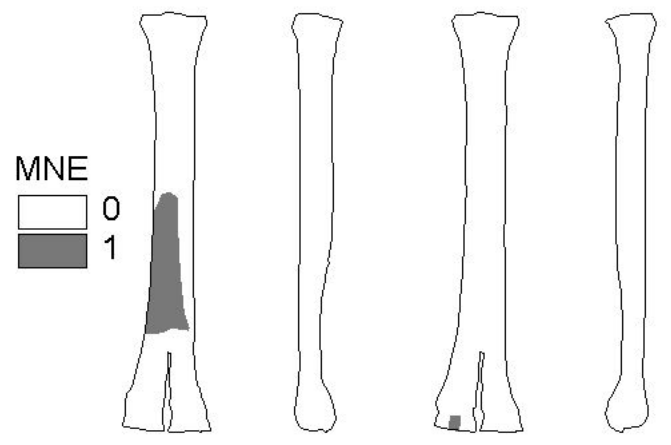

Figura 7.67. MNE Metapodio general

Falange proximal general (PHF)

Este hueso presentó dos elementos completos, un fragmento de epífisis proximal y cinco especímenes de la porción distal. A partir de ello se calculó un MNE igual a 5 elementos.

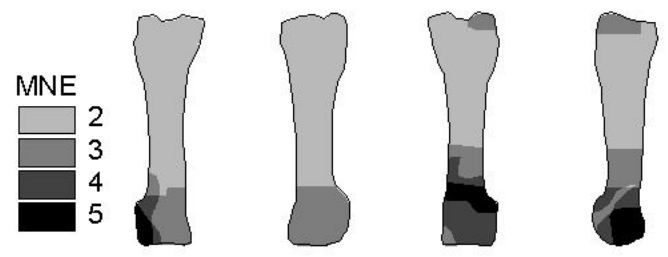

Figura 7.68. MNE Falange proximal general

Falange medial (PHS)

Para este elemento se identificaron dos elementos completos. MNE es igual a 2. 


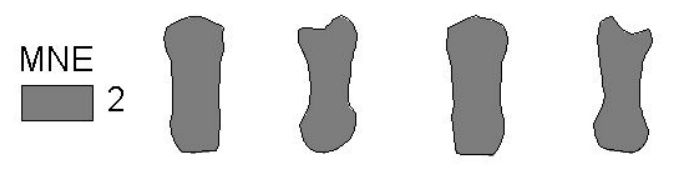

Figura 7.69. MNE Falange medial

Falange distal (PHT)

A partir del registro de un elemento completo y otro fragmentado se construyó un MNE igual a 2.
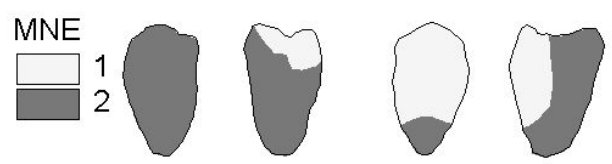

Figura 7.70. MNE Falange distal

Con los resultados obtenidos a partir del cálculo del MNE se confeccionó una tabla (7.26). En ella se incluyó además el cómputo del MNI, el MAU y el \%MAU del subconjunto de camélidos adultos.

Tabla 7.26. Abundancia relativa de partes esqueletarias expresadas como NISP, MNE comprehensivo, MAU y \%MAU.

\begin{tabular}{cccccccrr}
\hline Elemento & NISP & I & D & S/D & MNE & MNI & MAU & \%MAU \\
CRN & 3 & - & 2 & - & 2 & 2 & 2.00 & 100.00 \\
TFR & 8 & - & - & 8 & - & - & - & 0.00 \\
AT & 1 & 1 & - & - & 1 & 1 & 1.00 & 50.00 \\
CE & 1 & - & - & 1 & 1 & 1 & 0.20 & 10.00 \\
TH & 1 & - & - & 1 & 1 & 1 & 0.07 & 3.57 \\
VT & 1 & - & - & 1 & 1 & 1 & - & 0.00 \\
SN & 1 & - & - & 1 & 1 & 1 & 0.50 & 25.00 \\
HM & 3 & 1 & 1 & - & 2 & 1 & 1.00 & 50.00 \\
RDU & 2 & - & 1 & - & 1 & 1 & 0.50 & 25.00 \\
CPA & 1 & 1 & - & - & 1 & 1 & 0.50 & 25.00 \\
CPF & 2 & 1 & 1 & - & 2 & 1 & 0.50 & 25.00 \\
CPS & 1 & 1 & - & - & 1 & 1 & 0.50 & 25.00 \\
CPT & 1 & - & 1 & - & 1 & 1 & 0.50 & 25.00 \\
CPU & 1 & - & 1 & - & 1 & 1 & 0.50 & 25.00 \\
MC & 1 & - & 1 & - & 1 & 1 & 0.50 & 25.00 \\
FM & 1 & 1 & - & - & 1 & 1 & 0.50 & 25.00 \\
AS & 1 & 1 & - & - & 1 & 1 & 0.50 & 25.00 \\
CL & 1 & - & 1 & - & 1 & 1 & 0.50 & 25.00 \\
MT & 1 & - & 1 & - & 1 & 1 & 0.50 & 25.00 \\
MP & 2 & - & - & 1 & 1 & 1 & 0.25 & 12.50 \\
PHF & 8 & - & - & 5 & 5 & 1 & 0.63 & 31.25 \\
PHS & 2 & - & - & 2 & 2 & 1 & 0.25 & 12.50 \\
PHT & 2 & - & - & 2 & 2 & 1 & 0.25 & 12.50 \\
Total & 46 & & & & & & \\
\hline \multicolumn{7}{c}{ D $=$ derecho, I = izquierdo, S/D = axial o sin datos }
\end{tabular}




\subsubsection{1.c. Número Mínimo de Individuos (MNI)}

Por lo que se observó tanto en las figuras precedentes (7.57 a 7.70) como en la Tabla 7.26, el MNI de este subconjunto es igual a 2. Este número fue formulado a partir del cálculo de un MNE de 2 para el cráneo. Este resultado junto con la determinación por medio de la osteometría de un elemento de la especie L. guanicoe y otra de L. glama estaría evidenciando la presencia de al menos dos animales adultos.

\subsubsection{1.d. Unidades anatómicas representadas (MAU)}

En cuanto a las partes anatómicas representadas en este conjunto se puede apreciar en la Figura 7.71 que la proporción de partes esqueletarias presentes es uniforme.

Para el esqueleto axial los huesos más representados son el cráneo y el atlas, seguido por el esternón y las vértebras. Este último elemento se manifiesta con una frecuencia baja en relación a los anteriores.

Para el esqueleto apendicular el hueso mas representado es el húmero, dándose el resto en la misma proporción. En el caso de los elementos del pie salvo el caso de la falange proximal, el resto de las unidades anatómicas están escasamente representadas.

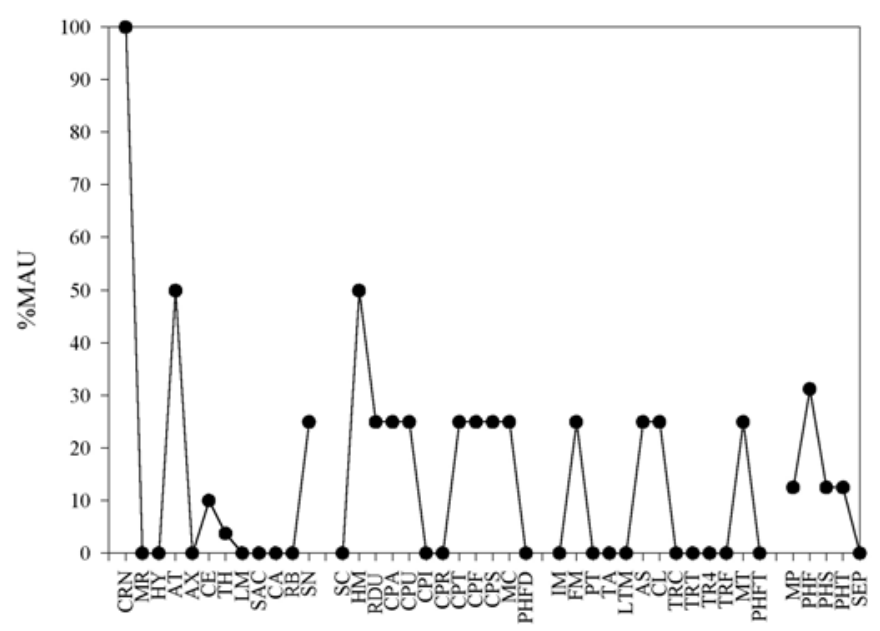

Figura 7.71. Abundancia relativa de elementos esqueletarios.

Teniendo en cuenta esta representación de unidades anatómicas se procedió al análisis de estas frecuencias en relación a la anatomía económica de los camélidos adultos (Figura $7.72 \mathrm{a}, \mathrm{b}$ y c) 

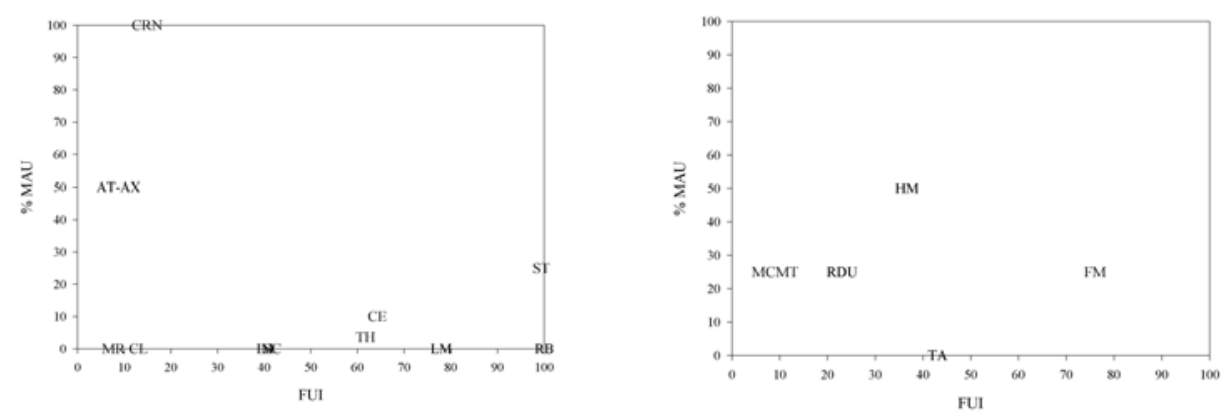

$\mathrm{b}$

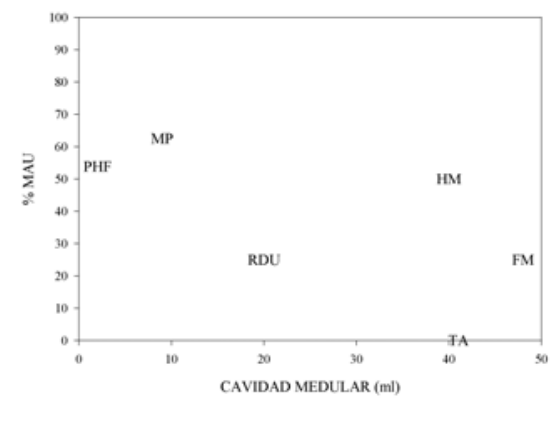

Figura 7.72. a) Relación \%MAU VS FUI huesos "no-largos"; b) Relación \%MAU VS FUI huesos "largos"; c) Relación \%MAU VS Cavidad Medular.

Para el primer caso representado en la Figura 7.72.a los elementos "no-largos" presentan gráficamente una tendencia similar a la planteada para la curva de utilidad inversa, repitiendo de algún modo el patrón observado para camélidos adultos del Núcleo E de Loma Alta. No obstante si realizamos un estudio de correlación entre los resultados de la proporción de unidades anatómicas representadas con el índice de utilidad de carne se observó como resultado una correlación negativa débil sin significancia estadística $\left(r_{s}-.2521\right.$ p .241), resultado que difiere notablemente al obtenido para el caso del Núcleo E.

Para los elemento "largos" se ve que todos están representados independientemente del índice de utilidad lo cual se expresa como una correlación negativa débil sin significancia estadística $\left(r_{s}-.1690\right.$ p .374). Por último la relación entre el \%MAU y los valores de cavidad medular muestra una correlación negativa estadísticamente significativa $\left(r_{s}-.7537\right.$ p.042)

Evaluando los resultados obtenidos mediante la aplicación de estos análisis podemos ver que el conjunto presenta evidencias de descarte de partes que poseen un bajo índice de utilidad de carne y de médula ósea. Lo que esto significa en términos 
económicos será discutido más adelante cuando se comparen estos resultados con los modelos generales. Además si analizamos los valores obtenidos podemos advertir que el resultado corresponde a lo que Lyman (1994b Figura 7.13) define como "clase 5" de las "combinaciones posibles de los coeficientes de correlación obtenidos entre el \%MAU, la densidad ósea y el índice de utilidad de carne". Por ello el patrón no podría definirse por la destrucción diferencial o el transporte selectivo, resultados que nos parecen pertinentes dado el contexto arqueológico del que proceden estos restos.

\subsubsection{1.e. Fragmentación del subconjunto}

Siguiendo la metodología planteada para los conjuntos ya analizados se procedió a verificar el largo total de los especímenes y elementos identificados según su inclusión en distintos módulos de tamaño.

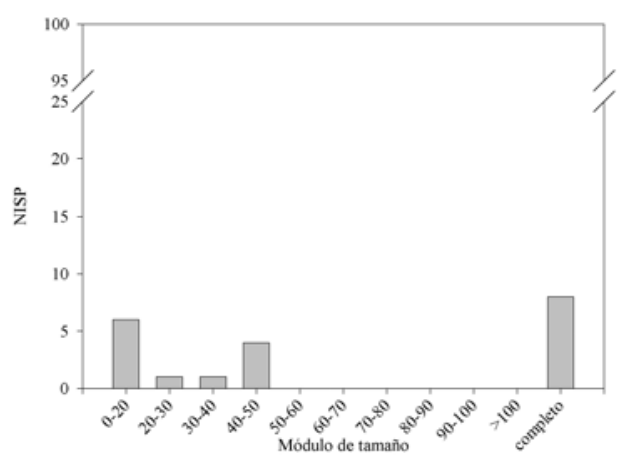

Figura 7.73. Módulos de tamaño expresado en NISP para especímenes y elementos del subconjunto adulto de camélidos

Como se puede observar en la Figura 7.73 en este caso son los elementos completos los que se presentan en mayor frecuencia. El resto de la muestra se comporta de modo similar a los del conjunto de camélidos del Núcleo E, tanto el de los adultos como el de los subadultos.

\section{Esqueleto axial}

Si bien la cantidad de especímenes identificados para esta parte esqueletal básica es baja, el porcentaje de área preservado se presenta de modo similar. El área representada por los fragmentos no supera en todos los casos el $10 \%$ del total de superficie de cada elemento. 


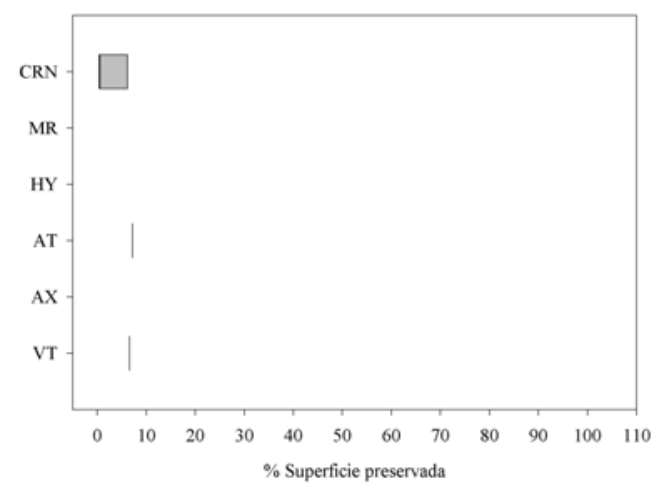

Figura 7.74. Fragmentación de elementos del esqueleto axial.

\section{Esqueleto apendicular delantero}

Para esta parte esqueletal se vuelve a repetir un patrón ya observado en otras muestras. Los elementos de mayor tamaño se encuentran fragmentados y los especímenes presentan áreas preservadas con valores muy bajos. Por otro lado los elementos del carpo se encuentran en su gran mayoría completos (Figura 7.75)

En el caso del húmero en el que se identificaron especímenes para ambos lados, se puede observar que la superficie preservada mantiene el mismo valor independientemente de la lateralidad.
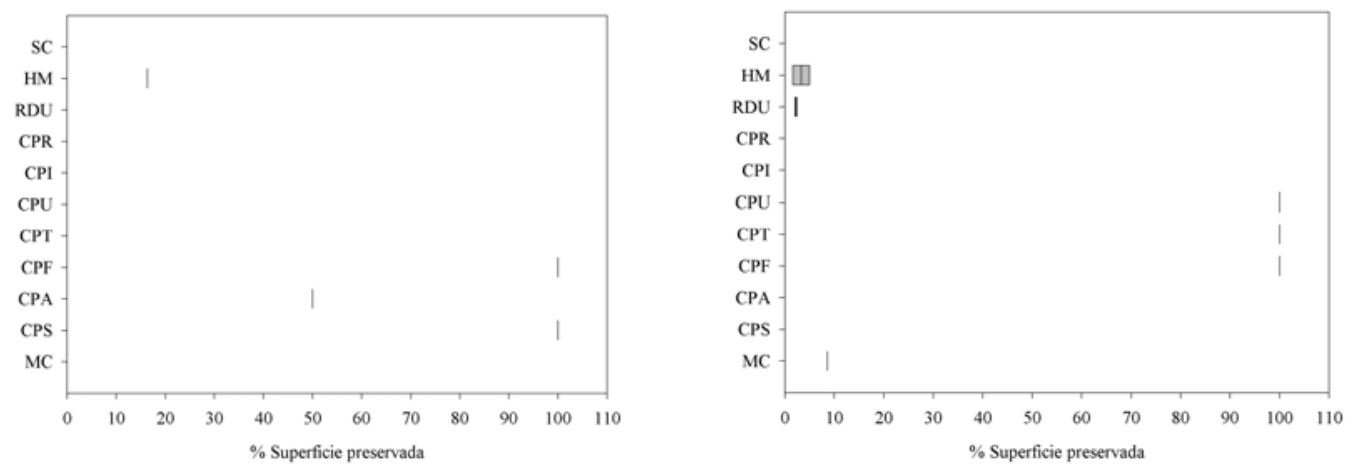

Figura 7.75. Fragmentación esqueleto apendicular delantero (izquierdo y derecho)

\section{Esqueleto apendicular trasero}

Para el caso de esta parte esqueletal se repite lo observado precedentemente: alta fragmentación en los elementos más grandes y muy baja fragmentación a nula en los elementos del tarso. 

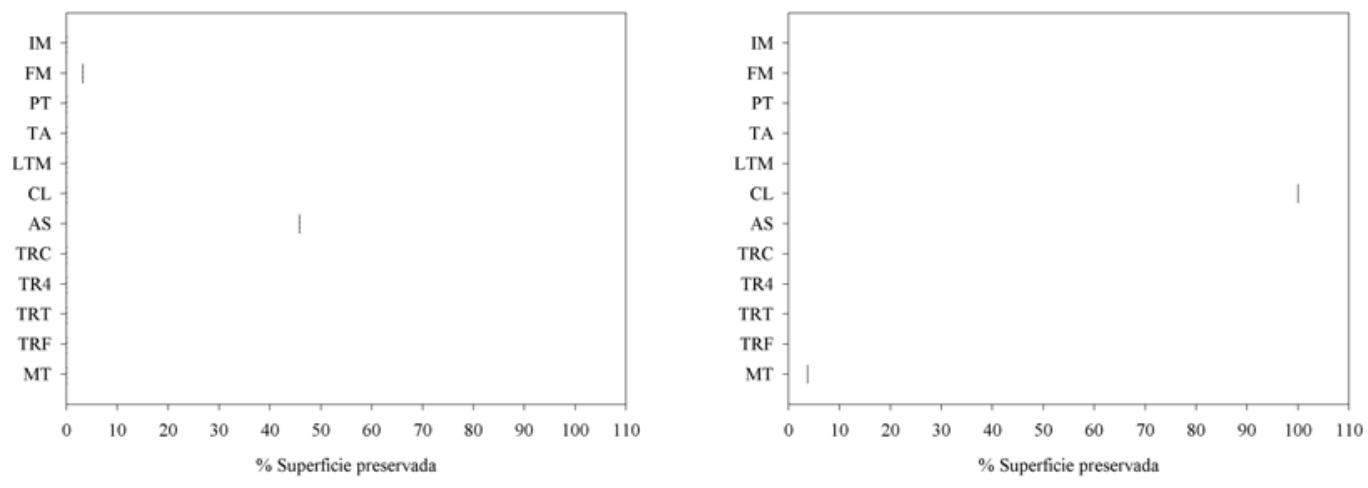

Figura 7.76. Fragmentación esqueleto apendicular trasero (izquierdo y derecho)

Por último la Figura 7.77 muestra el tipo de fracturas presentes en el conjunto. Las mayores frecuencias se observan en los especímenes en el que el estado en el cual se formó la fractura es el seco seguido por las efectuadas en estado fresco.

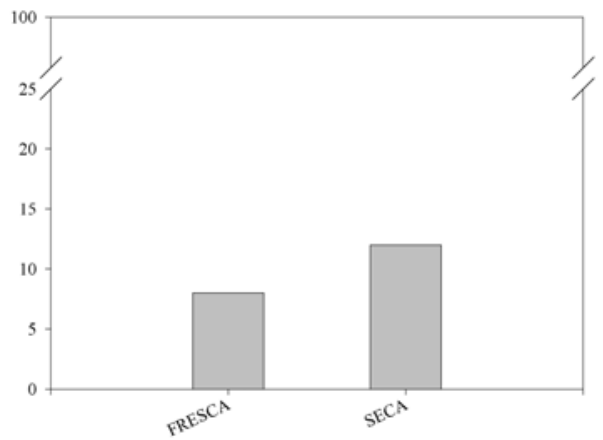

Figura 7.77. Cantidad (NISP) de especímenes y elementos del subconjunto adulto de camélidos según tipo de fractura.

\subsubsection{1.f. Utilización de las carcasas}

De los 31 elementos de camélidos adultos uno solo fue afectado por acción antrópica. Ser trata de una radioulna derecha que presenta un negativo de impacto. Esto podría indicar que estamos ante alguna acción tendiente al procesamiento primario de al menos un animal.

\subsubsection{1.g. Termoalteraciones}

El 13\% de la muestra presentó signos de termoalteración $(n=6)$ sufridos en toda la gama de temperaturas. 
Tabla 7.27. Termoalteración del conjunto de camélidos adultos.

\begin{tabular}{cccccc}
\hline Descripción & Sin alteración & $\begin{array}{c}\text { Oxidación } \\
\text { incompleta/carbonización } \\
\text { marrón claro-negro } \\
\text { (moteado) }\end{array}$ & Carbonizado & Calcinado & Total \\
Color & - & $200{ }^{\circ} \mathrm{C}-300{ }^{\circ} \mathrm{C}$ & $300{ }^{\circ} \mathrm{C}$ & $>500{ }^{\circ} \mathrm{C}$ & \\
Nemperatura & $<200{ }^{\circ} \mathrm{C}$ & 1 & 3 & 2 & 46 \\
\hline
\end{tabular}

Respecto de la relación entre tipo de fractura y tipo de en la Tabla 7.28 se ve que aquellos elementos en los que no se observó termoalteración o un grado bajo de acción del calor (Tipo 4) son los únicos en los cuales pudo identificarse fracturas realizadas en estado fresco. Por otro lado la fractura de tipo seca se presenta tanto en elementos afectados por altas temperaturas como en elementos que no presentan signos de acción del calor, al menos manifestada a través del cambio del color.

Tabla 7.28. Relación entre tipo de termoalteración y tipo de fractura del conjunto de camélidos adultos.

\begin{tabular}{cccc}
\hline Tipo de alteración & Fresca & Seca & Total \\
Sin Alteración & 7 & 8 & 15 \\
Oxidación incompleta & 1 & - & 1 \\
Carbonizado & - & 2 & 2 \\
Calcinado & - & 2 & 2 \\
Total & 8 & 12 & 20 \\
\hline
\end{tabular}

\subsubsection{Camélidos subadultos}

Está compuesto por un NISP $=6$ (Tabla 7.30), lo que equivale al $11,5 \%$ de la muestra de camélidos. En este subconjunto los elementos identificados corresponden al pie de un animal.

\subsubsection{2.a. Supervivencia del material óseo mediada por la densidad ósea}

Si bien la cantidad de especímenes que representan esta categoría es baja, igualmente ensayaremos aplicar el análisis de correlación entre los valores de densidad ósea y las unidades anatómicas representadas pero como ninguno de los tres elementos posee más de cuatro "scan sites" solo se realizó la apreciación global del conjunto (Morlan 1994) la cual sugiere que habría una correlación positiva débil pero sin significancia estadística. Este resultado estaría mostrando que se han preservado en mayor medida fragmentos que corresponden a valores de densidad altos, aunque de todos modos no permite explicar la presencia de estos elementos en la muestra por medio de este único agente. 
Tabla 7.29. Correlación entre el \%MAU y la densidad ósea.

\begin{tabular}{cccc}
\hline Elemento & Rank & $r_{\mathrm{s}}$ & $p$ \\
Arqueofauna & 29 &, 147 &, 090 \\
\hline
\end{tabular}

7.2.1.2.b. Número Mínimo de Elementos (MNE)

Metapodio (MP)

Para este elemento se identificaron como zonas diagnósticas a los cóndilos tanto mediales como laterales y un fragmento distal de diáfisis. Sobre estos especímenes se construyó un MNE igual a 1.
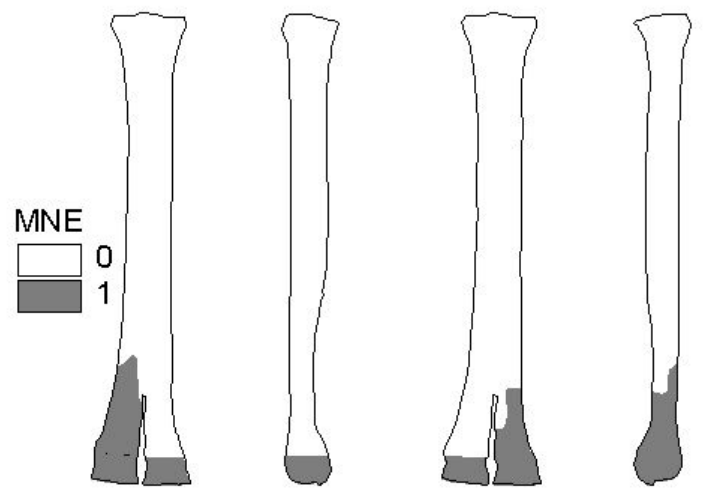

Figura 7.78. MNE Metapodio general

Falange proximal (PHF)

Para este elemento sólo se pudo identificar una diáfisis. Esto nos permite calcular un MNE igual a 1.
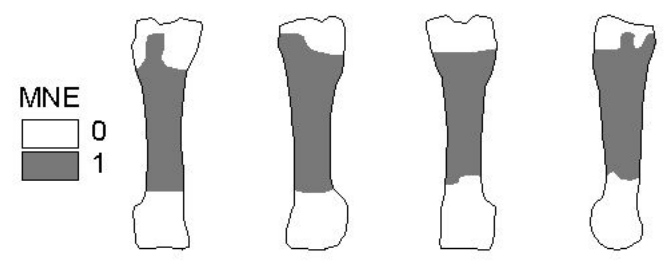

Figura 7.79. MNE Falange proximal general

Falange medial (PHS)

Para este elemento se identificaron una epífisis proximal completa y una diáfisis con su epífisis distal fusionada. Esto nos ofrece un MNE igual a 1.
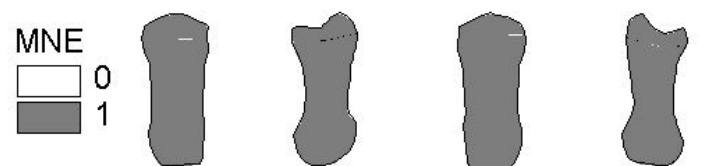

Figura 7.80 MNE Falange medial 
Tabla 7.30. Abundancia relativa de partes esqueletarias expresadas como NISP, MNE comprehensivo, MAU y \%MAU.

\begin{tabular}{crrrrrrrr}
\hline Elemento & NISP & I & D & S/D & MNE & MNI & MAU & \%MAU \\
MP & 3 & - & - & 1 & 1 & 1 & 0.25 & 100 \\
PHF & 1 & - & - & 1 & 1 & 1 & 0.125 & 50 \\
PHS & 2 & - & - & 1 & 1 & 1 & 0.125 & 50 \\
Total & 6 & & & & \\
\hline \multicolumn{7}{c}{ D = derecho, I = izquierdo, S/D = axial o sin datos }
\end{tabular}

$\mathrm{D}=$ derecho, $\mathrm{I}=$ izquierdo, $\mathrm{S} / \mathrm{D}=$ axial o sin datos

\subsubsection{2.c. Número Mínimo de Individuos (MNI)}

El MNI obtenido para el conjunto de camélidos subadultos es de un individuo. Este valor se repite en cada uno de los elementos que integran la muestra.

\subsubsection{2.d. Unidades anatómicas representadas (MAU)}

Los tres elementos que componen este conjunto pertenecen a la porción distal del esqueleto apendicular. Si bien no se han realizado remontajes mecánicos entre los especímenes del conjunto subadulto es posible que estos pertenezcan al mismo miembro.

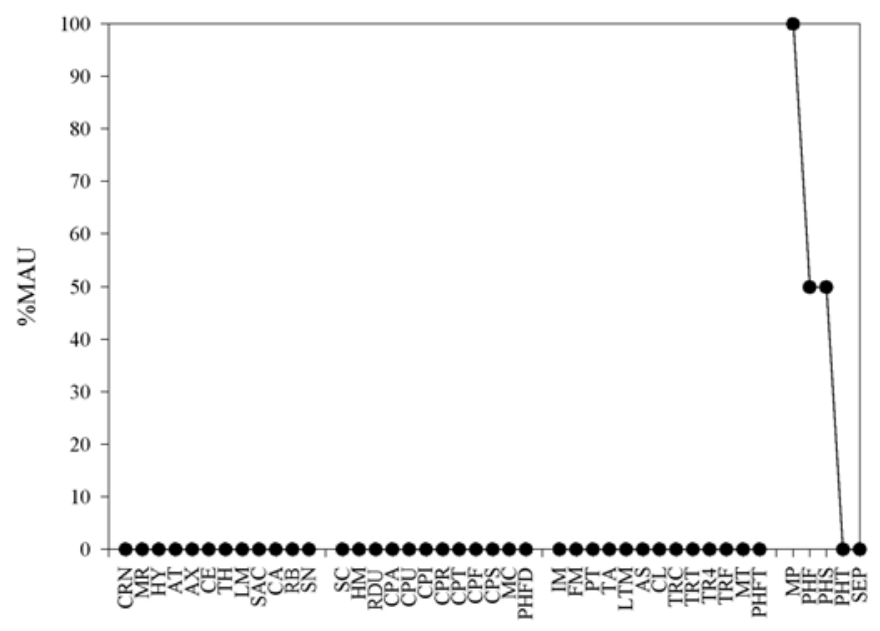

Figura 7.81. Abundancia relativa de elementos esqueletarios.

\subsubsection{2.e. Fragmentación del subconjunto}

De los seis especímenes identificados en esta muestra solo dos se presentan fragmentados. El resto son cóndilos o epífisis y diáfisis que se encuentran sin fusionar y por lo tanto se encuentran sueltas. No obstante para estos últimos especímenes se los trató como si efectivamente pertenecieran al mismo elemento razón por lo cual la 
fragmentación del conjunto es mínima presentándose uno de los fragmentos en el módulo comprendido entro los 30-40 mm y el otro en el módulo de 40-50 mm.

\subsubsection{2.f. Utilización de las carcasas}

No se registraron huellas o marcas que permitan ofrecer datos sobre la utilización de la carcasa de este animal juvenil o de al menos los elementos identificados.

\subsubsection{2.g. Termoalteraciones}

Al igual que las marcas, no se observaron indicios de termoalteración en la muestra.

\subsubsection{Subconjunto no camélido}

El subconjunto está compuesto por un NISP $=454$. Aquí se incluyen taxones de tamaños corporales 1, 2, y 4. En el tamaño corporal 4 se incluyen tanto los cérvidos como los artiodáctilos.

\subsubsection{Marcas de procesamiento y relacionadas con el uso de huesos como artefactos}

Este conjunto esta conformado en mayor frecuencia por especímenes asignados al tamaño corporal 4 e identificados como artiodáctilos. Entre ellos se han identificado marcas y huellas asignables al procesamiento primario y secundario así como al trabajo del hueso con el fin de utilizarlo como instrumento. En la Tabla 7.31 se observa todas las marcas se encuentran en fragmentos de huesos largos (diáfisis) tanto para los especímenes del tamaño corporal 4 como para el que no pudo ser asignado a ninguna categoría (tamaño corporal 9).

Tabla 7.31. Marcas en huesos del conjunto no camélido expresado en NISP.

\begin{tabular}{ccccccc}
\hline Taxón & T. corporal & Elemento & Porción & Formatización & Impacto & Total \\
Artiodactyla & 4 & LB & AST & 1 & - & 1 \\
Artiodactyla & 4 & LB & FK & - & 2 & 2 \\
No identificable & 9 & LB & IFK & - & 2 & 2 \\
Total general & & & & 1 & 4 & 5 \\
\hline
\end{tabular}

7.2.2.2. Termoalteración

Respecto de la termoalteración global del conjunto según la especie o tamaño corporal vemos que solo Chaetophractus vellerosus y Artiodactyla presentan elementos 
o especímenes termoalterados en rangos menores a los $300^{\circ} \mathrm{C}$. Los no identificados de tamaño corporal 1 y 4 también presentan signos de cambio por acción del calor. Para la primera categoría se halló un espécimen carbonizado, en tanto que para la segunda se identificaron un $56 \%$ de la muestra con modificaciones producto de calor.

Tabla 7.32. Termoalteración del conjunto de no camélido.

\begin{tabular}{|c|c|c|c|c|c|c|}
\hline & Descripción & $\begin{array}{c}\text { Sin } \\
\text { alteración }\end{array}$ & $\begin{array}{c}\text { Oxidación } \\
\text { incompleta/carboniza } \\
\text {-ción }\end{array}$ & Carbonizado & Calcinado & \\
\hline & Color & - & $\begin{array}{l}\text { marrón claro-negro } \\
\text { (moteado) }\end{array}$ & negro & gris-blanco & \\
\hline & Temperatura & $<200^{\circ} \mathrm{C}$ & $200{ }^{\circ} \mathrm{C}-300^{\circ} \mathrm{C}$ & $300^{\circ} \mathrm{C}$ & $>500{ }^{\circ} \mathrm{C}$ & \\
\hline Taxón & T. corporal & & & & & \\
\hline AVE & 1 & 3 & - & - & - & 3 \\
\hline C. vellerosus & 2 & 12 & 2 & 1 & - & 15 \\
\hline Rodentia & 1 & 7 & - & - & - & 7 \\
\hline Rodentia & 2 & 1 & - & - & - & 1 \\
\hline Ctenomyidae & 1 & 1 & - & - & - & 1 \\
\hline Microcavia sp. & 1 & 1 & - & - & - & 1 \\
\hline Lagidium sp. & 2 & 1 & - & - & - & 1 \\
\hline Artiodactyla & 4 & 122 & 2 & 8 & 10 & 142 \\
\hline H. antisensis & 4 & 1 & - & - & - & 1 \\
\hline No identificable & 1 & 3 & - & 1 & - & 4 \\
\hline No identificable & $1-2$ & 2 & - & - & - & 2 \\
\hline No identificable & $3-4$ & 9 & - & 4 & - & 13 \\
\hline No identificable & 4 & 52 & 7 & 48 & 13 & 120 \\
\hline No identificable & 9 & 126 & - & 8 & 9 & 143 \\
\hline Total general & & 341 & 11 & 70 & 32 & 454 \\
\hline
\end{tabular}

\subsubsection{Fragmentación del subconjunto de no camélido.}

En los dos primeros tamaños corporales la proporción de elementos completos para todos los taxones presentes es en general mayor que la de los elementos fragmentados. Este patrón no se repite para el tamaño corporal 4 el cual presenta una proporción mayor de especímenes fragmentados, especialmente en las categorías menores, y ningún elemento completo. Este patrón se presenta en todas las categorías asignadas a este tamaño corporal. 


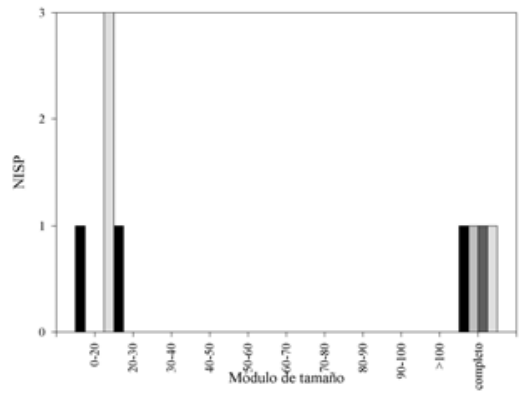

a
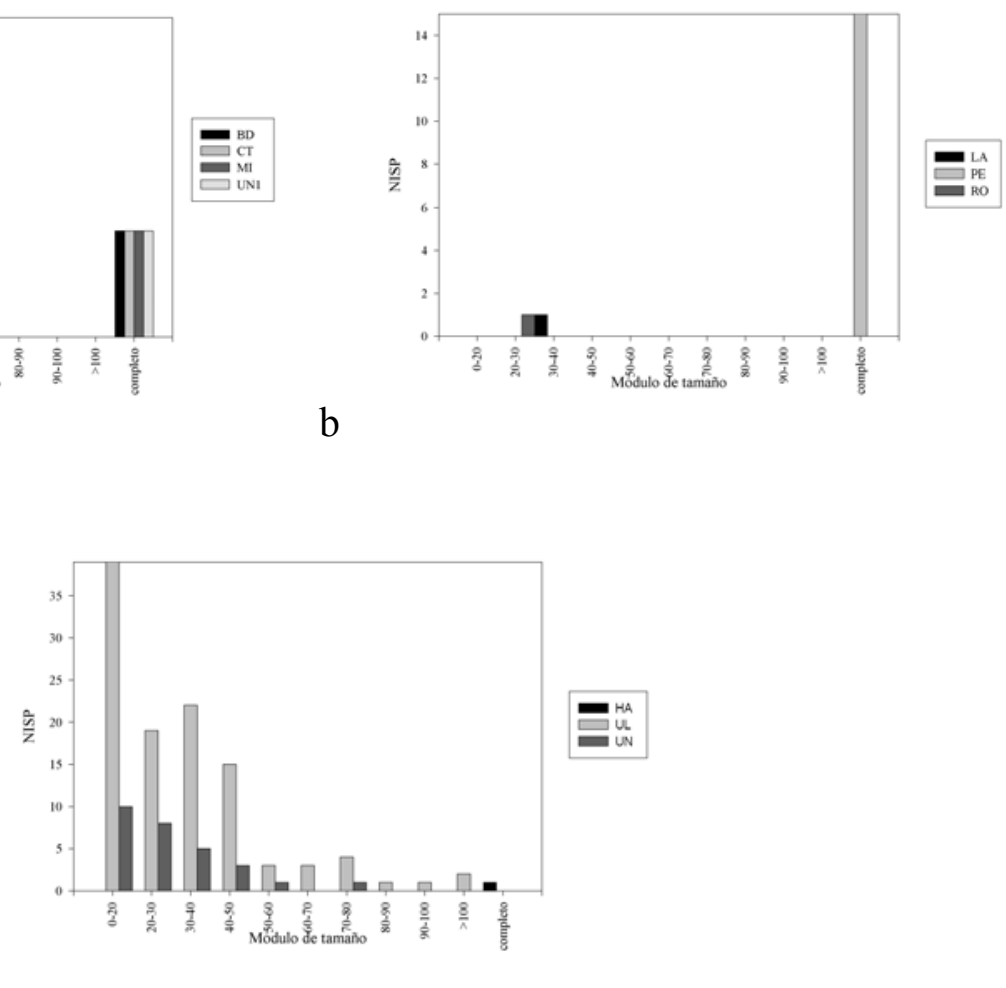

Figura 7.82. Fragmentación del conjunto no camélido expresado en NSP. a) Tamaño corporal 1, b) Tamaño corporal 2 y c) Tamaño corporal 4. 


\subsection{Loma Alta Núcleo G-Análisis faunístico}

La muestra recuperada corresponde a un valor de NSP $=451$, lográndose identificar a nivel taxonómico un 21,60\%. El volumen excavado para el conjunto es de $0,5 \mathrm{~m}^{3}$ resultando en una densidad de huesos de 902 fragmentos por $\mathrm{m}^{3}$.

Recinto 87(R87). Esta estructura fue excavada en su totalidad alcanzando una superficie de excavación aproximadamente $4 \mathrm{~m}^{2}$. Respecto a los otros recintos que conforman este núcleo, R87 posee una mayor densidad de restos óseos por volumen excavado, por lo que no debería descartarse la posibilidad de que haya funcionado como algún tipo de estructura receptora de desechos (basurero).

Del total de este conjunto se identificó a nivel taxonómico a un $8,90 \%$ del total. En esta unidad de excavación se hallaron elementos o especímenes correspondientes a cuatro taxones diferentes de los cuales la frecuencia mayor fue asignada a artiodáctilos y camélidos (Tabla 7.33) correspondiendo a este último taxón un 35,29\% especímenes identificados.

Tabla 7.33. Composición del conjunto faunístico del Recinto 87.

\begin{tabular}{lcr}
\hline \multicolumn{1}{c}{ Taxón } & Tamaño corporal & Total NSP \\
AVE & 1 & 1 \\
Rodentia & 1 & 6 \\
Chaetophractus & 2 & 2 \\
Lama sp. & 4 & 13 \\
Artiodactyla & 4 & 12 \\
$\quad$ & & 34 \\
$\quad$ Subtotal Identificados & 1 & \\
$\quad$ No identificable & 2 & 13 \\
$\quad$ No identificable & $2-3$ & 1 \\
$\quad$ No identificable & $3-4$ & 7 \\
$\quad$ No identificable & 4 & 53 \\
$\quad$ No identificable & & 348 \\
Subtotal No identificables & & \\
& & \\
\hline
\end{tabular}

Para el conjunto se identificaron cinco taxones y cinco tipos de tamaño corporal. Dentro de los elementos y especímenes hallados en este recinto y asignados a Lama $s p$ solo uno presentaba las condiciones para realizar su asignación específica dentro del 
grupo, pero por ser un elemento de la región del carpo no pudo ser atribuida a ninguno de los taxones.

Recinto 88 (R88). De este conjunto se identificó a nivel taxonómico el total de los especímenes recuperados. Corresponden a cinco taxones diferentes de los cuales la frecuencia mayor fue asignada a artiodáctilos (Tabla 7.34).

Tabla 7.34 Composición del conjunto faunístico del Recinto 88.

\begin{tabular}{lcr}
\hline \multicolumn{1}{c}{ Taxón } & Tamaño corporal & Total NSP \\
Chaetophractus vellerosus & 2 & 2 \\
Rodentia & 1 & 1 \\
Artiodactyla & 4 & 21 \\
Lama sp. & 4 & 1 \\
Lama glama & 4 & 1 \\
$\quad$ & & \\
Subtotal Identificados & & 26 \\
& TOTAL & 26 \\
\hline
\end{tabular}

Lama glama fue identificada mediante la comparación de las medidas obtenidas para un maléolo lateral (LTM). Las medidas usadas fueron L, A y P (Izeta 2002 y Anexo 2 de esta Tesis).

Recinto 89 (R89). La identificación taxonómica de los especímenes hallados alcanzó al 93,02\% de la muestra. Se reconocieron camélidos y artiodáctilos del mismo tamaño corporal (4). En cuanto a los no identificables fue hallado solo un fragmento correspondiente al tamaño corporal 1 y dos al tamaño corporal 3-4, el que probablemente deba ser reasignado al tamaño 4.

Para el conjunto se identificaron dos taxones y dos tipos de tamaño corporal.

Tabla 7.35. Composición del conjunto faunístico del Recinto 89.

\begin{tabular}{ccr} 
Taxón & Tamaño corporal & Total NSP \\
Artiodactyla & 4 & 38 \\
Lama $s p$. & 4 & 2 \\
Subtotal Identificados & & 40 \\
No identificable & $1-2$ & 1 \\
No identificable & $3-4$ & 2 \\
Subtotal No identificables & & 3 \\
& & 43 \\
\hline
\end{tabular}


Análisis del nivel de ocupación R87, R88 y R89. Dentro de los especímenes y elementos a los que se les pudo asignar algún estadio de meteorización la gran mayoría del conjunto $(54,54 \%)$ presenta estadio de meteorización 1. El estadio 2 está representado por el 40,66\% del conjunto. Estos dos representan en conjunto el 95,20\% del conjunto.

Tabla 7.36. Meteorización del conjunto faunístico del Núcleo G. Loma Alta

\begin{tabular}{crrrrrr}
\hline Tamaño corporal & \multicolumn{9}{c}{ Meteorización } & \multicolumn{1}{r}{ Total NSP } \\
1 & 1 & 2 & 3 & 9 & 7 & \\
$1-2$ & 21 & - & - & - & - & 21 \\
2 & 1 & - & - & - & - & 1 \\
$2-3$ & 3 & 2 & - & - & - & 5 \\
$3-4$ & 5 & 1 & 1 & - & - & 7 \\
4 & 13 & 4 & 3 & 9 & 247 & 276 \\
Total & 71 & 38 & 6 & 26 & - & 141 \\
& 114 & 85 & 10 & 31 & 247 & 451 \\
\hline
\end{tabular}

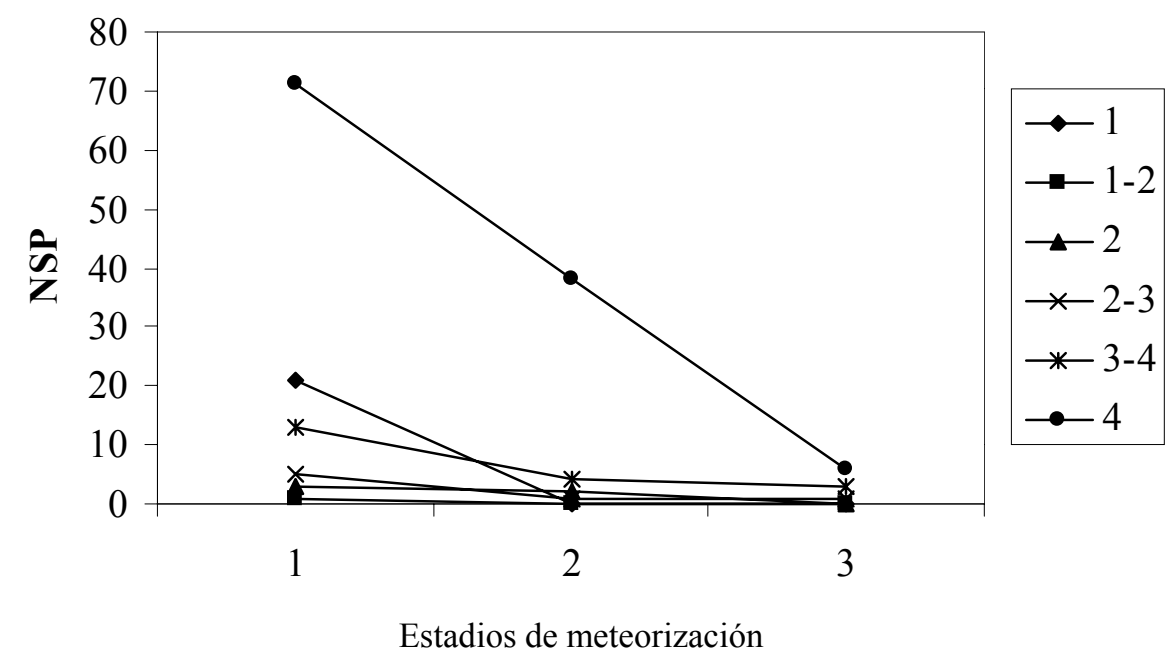

Figura 7.83. Estadios de meteorización según tamaño corporal. Núcleo G, Loma Alta

La acción de roedores sobre huesos de la muestra afectó a siete especímenes, lo que representa el 1,55\% de la muestra. La acción de carnívoros no ha sido registrada en el conjunto.

Tabla 7.37 Modificaciones por agentes naturales. Núcleo G. Loma Alta

\begin{tabular}{ccccr}
\hline Tamaño corporal & Sin modificaciones & $\begin{array}{c}\text { Daño ligero } \\
\text { por roedor }\end{array}$ & $\begin{array}{c}\text { Daño moderado - } \\
\text { grave por roedor }\end{array}$ & Total general \\
1 & 21 & - & - & 21 \\
$1-2$ & 1 & - & - & 1 \\
2 & 5 & - & - & 5 \\
$2-3$ & 7 & - & - & 7 \\
$3-4$ & 276 & 5 & 2 & 276 \\
4 & 134 & 5 & 2 & 441 \\
Total general & 444 & & & 451 \\
\hline
\end{tabular}


En general se puede apreciar que la conservación de los especímenes recuperados es buena. Asimismo la baja meteorización a la que ha estado expuesto el conjunto y la mínima acción registrada de agentes naturales que pudiera haberla modificarlo nos muestra una buena integridad del conjunto.

\subsubsection{Análisis del subconjunto de camélidos}

El subconjunto de camélidos de este nivel de ocupación esta compuesto por un NISP $=17$, correspondiendo dieciséis a Lama sp., y dos a Lama glama (Tabla 7.88)

Tabla 7.38. Camelidae, huesos del esqueleto axial y apendicular. Núcleo G, Loma Alta.

\begin{tabular}{cccr}
\hline Elemento & L. glama & Lama sp. & NISP \\
CRN & - & 1 & 1 \\
TH & - & 1 & 1 \\
RB & - & 1 & 1 \\
& & & \\
SC & - & 1 & 1 \\
HM & - & 1 & 1 \\
CPR & - & 1 & 1 \\
IM & - & 1 & 1 \\
TA & - & 2 & 2 \\
LTM & 1 & - & 1 \\
MP & - & 2 & 2 \\
PHF & - & 4 & 4 \\
PHS & - & 1 & 1 \\
Total & 1 & 16 & 17 \\
\hline
\end{tabular}

\subsubsection{Camélidos adultos}

Esta muestra está conformada por un NISP $=12$ (Tabla 7.40) lo que constituye un $70,6 \%$ de la muestra de camélidos.

\subsubsection{1.a. Supervivencia del material óseo mediada por la densidad ósea}

Debido a lo escaso de la muestra solo se realizó este análisis sobre la tibia y el conjunto global. Esto nos muestra como resultado que en los dos casos la correlación es negativa y sin significancia estadística. Lo que implica que en general se encuentran representadas partes de baja densidad ósea en una mayor frecuencia que aquellas con densidades más altas, aunque este resultado no explica la conformación del conjunto por este atributo. 
Tabla 7.39. Correlación entre el \%MAU y la densidad ósea.

\begin{tabular}{cccc}
\hline Elemento & Rank & $r_{\mathrm{s}}$ & $p$ \\
Tibia & 5 & -.7071 & .091 \\
Arqueofauna & 29 & -.0101 &, 463 \\
\hline
\end{tabular}

\subsubsection{1.b. Número Mínimo de Elementos (MNE)}

Cráneo (CRN)

Sólo se pudo identificar un espécimen asignado al petroso del temporal del lado derecho. Esto permite contabilizar para el MNE un resultado igual a 1.

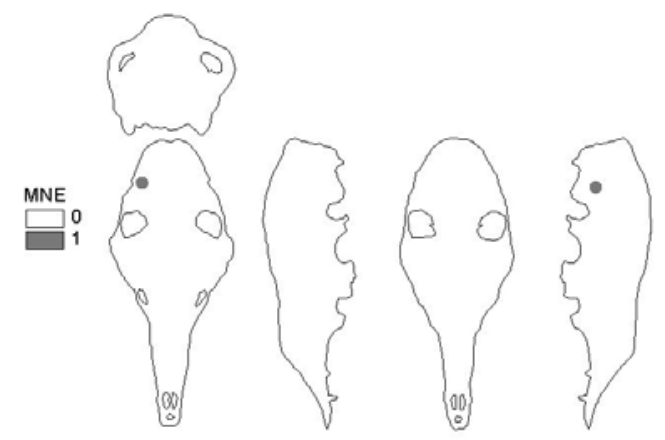

Figura 7.84. MNE Cráneo

Innominado (IM)

Para este elemento se identificó como zona diagnóstica el tubérculo isquiático del lado izquierdo, lo que es igual a un MNE de 1.
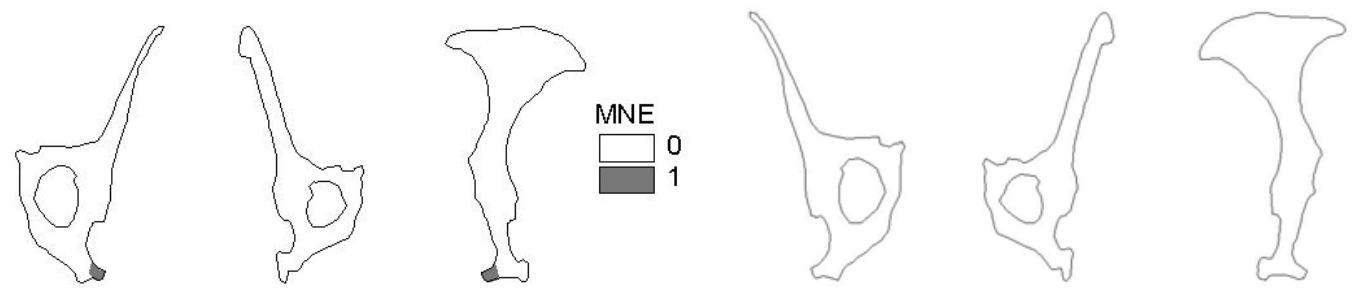

Figura 7.85 MNE Innominado izquierdo y derecho

Tibia (TA)

Para la tibia se halló un fragmento de la cresta anterior perteneciente al lado izquierdo. MNE igual a 1 . 

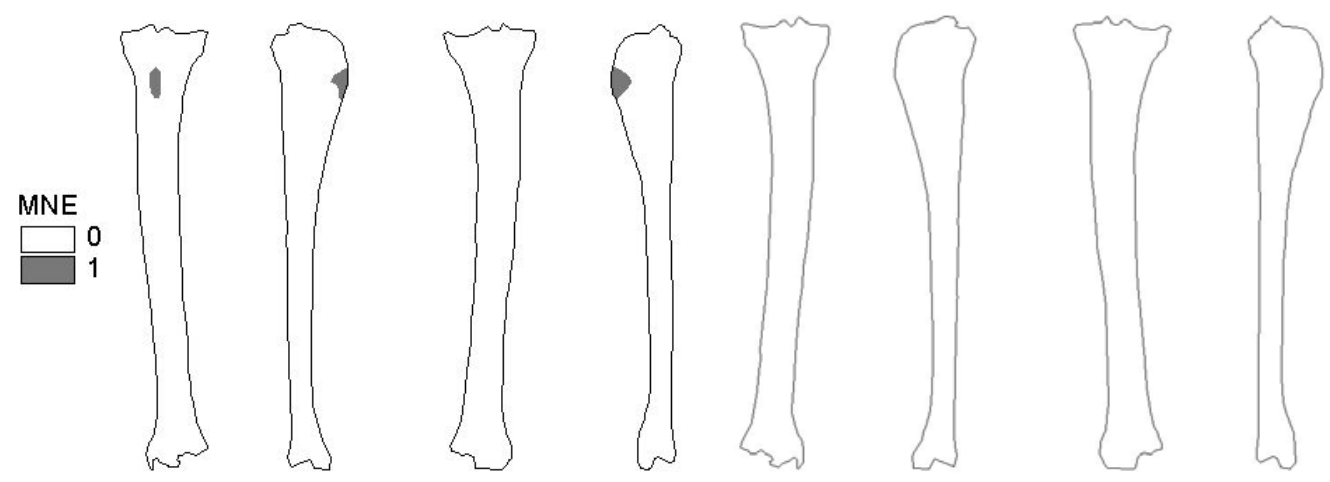

Figura 7.86. MNE Tibia izquierda y derecha

Falange proximal general (PHF)

Para este elemento se construyó el MNE a partir de la identificación de tres zonas diagnósticas: epífisis proximal, diáfisis y epífisis distal. El resultado de esta identificación permitió el cálculo de un MNE igual a 3 elementos.
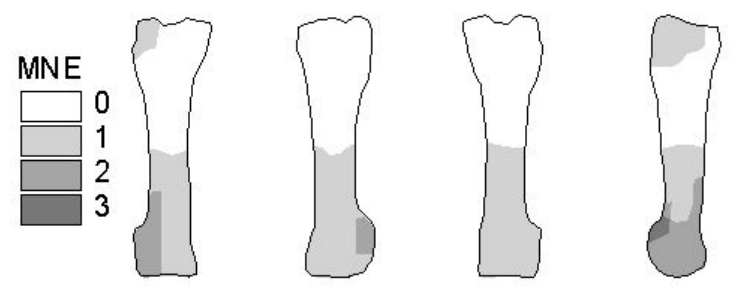

Figura 7.87. MNE Falange proximal general

Los resultados de MNE derivados para los elementos correspondientes al subconjunto de camélidos adultos permitieron efectuar el cálculo del MNI, MAU y $\%$ MAU que se presentan en la Tabla 7.40.

Tabla 7.40. Abundancia relativa de partes esqueletarias.

\begin{tabular}{ccccccccr}
\hline Elemento & NISP & I & D & S/D & MNE & MNI & MAU & \%MAU \\
CRN & 1 & - & 1 & - & 1 & 1 & 1.00 & 100.00 \\
TH & 1 & - & - & 1 & 1 & 1 & 0.07 & 7.14 \\
RB & 1 & - & - & 1 & 1 & 1 & 0.04 & 3.57 \\
& & & & & & & & \\
CPR & 1 & - & 1 & - & 1 & 1 & 0.50 & 50.00 \\
IM & 1 & 1 & - & - & 1 & 1 & 0.50 & 50.00 \\
TA & 1 & 1 & - & - & 1 & 1 & 0.50 & 50.00 \\
LTM & 1 & 1 & - & - & 1 & 1 & 0.50 & 50.00 \\
MP & 1 & - & - & 1 & 1 & 1 & 0.25 & 25.00 \\
PHF & 4 & - & - & 4 & 3 & 1 & 0.375 & 37.50 \\
Total NISP & 12 & & & & & & \\
\hline \multicolumn{7}{c}{ D = derecho, I = izquierdo, S/D = axial o sin datos }
\end{tabular}




\subsubsection{1.c. Número Mínimo de Individuos (MNI)}

Se calculó un MNI de un individuo ya que todos los elementos identificados coinciden en ese valor. Este ejemplar correspondería a una llama.

\subsubsection{1.d. Unidades anatómicas representadas (MAU)}

Teniendo a la vista los resultados de la Tabla 7.40 se construyó el perfil de unidades anatómicas representadas en este conjunto. Lo que se puede observar (Figura 7.88) es que del esqueleto axial solo se presenta un fragmento de cráneo y que este representa el porcentual mas alto para la muestra. Para el esqueleto apendicular anterior no se presenta ningún elemento, en tanto que para el posterior están representados el innominado, la tibia y el maléolo lateral. Por último se puede ver que los elementos distales del esqueleto apendicular a pesar de ser los más numerosos en cuanto a su MNE no estarían tan representados al estandarizarlo respecto de la frecuencia de unidades anatómicas esperadas para cada unidad anatómica.

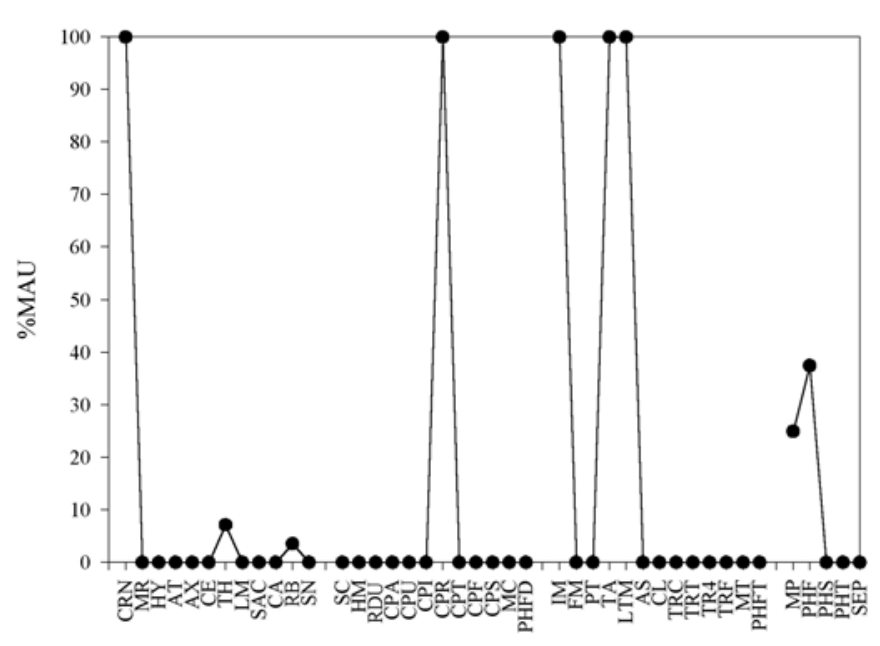

Figura 7.88. Abundancia relativa de elementos esqueletarios.

\subsubsection{1.e. Fragmentación del subconjunto}

La fragmentación del conjunto en términos de los módulos de tamaño a los que se pudo asignar a cada espécimen o elemento muestra que los pequeños son los más representados. Por otro lado el aporte de elementos completos a la muestra es relativamente bajo. 


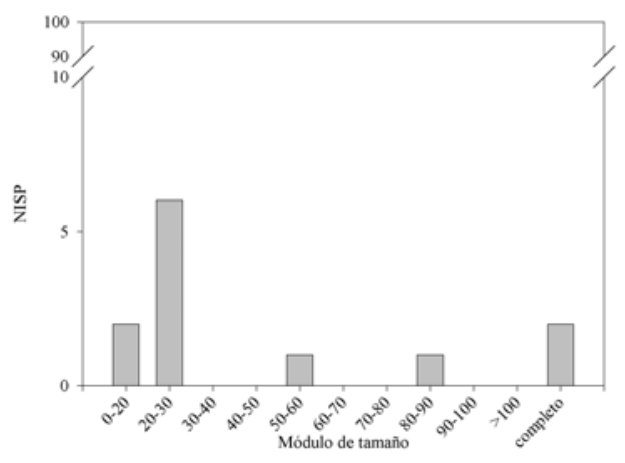

Figura 7.89. Módulos de tamaño expresado en NISP para especímenes y elementos del subconjunto adulto de camélidos

Respecto del tipo de fractura, se pudo observar que aquellas efectuadas con el elemento en estado seco son las representadas en mayor número. La fractura realizada en estado fresco se presenta en una muy baja frecuencia.

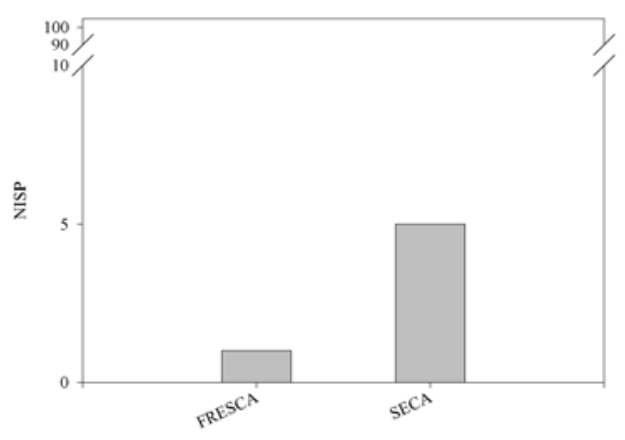

Figura 7.90. Cantidad (NISP) de especímenes y elementos del subconjunto adulto de camélidos según tipo de fractura.

\subsubsection{1.f. Termoalteraciones}

En esta submuestra se pudo identificar la acción de calor en tres fragmentos, dos de los cuales parecen haber estado sometidos a grandes temperaturas (Tabla 7.41).

Tabla 7.41. Termoalteración del conjunto de camélidos adultos.

\begin{tabular}{cccccr}
\hline Descripción & Sin alteración & $\begin{array}{c}\text { Oxidación } \\
\text { incompleta/carbonización } \\
\text { marrón claro-negro } \\
\text { (moteado) }\end{array}$ & Carbonizado & Calcinado & \\
Color & - & $200{ }^{\circ} \mathrm{C}-300{ }^{\circ} \mathrm{C}$ & $300{ }^{\circ} \mathrm{C}$ & $>500{ }^{\circ} \mathrm{C}$ & \\
Temperatura & $<200{ }^{\circ} \mathrm{C}$ & 0 & 1 & 2 & 12 \\
NISP & 9 & & gris-blanco & \\
\hline
\end{tabular}




\subsubsection{Camélidos subadultos}

Compuesto por un NISP $=5$, valor que indica el $29,4 \%$ de la muestra. Estos especímenes identificados corresponden al esqueleto apendicular delantero y trasero.

\subsubsection{2.a. Supervivencia del material óseo mediada por la densidad ósea}

El resultado este análisis arrojó como producto una correlación positiva para el húmero y una correlación negativa para la escápula y la tibia. Esto podría interpretarse como una preservación mayor de zonas diagnósticas con valores de densidad bajos para los dos últimos elementos, en tanto que se habrían preservado en zonas con densidades más altas para el húmero. El valor obtenido para el conjunto arrojó un resultado similar al del caso del húmero.

Tabla 7.42. Correlación entre el \%MAU y la densidad ósea.

\begin{tabular}{cccc}
\hline Elemento & Rank & $r_{s}$ & $p$ \\
Escápula & 4 & -.774 & .113 \\
Húmero & 5 & .707 & .091 \\
Tibia & 5 & -.288 & .319 \\
Arqueofauna & 29 & .092 & .261 \\
\hline
\end{tabular}

\subsubsection{2.b. Número Mínimo de Elementos (MNE)}

Escápula (SC)

Para este elemento se identificó un fragmento de la escápula derecha mediante la identificación de la zona correspondiente a la cavidad glenoidea. $\mathrm{MNE}=1$.
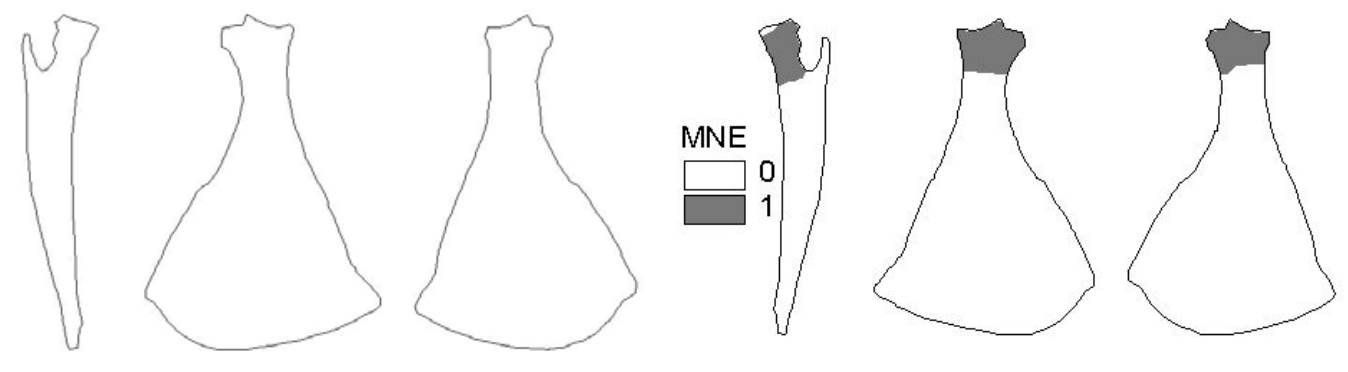

Figura 7.91. MNE Escápula izquierda y derecha

Húmero (HM)

Se identificó un fragmento distal de diáfisis mediante la ubicación del foramen posterolateral. MNE igual a 1 . 


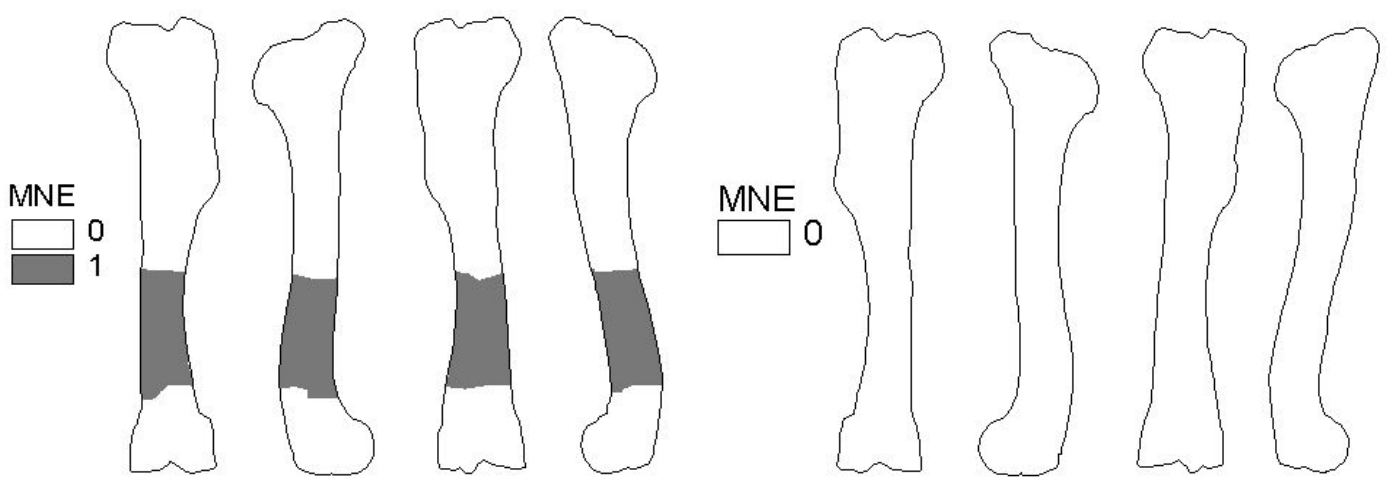

Figura 7.92. MNE Húmero izquierdo y derecho

Tibia (TA)

Se identificó un fragmento de diáfisis distal mediante las siguientes zonas diagnósticas: diáfisis distal posterior, diáfisis distal anterior, muesca medial y muesca lateral. Se calculó sobre esta base un MNE igual a 1 .
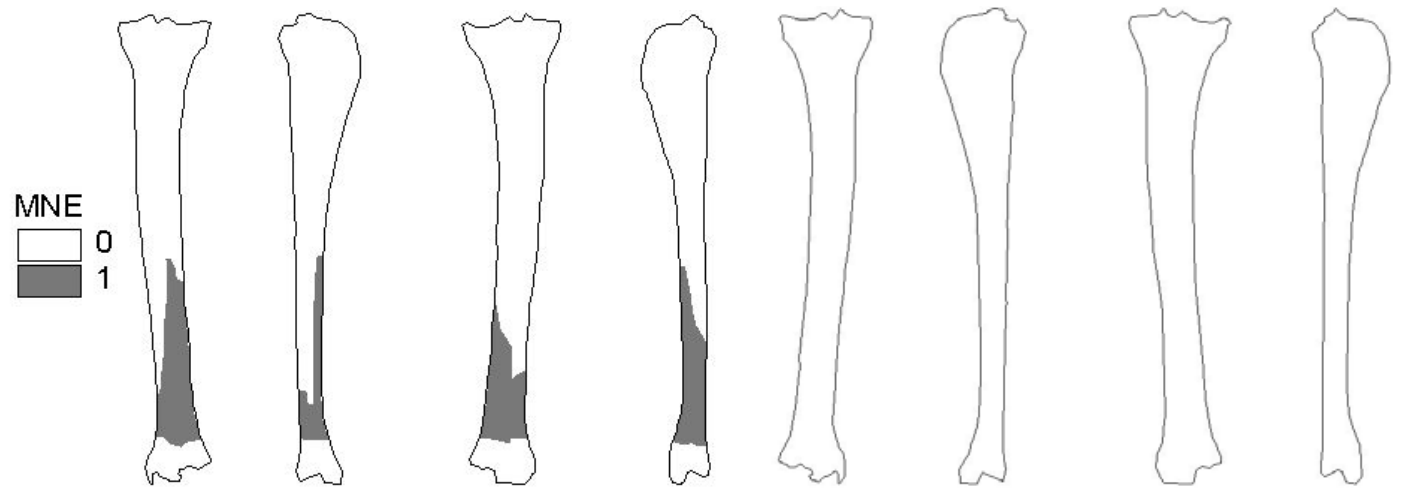

Figura 7.93. MNE Tibia izquierda y derecha

Metapodio (MP)

En base a la identificación de un cóndilo sin fusionar se asignó a este elemento un MNE igual a 1.

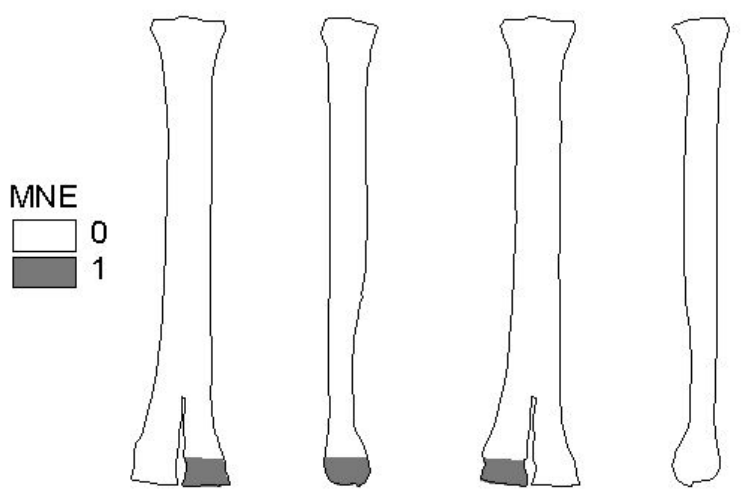

Figura 7.94. MNE Metapodio general 


\section{Falange medial (PHS)}

La identificación de la diáfisis y epífisis distal permitió calcular un MNE igual a 1.

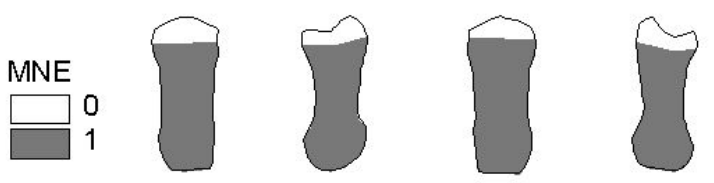

Figura 7.95. MNE Falange medial

Sobre la base de los valores de MNE obtenidos para este subconjunto se procedió al cálculo del MNI, MAU y \%MAU y cuyos valores se presentan en la Tabla 7.43 .

Tabla 7.43. Abundancia relativa de partes esqueletarias expresadas como NISP, MNE comprehensivo, MAU y \%MAU.

\begin{tabular}{cccccccrr}
\hline Elemento & NISP & I & D & S/D & MNE & MNI & MAU & \%MAU \\
SC & 1 & - & 1 & - & 1 & 1 & 0.50 & 100 \\
HM & 1 & 1 & - & - & 1 & 1 & 0.50 & 100 \\
TA & 1 & 1 & - & - & 1 & 1 & 0.50 & 100 \\
MP & 1 & - & - & 1 & 1 & 1 & 0.25 & 25 \\
PHS & 1 & - & - & 1 & 1 & 1 & 0.125 & 12.5 \\
Total NISP & 5 & & & & \\
\hline \multicolumn{7}{c}{ D = derecho, I = Izquierdo, S/D = Axial o sin datos }
\end{tabular}

\subsubsection{2.c. Número Mínimo de Individuos (MNI)}

Al igual que en el caso de los restos de camélidos adultos se calculó un MNI de un individuo ya que todos los elemento identificados coinciden en ese valor.

\subsubsection{2.d. Fragmentación del subconjunto}

Los tamaños expresados por medio de módulos de tamaño según el largo máximo de cada elemento nos permiten observar que estos son variables. A pesar de lo reducido de la muestra se puede observar que no existe una selectividad en cuanto al registro de los tamaños ya que las frecuencias de cada módulo son similares. 


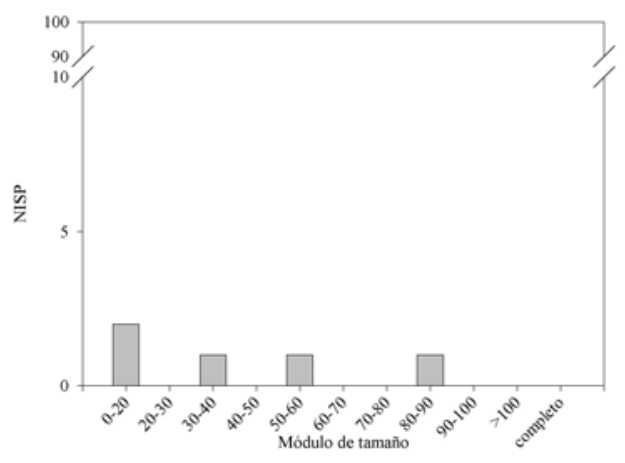

Figura 7.96. Módulos de tamaño expresado en NISP para especímenes y elementos del subconjunto adulto de camélidos

Respecto del estado en que se encontraba el hueso al producirse la fractura se puede advertir que se distribuye de modo similar entre fracturas frescas y secas.

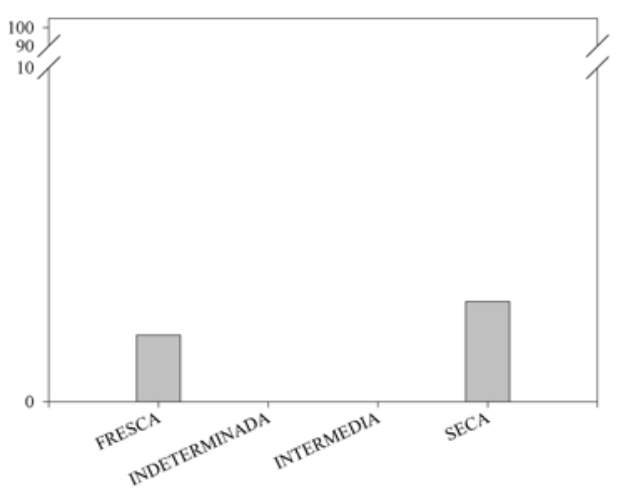

Figura 7.97. Cantidad (NISP) de especímenes y elementos del subconjunto subadulto de camélidos según tipo de fractura.

\subsubsection{Subconjunto no camélido}

El subconjunto está formado por un NISP $=434$. Aquí se incluyen taxones de tamaños corporales 1, 2, y 4 . En este caso el tamaño corporal 4 incluye a los artiodáctilos.

\subsubsection{Marcas de procesamiento primario y secundario (Impactos)}

Para esta muestra se identificaron dos especímenes con huellas de impacto. Una corresponde a un artiodáctilo de tamaño corporal 4 y está producida sobre una lasca ósea de hueso largo. La otra pertenece también a una astilla de hueso largo y corresponde a un individuo cuyo taxón no pudo ser identificado pero que fue asignado al tamaño corporal 3-4. 
Tabla 7.44. Marcas en huesos del conjunto no camélido expresado en NISP.

\begin{tabular}{ccccrr}
\hline Taxón & T. Corporal & Elemento & Porción & Impacto & Total general \\
Artiodactyla & 4 & LB & FK & 1 & 1 \\
No identificable & $3-4$ & LB & AST & 1 & 1 \\
Total general & & & & 2 & 2 \\
\hline
\end{tabular}

\subsubsection{Termoalteración}

En todo el conjunto de no camélidos los únicos especímenes que presentaron indicios de la acción de calor fueron los asignados tanto a artiodáctilos de tamaño corporal 4 como a especímenes de taxones no identificables de los tamaños corporales 3-4 y 4. Para estos especímenes se identificó un 16,90\% de huesos quemados para artiodáctilos del tamaño corporal 4, un 5,43\% para no identificables de tamaño corporal 3-4 y un 9,43\% para los no identificables de tamaño corporal 4.

Tabla 7.45. Termoalteración del conjunto "no camélidos".

\begin{tabular}{|c|c|c|c|c|c|c|}
\hline & Descripción & $\begin{array}{c}\text { Sin } \\
\text { alteración }\end{array}$ & $\begin{array}{c}\text { Oxidación } \\
\text { incompleta/carbonización }\end{array}$ & Carbonizado & Calcinado & \\
\hline & Color & - & $\begin{array}{l}\text { marrón claro-negro } \\
\text { (moteado) }\end{array}$ & negro & $\begin{array}{c}\text { gris- } \\
\text { blanco }\end{array}$ & \\
\hline & Temperatura & $<200{ }^{\circ} \mathrm{C}$ & $200^{\circ} \mathrm{C}-300^{\circ} \mathrm{C}$ & $300^{\circ} \mathrm{C}$ & $>500{ }^{\circ} \mathrm{C}$ & \\
\hline AVE & 1 & 1 & - & - & - & 1 \\
\hline $\begin{array}{c}\text { Chaetophractus } \\
\text { vellerosus }\end{array}$ & 2 & 4 & - & - & - & 4 \\
\hline Rodentia & 1 & 7 & - & - & - & 7 \\
\hline Artiodactyla & 4 & 59 & 6 & 5 & 1 & 71 \\
\hline No identificable & 1 & 13 & - & - & - & 13 \\
\hline No identificable & $1-2$ & 1 & - & - & - & 1 \\
\hline No identificable & 2 & 1 & - & - & - & 1 \\
\hline No identificable & $2-3$ & 6 & 1 & - & - & 7 \\
\hline No identificable & $3-4$ & 261 & 1 & - & 14 & 276 \\
\hline No identificable & 4 & 48 & - & 1 & 4 & 53 \\
\hline Total general & & 401 & 8 & 6 & 19 & 434 \\
\hline
\end{tabular}

\subsubsection{Fragmentación del subconjunto de no camélidos.}

Para el Tamaño corporal 1 (Figura 7.98.a) los elementos presentes se encuentran en gran medida fragmentados. Los únicos completos son los que pertenecen a los taxones definidos como roedores y no identificables de tamaño corporal 1. Para el tamaño corporal 2 (Figura 7.98.b) la muestra es pequeña y esta básicamente compuesta por placas de Chaetophractus vellerosus las que en general se encuentran completas salvo en un caso. Por último para el tamaño corporal 4 (Figura 7.98.c) se puede observar que para las dos categorías definidas las frecuencias correspondientes a cada módulo de 
tamaño son similares, lo que quizás pueda significar que estas dos categorías correspondan a una sola.

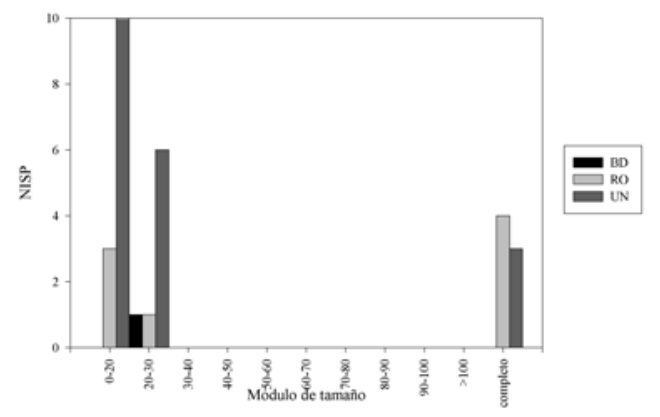

a

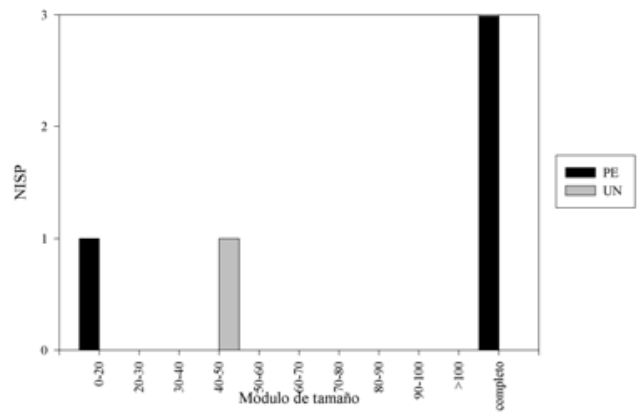

b

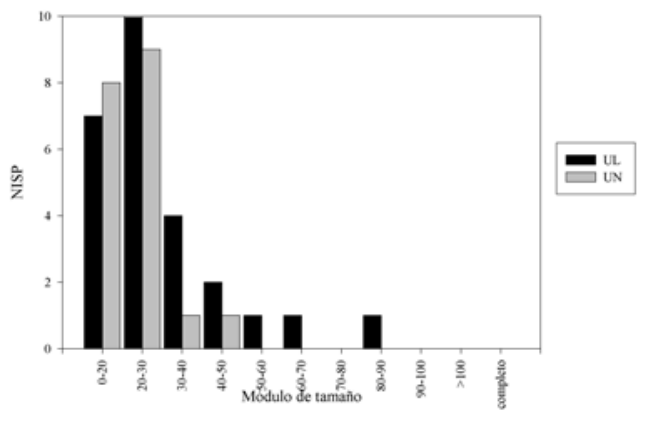

c

Figura 7.98. Fragmentación del conjunto "no camélido" expresado en NSP. a) Tamaño corporal 1, b) Tamaño corporal 2 y c) Tamaño corporal 4. 


\subsection{Potrero Antigal - Análisis faunístico}

Como se describió en el Capítulo 5 este sitio presenta los restos faunísticos provenientes de un solo sondeo. La muestra recuperada es pequeña por ello se realizarán solo algunas consideraciones.

El número de especímenes total recuperado durante la excavación fue de 136. Solo 30 de ellos $(22,05 \%)$ pudieron ser asignados dentro de alguna categoría taxonómica. Tomando en cuenta el volumen excavado $\left(60 \mathrm{dm}^{3}\right)$ la relación NSP/Volumen es de 2,26 fragmentos por $\mathrm{dm}^{3}$.

Tabla 7.46. Composición de la muestra. Potrero Antigal

\begin{tabular}{lcr}
\hline \multicolumn{1}{c}{ Taxón } & Tamaño corporal & Total NSP \\
Chaetophractus vellerosus & 2 & 3 \\
Rodentia & 1 & 5 \\
Microcavia sp. & 1 & 2 \\
Lama sp. & 4 & 20 \\
$\quad$ Subtotal Identificados & & 30 \\
No identificable & 2 & 1 \\
No identificable & 4 & 5 \\
No identificable & 9 & 100 \\
Subtotal No Identificables & & 106 \\
$\quad$ TOTAL & & 136 \\
\hline
\end{tabular}

Como puede observarse en la Tabla 7.46 hay especímenes de cuatro taxones y dos categorías de tamaños corporales de taxones no identificables. Los elementos o especímenes mas representados son los que se asignaron al tamaño corporal 4 tanto por los identificados como los no identificables taxonómicamente.

En cuanto a las modificaciones producidas por agentes tafonómicos se puede observar que en general la meteorización es baja, presentándose el grueso del material con la misma meteorización independientemente del tipo de tamaño corporal (Tabla 7.47 y Figura 7.99)

Tabla 7.47. Meteorización del conjunto faunístico de Potrero Antigal.

\begin{tabular}{|c|c|c|c|}
\hline \multirow[t]{2}{*}{ Tamaño corporal } & \multicolumn{2}{|c|}{ Meteorización } & Total NSP \\
\hline & 2 & 3 & \\
\hline 1 & 6 & - & 7 \\
\hline 2 & 4 & - & 4 \\
\hline 4 & 23 & 2 & 25 \\
\hline 9 & 92 & 8 & 100 \\
\hline Total & 125 & 10 & 136 \\
\hline
\end{tabular}




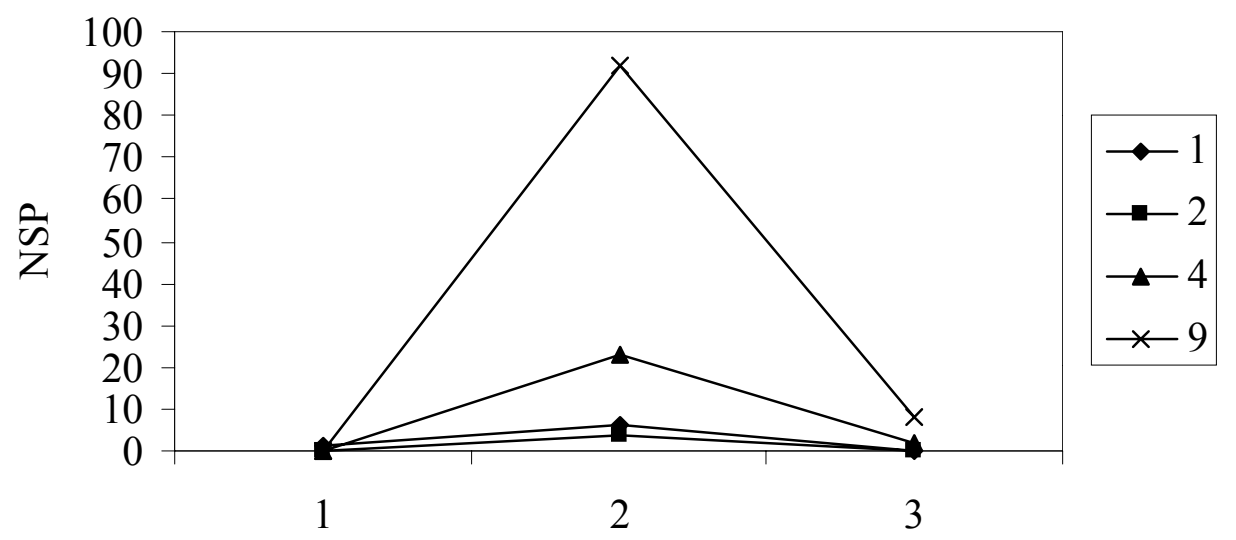

Estadios de meteorización

Figura 7.99. Estadios de meteorización según tamaño corporal. Potrero Antigal.

En cuanto a la acción roedores sobre el conjunto se observa en la Tabla 7.47 que solo un espécimen $(0,73 \%)$ de la muestra presenta señales de haber sido afectado por este agente, razón por la cual la acción sobre el conjunto habría sido mínima. No se registró la acción de carnívoros.

Tabla 7.48. Modificaciones por agentes naturales del conjunto faunístico Potrero Antigal.

\begin{tabular}{cccr}
\hline Tamaño corporal & Sin modificaciones & Daño ligero por roedor & Total general \\
1 & 7 & - & 7 \\
2 & 4 & - & 4 \\
4 & 25 & - & 25 \\
9 & 99 & 1 & 100 \\
Total general & 135 & 1 & 136 \\
\hline
\end{tabular}

\subsubsection{Análisis del subconjunto Tamaño Corporal 4.}

Debido a lo escaso del material asignado a camélido se realizará solo una breve descripción de algunos atributos de la muestra. A lo identificado como camélido se le ha anexado en esta oportunidad los cinco especímenes correspondientes al tamaño corporal 4.

Tabla 7.49. Tamaño Corporal 4, huesos del esqueleto axial y apendicular. Potrero Antigal

\begin{tabular}{cccr}
\hline Elemento & Lama $s p$. & Artiodactyla & Total NISP \\
CRN & 3 & - & 3 \\
TFR & 3 & - & 3 \\
VT & 4 & - & 4
\end{tabular}




\begin{tabular}{cccc} 
& & Continuación de Tabla 7.49 \\
\hline SC & 1 & - & 1 \\
RDU & 1 & - & 1 \\
& & & \\
TA & 1 & - & 1 \\
CL & 1 & - & 1 \\
& & - & \\
MP & 1 & 2 & 7 \\
LB & 5 & 2 & 2 \\
FB & - & 1 & 1 \\
US & - & 5 & 25 \\
Total & 20 & &
\end{tabular}

Como se muestra en la Figura 7.100 el número de especímenes identificados en este conjunto asignados a la clase de adultos se encuentra más representada que la clase subadulta en una relación dos a uno.

En cuanto a los elementos representados en cada clase de edad tenemos que para los subadultos se identificaron un fragmento de hueso plano del cráneo y un fragmento de vértebra. Ahora bien, este criterio puede llevar a confusión ya que en los cráneos de individuos adultos sometidos a hervido suelen separarse los huesos que componen la caja craneana por las suturas (Nasti 1994/1995). De todos modos por el tamaño general del espécimen se lo asigno a esta clase de edad. Por el contrario para los adultos tenemos representados un fragmento de escápula, uno de radioulna, uno de tibia, un fragmento de metapodio y un fragmento de vértebra.

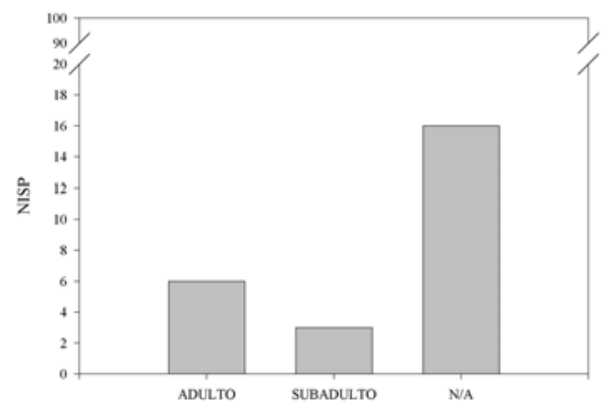

Figura 7.100. Representación de clases de edad.

\subsubsection{Fragmentación del conjunto}

En este grupo no se encontró ningún elemento completo y los módulos de tamaño están representados desde 0-20 $\mathrm{mm}$ hasta 50-60 $\mathrm{mm}$. Esto nos ofrece una idea de la fragmentación y posiblemente de la selección de tamaños aunque no es posible 
aún determinar si esto se debe efectivamente a ello o es una cuestión referida al tamaño de la muestra.

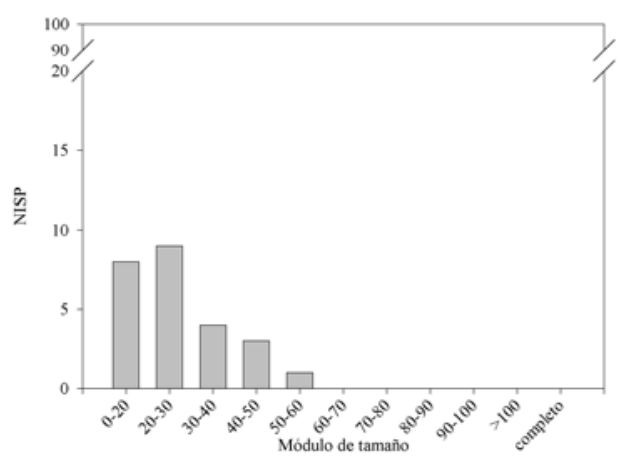

Figura 7.101. Módulos de tamaño expresado en NISP para especímenes y elementos de tamaño corporal 4.

En cuanto a los estados iniciales de los huesos al ser fracturados la frecuencia de la categoría seca es la mayor (sin contar el tipo indeterminado). Las fracturas realizadas en estado fresco han sido halladas en poca cantidad dentro de este conjunto.

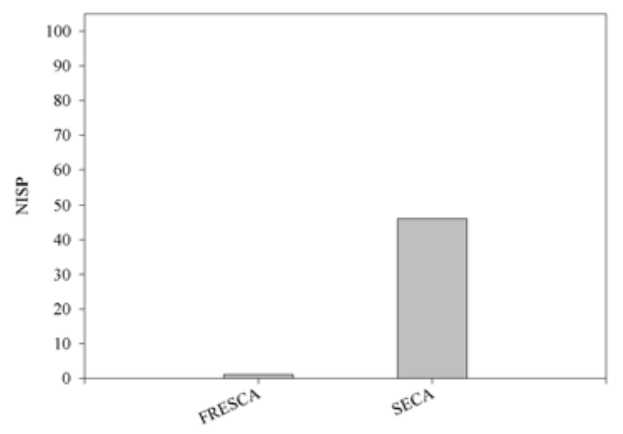

Figura 7.102. Cantidad (NISP) de especímenes y elementos de tamaño corporal 4 según tipo de fractura.

\subsubsection{Utilización de las carcasas}

Las únicas huellas halladas en este conjunto corresponden a marcas de corte. Estas fueron ubicadas en el cuerpo de una vértebra (camélido subadulto) y una lasca ósea de hueso largo (camélido sin edad asignable) Estas marcas posiblemente correspondan a un procesamiento secundario de unidades mayores (reducción de unidades anatómicas). 
Tabla 7.50. Marcas en huesos de tamaño corporal 4 expresado en NISP.

\begin{tabular}{ccccr}
\hline Elemento & Porción & Marcas de corte & Impacto & Total \\
VT & CN & 1 & - & 1 \\
LB & FK & - & 2 & 2 \\
\hline
\end{tabular}

\subsubsection{Termoalteraciones}

En cinco especímenes pertenecientes a las dos cases de edad (adultos y subadultos) fue posible identificar signos de acción del calor.

Tabla 7.51. Termoalteración del conjunto de tamaño corporal 4.

\begin{tabular}{cccccc}
\hline Descripción & Sin alteración & $\begin{array}{c}\text { Oxidación } \\
\text { incompleta/carbonización } \\
\text { marrón claro-negro } \\
\text { (moteado) }\end{array}$ & Carbonizado & Calcinado & \\
Color & - & $200^{\circ} \mathrm{C}-300^{\circ} \mathrm{C}$ & $300{ }^{\circ} \mathrm{C}$ & $>500{ }^{\circ} \mathrm{C}$ & \\
Temperatura & $<200{ }^{\circ} \mathrm{C}$ & - & 4 & - & 25 \\
NISP & 21 & gris-blanco & \\
\hline
\end{tabular}

En cuanto a la relación entre el tipo de alteración y el estado de la fractura se puede visualizar en la Tabla 7.52 que los elementos que no presentan signos de termoalteración el 57\% presentan fractura realizada en estado seco.

Tabla 7.52. Relación entre tipo de termoalteración y tipo de fractura del conjunto de tamaño corporal 4.

\begin{tabular}{lcccc}
\hline \multicolumn{1}{c}{ Tipo de alteración } & Fresca & Indeterminada & Seca & Total \\
Sin alteración & 1 & 8 & 12 & 21 \\
Oxidación incompleta & - & - & - & - \\
Carbonizado & - & 3 & 1 & 4 \\
Calcinado & - & - & - & - \\
$\quad$ Total & 1 & 11 & 13 & 25 \\
\hline
\end{tabular}

\subsubsection{Subconjunto no camélido (otros tamaños corporales)}

Para los otros tamaños corporales presentes en la muestra se pudo observar en cuanto a las modificaciones óseas que en una lasca ósea de hueso largo se hallaron marcas de impacto.

Respecto de los elementos quemados se identificó un fragmento proximal de costilla asignado al tamaño corporal 2. El resto de los especímenes quemados corresponden a la categoría 9 (tamaño no asignable). Los especímenes se presentan tanto carbonizados como calcinados, lo que indicaría un rango de temperaturas superiores a $\operatorname{los} 300^{\circ} \mathrm{C}$. 


\subsection{Tesoro 1 - Análisis faunístico}

Al igual que el sitio anterior la muestra recuperada vuelve a ser pequeña. Por ello se realizarán solo algunas observaciones sobre este nuevo conjunto.

El número de especímenes total recuperado durante la excavación fue de 14 los cuales pudieron ser asignados dentro de alguna categoría taxonómica. Tomando en cuenta el volumen excavado $\left(67,5 \mathrm{dm}^{3}\right)$ la relación NSP/Volumen es de 0,20 fragmentos por $\mathrm{dm}^{3}$.

Tabla 7.53. Composición de la muestra. Tesoro 1.

\begin{tabular}{|c|c|c|}
\hline $\begin{array}{c}\text { Taxón } \\
\text { Chaetophractus vellerosus }\end{array}$ & $\begin{array}{c}\text { Tamaño corporal } \\
2\end{array}$ & Total NSP \\
\hline Microcavia & 1 & 1 \\
\hline Artiodactyla & 4 & 1 \\
\hline Lama sp. & 4 & 11 \\
\hline TOTA & & 14 \\
\hline
\end{tabular}

En cuanto a las características generales del conjunto fueron identificados cuatro taxones sobre los que se registró la presencia de los estadios de meteorización 1 y 2 . No se halló en ningún espécimen rastros de acción de agentes tafonómicos ni de marcas de acción humana. Tampoco se encontraron especímenes quemados.

Por último y en cuanto a la fragmentación se observó que están presentes los módulos de tamaño 0-20, 20-30, 30-40, 50-60 y 70-80 mm lo que indicaría que no hubo selección del tamaño en esta muestra. 


\subsection{Antigal de Tesoro o Tesoro 2 - Análisis faunístico}

Para todo el nivel de ocupación del sector excavado en el Recinto 19 del sitio se registró un $\mathrm{NSP}=456$ y un $\mathrm{NISP}=431$, resultando que los elementos y especímenes identificados a algún nivel taxonómico alcanzan al 94,51 \% del conjunto.

Tabla 7.54. Composición de la muestra. Antigal de Tesoro o Tesoro 2.

\begin{tabular}{lcr}
\hline \multirow{2}{*}{ AVES Taxón } & Tamaño corporal & Total NSP \\
Rodentia & 2 & 1 \\
Artiodactyla & 1 & 2 \\
Lama $s p$. & 4 & 408 \\
$\quad$ Subtotal Identificados & 4 & 20 \\
$\quad$ & & 431 \\
$\quad$ No Identificable & 1 & 10 \\
$\quad$ No Identificable & $2-3$ & 5 \\
$\quad$ No Identificable & 4 & 9 \\
$\quad$ No Identificable & 9 & 1 \\
$\quad$ Subtotal No Identificables & & 25 \\
$\quad$ TOTAL & & \\
$\quad$
\end{tabular}

En la Tabla 7.54 se describe la composición de la muestra, en la cual se puede observar que se han identificado cuatro taxones y cuatro tipos de tamaño corporal.

En cuanto a la acción de agentes tafonómicos sobre esta muestra se pude apreciar en la Tabla 7.55 que del total de especímenes o elementos sobre los que se pudo identificar algún tipo de meteorización $(\mathrm{NSP}=199)$ el 68,34\% presenta el estadio 1. Solo un espécimen presenta meteorización 4.

En cuanto a otros agentes tafonómicos no se hallaron modificaciones por carnívoro o roedor

Tabla 7.55. Meteorización del conjunto faunístico de R19. Antigal de Tesoro

\begin{tabular}{crrrrrr}
\hline TAMAÑ CORPORAL & \multicolumn{3}{c}{ METEORIZACIÓN } & TOTAL NSP \\
& 1 & 2 & 4 & 9 & \\
1 & 7 & 1 & - & 4 & 12 \\
2 & 1 & - & - & - & 1 \\
$2-3$ & 5 & - & - & - & 5 \\
4 & 122 & 61 & 1 & 253 & 437 \\
9 & 1 & - & - & - & 1 \\
& TOTAL & 136 & 62 & 1 & 257 & 456 \\
\hline
\end{tabular}




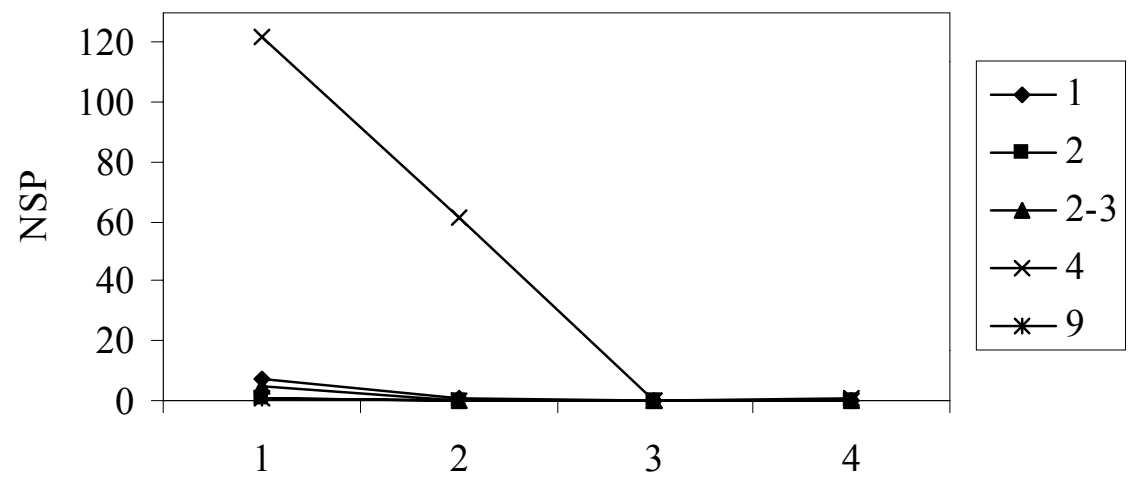

Estadios de meteorización

Figura 7.103. Estadios de meteorización según tamaño corporal. Antigal de Tesoro.

\subsubsection{Análisis del subconjunto de camélidos.}

Este subconjunto está compuesto por un NISP $=20$, correspondiendo todos a Lama sp. Fue posible discriminar según clases de edad asignándose 14 especímenes a la categoría adultos y 6 a subadultos.

\subsubsection{Camélidos adultos}

Este subconjunto está compuesto por un NISP $=14$ (Tabla 7.57) lo que representa un $70 \%$ del total de la muestra de camélidos.

\subsubsection{1.a. Supervivencia del material óseo mediada por la densidad ósea}

Como puede observarse en la Tabla 7.56 se efectuó el análisis de correlación entre las zonas diagnósticas preservadas y la densidad ósea tanto para elementos como para el total de la muestra. En el caso de los elementos individuales todas las correlaciones resultaron sin significancia estadística. Para la mandíbula la correlación es negativa lo que significaría que se habría conservado una zona de relativa baja densidad. El húmero no presenta correlación con la densidad ósea. El innominado y el calcáneo presentan valores positivos lo que se podría interpretar como una preservación de porciones con densidades relativas más altas.

El resultado obtenido para el conjunto de todos lo elementos fue positivo y estadísticamente significativo. Si hiciéramos una interpretación lineal de estos valores lo que deberíamos decir es que la conformación del conjunto estaría mediada por la densidad ósea. Pero por otro lado hemos observado que los análisis efectuados para cada elemento en particular nos muestra una diversidad en cuanto a resultados. Por ello 
creemos que el valor global se encontraría sobredimensionado producto de la inclusión de elementos más densos como por ejemplo los del carpo.

En casos en los que indicadores tafonómicos como la meteorización o la acción de carnívoros y roedores sea baja (como en el presente caso) estimamos que se deben realizar las correlaciones por separado a los fines de poder verificar los resultados que se obtengan para el conjunto de todos los elementos.

En conclusión creemos que al menos en esta muestra la densidad ósea puede haber sido un factor que ha contribuido a la conformación del registro pero que no ha sido la estrictamente determinante ya que de todos modos se registra la presencia de partes menos densas que en el primer caso deberían haber desaparecido.

Tabla 7.56. Correlación entre el \%MAU y la densidad ósea.

\begin{tabular}{cccc}
\hline Elemento & Rank & $r_{\mathrm{s}}$ & $p$ \\
Mandíbula & 8 &,- 247 &, 277 \\
Húmero & 5 &, 000 &, 500 \\
Innominado & 8 &, 408 &, 182 \\
Calcáneo & 4 &, 258 &, 371 \\
Arqueofauna & 29 &, 210 &, $026^{*}$ \\
\hline * Estadísticamente significativo al nivel de $\mathrm{p}>0.5$
\end{tabular}

\subsubsection{1.b. Número Mínimo de Elementos (MNE)}

Debido al bajo número de especímenes analizados se procedió a realizar la cuantificación mediante el conteo de las zonas diagnósticas registradas para cada elemento. El resultado de esta operación se encuentra expresado en la Tabla 7.57.

Tabla 7.57. Abundancia relativa de partes esqueletarias expresadas como NISP, MNE comprehensivo, MAU y \%MAU.

\begin{tabular}{|c|c|c|c|c|c|c|c|c|}
\hline Elemento & NISP & $\bar{I}$ & $\bar{D}$ & $\mathrm{~S} / \mathrm{D}$ & MNE & MNI & MAU & $\% \mathrm{MAU}$ \\
\hline MR & 1 & - & - & 1 & 1 & 1 & 1 & 100 \\
\hline TFR & 1 & - & - & 1 & 1 & 1 & - & - \\
\hline HM & 1 & - & - & 1 & 1 & 1 & 0.5 & 50 \\
\hline CPA & 1 & - & 1 & - & 1 & 1 & 0.5 & 50 \\
\hline $\mathrm{CPF}$ & 1 & - & 1 & - & 1 & 1 & 0.5 & 50 \\
\hline CPI & 1 & 1 & - & - & 1 & 1 & 0.5 & 50 \\
\hline CPR & 1 & - & 1 & - & 1 & 1 & 0.5 & 50 \\
\hline CPU & 1 & - & 1 & - & 1 & 1 & 0.5 & 50 \\
\hline IM & 1 & - & - & 1 & 1 & 1 & 0.5 & 50 \\
\hline AS & 1 & - & 1 & - & 1 & 1 & 0.5 & 50 \\
\hline CL & 1 & 1 & - & - & 1 & 1 & 0.5 & 50 \\
\hline MP & 1 & - & - & 1 & 1 & 1 & 0.25 & 25 \\
\hline PHT & 2 & - & - & 2 & 2 & 1 & 0.13 & 12.5 \\
\hline Total & 14 & & & & & & & \\
\hline
\end{tabular}




\subsubsection{1.c. Número Mínimo de Individuos (MNI)}

El número mínimo de individuos para este subconjunto fue estimado en uno, ya que es el valor expresado para cada uno de los elementos y no se determinaron diferencias a nivel osteométrico.

\subsubsection{1.d. Unidades anatómicas representadas (MAU)}

Las unidades anatómicas mínimas identificadas para este conjunto se han graficado en la Figura 7.104. Allí se pude apreciar que para el esqueleto axial el único elemento presente es la mandíbula la que en términos económicos poseería un valor bajo. Para el esqueleto apendicular delantero se puede observar que están presentes tanto elementos de alto valor como de bajo valor. Esto últimos pueden ser interpretados como "riders" que ingresan al conjunto debido a que vienen unidos a elementos de mayor valor económico (Binford 1981). Creemos que este puede ser el caso por ejemplo de los carpianos.

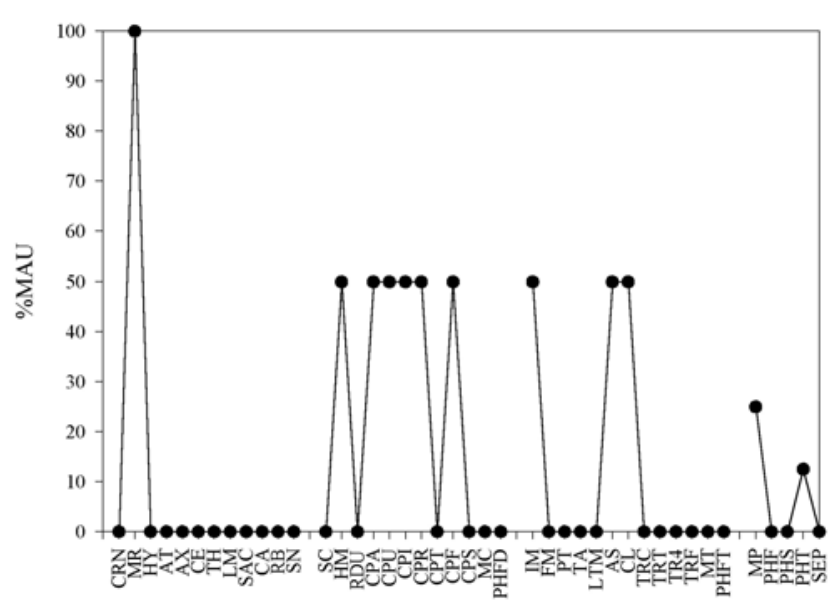

Figura 7.104. Abundancia relativa de elementos esqueletarios.

Lo expresado anteriormente puede visualizarse en los gráficos que se presentan en la Figura 7.105. Allí se puede ver que para los elementos "no largos" el único representado posee baja utilidad económica en términos del índice de carne. Para el caso de los elementos largos se encuentra representado el húmero el que posee un volumen alto de la cavidad medular y un valor medio respecto del índice de utilidad de carne. La presencia de fragmentos de innominado, calcáneo y astrágalo no dan cuenta en este caso 
de si ingresaron al conjunto como "riders" de elementos de mayor utilidad o no, razón por la cual no se trataran en este caso.

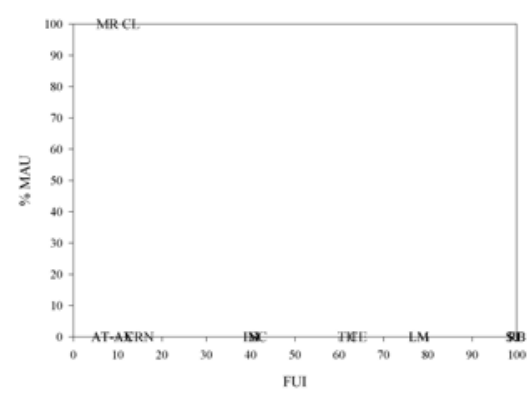

a

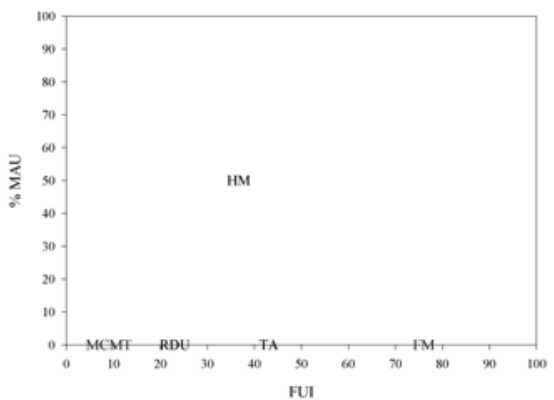

$\mathrm{b}$

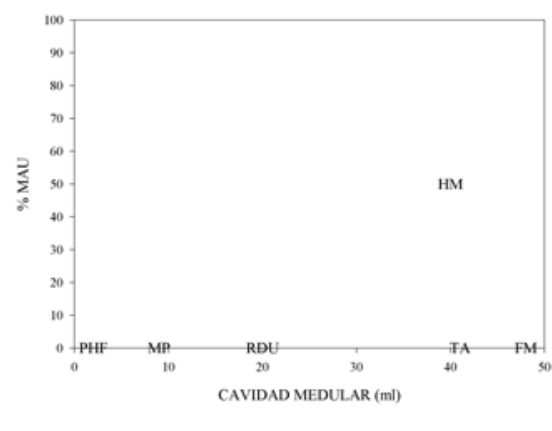

$\mathrm{c}$

Figura 7.105. a) Relación \%MAU VS FUI huesos "no-largos"; b) Relación \%MAU VS FUI huesos "largos"; c) Relación \%MAU VS Cavidad Medular.

\subsubsection{1.e. Fragmentación del subconjunto}

Los módulos de tamaño presentes en este conjunto no superan los $50 \mathrm{~mm}$ de longitud máxima. La categoría "elementos completos" es la que presenta la frecuencia más alta en este conjunto (Figura 7.106) y está representado por los carpianos y las falanges distales.

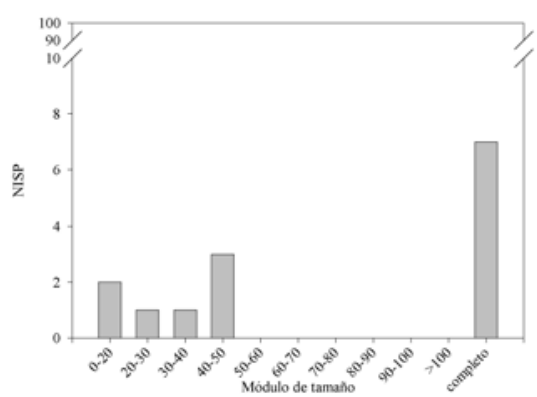

Figura 7.106. Módulos de tamaño expresado en NISP para especímenes y elementos del subconjunto adulto de camélidos 


\subsubsection{1.f. Utilización de las carcasas y Termoalteraciones}

No hay registro de utilización de las carcasas por medio de marcas o huellas en el material óseo de este subconjunto. Pero si se registraron tres especímenes de los catorce con señales de alteración térmica, los cuales podrían haber estado expuestos a temperaturas mayores a $\operatorname{los} 300^{\circ} \mathrm{C}$.

Tabla 7.58. Termoalteración del conjunto de camélidos adultos.

\begin{tabular}{cccccc}
\hline Descripción & Sin alteración & $\begin{array}{c}\text { Oxidación } \\
\text { incompleta/carbonización } \\
\text { marrón claro-negro } \\
\text { (moteado) }\end{array}$ & Carbonizado & Calcinado & Total \\
Color & - & $200^{\circ} \mathrm{C}-300^{\circ} \mathrm{C}$ & $300{ }^{\circ} \mathrm{C}$ & gris-blanco & \\
Temperatura & $<200{ }^{\circ} \mathrm{C}$ & - & 3 & 1 & 14 \\
NISP & 10 & $-\mathrm{C}$ & \\
\hline
\end{tabular}

Considerando la relación tipo de estado al realizarse la fractura y tipo de alteración térmica (Tabla 7.59) se observó que en la muestra afectada por calor cuatro de los siete casos presenta asociado algún tipo de fractura. Tres de ellas manifiestan características de fractura realizada en estado seco y la tercera en estado un estado intermedio. En tanto no se registraron fracturas frescas.

Tabla 7.59. Relación entre tipo de termoalteración y tipo de fractura del conjunto de camélidos adultos.

\begin{tabular}{lcccc}
\hline Tipo de alteración & Fresca & Intermedia & Seca & Total \\
Sin alteración & - & 3 & - & 3 \\
Carbonizado & - & 1 & 2 & 3 \\
Calcinado & - & - & 1 & 1 \\
$\quad$ Total & 1 & 4 & 3 & 7 \\
\hline
\end{tabular}

\subsubsection{Camélidos subadultos}

Conjunto compuesto por un NISP igual a 6 lo que representa el $30 \%$ de la muestra de camélidos.

\subsubsection{2.a. Supervivencia del material óseo mediada por la densidad ósea}

Los resultados obtenidos y volcados en la Tabla 7.60 muestran que del metacarpo se preservaron zonas con densidad ósea baja en tanto que el conjunto global se comporta de manera inversa ya que al tomar en cuenta todos los elementos en general se nota la preservación de zonas con densidad relativamente mas alta. De todos modos ninguna de las correlaciones es significativa estadísticamente. 
Tabla 7.60. Correlación entre el \%MAU y la densidad ósea.

\begin{tabular}{cccc}
\hline Elemento & Rank & $r_{\mathrm{s}}$ & $p$ \\
Metacarpo & 4 & -.258 & .371 \\
Arqueofauna & 29 & .429 & .348 \\
\hline
\end{tabular}

\subsubsection{2.b. Número Mínimo de Elementos (MNE)}

Solo se identificaron seis elementos pertenecientes al esqueleto apendicular. En el caso del metacarpo se identificó un elemento completo y un cóndilo distal. El MNE de la falange proximal y de la falange medial se construyó a partir de la identificación de una epífisis proximal y una diáfisis completa para cada uno de los elementos.

Tabla 7.61. Abundancia relativa de partes esqueletarias.

\begin{tabular}{crcccrrrr}
\hline Elemento & NISP & I & D & S/D & MNE & MNI & MAU & \%MAU \\
MC & 2 & - & - & 2 & 1 & 1 & 0.25 & 100 \\
PHF & 2 & - & - & 2 & 1 & 1 & 0.13 & 50 \\
PHS & 2 & - & - & 2 & 1 & 1 & 0.13 & 50 \\
\multicolumn{5}{c}{ Total } & 6 & & & \\
\multicolumn{5}{c}{ D = derecho, I = izquierdo, S/D = axial o sin datos }
\end{tabular}

\subsubsection{2.c. Número Mínimo de Individuos (MNI)}

El número calculado para este conjunto fue basado a partir de los datos presentados en la Tabla 7.61 y proporcionó como resultado la presencia de un solo individuo.

\subsubsection{2.d. Fragmentación del subconjunto}

Para este conjunto se registró una mayor frecuencia en términos de NISP de especímenes con tamaños entre $0-20 \mathrm{~mm}$. Salvo los completos el resto no supera los 50 $\mathrm{mm}$.

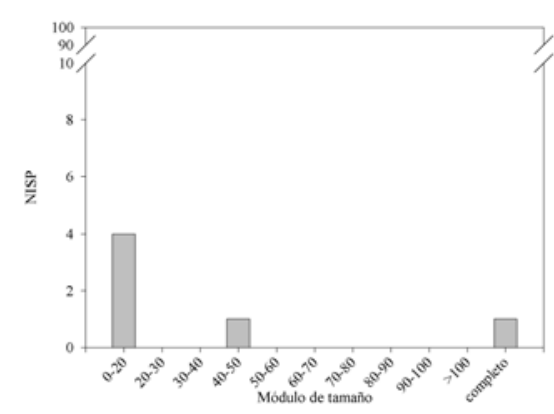


Figura 7.107. Módulos de tamaño expresado en NISP para especímenes y elementos del subconjunto subadulto de camélidos

\subsubsection{2.e. Utilización de las carcasas y termoalteración}

Al igual que en el conjunto adulto no se registró la utilización de las carcasas por medio de marcas o huellas en el material óseo.

Por otro lado y respecto de la termoalteración se identificó la presencia de un elemento calcinado (Tabla 7.62).

En cuanto a las fracturas se registró un solo espécimen con fractura fresca y sin rasgos de alteración térmica.

Tabla 7.62. Termoalteración del conjunto de camélidos adultos.

\begin{tabular}{cccccc}
\hline Descripción & Sin alteración & $\begin{array}{c}\text { Oxidación } \\
\text { incompleta/carbonización } \\
\text { marrón claro-negro } \\
\text { (moteado) }\end{array}$ & Carbonizado & Calcinado & \\
Color & - & $200^{\circ} \mathrm{C}-300^{\circ} \mathrm{C}$ & $300{ }^{\circ} \mathrm{C}$ & $>500{ }^{\circ} \mathrm{C}$ & \\
$\begin{array}{c}\text { Temperatura } \\
\text { NISP }\end{array}$ & $<200{ }^{\circ} \mathrm{C}$ & - & - & 1 & 6 \\
\hline
\end{tabular}

\subsubsection{Subconjunto no camélido}

El subconjunto no presentó marcas asociadas a procesamiento primario, secundario o formatización.

Con respecto a la alteración térmica esta se ha registrado tanto en los "no identificables" de tamaño corporal 4 como en "no identificables" de otros tamaños corporales. Huesos carbonizados se presentan para el tamaño corporal 1, 2-3 y 4, en tanto que la clase 2-3 también presenta un elemento calcinado.

Tabla 7.63. Termoalteración del conjunto de no camélido.

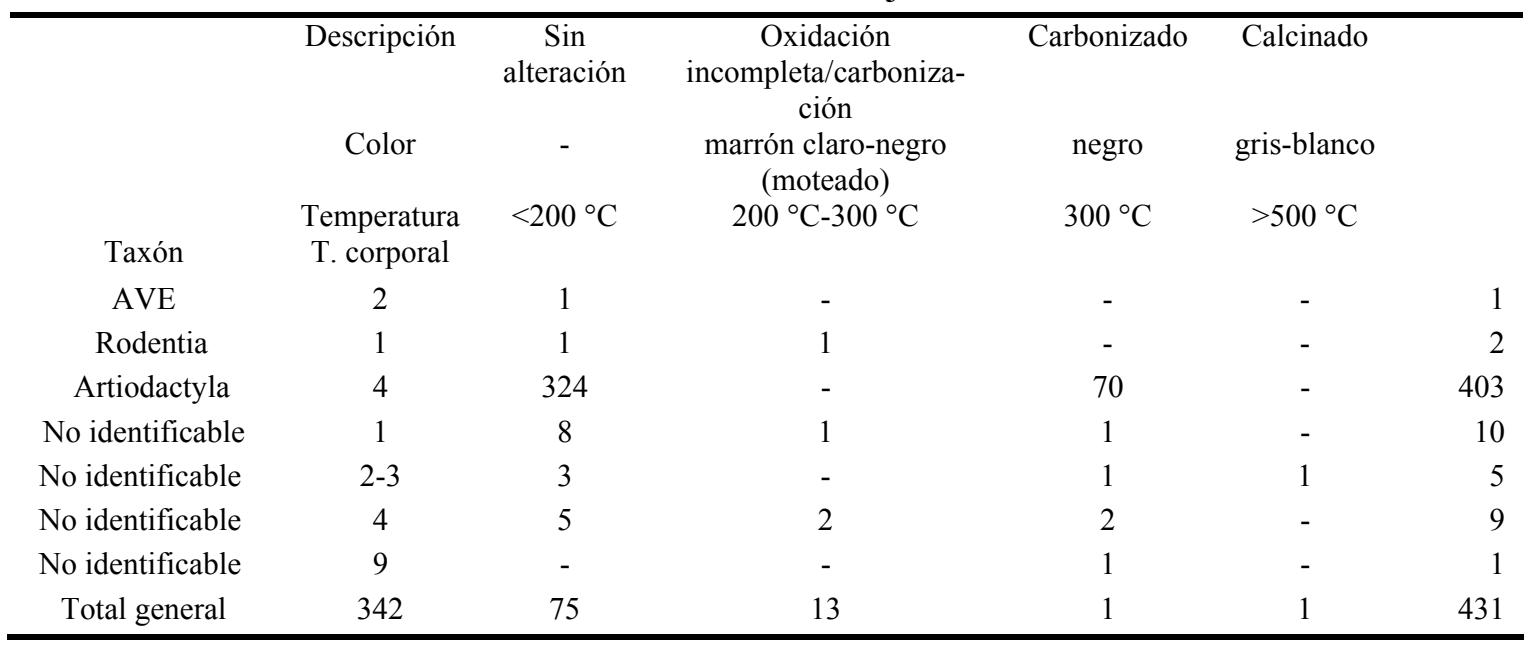


En cuanto a la fragmentación del conjunto se pudo observar para el tamaño corporal 1 que hay elementos fragmentados y completos. Para los no identificables es mayor la proporción de los fragmentados en relación con los completos, en tanto que para los roedores sólo se presenta uno fragmentado y otro completo.

Para el tamaño corporal 2 sólo hay un elemento completo asignado a ave. En tanto que para el tamaño corporal 4, sean estos artiodáctilos o no identificables, los especímenes se presentan totalmente fragmentados con la mayor frecuencia de casos en los tamaños más pequeños.
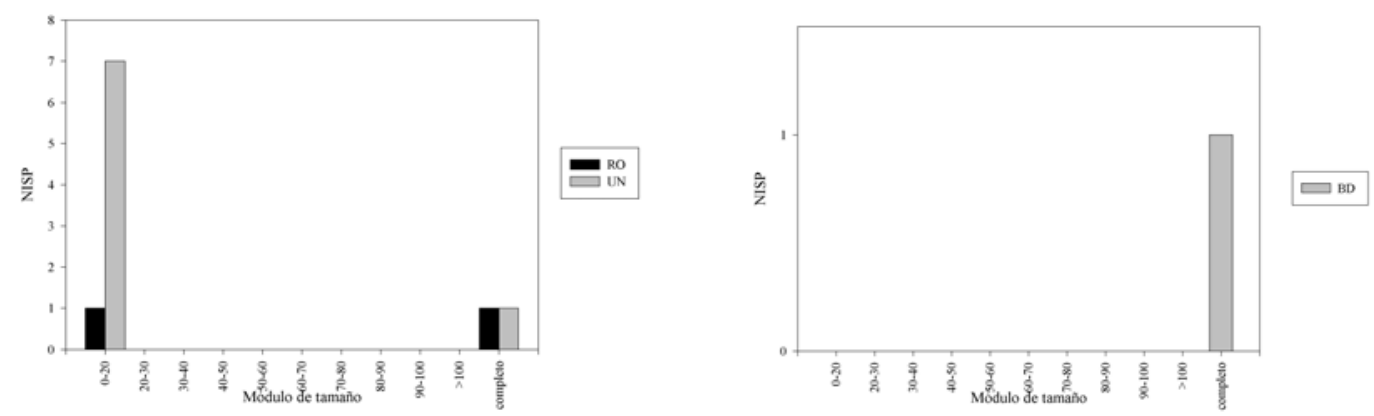

a

$\mathrm{b}$

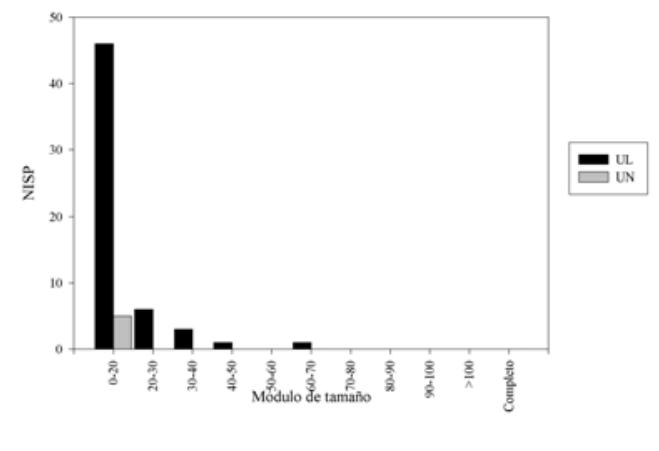

Figura 7.108. Fragmentación del conjunto no camélido expresado en NSP. a) Tamaño corporal 1, b) Tamaño corporal 2 y c) Tamaño corporal 4. 


\subsection{Yutopián - Estructura 1 - Análisis faunístico}

El total de especímenes y elementos recuperados arrojó un NSP=2241. De este total se clasificó a nivel taxonómico el 96,16\%.

Tabla 8.1. Composición del conjunto faunístico de la Estructura 1.

\begin{tabular}{|c|c|c|}
\hline Taxón & Tamaño corporal & NSP \\
\hline AVES & 1 & 1 \\
\hline AVES & $1-2$ & 2 \\
\hline AVES & 2 & 1 \\
\hline Chaetophractus vellerosus & 2 & 13 \\
\hline Rodentia & 1 & 22 \\
\hline Rodentia & 2 & 27 \\
\hline Chinchillidae & 1 & 2 \\
\hline Ctenomys $s p$ & 1 & 8 \\
\hline Microcavia sp. & 1 & 1 \\
\hline Lagidium viscacia & 2 & 1 \\
\hline Canidae & 2 & 1 \\
\hline Artiodactyla & $3-4$ & 2 \\
\hline Artiodactyla & 4 & 1952 \\
\hline Lama sp. & 4 & 119 \\
\hline Lama guanicoe & 4 & 1 \\
\hline Hippocamelus antisensis & 4 & 2 \\
\hline Subtotal Identificados & & 2155 \\
\hline No identificable & 1 & 29 \\
\hline No identificable & $1-2$ & 14 \\
\hline No identificable & 2 & 6 \\
\hline No identificable & $2-3$ & 2 \\
\hline No identificable & 4 & 12 \\
\hline No identificable & 9 & 23 \\
\hline Subtotal No identificables & & 86 \\
\hline & TOTAL & 2241 \\
\hline
\end{tabular}

Se identificaron un total de doce taxones diferentes. De este total algunas categorías se pudieron dividir de acuerdo a la asignación de algunos especímenes o elementos a distintos tamaños corporales. Para AVES se sugiere la presencia de al menos dos tamaños corporales. Dos especímenes de este taxón no han podido asignarse a ninguno de los tamaños corporales 1 o 2 por lo cual se procedió a definir uno denominado 1-2, el que si bien no ha sido definido por ningún tamaño corporal, por sus características pertenecería a un individuo del grupo de los más pequeños y no a un 
tamaño mayor. Lo mismo sucede con Artiodactyla (tamaño corporal 3-4). Por ultimo Rodentia presenta los tamaños corporales 1 y 2 .

Dentro del genero Lama fue posible la identificación de un elemento a Lama guanicoe. Este corresponde a un radioulna sobre el cual se aplicaron las siguientes medidas: \#131, \#132 y \#133 de Kent (1982).

En cuanto a los agentes tafonómicos que actuaron sobre el conjunto se puede observar que los especímenes o elementos que presentan el estadio de meteorización 1 son los mas frecuentes en la muestra (67,53\%), seguidos por aquellos con estadio 2 (27,05\%). En conjunto estos dos representan el 94,58\% de la muestra. Este resultado nos permite sugerir que el conjunto presenta en general una meteorización relativamente baja. Un total de veintisiete especímenes presentan el estadio 3, el cual es el estadio más alto registrado. Esto últimos corresponden al tamaño corporal 4, los cuales por su tamaño general pueden haber estado expuestos más tiempo a los agentes subaéreos de meteorización.

Tabla 8.2. Meteorización del conjunto faunístico de la Estructura 1. Yutopián

\begin{tabular}{|c|c|c|c|c|c|c|}
\hline \multirow[t]{2}{*}{ Tamaño corporal } & \multicolumn{5}{|c|}{ Meteorización } & Total NSP \\
\hline & 1 & 2 & 3 & 4 & 5 & \\
\hline 1 & 55 & 5 & - & - & - & 60 \\
\hline $1-2$ & 11 & - & - & - & - & 11 \\
\hline 2 & 16 & 29 & - & - & - & 45 \\
\hline $2-3$ & 2 & - & - & - & - & 2 \\
\hline $3-4$ & 2 & - & - & - & - & 2 \\
\hline 4 & 248 & 97 & 27 & - & - & 372 \\
\hline 9 & 3 & 4 & - & - & - & 7 \\
\hline TOTAL & 337 & 135 & 27 & - & - & 499 \\
\hline
\end{tabular}

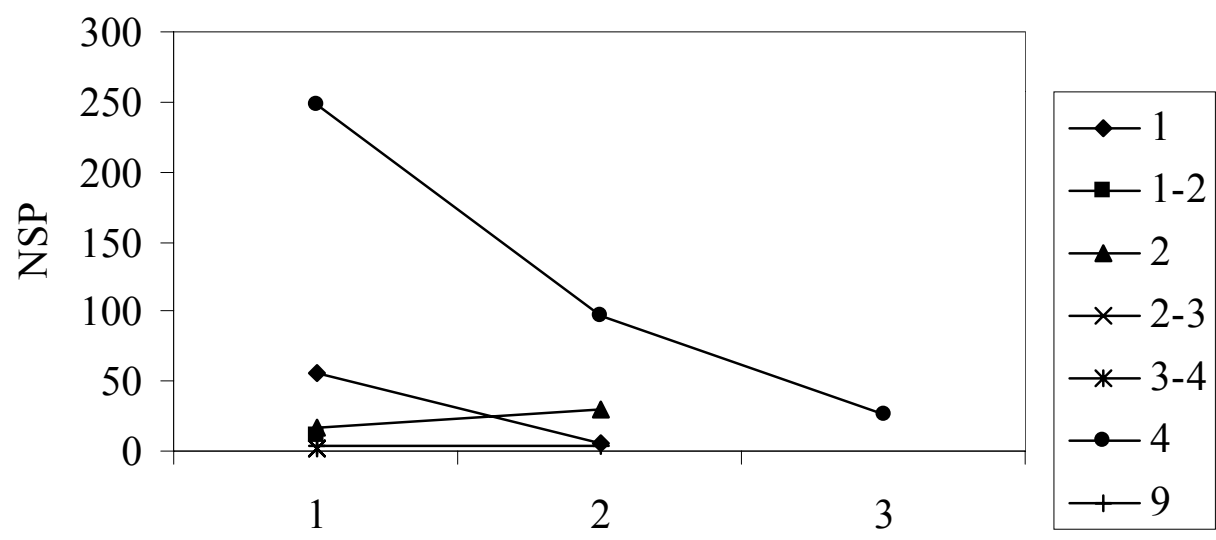

Estadios de meteorización

Figura 8.1. Estadios de meteorización según tamaño corporal. Estructura 1, Yutopián. 
La acción de roedores y carnívoros se registró en especímenes del tamaño corporal 4, reconociéndose en cuatro especímenes de la muestra. Tres de ellos presentan efectos moderados en tanto que el otro ha sido dañado en gran parte del espécimen. En cuanto a marcas de carnívoros se registraron tres especímenes, dos de los cuales presentan características similares a las huellas dejadas por este agente, pero que no ha podido ser identificado con total seguridad. No obstante ello la frecuencia de este tipo de marcas no supera el $0,26 \%$ de la muestra.

Tabla 8.3 Modificaciones por agentes naturales del conjunto faunístico de la Estructura 1. Yutopián

\begin{tabular}{crccccr}
\hline $\begin{array}{c}\text { Tamaño } \\
\text { Corporal }\end{array}$ & $\begin{array}{c}\text { Sin } \\
\text { modificaciones }\end{array}$ & $\begin{array}{c}\text { Daño ligero } \\
\text { por roedor }\end{array}$ & $\begin{array}{c}\text { Daño } \\
\text { moderado/grave } \\
\text { por roedor }\end{array}$ & $\begin{array}{c}\text { Mordisqueo } \\
\text { combinado de } \\
\text { roedor y } \\
\text { carnívoro }\end{array}$ & $\begin{array}{c}\text { Posible } \\
\text { mordisqueo de } \\
\text { carnívoro }\end{array}$ & $\begin{array}{c}\text { Total } \\
\text { NSP }\end{array}$ \\
1 & 63 & - & - & - & - & 63 \\
$1-2$ & 16 & - & - & - & - & 16 \\
2 & 49 & - & - & - & - & 49 \\
$2-3$ & 2 & - & - & - & - & 2 \\
$3-4$ & 2 & - & - & - & - & 2 \\
4 & 2080 & 2 & - & - & - & 23 \\
9 & 23 & - & - & 1 & 2 & 2241 \\
\hline
\end{tabular}

\subsubsection{Análisis del Subconjunto Camelidae}

Para este conjunto se calculó un NISP $=120$ y de ellos solo uno fue determinado a nivel específico asignándose a Lama guanicoe.

Tabla 8.4. Camelidae, huesos del esqueleto axial y apendicular. Estructura 1, Yutopián.

\begin{tabular}{lccc}
\hline Elemento & L. guanicoe & Lama sp. & NISP \\
CRN & - & 7 & 7 \\
MR & - & 8 & 8 \\
MMR & - & 2 & 2 \\
AT & - & 3 & 3 \\
CE & - & 1 & 1 \\
RB & - & 11 & 11 \\
SN & - & 1 & 1 \\
& - & & \\
SC & - & 2 & 2 \\
HM & - & 3 & 3 \\
RDU & 1 & 5 & 6 \\
CPF & - & 3 & 3 \\
CPR & - & 5 & 5 \\
CPS & - & 1 & 1 \\
CPT & - & 2 & 2 \\
\hline & & & Continúa
\end{tabular}




\begin{tabular}{lccc} 
& \multicolumn{3}{c}{ Continuación de } \\
\hline CPU & - & 2 & 2 \\
MC & - & 3 & 3 \\
& & & \\
IM & - & 5 & 5 \\
FM & - & 4 & 4 \\
TA & - & 1 & 1 \\
AS & - & 4 & 4 \\
CL & - & 1 & 1 \\
TR4 & - & 2 & 2 \\
TRC & - & 1 & 1 \\
TRT & - & 1 & 1 \\
MT & - & 3 & 3 \\
& - & & \\
MP & - & 10 & 10 \\
PHF & - & 11 & 11 \\
PHS & - & 7 & 7 \\
PHT & - & 7 & 7 \\
SEP & - & 3 & 3 \\
Total general & 1 & 119 & 120 \\
\hline
\end{tabular}

\subsubsection{Camélidos adultos}

Este subconjunto esta compuesto por un NISP $=100$ (Tabla 8.4) lo que constituye el $83.34 \%$ del subconjunto de camélidos.

Los especímenes identificados corresponden tanto a huesos del esqueleto axial como del apendicular.

\subsubsection{1.a. Supervivencia del material óseo mediada por la densidad ósea}

El resultado de este análisis muestra que las correlaciones efectuadas ofrecen seis resultados positivos, uno negativo, y tres no presentan correlación. El resultado general muestra una correlación positiva perfecta con significación estadística lo que nos sugeriría que el conjunto estaría severamente afectado por la densidad ósea.

Sin embargo al observar el comportamiento de cada elemento en particular y comparando esto con los estadios de meteorización identificados y el nivel de identificación taxonómica del conjunto se nota una incongruencia entre los resultados. Una posible explicación es que el conjunto esté modelado por procedimientos de recolección de campo que privilegiaron la recolección de huesos completos (Hill 2001). La alta representación de elementos del carpo y el tarso $(67,74 \%$ del subconjunto de camélidos adultos) puede apoyar este concepto. Por otro lado al hacer el ejercicio de excluirlos del análisis se observa que la correlación es positiva débil sin significancia estadística. Este último resultado es el que más se asemeja al obtenido en otros de los conjuntos estudiados. 
Tabla 8.5. Correlación entre el \%MAU y la densidad ósea.

\begin{tabular}{cccc}
\hline Elemento & Rank & $r_{\mathrm{s}}$ & $p$ \\
Mandíbula & 8 &, 412 &, 155 \\
Escápula & 4 &,- 316 &, 342 \\
Húmero & 5 &, 000 &, 500 \\
Radioulna & 6 &, 092 &, 431 \\
Metacarpo & 4 &, 258 &, 371 \\
Innominado & 8 &, 264 &, 283 \\
Fémur & 5 &, 000 &, 500 \\
Tibia & 5 &, 000 &, 500 \\
Calcáneo & 4 &, 258 &, 371 \\
Metatarso & 4 &, 316 &, 342 \\
Arqueofauna & 29 & 1,000 &, 000 \\
Arqueofauna* & 21 &, 153 &, 091 \\
\hline *Sin los elementos del carpo y el tarso.
\end{tabular}

\subsubsection{1.b. Número Mínimo de Elementos (MNE)}

Cráneo (CRN)

Se identificaron dos zonas diagnósticas: el petroso y un cóndilo del occipital. En base a dos fragmentos de petroso izquierdo se pudo establecer un MNE igual a 2

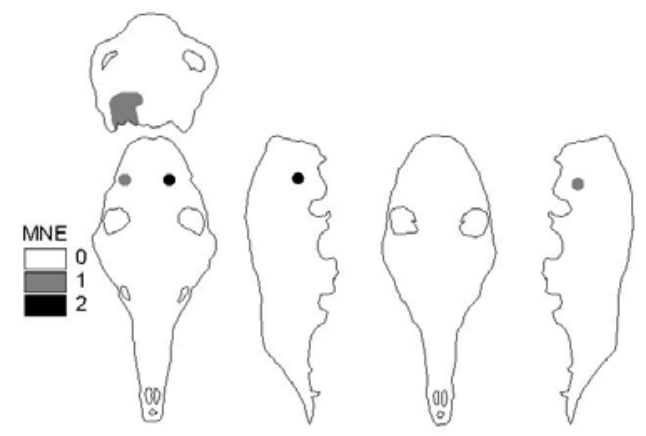

Figura 8.2. MNE Cráneo

Mandibula (MR)

Las zonas diagnósticas determinadas para este elemento de la cabeza corresponden todas a la rama ascendente. Entre los hallados se encuentra el cóndilo articular sobre el cual se procedió al cálculo de un MNE de 2 elementos.

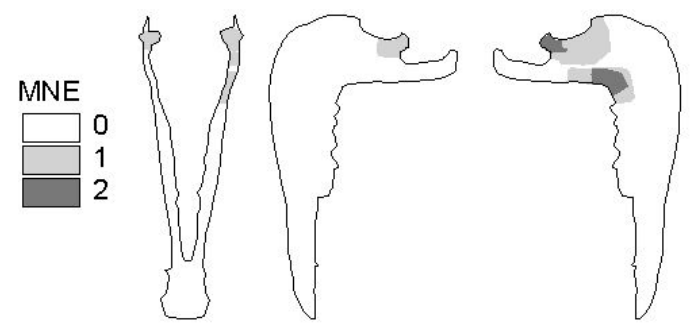

Figura 8.3. MNE Mandíbula

Molar mandibular (MMR) 
Se identificó un segundo molar completo. $(\mathrm{MNE}=1)$

$\operatorname{Atlas}(A T)$

Las zonas diagnósticas que representan a este elemento corresponden a cavidades articulares caudales (Figura 8.4) El MNE comprehensivo es igual a 2.
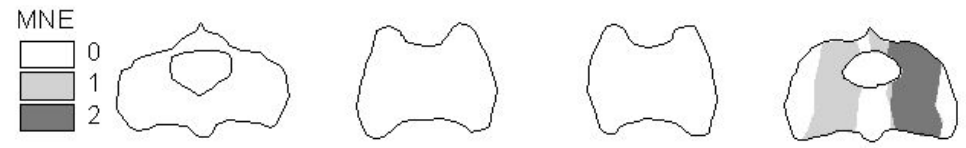

Figura 8.4. MNE Atlas

Cervicales 3-7 (CE)

Para este elemento se identificó la siguiente zona diagnóstica: cuerpo vertebral. El MNE comprehensivo calculado es igual a 1.

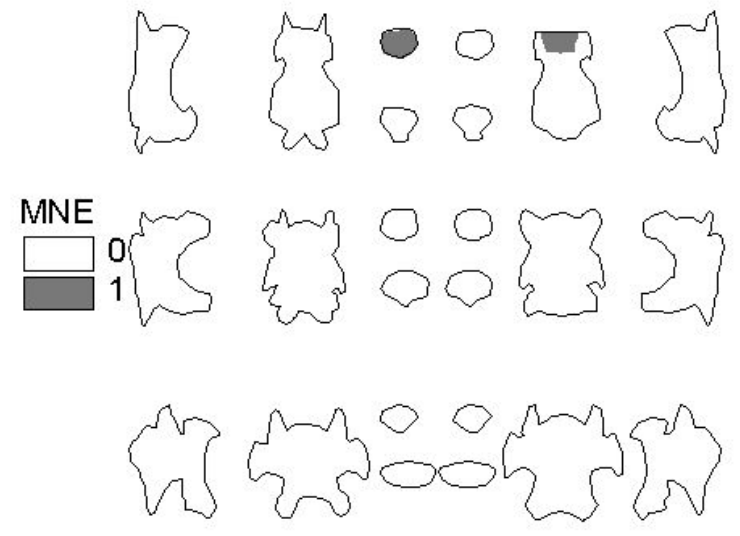

Figura 8.5. MNE Cervicales 3 a 7

Costillas (RB) y Esternón (SN)

Se identificaron seis porciones distales de costillas $(\mathrm{MNE}=6)$ y un fragmento de esternebra $(\mathrm{MNE}=1)$.

Escápula (SC)

Este elemento está representado por la presencia de dos especímenes cuyas zonas diagnósticas corresponden a la cavidad glenoidea. El MNE calculado tanto para la escápula izquierda como para el elemento derecho corresponde a uno y el MNE total es igual a 2 . 

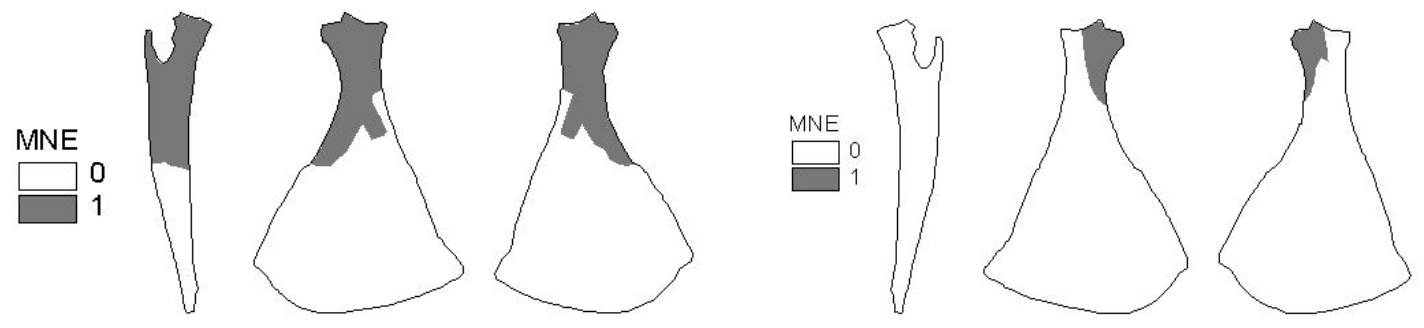

Figura 8.6. MNE Escápula izquierda y derecha

Humero (HM)

Para este elemento se identificaron las siguientes zonas diagnósticas: cóndilo lateral y cóndilo medial. Para el lado izquierdo se calculó un MNE igual a 1.
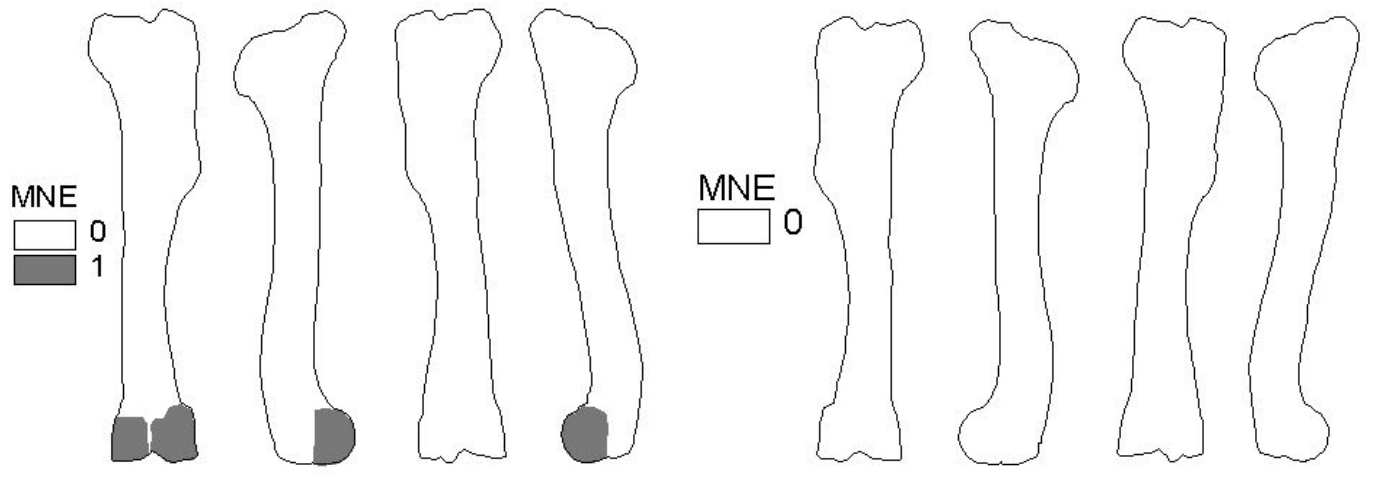

Figura 8.7. MNE Húmero izquierdo y derecho

\section{Radioulna $(R D U)$}

Para este elemento las zonas diagnósticas que permitieron identificar a este elemento son: proceso olecraniano, proceso anconeal, facetas articulares, cavidad glenoidea lateral, cavidad glenoidea medial. El MNE obtenido arrojó como resultado para el elemento izquierdo un valor igual a 1 y para el derecho 2 , lo cual hace un total de un mínimo de 3 elementos.

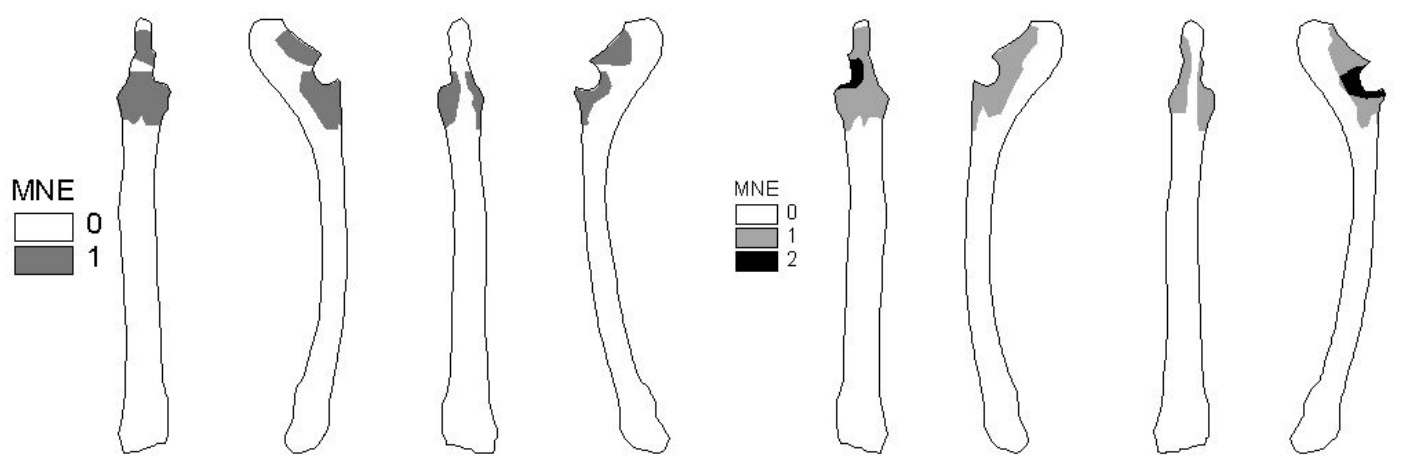

Figura 8.8. MNE Radioulna izquierda y derecha 


\section{Carpo cuarto $(C P F)$}

Se calculó un MNE igual a 3 para este elemento, asignándose 2 al lado izquierdo y 1 al lado derecho. Este elemento presenta ejemplares fragmentados.

\section{Carpo radial (CPR)}

Para este elemento el MNE es igual a 5, asignándose 2 al lado izquierdo y 3 al lado derecho. Este elemento se presenta completo y fragmentado.

Carpo segundo (CPS)

El MNE es igual a 1 para este elemento, asignándose al lado izquierdo.

\section{Carpo tercero $(C P T)$}

El cálculo del MNE arrojó un resultado de 2 elementos, asignándose 1 al lado izquierdo y 1 al lado derecho. Este elemento se presenta en todos los casos de manera completa.

\section{Carpo ulnar (CPU)}

Se computó un MNE igual a 2, designándose todos al lado izquierdo. Este elemento se presenta completo y fragmentado.

\section{Metacarpo (MC)}

Para este elemento las zonas diagnósticas utilizadas fueron epífisis proximal, y diáfisis posterior. El MNE comprehensivo para este elemento es de 1 para el lado izquierdo y 1 para el derecho haciendo un total de 2 elementos (Figura 8.9)
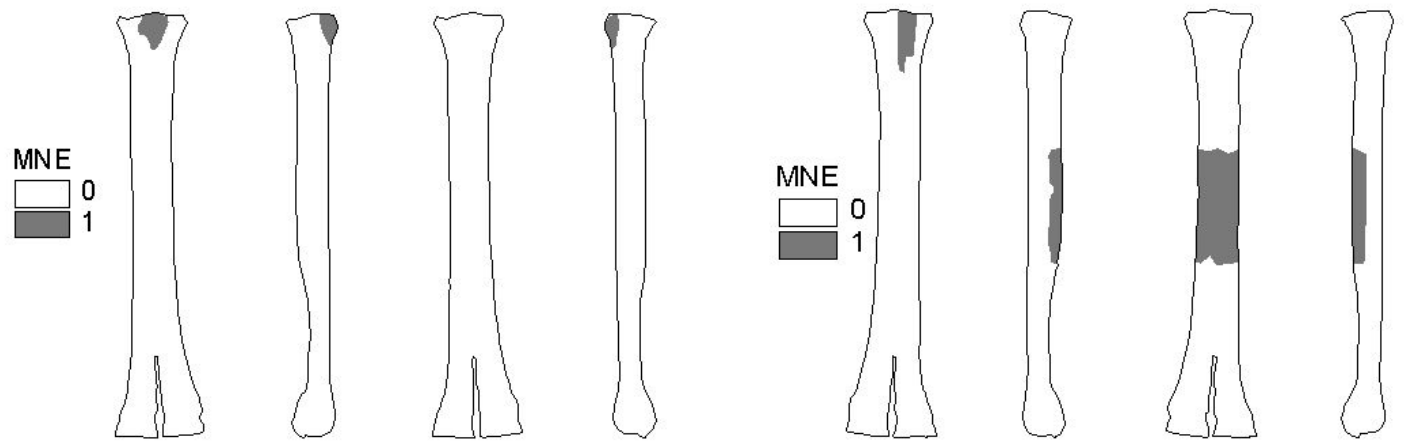

Figura 8.9. MNE Metacarpo izquierdo y derecho

Innominado (IM) 
Las zonas diagnósticas reconocidas parta este elemento son la hoja del ilium, el acetábulo y la diáfisis del pubis. Sobre la base de estas zonas se logró determinar un MNE igual a 1 para el elemento izquierdo y un MNE igual a 2 para el derecho. Esto es un total de 3 elementos (Figura 8.10)
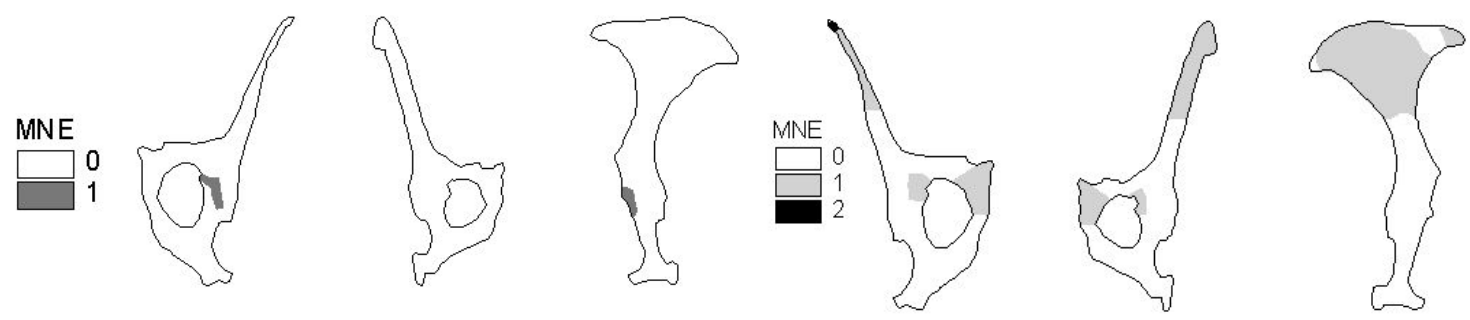

Figura 8.10. MNE Innominado izquierdo y derecho

Fémur (FM)

Sólo esta representado por un espécimen que corresponde a la zona donde se ubica el foramen nutricio posterolateral. El MNE alcanzado es igual a 1 elemento izquierdo (Figura 8.11)
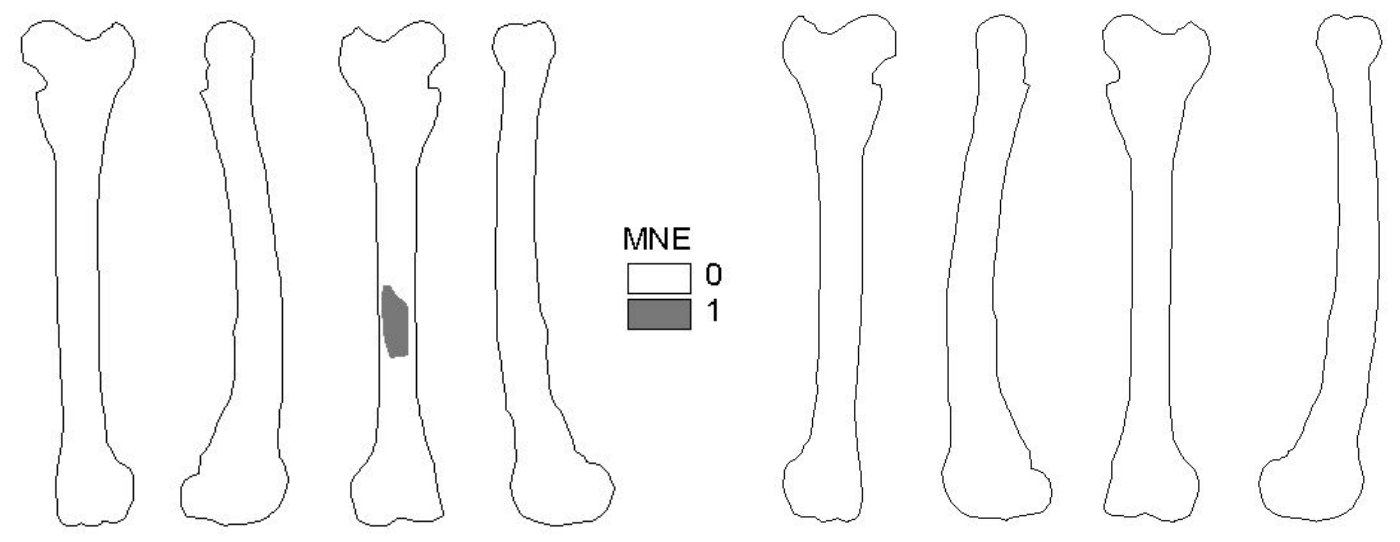

Figura 8.11. MNE Fémur izquierdo y derecho

Tibia (TA)

Las zonas diagnósticas utilizadas para identificar a los especímenes de este elemento corresponden a la diáfisis anterior distal y al surco medial. Se calculó un MNE igual a 1 para el elemento izquierdo (Figura 8.12) 

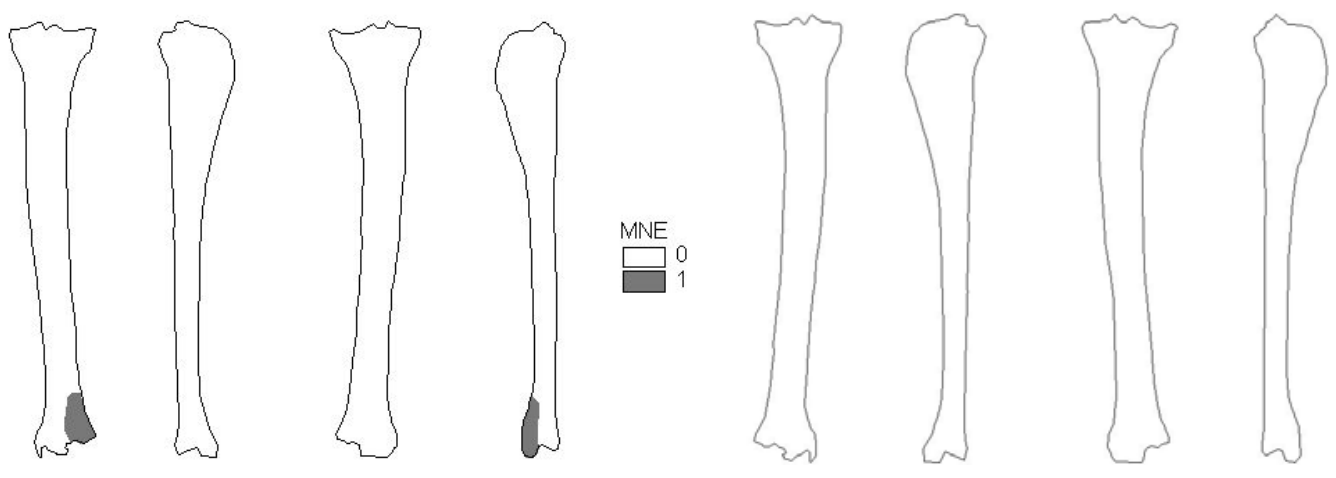

Figura 8.12. MNE Tibia izquierda y derecha

Astrágalo (AS)

Para el elemento izquierdo se calculo un MNE igual a 2 en tanto que el derecho no esta presente en el registro.
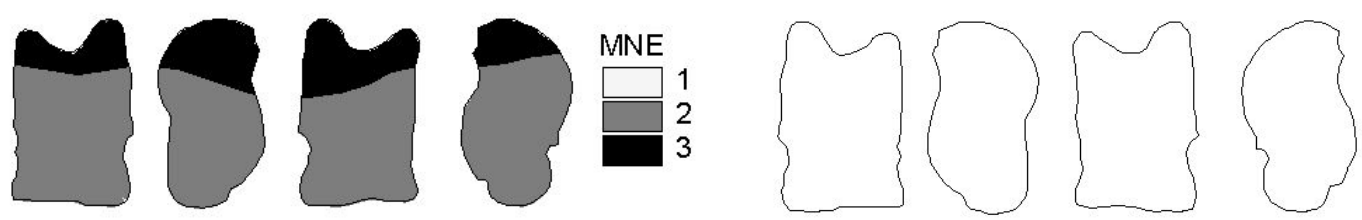

Figura 8.13. MNE Astrágalo izquierdo y derecho

\section{Calcáneo $(C L)$}

El MNE calculado para cada lado corresponde a 1 elemento para el izquierdo y ninguno para el derecho $(\mathrm{MNE}=1)$
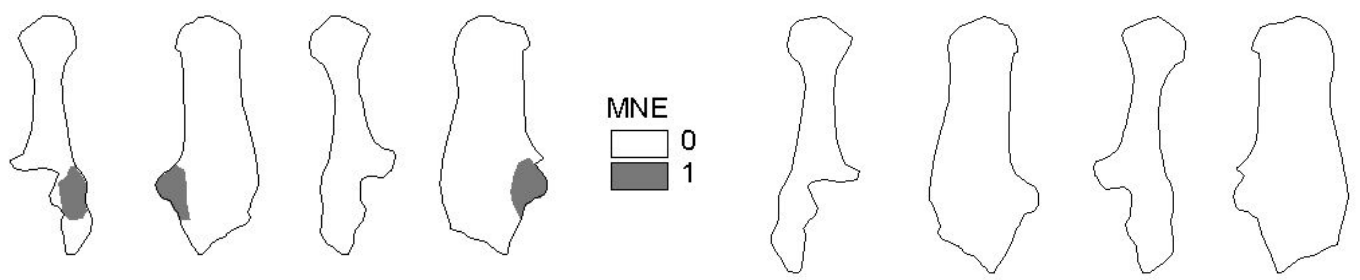

Figura 8.14. MNE Calcáneo izquierdo y derecho

Tarso cuarto (TR4)

Un MNE igual a 2 fue el calculado para este elemento, asignándose todos al lado izquierdo. Este elemento se presenta en todos los casos de manera completa.

Tarso central (TRC)

Se calculó un MNE igual a 1. Este corresponde al lado derecho. Este elemento se presenta en todos los casos de manera completa. 
Tarso tercero (TRT)

Se estimó en 1 el MNE. En cuanto a la lateralidad esta fue determinada al lado izquierdo. Este elemento se presenta en todos los casos de manera completa.

Metatarso (MT)

Este elemento presenta tres especímenes a partir de los cuales se pudo establecer un MNE igual a 1 para el lado izquierdo y de 2 para el lado derecho (Figura 8.15). El MNE total es igual a 3.
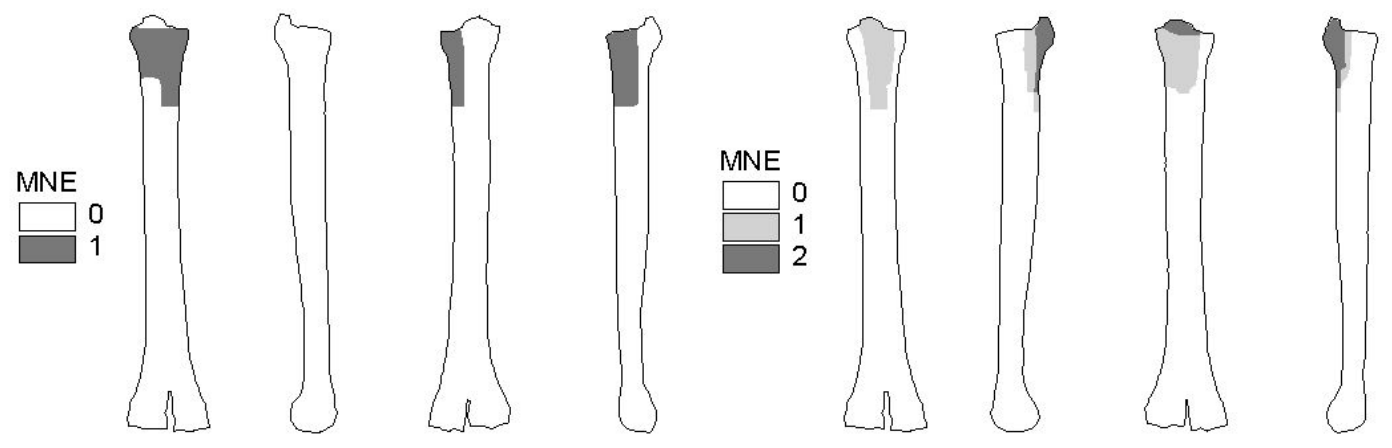

Figura 8.15. MNE Metatarso izquierdo y derecho

Metapodio general (MP)

Se logró un MNE igual a 1 (Figura 8.16) en base a un fragmento de epífisis y diáfisis proximal de la porción craneal.
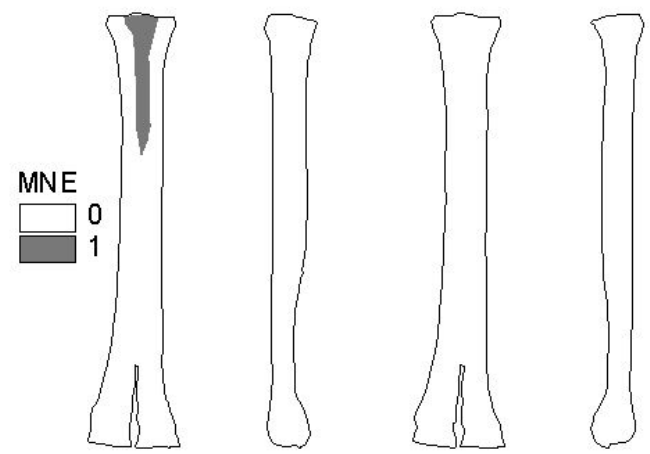

Figura 8.16 MNE Metapodio general

Falange proximal (PHF)

Para este elemento las zonas diagnósticas utilizadas fueron la epífisis proximal, epífisis distal y diáfisis. Sobre los especímenes asignados a esta categoría se calculó un MNE igual a 6 elementos (Figura 8.17) 

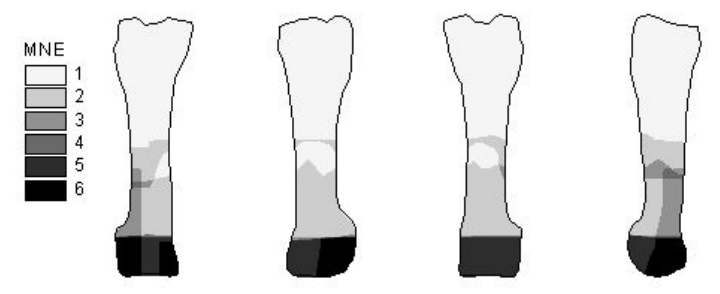

Figura 8.17. MNE Falange proximal general

Falange medial (PHS)

Para este elemento, al igual que para el caso de todas las falanges, las zonas diagnósticas utilizadas fueron la epífisis proximal, epífisis distal y diáfisis. El cálculo del MNE arrojó una cantidad de 4 elementos (Figura 8.18)
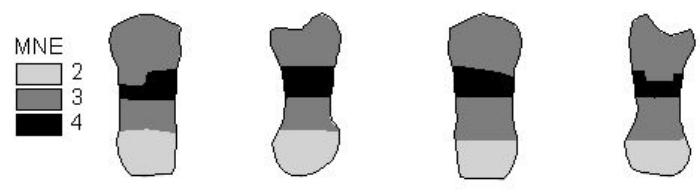

Figura 8.18. MNE Falange medial

Falange distal (PHT)

Para este elemento las zonas diagnósticas utilizadas fueron la epífisis proximal, epífisis distal y diáfisis, siendo el MNE calculado igual a 7.
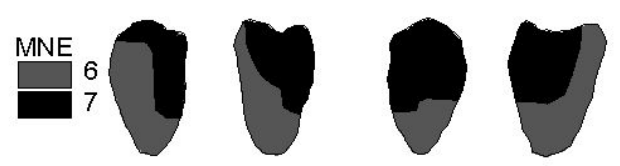

Figura 8.19. MNE Falange distal

Sesamoideos (SEP)

Se identificaron tres elementos completos $(\mathrm{MNE}=3)$

A partir de los resultados obtenidos en el cálculo del MNE comprehensiva se procedió a la confección de la Tabla 8.6 Los valores de NISP para cada elemento y el cálculo de estimadores como el MNE, MNI, MAU y \%MAU son presentados allí. 
Tabla 8.6. Abundancia relativa de partes esqueletarias expresadas como NISP, MNE comprehensivo, MAU y \%MAU.

\begin{tabular}{|c|c|c|c|c|c|c|c|c|}
\hline Elemento & NISP & I & $\bar{D}$ & $\mathrm{~S} / \mathrm{D}$ & $\overline{M N E}$ & $\overline{M N I}$ & MAU & $\% \mathrm{MAU}$ \\
\hline CRN & 7 & - & 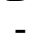 & 2 & 2 & 2 & 2.00 & 80.00 \\
\hline MR & 8 & - & - & 2 & 2 & 2 & 2.00 & 80.00 \\
\hline MMR & 2 & - & 2 & - & 1 & 1 & 0.17 & 6.67 \\
\hline AT & 3 & - & - & 2 & 2 & 2 & 2.00 & 80.00 \\
\hline $\mathrm{CE}$ & 1 & - & - & 1 & 1 & 1 & 0.20 & 8.00 \\
\hline RB & 11 & - & - & 6 & 6 & 1 & 0.25 & 10.00 \\
\hline SN & 1 & - & - & 1 & 1 & 1 & 0.14 & 5.71 \\
\hline $\mathrm{SC}$ & 2 & 1 & 1 & - & 2 & 2 & 1.00 & 40.00 \\
\hline HM & 2 & 1 & - & - & 1 & 1 & 0.50 & 20.00 \\
\hline RDU & 4 & 1 & 2 & - & 3 & 2 & 1.50 & 60.00 \\
\hline $\mathrm{CPF}$ & 3 & 2 & 1 & - & 3 & 2 & 1.50 & 60.00 \\
\hline CPR & 5 & 2 & 3 & - & 5 & 3 & 2.50 & 100.00 \\
\hline CPS & 1 & 1 & - & - & 1 & 1 & 0.50 & 20.00 \\
\hline CPT & 2 & 1 & 1 & - & 2 & 1 & 1.00 & 40.00 \\
\hline CPU & 2 & 2 & - & - & 2 & 2 & 1.00 & 40.00 \\
\hline $\mathrm{MC}$ & 3 & 1 & 1 & - & 2 & 1 & 1.00 & 40.00 \\
\hline IM & 5 & 1 & 2 & - & 3 & 2 & 1.50 & 60.00 \\
\hline FM & 1 & 1 & - & - & 1 & 1 & 0.50 & 20.00 \\
\hline TA & 1 & 1 & - & - & 1 & 1 & 0.50 & 20.00 \\
\hline AS & 4 & 3 & - & - & 3 & 3 & 1.50 & 60.00 \\
\hline CL & 1 & 1 & - & - & 1 & 1 & 0.50 & 20.00 \\
\hline TR4 & 2 & 2 & - & - & 2 & 2 & 1.00 & 40.00 \\
\hline TRC & 1 & - & 1 & - & 1 & 1 & 0.50 & 20.00 \\
\hline TRT & 1 & 1 & - & - & 1 & 1 & 0.50 & 20.00 \\
\hline MT & 3 & 1 & 2 & - & 3 & 2 & 1.50 & 60.00 \\
\hline MP & 1 & - & - & 1 & 1 & 2 & 0.25 & 10.00 \\
\hline PHF & 9 & - & - & 6 & 6 & 1 & 0.75 & 30.00 \\
\hline PHS & 4 & - & - & 4 & 4 & 1 & 0.50 & 20.00 \\
\hline PHT & 7 & - & - & 7 & 7 & 1 & 0.88 & 35.00 \\
\hline SEP & 3 & - & - & 3 & 3 & 1 & 0.38 & 15.00 \\
\hline Total general & 100 & & & & & & & \\
\hline
\end{tabular}

\subsubsection{1.c. Número Mínimo de Individuos (MNI)}

En base a tres astrágalos izquierdos y tres carpos radiales derechos se obtuvo un MNI de tres individuos adultos. Se recuerda que por osteometría se pudo asignar a uno de estos a guanaco.

\subsubsection{1.d. Unidades anatómicas representadas (MAU)}

Como puede observarse, en términos generales los elementos del esqueleto axial desde el axis hacia la región caudal se encuentran menos representados que los 
elementos del esqueleto apendicular. No obstante el cráneo, la mandíbula, el hioides y las piezas dentales (todos elementos que componen la cabeza), así como el atlas están más representados que los elementos más posteriores del esqueleto axial.

Para el esqueleto apendicular los elementos más representados corresponden a los miembros anteriores. Se puede observar que las frecuencias más altas corresponden a los elementos más pequeños.

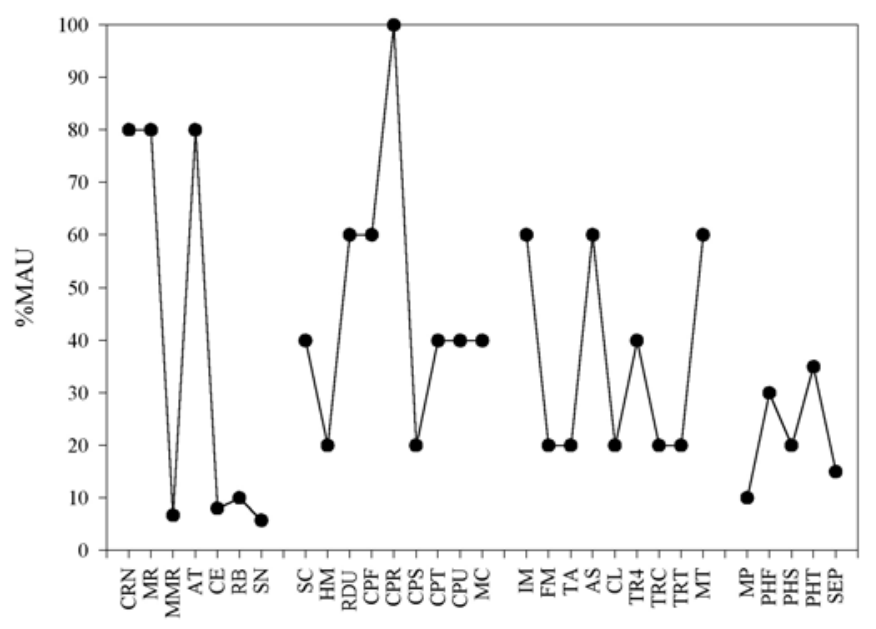

Figura 8.20. Abundancia relativa de elementos esqueletarios.

Como puede observarse en la Figura 8.21.a los elementos "no-largos" presentan una tendencia similar a la planteada para la curva de utilidad inversa. Esto se nota al realizar la correlación de los valores cuyo resultado es una relación negativa estadísticamente significativa $\left(r_{s}-.7939 \mathrm{p}\right.$.003). Esto nos muestra la alta proporción de elementos de bajo rendimiento en términos de rendimiento de carne como lo es el cráneo. Para los huesos largos esta relación también es negativa y estadísticamente significativa $\left(r_{s}-.7590 \mathrm{p} .040\right)$. Con respecto a la relación entre el \%MAU y la cavidad medular se observa una relación negativa estadísticamente significativa $\left(r_{s}-.7590 \mathrm{p}\right.$ .040). Estos resultados permiten afirmar que el conjunto está compuesto por unidades anatómicas de bajo rendimiento económico en relación al índice de utilidad de carne y el volumen de la cavidad medular. 

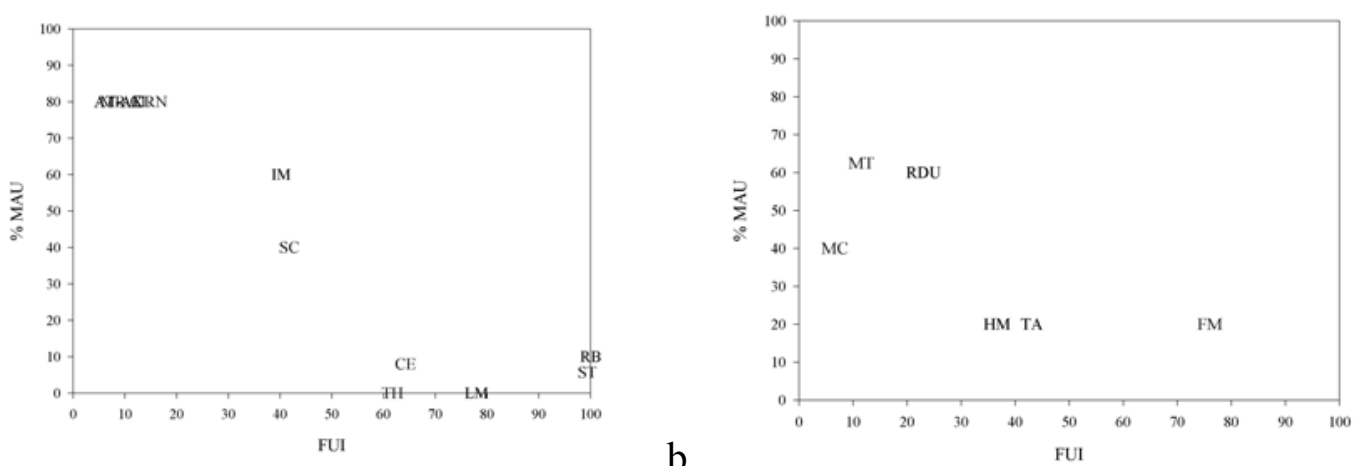

a

$\mathrm{b}$

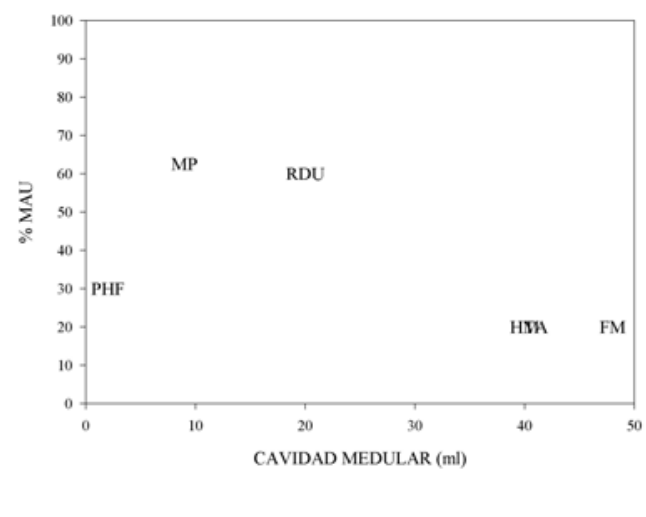

Figura 8.21. a) Relación \%MAU VS FUI huesos "no-largos"; b) Relación \%MAU VS FUI huesos "largos"; c) Relación \%MAU VS Cavidad Medular.

\subsubsection{1.e. Fragmentación del subconjunto}

El resultado de este análisis muestra que el conjunto en su gran mayoría se encuentra representado por fragmentos, registrándose las mayores frecuencias en los módulos de tamaños más pequeños. Por otro lado los elementos completos son en general los que corresponden al carpo y al tarso.

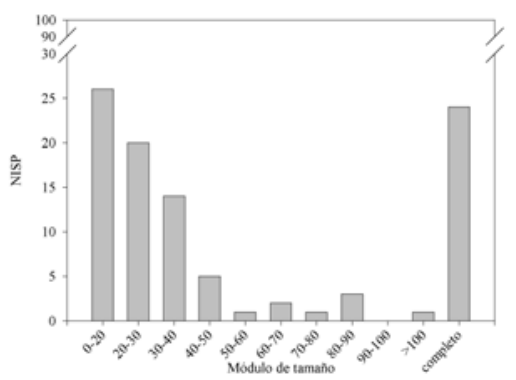

Figura 8.22. Módulos de tamaño expresado en NISP para especímenes y elementos del subconjunto adulto de camélidos

Esqueleto axial 
Para el esqueleto axial (Figura 8.23) el perfil de fragmentación de estos elementos muestra una gran fragmentación ya que ninguno presenta más del diez por ciento del área del elemento. El cráneo presenta superficies que no exceden el 2\% y que representan largos máximos de los especímenes comprendidos entre 11 y $36 \mathrm{~mm}$. La mandíbula presenta especímenes cuyas superficies relativas están comprendidas entre el 2 y $5 \%(19-55 \mathrm{~mm})$. El atlas es el que presenta mayor cantidad de superficie relativa preservada pero en términos de longitudes máximas están comprendidas entre los 11 a $20 \mathrm{~mm}$. Por último las vértebras están representadas por aproximadamente un 2\% (20 $\mathrm{mm})$

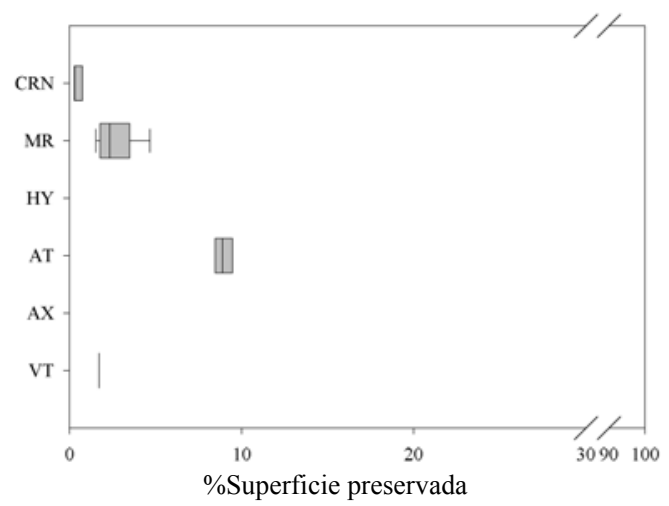

Figura 8.23. Fragmentación de elementos del esqueleto axial.

Esqueleto apendicular delantero

En el caso del miembro anterior izquierdo se pude observar que salvo los elementos del carpo el resto presenta superficies preservadas en valores que parten desde el $2 \%$ hasta menos del 30\%. Estos valores traducidos al rango de valores del largo máximo corresponden a $132 \mathrm{~mm}$ para la escápula, 30-31 mm para el húmero y 26-35 mm para el radioulna.

La pata derecha presenta valores similares para el radioulna $(30-89 \mathrm{~mm})$ en tanto que en el caso de la escápula el largo máximo corresponde a $75 \mathrm{~mm}$.

Para ambos lados los carpianos presentan elementos que se encuentran fragmentados. 

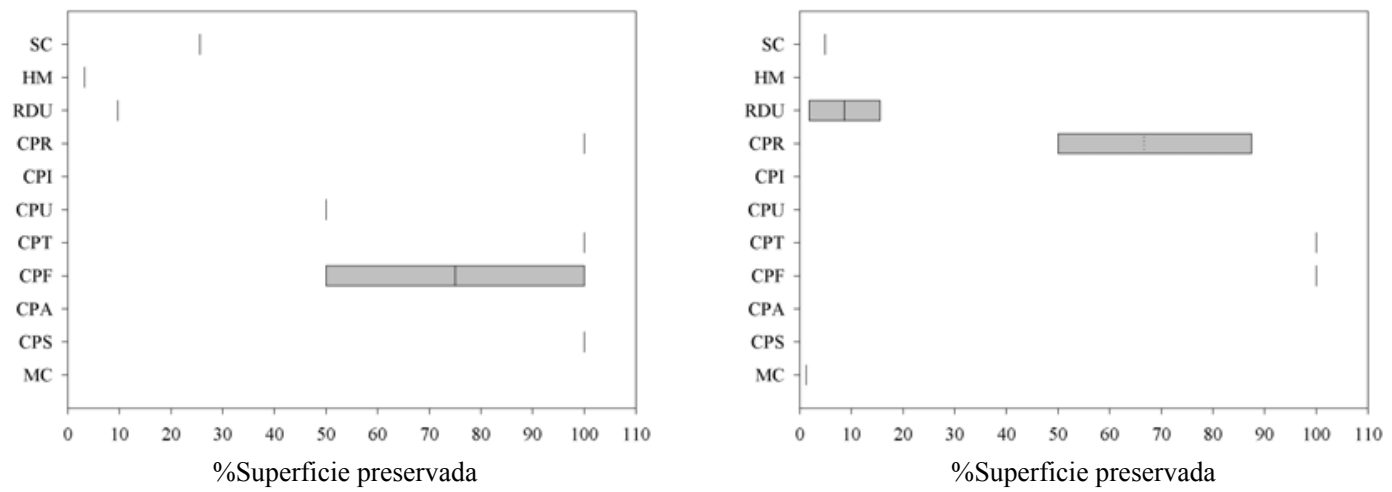

Figura 8.24. Fragmentación esqueleto apendicular delantero (izquierdo y derecho)

Esqueleto apendicular trasero

El miembro trasero izquierdo presenta un mayor número de elementos que el derecho. Los huesos largos presentan pequeños sectores preservados. Por ejemplo las superficies preservadas apenas superan el 10\% en el caso del metatarso. En términos de largos máximos de los especímenes el innominado izquierdo presenta un valor de 37 mm, el fémur de $82 \mathrm{~mm}$, la tibia $32 \mathrm{~mm}$, el calcáneo $23 \mathrm{~mm}$ y el metatarso $38 \mathrm{~mm}$.

La pata trasera derecha está representada solo por tres elementos. El innominado con valores comprendidos entre los 24 y $46 \mathrm{~mm}$ y el metatarso (46-48 mm).
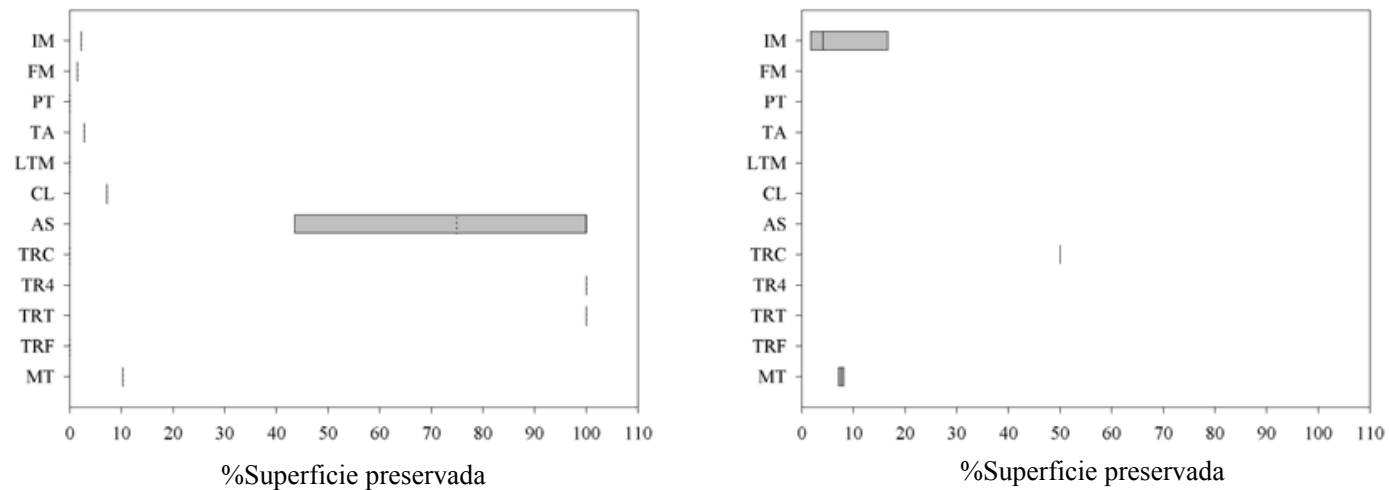

Figura 8.25. Fragmentación esqueleto apendicular trasero (izquierdo y derecho)

Respecto del estado en el que se hallaban los fragmentos cuando se produjo la fractura se ve que la categoría seca es la que se presenta en mayor frecuencia. 


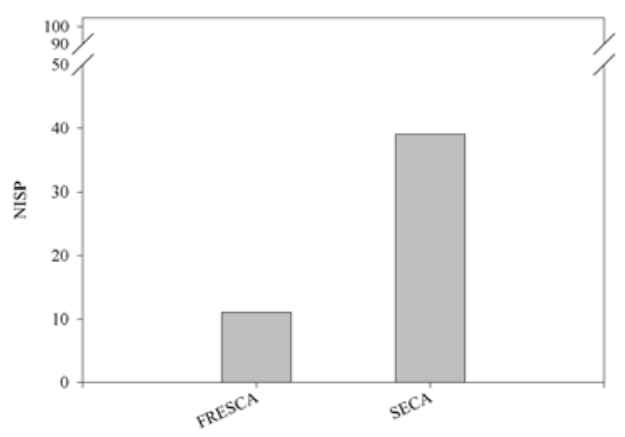

Figura 8.26. Cantidad (NISP) de especímenes y elementos del subconjunto adulto de camélidos según tipo de fractura.

\subsubsection{1.f. Utilización de las carcasas}

De los 31 elementos identificados para este conjunto sólo uno presentó huellas de acción antrópica siendo este un fragmento de innominado (ileon) derecho el cual presentó marcas de corte en el tubérculo coxal. La única marca del conjunto evidencia que al menos en el sitio se habría efectuado alguna acción tendiente al procesamiento primario de al menos uno de los animales. Quizás con el fin de desmembrar los cuartos traseros del animal.

Tabla 8.7. Marcas en hueso de camélidos adultos expresado en NISP

\begin{tabular}{ccccc}
\hline Elemento & Porción & Marcas de corte & Impactos & Total general \\
IM & IL & 1 & - & 1 \\
Total general & & 1 & - & 1 \\
\hline
\end{tabular}

\subsubsection{1.g. Termoalteraciones}

El 54,63\% de la muestra presentó signos de termoalteración $(\mathrm{n}=53)$, lo que implicaría una intensa acción del calor. Asimismo aunque el conjunto es pequeño estos especímenes muestran signos de haber sido sometidos a toda la escala de temperaturas.

Tabla 8.8. Termoalteración del conjunto de camélidos adultos.

\begin{tabular}{cccccc}
\hline Descripción & Sin alteración & $\begin{array}{c}\text { Oxidación } \\
\text { incompleta/carbonización } \\
\text { marrón claro-negro } \\
\text { (moteado) }\end{array}$ & Carbonizado & Calcinado & Total \\
Color & - & $200^{\circ} \mathrm{C}-300^{\circ} \mathrm{C}$ & $300{ }^{\circ} \mathrm{C}$ & $>500{ }^{\circ} \mathrm{C}$ & \\
Temperatura & $<200{ }^{\circ} \mathrm{C}$ & 6 & 33 & 14 & 97 \\
NISP & 44 & gris-blanco & \\
\hline
\end{tabular}


Respecto de la relación entre tipo de estado al realizarse la fractura y tipo de alteración térmica podemos ver los resultados obtenido en la Tabla 8.9. Allí se ve que las fracturas secas o frescas se presentan tanto para los elementos que no presentan tipos de alteración como en aquellos que si la presentan. El único caso son los especímenes con alteración 4 los que presentan solo fractura seca. Esto podría ser explicado como el resultado de un proceso de alteración térmica lenta y/o indirecta que deshidrataría y deformaría al hueso hasta producir el tipo de fractura seca.

Tabla 8.9. Relación entre tipo de termoalteración y tipo de fractura del conjunto de camélidos adultos.

\begin{tabular}{cccr}
\hline Tipo de alteración & Fresca & Seca & Total \\
Sin Alteración & 9 & 3 & 12 \\
Oxidación incompleta & - & 5 & 5 \\
Carbonizado & 1 & 22 & 23 \\
Calcinado & 1 & 9 & 10 \\
Total & 11 & 39 & 50 \\
\hline
\end{tabular}

\subsubsection{Camélidos subadultos}

Este subconjunto esta compuesto por un NISP $=20$ (Tabla 8.11). Este número de especímenes identificados corresponde a huesos del esqueleto apendicular.

\subsubsection{2.a. Supervivencia del material óseo mediada por la densidad ósea}

El resultado muestra que en los dos elementos sobre los que se efectuó el análisis una de las correlaciones efectuadas es negativa en tanto la otra no presenta correlación. El resultado general muestra una correlación negativa con significación estadística, lo que implicaría que este conjunto al contrario de lo que sucede con el de los camélidos adultos ha preservado mayormente las zonas diagnósticas menos densas.

Tabla 8.10. Correlación entre el \%MAU y la densidad ósea.

\begin{tabular}{cccc}
\hline Elemento & Rank & $r_{s}$ & $p$ \\
Radioulna & 6 &, 000 & 1,000 \\
Fémur & 5 &,- 866 &, 058 \\
Arqueofauna & 29 &,- 371 &, 000 \\
\hline
\end{tabular}

\subsubsection{2.b. Número Mínimo de Elementos (MNE)}

\section{Húmero (HM)}

Se identificó un elemento completo para el lado derecho $(\mathrm{MNE}=1)$ 


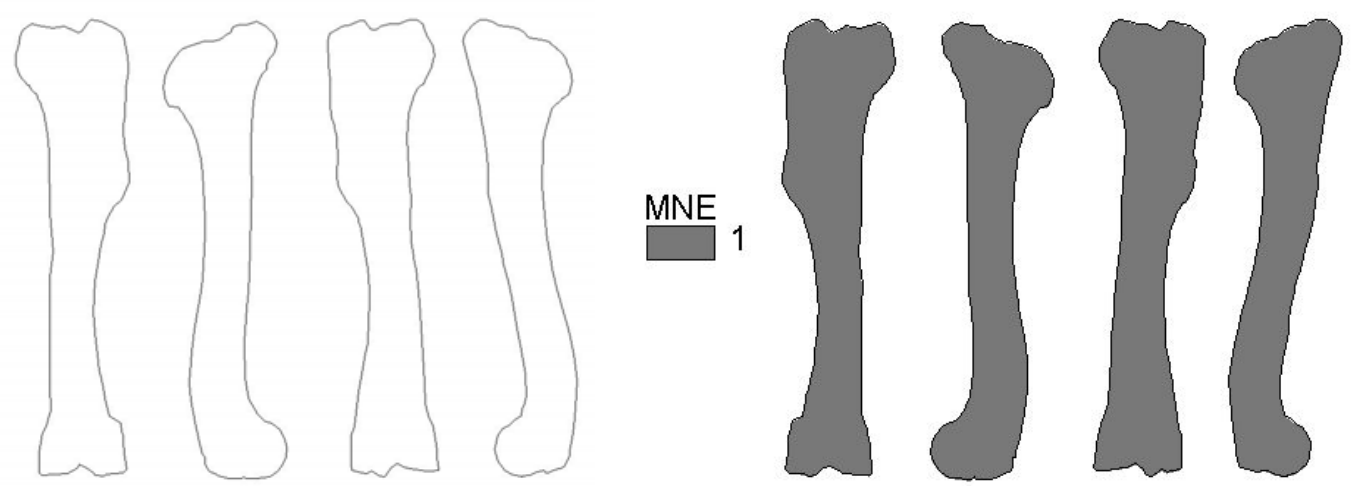

Figura 8.27. MNE Húmero izquierdo y derecho

\section{Radioulna (RDU)}

Para este elemento se identificaron dos fragmentos de diáfisis correspondientes al olécranon y a la epífisis distal. El MNE obtenido es de 2, asignando 1 elemento a cada lado.
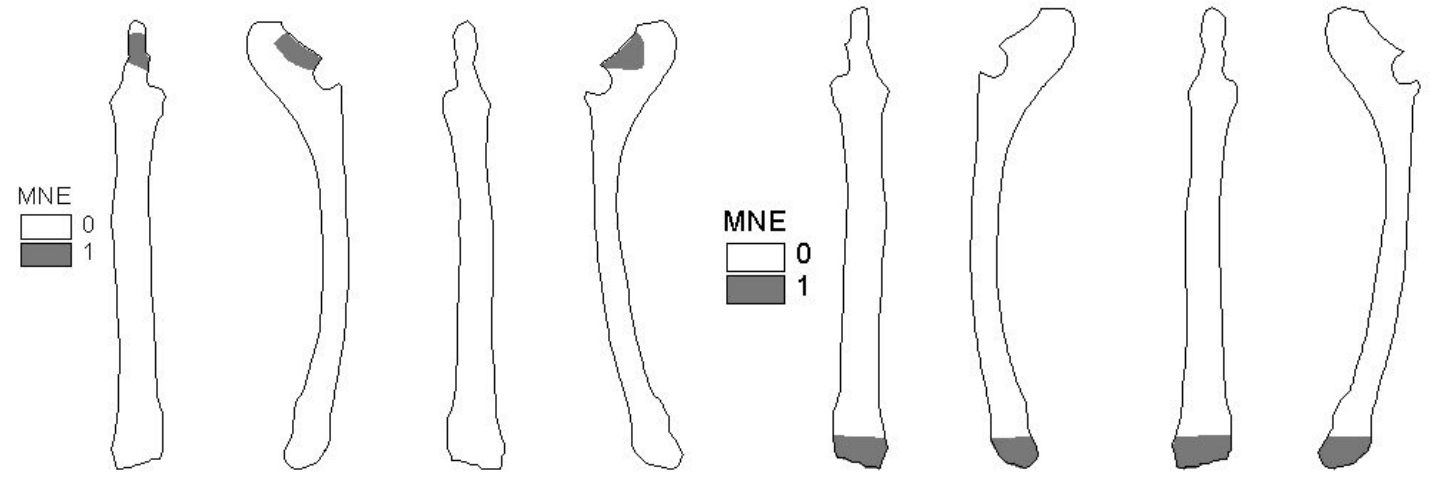

Figura 8.28. MNE Radioulna izquierda y derecha

Fémur (FM)

Se identificó como zona diagnóstica el trocánter mayor, la diáfisis distal y la epífisis distal. Todas éstas corresponden al lado derecho y permitieron calcular un $\mathrm{MNE}=1$.
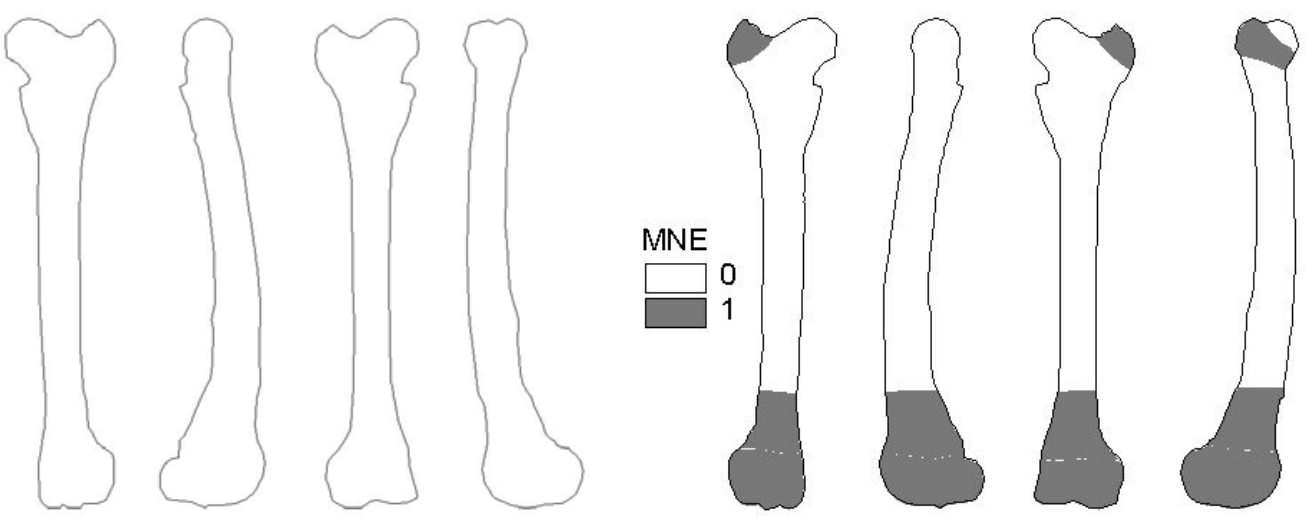
Figura 8.29. MNE Fémur izquierdo y derecho

Metapodio (MP)

Sobre la base de los cóndilos sin fusionar se contabilizó un MNE igual a 6.
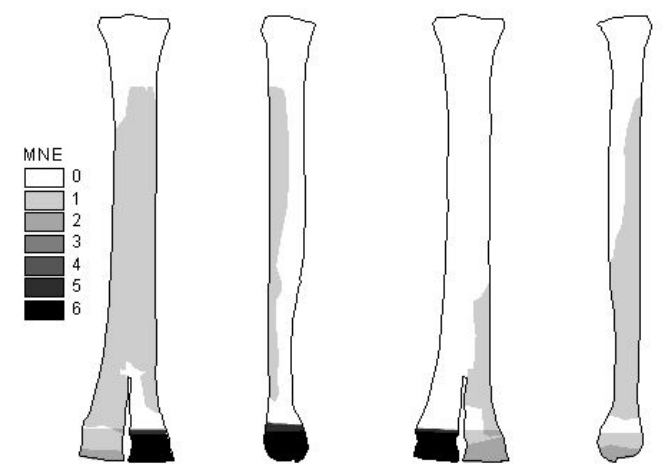

Figura 8.30. MNE Metapodio general

Falange proximal (PHF)

Se identificaron dos elementos en base a la epífisis proximal. El MNE obtenido es igual a 2 .
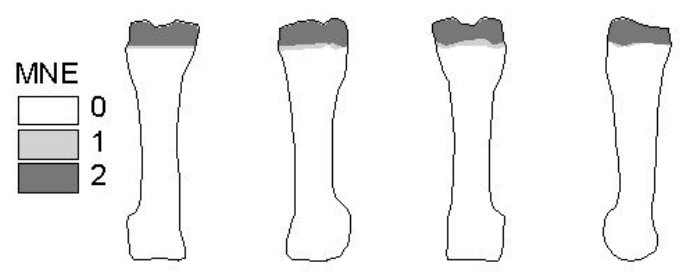

Figura 8.31. MNE Falange proximal general

\section{Falange medial (PHS)}

Se identificaron 2 elementos en base a la diáfisis y la epífisis distal fusionada.
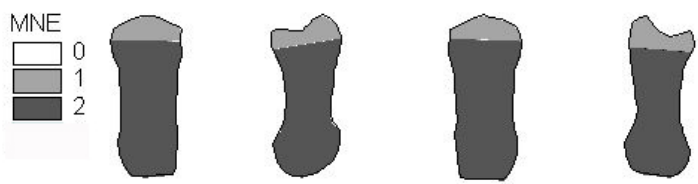

Figura 8.32. MNE Falange medial

Los resultados presentados más arriba se volcaron en la Tabla 8.11 y se utilizaron para el cálculo del MNI, MAU y \%MAU. 
Tabla 8.11. Abundancia relativa de partes esqueletarias expresadas como NISP, MNE comprehensivo, MAU y \%MAU.

\begin{tabular}{ccccccccc}
\hline Elemento & NISP & I & D & S/D & MNE & MNI & MAU & $\%$ MAU \\
HM & 1 & - & 1 & - & 1 & 1 & 0.50 & 33.33 \\
RDU & 2 & 1 & 1 & - & 2 & 1 & 1.00 & 66.67 \\
& & & & & & & & \\
FM & 3 & - & 1 & - & 1 & 1 & 0.50 & 33.33 \\
& & & & & & & & \\
MP & 9 & - & - & 6 & 6 & 2 & 1.50 & 100.00 \\
PHF & 2 & - & - & 2 & 2 & 1 & 0.25 & 16.67 \\
PHS & 3 & - & - & 2 & 2 & 1 & 0.25 & 16.67 \\
Total general & 20 & & & & \\
\hline \multicolumn{7}{c}{$\mathrm{D}=$ derecho, I = izquierdo, S/D = axial o sin datos }
\end{tabular}

\subsubsection{2.c. Número Mínimo de Individuos (MNI)}

El número mínimo de individuos calculado para este conjunto es de 2. Este valor es resultado de la presencia de 6 metapodios. El resto de los elementos solo permiten identificar 1 solo individuo.

\subsubsection{2.d. Unidades anatómicas representadas (MAU)}

La representación de los elementos para este conjunto muestra una alta presencia de huesos que corresponden a los segmentos distales del esqueleto apendicular. Para las partes proximales de las patas se registran las piezas óseas con mayor utilidad en términos de la anatomía económica de los animales.

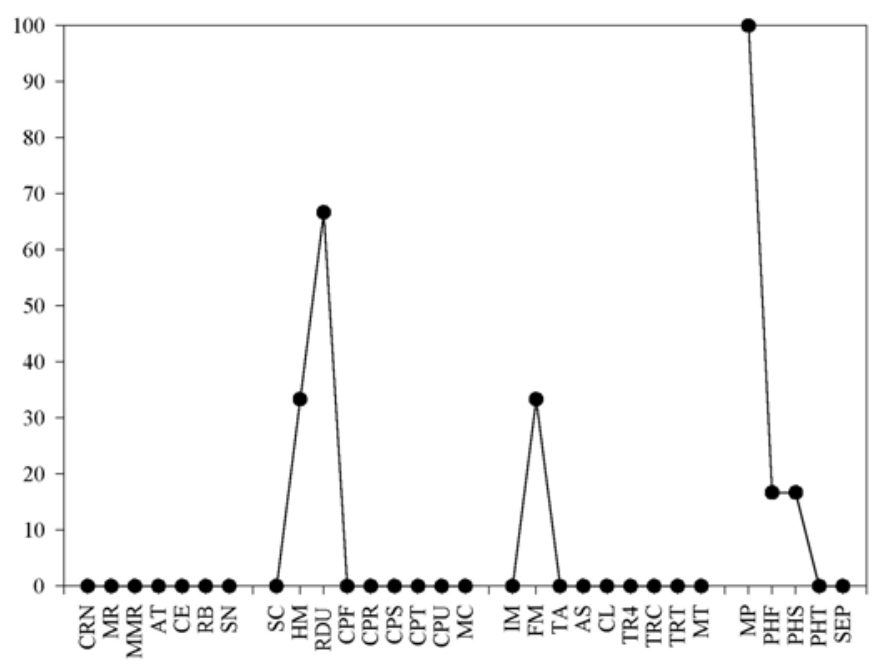

Figura 8.33. Abundancia relativa de elementos esqueletarios. 


\subsubsection{2.e. Fragmentación del subconjunto}

El conjunto de camélidos subadultos presentó un alto grado de fragmentación. El módulo de tamaño más representado resultó ser el de 0-20 $\mathrm{mm}$. El resto del conjunto se reparte en distintos módulos. Los elementos completos solo representan una proporción pequeña dentro de la muestra. En cuanto al tipo de estado al realizarse la fractura se puede observar en la Figura 8.34.b que la categoría seca se presenta en mayor frecuencia que la fractura fresca, aunque la diferencia no es mínima.

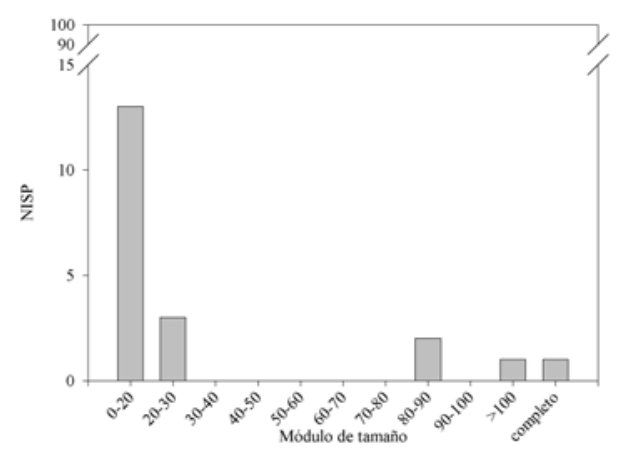

a

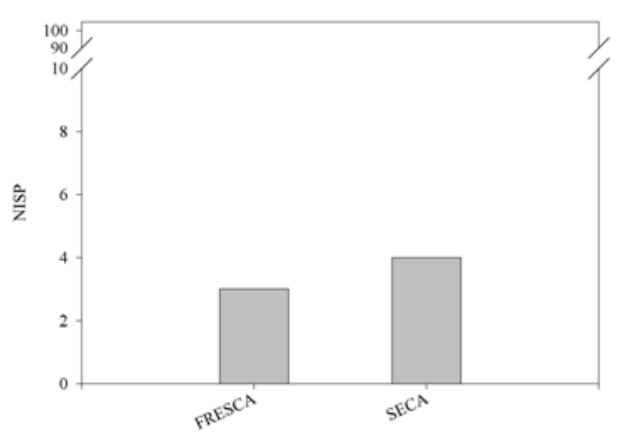

b

Figura 8.34.a) Módulos de tamaño expresado en NISP para especímenes y elementos del subconjunto subadulto de camélidos, b) Cantidad (NISP) de especímenes y elementos del subconjunto subadulto de camélidos según tipo de fractura.

\subsubsection{2.f. Utilización de las carcasas}

Se registraron en el conjunto huellas de impacto realizadas en diáfisis de metacarpo y metapodio.

Tabla 8.12. Marcas en huesos del conjunto no camélido expresado en NISP.

\begin{tabular}{ccccc}
\hline Elemento & Porción & Marcas de corte & Impactos & Total general \\
MC & FK & - & 1 & 1 \\
MP & DSH & - & 1 & 1 \\
Total general & & - & 2 & 2 \\
\hline
\end{tabular}

\subsubsection{2.g. Termoalteraciones}

Se vuelve a repetir el mismo patrón que para los especímenes de los camélidos adultos. En este caso el 55\% de la muestra presenta signos de termoalteración en todas las categorías. 
Tabla 8.13. Termoalteración del conjunto de camélidos subadultos.

\begin{tabular}{|c|c|c|c|c|c|}
\hline Descripción & Sin alteración & Oxidación & Carbonizado & Calcinado & Total \\
\hline Color & - & $\begin{array}{l}\text { incompleta/carbonización } \\
\text { marrón claro-negro } \\
\text { (moteado) }\end{array}$ & negro & gris-blanco & \\
\hline Temperatura & $<200^{\circ} \mathrm{C}$ & $200{ }^{\circ} \mathrm{C}-300{ }^{\circ} \mathrm{C}$ & $300^{\circ} \mathrm{C}$ & $>500{ }^{\circ} \mathrm{C}$ & \\
\hline NISP & 9 & 1 & 8 & 2 & 20 \\
\hline
\end{tabular}

En cuanto a la alteración térmica y el tipo de estado al producirse la fractura se observa en la Tabla 8.14 que para los que no registraron alteración térmica presentaron en todos los casos la clase fresca, en cambio las termoalteradas presentaron el tipo seca. Nuevamente como en el caso del subconjunto de camélidos adultos la fractura se relaciona con la acción de algún tipo de proceso térmico.

Tabla 8.14. Relación entre el tipo de termoalteración y tipo de fractura del conjunto de camélidos subadultos.

\begin{tabular}{cccc}
\hline Tipo de alteración & Fresca & Seca & Total general \\
Sin alteración & 3 & - & 3 \\
Oxidación incompleta & - & 1 & 1 \\
Carbonizado & - & 3 & 3 \\
Total & 3 & 4 & 7 \\
\hline
\end{tabular}

\subsubsection{Subconjunto no camélido}

Este subconjunto esta constituido por diez taxones que representan toda la escala de tamaños corporales.

\subsubsection{1.a. Marcas de procesamiento}

Se identificaron especímenes con signos de formatización, machacado e impacto en fragmentos del esqueleto axial y del apendicular de artiodáctilos y "no identificables" de tamaño corporal 4. Para el esqueleto axial se identificó la existencia de machacado en un fragmento de cráneo. Para el esqueleto apendicular, se observó una lasca ósea formatizada, otras dos con machacado y una cuarta con un impacto en lasca ósea de hueso largo.

Tabla 8.15. Marcas en huesos del conjunto no camélido expresado en NISP.

\begin{tabular}{cccccccc}
\hline Taxón & T.corporal & Elemento & Porción & Formatización & Machacado & Impacto & Total \\
UL & 4 & CRN & US & - & 1 & - & 1 \\
UL & 4 & LB & FK & 1 & 1 & 1 & 3 \\
UN & 4 & LB & FK & - & 1 & - & 1 \\
Total & & & & 1 & 3 & 1 & 5 \\
\hline
\end{tabular}




\subsubsection{1.b. Termoalteración}

Signos de alteración térmica fueron hallados en los siguientes taxones: Ctenomyidae, Chaetophractus vellerosus, Rodentia (T. corporal 1 y 2), Hippocamelus antisensis y Artiodactyla (T. corporal 4). Además las clases de tamaño corporal 1, 2 y 4 de los especímenes "no identificables" fueron identificados con signos de alteración térmica.

Tabla 8.16. Termoalteración del conjunto no camélido.

\begin{tabular}{|c|c|c|c|c|c|c|}
\hline & Descripción & Sin & Oxidación & Carbonizado & Calcinado & \\
\hline & & alteración & incompleta/carboniza & & & \\
\hline & & & -ción & & & \\
\hline & Color & - & marrón claro-negro & negro & gris- & \\
\hline & & & (moteado) & & blanco & \\
\hline Taxón & $\begin{array}{c}\text { Temperatura } \\
\text { T. corporal }\end{array}$ & $<200^{\circ} \mathrm{C}$ & $200^{\circ} \mathrm{C}-300^{\circ} \mathrm{C}$ & $300{ }^{\circ} \mathrm{C}$ & $>500^{\circ} \mathrm{C}$ & \\
\hline AVE & 1 & 1 & - & - & - & 1 \\
\hline AVE & $1-2$ & 2 & - & - & - & 2 \\
\hline AVE & 2 & 1 & - & - & - & 1 \\
\hline C. vellerosus & 2 & 8 & - & 3 & 2 & 13 \\
\hline Rodentia & 1 & 21 & - & 1 & - & 22 \\
\hline Rodentia & 2 & 25 & - & 2 & - & 27 \\
\hline Ctenomyidae & 1 & 6 & - & 2 & - & 8 \\
\hline Microcavia & & 1 & - & - & - & 1 \\
\hline Chinchillidae & 1 & 2 & - & - & - & 2 \\
\hline Lagidium sp. & 2 & 1 & - & - & - & 1 \\
\hline Canidae & 2 & 1 & - & - & - & 1 \\
\hline Artiodactyla & $3-4$ & 2 & - & - & - & 2 \\
\hline Artiodactyla & 4 & 856 & 158 & 701 & 237 & 1952 \\
\hline H. antisensis & 4 & 1 & - & 1 & - & 2 \\
\hline No identificable & 1 & 19 & 1 & 7 & 2 & 29 \\
\hline No identificable & $1-2$ & 14 & - & - & - & 14 \\
\hline No identificable & 2 & - & - & 1 & 5 & 6 \\
\hline No identificable & $2-3$ & 2 & - & - & - & 2 \\
\hline No identificable & 4 & 2 & 1 & 8 & 1 & 12 \\
\hline No identificable & 9 & 19 & 2 & 1 & 1 & 23 \\
\hline Total general & & 984 & 162 & 727 & 248 & 2121 \\
\hline
\end{tabular}

\subsubsection{1.c. Fragmentación del conjunto no camélido}

Para el tamaño corporal 1 (Figura 8.35.a) se observó que si bien existe una relativamente alta fragmentación los módulos de tamaño más representados son los que se ubican dentro de los valores máximos para los elementos de este tamaño corporal. En el caso del tamaño corporal 2 se observa un patrón similar. Por último, para el tamaño corporal 4 se observó que el conjunto vuelve a comportarse con la distribución normal para este tipo de tamaño corporal, es decir presentando gran cantidad de especímenes en los módulos de tamaño más chicos. 


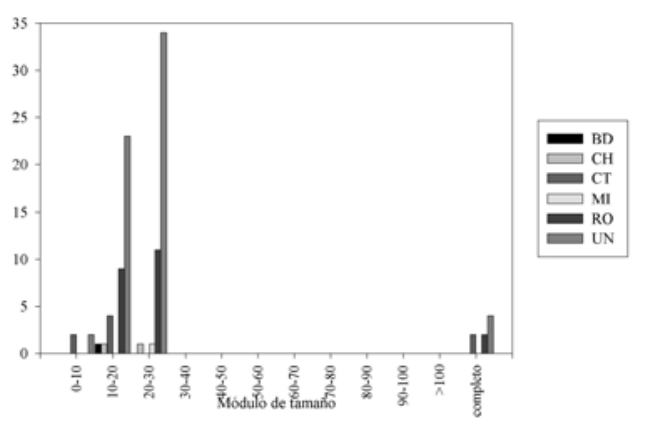

a

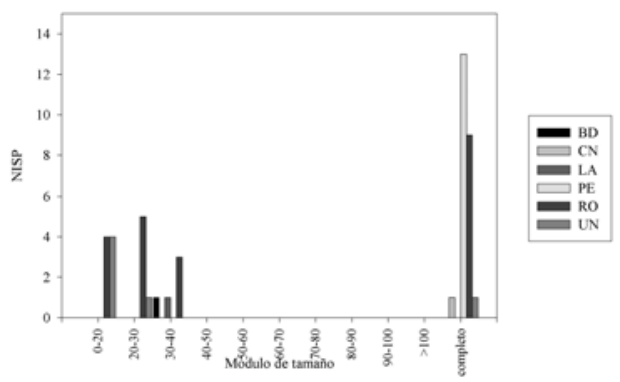

b

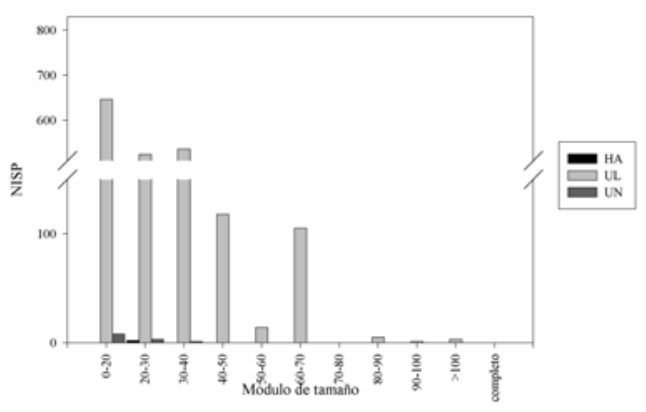

$\mathrm{C}$

Figura 8.35. Fragmentación del conjunto no camélido expresado en NSP. a) Tamaño corporal 1, b) Tamaño corporal 2 y c) Tamaño corporal 4. 


\subsection{Yutopián-Patio de Núcleo 1 - Análisis faunístico}

El número de especímenes identificados en este patio asciende a 143. El 59,44\% del conjunto se identificó taxonómicamente determinándose la presencia de cuatro taxones y de tres categorías de tamaño corporal para los especímenes no identificables a nivel taxonómico.

Tabla 8.17. Composición del conjunto faunístico del Patio Núcleo 1.

\begin{tabular}{lcl}
\hline Taxón & Tamaño corporal & NSP \\
Chaetophractus vellerosus & 2 & 9 \\
Rodentia & 1 & 1 \\
Artiodactyla & 4 & 64 \\
Lama sp. & 4 & 11 \\
& & \\
\hline Subtotal Identificados & & 85 \\
\hline & 2 & 3 \\
No identificable & 4 & 16 \\
No identificable & 9 & 39 \\
No identificable & & \\
& & 58 \\
\hline Subtotal No identificables & & \\
\hline & TOTAL & 143 \\
\hline
\end{tabular}

En cuanto a las modificaciones producidas por agentes tafonómicos se puede observar que la meteorización es baja, presentándose el grueso del material con la misma meteorización independientemente del tipo de tamaño corporal (Tabla 8.18 y Figura 8.36.)

Tabla 8.18. Meteorización del conjunto faunístico del Patio Núcleo 1. Yutopián

\begin{tabular}{lrrrrrrr}
\hline Tamaño corporal & \multicolumn{9}{c}{ Meteorización } & \multicolumn{3}{c}{ Total NSP } \\
1 & 1 & 2 & 3 & 4 & 5 & 1 \\
2 & - & 1 & - & - & - & 12 \\
4 & 1 & 11 & - & - & - & 86 \\
9 & 42 & 44 & - & - & - & 5 \\
TOTAL & - & 5 & - & - & - & 101 \\
\hline
\end{tabular}




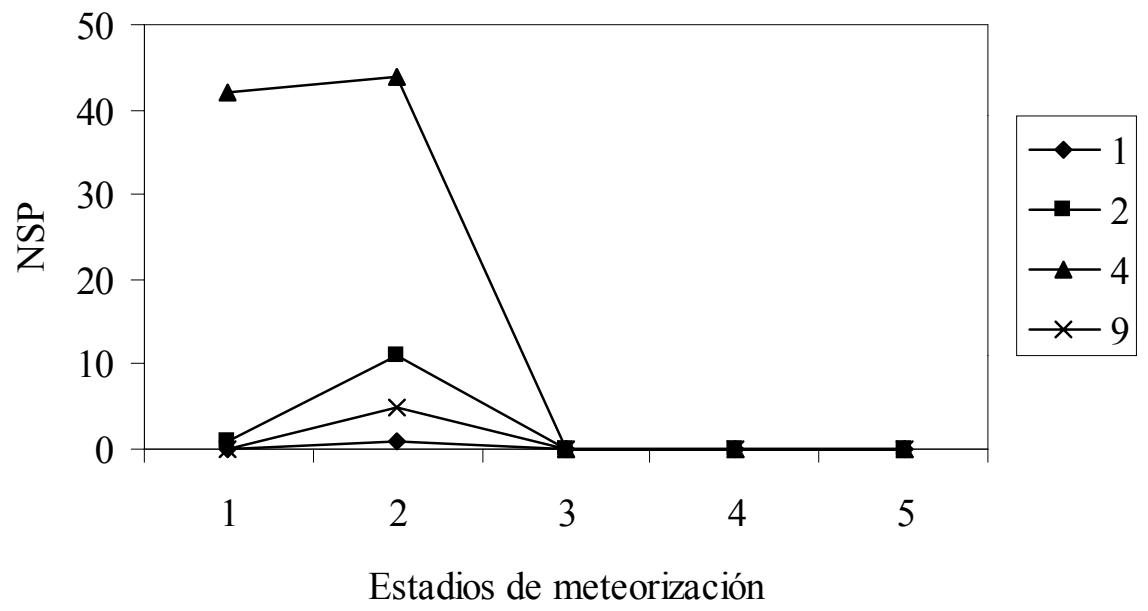

Figura 8.36. Estadios de meteorización según tamaño corporal. Patio Núcleo 1, Yutopián

En cuanto a la acción roedores sobre el conjunto se observa en la Tabla 8.19 que solo un espécimen $(0,69 \%)$ de la muestra presenta señales de haber sido afectado por este agente. Respecto a la acción de carnívoros no se registraron signos en la muestra. Teniendo en cuenta estos dos indicadores la acción sobre el conjunto habría sido mínima.

Tabla 8.19. Modificaciones por agentes naturales del conjunto faunístico del Patio Núcleo 1. Yutopián

\begin{tabular}{cccr}
\hline Tamaño Corporal & Sin modificaciones & Daño ligero por roedor & Total NSP \\
1 & 1 & - & 1 \\
2 & 12 & - & 12 \\
4 & 90 & 1 & 91 \\
9 & 39 & - & 39 \\
Total NSP & 142 & 1 & 143 \\
\hline
\end{tabular}

\subsubsection{Análisis del Subconjunto Camelidae}

Este subconjunto está conformado por un NISP $=11$. En cuanto a las edades representadas se pudo identificar la presencia de al menos un individuo adulto y uno juvenil. 
Tabla 8.20. Camelidae, huesos del esqueleto axial y apendicular. Patio Núcleo 1, Yutopián.

\begin{tabular}{|c|c|c|}
\hline Elemento & & NISP \\
\hline CRN & & 1 \\
\hline MUN & & 1 \\
\hline $\mathrm{RB}$ & & 3 \\
\hline FM & & 1 \\
\hline CPI & & 1 \\
\hline AS & & 1 \\
\hline MP & & 2 \\
\hline \multirow[t]{2}{*}{ SEP } & & 1 \\
\hline & Total & 11 \\
\hline
\end{tabular}

\subsubsection{Fragmentación del subconjunto}

En este conjunto los módulos de tamaño están casi todos representados. Esto nos sugiere como primera aproximación que posiblemente no hubo una selección de tamaños durante la depositación de los fragmentos. No obstante lo reducido se mantiene el perfil general observado para sitios de este período y de la región, es decir mayor cantidad de fragmentos asignados a los módulos de tamaño más pequeños en relación con los mayores.

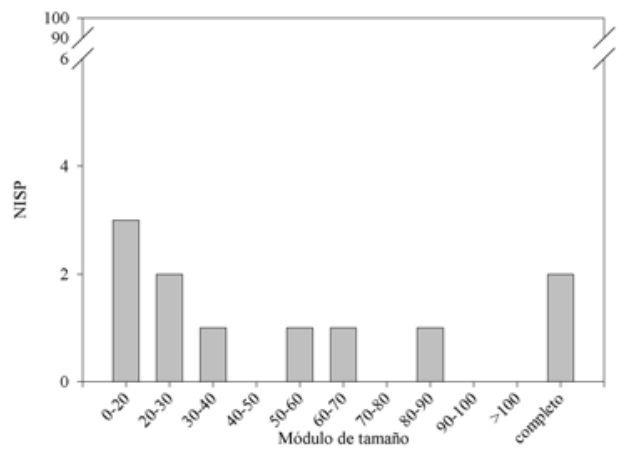

Figura 8.37. Módulos de tamaño expresado en NISP para especímenes y elementos del subconjunto.

En cuanto al estado inicial de los huesos al ser fracturados la categoría seca es la única presente (sin contar el tipo indeterminado). Las fracturas realizadas en estado fresco no han sido halladas en este conjunto. 
Por otro lado no se observaron marcas de corte, impactos o cualquier otra de las categorías utilizadas en este trabajo.

\subsubsection{Termoalteraciones}

En cuatro especímenes se identificaron signos de acción del calor. Dentro de esta muestra se encuentran especímenes asignados a las dos clases de edad presentando la adulta el tipo 1 y la subadulta el tipo 2 .

Tabla 8.21. Termoalteración. Patio Núcleo 1. Yutopián.

\begin{tabular}{cccccc}
\hline Descripción & Sin alteración & $\begin{array}{c}\text { Oxidación } \\
\text { incompleta/carbonización } \\
\text { marrón claro-negro } \\
\text { (moteado) }\end{array}$ & Carbonizado & Calcinado & Total \\
Color & - & $200^{\circ} \mathrm{C}-300{ }^{\circ} \mathrm{C}$ & $300{ }^{\circ} \mathrm{C}$ & $>500{ }^{\circ} \mathrm{C}$ & \\
Temperatura & $<200{ }^{\circ} \mathrm{C}$ & - & 3 & 1 & 11 \\
NISP & 7 & & gris-blanco & \\
\hline
\end{tabular}

En cuanto a la relación entre el tipo de alteración y el estado de la fractura se puede visualizar en la Tabla 8.22 que el único elemento que ofrece signos de termoalteración presenta fractura realizada en estado seco.

Tabla 8.22. Relación entre tipo de termoalteración y tipo de fractura. Patio Núcleo 1. Yutopián.

\begin{tabular}{lcccc}
\hline \multicolumn{1}{c}{ Tipo de alteración } & Fresca & Indeterminada & Seca & Total \\
Sin alteración & - & - & 1 & 1 \\
Oxidación incompleta & - & - & - & - \\
Carbonizado & - & - & - & - \\
Calcinado & - & - & - & - \\
$\quad$ Total & - & - & 1 & 1 \\
\hline
\end{tabular}

\subsubsection{Subconjunto no camélido (otros tamaños corporales)}

Para los otros tamaños corporales de la muestra no se observaron modificaciones óseas asignables a las categorías utilizadas en esta tesis.

En cuanto a los elementos quemados se identificaron especímenes quemados en dos taxones y dos categorías de "no identificables" taxonómicamente. Dos placas de Chaetophractus vellerosus mostraron alteraciones térmicas de tipo 1 y 2 . Para la categoría artiodáctilos de tamaño corporal 4 se identificaron fragmentos de falange proximal, dientes, mandíbula y hueso largo del tipo 1 y metapodios y hueso largo del tipo 2. Por último en la categoría "no identificables" y para el tamaño corporal 4 se identificaron alteraciones del tipo 1 y 2 . 
Los especímenes se presentan tanto carbonizados como calcinados, lo que indicaría un rango de temperaturas superiores a $\operatorname{los} 300^{\circ} \mathrm{C}$. 


\subsection{Yutopián - Estructura 3 - Análisis faunístico}

El volumen correspondiente al nivel de ocupación y los dos pozos fue de aproximadamente $11 \mathrm{~m}^{3}$ obteniéndose una densidad de 312,36 restos óseos por $\mathrm{m}^{3}$.

Se logró identificar a nivel taxonómico al 89,43\% del total de los especímenes o elementos recuperados.

Tabla 8.23. Composición del conjunto faunístico de la Estructura 3.

\begin{tabular}{lcr}
\hline Taxón & Tamaño corporal & Total NSP \\
AVE & 2 & 1 \\
Chaetophractus vellerosus & 2 & 72 \\
Rodentia & 1 & 19 \\
Rodentia & $1-2$ & 1 \\
Rodentia & 2 & 42 \\
Ctenomys sp. & 1 & 1 \\
Lagidium sp. & 2 & 1 \\
Artiodactyla & $3-4$ & 13 \\
Artiodactyla & 4 & 2783 \\
Lama sp. & 4 & 138 \\
Lama glama & 4 & 1 \\
H. antisensis & 4 & 1 \\
\hline Subtotal Identificados & & 3073 \\
\hline & 1 & 17 \\
No identificable & $1-2$ & 24 \\
No identificable & 2 & 3 \\
No identificable & $2-3$ & 5 \\
No identificable & $3-4$ & 52 \\
No identificable & 4 & 32 \\
No identificable & 9 & 363 \\
No identificable & & \\
& & \\
\hline Subtotal No identificables & & \\
\hline & & \\
\hline
\end{tabular}

En el conjunto se observó la presencia de nueve taxones dos de los cuales (Rodentia y Artiodactyla) presentan una diferencia interna basada en clases de tamaño corporal, lo que aumentaría a doce el número de los taxones identificados. Dentro de la categoría no identificables se distinguieron siete clases de tamaño corporal.

En cuanto a la meteorización a la que se vio sometido el conjunto se puede ver en los datos presentados en la Tabla 8.24 y la Figura 8.38 que el grueso de los especímenes y elementos sobre los que se pudo definir algún estadio de meteorización 
presentan el tipo 1. Los únicos especímenes que presentaron otros estadios de meteorización corresponden al tamaño corporal 4.

Tabla 8.24. Meteorización del conjunto faunístico de la Estructura 3. Yutopián

\begin{tabular}{crrrrrrr}
\hline Tamaño corporal & 1 & 2 & 3 & 4 & 7 & Total NSP \\
1 & 34 & - & - & - & 3 & 37 \\
$1-2$ & 25 & - & - & - & - & 25 \\
2 & 118 & - & - & - & 1 & 119 \\
$2-3$ & 3 & - & - & - & 2 & 5 \\
$3-4$ & 20 & - & - & - & 45 & 65 \\
4 & 577 & 64 & 21 & 1 & 2490 & 3153 \\
9 & - & - & - & - & 32 & 32 \\
TOTAL & 777 & 64 & 21 & 1 & 2573 & 3436 \\
\hline
\end{tabular}

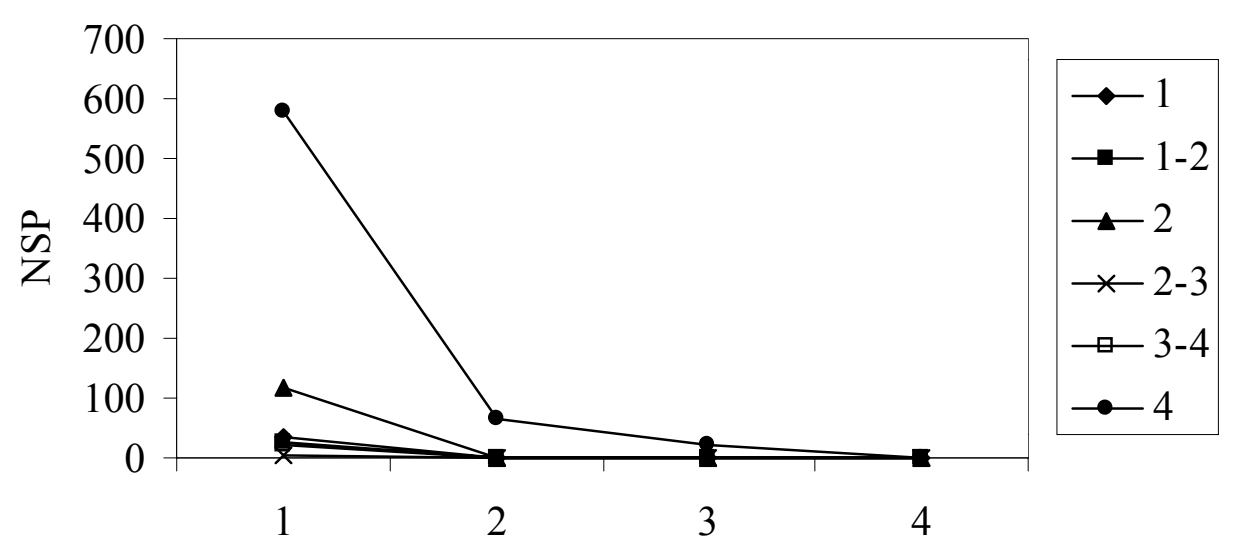

Estadios de meteorización

Figura 8.38. Estadios de meteorización según tamaño corporal. Estructura 3, Yutopián

En general la muestra parecería haberse depositado de modo simultáneo ya que la gran mayoría no muestra signos de haber estado expuesto a la acción de distintos agentes que caracterizan a la meteorización subaérea.

La acción de carnívoros y roedores en el conjunto es baja. Para el primero solo se identificaron huellas en un espécimen de tamaño corporal 2 y en dos de tamaño corporal 4 lo que implica que solo el $0,08 \%$ de la muestra se vio afectada por este primer agente. En cuanto a la acción de roedores también afectaron a tres especímenes por lo cual la frecuencia de huesos que presentan la acción de este agente es realmente baja. 
Tabla 8.25. Modificaciones por agentes naturales del conjunto faunístico de la Estructura 3. Yutopián

\begin{tabular}{lrccr}
\hline Tamaño Corporal & Sin modificaciones & $\begin{array}{c}\text { Daño ligero por } \\
\text { roedor }\end{array}$ & $\begin{array}{c}\text { Mordisqueo de } \\
\text { carnívoro }\end{array}$ & Total \\
1 & 37 & - & - & 37 \\
$1-2$ & 25 & - & - & 25 \\
2 & 119 & - & - & 119 \\
$2-3$ & 4 & - & 1 & 5 \\
$3-4$ & 65 & - & - & 65 \\
4 & 3148 & 3 & 2 & 3153 \\
9 & 32 & - & - & 32 \\
Total general & 3430 & 3 & 3 & 3436 \\
\hline
\end{tabular}

Teniendo en cuenta estos dos aspectos de la muestra la idea de la depositación en corto tiempo de los especímenes y elementos de los distintos tamaños corporales analizados parece cobrar fuerza.

\subsubsection{Análisis del subconjunto de camélidos.}

El subconjunto de camélidos esta compuesto por un NISP $=139$. Correspondiendo sólo uno a Lama glama y los otros 138 a Lama sp.

Tabla 8.26. Camelidae, huesos del esqueleto axial y apendicular. Estructura 3, Yutopián.

\begin{tabular}{lccr}
\hline Elemento & L. glama & Lama sp. & NISP \\
CRN & - & 4 & 4 \\
IC & - & 2 & 2 \\
MUN & - & 31 & 31 \\
PMR & - & 1 & 1 \\
HY & - & 1 & 1 \\
& & & \\
AX & - & 11 & 11 \\
CE & - & 2 & 2 \\
TH & - & 2 & 2 \\
RB & - & 7 & 7 \\
& & & \\
HM & - & 4 & 4 \\
RDU & - & 2 & 2 \\
CPF & - & 2 & 2 \\
CPR & - & 1 & 1 \\
CPU & - & 1 & 1 \\
MC & - & 2 & 2 \\
IM & - & 3 & 3 \\
FM & - & 3 & 3 \\
\hline & & & Continúa
\end{tabular}




\begin{tabular}{lccc} 
& \multicolumn{3}{c}{ Continuación de Tabla 8.26} \\
\hline PT & - & 1 & 1 \\
TA & - & 2 & 2 \\
AS & - & 1 & 1 \\
TRT & - & 3 & 3 \\
MT & - & 3 & 3 \\
& & & \\
MP & - & 12 & 12 \\
PHF & - & 17 & 17 \\
PHS & 1 & 6 & 7 \\
PHT & - & 5 & 5 \\
SEP & - & 9 & 9 \\
& & & \\
Total general & 1 & 138 & 139 \\
\hline
\end{tabular}

\subsubsection{Camélidos adultos}

Esta muestra se compone por un NISP igual a 119 lo que corresponde al 85,61\% del conjunto de camélidos recuperados en la estructura.

\subsubsection{1.a. Supervivencia del material óseo mediada por la densidad ósea}

De los siete elementos sobre los que se pudo determinar la correlación entre los valores de densidad ósea y el valor de las unidades anatómicas mínimas estandarizadas se observó que seis presentaron correlaciones positivas y sólo una resultó ser negativa. Para el conjunto total (29 elementos) la correlación fue negativa. En todos los casos las correlaciones no presentan significancia estadística. En suma, a pesar de que los elementos del esqueleto apendicular tienden a presentar zonas diagnósticas de densidad ósea más elevada, hay una parte del conjunto que no presenta tal condición. El resultado de la correlación global estaría mostrando, entonces, una tendencia a la representación de partes de elementos con densidades óseas bajas.

Tabla 8.27. \%MAU vs. VD.

\begin{tabular}{lccc}
\hline Elemento & Rank & $r_{s}$ & $p$ \\
Húmero & 5 &, 288 &, 319 \\
Radioulna & 6 &, 207 &, 347 \\
Metacarpo & 4 &,- 632 &, 184 \\
Innominado & 8 &, 433 &, 166 \\
Fémur & 5 &, 577 &, 154 \\
Tibia & 5 &, 577 &, 154 \\
Metatarso & 4 &, 894 &, 053 \\
Arqueofauna & 29 & -.233 &, 416 \\
\hline
\end{tabular}

8.3.1.1.b. Número Mínimo de Elementos (MNE) 


\section{Cráneo $(C R N)$}

De este elemento se pudo identificar la presencia de las siguientes zonas diagnósticas: petroso del temporal, esfenoides y meato acústico externo. Sobre estas regiones se pudo construir un MNE igual a un elemento.

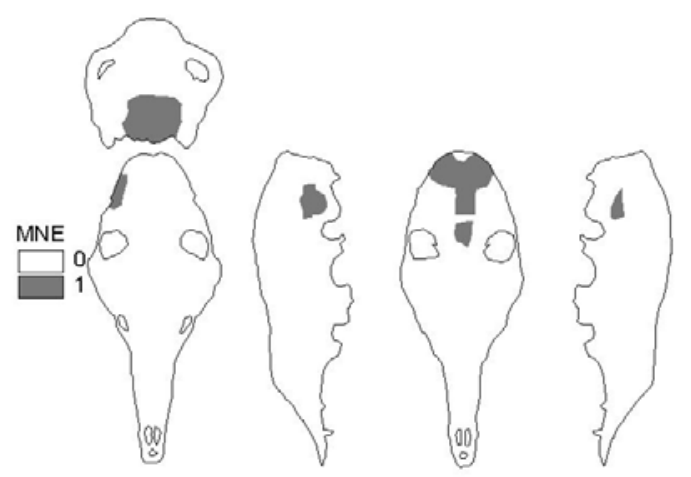

Dientes (IC, MUN y PMR)

Figura 8.39. MNE Cráneo

Se hallaron dientes sueltos los cuales fueron identificados como dos incisivos, treinta y un fragmentos de molariformes y un premolar mandibular. Ninguno de los incisivos pudo determinar a que especie pertenecieran ya que presentaban características asignables al grupo de camélidos grandes.

Hioides (HY)

Se halló un fragmento de la porción proximal del elemento. $\mathrm{MNE}=1$

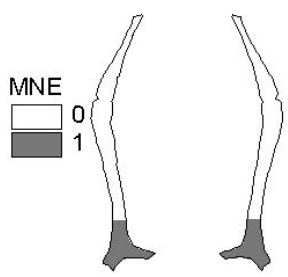

Figura 8.40. MNE Hioides

$\operatorname{Axis}(A X)$

De este elemento se identificaron las porciones proximales que están representados por la apófisis odontoides y la faceta articular del axis con el atlas. El MNE calculado fue igual a 2 elementos.
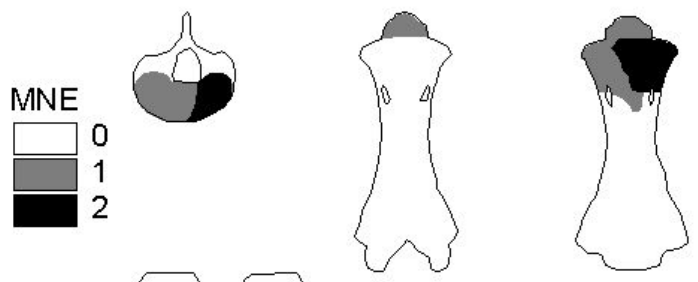

Figura 8.41. MNE Axis 
Cervicales 3-7 (CE)

Sólo fue posible asignar a estos elementos dos fragmentos correspondientes al segmento caudal del arco neural. Al igual que para el axis se obtuvo un MNE igual a 2.

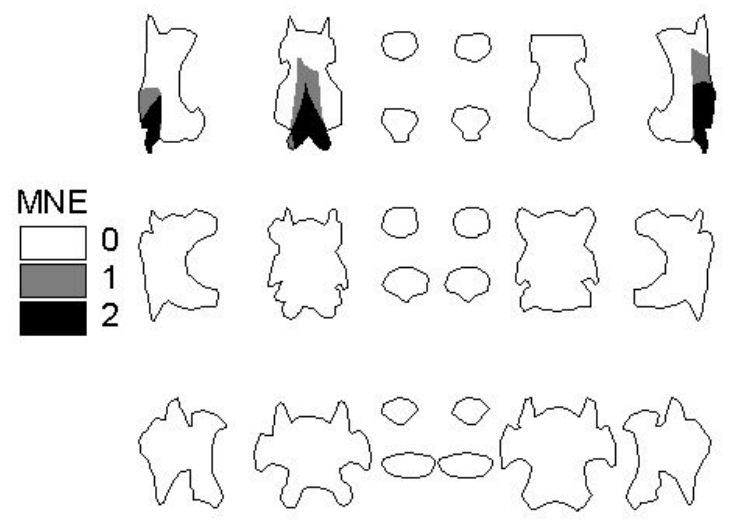

Figura 8.42. MNE Cervicales 3 a 7

Torácicas 1-14 (TH)

Se identificó un fragmento de cuerpo vertebral y un elemento completo. Siendo el MNE igual a 2 elementos.

Húmero (HM)

Se reconocieron para este elemento las siguientes zonas diagnósticas: teres mayor, tuberosidad deltoidea y el epicóndilo medial. Mediante la asignación de la lateralidad se obtuvo un MNE igual a 2, asignando 2 elementos a cada lado.

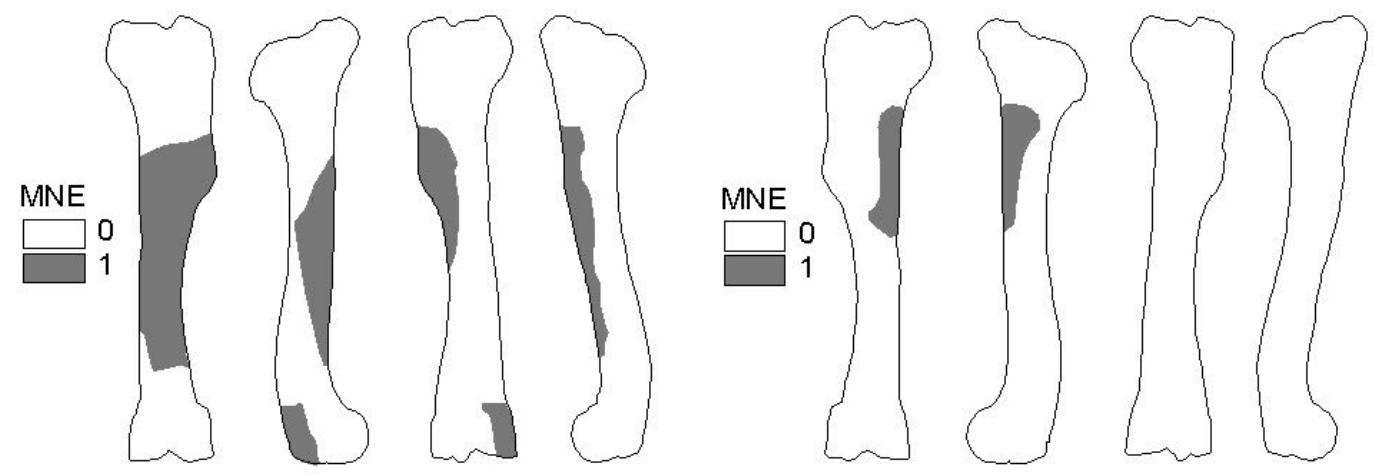

Figura 8.43. MNE Húmero izquierdo y derecho

Radioulna (RDU)

Para este elemento se identificaron dos fragmentos de diáfisis correspondientes a las porciones posteromedial y posterolateral. El MNE obtenido es de 2 ( 1 elemento por lado). 

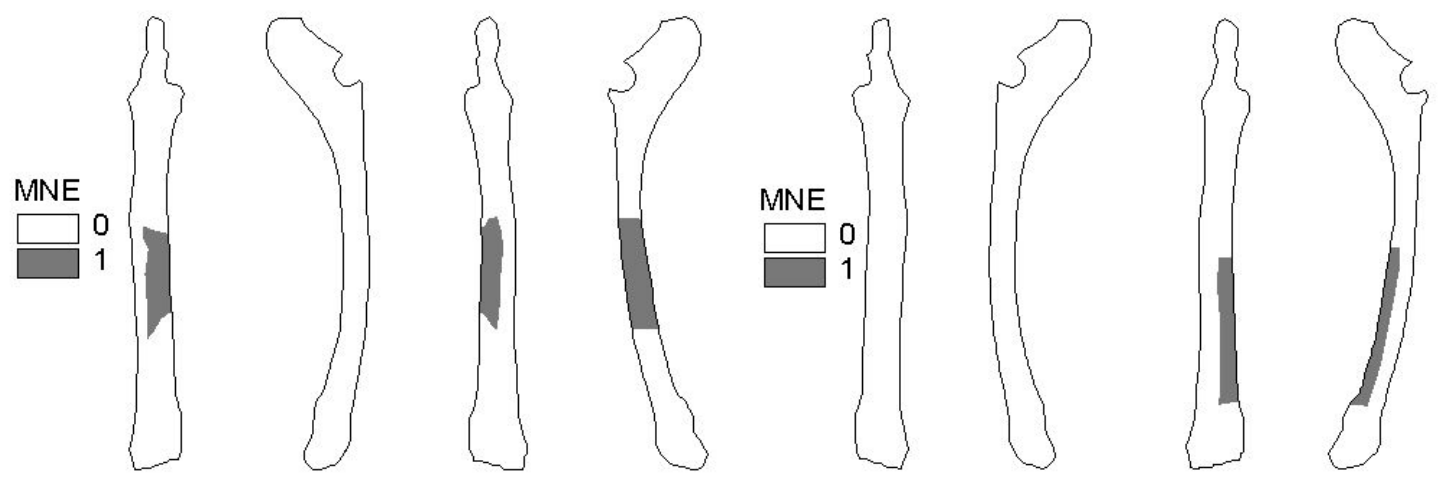

Figura 8.44. MNE Radioulna izquierda y derecha

Carpianos (CPR, CPF y CPU)

Se identificaron tres carpianos en este conjunto. Para el CPR y el CPU se asignaron 1 elemento al lado derecho para cada elemento. Para el CPU se identificaron dos fragmentos asignándose un MNE igual a 2.

\section{Metacarpo (MC)}

Para este elemento se identificaron partes de la epífisis proximal. Las zonas diagnósticas que se reconocieron fueron las facetas articulares del metacarpo con el carpo cuarto (unciforme) y el carpo tercero (mágnum).
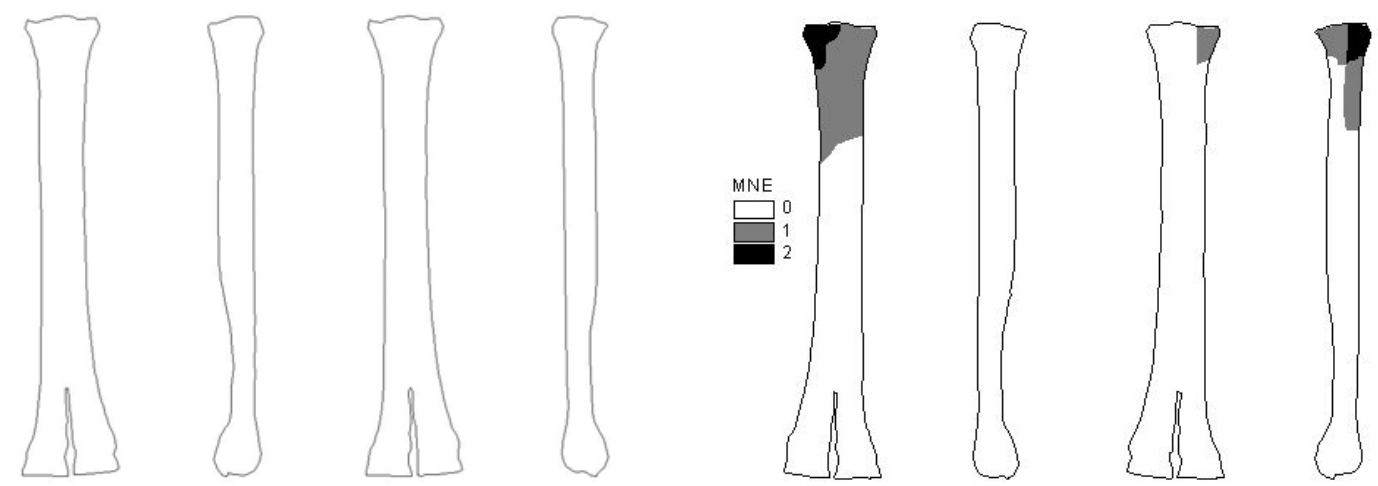

Figura 8.45. MNE Metacarpo izquierdo y derecho

Innominado (IM)

Se identificaron tres fragmentos cuyas zonas diagnósticas identificadas son: hoja del ilio, acetábulo y tubérculo isquiático. El MNE calculado es igual a 1.
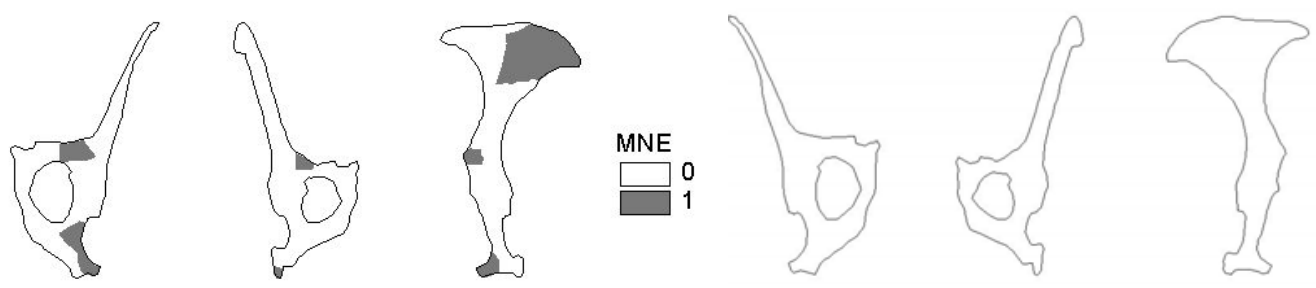

Figura 8.46. MNE Innominado izquierdo y derecho 
Fémur (FM)

Se identificó como zona diagnóstica el foramen nutricio posterolateral. MNE=3.
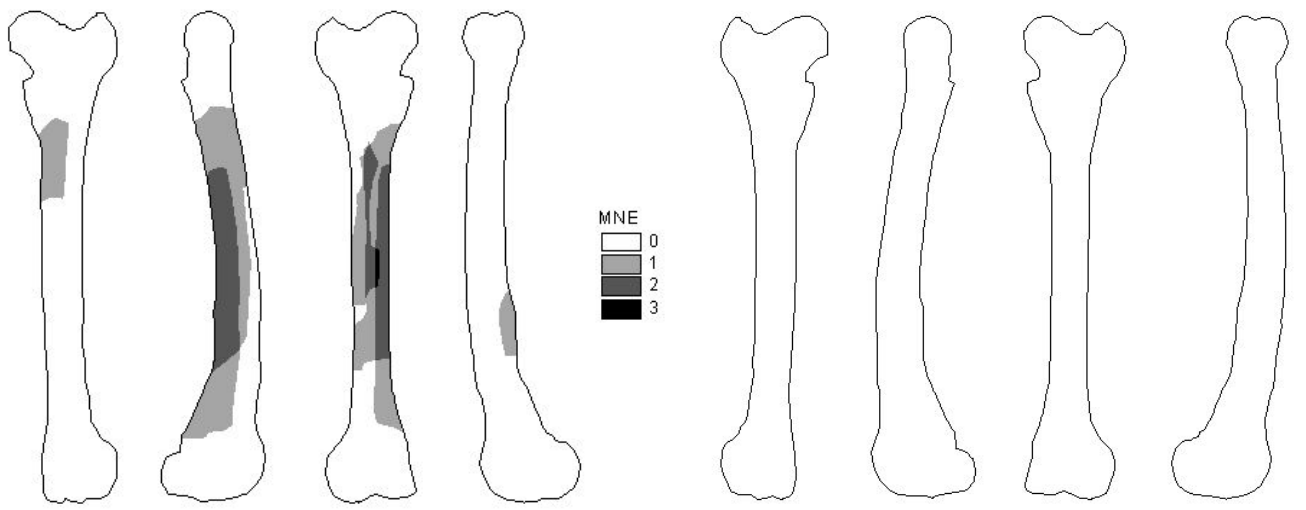

Figura 8.47. MNE Fémur izquierdo y derecho

Patela o Rótula (PT)

Se identificó un elemento al cual no se pudo asignar lateralidad. El MNE es igual a uno.

Tibia (TA)

Se calculó un MNE igual a 1. Este corresponde al lado izquierdo de acuerdo a la ubicación del foramen nutricio posterolateral.
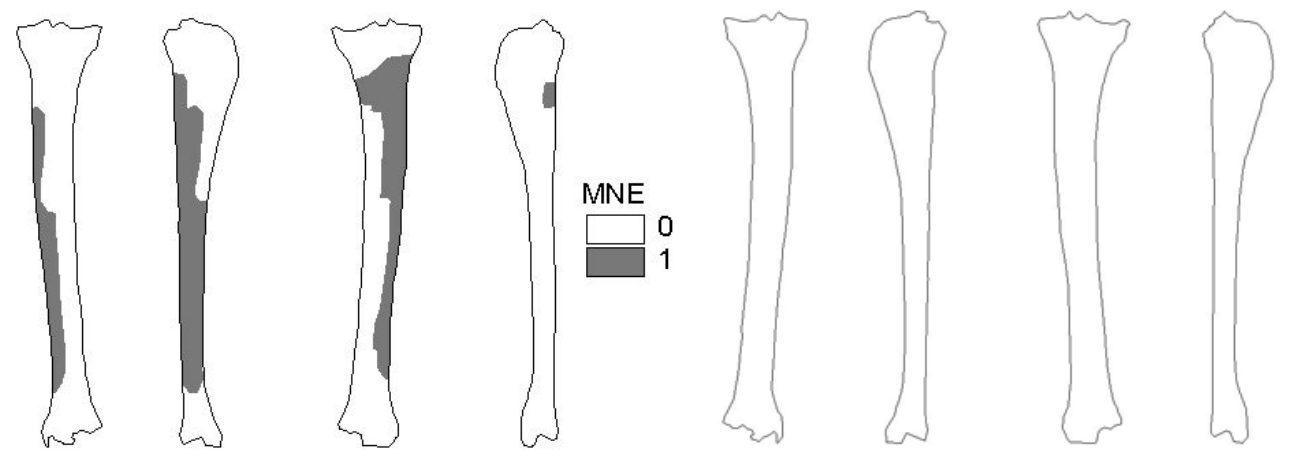

Figura 8.48. MNE Tibia izquierda y derecha

Astrágalo (AS)

Se halló un elemento completo asignado al lado derecho. MNE=1.
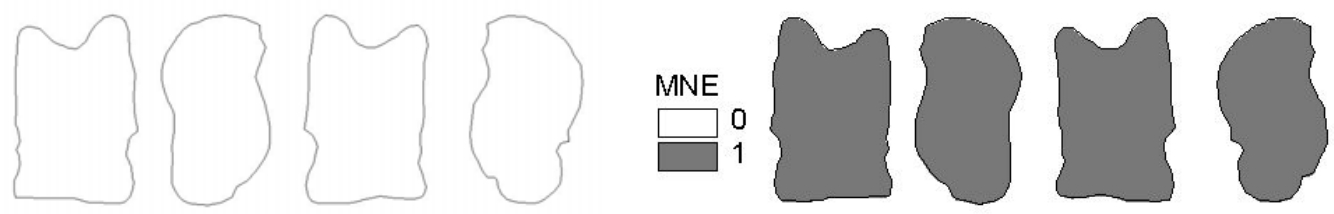

Figura 8.49. MNE Astrágalo izquierdo y derecho

Tarso Tercero (TRT) 
Se hallaron 3 elementos completos, 2 del lado derecho y 1 del lado izquierdo. El MNE es igual a 3.

Metatarso (MT)

Se identificaron 3 fragmentos, 2 de la epífisis proximal y 1 de la diáfisis. El MNE calculado dio como resultado 1 elemento.
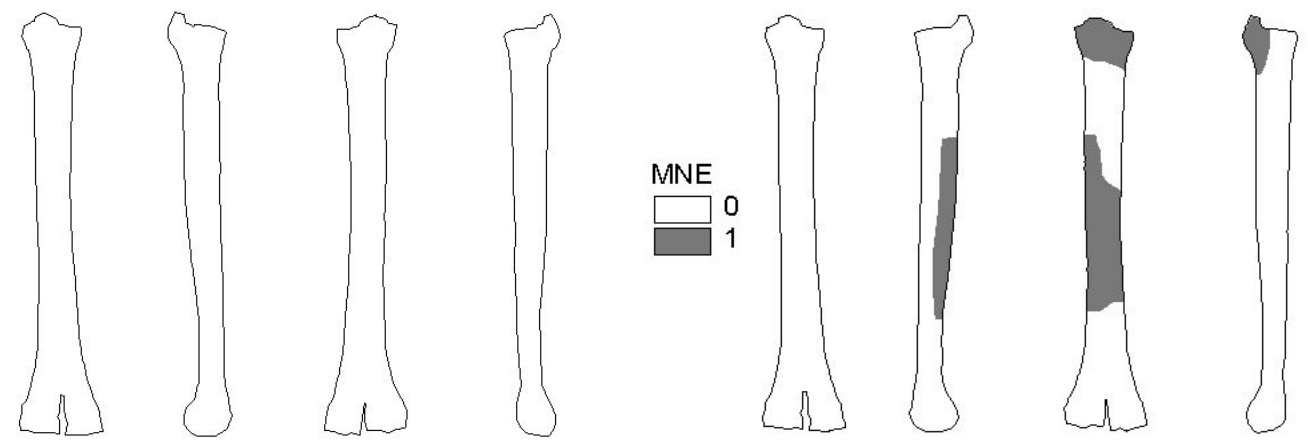

Figura 8.50 MNE Metatarso izquierdo y derecho

\section{Metapodio (MP)}

Basándose en dos especímenes se calculó un MNE igual a 2. Las zonas diagnósticas (cóndilos) no permitieron asignar a estos fragmentos al metacarpo o metatarso.
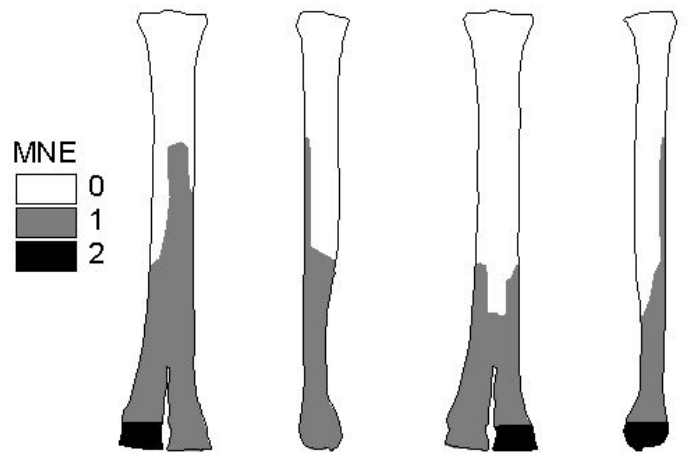

Figura 8.51. MNE Metapodio general

Falange proximal (PHF)

Se identificaron catorce especímenes que permitieron calcular un MNE igual a nueve. 


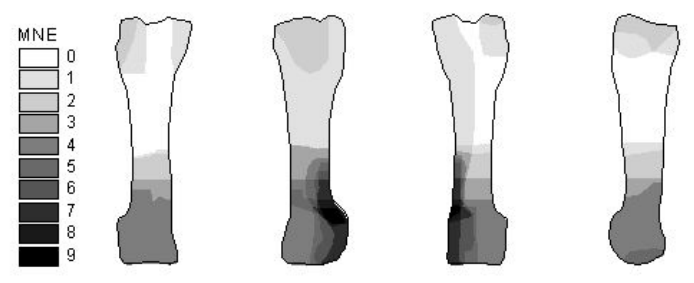

Figura 8.52. MNE Falange proximal general

Falange medial (PHS)

Sobre la base de tres fragmentos se obtuvo un MNE igual a tres.
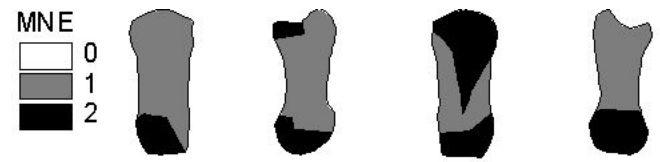

Figura 8.53. MNE Falange medial

Falange distal (PHT)

A partir de la identificación de cinco fragmentos hallados se calculo un MNE igual a cinco.
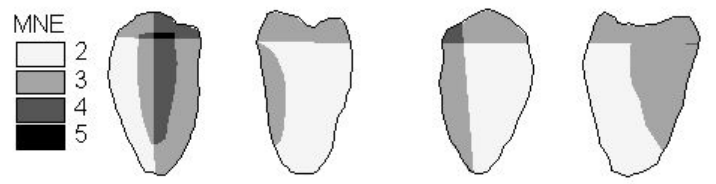

Figura 8.54. MNE Falange distal

\section{Sesamoides}

Se encontraron nueve elementos completos. Su MNE es igual al NISP (9).

Los resultados obtenidos se volcaron en la Tabla 8.28. A partir de ellos se calcularon los índices MNI, MAU y \%MAU.

Tabla 8.28. Abundancia relativa de partes esqueletarias expresadas como NISP, MNE comprehensivo, MNI, MAU y \%MAU.

\begin{tabular}{lrccccccc}
\hline Elemento & NISP & I & D & S/D & MNE & MNI & MAU & $\%$ MAU \\
CRN & 4 & - & - & 1 & 1 & 1 & 1.00 & 50.00 \\
IC & 2 & - & - & - & - & - & - & - \\
MUN & 31 & - & - & - & - & - & - & - \\
PMR & 1 & - & - & - & - & - & - & - \\
HY & 1 & - & - & 1 & 1 & 1 & 0.50 & 25.00 \\
AX & 11 & - & - & 2 & 2 & 2 & 2.00 & 100.00 \\
CE 3-7 & 2 & - & - & 2 & 2 & 1 & 0.40 & 20.00 \\
\hline
\end{tabular}




\begin{tabular}{|c|c|c|c|c|c|c|c|c|}
\hline & & & & & & \multicolumn{3}{|c|}{ Continuación de Tabla 8.28} \\
\hline TH 1-14 & 2 & - & - & 2 & 1 & 1 & 0.14 & 7.14 \\
\hline RB 1-28 & 5 & - & - & 3 & 3 & 1 & 0.11 & 5.36 \\
\hline HM & 4 & 1 & 1 & - & 2 & 1 & 1.00 & 50.00 \\
\hline RDU & 2 & 1 & 1 & - & 2 & 1 & 1.00 & 50.00 \\
\hline $\mathrm{CPF}$ & 2 & 2 & - & - & 2 & 2 & 1.00 & 50.00 \\
\hline CPR & 1 & - & 1 & - & 1 & 1 & 0.50 & 25.00 \\
\hline CPU & 1 & - & 1 & - & 1 & 1 & 0.50 & 25.00 \\
\hline $\mathrm{MC}$ & 2 & - & 2 & - & 2 & 2 & 1.00 & 50.00 \\
\hline IM & 3 & 1 & - & - & 1 & 1 & 0.50 & 25.00 \\
\hline FM & 3 & 3 & - & - & 3 & 3 & 1.50 & 75.00 \\
\hline PT & 1 & - & - & 1 & 1 & 1 & 0.50 & 25.00 \\
\hline TA & 1 & 1 & - & - & 1 & 1 & 0.50 & 25.00 \\
\hline AS & 1 & - & 1 & - & 1 & 1 & 0.50 & 25.00 \\
\hline TRT & 3 & 1 & 2 & - & 3 & 2 & 1.50 & 75.00 \\
\hline MT & 3 & - & 1 & - & 1 & 1 & 0.50 & 25.00 \\
\hline MP & 2 & - & - & 2 & 2 & 1 & 0.50 & 25.00 \\
\hline PHF & 14 & - & - & 9 & 9 & 2 & 1.13 & 56.25 \\
\hline PHS & 3 & - & - & 2 & 2 & 1 & 0.25 & 12.50 \\
\hline PHT & 5 & - & - & 5 & 5 & 1 & 0.63 & 31.25 \\
\hline SEP & 9 & - & - & 9 & 9 & 2 & 1.13 & 56.25 \\
\hline Total general & 119 & & & & & & & \\
\hline
\end{tabular}

\subsubsection{1.c. Número Mínimo de Individuos (MNI)}

Se calculó un MNI igual a 3 sobre la base de los tres fémures izquierdos hallados en el conjunto. Uno de estros individuos corresponde a una llama según el resultado obtenido mediante la aplicación de técnicas osteométricas.

\subsubsection{1.d. Unidades anatómicas representadas (MAU)}

En cuanto a las unidades anatómicas representadas se puede observar en la Figura 8.55 que están representadas todas las partes del esqueleto. Dentro del esqueleto axial la mayor frecuencia la obtuvo el axis el que proporcionalmente esta más representado en el conjunto (\%MAU $=100)$. El esqueleto apendicular trasero se encuentra más representado que el anterior tanto para su parte proximal como para su parte distal. 


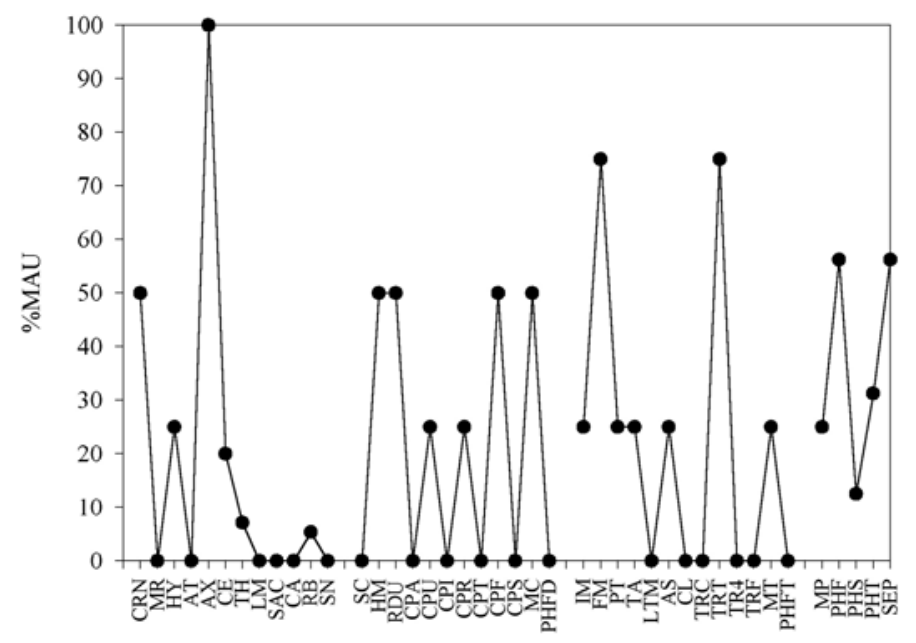

Figura 8.55. Abundancia relativa de elementos esqueletarios.

Teniendo en cuenta como se distribuyen las partes anatómicas preservadas para el conjunto se analizó esto en términos de rendimiento económico. Para los elementos clasificados como "no largos" se puede observar en la Figura 8.56.a que los elementos más representados en el conjunto son los que tiene una menor utilidad económica en términos de su rendimiento de carne, esto puede ser visto tanto en la expresión gráfica como en el resultado de la correlación en donde se obtuvo un valor de $r_{s}-.4815 \mathrm{p} .079$. En el caso de los elementos largos la relación es inversa obteniéndose un valor de $r_{s}$ $.3086 \mathrm{p}$.276. Por último y evaluando el porcentual de unidades anatómicas representadas y el volumen de la cavidad medular se obtuvo un $r_{s}-.0304 \mathrm{p} .477$. Estos resultados no explicarían para el caso del esqueleto axial la razón de la alta proporción de esta unidad anatómica por lo que se debería justificar su presencia no por su utilidad cárnica sino quizás por su contenido de grasa ósea u otros subproductos no relacionados con lo que se está evaluando en este caso. Para el conjunto apendicular el índice de utilidad de carne explicaría mejor el perfil del conjunto que el volumen de la cavidad medular. 

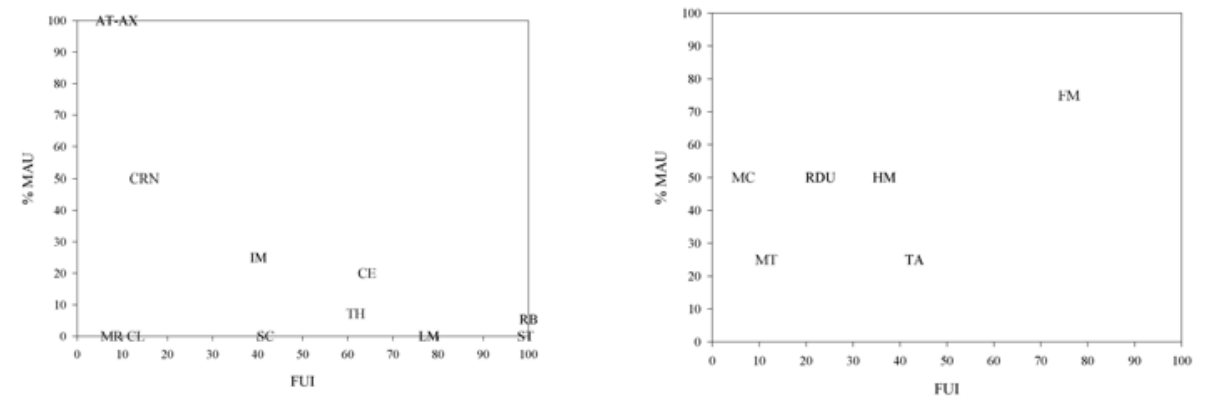

a

b

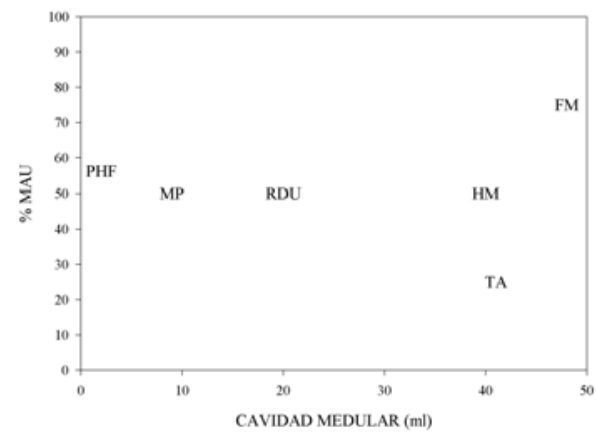

Figura 8.56. a) Relación \%MAU VS FUI huesos "no-largos”; b) Relación \%MAU VS FUI huesos "largos"; c) Relación \%MAU VS Cavidad Medular.

\subsubsection{1. e. Fragmentación del subconjunto}

Para este caso la fragmentación mantiene el mismo perfil observado para otros conjuntos en cuanto a los especímenes que presentan fragmentación. Sin embargo la frecuencia relativa de elementos completos es mayor que otros conjuntos del área. De todos modos los elementos completos son en general dientes, carpianos, tarsianos, sesamoideos y una patela, todos ellos de dimensiones relativamente pequeñas y con utilidades económicas muy bajas

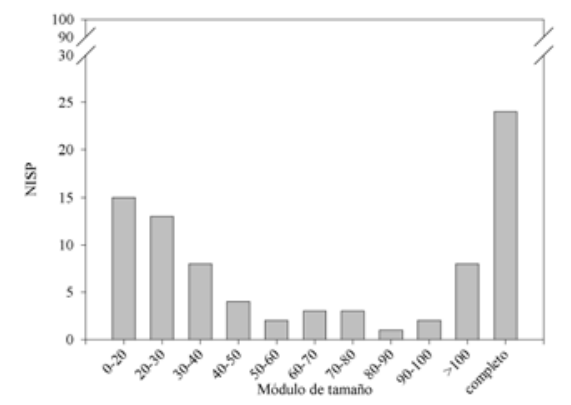

Figura 8.57. Módulos de tamaño expresado en NISP para especímenes y elementos del subconjunto adulto de camélidos 
Se analizó la estructura del conjunto fragmentado de acuerdo a su asignación a partes esqueletarias mayores.

\section{Esqueleto axial}

En este caso se puede observar que el conjunto no presenta especímenes completos y que el área preservada para cada elemento suele ser bastante baja. El elemento con mayor superficie preservada es el hioides y este valor no supera el $30 \%$ del total del elemento (largo máximo $30 \mathrm{~mm}$ ). Para el caso del cráneo la superficie preservada varía entre el 0,4 y 5,1 \% del total de la superficie del elemento lo que traducido en términos absolutos implican largos máximos que van desde 27 hasta 47 $\mathrm{mm}$. El axis presenta variabilidad respecto de la superficie preservada la cual va desde el $8,6 \%$ hasta el $22,1 \%$ del total, lo que expresado en largo máximo corresponde al rango de medidas ubicadas entre 29 y $54 \mathrm{~mm}$. Por último para las vértebras se preservó entre el 4,5\% y 5,69\% de superficie cuyos largos máximos varían entre los 70 y $79 \mathrm{~mm}$.

Si tenemos en cuenta que se encontraron especímenes de módulos de tamaño superiores a los $50 \mathrm{~mm}$ y que la anatomía económica de los camélidos no explica la presencia de elementos del esqueleto axial en mayor frecuencia que aquellos pertenecientes al apendicular, podríamos suponer que el área preservada y los largos máximos de especímenes identificados para el conjunto serían producto de una reducción secundaria con el fin de extracción de grasa ósea o por el efecto "pot-sizing" (Lupo y O’Connell 2002)

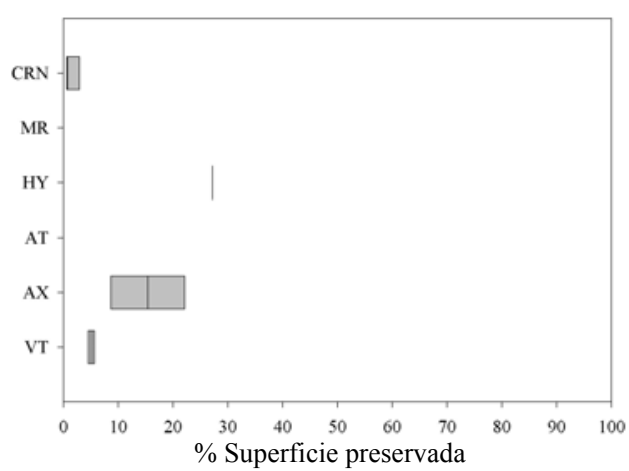

Figura8.58. Fragmentación de elementos del esqueleto axial.

Esqueleto apendicular delantero 
En esta parte esqueletal básica se observó que la fragmentación de los distintos elementos representados sigue una configuración similar. Respecto al húmero, tanto para el lado izquierdo como para el derecho, la superficie preservada no supera el $22 \%$ del total y los largos máximos de los fragmentos se ubican dentro de los módulos de tamaño 41-50, 71-80 y 141-150 mm. El primero y el último corresponden al lado izquierdo y el módulo 71-80 al lado derecho. Para el radioulna el porcentaje de superficie calculado corresponde al 10,91\% para el lado izquierdo y el 6,43\% para el lado derecho. El tamaño de los especímenes de ambos elementos es del orden de los 127 $\mathrm{mm}$ (izquierdo) y $85 \mathrm{~mm}$ (derecho). Para los carpianos la superficie preservada varia entre el $50 \%$ y el $100 \%$. Por último para el metacarpo se observó que la superficie conservada varió entre el 4,09\% y 10,54\% con los largos máximos ubicados entre 29 y $59 \mathrm{~mm}$.
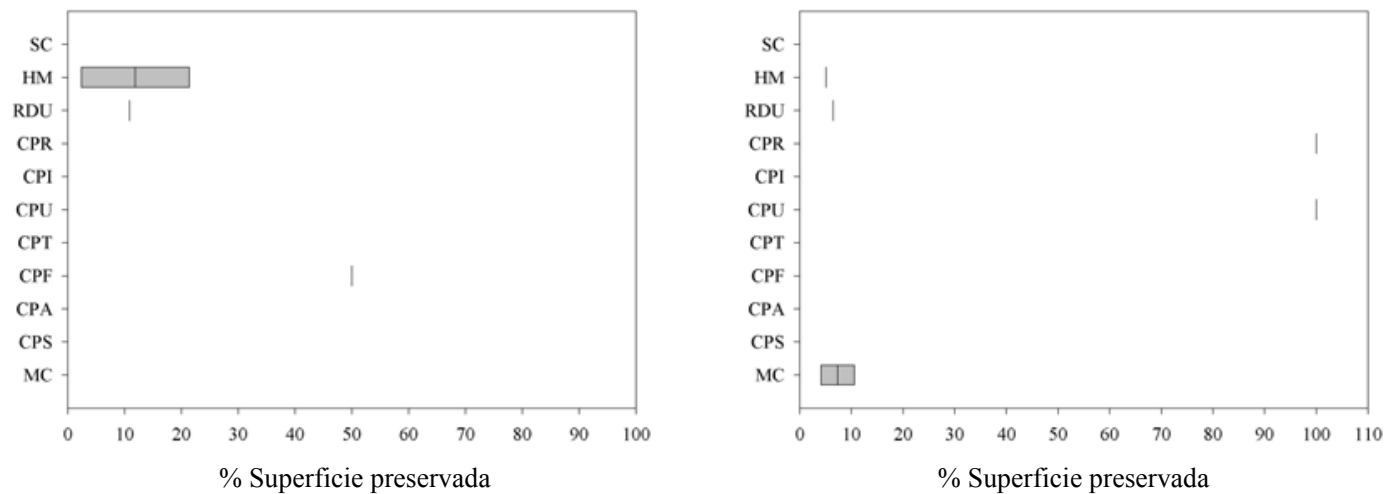

Figura 8.59. Fragmentación esqueleto apendicular delantero (izquierdo y derecho)

El perfil de fragmentación para el esqueleto apendicular delantero nos permite observar una gran diferencia con respecto al del esqueleto axial. En general para el húmero y el radioulna se presentan especímenes con valores relativos de conservación de superficie bajos pero que constituyen largos máximos relativamente altos. En cambio, para el metacarpo también la superficie conservada es relativamente baja pero al contrario que en el caso anterior los valores de longitud máxima son pequeños. Esto diferencia podría ser explicada como un uso diferencial de los elementos. En tanto que para los primeros se habría priorizado la extracción de carne y medula ósea, en donde la reducción de los especímenes no sería importante, para el metacarpo se habría procedido la reducción del elemento a pequeños fragmentos quizás con el fin de la extracción de gasa ósea. 


\section{Esqueleto apendicular trasero}

Esta parte esqueletal básica exhibe diferencias en cuanto a la representación de elementos respecto de la lateralidad. Como se pude observar en la Figura 8.60 para la pata izquierda se conservaron en general más fragmentos de los elementos superiores (Innominado, Fémur y Tibia) en tanto que para la pata derecha están representados los elementos más distales (metatarso y tarso tercero).

Con respecto a las superficies preservadas y su relación con los largos máximos se encontró que el innominado conservó desde el 3,79\% hasta el 11,6\%. Esto implica largos de los fragmentos que oscilan entre 36 y $77 \mathrm{~mm}$. Para el fémur el tamaño de los fragmentos fue de $2,73 \%$ a $17,62 \%$ con longitudes que variaron entre los 106 y $204 \mathrm{~mm}$. La tibia esta representa en un 27,54\% $(215 \mathrm{~mm})$ Las tarsianos fueron encontrados completos por lo que su superficie preservada es del 100\%. Por último para el metatarso se calculó una superficie conservada de 4.83\% y 12.92\% (44 y 99 mm respectivamente). Nuevamente estaríamos frente a una situación similar al lo planteado para el miembro anterior aunque en el caso del metatarso esta situación no sería tan clara como la planteada para el metacarpo.
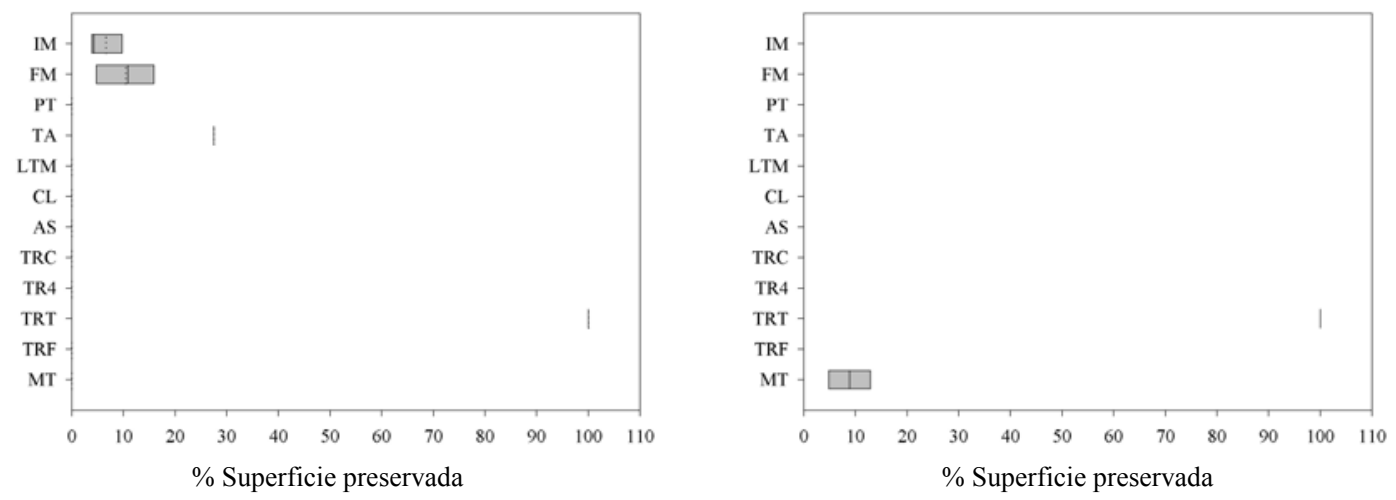

Figura 8.60. Fragmentación esqueleto apendicular trasero (izquierdo y derecho)

Teniendo en cuenta los resultados anteriores nos resta examinar como se comporta la muestra con respecto a los estados del hueso al producirse la fragmentación resultando que tanto las clases fresca como seca se presentaron en frecuencias similares. Hay que remarcar que los elementos axiales, el metacarpo y el metatarso presentan fractura seca y que el húmero, radioulna, innominado y fémur exhiben fractura fresca, de algún modo avalando la idea de la utilización diferencial de los elementos como ha sido planteado más arriba. 


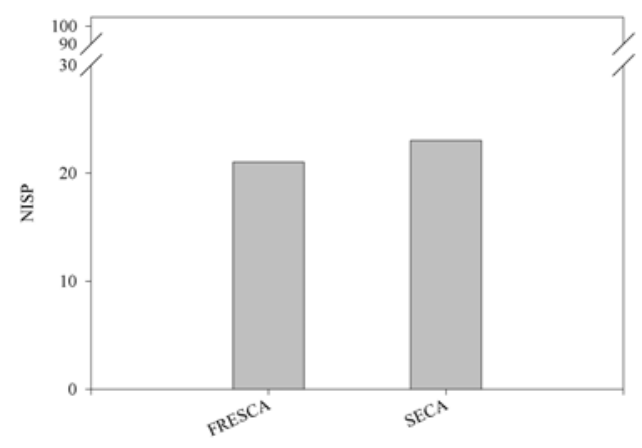

Figura 8.61. Cantidad (NISP) de especímenes y elementos del subconjunto adulto de camélidos según tipo de fractura.

\subsubsection{1.f. Utilización de las carcasas}

Solo se pudieron observar marcas de impacto en tres especímenes correspondiendo estos a un metacarpo, una falange proximal y una tibia como puede observarse en la Tabla 8.29 y en la Figura 8.62.

Tabla 8.29. Marcas en hueso de camélidos adultos expresado en NISP

\begin{tabular}{llcc}
\hline Elemento & Porción & Impacto & NISP \\
MC & PRS & 1 & 1 \\
PHF & PRS & 1 & 1 \\
TA & SH & 1 & 1 \\
Total & & 3 & 3 \\
\hline
\end{tabular}

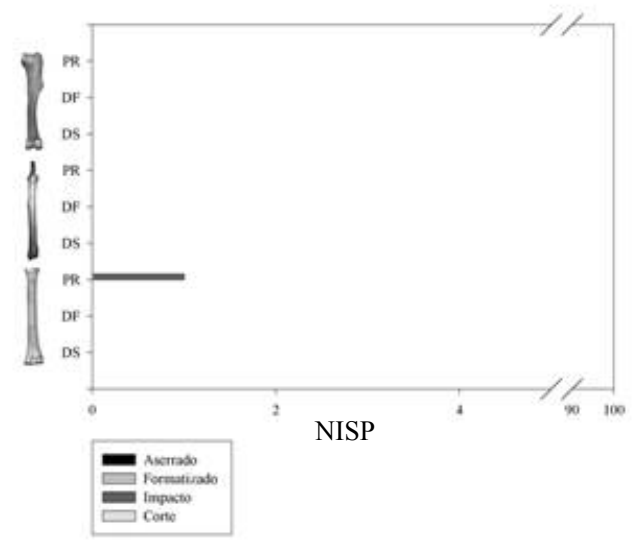

a

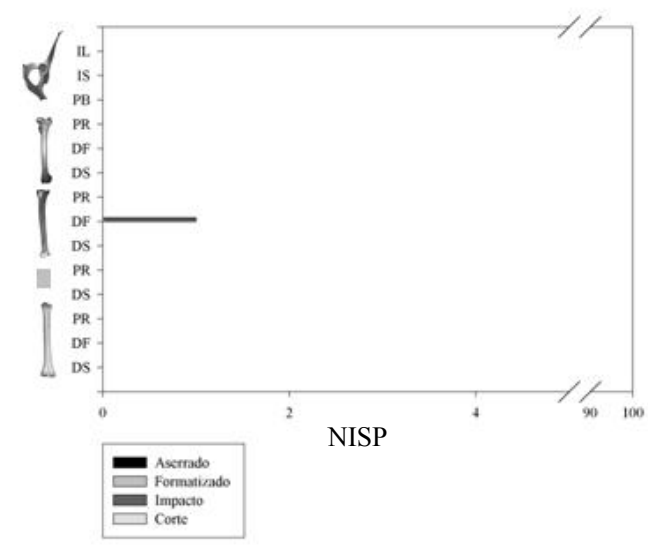

b

Figura 8.62. a) esqueleto apendicular delantero; b) esqueleto apendicular trasero. 


\subsubsection{1.g. Termoalteraciones}

La termoalteración afectó al $19 \%$ de la muestra. Presentó todos los tipos de alteraciones, presentando en mayor frecuencia elementos carbonizados siendo afectado mayormente los sesamoideos, tarsianos, falanges, un fragmento de metatarso, de axis y de innominado. La clase 2 se identificó en falanges y una vértebra torácica. En tanto que el tipo 4 se observó en un fragmento de tibia, patela y metacarpo.

Tabla 8.30. Termoalteración del conjunto de camélidos adultos.

\begin{tabular}{cccccr}
\hline Descripción & Sin alteración & $\begin{array}{c}\text { Oxidación } \\
\text { incompleta/carbonización } \\
\text { marrón claro-negro } \\
\text { (moteado) }\end{array}$ & Carbonizado & Calcinado & \\
Color & - & $200{ }^{\circ} \mathrm{C}-300{ }^{\circ} \mathrm{C}$ & $300{ }^{\circ} \mathrm{C}$ & $>500{ }^{\circ} \mathrm{C}$ & \\
Temperatura & $<200{ }^{\circ} \mathrm{C}$ & 3 & 13 & 3 & 119 \\
NISP & 100 & gris-blanco & \\
\hline
\end{tabular}

La relación termoalteración y tipo de fractura arrojó como resultado que los elementos se comportaron independientemente respecto del tipo de alteración térmica y su correlato con el tipo de fractura. Las proporciones son similares para todas las categorías.

Tabla 8.31. Relación entre tipo de termoalteración y tipo de fractura del conjunto de camélidos adultos.

\begin{tabular}{lccc}
\hline \multicolumn{1}{c}{ Tipo de alteración } & Fresca & Seca & Total \\
Sin alteración & 19 & 14 & 39 \\
Oxidación incompleta & 1 & 1 & 2 \\
Carbonizado & - & 7 & 8 \\
Calcinado & 1 & 1 & 2 \\
$\quad$ Total & 21 & 23 & 44 \\
\hline
\end{tabular}

\subsubsection{Camélidos subadultos}

Se registró un NISP igual a 20 lo que representa un $14.39 \%$ de la muestra de camélidos.

\subsubsection{2.a. Supervivencia del material óseo mediada por la densidad ósea}

De las tres correlaciones efectuadas una presentó fue negativa, otra positiva y la última no presentó correlación. En todos los casos los resultados no son estadísticamente significativos.

El conjunto parecería no haber sido afectado por factores asociados a la densidad ósea como se ve en el resultado de la correlación efectuada para todo el conjunto, ya que en total sugeriría que se han preservado zonas diagnósticas con densidades óseas 
bajas. Para el húmero se observó que las porciones preservadas son más densas y para la tibia no se encontró correlación entre los valores de \%MAU y densidad ósea.

Tabla 8.32. \%MAU vs. VD.

\begin{tabular}{lccc}
\hline Elemento & Rank & $r_{s}$ & $p$ \\
Húmero & 5 &, 288 &, 240 \\
Tibia & 5 &, 000 &, 500 \\
Arqueofauna & 29 &,- 077 &, 240 \\
\hline
\end{tabular}

\subsubsection{2.b. Número Mínimo de Elementos (MNE)}

Costillas (RB)

Se identificaron 2 fragmentos de costilla asignadas a la clase de edad subadulto. Estos dos fragmentos permitieron reconocer a 2 elementos distintos razón por la cual se asignó un MNE igual a 2.

Húmero (HM)

Se identificó una epífisis distal para el lado izquierdo. El MNE es 1.
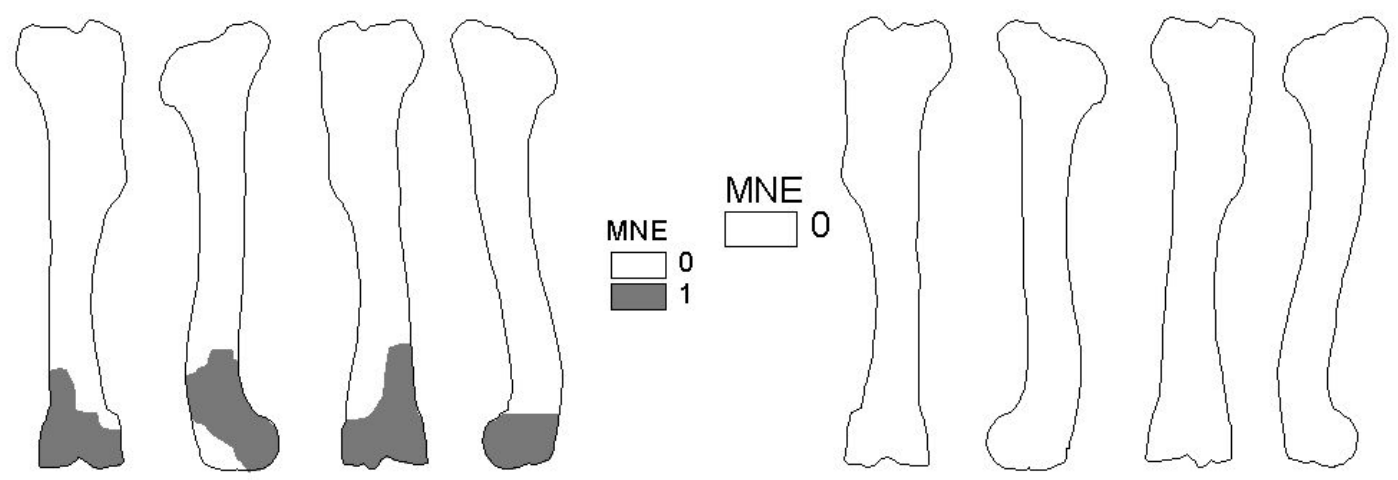

Figura 8.63. MNE Húmero izquierdo y derecho

Tibia (TA)

Se halló, al igual que en el caso del húmero, una epífisis distal completa pero esta vez para el lado derecho. El MNE calculado fue igual a 1.
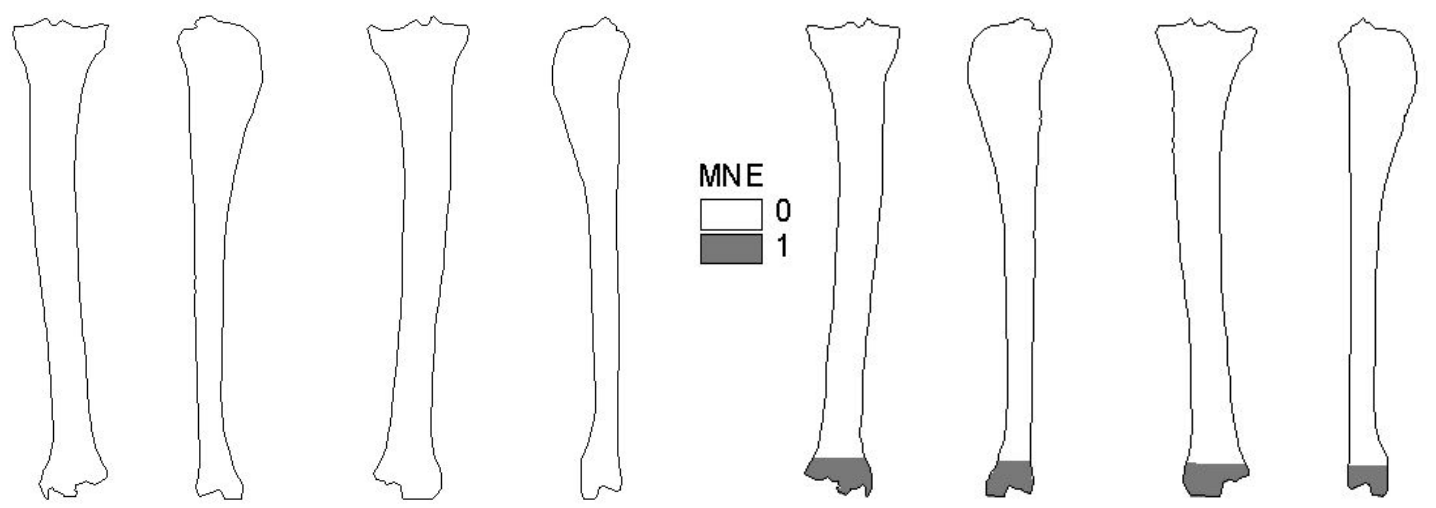

Figura 8.64. MNE Tibia izquierda y derecha 
Metapodio (MP)

Se identificaron las siguientes zonas diagnósticas: diáfisis distal (con cóndilos), cóndilo lateral y cóndilo medial. Sobre estas zonas se construyó un MNE igual a 5.
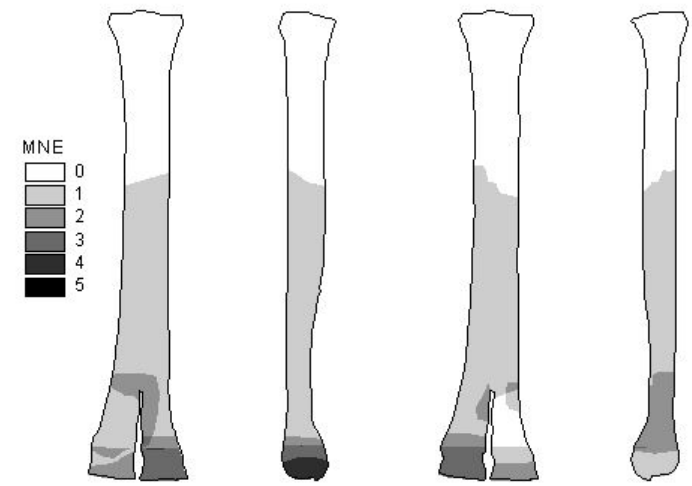

Figura 8.65. MNE Metapodio

Falange Proximal (PHF)

Solo se identificaron las epífisis proximales sin fusionar. El total calculado fue de 3 elementos.
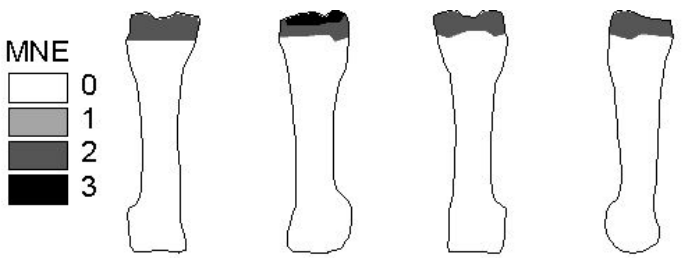

Figura 8.66. MNE Falange proximal

Falange Medial (PHS)

Se identificaron epífisis proximales, diáfisis y epífisis distales fusionadas. El MNE calculado ascendió a 2 elementos.
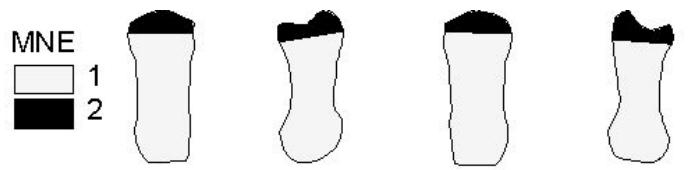

Figura 8.67 MNE Falange medial

A partir del cálculo de los números mínimos de elementos se para este subconjunto se procedió a computar los demás índices (MNI, MAU y \%MAU). 
Tabla 8.33. Abundancia relativa de partes esqueletarias expresadas como NISP, MNE comprehensivo, MAU y \%MAU.

\begin{tabular}{lrrrrrrrr}
\hline Elemento & NISP & I & D & S/D & MNE & MNI & MAU & \%MAU \\
RB & 2 & - & 1 & 1 & 2 & 1 & 0.07 & 5.60 \\
HM & 1 & 1 & - & - & 1 & 1 & 0.50 & 40.00 \\
TA & 1 & - & 1 & - & 1 & 1 & 0.50 & 40.00 \\
MP & 10 & - & - & 5 & 5 & 2 & 1.25 & 100.00 \\
PHF & 3 & - & - & 3 & 3 & 1 & 0.38 & 30.40 \\
PHS & 3 & - & - & 2 & 2 & 1 & 0.25 & 20.00 \\
Total general & 20 & & & & & \\
\hline \multicolumn{7}{c}{ D = derecho, I = izquierdo, S/D = axial o sin datos }
\end{tabular}

\subsubsection{2.c. Número Mínimo de Individuos (MNI)}

El número mínimo de individuos obtenido es de 2 y se calculó basándose en la cantidad de metapodios. El resto de los elementos sólo denotan la presencia de un solo animal.

\subsubsection{2.d. Unidades anatómicas representadas (MAU)}

Las unidades anatómicas representadas en el conjunto se graficaron en la Figura 8.68 Lo que se puede observar es la gran representación que tiene los elementos del autopodio en relación con el resto de los elementos del esqueleto. El esqueleto axial está representado solo por dos fragmentos de costilla. Para el esqueleto apendicular delantero sólo está presente el húmero, en tanto que para el trasero solo se pudo identificar la presencia de la tibia.

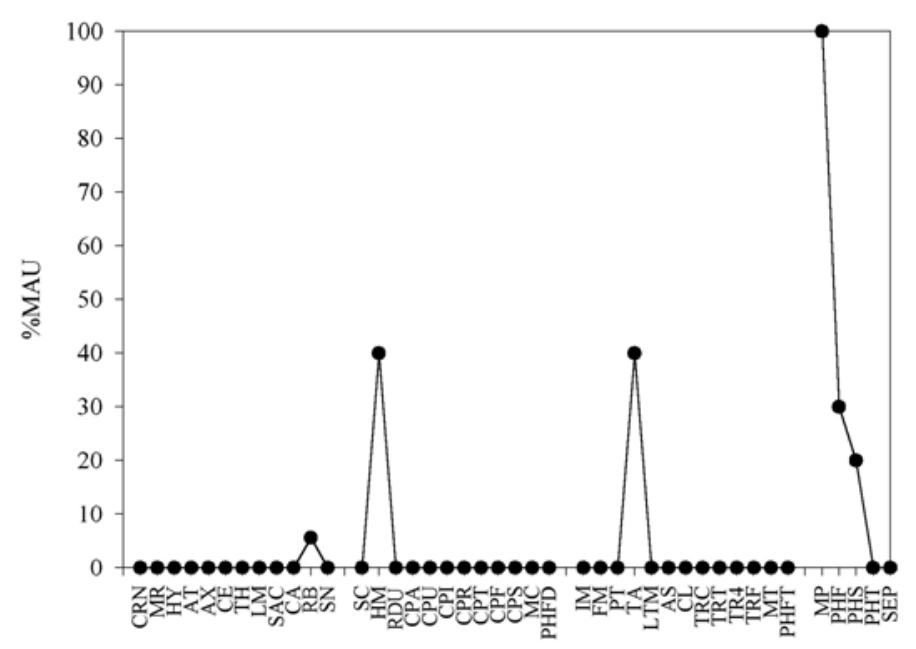

Figura 8.68. Abundancia relativa de elementos esqueletarios. 
Respecto de la utilidad económica de los elementos representados se pueden realizar las siguientes consideraciones: la costilla es uno de los elementos del esqueleto axial que presenta el valor más alta de índice de utilidad de carne y es el único representado en este conjunto para esta parte esqueletal básica. Para el esqueleto apendicular delantero se identificó la presencia del húmero, el cual dentro del ranking de utilidad de carne se ubica en el primer puesto dentro de los electos de este miembro. Para el esqueleto apendicular trasero el elemento presente es la tibia el cual se ubica en cuanto a índice de utilidad de carne detrás del fémur. Por último tanto los metapodios como las falanges son los últimos en este índice de utilidad de carne. Con respecto al volumen de la cavidad medular se puede decir que el húmero y la tibia son junto al fémur los tres elementos con mayor capacidad interna para contener médula.

Tomando en cuenta los dos índices utilizados la presencia del húmero y la tibia podría definirse mediante estos indicadores de la anatomía económica. Respecto de la sobre abundancia de los metapodios y las falanges es interesante notar que si bien son de baja utilidad económica, al menos un metapodio y una segunda falange fueron recuperadas de un pozo hallado debajo del piso de ocupación y los que posiblemente sean los que aumenten el MNI de un individuo a dos.

\subsubsection{2. e. Fragmentación del subconjunto}

El conjunto de camélidos subadultos presentó un alto grado de fragmentación. El módulo de tamaño más representado resultó ser el de 0-20 mm. El resto del conjunto se reparte en distintos módulos. Los elementos completos solo representan una proporción pequeña dentro de la muestra. En cuanto al tipo de estado al realizarse la fractura se puede observar en la Figura 8.69.b que la categoría fresca se presenta en mayor frecuencia que la fractura seca.

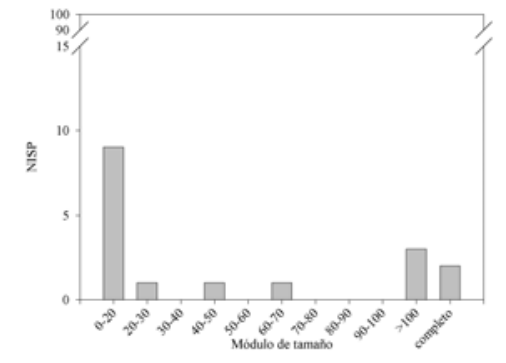

a

Figura 8.69. a) módulos de tamaño, b) especímenes y elementos del subconjunto subadulto de camélidos según tipo de fractura. 


\subsubsection{2.f. Utilización de las carcasas}

Sólo se registró en el conjunto una huella de impacto realizada en la porción distal de la diáfisis de un húmero.

Tabla 8.34. Marcas en hueso de camélidos subadultos expresado en NISP

\begin{tabular}{ccrr}
\hline Elemento & Porción & Impacto & NISP \\
HM & DSS & 1 & 1 \\
& & & \\
Total & & & 1 \\
\hline
\end{tabular}

\subsubsection{2.g. Termoalteraciones}

Fueron identificados efectos de calor sobre tres especímenes. Estos se hallaron carbonizados correspondiendo en todos los casos a epífisis de falanges (dos proximales y una medial)

Tabla 8.35 Termoalteración del conjunto de camélidos subadultos.

\begin{tabular}{cccccc}
\hline Descripción & Sin alteración & $\begin{array}{c}\text { Oxidación } \\
\text { incompleta/carbonización } \\
\text { marrón claro-negro } \\
\text { (moteado) }\end{array}$ & Carbonizado & Calcinado & \\
Color & - & $200^{\circ} \mathrm{C}-300^{\circ} \mathrm{C}$ & $300{ }^{\circ} \mathrm{C}$ & $>500{ }^{\circ} \mathrm{C}$ & \\
Temperatura & $<200{ }^{\circ} \mathrm{C}$ & 0 & 3 & 0 & 20 \\
NISP & 17 & 0 & 3 & 0 \\
\hline
\end{tabular}

En cuanto a la alteración térmica y el tipo de estado al producirse la fractura se observa en la Tabla 8.36 que los que no registraron alteración térmica presentaron en todos los casos la clase fresca, en cambio las termoalteradas presentaron el tipo seca.

Tabla 8.36. Relación entre tipo de termoalteración y tipo de fractura del conjunto de camélidos subadultos.

\begin{tabular}{cccc}
\hline Tipo de alteración & Fresca & Seca & Total general \\
Sin alteración & 6 & - & 6 \\
Carbonizado & - & 1 & 1 \\
Total & 6 & 1 & 7 \\
\hline
\end{tabular}

\subsubsection{Subconjunto no camélido}

Este subconjunto esta representado por siete taxones que representan a toda la escala de tamaños corporales. 


\subsubsection{Marcas de procesamiento}

Se identificaron marcas de corte, raspado e impacto en fragmentos asignados al esqueleto axial y al apendicular de artiodáctilos de tamaño corporal 4. Para el esqueleto axial se identificó la existencia de marcas de corte en el arco neural de una vértebra. Para el esqueleto apendicular, se observó marcas de raspado e impacto en lasca ósea de hueso largo y en una epífisis determinada como fragmento de cabeza, la que no se pudo asignar a nivel elemento pero debe pertenecer o a un húmero o un fémur.

Tabla 8.37. Marcas en huesos del conjunto no camélido expresado en NISP.

\begin{tabular}{ccllcccc}
\hline CLASE & BDSZ & EL & POR & Marcas de Corte & Raspado & Impacto & Total general \\
UL & 4 & LB & FK & - & 1 & 4 & 5 \\
UL & 4 & LB & HE & - & - & 1 & 1 \\
UL & 4 & VT & NAS & 1 & - & - & 1 \\
Total general & & & & 1 & 1 & 5 & 7 \\
\hline
\end{tabular}

\subsubsection{Termoalteración}

Signos de alteración térmica fueron hallados en los siguientes taxones: Chaetophractus vellerosus, Rodentia (T. corporal 1 y 2) y Artiodáctilos (T. corporal 4). Además las clases de tamaño corporal 1-2, 2-3, 3-4 y 4 de los especímenes "no identificables" taxonómicamente fueron identificados con signos de alteración térmica.

Tabla 8.38. Termoalteración del conjunto de no camélido.

\begin{tabular}{|c|c|c|c|c|c|c|}
\hline Taxón & $\begin{array}{l}\text { Temperatura } \\
\text { T. corporal }\end{array}$ & $\begin{array}{l}\text { Sin } \\
\text { alteración } \\
<200{ }^{\circ} \mathrm{C}\end{array}$ & $\begin{array}{c}\text { Oxidación } \\
\text { incompleta/carboniza } \\
\text {-ción } \\
200^{\circ} \mathrm{C}-300{ }^{\circ} \mathrm{C}\end{array}$ & Carbonizado & Calcinado & Total \\
\hline AVE & 2 & 1 & - & - & - & 1 \\
\hline C. vellerosus & 2 & 60 & 3 & 7 & 2 & 72 \\
\hline Rodentia & 1 & 18 & - & 1 & - & 19 \\
\hline Rodentia & $1-2$ & 1 & - & - & - & 1 \\
\hline Rodentia & 2 & 41 & - & 1 & - & 42 \\
\hline Ctenomyidae & 1 & 1 & - & - & - & 1 \\
\hline Lagidium $s p$. & 2 & 1 & - & & - & 1 \\
\hline Artiodactyla & $3-4$ & 11 & - & 2 & - & 13 \\
\hline Artiodactyla & 4 & 1774 & 177 & 576 & 256 & 2783 \\
\hline H. antisensis & 4 & 1 & - & - & - & 1 \\
\hline No identificable & 1 & 16 & - & - & 1 & 17 \\
\hline No identificable & $1-2$ & 21 & - & 2 & 1 & 24 \\
\hline No identificable & 2 & 3 & - & - & - & 3 \\
\hline No identificable & $2-3$ & 3 & - & - & 2 & 5 \\
\hline No identificable & $3-4$ & 43 & 1 & 6 & 2 & 52 \\
\hline No identificable & 4 & 111 & - & 109 & 10 & 230 \\
\hline No identificable & 9 & & - & 16 & 16 & 32 \\
\hline Total general & & 2106 & 181 & 720 & 290 & 3297 \\
\hline
\end{tabular}




\subsubsection{Fragmentación del conjunto no camélido}

Para el tamaño corporal 1 (Figura 8.70.a) se observó que los roedores y no identificables presentan especímenes fragmentados y completos. Ctenomys sp solo presentó elementos completos. En el caso del tamaño corporal 2 también se observa el mismo patrón (Figura 8.70.b). Por último, para el tamaño corporal 3-4 se observó la presencia de un solo elemento completo y el resto se ubicó en los módulos de tamaño más pequeños

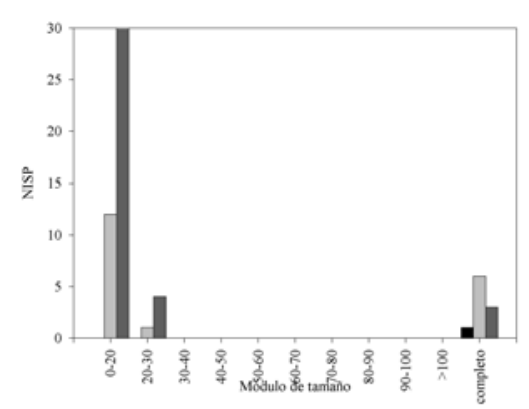

a
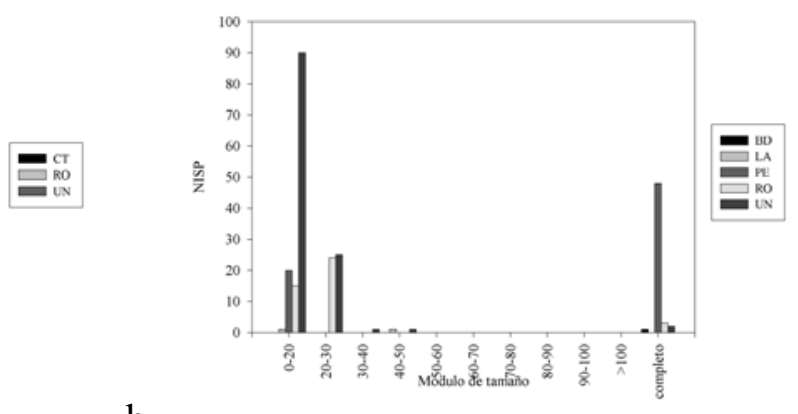

b

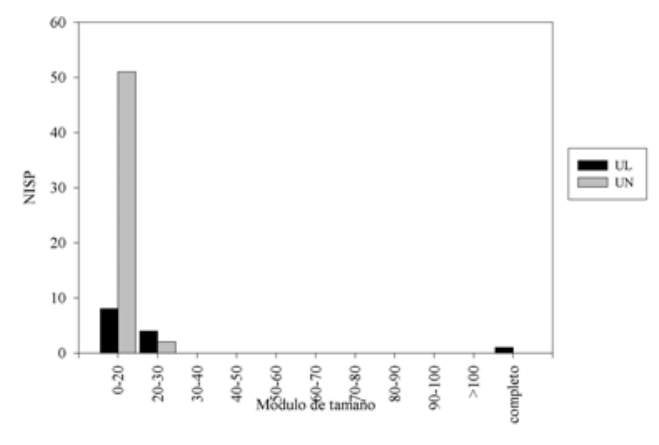

$\mathrm{c}$

Figura 8.70. Fragmentación del conjunto no camélido expresado en NSP. a) Tamaño corporal 1, b) Tamaño corporal 2 y c) Tamaño corporal 3-4. 


\subsection{Yutopián - Estructura 4-Ocupación Superior - Análisis faunístico}

El total de especímenes y elementos recuperados arrojó un NSP=1897. De este total se identificó a nivel taxonómico el 30,99\%. Se identificaron un total de seis taxones diferentes. De este total algunas categorías se pudieron dividir de acuerdo a la asignación de algunos especímenes o elementos a distintos tamaños corporales. Para Rodentia se sugiere la presencia de al menos dos tamaños corporales. Lo mismo sucede con Artiodactyla que presenta dos categorías (tamaño corporal 3-4 y 4).

Tabla 8.39. Composición del conjunto faunístico de la Estructura 4 - Ocupación Superior.

\begin{tabular}{ccr}
\hline Taxón & Tamaño corporal & NSP \\
Chaetophractus vellerosus & 2 & 9 \\
Rodentia & 1 & 26 \\
Rodentia & 2 & 53 \\
Carnivora & 2 & 3 \\
Artiodactyla & $3-4$ & 1 \\
Artiodactyla & 4 & 367 \\
Lama sp. & 4 & 126 \\
H. antisensis & 4 & 3 \\
& & \\
Subtotal Identificados & & 588 \\
& 1 & \\
No identificable & 2 & 14 \\
No identificable & $2-3$ & 1 \\
No identificable & 4 & 606 \\
No identificable & 9 & 686 \\
No identificable & & \\
Subtotal No identificables & & \\
& & \\
& &
\end{tabular}

En cuanto a los agentes tafonómicos que actuaron sobre el conjunto se puede observar que los especímenes o elementos presentan el estadio de meteorización 1 y el estadio 2. En conjunto estos dos estadios representan el $100 \%$ de los elementos o especímenes sobre los que se pudo identificar algún estadio de meteorización en la muestra. Este resultado nos permite sugerir que el conjunto presenta en general una meteorización relativamente baja. 
Tabla 8.40. Meteorización del conjunto faunístico de la Estructura 4 - Ocupación Superior. Yutopián

\begin{tabular}{crrrrrrr}
\hline Tamaño corporal & \multicolumn{9}{c}{ Meteorización } \\
& 1 & 2 & 3 & 4 & 7 & Total NSP \\
1 & 22 & 6 & - & - & - & 28 \\
2 & 29 & 48 & - & - & 2 & 79 \\
$2-3$ & - & 1 & - & - & - & 1 \\
$3-4$ & 1 & - & - & - & - & 1 \\
4 & 184 & 202 & - & - & 716 & 1102 \\
9 & - & 2 & - & - & 684 & 686 \\
& TOTAL & 236 & 259 & - & - & 1402 & 1897 \\
\hline
\end{tabular}

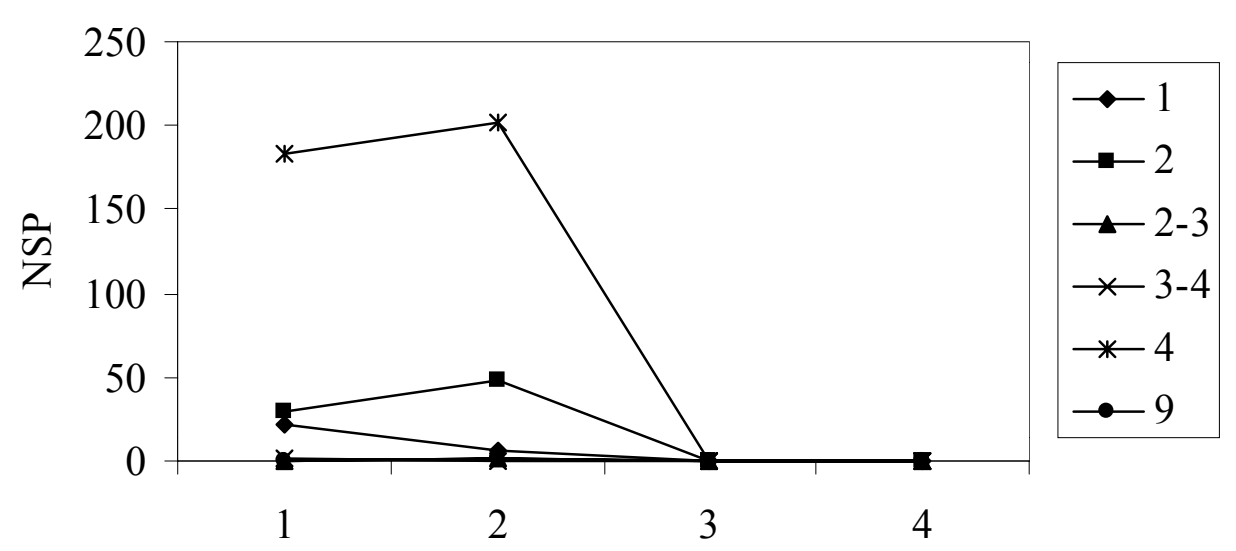

Estadios de meteorización

Figura 8.71. Estadios de meteorización según tamaño corporal. Estructura 4 Ocupación Superior, Yutopián

La acción de roedores y carnívoros se registró en especímenes del tamaño corporal 2 y 4 . La acción de roedores se reconoció en trece fragmentos del total de la muestra. Doce de ellos presentan una acción moderada en tanto que el otro presenta un daño que afecta una gran porción del hueso. En cuanto a marcas de carnívoros no se registraron evidencias de la acción de este agente en la muestra.

Tabla 8.41. Modificaciones por agentes naturales del conjunto faunístico de la Estructura 4 - Ocupación Superior. Yutopián

\begin{tabular}{ccccr}
\hline Tamaño Corporal & $\begin{array}{c}\text { Sin } \\
\text { modificaciones }\end{array}$ & $\begin{array}{c}\text { Daño ligero } \\
\text { por roedor }\end{array}$ & $\begin{array}{c}\text { Daño moderado/grave por } \\
\text { roedor }\end{array}$ & Total NSP \\
1 & 28 & - & - & 28 \\
2 & 78 & 1 & - & 79 \\
$2-3$ & 1 & - & - & 1 \\
$3-4$ & 1 & - & - & 1 \\
4 & 1090 & 10 & - & 1101 \\
9 & 686 & - & 1 & 686 \\
Total NSP & 1884 & 11 & 1896 \\
\hline
\end{tabular}


8.4.1. Análisis del subconjunto de camélidos.

Para este conjunto se calculó un NISP $=126$.

Tabla 8.42. Camelidae, huesos del esqueleto axial y apendicular. Estructura 4 -

\begin{tabular}{cr} 
Ocupación Superior, Yutopiá \\
\hline Elemento & Lama sp. \\
CRN & 5 \\
MR & 2 \\
HY & 1 \\
IC & 1 \\
TFR & 14 \\
CE & 2 \\
RB & 18
\end{tabular}

$\begin{array}{cl}\text { SC } & 1 \\ \text { HM } & 2 \\ \text { RDU } & 6 \\ \text { CPA } & 1 \\ \text { CPF } & 3 \\ \text { CPI } & 1 \\ \text { CPR } & 3 \\ \text { CPU } & 3\end{array}$

IM $\quad 10$

PT 2

LTM 2

TA 6

AS 3

FM 2

CL 1

TR4 2

TRC 2

TRF 1

TRT 4

MT 1

MP 7

PHF 7

PHS 6

PHT 3

SEP 4

Total general $\quad 126$

\subsubsection{Camélidos adultos}

8.4.1.1.a. Supervivencia del material óseo mediada por la densidad ósea

De los nueve elementos sobre los que se pudo determinar la correlación entre los valores de densidad ósea y el valor de las unidades anatómicas mínimas estandarizadas 
se observó que cuatro presentaron correlaciones positivas (una estadísticamente significativa), tres resultaron ser negativas y dos no presentaron correlaciones. Para el conjunto (29 elementos) la correlación fue positiva.

En cuanto a cada elemento en particular la única observación notable es para la mandíbula ya que la correlación es positiva y estadísticamente significativa lo que estaría mostrando que la preservación de este elemento podría estar relacionada con la densidad ósea.

\section{Tabla 8.43. \%MAU vs. VD.}

\begin{tabular}{cccc}
\hline Elemento & Rank & $r_{\mathrm{s}}$ & $p$ \\
Mandíbula & 8 &, 755 &, $015^{*}$ \\
Escápula & 4 &,- 744 &, 113 \\
Húmero & 5 &, 577 &, 154 \\
Radioulna & 6 &,- 292 &, 287 \\
Innominado & 8 &, 158 &, 367 \\
Fémur & 5 &,- 707 &, 091 \\
Tibia & 5 &, 111 &, 429 \\
Calcáneo & 4 &, 000 &, 500 \\
Metatarso & 4 &, 000 &, 500 \\
Arqueofauna & 29 &, 055 &, 304 \\
\hline \multicolumn{4}{c}{$*$ Significativo al nivel $\mathrm{p}>, 05$}
\end{tabular}

8.4.1.1.b. Número Mínimo de Elementos (MNE)

Cráneo (CRN)

Se identificaron dos zonas diagnósticas: el petroso y un cóndilo del occipital. En base a tres fragmentos de petroso izquierdo es que se pudo establecer un $\mathrm{MNE}=3$

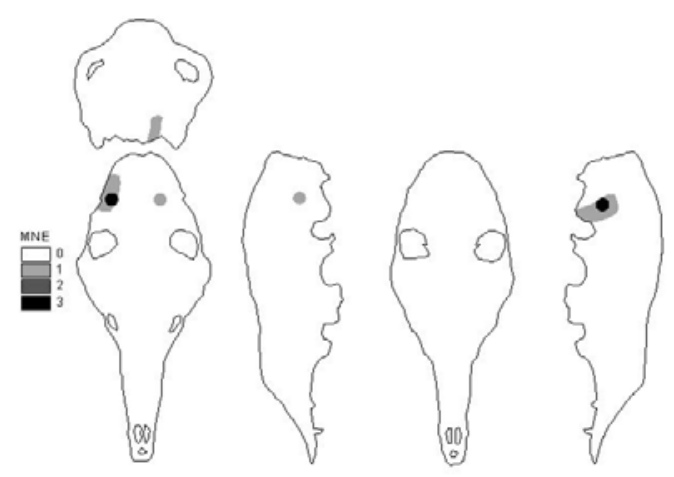

Figura 8.72. MNE Cráneo

Mandibula (MR)

Las zonas diagnósticas determinadas para este elemento de la cabeza corresponden tanto a la rama ascendente como a la dentaria. Entre los hallados se encuentra el cóndilo articular y el foramen mandibular sobre los cuales se procedió al calculo de un $\mathrm{MNE}=1$. 


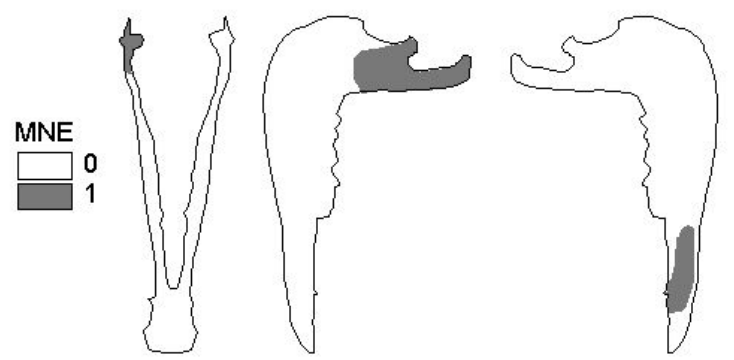

Figura 8.73 MNE Mandíbula

Hioideo (HY)

Las zonas diagnósticas que se reconocieron en este elemento corresponden a la porción distal del cuerpo. Se obtuvo un valor de MNE comprehensivo igual a uno (Figura 8.74)

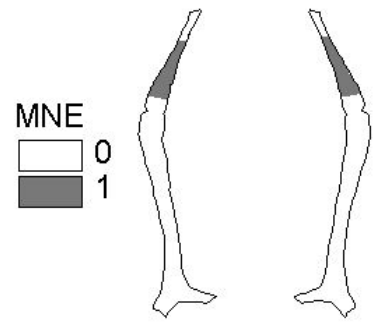

Figura 8.74. MNE Hioideo

Dientes (IC y TFR)

Se identificaron un total de quince fragmentos correspondientes a camélidos. Catorce de ellos son restos de dientes generales. Del resto se obtuvo un MNE igual a 1 para incisivos. En general el estado de los dientes es fragmentario.

Cervicales 3-7 (CE)

Para este elemento se identificaron las siguientes zonas diagnósticas: Cuerpo vertebral y prezigoapófisis. El MNE comprehensivo calculado es igual a 1.
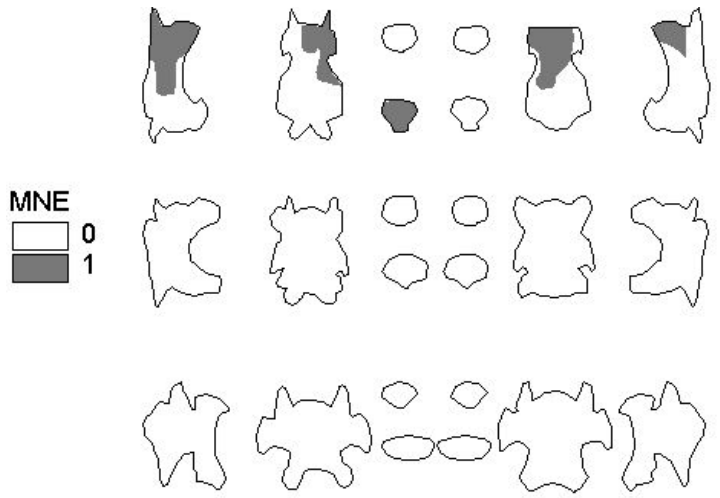

Figura 8.75. MNE Cervicales 3 a 7 


\section{Escápula (SC)}

Este elemento esta representado por la presencia de un espécimen cuyas zona diagnóstica corresponde a la cavidad glenoidea. El MNE calculado para la escápula derecha corresponde a 1 .
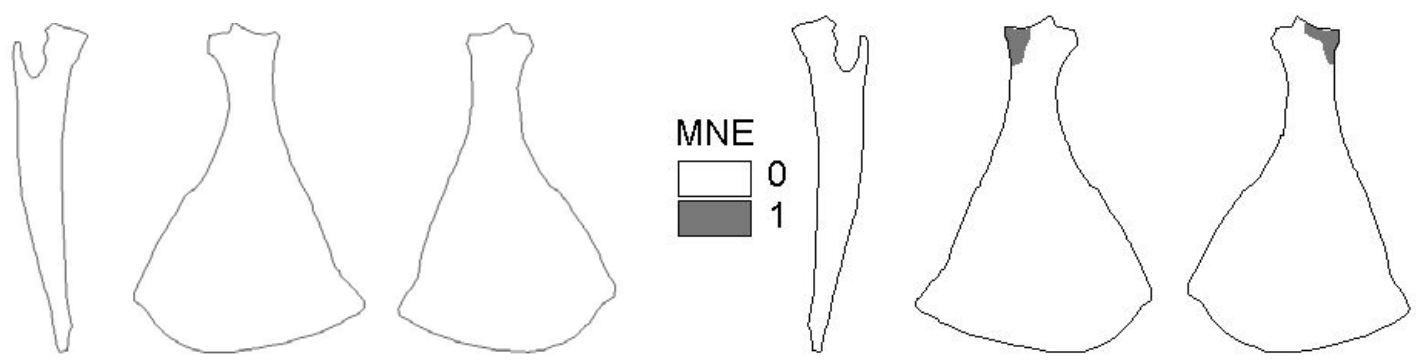

Figura 8.76. MNE Escápula izquierda y derecha

Húmero (HM)

Se identificaron las siguientes zonas diagnósticas: cóndilo medial y agujero nutricio posterolateral. Para el lado derecho se calculó un MNE igual a 1.
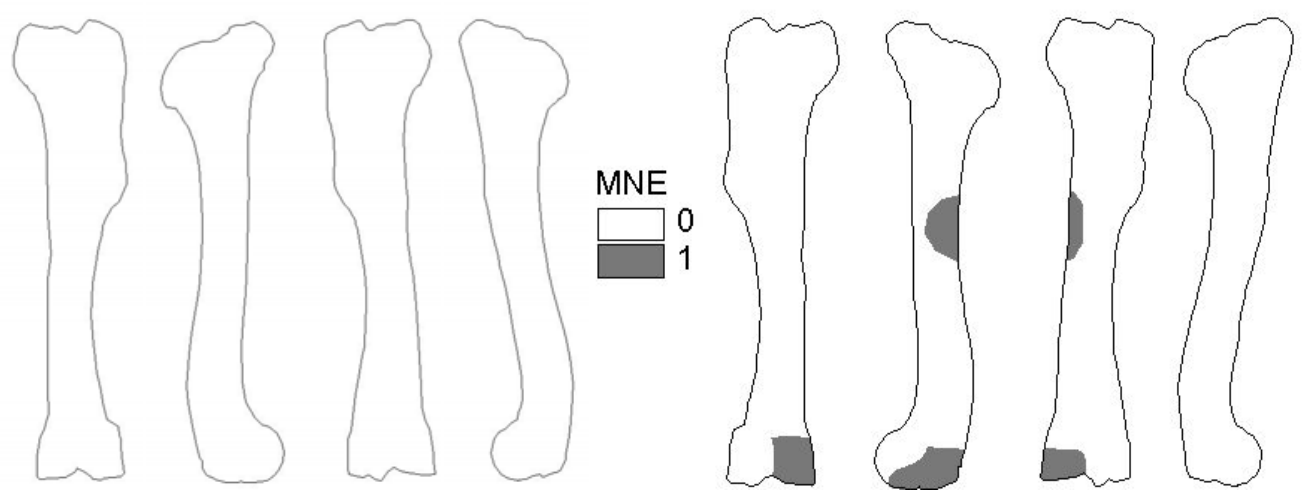

Figura 8.77. MNE Húmero izquierdo y derecho

\section{Radioulna (RDU)}

Las zonas diagnósticas que permitieron identificar a este elemento son: proceso olecraniano, proceso anconeal, facetas articulares, cavidad glenoidea lateral, cavidad glenoidea medial. El MNE obtenido arrojó como resultado para el elemento izquierdo y para el derecho un valor igual a 1, lo cual hace un total de un mínimo de 2 elementos. 

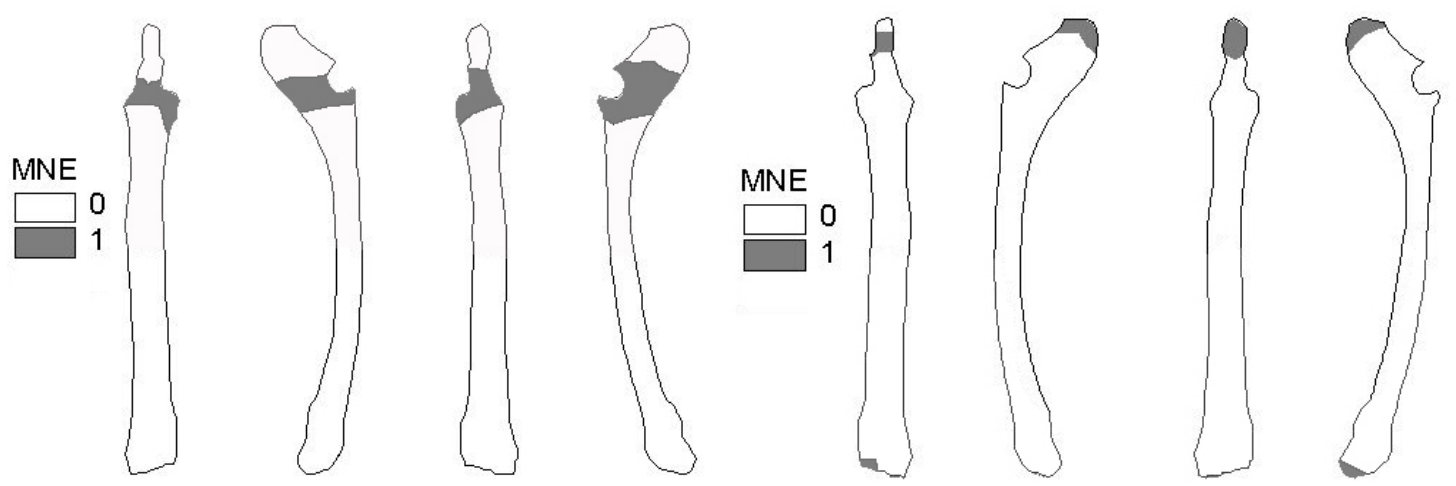

Figura 8.78. MNE Radioulna izquierda y derecha

Carpo accesorio (CPA)

Se calculó un MNE igual a 1 para este elemento, asignándose al lado izquierdo.

Carpo cuarto $(C P F)$

El MNE para este elemento del carpo fue igual a 3, asignándose todos al lado izquierdo. Este elemento se presenta en todos los casos de manera completa.

Carpo intermedio (CPI)

Un MNE igual a 1 se computó para este elemento, asignándose al lado izquierdo.

Carpo radial (CPR) y Carpo ulnar (CPU)

Se calculó un MNE igual a 3 para cada uno de los elementos (3 CPR y 3 CPU), clasificándose todos como pertenecientes al lado izquierdo. Estos elementos se presentan fragmentados.

Innominado (IM)

Las zonas diagnósticas reconocidas parta este elemento son la hoja del ilium y el acetábulo. Sobre la base de estas zonas se logró determinar un MNE igual a 1 para el elemento izquierdo y un MNE igual a 1 para el derecho. Esto es un total de 2 elementos (Figura 8.79)
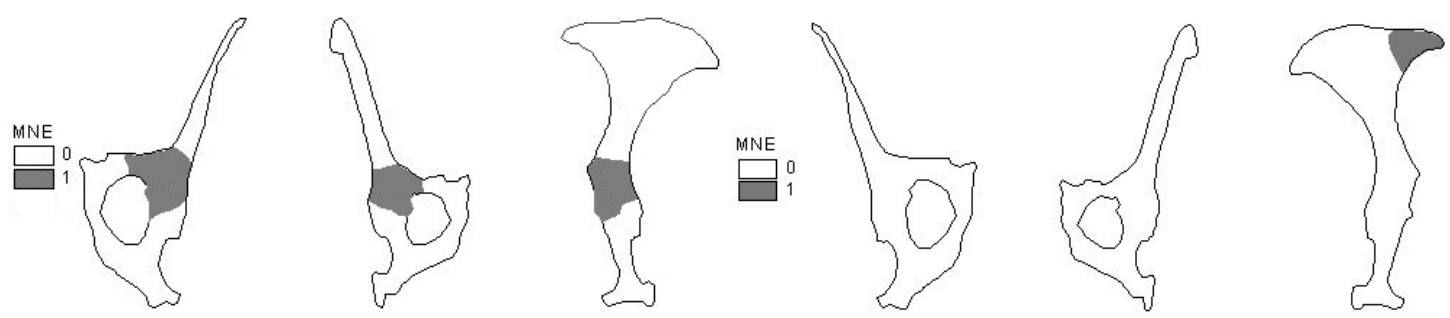
Figura 8.79. MNE Innominado izquierdo y derecho

Fémur (FM)

Sólo esta representado por un espécimen que corresponde a la zona donde se ubica la tróclea. El MNE alcanzado es igual a 1 elemento izquierdo.
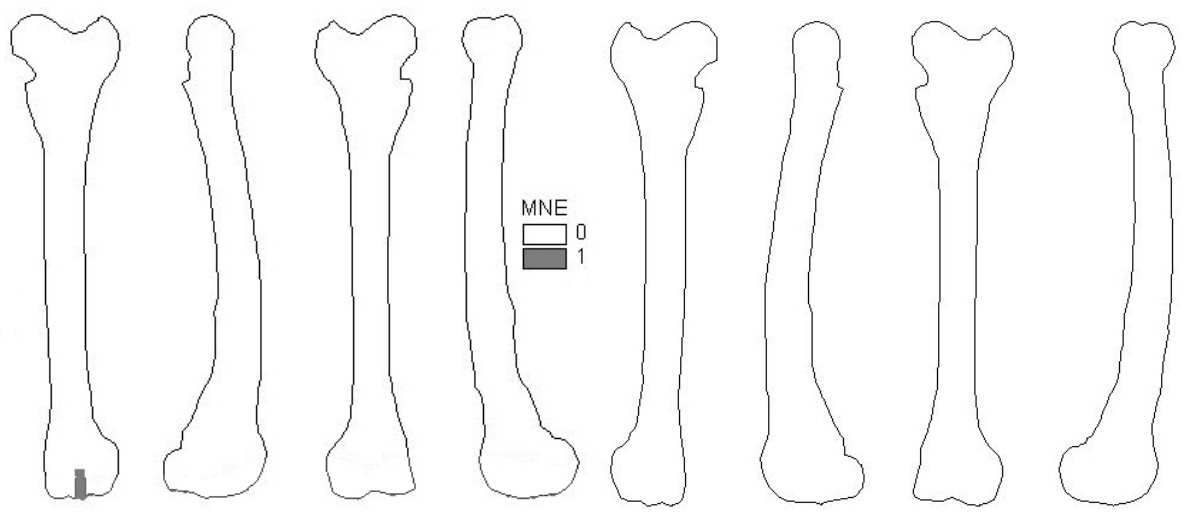

Figura 8.80. MNE Fémur izquierdo y derecho

\section{Patela o Rótula (PT)}

Se calculó un MNE igual a 1, asignándose al lado izquierdo. Este elemento se presenta de manera completa.

Tibia (TA)

La zonas diagnóstica utilizada corresponde a la diáfisis posterior (agujero nutricio posterolateral). Se calculó un MNE igual a 1 para el elemento izquierdo y 2 para el derecho, lo cual hace un total de 3 elementos.
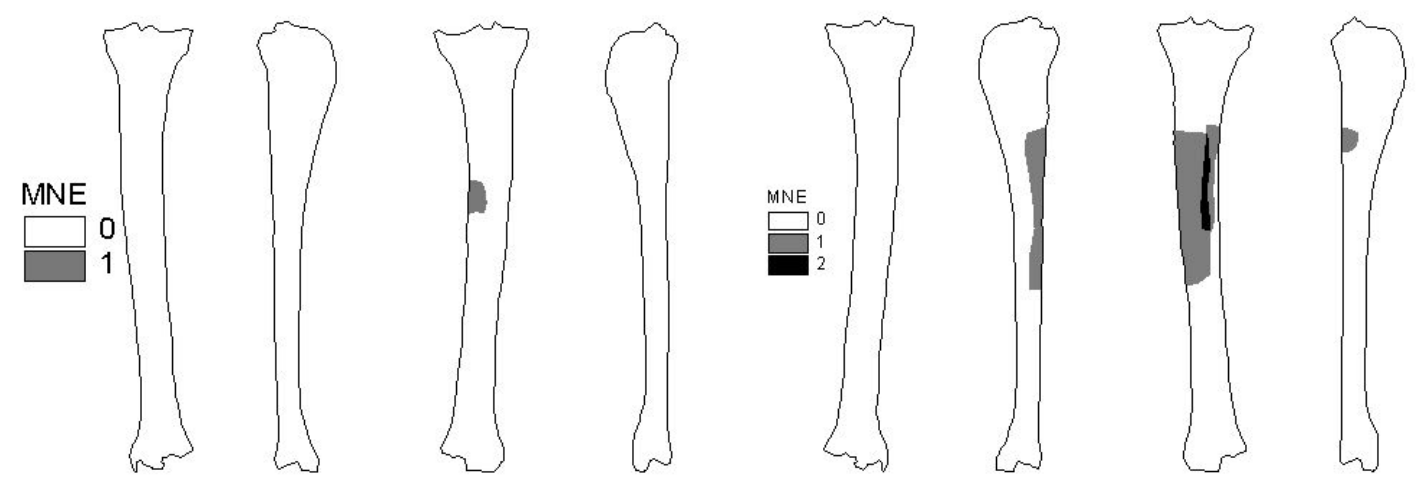

Figura 8.81. MNE Tibia izquierda y derecha

Astrágalo (AS)

Para el elemento izquierdo se calculó un MNE igual a 2 en tanto que el derecho presenta un espécimen $(\mathrm{MNE}=1)$. El total es de 3 elementos. 

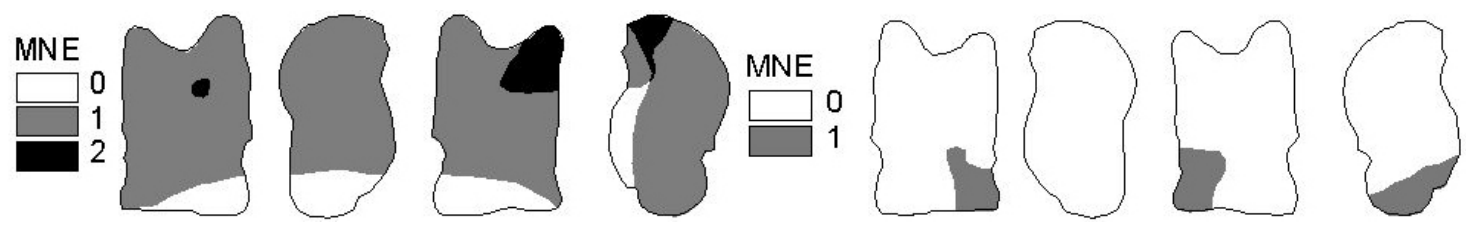

Figura 8.82. MNE Astrágalo izquierdo y derecho

Calcáneo (CL)

El MNE calculado para cada lado corresponde a 1 elemento para el derecho y ninguno para el izquierdo $(\mathrm{MNE}=1)$
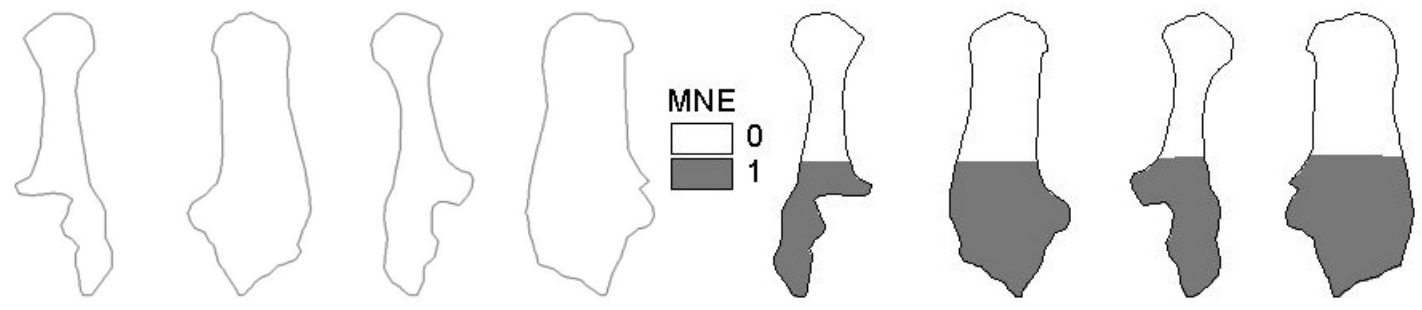

Figura 8.83. MNE Calcáneo izquierdo y derecho

\section{Maléolo Lateral (LTM)}

Se calculó un MNE igual a 2 para este elemento, asignándose 1 al lado izquierdo y 1 al lado derecho. Este elemento se presenta en ambos casos de manera completa.

Tarso cuarto (TR4)

El MNE que se computó fue igual a 2, clasificándose 1 al lado izquierdo y 1 al lado derecho. Este elemento se presenta en todos los casos completo.

Tarso central (TRC)

Se calculó un MNE igual a 2 para este elemento asignándose 1 al lado izquierdo y 1 al derecho. Este elemento se presenta fragmentado.

Tarso primero (TRF)

Se calculó un MNE igual a 1 elemento izquierdo. Este elemento se presenta completo.

Tarso tercero (TRT)

El MNE calculado fue de 4 elementos, asignándose 3 al lado izquierdo y 1 al derecho. Este se presenta en todos los casos completo. 
Metatarso (MT)

El metatarso presenta un espécimen a partir del cual se pudo establecer un MNE igual a 1 para el lado derecho (Figura).
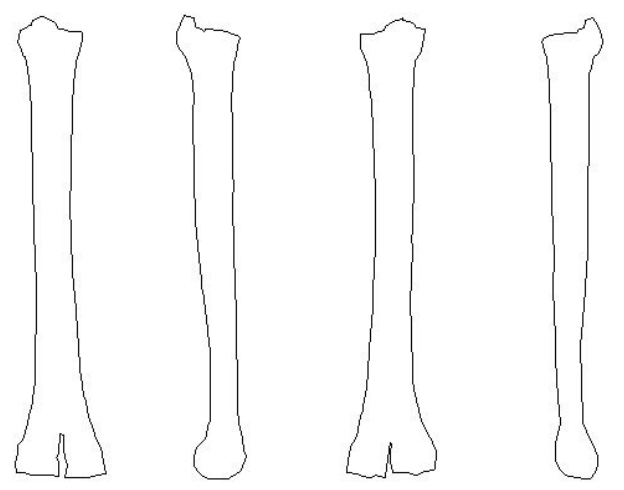

Figura 8.84. MNE Metatarso izquierdo y derecho

\section{Metapodio general}

Se logró un MNE igual a (Figura 8.85), en base a un fragmento de epífisis y fragmentos de cóndilos.
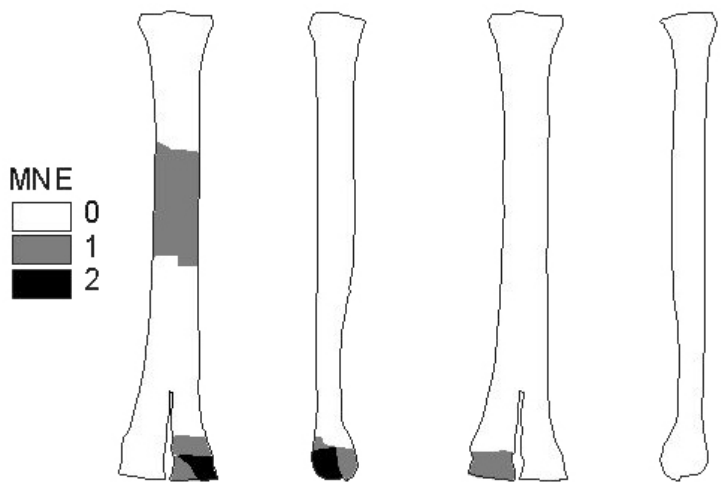

Figura 8.85. MNE Metapodio general

Falange proximal (PHF)

Para este elemento las zonas diagnósticas utilizadas fueron la epífisis proximal, epífisis distal y diáfisis. Sobre los especímenes asignados a esta categoría se calculó un MNE igual a 2 (Figura 8.86).
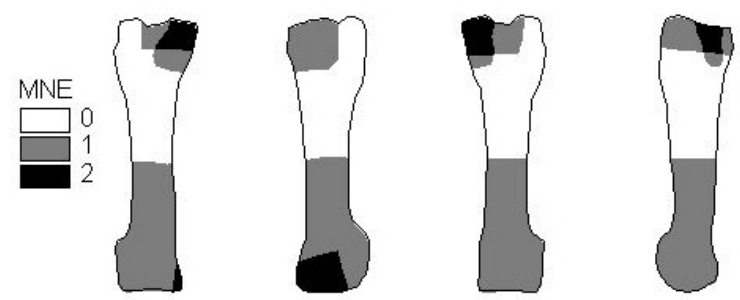

Figura 8.86. MNE Falange proximal general 


\section{Falange medial (PHS)}

Para este caso, al igual que para todas las falanges, las zonas diagnósticas utilizadas fueron la epífisis proximal, epífisis distal y diáfisis. El cálculo del MNE arrojó una cantidad de 4 elementos (Figura 8.87)
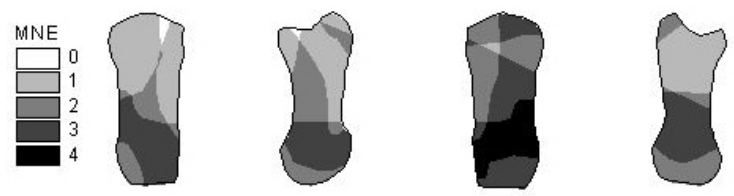

Figura 8.87. MNE Falange medial

Falange distal (PHT)

Las zonas diagnósticas utilizadas fueron la epífisis proximal, epífisis distal y diáfisis (Figura 8.88) siendo el MNE calculado igual a 3.
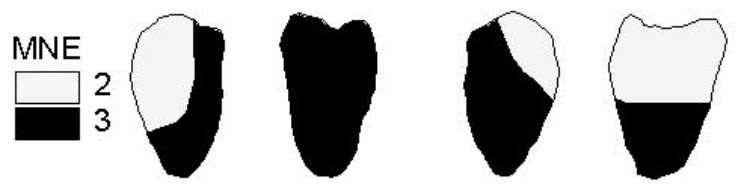

Figura 8.88. MNE Falange distal

Sesamoideos (SEP)

Se identificaron cuatro elementos completos $(\mathrm{MNE}=4)$

Nuevamente sobre estos resultados se procedió a tabularlos y mediante ello calcular los índices MNI, MAU y \%MAU.

Tabla 8.44. Abundancia relativa de partes esqueletarias expresadas como NISP, MNE comprehensivo, MAU y \%MAU.

\begin{tabular}{crccccccr}
\hline Elemento & NISP & I & D & S/D & MNE & MNI & MAU & \%MAU \\
CRN & 5 & - & - & 3 & 3 & 3 & 3.00 & 100.00 \\
MR & 2 & - & - & 1 & 1 & 1 & 1.00 & 33.33 \\
HY & 1 & - & - & 1 & 1 & 1 & 0.50 & 16.67 \\
IC & 1 & - & - & 1 & 1 & 1 & 0.08 & 2.78 \\
TFR & 14 & - & - & - & - & - & - & - \\
CE & 2 & - & - & 1 & 1 & 1 & 0.40 & 13.33 \\
RB & 18 & - & - & 6 & 6 & 1 & 0.21 & 7.14 \\
& & & & & & & & \\
SC & 1 & - & 1 & - & 1 & 1 & 0.50 & 16.67 \\
HM & 1 & - & 1 & - & 1 & 1 & 0.50 & 16.67 \\
RDU & 3 & 1 & 1 & - & 2 & 1 & 1.00 & 33.33 \\
CPA & 1 & 1 & - & - & 1 & 1 & 0.50 & 16.67 \\
CPF & 3 & 3 & - & - & 3 & 3 & 1.50 & 50.00 \\
CPI & 1 & 1 & - & - & 1 & 1 & 0.50 & 16.67 \\
\hline
\end{tabular}




\begin{tabular}{crrrrrrrr} 
& & & & \multicolumn{6}{c}{ Continuación de Tabla 8.44 } \\
\hline CPR & 3 & 3 & - & - & 3 & 3 & 1.50 & 50.00 \\
CPU & 3 & 3 & - & - & 3 & 3 & 1.50 & 50.00 \\
& & & & & & & & \\
IM & 10 & 1 & 1 & - & 2 & 1 & 1.00 & 33.33 \\
PT & 2 & 1 & - & 1 & 2 & 1 & 1.00 & 33.33 \\
FM & 1 & 1 & - & - & 1 & 1 & 0.50 & 16.67 \\
TA & 3 & 1 & 2 & - & 3 & 2 & 1.50 & 50.00 \\
LTM & 2 & 1 & 1 & - & 2 & 1 & 1.00 & 33.33 \\
AS & 3 & 2 & 1 & - & 3 & 2 & 1.50 & 50.00 \\
CL & 1 & - & 1 & - & 1 & 1 & 0.50 & 16.67 \\
TR4 & 2 & 1 & 1 & - & 2 & 1 & 1.00 & 33.33 \\
TRC & 2 & 1 & 1 & - & 2 & 1 & 1.00 & 33.33 \\
TRF & 1 & 1 & & - & 1 & 1 & 0.50 & 16.67 \\
TRT & 4 & 3 & 1 & - & 4 & 3 & 2.00 & 66.67 \\
MT & 1 & - & 1 & - & 1 & 1 & 0.50 & 16.67 \\
& & & & & & & & \\
MP & 3 & - & - & 2 & 2 & 1 & 0.50 & 16.67 \\
PHF & 5 & - & - & 2 & 2 & 1 & 0.25 & 8.33 \\
PHS & 5 & - & - & 4 & 2 & 1 & 0.25 & 8.33 \\
PHT & 3 & - & - & 3 & 3 & 1 & 0.38 & 12.50 \\
SEP & 4 & - & - & 4 & 4 & 1 & 0.50 & 16.67 \\
Total general & 111 & & & & & & \\
\hline \multicolumn{7}{l}{ D = derecho, I= izquierdo, S/D = axial o sin datos }
\end{tabular}

\subsubsection{1.c. Número Mínimo de Individuos (MNI)}

Se calcularon tres individuos mediante la identificación de tres petrosos derechos, tres carpos cuartos izquierdos, tres carpos radiales izquierdos, tres carpos lunares izquierdos y tres tarsos terceros izquierdos.

\subsubsection{1.d. Unidades anatómicas representadas (MAU)}

Como puede observarse en la Figura 8.89 los elementos del esqueleto axial y del apendicular se encuentran casi todos representados en este conjunto. Para el esqueleto axial se nota que los elementos de la cabeza son los que están mayormente representados, no solo a nivel de parte esqueletal básica, sino también en el global del conjunto. Para el esqueleto apendicular los elementos más representados corresponden a los miembros posteriores. Se puede observar que las frecuencias más altas corresponden a los elementos más pequeños. 


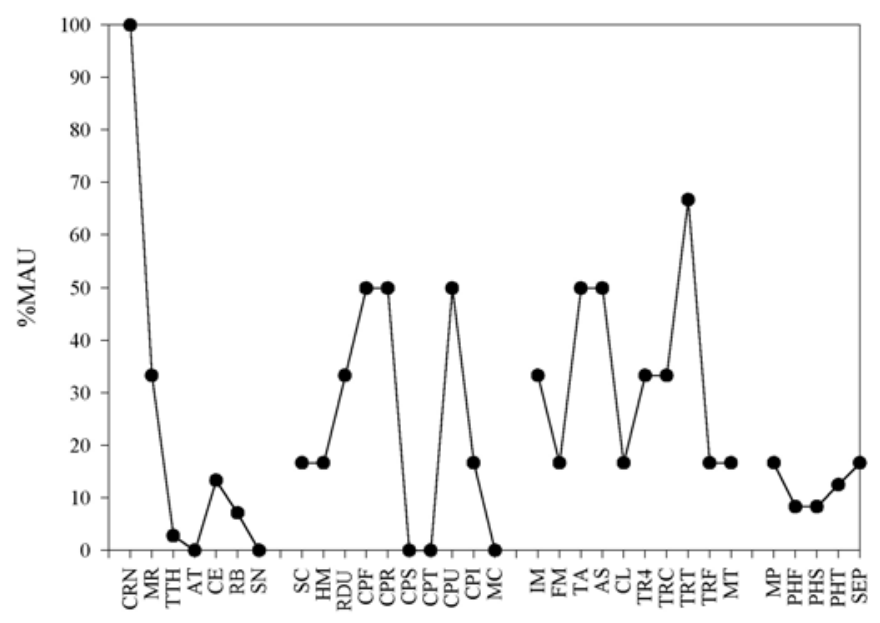

Figura 8.89. Abundancia relativa de elementos esqueletarios.

Como puede observarse en la Figura 8.90.a los elemento "no-largos" presentan una tendencia similar a la planteada para la curva de utilidad inversa (Reverse Utility Curve). Esto se nota al realizar la correlación de los valores cuyo resultado es una relación negativa estadísticamente no significativa $\left(r_{s}-.4329 \mathrm{p} .106\right)$. Esto nos muestra la alta proporción de elementos de bajo rendimiento como el cráneo. Para los huesos largos esta relación es positiva y estadísticamente no significativa $\left(r_{s} .5161 \mathrm{p} .147\right)$. Con respecto a la relación entre el \%MAU y la cavidad medular se observa una relación positiva estadísticamente no significativa $\left(r_{s} .3189\right.$ p .269). Estos resultados permiten afirmar que el conjunto apendicular podría haber sido formado debido a su relativa alta utilidad económica, al contrario de lo que sucedería con los elementos del esqueleto axial.

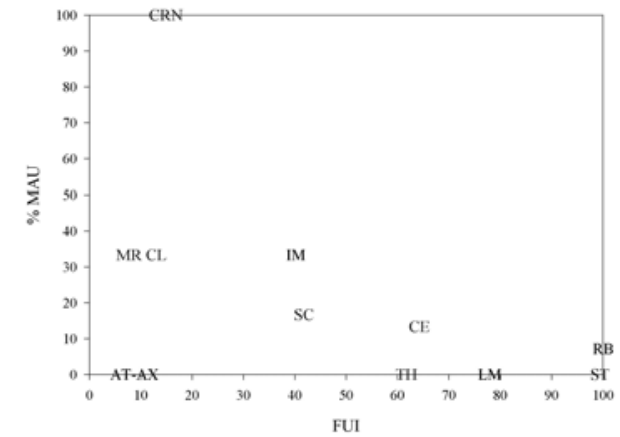

a

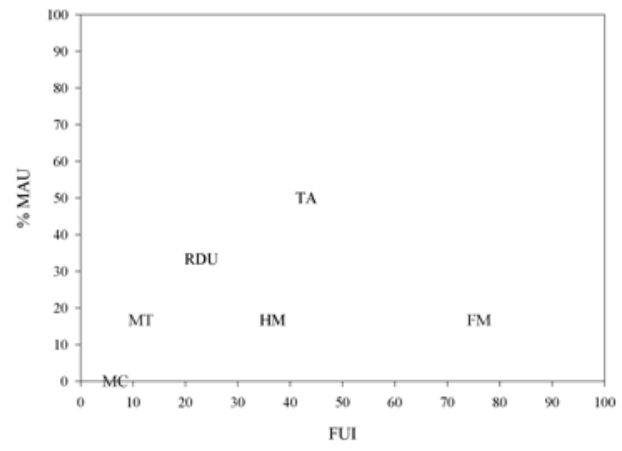

b 


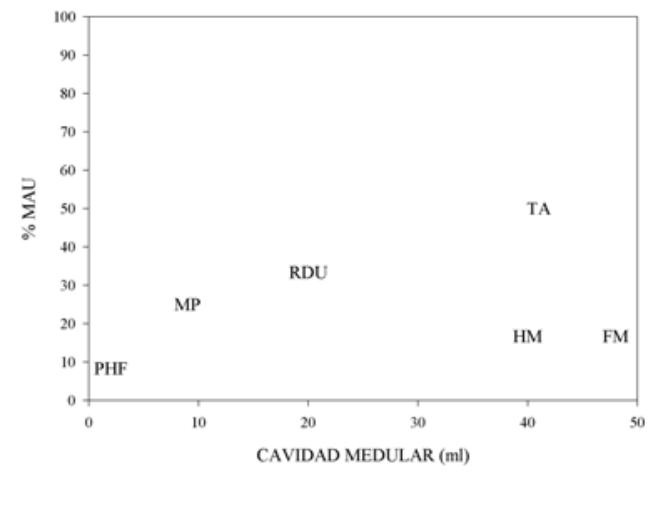

Figura 8.90. a) Relación \%MAU VS FUI huesos "no-largos"; b) Relación \%MAU VS FUI huesos "largos"; c) Relación \%MAU VS Cavidad Medular.

\subsubsection{1.d. Fragmentación del subconjunto}

El resultado de este análisis muestra que el conjunto en su gran mayoría se encuentra representado por fragmentos. Las mayores frecuencias se registran en los módulos de tamaños más pequeños. Los elementos completos son en general los que corresponden al carpo y al tarso y se encuentran con una frecuencia similar a los especímenes más pequeños.

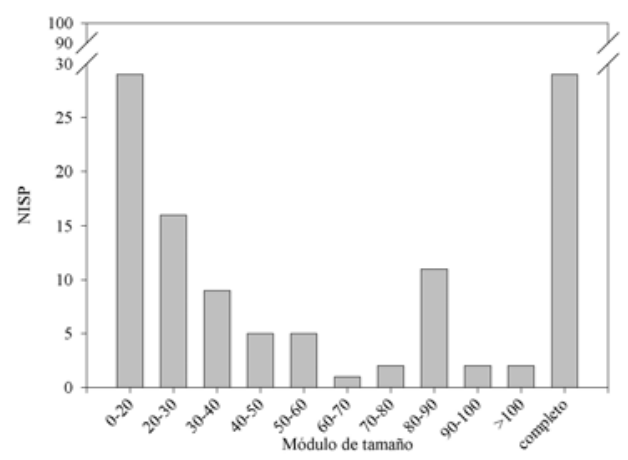

Figura 8.91. Módulos de tamaño expresado en NISP para especímenes y elementos del subconjunto adulto de camélidos

\section{Esqueleto axial}

Para el esqueleto axial (Figura 8.92) el perfil de fragmentación muestra un gran fraccionamiento. Ningún elemento presenta más del diez por ciento del área en este caso. El cráneo presenta superficies que no exceden el $2 \%$ y que representan largos máximos de los especímenes comprendidos entre 17 y $52 \mathrm{~mm}$. La mandíbula presenta 
especímenes cuyas superficies relativas están comprendidas entre el 3 y 8\% (37-51 $\mathrm{mm})$. Por último las vértebras están representadas por valores que fluctúan entre un $2 \%$ y un $8 \%(46-68 \mathrm{~mm})$

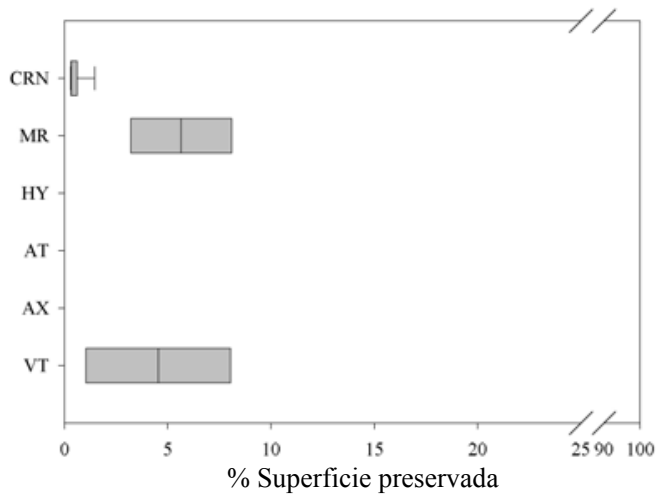

Figura 8.92. Fragmentación de elementos del esqueleto axial.

\section{Esqueleto apendicular delantero}

En el caso del miembro anterior izquierdo se puede observar que el único elemento identificado además de los elementos del carpo es el radioulna. Este presenta superficies menores al 15\% (59 $\mathrm{mm})$

La pata derecha presenta valores menores para el radioulna $(18-33 \mathrm{~mm})$ en tanto que en el caso de la escápula el largo máximo corresponde a $41 \mathrm{~mm}$ y en del húmero a $38 \mathrm{~mm}$.

Para el lado izquierdo los carpianos presentan elementos que se encuentran fragmentados.
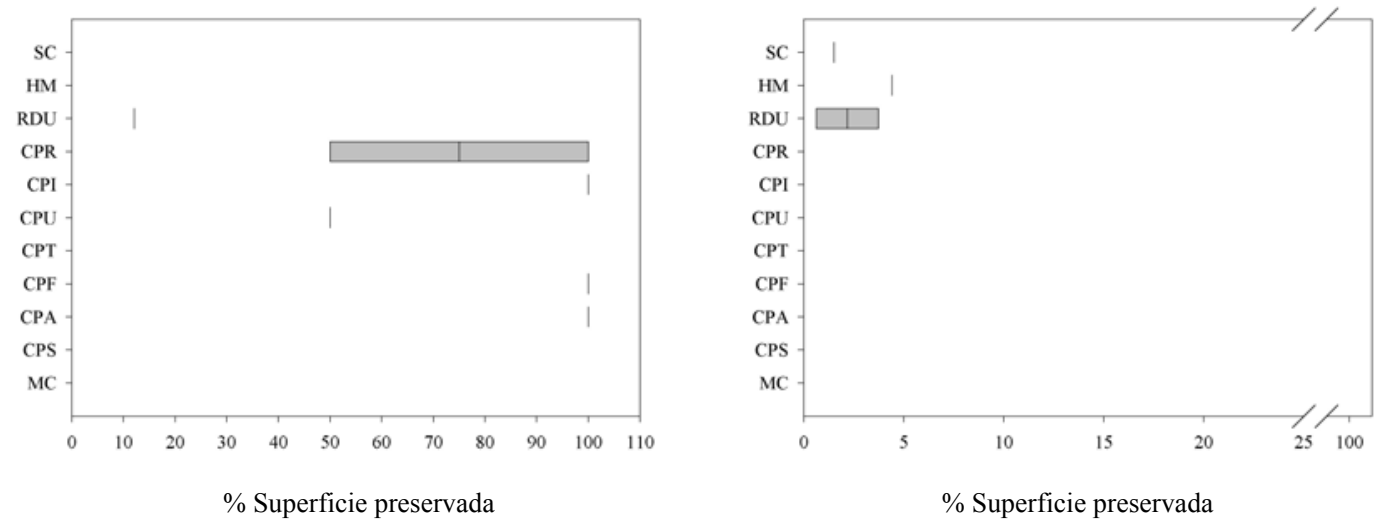

Figura 8.93. Fragmentación esqueleto apendicular delantero (izquierdo y derecho) 
Esqueleto apendicular trasero

Para la pata trasera izquierda se puede observar en la Figura 8.94 que los elementos de menor tamaño se encuentran en general completos. El astrágalo presenta superficies que van desde el 6,8\% al 83\%. El innominado presenta una superficie relativa del 19,34\% (largo máximo: $89 \mathrm{~mm}$ ), el fémur de 0,36\% (largo máximo: $23 \mathrm{~mm}$ ) y la tibia de 0,76\% (largo máximo: $100 \mathrm{~mm}$ ).

Para el lado derecho la superficie del innominado es menor (3,94\%, largo máximo: $27 \mathrm{~mm}$ ) y el de la tibia es mayor (2,29 a 9,32\%, largo máximo: 81-139 mm). El metatarso preservó un $11,26 \%$ de su superficie (largo máximo: $44 \mathrm{~mm}$ ). Para el miembro derecho los elementos del tarso se encuentran relativamente más fragmentados que en el izquierdo
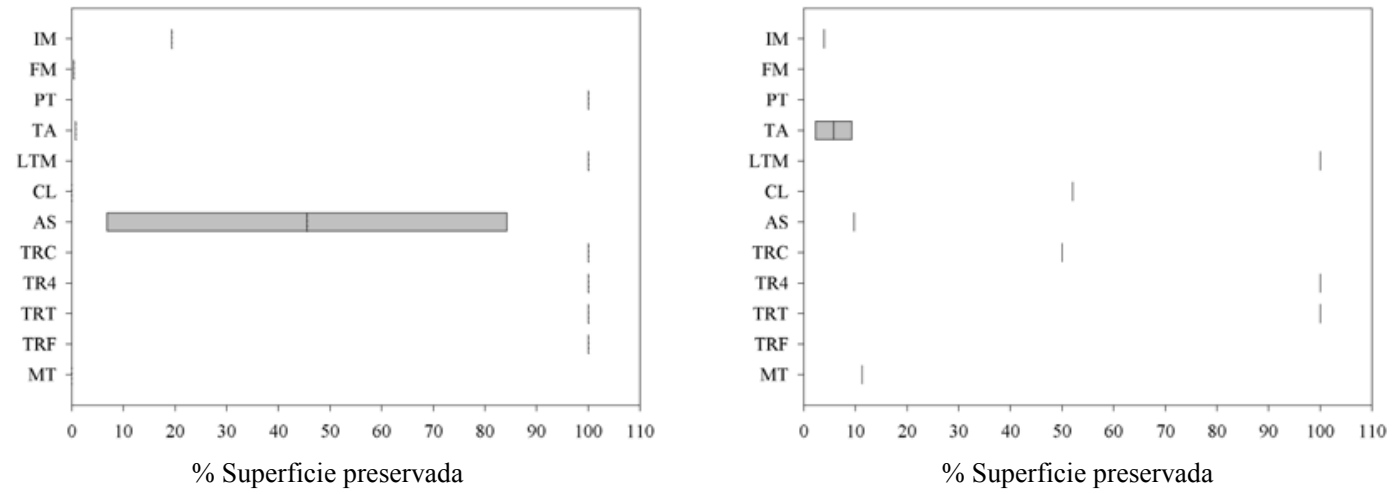

Figura 8.94. Fragmentación esqueleto apendicular trasero (izquierdo y derecho)

Respecto del estado en el que se hallaba el fragmento cuando se produjo la fractura se ve que la categoría seca es la que se presenta en mayor frecuencia.

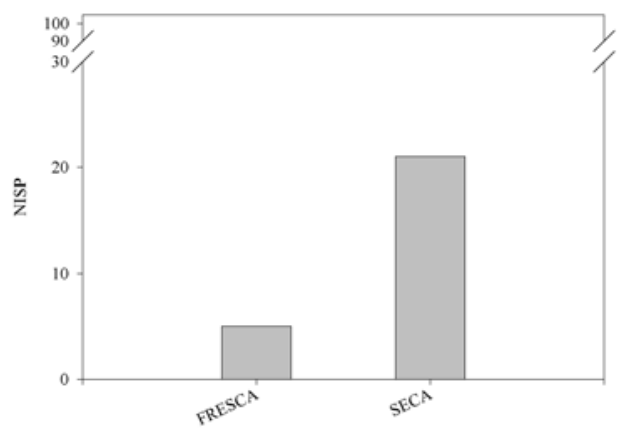

Figura 8.95 Cantidad (NISP) de especímenes y elementos del subconjunto adulto de camélidos según tipo de fractura. 


\subsubsection{1.d. Utilización de las carcasas}

De los 111 elementos identificados para este conjunto sólo uno presentó huellas de acción antrópica siendo éste un fragmento de tibia derecha la cual presentó marcas de raspado. La única marca del conjunto evidencia que al menos en el sitio se habría efectuado alguna acción tendiente al procesamiento primario de al menos uno de los animales.

Tabla 8.45. Marcas en hueso de camélidos adultos expresado en NISP

\begin{tabular}{cccc}
\hline Elemento & Porción & Raspado (estrías paralelas) & Total general \\
TA & FK & 1 & 1 \\
Total general & & 1 & 1 \\
\hline
\end{tabular}

\subsubsection{1.e. Termoalteraciones}

El 33,33\% de la muestra presentó signos de termoalteración $(\mathrm{n}=37)$, lo que implica que una alta proporción del conjunto fue sometido a acción del calor. Estos especímenes muestran signos de haber sido expuestos a toda la escala de temperaturas.

Tabla 8.46. Termo alteración del conjunto de camélidos adultos.

\begin{tabular}{cccccc}
\hline Descripción & Sin alteración & $\begin{array}{c}\text { Oxidación } \\
\text { incompleta/carbonización } \\
\text { marrón claro-negro } \\
\text { (moteado) }\end{array}$ & Carbonizado & Calcinado & Total \\
Color & - & $200^{\circ} \mathrm{C}-300^{\circ} \mathrm{C}$ & $300{ }^{\circ} \mathrm{C}$ & $>500{ }^{\circ} \mathrm{C}$ & \\
Temperatura & $<200{ }^{\circ} \mathrm{C}$ & 7 & 13 & 17 & 111 \\
NISP & 87 & $7 r i s-b l a n c o$ & \\
\hline
\end{tabular}

Respecto de la relación entre tipo de estado al realizarse la fractura y tipo de alteración térmica podemos ver los resultados obtenido en la Tabla 8.47. Allí se observa que las fracturas frescas solo se presentan en especímenes sin signos de alteración por calor. La fractura seca se presenta tanto en especímenes que presentan cambio de color por calor como aquellos que no tienen signos de termoalteración.

Tabla 8.47. Relación entre tipo de termoalteración y tipo de fractura del conjunto de camélidos adultos.

\begin{tabular}{lccr}
\hline \multicolumn{1}{c}{ Tipo de alteración } & Fresca & Seca & Total \\
Sin alteración & 5 & 16 & 21 \\
Oxidación incompleta & - & 1 & 1 \\
Carbonizado & - & 2 & 2 \\
Calcinado & - & 2 & 2 \\
$\quad$ Total & 5 & 21 & 26 \\
\hline
\end{tabular}




\subsubsection{Camélidos subadultos}

\subsubsection{2.a. Supervivencia del material óseo mediada por la densidad ósea}

La correlación entre los valores de densidad ósea y el porcentual de las unidades anatómicas representadas en el conjunto arrojaron como resultado que para dos elementos la correlación es positiva, para una es negativa y para el conjunto total la correlación es negativa y estadísticamente significativa. Para el húmero no se registra correlación. Para el radioulna la relación es positiva (preservación de zonas más densas) al igual que para el fémur. Por último para la tibia la preservación de las zonas diagnósticas tiende a ser las menos densas

El resultado del análisis sobre toda la muestra nos permite sugerir que la muestra no habría sido afectada por cuestiones relacionadas a la conservación diferencial mediada por la densidad ósea. Esto puede estimarse a partir de que las partes preservadas tienden a ser las menos densas y por ende las más susceptibles a ser destruidas.

Tabla 8.48. \%MAU vs. VD.

\begin{tabular}{lccc}
\hline Elemento & Rank & $r_{s}$ & $p$ \\
Húmero & 5 &, 000 &, 500 \\
Radioulna & 6 &, 097 &, 427 \\
Fémur & 5 &, 288 &, 319 \\
Tibia & 5 &,- 447 &, 225 \\
Arqueofauna & 29 &,- 223 &, $019^{*}$ \\
\hline \multicolumn{4}{c}{ *Significativo al nivel $\mathrm{p}>, 05$}
\end{tabular}

\subsubsection{2.b. Número Mínimo de Elementos (MNE)}

Húmero (HM)

Se identificó un elemento por medio de la identificación de un epífisis distal completa del lado izquierdo $(\mathrm{MNE}=1)$

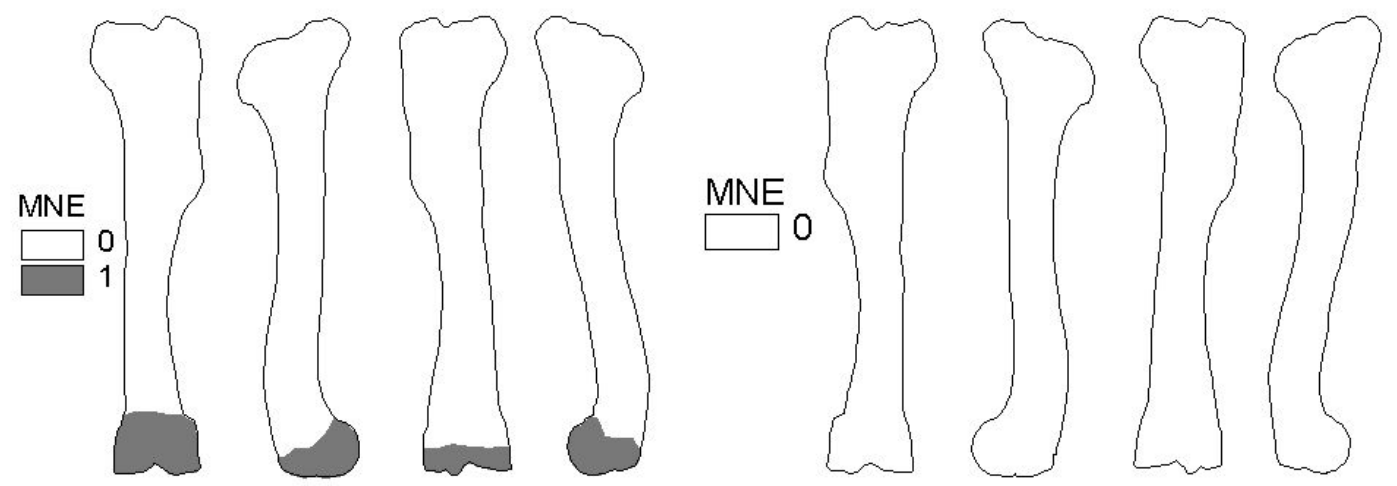

Figura 8.96. MNE Húmero izquierdo y derecho 
Radioulna (RDU)

Para este elemento se identificaron dos fragmentos correspondientes al olécranon y a la epífisis distal. El MNE obtenido es de 2, asignando un elemento a cada lado.
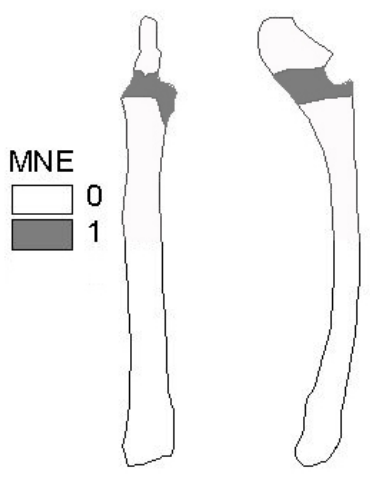
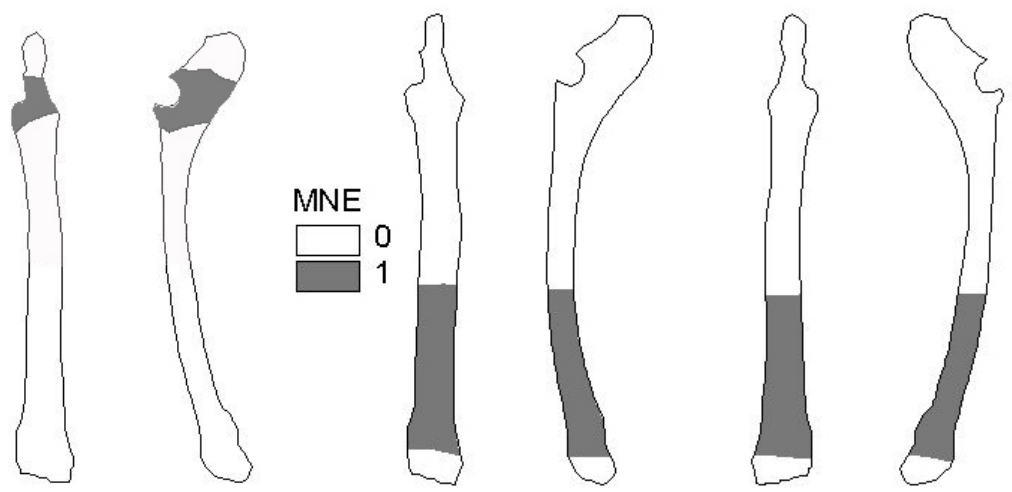

Figura 8.97. MNE Radioulna izquierda y derecha

Fémur (FM)

Se identificó como zona diagnóstica el trocánter menor. Este corresponde al lado izquierdo y permitió calcular un $\mathrm{MNE}=1$.
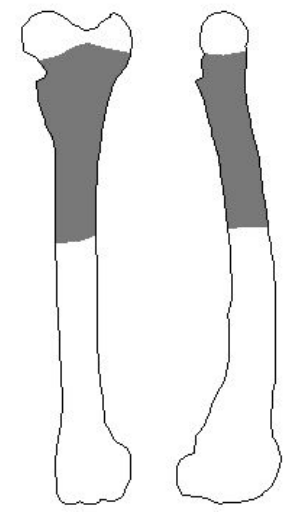
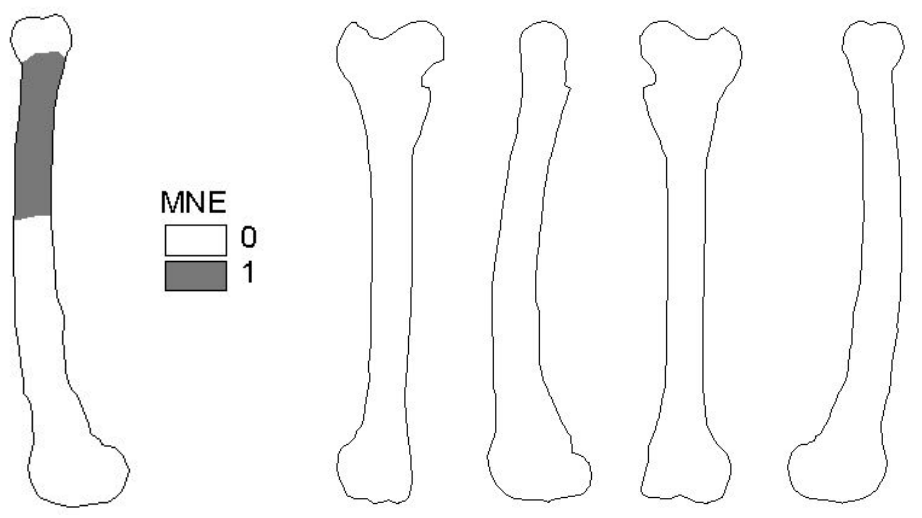

Figura 8.98. MNE Fémur izquierdo y derecho

Tibia (TA)

Las zonas diagnósticas utilizadas corresponden al cóndilo lateral, cóndilo medial y a la epífisis distal. Se calculó un MNE igual a 2 para el elemento izquierdo.
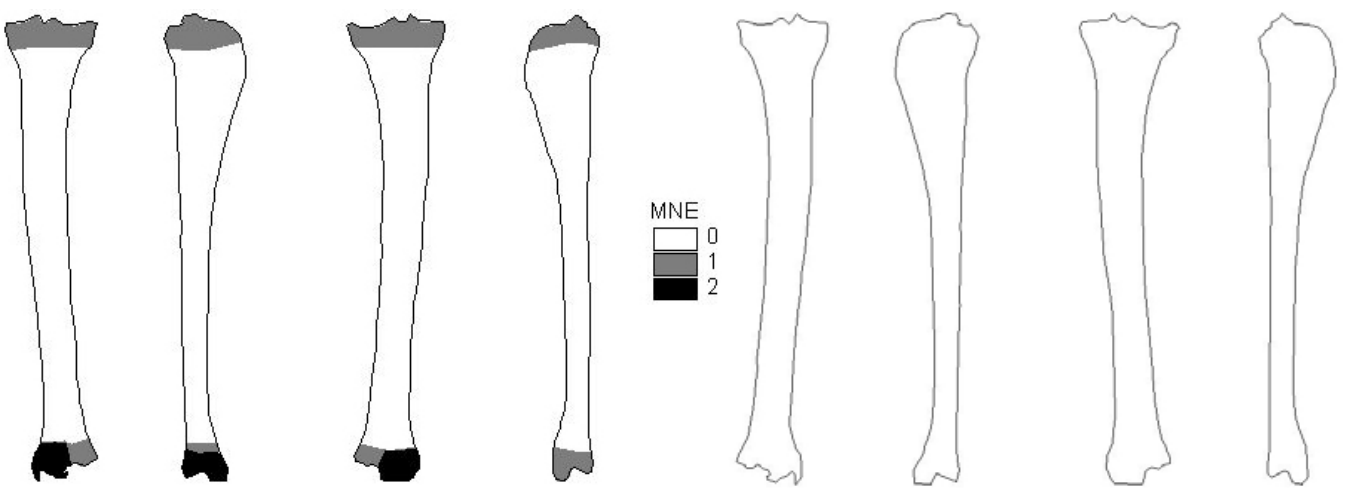
Figura 8.99. MNE Tibia izquierda y derecha

Metapodio (MP)

Sobre la base de las epífisis distales sin fusionar se contabilizó un MNE=2.
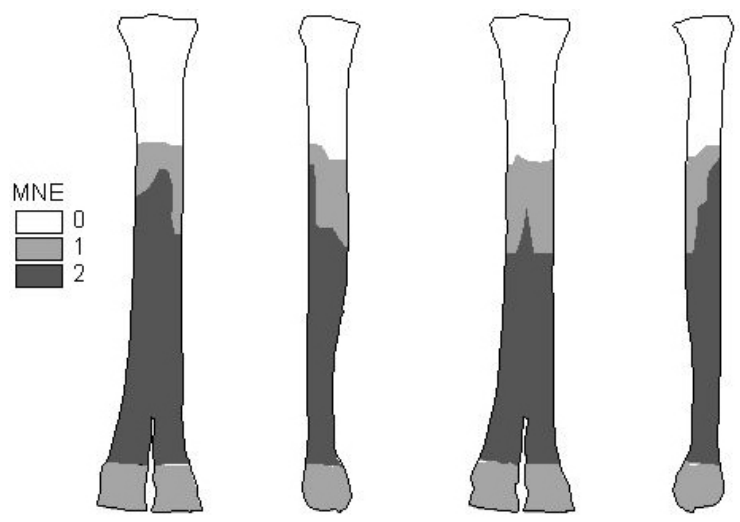

Figura 8.100. MNE Metapodio general

Falange proximal (PHF)

Se identificaron dos elementos en base a la epífisis proximal $(\mathrm{MNE}=2)$

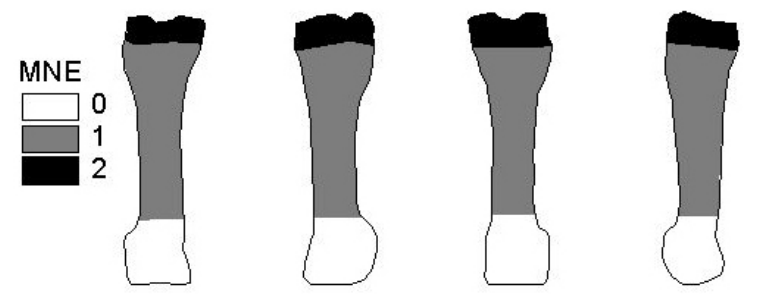

Figura 8.101. MNE Falange proximal general

Falange medial (PHS)

En este caso se reconocieron dos elementos en base a la diáfisis $(\mathrm{MNE}=2)$
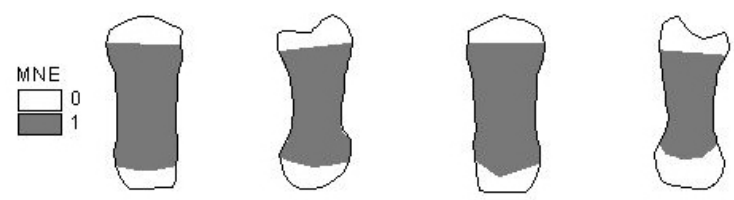

Figura 8.102. MNE Falange medial

La síntesis de los resultados obtenidos y el cálculo de los indicadores derivados del MNE se encuentran en la tabla 8.49. 
Tabla 8.49. Abundancia relativa de partes esqueletarias expresadas como NISP, MNE comprehensivo, MAU y \%MAU.

\begin{tabular}{ccccccccr}
\hline EL & NISP & I & D & S/D & MNE & MNI & MAU & $\%$ MAU \\
HM & 1 & 1 & - & - & 1 & 1 & 0.50 & 50.00 \\
RDU & 3 & 1 & 1 & - & 2 & 1 & 1.00 & 100.00 \\
& & & & & & & & \\
FM & 1 & 1 & - & - & 1 & 1 & 0.50 & 50.00 \\
TA & 3 & 2 & - & - & 2 & 2 & 1.00 & 100.00 \\
& & & & & & & & \\
MP & 4 & - & - & 2 & 2 & 1 & 0.50 & 50.00 \\
PHF & 2 & - & - & - & 2 & 1 & 0.25 & 25.00 \\
PHS & 1 & - & - & - & 1 & 1 & 0.13 & 12.50 \\
Total general & 15 & & \multicolumn{7}{l}{} \\
\hline \multicolumn{7}{c}{ D = derecho, I = izquierdo, S/D = axial o sin datos }
\end{tabular}

8.4.1.2.b. Número Mínimo de Individuos (MNI)

El número mínimo de individuos se calculó en base a la presencia de dos tibias izquierdas. El resto de los elementos solo permiten calcular la presencia de un solo individuo.

\subsubsection{2.c. Unidades anatómicas representadas (MAU)}

La representación de los elementos para este conjunto muestra una alta presencia de elementos que corresponden a los segmentos proximales del esqueleto apendicular. Para las partes proximales de las patas se registran los elementos con mayor utilidad en términos de la anatomía económica de los animales.

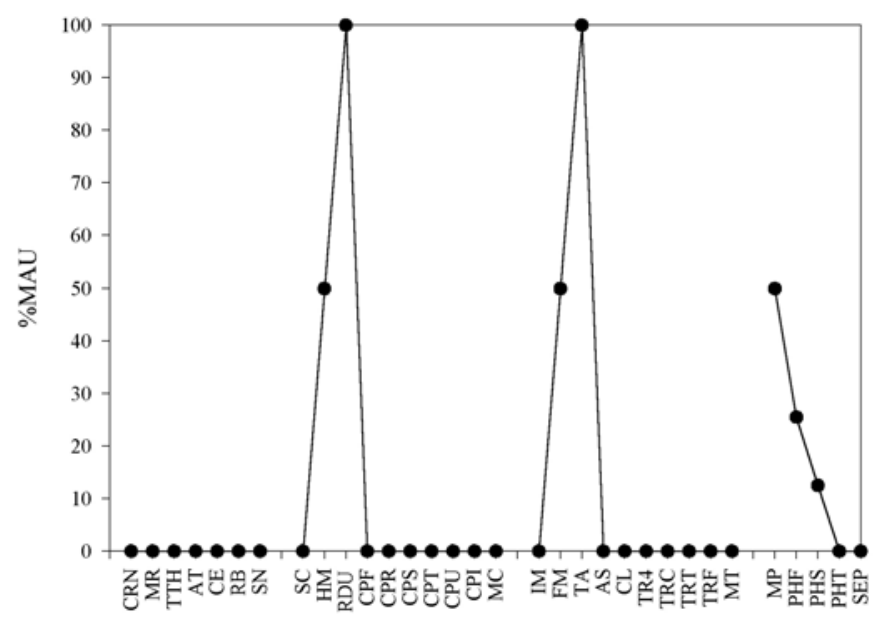

Figura 8.103. Abundancia relativa de elementos esqueletarios. 


\subsubsection{2.d. Fragmentación del subconjunto}

El conjunto de camélidos subadultos presentó un alto grado de fragmentación. El módulo de tamaño más representado resultó ser el de 0-20 mm. El resto del grupo se reparte en distintos módulos. Los elementos completos solo representan una proporción pequeña dentro de la muestra. En cuanto al tipo de estado al realizarse la fractura se puede observar en la Figura 8.104.b que la categoría seca se presenta en mayor frecuencia que la fractura fresca, aunque la diferencia no es grande.

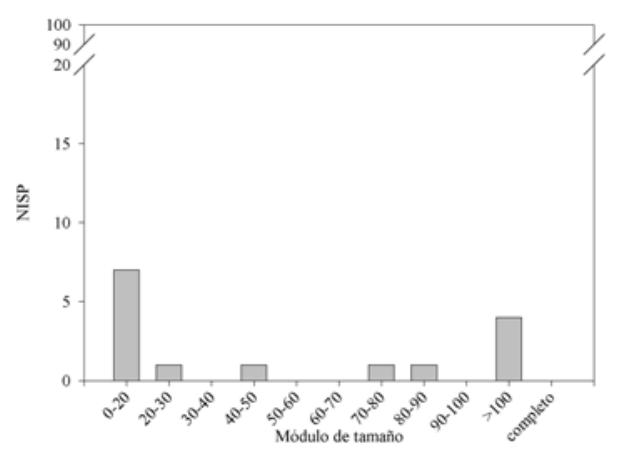

a

Figura 8.104. a) Módulos de tamaño expresado en NISP y b) tipo de fractura.

\subsubsection{2.e. Utilización de las carcasas}

Sólo se registraron en el conjunto huellas de impacto realizadas en diáfisis de radioulna y marcas de machacado en diáfisis de metapodio.

Tabla 8.50 Marcas en huesos del conjunto no camélido expresado en NISP.

\begin{tabular}{ccccc}
\hline Elemento & Porción & Machacado & Impacto & Total general \\
RDU & DSH & - & 1 & 1 \\
MP & DSH & 1 & - & 1 \\
Total general & & 1 & 1 & 2 \\
\hline
\end{tabular}

\subsubsection{2.f. Termoalteraciones}

En solo un espécimen se identificó signos de acción del calor del tipo 1. Este corresponde a un fragmento de tibia.

Tabla 8.51. Termoalteración del conjunto de camélidos subadultos.

\begin{tabular}{cccccc}
\hline Descripción & Sin alteración & $\begin{array}{c}\text { Oxidación } \\
\text { incompleta/carbonización } \\
\text { marrón claro-negro } \\
\text { (moteado) }\end{array}$ & Carbonizado & Calcinado & \\
Color & - & $200^{\circ} \mathrm{C}-300{ }^{\circ} \mathrm{C}$ & $300{ }^{\circ} \mathrm{C}$ & $>500{ }^{\circ} \mathrm{C}$ & \\
Temperatura & $<200{ }^{\circ} \mathrm{C}$ & - & 1 & - & 15 \\
NISP & 14 & - & gris-blanco & \\
\hline
\end{tabular}


La termoalteración no está relacionada con ningún tipo de fractura ya que el único espécimen quemado no presenta ninguna característica de fractura realizada en fresco o en seco.

\subsubsection{Subconjunto no camélido}

\subsubsection{Marcas de procesamiento}

Se identificaron especímenes con signos de marcas de corte, raspado y machacado en fragmentos asignados al esqueleto axial y al apendicular de artiodáctilos de tamaño corporal 4. Para el esqueleto axial se identificó la existencia de marcas de corte en un fragmento de costilla. Para el esqueleto apendicular, se observó una lasca ósea con raspado, otras dos con machacado (una corresponde a un metapodio) y una cuarta con marcas de corte en lasca ósea de metapodio.

Tabla 8.52. Marcas en hueso de camélidos adultos expresado en NISP

\begin{tabular}{ccccccc}
\hline Taxón & Elemento & Porción & Marcas de corte & Raspado & Machacado & Total general \\
UL & LB & AST & - & 1 & - & 1 \\
UL & LB & FK & - & - & 1 & 1 \\
UL & RB & BL & 1 & - & - & 1 \\
UL & MP & DF & - & - & 1 & 1 \\
UL & MP & DSS & 1 & - & - & 1 \\
Total general & & & 2 & 1 & 2 & 5 \\
\hline
\end{tabular}

\subsubsection{Termoalteración}

Fueron hallado signos de alteración térmica en los siguientes taxones: Chaetophractus vellerosus, Rodentia (T. corporal 2), y Artiodáctilos (T. corporal 3-4 y 4). Además las clases de tamaño corporal 1, 2, 2-3 y 4 de los especímenes no identificables taxonómicamente fueron identificados con rastros de alteración térmica.

Tabla 8.53. Termoalteración del conjunto no camélido.

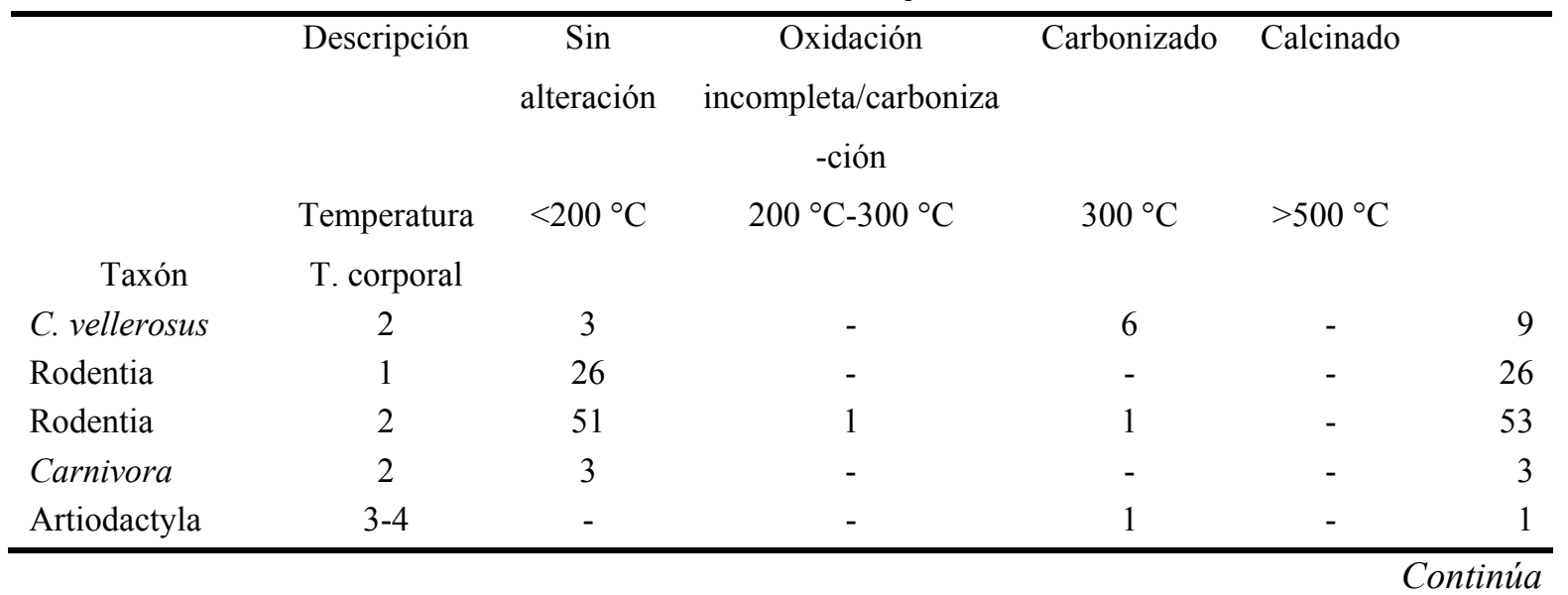




\begin{tabular}{lcccccr}
\hline Artiodactyla & 4 & 246 & 54 & 38 & 29 & 367 \\
H. antisensis & 4 & 3 & - & - & - & 3 \\
No identificable & 1 & 2 & - & - & - & 2 \\
No identificable & 2 & 14 & - & - & - & 14 \\
No identificable & $2-3$ & - & - & 1 & - & 1 \\
No identificable & 4 & 517 & 15 & 73 & 1 & 606 \\
No identificable & 9 & 497 & - & 175 & 7 & $686^{*}$ \\
Total general & & 1362 & 70 & 295 & 37 & $1771^{*}$ \\
\hline
\end{tabular}

*Incluye siete especímenes sobre los que no se registró la categoría alteración térmica por su alta fragmentación.

\subsubsection{2. .Fragmentación del conjunto no camélido}

Para el tamaño corporal 1 (Figura 8.105.a) se observó que para Rodentia los especímenes presentes en el modulo 0-100 mm son los más frecuentes presentando un perfil de fragmentación similar al del tamaño corporal 4 , lo que daría cuenta de una gran fragmentación de este conjunto. En el caso del tamaño corporal 2 se observa un patrón similar. Por último, para el tamaño corporal 4 se observó que el conjunto vuelve a comportarse con la distribución normal para este tipo de tamaño corporal, es decir presentando gran cantidad de especímenes en los módulos de tamaño más chicos. En resumen los tres tamaños corporales presentados en este punto presentan en mayor cantidad especímenes correspondientes a los módulos de tamaño más pequeños.
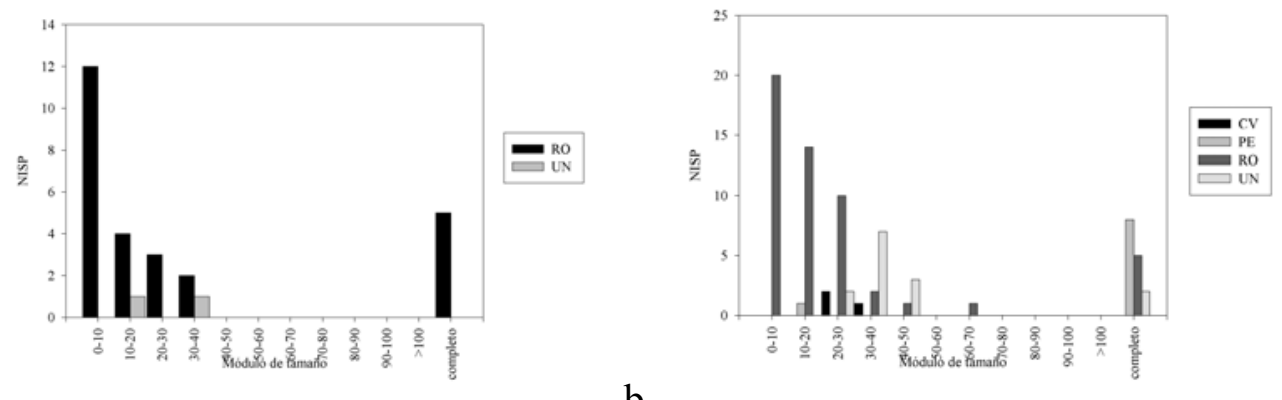

a

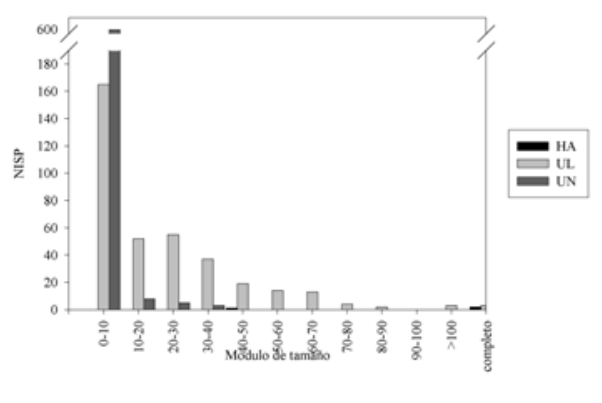

Figura 8.105. Fragmentación del conjunto no camélido expresado en NSP. a) Tamaño corporal $1, b)$ Tamaño corporal 2 y c) Tamaño corporal 4. 


\subsection{Estructura 4 - Ocupación Inferior - Análisis faunístico}

El número de especímenes identificados en este nivel de ocupación asciende a 21. El 80,95\% del conjunto se identificó taxonómicamente determinándose la presencia de cinco taxones y de una categoría de tamaño corporal para los especímenes no identificables a nivel taxonómico. Entre los identificados se hallaron dos dientes

\section{humanos.}

Tabla 8.54. Composición del conjunto faunístico de la Estructura 4 - Ocupación Inferior.

\begin{tabular}{lcr}
\hline \multicolumn{1}{c}{ Taxón } & Tamaño corporal & Total \\
Chaetophractus vellerosus & 2 & 3 \\
Rodentia & 1 & 1 \\
Homo sapiens & 4 & 2 \\
Artiodactyla & 4 & 4 \\
Lama sp. & 4 & 9 \\
No identificable & 9 & 2 \\
Total general & & 21 \\
\hline
\end{tabular}

Los primeros análisis efectuados con el fin de ver el estado del conjunto respecto de los distintos indicadores tafonómicos utilizados en este trabajo nos muestra (Tabla 8.55 y Figura 8.106) que solo se registraron los estadios de meteorización 1 y 2 y que sobre cuatro especímenes no se pudo identificar ningún estadio.

Con respecto a los otros agentes analizados no se registraron modificaciones por carnívoros o roedores, lo cual dado el tamaño de la muestra sería lo esperable ya que según Mondini (2002) en conjuntos arqueológicos la expectativa de encontrar huellas de carnívoros es menor al 5\%. Si a esto le sumamos el tamaño de esta muestra es lógico no haber hallado ningún rastro de este tipo de agentes.

Tabla 8.55. Meteorización del conjunto faunístico de la Estructura 4 - Ocupación Inferior. Yutopián

\begin{tabular}{|c|c|c|c|c|c|c|}
\hline \multirow[t]{2}{*}{ Tamaño corporal } & \multicolumn{5}{|c|}{ Meteorización } & \multirow[t]{2}{*}{ Total NSP } \\
\hline & 1 & 2 & 3 & 4 & 7 & \\
\hline 1 & 1 & - & - & - & - & 1 \\
\hline 2 & - & 3 & - & - & - & 3 \\
\hline 4 & 9 & 6 & - & - & - & 15 \\
\hline 9 & - & - & - & - & 2 & 2 \\
\hline TOTAL & 10 & 9 & - & - & 2 & 21 \\
\hline
\end{tabular}




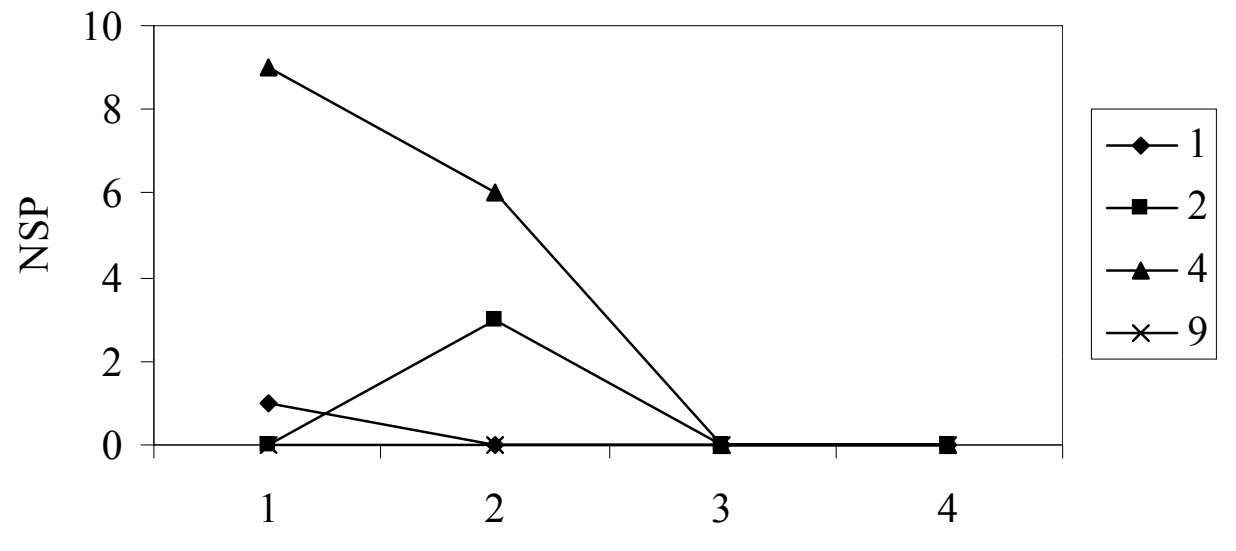

Estadios de meteorización

Figura 8.106. Estadios de meteorización según tamaño corporal. Estructura 4 Ocupación Inferior, Yutopián

\subsubsection{Análisis del subconjunto de camélidos.}

Este subconjunto se compone por 9 especímenes, los cuales representan el $42,85 \%$ de la muestra. El único elemento asignado a una clase de edad se determinó como subadulto.

Tabla 8.56. Camelidae, huesos del esqueleto axial y apendicular. Estructura 4 Ocupación Inferior, Yutopián.

\begin{tabular}{ccr}
\hline Elemento & Lama sp & NISP \\
MUN & 6 & 6 \\
RB & 1 & 1 \\
PHF & 1 & 1 \\
PHT & 1 & 1 \\
& & \\
Total general & 9 & 9 \\
\hline
\end{tabular}

\subsubsection{Número Mínimo de Elementos (MNE)}

Dientes (MUN) y Costillas (RB)

Se identificaron seis especímenes correspondientes a fragmentos de un molariforme y un fragmento de costilla. Sobre ellos se calcularon un $\mathrm{MNE}=1$ para cada elemento.

Falange proximal (PHF)

Se identificó un elemento en base a la epífisis proximal $(\mathrm{MNE}=1)$ 

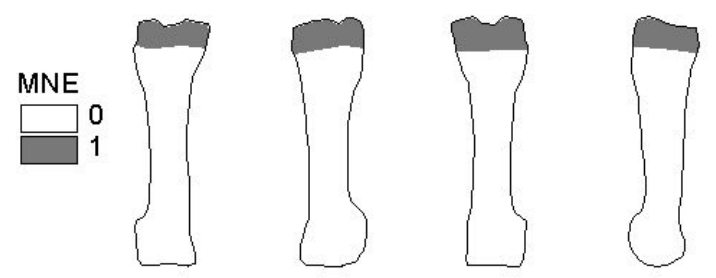

Figura 8.107. MNE Falange proximal general

Falange distal (PHT)

Se identificó un elemento completo $(\mathrm{MNE}=1)$
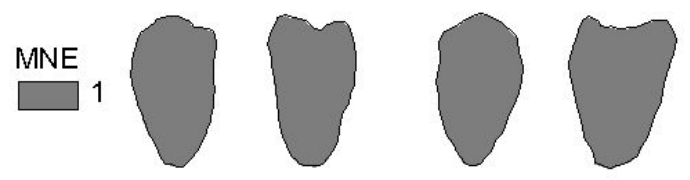

Figura 8.108. MNE Falange distal

Tabla 8.57. Abundancia relativa de partes esqueletarias expresadas como NISP, MNE comprehensivo, MAU y \%MAU.

\begin{tabular}{ccccccccc}
\hline Elemento & NISP & D & I & S/D & MNE & MNI & MAU & $\%$ MAU \\
MUN & 6 & - & - & 1 & 1 & 1 & - & - \\
TFR & 1 & - & - & 1 & 1 & 1 & - & - \\
RB & 1 & - & - & 1 & 1 & 1 & 0.04 & 73,23 \\
& 1 & - & - & 1 & 1 & 1 & 0.13 & 100,00 \\
PHF & 1 & - & - & 1 & 1 & 1 & 0.13 & 100,00 \\
PHT & 18 & & & & \\
Total general & 18 & \\
\multicolumn{7}{c}{ D = derecho, I = Izquierdo, S/D = Axial o sin datos }
\end{tabular}

\subsubsection{Numero Mínimo de Individuos (MNI)}

En base todos lo elementos se pudo calcular un individuo, el cual sería juvenil de acuerdo a la asignación realizada para la falange proximal.

\subsubsection{Unidades anatómicas representadas (MAU)}

Como puede observarse, en la muestra se hallan representados elementos del esqueleto axial al igual que elementos del esqueleto apendicular. Para la segunda parte esqueletal básica los elementos representados corresponden a las porciones distales de los miembros. 


\subsubsection{Fragmentación del subconjunto}

En la Figura 8.109 se observa que los elementos completos son los que están representados en mayor frecuencia. El resto de la muestra (un fragmento) se asignó al módulo 60-70 mm.

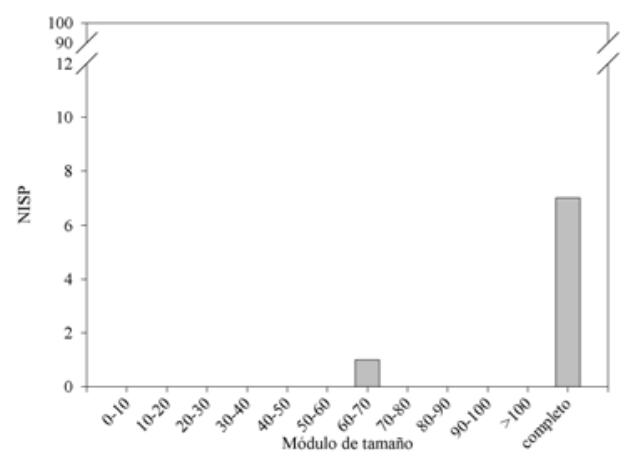

Figura 8.109. Módulos de tamaño expresado en NISP para especímenes y elementos del subconjunto adulto de camélidos

\subsubsection{Utilización de las carcasas}

No se observaron marcas de corte, impactos o cualquier otra de las categorías utilizadas en este trabajo.

\subsubsection{Termoalteraciones}

En un espécimen se identificaron signos de acción del calor del tipo 1: corresponde a una falange distal.

Tabla 8.58. Termoalteración del conjunto de camélidos

\begin{tabular}{cccccc}
\hline Descripción & Sin alteración & $\begin{array}{c}\text { Oxidación } \\
\text { incompleta/carbonización } \\
\text { marrón claro-negro } \\
\text { (moteado) }\end{array}$ & Carbonizado & Calcinado & \\
Color & - & $200{ }^{\circ} \mathrm{C}-300{ }^{\circ} \mathrm{C}$ & $300{ }^{\circ} \mathrm{C}$ & $>500{ }^{\circ} \mathrm{C}$ & \\
Temperatura & $<200{ }^{\circ} \mathrm{C}$ & - & 1 & - & 9 \\
NISP & 8 & - & gris-blanco & \\
\hline
\end{tabular}

\subsubsection{Subconjunto no camélido (otros tamaños corporales)}

Para los otros tamaños corporales presentes en la muestra solo se pudo observar modificaciones óseas asignables a la categoría machacado en un fragmento de lasca ósea de hueso largo.

En cuanto a los alterados por calor se identificaron especímenes quemados en dos placas de Chaetophractus vellerosus (alteraciones térmicas de tipo 1). 
Los dos dientes humanos corresponden a molares y en ambos casos se encontraron completos. Sólo se procedió al registro del largo máximo (altura del diente) obteniéndose un valor de $28.4 \mathrm{~mm}$ y $20.0 \mathrm{~mm}$ para cada una de las piezas dentales. 


\subsection{Yutopián - Estructura 5 - Análisis faunístico}

Esta estructura fue excavada mediante capas artificiales de $10 \mathrm{~cm}$. Las capas superiores $(0-40 \mathrm{~cm})$ no fueron tomadas en cuenta en el presente análisis. Una de las causa principales es que en este primer tramo fueron halladas cuevas de roedores. Además de los rasgos hallados en el campo se nota una diferencia en el estado de los especímenes óseos ya que para los primeros cuatro niveles se hallaron 143 especímenes con marcas de acción de roedores, en tanto que para las capas inferiores solo se identificó solo uno con marcas de acción de roedores.

Los especímenes y elementos recuperados en las capas inferiores a los $40 \mathrm{~cm}$ sumaron un NSP $=303$. De este total se identificó a nivel taxonómico el 67,98\%.

Tabla 8.59. Composición del conjunto faunístico de la Estructura 5.

\begin{tabular}{|c|c|c|}
\hline Taxón & Tamaño corporal & NSP \\
\hline Chaetophractus vellerosus & 2 & 10 \\
\hline Rodentia & 1 & 4 \\
\hline Rodentia & 2 & 6 \\
\hline Homo sapiens & 4 & 1 \\
\hline Artiodactyla & 4 & 99 \\
\hline Lama sp. & 4 & 82 \\
\hline Lama glama & 4 & 1 \\
\hline Lama $(V)$ vicugna & 4 & 3 \\
\hline Subtotal Identificados & & 206 \\
\hline No identificable & 2 & 3 \\
\hline No identificable & $3-4$ & 1 \\
\hline No identificable & 4 & 41 \\
\hline No identificable & 9 & 52 \\
\hline Subtotal No identificables & & 97 \\
\hline & TOTAL & 303 \\
\hline
\end{tabular}

Se identificaron un total de siete taxones diferentes. De este total algunas categorías se pudieron dividir de acuerdo a la asignación de algunos especímenes o elementos a distintos tamaños corporales. Este es el caso para Rodentia donde se sugiere la presencia de al menos dos tamaños corporales. Para Homo sapiens se identificó un molar.

Dentro del género Lama fue posible la identificación de un espécimen de Lama glama y tres de L. (V) vicugna. El primero corresponde a un carpo tercero sobre el cual 
se aplicaron las siguientes medidas: L, A, P (Izeta 2002 y Anexo 2 de esta Tesis). La identificación de vicuña se basó en las características de tres incisivos inferiores.

En cuanto a los agentes tafonómicos que actuaron sobre el conjunto se puede observar que los especímenes o elementos que presentan el estadio de meteorización 2 es el de mayor frecuencia en la muestra (42,57\%), seguido por el estadio 1 (30,63\%). En conjunto estos dos estadios representan el $73,20 \%$ de la muestra. Este resultado nos permite sugerir que el conjunto presenta en general una meteorización relativamente baja con tendencia a presentar niveles intermedios. Un total de nueve especímenes presentan el estadio 3, el cual es el estadio más alto registrado. Esto últimos corresponden al tamaño corporal 4, los cuales por su tamaño general pueden haber estado expuesto más tiempo a los agentes subaéreos de meteorización.

Tabla 8.60. Meteorización del conjunto faunístico de la Estructura 5. Yutopián

\begin{tabular}{crrrrrrr}
\hline Tamaño corporal & 1 & 2 & 3 & 4 & 7 & Total NSP \\
1 & 3 & 1 & - & - & - & 4 \\
2 & 5 & 14 & - & - & - & 19 \\
$3-4$ & - & 1 & - & - & - & 1 \\
4 & & 84 & 102 & 9 & - & 32 & 227 \\
9 & & - & 11 & - & - & 41 & 52 \\
& TOTAL & 92 & 129 & 9 & - & 73 & 303 \\
\hline
\end{tabular}

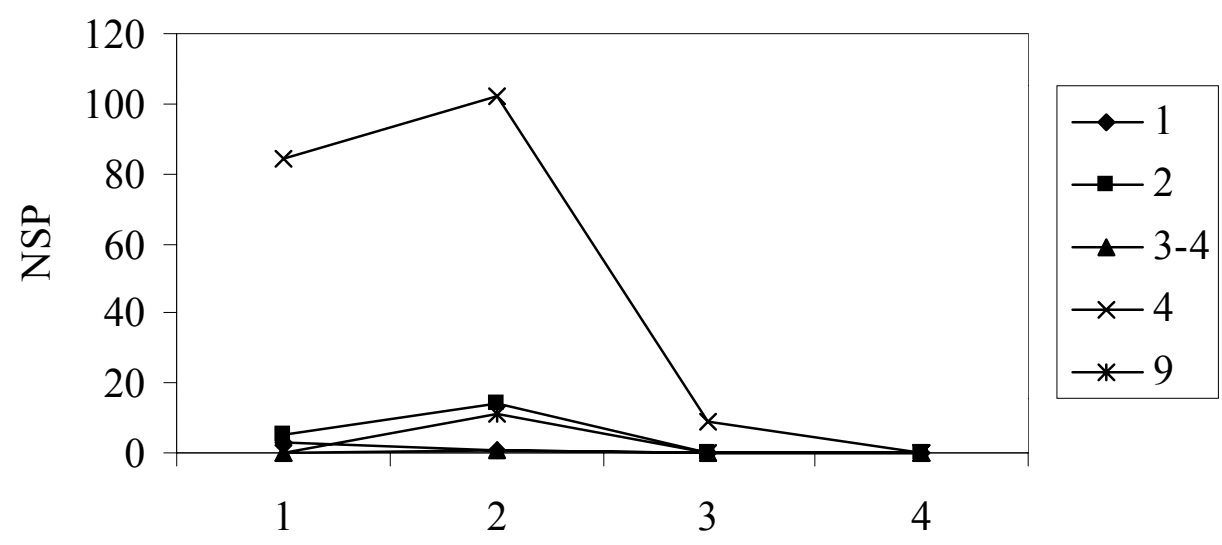

Estadios de meteorización

Figura 8.110. Estadios de meteorización según tamaño corporal. Estructura 5, Yutopián

La acción de roedores se registró en un espécimen del tamaño corporal 4. Este presenta una acción moderada. En cuanto a marcas de carnívoros no se registraron en el conjunto. 
Tabla 8.61. Modificaciones por agentes naturales del conjunto faunístico de la Estructura 5. Yutopián

\begin{tabular}{cccr}
\hline Tamaño Corporal & Sin modificaciones & Daño ligero por roedor & Total NSP \\
1 & 4 & - & 4 \\
2 & 19 & - & 19 \\
$3-4$ & 1 & - & 1 \\
4 & 226 & 1 & 227 \\
9 & 52 & - & 52 \\
Total NSP & 302 & 1 & 303 \\
\hline
\end{tabular}

8.6.1. Análisis del subconjunto de camélidos.

Para este conjunto se calculó un NISP=86, correspondiendo uno a Lama glama, tres a Lama (Vicugna) vicugna y el resto (82) a Lama sp.

Tabla 8.62. Camelidae, huesos del esqueleto axial y apendicular. Estructura 5, Yutopián.

\begin{tabular}{ccccr}
\hline Elemento & Lama glama & Lama sp. & L. (V). Vicugna & NISP \\
MR & - & 1 & - & 1 \\
CAN & - & 1 & - & 1 \\
IC & - & - & 3 & 3 \\
MUN & - & 6 & - & 6 \\
TFR & - & 7 & - & 7 \\
VT & - & 1 & - & 1 \\
RB & - & 34 & - & 34 \\
& & & & \\
SC & - & 1 & - & 1 \\
HM & - & 1 & - & 1 \\
RDU & - & 4 & - & 4 \\
CPR & - & 1 & - & 1 \\
CPT & 1 & 1 & - & 2 \\
MC & - & 1 & - & 1 \\
& & & & \\
IM & - & 1 & - & 1 \\
FM & - & 2 & - & 2 \\
TA & - & 4 & - & 4 \\
LTM & - & 1 & - & 1 \\
AS & - & 1 & - & 1 \\
CL & - & 1 & - & 1 \\
TRC & - & 1 & - & 1 \\
& & & & \\
MP & - & 3 & - & 3 \\
PHF & - & 4 & - & 4 \\
PHS & - & 1 & - & 1 \\
PHT & - & 2 & - & 2 \\
SEP & - & 2 & & \\
Total general & 1 & 82 & & \\
\hline
\end{tabular}




\subsubsection{Camélidos adultos}

\subsubsection{1.a. Supervivencia del material óseo mediada por la densidad ósea}

De los cinco elementos sobre los que se pudo determinar la correlación entre los valores de densidad ósea y el valor de las unidades anatómicas mínimas estandarizadas se observó que una presentó resultado positivo, tres negativos y una no presentó correlación. Para el conjunto total (29 elementos) la correlación fue positiva. En todos los casos las correlaciones no presentan significancia estadística. Lo que se puede interpretar de estos resultados es que a pesar de que los elementos del esqueleto apendicular tienden a presentar en general zonas diagnósticas de densidad ósea más baja hay una parte del conjunto que no presenta tal condición y es lo que estaría representando el resultado de la correlación global. Por ello desestimamos la acción de la densidad ósea como factor determinante de la configuración de este conjunto.

\begin{tabular}{cccc}
\multicolumn{4}{c}{ Tabla } \\
8.63. \%MAU vs. VD. \\
\hline Elemento & Rank & $r_{\mathrm{s}}$ & $p$ \\
Húmero & 5 &, 707 &, 091 \\
Metacarpo & 4 &,- 258 &, 371 \\
Innominado & 8 &,- 204 &, 330 \\
Fémur & 5 &,- 707 &, 091 \\
Calcáneo & 4 &, 000 &, 500 \\
Arqueofauna & 29 &, 106 &, 165 \\
\hline
\end{tabular}

\subsubsection{1.b. Número Mínimo de Elementos (MNE)}

\section{Mandibula (MR)}

La zona diagnóstica determinada para este elemento de la cabeza corresponde a un fragmento del borde inferior de la rama horizontal. $\mathrm{MNE}=1$.

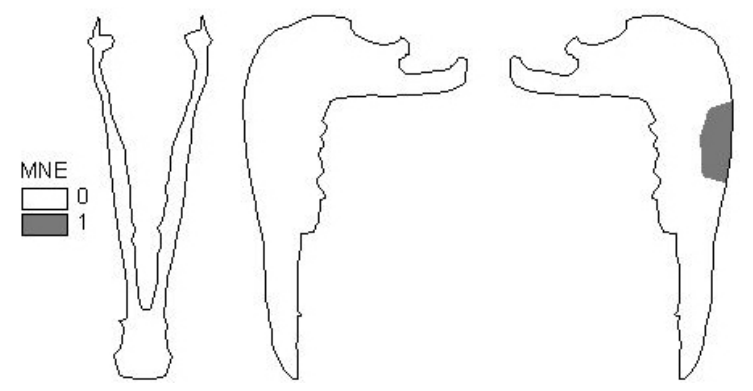

Figura 8.111. MNE Mandíbula

Dientes (IC, CAN, MUN, TFR)

Se identificaron piezas dentales completas y fragmentos. Se estimó un MNE de 3 para los incisivos y 1 para los caninos. Por último se reconocieron dos molares los 
cuales no pudieron asignarse al maxilar o a la mandíbula $(\mathrm{MNE}=2)$ y siete fragmentos de esmalte dental de dientes no identificados.

Vértebras (VT)

Para este elemento se identificó la siguiente zona diagnóstica: proceso transverso. El MNE comprehensivo calculado es igual a.

Costillas (RB)

Se identificaron treinta y cuatro fragmentos de porciones mediales de costillas. Sobre esto se obtuvo un $\mathrm{MNE}=10$.

\section{Húmero (HM)}

En este caso se identificó la siguiente zona diagnóstica: tubérculo teres mayor. Para el lado derecho se calculó un MNE igual a 1.
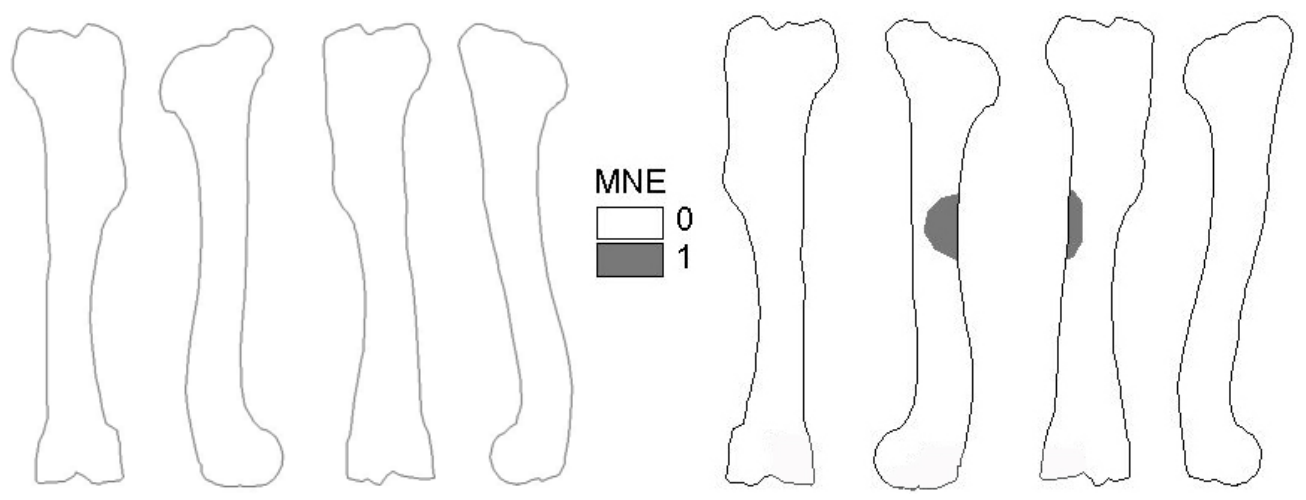

Figura 8.112. MNE Húmero izquierdo y derecho

Carpo radial (CPR)

Se calculó un MNE igual a 1 para este elemento, asignándose al lado izquierdo. Este elemento se presenta completo.

\section{Carpo tercero $(C P T)$}

Para este elemento se computó un MNE igual a 1 para este elemento, asignándose al lado derecho. Este elemento se presenta fragmentado.

Metacarpo (MC)

Las zonas diagnósticas utilizadas fueron diáfisis distal y cóndilos. El MNE comprehensivo para este elemento es de 1 para el lado derecho. 

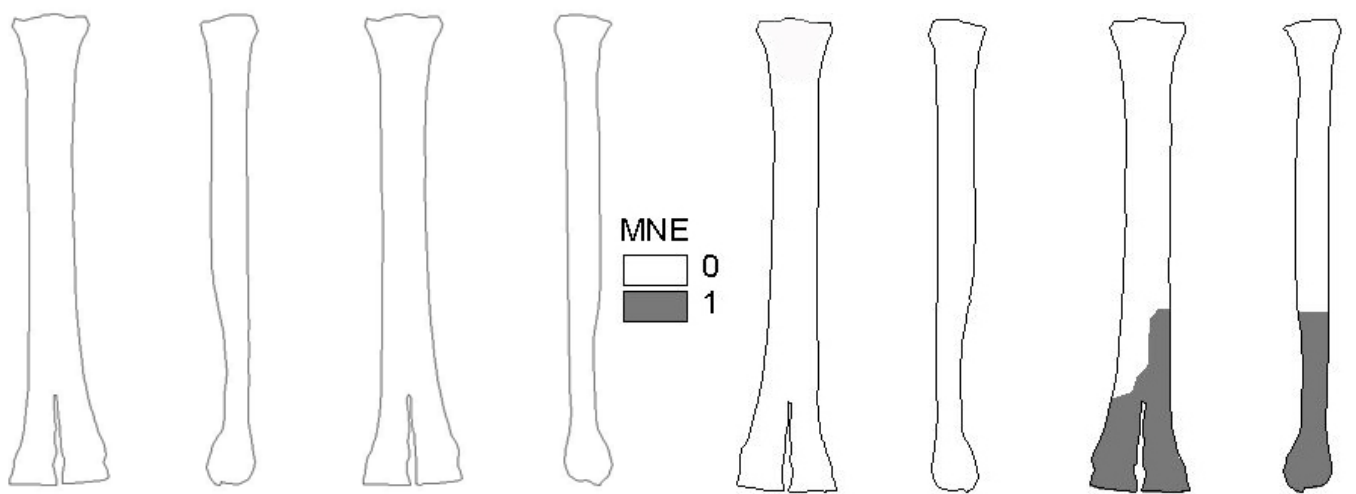

Figura 8.113. MNE Metacarpo izquierdo y derecho

Innominado (IM)

La zona diagnóstica reconocida para este elemento es el acetábulo sobre la que se logró determinar un MNE igual a 1 para el elemento izquierdo.
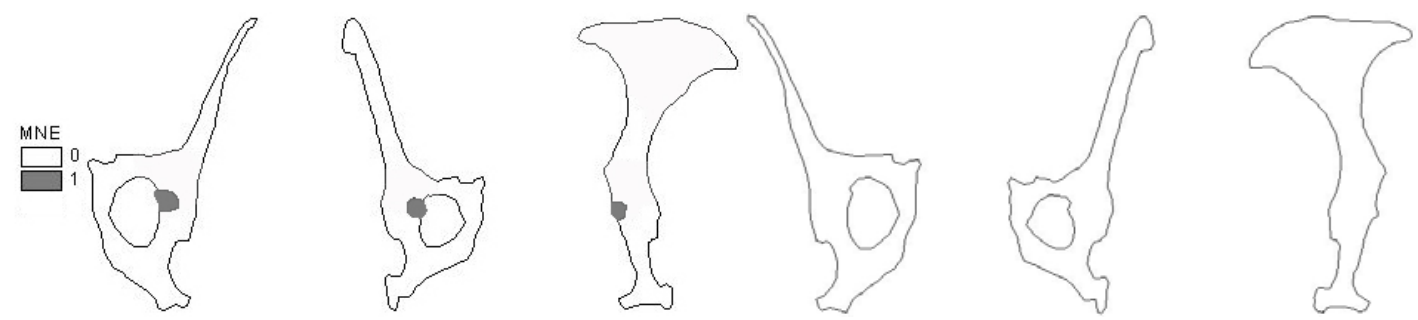

Figura 8.114. MNE Innominado izquierdo y derecho

Fémur (FM)

Sólo esta representado por un espécimen por cada lado. Estos corresponden a la tróclea y la epífisis y diáfisis distales. El MNE alcanzado es igual a 1 elemento izquierdo y 1 derecho, siendo el total de 2 elementos.
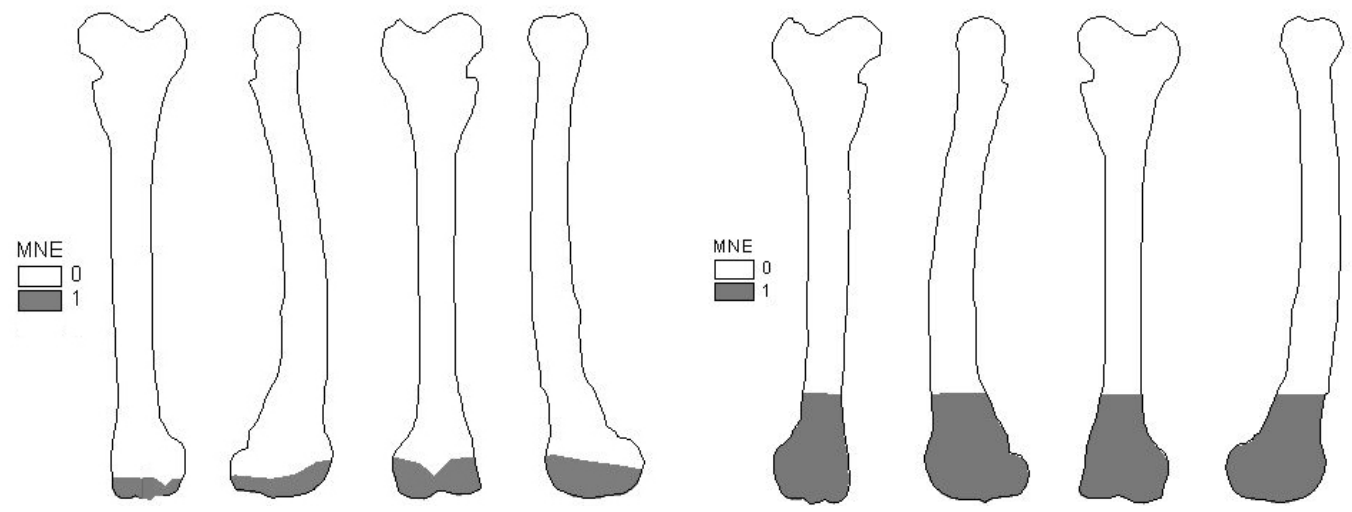

Figura 8.115. MNE Fémur izquierdo y derecho

Maléolo Lateral (LTM)

Se calculó un MNE igual a 1 para este elemento, asignándose al lado izquierdo. Este elemento se presenta en todos los casos de manera completa. 
Astrágalo (AS)

Para el elemento izquierdo se calculó un MNE igual a 1 en tanto que el derecho no esta presente en el registro.
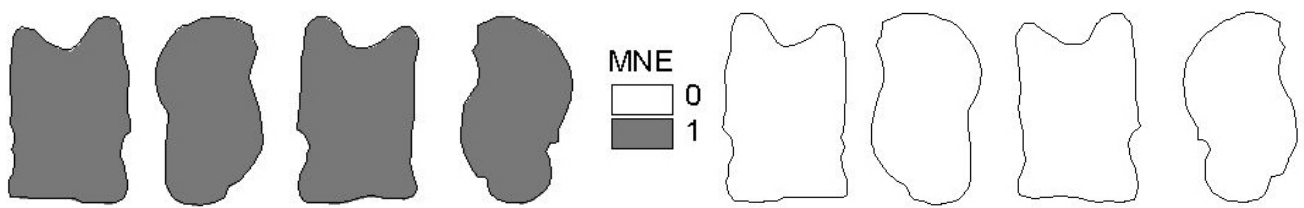

Figura 8.116. MNE Astrágalo izquierdo y derecho

Calcáneo (CL)

El MNE calculado para cada lado corresponde a 1 elemento para el derecho y ninguno para el izquierdo $(\mathrm{MNE}=1)$
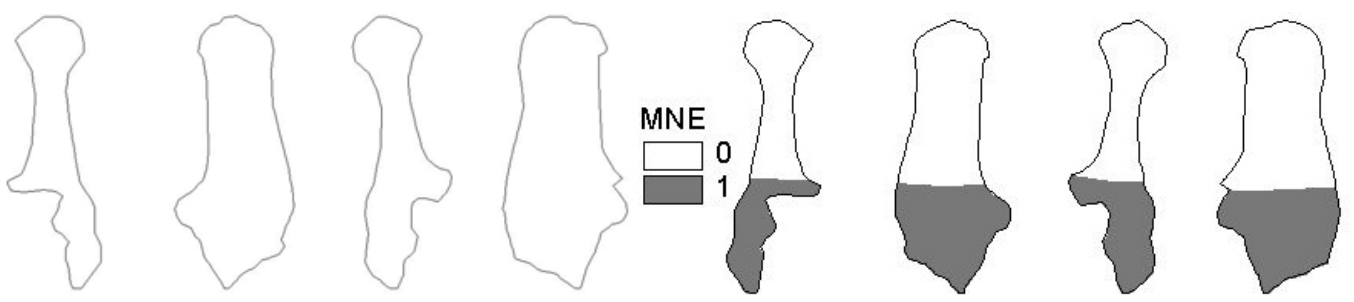

Figura 8.117. MNE Calcáneo izquierdo y derecho

Tarso central (TRC)

Se calculó un MNE igual a 1 para este elemento asignándose al lado izquierdo. Este elemento se presenta en todos los casos de manera completa.

\section{Metapodio general}

Se logró un MNE igual a 1 en base a un fragmento de diáfisis distal y un cóndilo.
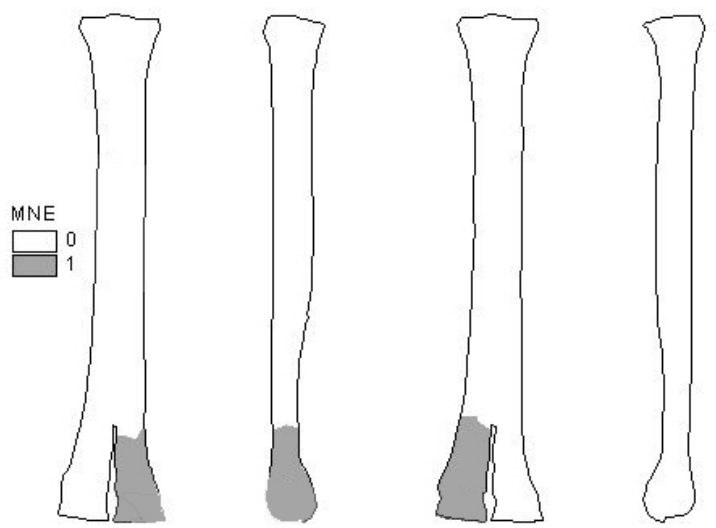

Figura 8.118. MNE Metapodio general

Falange proximal (PHF) 
La zona diagnóstica utilizada fue la epífisis distal. Sobre el espécimen asignado a este elemento se calculó un MNE igual a 1
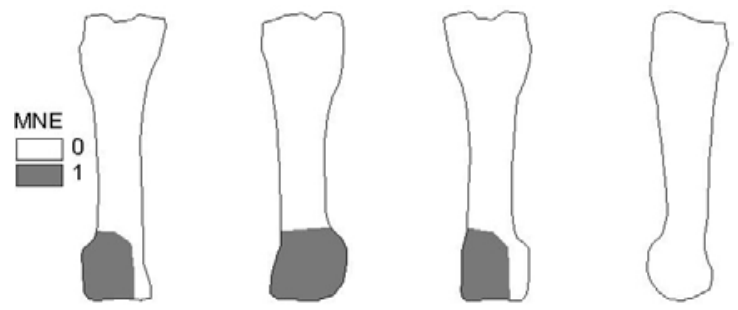

Figura 8.119. MNE Falange proximal general

Falange distal (PHT)

Para este elemento se identificaron la epífisis proximal, epífisis distal y diáfisis siendo el MNE calculado igual a 1.
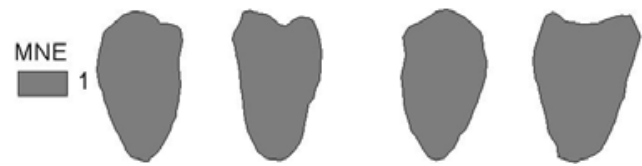

Figura 8.120. MNE Falange distal

Sesamoideos (SEP)

Se identificaron dos elementos completos $(\mathrm{MNE}=2)$

Sobre estos resultados de la estimación del MNE comprehensivo se procedió al cálculo de los demás índices utilizados en esta Tesis (MNI, MAU y \%MAU).

Tabla 8.64. Abundancia relativa de partes esqueletarias expresadas como NISP, MNE comprehensivo, MAU y \%MAU.

\begin{tabular}{crrrrrrrr}
\hline Elemento & NISP & I & D & S/D & MNE & MNI & MAU & $\%$ MAU \\
MR & 1 & - & - & 1 & 1 & 1 & 1.00 & 100.00 \\
CAN & 1 & - & - & 1 & 1 & 1 & 0.17 & 16.67 \\
IC & 3 & - & - & 3 & 3 & 1 & 0.25 & 25.00 \\
MUN & 6 & - & - & 2 & 2 & 1 & 0.17 & 16.67 \\
TFR & 7 & - & - & - & - & - & - & - \\
VT & 1 & - & - & 1 & 1 & 1 & - & - \\
RB & 34 & - & - & 10 & 10 & 1 & 0.36 & 35.71 \\
& & & & & & & & \\
HM & 1 & - & 1 & - & 1 & 1 & 0.50 & 50.00 \\
CPR & 1 & 1 & - & - & 1 & 1 & 0.50 & 50.00 \\
CPT & 2 & - & 1 & - & 1 & 1 & 0.50 & 50.00 \\
MC & 1 & - & 1 & - & 1 & 1 & 0.50 & 50.00 \\
& & & & & & & & \\
IM & 1 & 1 & - & - & 1 & 1 & 0.50 & 50.00 \\
FM & 2 & 1 & 1 & - & 2 & 1 & 1.00 & 100.00 \\
LTM & 1 & 1 & - & - & 1 & 1 & 0.50 & 50.00 \\
AS & 1 & 1 & - & - & 1 & 1 & 0.50 & 50.00 \\
\hline
\end{tabular}




\begin{tabular}{|c|c|c|c|c|c|c|c|c|}
\hline & & & & & & \multicolumn{3}{|c|}{ Continuación de Tabla 8.64} \\
\hline CL & 1 & - & 1 & - & 1 & 1 & 0.50 & 50.00 \\
\hline TRC & 1 & 1 & - & - & 1 & 1 & 0.50 & 50.00 \\
\hline MP & 1 & - & - & 1 & 1 & 1 & 0.25 & 25.00 \\
\hline PHF & 1 & - & - & 1 & 1 & 1 & 0.13 & 12.50 \\
\hline PHT & 2 & - & - & 1 & 1 & 1 & 0.13 & 12.50 \\
\hline SEP & 2 & - & - & 2 & 2 & 1 & 0.25 & 25.00 \\
\hline Total general & 71 & & & & & & & \\
\hline
\end{tabular}

\subsubsection{1.c. Número Mínimo de Individuos (MNI)}

En base a los resultados obtenidos para cada elemento se obtuvo un MNI de un individuo adulto. Todos los elementos coinciden en arrojar este valor. Sin embargo como se observó más arriba las determinaciones específicas arrojaron como resultado la presencia de un individuo perteneciente a llama y otro a vicuña por los que el mxMNI sería igual a 2.

\subsubsection{1.d. Unidades anatómicas representadas (MAU)}

Como puede observarse en la Figura 8.121 para el esqueleto axial se nota una preponderancia de los elementos de la cabeza (la mandíbula, y las piezas dentales) ya que los valores obtenidos para las costillas denotan un presencia moderada de este elemento.

Para el esqueleto apendicular los elementos más representados corresponden a los miembros posteriores. Se puede observar que las frecuencias más altas corresponden en este caso al fémur. Los elementos del carpo y del tarso no están representados en su totalidad, como sucede en otros conjuntos. 


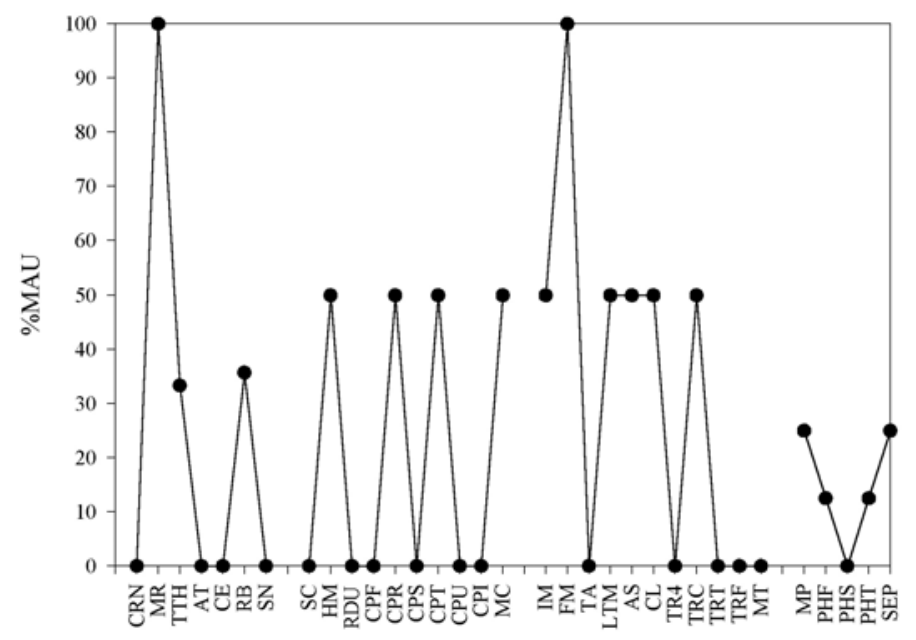

Figura 8.121. Abundancia relativa de elementos esqueletarios.

Como puede observarse en la Figura8.122.a los elementos "no-largos" presentan una tendencia similar a la planteada para la curva de utilidad inversa. Esto se advierte al realizar la correlación de los valores de densidad ósea y el \%MAU, cuyo resultado es negativo y estadísticamente no significativa $\left(r_{s}-.1566 \mathrm{p} .333\right)$. Esto nos muestra la relativa alta proporción de elementos de bajo rendimiento como la mandíbula. Para los huesos largos esta relación es positiva y estadísticamente no significativa $\left(r_{s} .3086 \mathrm{p}\right.$ .276). Con respecto a la relación entre el \%MAU y la cavidad medular se observa una relación positiva estadísticamente no significativa $\left(r_{s} .2648\right.$ p .306). Estos resultados nos sugieren la idea de que el conjunto apendicular podría haber sido formado debido a su relativa alta utilidad económica relacionada más a la carne que a la médula, al contrario de lo que sucedería con los elementos del esqueleto axial.

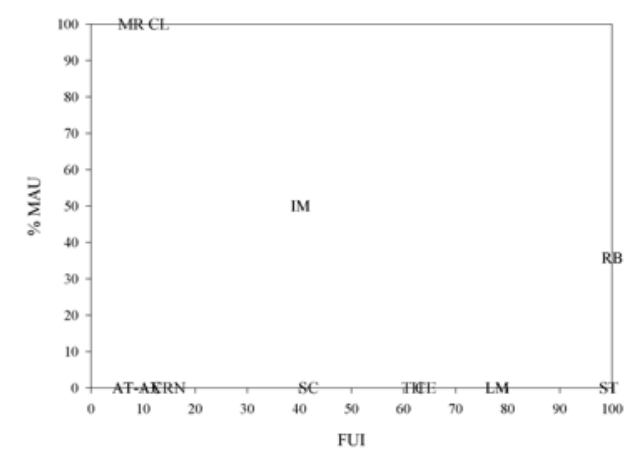

a

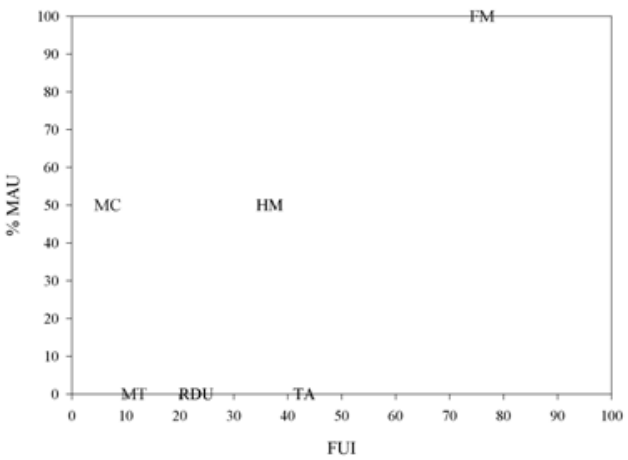

$\mathrm{b}$ 


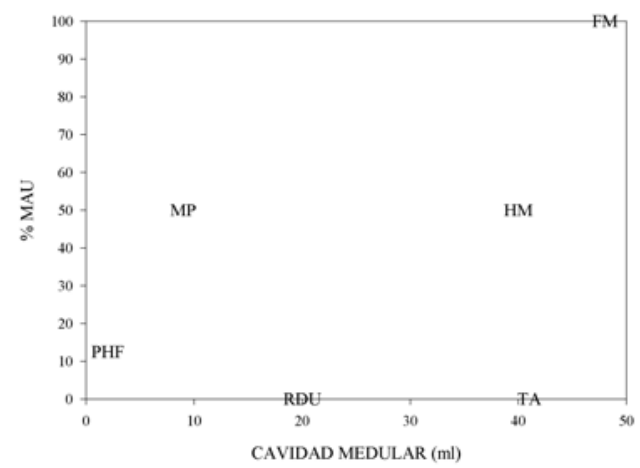

$\mathrm{C}$

Figura 8.122. a) Relación \%MAU VS FUI huesos "no-largos"; b) Relación \%MAU VS FUI huesos "largos"; c) Relación \%MAU VS Cavidad Medular.

\subsubsection{1.e. Fragmentación del subconjunto}

El resultado de este análisis muestra que el conjunto en su gran mayoría se encuentra representado por fragmentos. Las mayores frecuencias se registran en los módulos de tamaños más pequeños. Los elementos completos son en general los que corresponden al carpo y al tarso.

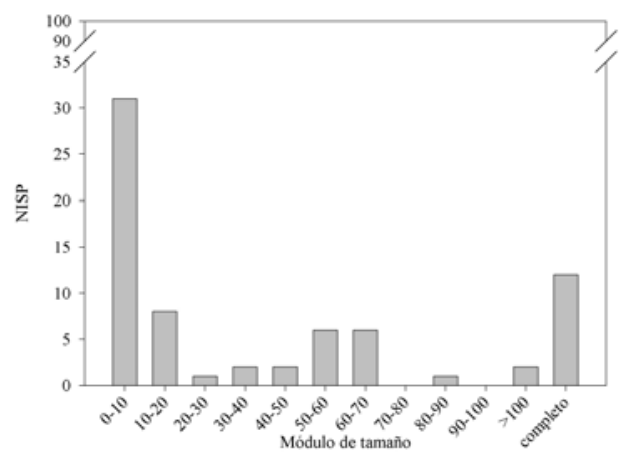

Figura 8.123. Módulos de tamaño expresado en NISP para especímenes y elementos del subconjunto adulto de camélidos

Esqueleto axial

El único elemento del esqueleto axial sobre el que se pudo realizar el cálculo de la superficie preservada fue la mandíbula. El total conservado ascendió a menos del 5\% (largo máximo: $56 \mathrm{~mm}$ ) 


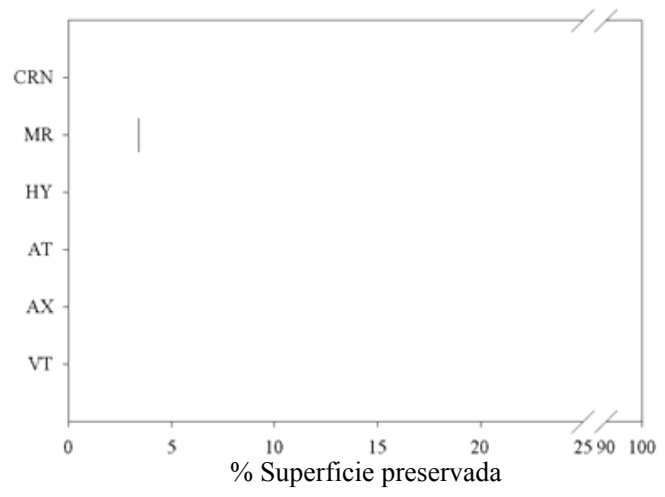

Figura 8.124. Fragmentación de elementos del esqueleto axial.

\section{Esqueleto apendicular delantero}

En el caso del miembro anterior se pude observar que salvo los elementos del carpo el resto presenta superficies preservadas en valores que van desde el $2 \%$ a menos del 20\%. Estos valores traducidos al rango de valores del largo máximo corresponden a $55 \mathrm{~mm}$ para el húmero y $60 \mathrm{~mm}$ para el metacarpo.
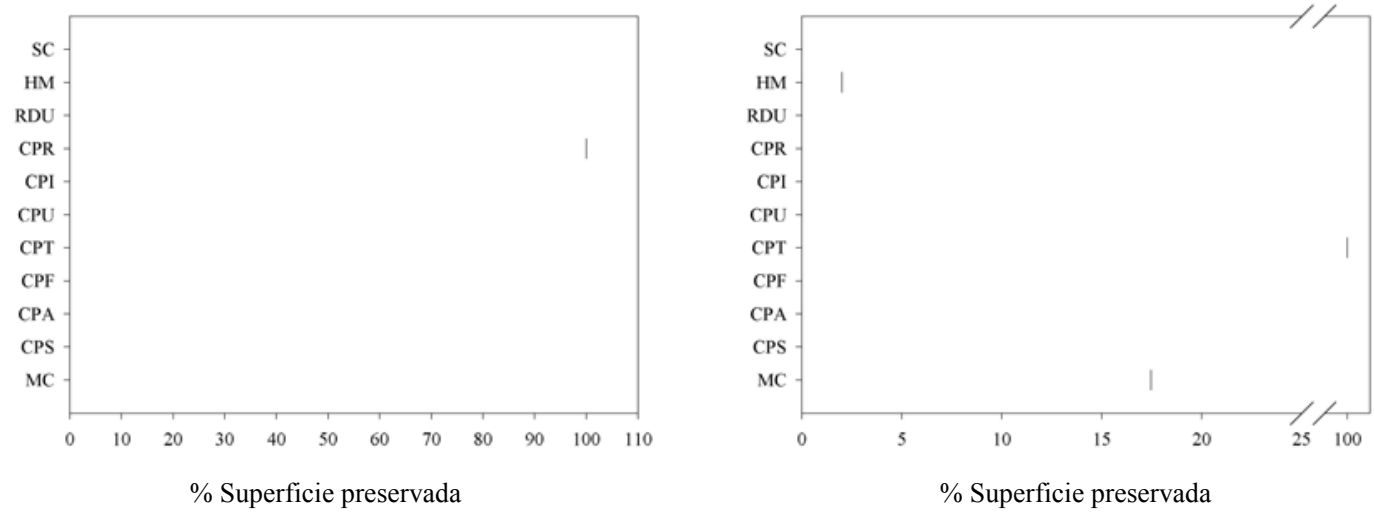

Figura 8.125. Fragmentación esqueleto apendicular delantero (izquierdo y derecho)

\section{Esqueleto apendicular trasero}

El miembro trasero izquierdo presenta un mayor número de elementos que el derecho. Las superficies preservadas para lo elementos de este lado apenas superan el $10 \%$ como en el caso del fémur. En términos de largos máximos de los especímenes el innominado izquierdo presenta un valor de $36 \mathrm{~mm}$ y el fémur de $45 \mathrm{~mm}$.

La pata trasera derecha está representada solo por dos elementos. El fémur con valores comprendidos entre los $61 \mathrm{~mm}$ y el calcáneo $(24 \mathrm{~mm})$. 

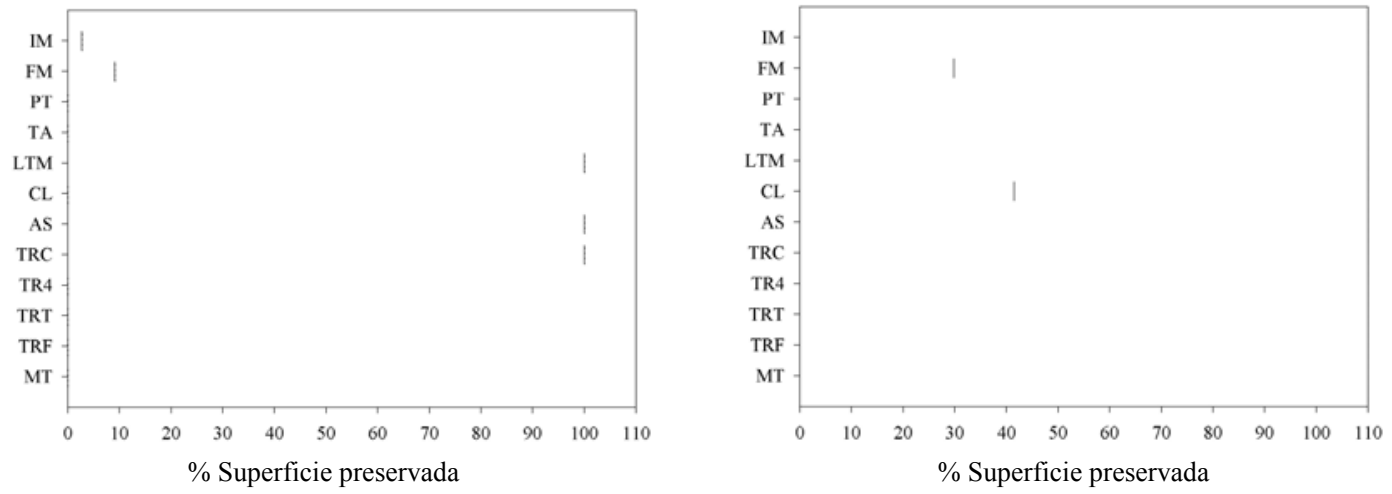

Figura 8.126. Fragmentación esqueleto apendicular trasero (izquierdo y derecho)

Respecto del estado en el que se hallaban los fragmentos cuando se produjo la fractura se ve que la categoría fresca es la que se presenta en mayor frecuencia.

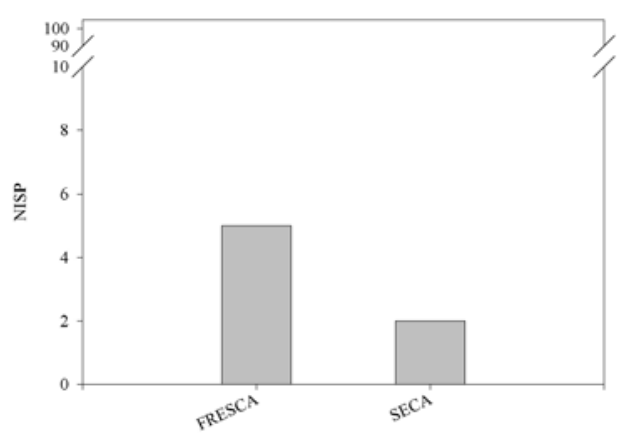

Figura 8.127. Cantidad (NISP) de especímenes y elementos del subconjunto adulto de camélidos según tipo de fractura.

\subsubsection{1.f. Utilización de las carcasas}

De los 71 elementos identificados para este conjunto sólo uno presentó huellas de acción antrópica siendo éste un fragmento de hoja de una costilla (marcas de machacado). La única traza del conjunto evidencia que al menos en el sitio se habría efectuado alguna acción tendiente al procesamiento primario de al menos un animal.

Tabla 8.65. Marcas en hueso de camélidos adultos expresado en NISP

\begin{tabular}{cccc}
\hline Elemento & Porción & Machacado & Total general \\
RB & BL & 1 & 1 \\
Total general & & 1 & 1 \\
\hline
\end{tabular}


El 22,53\% de la muestra presentó signos de termoalteración $(\mathrm{n}=12)$, lo que implica una moderada acción del calor sobre el conjunto. Aunque el conjunto es pequeño estos especímenes muestran signos de haber sido sometidos a toda la escala de temperaturas, principalmente a las superiores a $\operatorname{los} 300^{\circ} \mathrm{C}$.

Tabla 8.66. Termoalteración del conjunto de camélidos adultos.

\begin{tabular}{|c|c|c|c|c|c|}
\hline Descripción & Sin alteración & Carbonizado & $\begin{array}{c}\text { Carbonizado y } \\
\text { Calcinado }\end{array}$ & Calcinado & Total \\
\hline Color & - & negro & $\begin{array}{l}\text { negro-gris-blanco } \\
\text { (moteado) }\end{array}$ & gris-blanco & \\
\hline Temperatura & $<200^{\circ} \mathrm{C}$ & $300^{\circ} \mathrm{C}$ & $300^{\circ} \mathrm{C}->500^{\circ} \mathrm{C}$ & $>500{ }^{\circ} \mathrm{C}$ & \\
\hline NISP & 66 & 4 & 7 & 1 & 71 \\
\hline
\end{tabular}

Respecto de la relación entre tipo de estado al realizarse la fractura y tipo de alteración térmica podemos ver los resultados obtenidos en la Tabla 8.67 Allí se ve que la fractura fresca se presenta tanto para los elementos que no presentan tipos de alteración como en aquellos que si la presentan. La fractura seca está presente en dos especímenes sin alteración térmica.

Tabla 8.67. Relación entre tipo de termoalteración y tipo de fractura del conjunto de camélidos adultos.

\begin{tabular}{cccr}
\hline Tipo de alteración & Fresca & Seca & Total \\
Sin alteración & 2 & 2 & 4 \\
Carbonizado & - & - & - \\
Carb/Calc & 1 & - & 1 \\
Calcinado & - & - & - \\
Total & 3 & 2 & 5 \\
\hline
\end{tabular}

\subsubsection{Camélidos subadultos}

\subsubsection{2.a. Supervivencia del material óseo mediada por la densidad ósea}

De los dos elementos sobre los que se pudo determinar la correlación entre los valores de densidad ósea y el valor de las unidades anatómicas mínimas estandarizadas se observó que una presentó correlación positiva y una resultó ser negativa. Para el conjunto total (29 elementos) la correlación fue negativa estadísticamente significativa. Esto confirma que la conformación de este conjunto no ha sido mediada por la densidad ósea. 
Tabla 8.68. \%MAU vs. VD.

\begin{tabular}{cccc}
\hline Elemento & Rank & $r_{\mathrm{s}}$ & $p$ \\
Radioulna & 6 &, 154 &, 385 \\
Tibia & 5 &,- 210 &, 367 \\
Arqueofauna & 29 &,- 180 &, $048^{*}$ \\
\hline \multicolumn{4}{c}{$*$ Significante para $\mathrm{p}<, 05}$.
\end{tabular}

\subsubsection{2.b. Número Mínimo de Elementos (MNE)}

\section{Escápula (SC)}

Este elemento esta representado por la presencia de un elemento derecho completo. El MNE calculado es igual a 1.
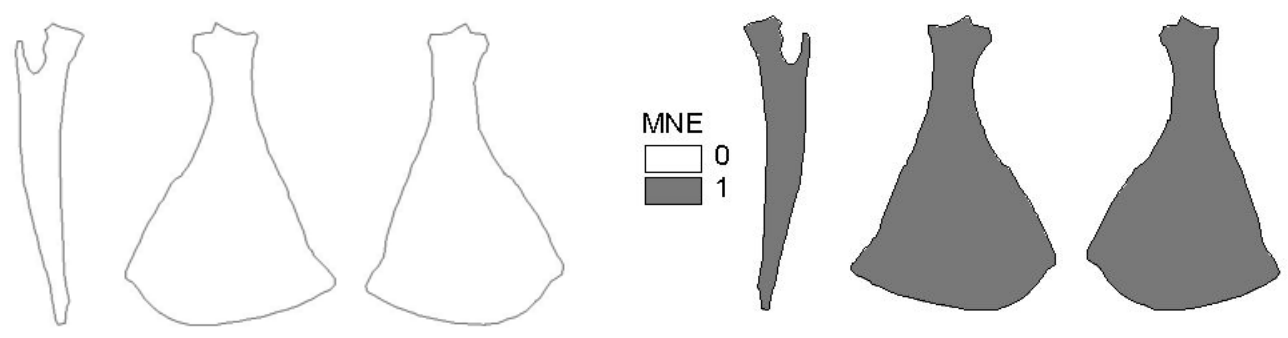

Figura 8.128. MNE Escápula izquierda y derecha

\section{Radioulna (RDU)}

Las zonas diagnósticas que permitieron identificar a este elemento son: proceso olecraniano, proceso anconeal, facetas articulares, cavidad glenoidea lateral, cavidad glenoidea medial, diáfisis, epífisis distal. El MNE obtenido arrojó como resultado para el elemento izquierdo un valor igual a 3 y para el derecho ninguno, lo cual hace un total de un mínimo de 3 elementos.
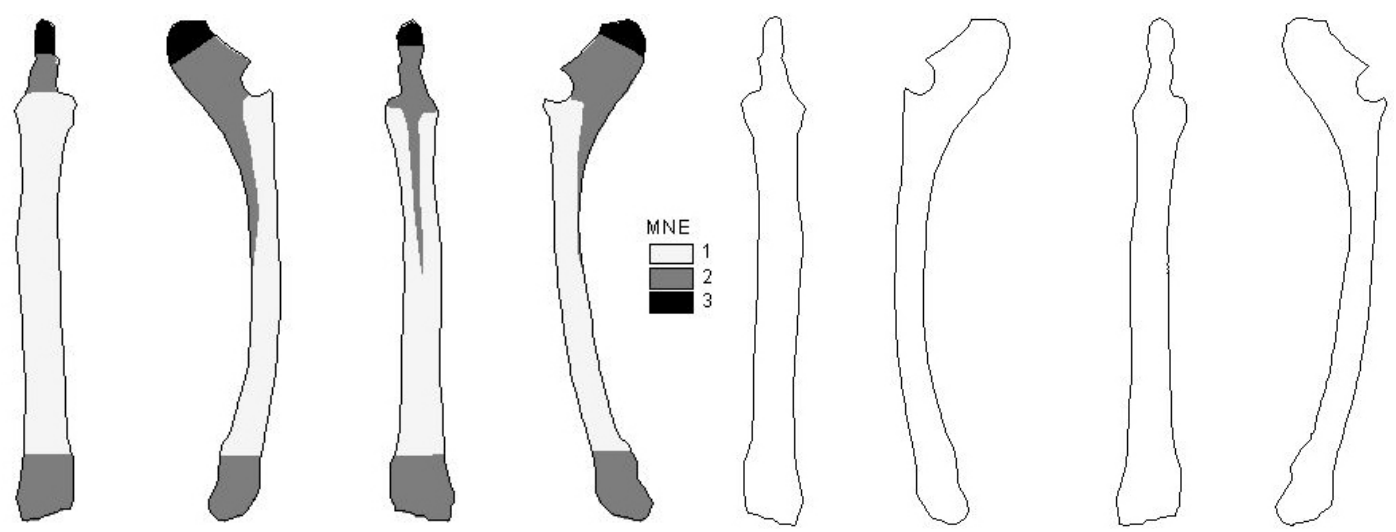

Figura 8.129. MNE Radioulna izquierda y derecha

Tibia (TA)

Las zonas diagnósticas utilizadas para identificar a los especímenes de este elemento corresponden a la epífisis proximal, diáfisis y epífisis distal. Se calculó un 
MNE igual a 2 para el elemento izquierdo y 1 para el derecho. El total es de 3 elementos.
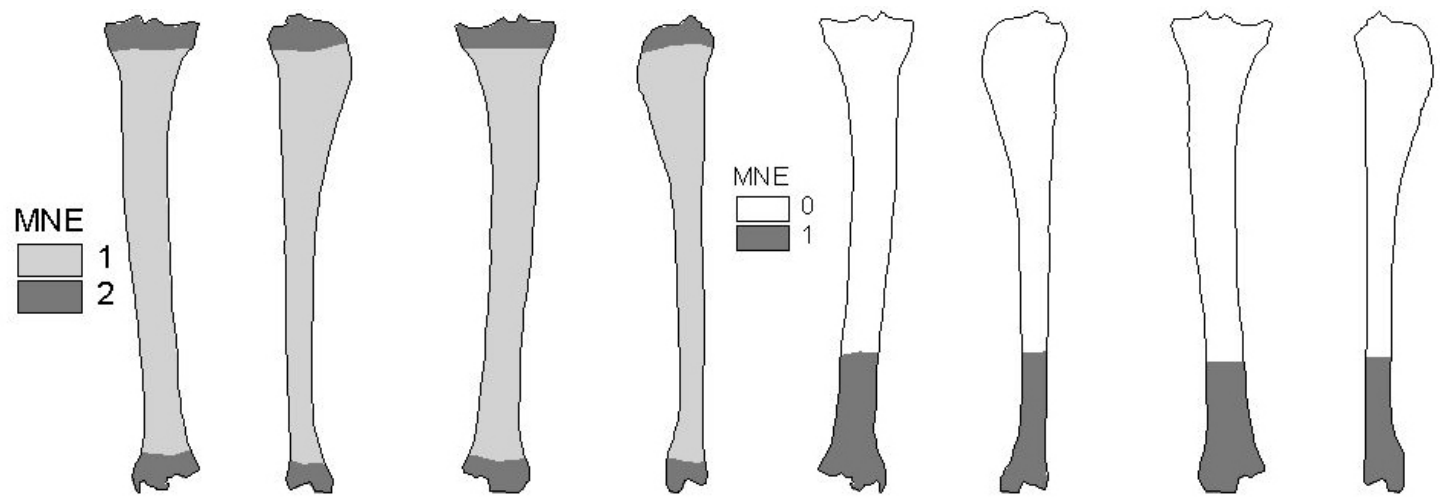

Figura 8.130. MNE Tibia izquierda y derecha

Metapodio general

Se logró un MNE igual a 1 en base a un fragmento diáfisis distal y un cóndilo.
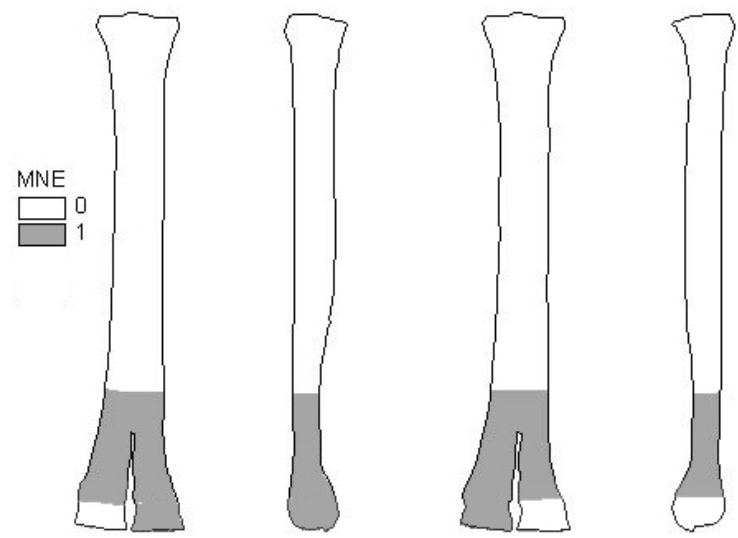

Figura 8.131. MNE Metapodio general

Falange proximal (PHF)

Para este elemento las zonas diagnósticas utilizadas fueron la epífisis proximal, epífisis distal y diáfisis. Sobre los especímenes asignados a esta categoría se calculó un MNE igual a 3 elementos.
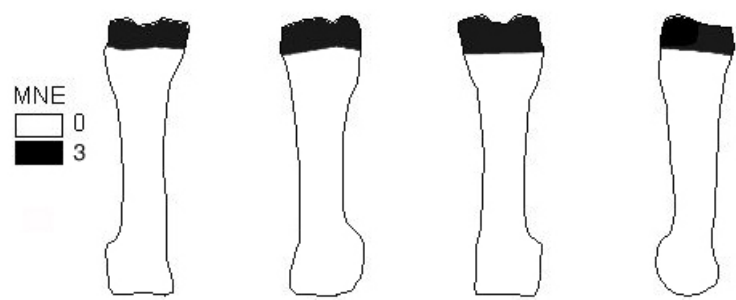

Figura 8.132. MNE Falange proximal

Falange medial (PHS)

Se identificó un elemento completo $(\mathrm{MNE}=1)$ 

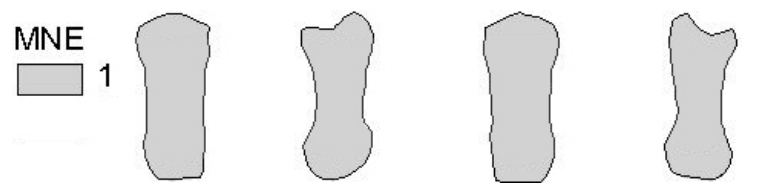

Figura 8.133. MNE Falange medial

Estos resultados se volcaron en la Tabla 8.69 Con ello se procedió al cálculo de los demás estimadores de abundancia esqueletal y taxonómica (MNI, MAU y \%MAU)

Tabla 8.69. Abundancia relativa de partes esqueletarias expresadas como NISP, MNE comprehensivo, MAU y \%MAU.

\begin{tabular}{ccccccccc}
\hline Elemento & NISP & I & D & S/D & MNE & MNI & MAU & $\%$ MAU \\
SC & 1 & - & 1 & - & 1 & 1 & 0.50 & 33.33 \\
& & & & & & & & \\
RDU & 4 & 3 & - & - & 3 & 3 & 1.50 & 100.00 \\
& & & & & & & & \\
TA & 4 & 2 & 1 & - & 2 & 2 & 1.00 & 66.67 \\
& 2 & - & - & 1 & 1 & 1 & 0.25 & 16.67 \\
MP & 3 & - & - & 3 & 3 & 1 & 0.12 & 8.33 \\
PHF & 1 & - & - & 1 & 1 & 1 & 0.12 & 8.33 \\
PHS & 15 & & \\
Total general & 15 &
\end{tabular}

\subsubsection{2.c. Número Mínimo de Individuos (MNI)}

En base a tres radioulnas izquierdas se obtuvo un MNI de tres individuos subadultos. La tibia arroja un valor de dos individuos, en tanto que el resto de los elementos solo permiten calcular un individuo.

\subsubsection{2.d. Unidades anatómicas representadas (MAU)}

La representación de los elementos para este conjunto muestra una alta presencia de huesos que corresponden a los segmentos proximales del esqueleto apendicular. Para las partes proximales de las patas se registran los elementos con mayor utilidad en términos de la anatomía económica de los animales. 


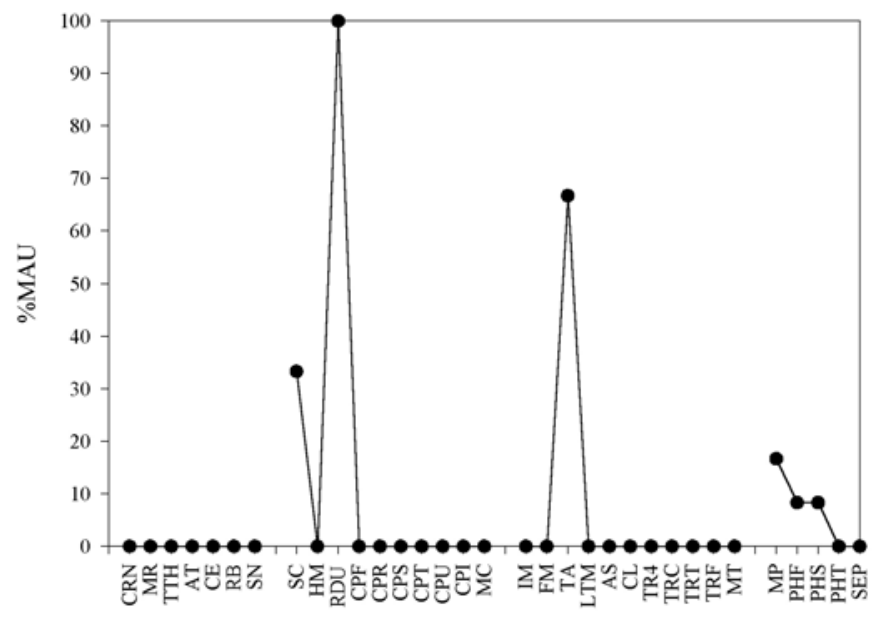

Figura 8.134. Abundancia relativa de elementos esqueletarios.

\subsubsection{2.e. Fragmentación del subconjunto}

El conjunto de camélidos subadultos presentó un alto grado de fragmentación. El módulo de tamaño más representado resultó ser el de 0-10 $\mathrm{mm}$. El resto del conjunto se reparte en distintos módulos. Los elementos completos en realidad refieren en este caso a aquellas epífisis sin fusionar que no presentaron ningún tipo de fragmentación y no a elementos completos por lo que la proporción en realidad es pequeña dentro de la muestra.

En cuanto al tipo de estado al realizarse la fractura solo se registró en dos especímenes la presencia de fractura fresca.

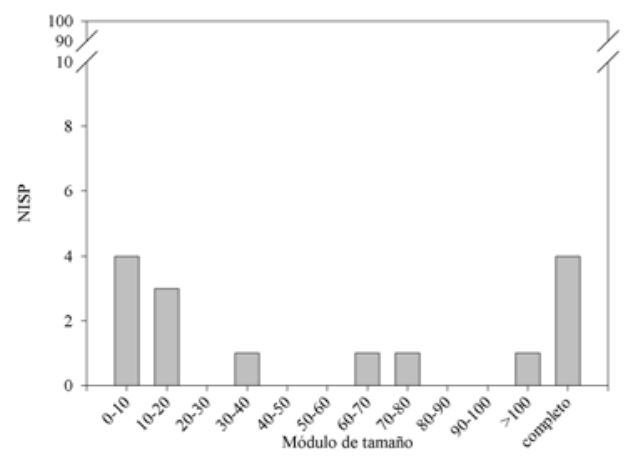

Figura 8.135. Módulos de tamaño expresado en NISP para especímenes y elementos del subconjunto subadulto de camélidos

8.6.1.2.f. Utilización de las carcasas y termoalteraciones 
No se registraron marcas o huellas de utilización de las carcasas así como tampoco no hay registro de termoalteración en el conjunto.

\subsubsection{Subconjunto no camélido}

La presencia de un molar humano en esta estructura repite lo hallado en la ocupación inferior de la estructura 4. El diente se halló completo y el largo máximo registrado para fue de $19.0 \mathrm{~mm}$.

\subsubsection{Marcas de procesamiento}

Se identificó un espécimen con signos de machacado. Este corresponde a la categoría "no identificable" de tamaño corporal 4 y está realizado sobre una lasca ósea de hueso largo.

Tabla 8.70. Marcas en huesos del conjunto no camélido expresado en NISP.

\begin{tabular}{ccccc}
\hline Elemento & Porción & Machacado & Impacto & Total general \\
LB & FK & 1 & - & 1 \\
Total general & & 1 & - & 1 \\
\hline
\end{tabular}

\subsubsection{Termoalteración}

Signos de alteración térmica fueron hallados 20 especímenes de Artiodáctilos (Tamaño corporal 4). Asimismo en las clases de tamaño corporal 4 de los especímenes "no identificables" taxonómicamente fueron identificadas 12 fragmentos con signos de alteración térmica.

Tabla 8.71. Termoalteración del conjunto no camélido.

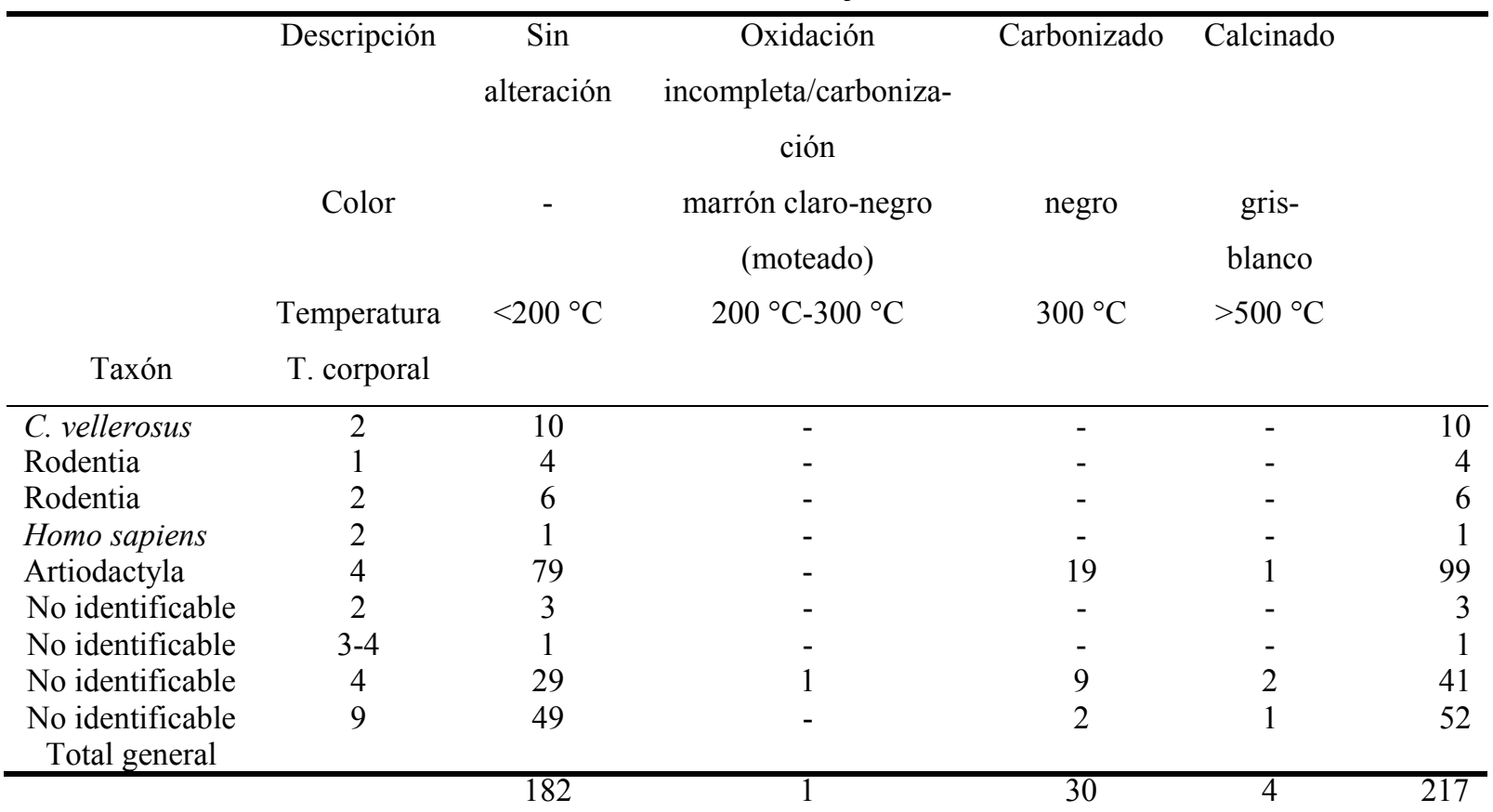




\subsubsection{Fragmentación del conjunto no camélido}

Para el tamaño corporal 1 (Figura 8.136.a) se observó que de un NISP $=4$ dos están fragmentados y dos se presentan completos. En el caso del tamaño corporal 2 se observa para Chaetophractus vellerosus (PE) y Rodentia (RO) el mismo patrón percibido para el tamaño corporal 1. Por último, para el tamaño corporal 4 se observó que el conjunto vuelve a comportarse con la distribución normal para este tipo de tamaño corporal, es decir presentando gran cantidad de especímenes en los módulos de tamaño más chicos.

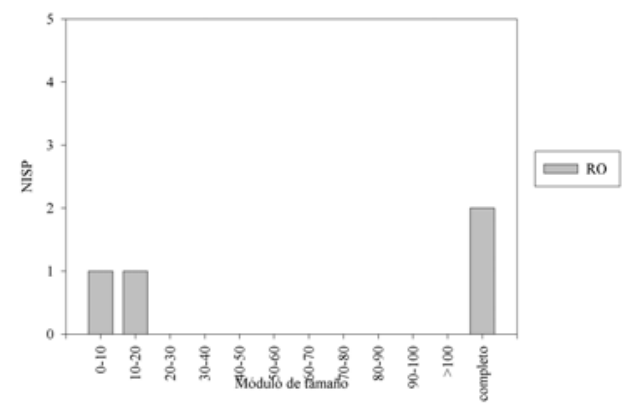

a

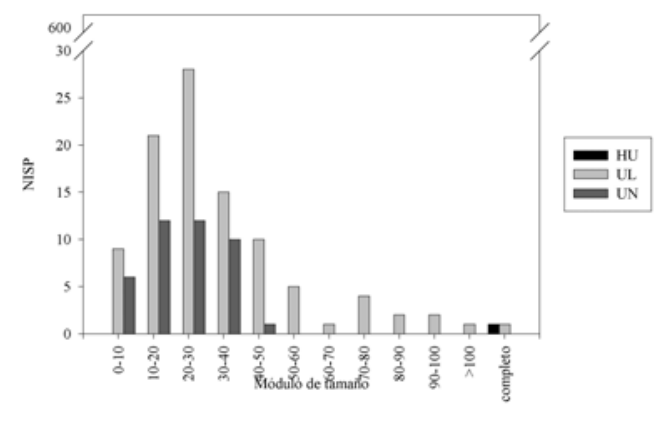

Figura 8.136. Fragmentación del conjunto no camélido expresado en NSP. a) Tamaño corporal 1, b) Tamaño corporal 2 y c) Tamaño corporal 4. 


\subsection{Yutopián - Estructura 11 - Análisis faunístico}

De esta estructura se excavó la totalidad de la superficie, la cual fue dividida en cuatro cuadrículas de $4 \mathrm{~m}^{2}$ cada una, representando un volumen excavado de $8 \mathrm{~m}^{3}$. La relación especímenes óseos de acuerdo al volumen excavado proporcionó como resultado 321,62 fragmentos por $\mathrm{m}^{3}$. Se identificó a nivel taxonómico el 96,15\% de la muestra.

Tabla 8.72. Composición del conjunto faunístico de la Estructura 11.

\begin{tabular}{lcr}
\hline Taxón & Tamaño corporal & Total \\
AVE & 1 & 1 \\
AVE & 2 & 1 \\
Chaeotophractus vellerosus & 2 & 150 \\
Rodentia & 1 & 3 \\
Lagidium sp. & 2 & 1 \\
Carnivora & 2 & 1 \\
Artiodactyla & 4 & 2163 \\
Lama sp. & 4 & 142 \\
Lama guanicoe & 4 & 4 \\
Lama glama & 4 & 6 \\
Lama (V.) vicugna & 4 & 1 \\
Hippocamelus antisensis & 4 & 1 \\
\hline & & \\
\hline Subtotal Identificados & & 2474 \\
\hline & & \\
No identificable & 1 & 6 \\
No identificable & $1-2$ & 3 \\
No identificable & $2-3$ & 7 \\
No identificable & $3-4$ & \\
No identificable & 4 & 97 \\
No identificable & 9 & 2573 \\
\hline Subtotal No identificables & & \\
\hline & & \\
\hline & & \\
\hline
\end{tabular}

En cuanto a la composición taxonómica de la muestra se puede ver en la Tabla 8.72 la presencia de once taxones, uno de los cuales presenta características que hicieron que se agruparan en dos tamaños corporales distintos (AVES). El grupo más frecuente es el del tamaño corporal 4 siendo los artiodáctilos los más representados dentro de este grupo y dentro de una determinación taxonómica más fina son los camélidos los más abundantes.

Sobre el conjunto se puede observar respecto de los estadios de meteorización registrados que el 95,57\% de la muestra presenta meteorización 1. Solo 30 especímenes 
presentan estadios más avanzados $(4,43 \%)$ y dentro de este número reducido solo tres presentan estadio de meteorización 5, uno de los más altos registrados en el total de muestras tratadas hasta el momento. En el grueso de la muestra, debido a su estado fragmentario, no puedo establecerse la acción de la meteorización subaérea.

Tabla 8.73. Meteorización del conjunto faunístico de la Estructura 11. Yutopián

\begin{tabular}{crrrrrr}
\hline Tamaño Corporal & \multicolumn{9}{c}{ Meteorización } \\
1 & 1 & 2 & 3 & 5 & 7 & Total NSP \\
$1-2$ & 17 & - & - & - & - & 17 \\
2 & 6 & - & - & - & - & 6 \\
$2-3$ & 153 & - & - & - & - & 153 \\
$3-4$ & 2 & - & - & - & 1 & 3 \\
4 & 2 & 1 & - & - & - & 3 \\
9 & 467 & 18 & 6 & 5 & 1888 & 2384 \\
TOTAL & 1 & - & - & - & 6 & 7 \\
\hline
\end{tabular}

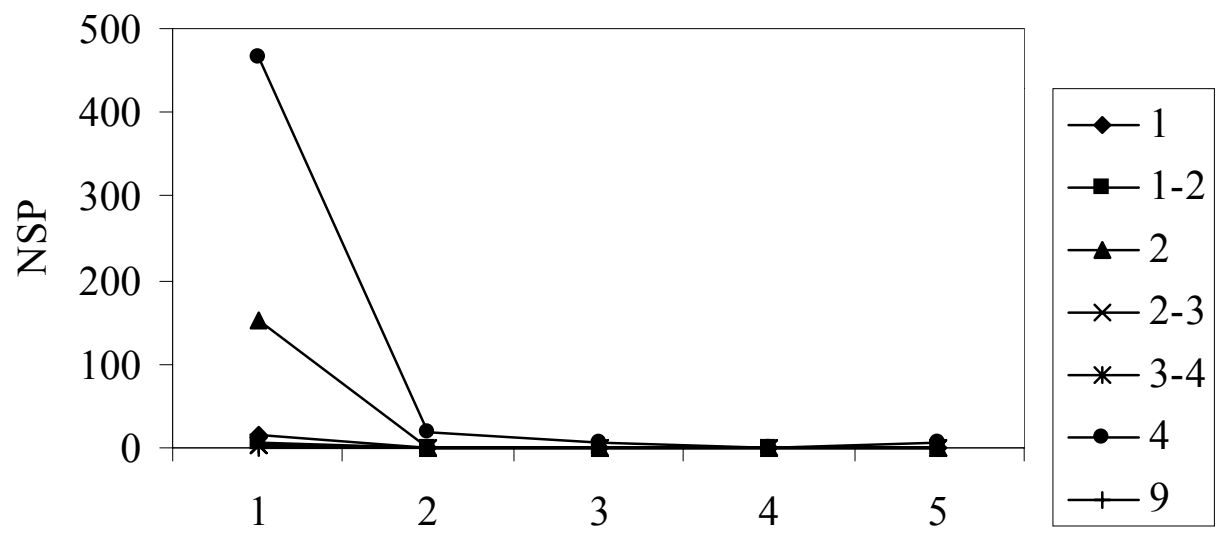

Estadios de meteorización

Figura 8.138. Estadios de meteorización según tamaño corporal. Estructura 11, Yutopián

Respecto de la acción de roedores y carnívoros se observó que del total de la muestra solo 6 especímenes mostraron evidencias de marcas de roedor o de carnívoros, representando en total el $0,23 \%$ de la muestra. 
Tabla 8.74. Modificaciones por agentes naturales del conjunto faunístico de la Estructura 11. Yutopián

\begin{tabular}{lrccr}
\hline Tamaño Corporal & Sin modificaciones & $\begin{array}{c}\text { Daño ligero por } \\
\text { roedor }\end{array}$ & $\begin{array}{c}\text { Mordisqueo de } \\
\text { carnívoro }\end{array}$ & $\begin{array}{c}\text { Total } \\
\text { general }\end{array}$ \\
1 & 17 & - & - & 17 \\
$1-2$ & 6 & - & - & 6 \\
2 & 153 & - & - & 153 \\
$2-3$ & 3 & - & - & 3 \\
$3-4$ & 3 & - & - & 3 \\
4 & 2378 & 3 & 3 & 2384 \\
9 & 7 & - & - & 7 \\
Total general & 2567 & 3 & 3 & 2573 \\
\hline
\end{tabular}

Tomando los resultados de estos dos análisis podemos ver que la acción de agentes tafonómicos naturales no ha tenido una acción representativa en la conformación del conjunto ya que los niveles de meteorización como las marcas de roedores o carnívoros se han registrado en frecuencias extremadamente bajas.

\subsection{Análisis del subconjunto de camélidos.}

Este conjunto está compuesto por un NISP $=153$, correspondiendo 4 a Lama guanicoe, 6 a Lama glama, 142 a Lama sp y 1 a Lama (Vicugna) vicugna.

Tabla 8.75. Camelidae, huesos del esqueleto axial y apendicular. Estructura 11, Yutopián.

\begin{tabular}{lccccr}
\hline Elemento & L. guanicoe & L. glama & Lama sp. & L. (V) vicugna & NISP \\
CRN & - & - & 1 & - & 1 \\
IC & - & - & 5 & - & 5 \\
CAN & - & - & 2 & - & 2 \\
MMR & - & - & 2 & - & 2 \\
PMR & - & - & 1 & - & 1 \\
MMX & - & - & 1 & - & 1 \\
MUN & - & - & 12 & - & 12 \\
MR & - & - & 39 & 1 & 40 \\
HY & - & - & 1 & - & 1 \\
HM & 2 & - & 5 & - & 7 \\
RDU & - & 2 & 7 & - & 9 \\
CPF & - & - & 1 & - & 1 \\
CPR & - & - & 1 & - & 1 \\
CPS & - & - & 1 & - & 1 \\
CPT & - & 1 & 2 & - & 3 \\
CPU & - & - & 3 & - & 3 \\
MC & - & - & 6 & - & 6 \\
IM & - & - & 2 & - & 2 \\
\hline & & & & & Continúa
\end{tabular}




\begin{tabular}{llllll}
\hline FM & - & - & 2 & - & 2 \\
TA & - & - & 2 & - & 2 \\
AS & - & - & 1 & - & 1 \\
CL & - & - & 2 & - & 2 \\
TR4 & - & - & 2 & - & 2 \\
TRC & - & - & 2 & - & 2 \\
TRT & - & 1 & 5 & - & 6 \\
MT & 1 & - & 2 & - & 3 \\
MP & - & - & 8 & - & \\
PHF & 1 & - & 10 & - & 11 \\
PHS & - & 1 & 6 & - & 7 \\
PHT & - & 1 & 2 & - & 3 \\
SEP & - & - & 6 & - & 6 \\
Total general & 4 & 6 & 142 & 1 & 153 \\
\hline
\end{tabular}

\subsubsection{Camélidos adultos}

\subsubsection{1.a. Supervivencia del material óseo mediada por la densidad ósea}

La correlación entre los valores de densidad ósea y el porcentual de las unidades anatómicas representadas en el conjunto arrojaron como resultado que para cinco elementos el resultado es positivo y para cuatro es negativo. Asimismo para el conjunto total (29 elementos) la correlación es negativa. En el caso de la mandíbula los valores obtenidos dan cuenta de una preservación mayor de elementos de densidad ósea baja. Para el húmero la relación es inversa a la anterior ya que se habrían conservado más zonas diagnósticas con valores de densidad ósea altos. Para la radioulna la relación es negativa (preservación de zonas menos densas). Para el metacarpo y el innominado se repite el mismo resultado que para la radioulna. Por último para el fémur, la tibia, el calcáneo y el metatarso la preservación de las zonas diagnósticas tienden a ser las más densas. Para el total del conjunto no habría preservación mediada por la densidad ósea ya que la muestra tiende a representar zonas con densidades óseas bajas. Este valor es obtenido aún con la inclusión de elementos densos como los carpianos y tarsianos.

Tabla 8.76. \%MAU vs. VD.

\begin{tabular}{lccc}
\hline Elemento & Rank & $r_{s}$ & $p$ \\
Mandíbula & 8 &,- 089 & .417 \\
Húmero & 5 &, 288 &, 319 \\
Radioulna & 6 &,- 462 &, 178 \\
Metacarpo & 4 &,- 210 &, 395 \\
Innominado & 8 &,- 204 &, 330 \\
Fémur & 5 &, 353 &, 280 \\
Tibia & 5 &, 707 &, 091 \\
Calcáneo & 4 &, 258 &, 371 \\
Metatarso & 4 &, 105 &, 447 \\
Arqueofauna & 29 &,- 640 &, 277 \\
\hline
\end{tabular}


8.7.1.1.b. Número Mínimo de Elementos (MNE)

\section{Cráneo (CRN)}

Para este elemento se pudo identificar una porción del occipital y algunos dientes del maxilar. El MNE obtenido es igual a 1.

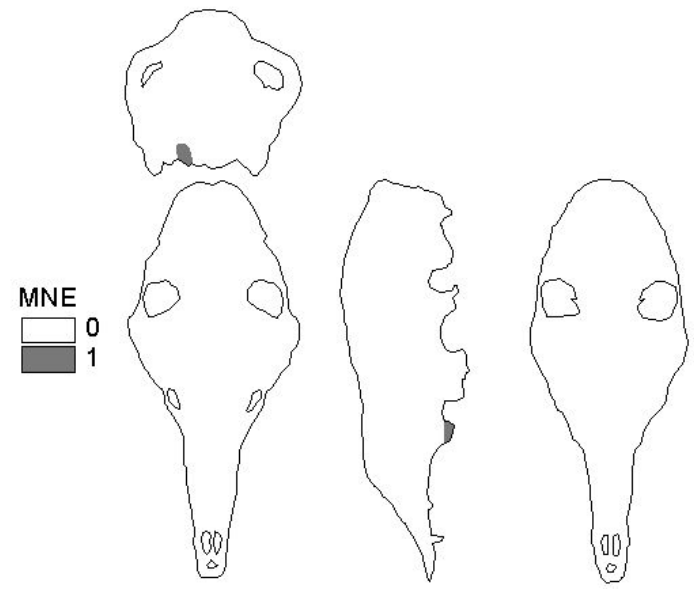

Figura 8.139. MNE Cráneo

Mandíbula (MR)

Las siguientes zonas diagnósticas fueron reconocidas: angular, coronoides y sínfisis. Además se identificaron dientes molares, premolares e incisivos. El MNE calculado ascendió a 2 elementos basados en dos fragmentos del angular derecho.

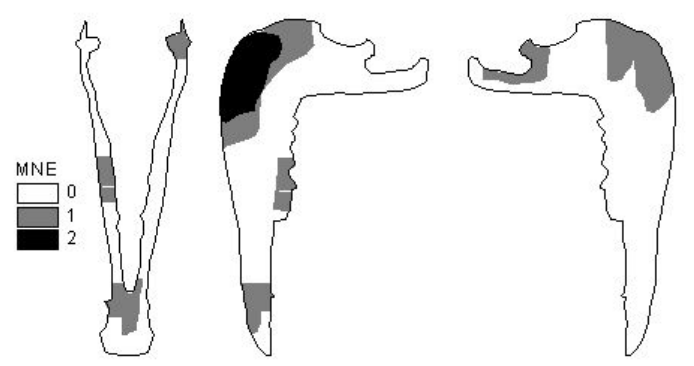

Figura 8.140. MNE Mandíbula

Dientes (IC, CAN, MMR, PMR, MMX, MUN)

Se identificaron piezas dentales completas y fragmentos. Se estimó un MNE de 4 para los incisivos y 2 para los caninos. Para el maxilar se identificó la presencia de un molar $(\mathrm{MNE}=1)$ Para la mandíbula se identificaron un premolar y dos molares $(\mathrm{MNE}=$ 1 y 2). Por último se identificaron dos molares los cuales no pudieron asignarse al maxilar o a la mandíbula $(\mathrm{MNE}=2)$

Hioides (HY) 
Se identificó un fragmento que corresponde al cuerpo del elemento. $\mathrm{MNE}=1$.

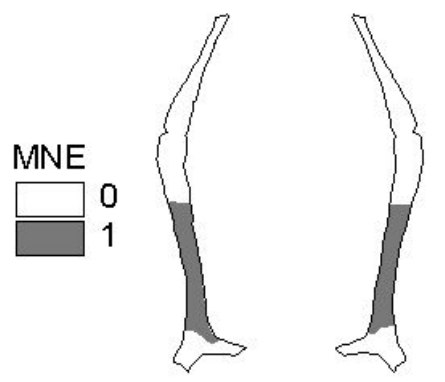

Figura 8.141. MNE Hioides

\section{Húmero (HM)}

Las zonas diagnósticas identificadas corresponden a: teres mayor, diáfisis distal, cabeza y tuberosidad deltoidea. Sobre esta identificación se logró un MNE igual a 2 elementos para el lado izquierdo y de 1 para el lado derecho. El total de elementos calculados para el húmero es de 3 .
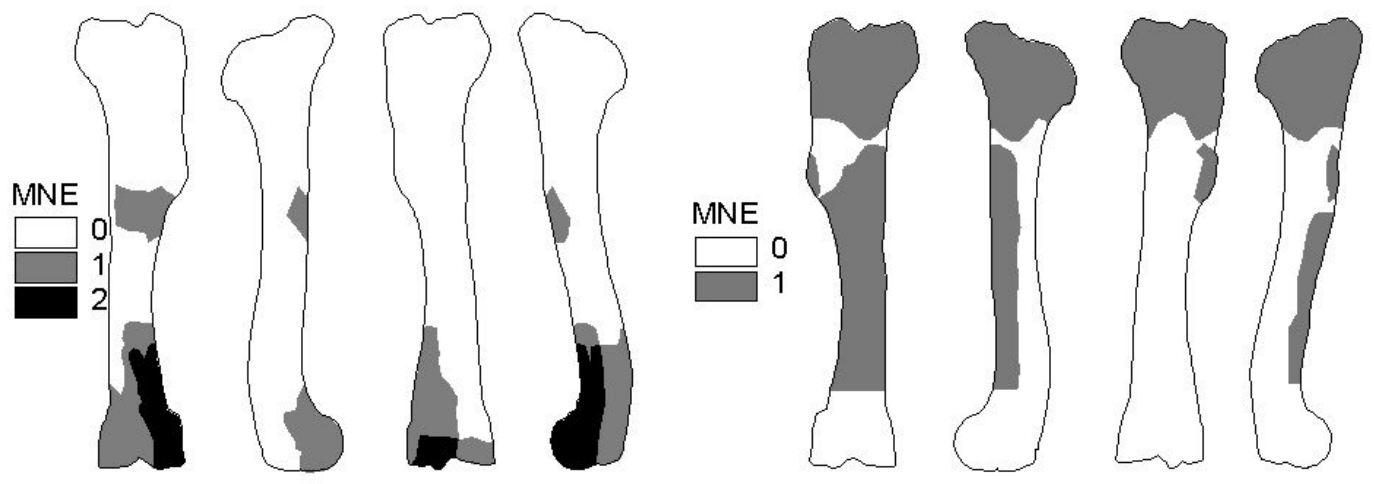

Figura 8.142. MNE Húmero izquierdo y derecho

\section{Radioulna (RDU)}

Las zonas diagnósticas identificadas para este elemento corresponden a: cavidad glenoidea lateral, cavidad glenoidea medial, diáfisis proximal posterior, tuberosidad radial, foramen nutricio posterolateral, faceta de articulación con el CPR, faceta de articulación con el CPI, epífisis proximal de la ulna, olécranon, proceso anconeal, facetas articulares, diáfisis proximal de la ulna. Sobre ello se calculó un MNE de 3 elementos para el lado izquierdo y de 1 elemento para el lado derecho, totalizando en conjunto 4 elementos. 

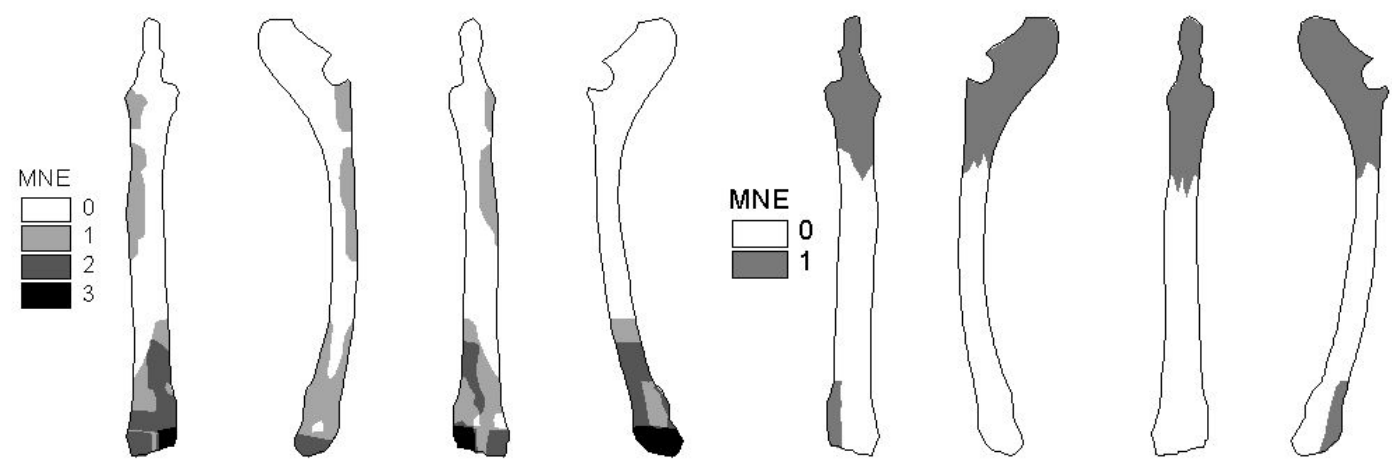

Figura 8.143. MNE Radioulna izquierda y derecha

Carpo cuarto (CPF), Carpo segundo (CPS)

Se identificó un elemento completo para cada hueso. Ambos se asignaron al lado derecho. $(\mathrm{MNE}=1 \mathrm{CPF}$ y $\mathrm{MNE}=1 \mathrm{CPS})$

\section{Carpo radial (CPR)}

Un elemento completo fue determinado y asignado al lado izquierdo, lo cual permite estimar un $\mathrm{MNE}=1$

\section{Carpo Tercero (CPT)}

Se identificaron dos elementos completos asignados al lado derecho. El obtenido es igual a 2

\section{Carpo Lunar (CPU)}

En este caso se reconocieron tres elementos completos de los cuales fueron asignados 2 al lado derecho y 1 al lado izquierdo. $\mathrm{MNE}=3$

\section{Metacarpo (MC)}

Las zonas diagnósticas utilizadas fueron las facetas articulares del metacarpo con el CPF y la porción caudal de la diáfisis. El MNE calculado ascendió a 3 elemento $(\mathrm{MNE}=3)$ 

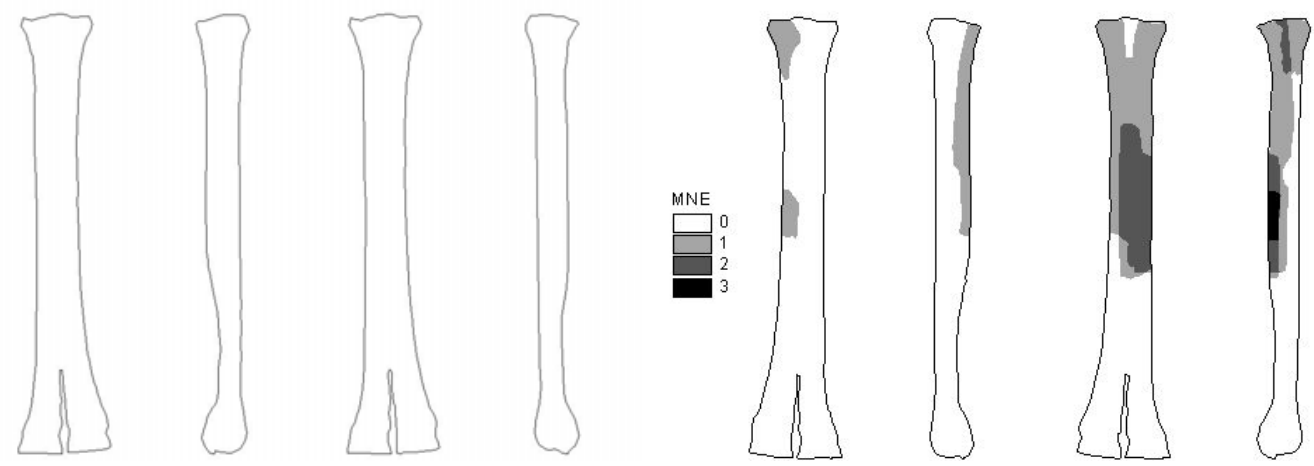

Figura 8.144. MNE Metacarpo izquierdo y derecho

\section{Innominado (IM)}

Se identificó un fragmento de acetábulo del lado izquierdo $(\mathrm{MNE}=1)$
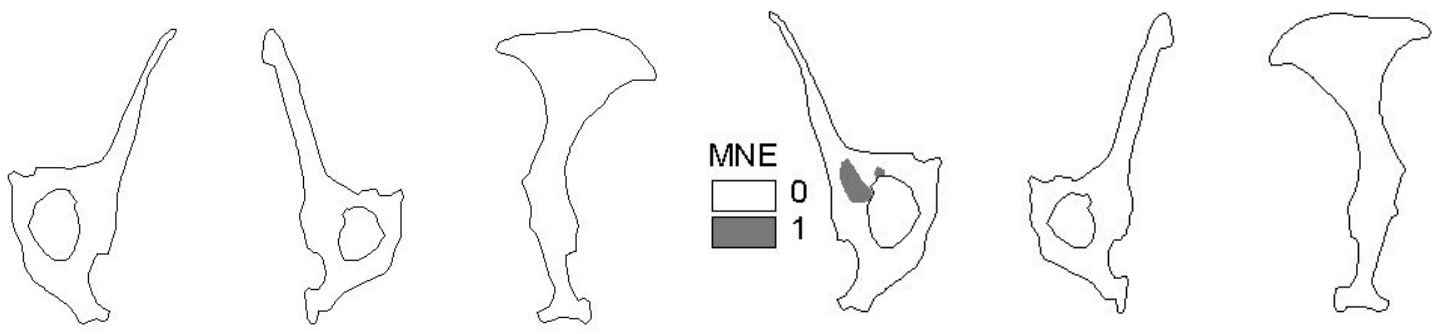

Figura 8.145. MNE Innominado izquierdo y derecho

Fémur (FM)

Para el fémur se han determinado especímenes para los elementos de ambos lados. Para el lado derecho se identificaron las siguientes zonas diagnósticas: línea áspera, fosa supracondiloidea y cóndilo lateral. Para el elemento derecho se pudo identificar la cabeza del fémur. Esto permitió calcular un MNE de 1 para cada lado. MNE total 2 elementos.
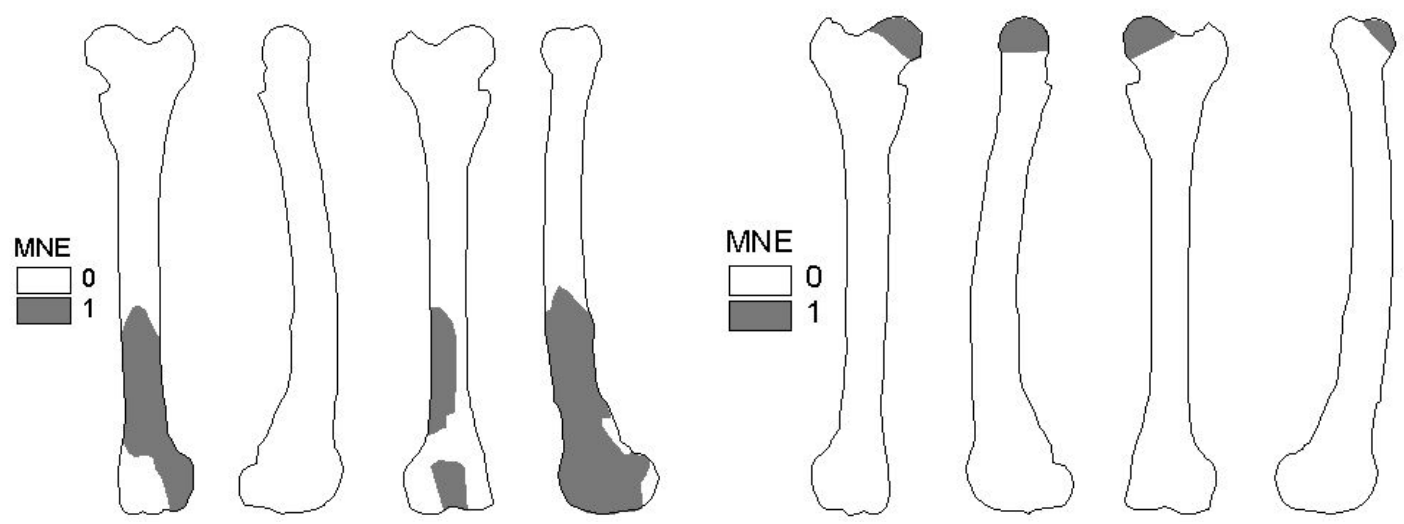

Figura 8.146. MNE Fémur izquierdo y derecho

Tibia (TA) 
Se identificó un fragmento ubicado en la porción proximal y posterior de la diáfisis. $\mathrm{MNE}=1$.
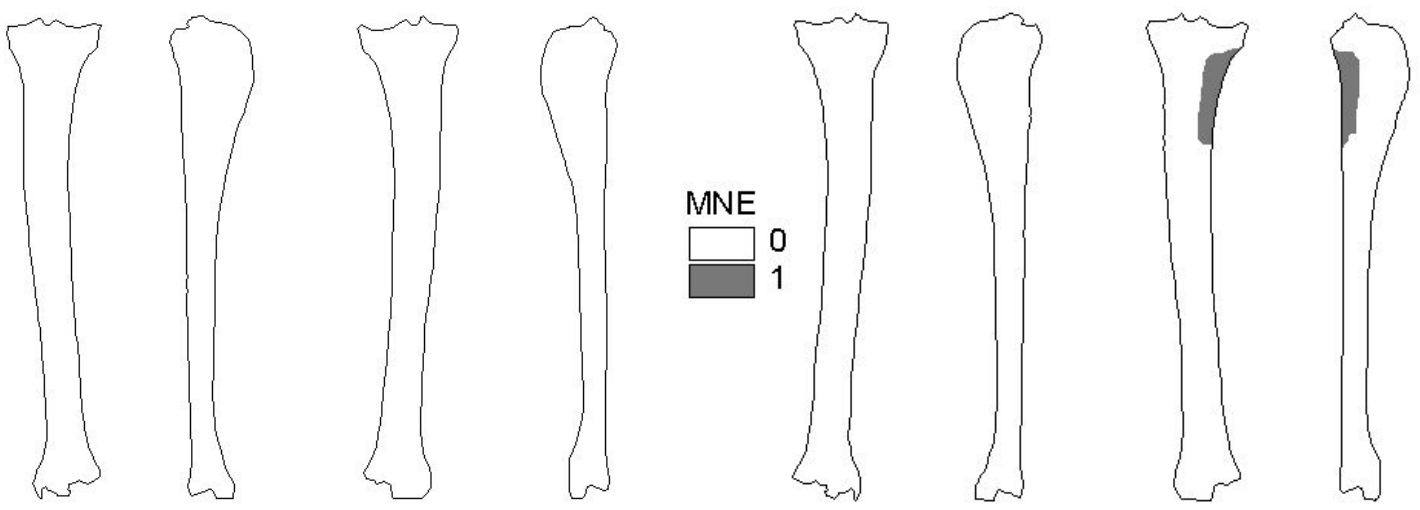

Figura 8.147. MNE Tibia izquierda y derecha

Astrágalo (AS)

Un elemento completo del lado izquierdo nos permitió calcular un MNE=1.
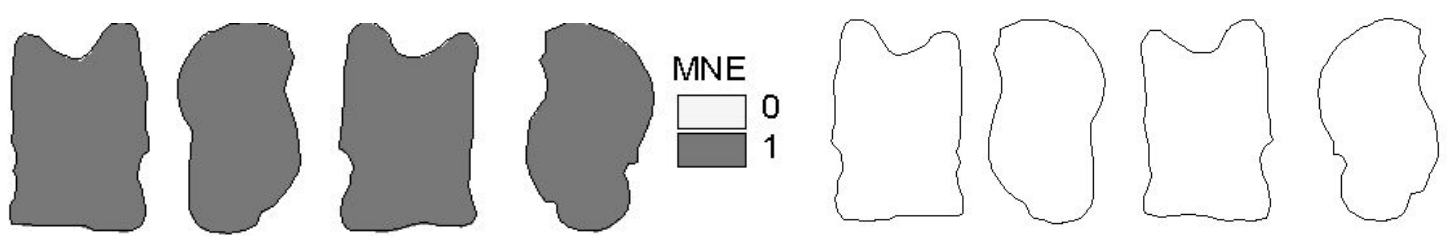

Figura 8.148. MNE Astrágalo izquierdo y derecho

Calcáneo (CL)

Se identificaron fragmentos para el lado izquierdo y el derecho. En ambos casos corresponde a la faceta de articulación entre el calcáneo y el tarso central (TRC). $\mathrm{MNE}=2$ (corresponde uno a cada lado)
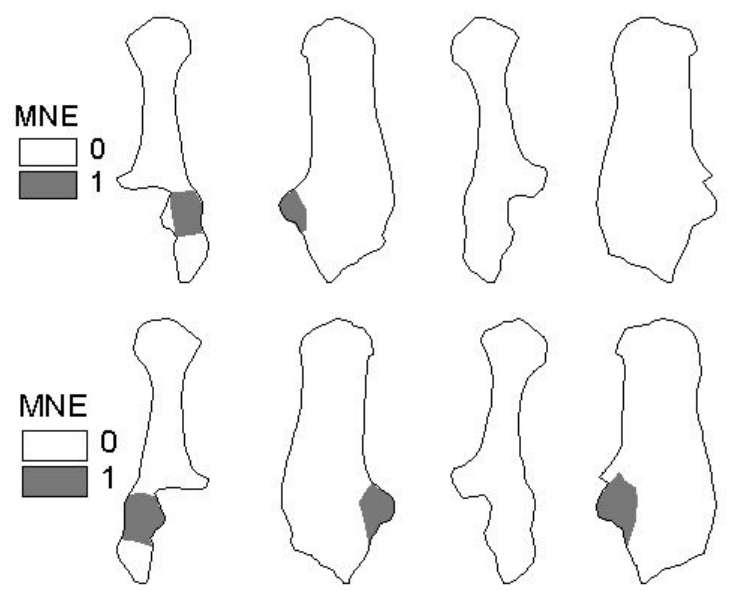

Figura 8.149. MNE Calcáneo izquierdo y derecho

Tarso cuarto (TR4) y Tarso central (TRC) 
Para ambos elementos se identificaron dos elementos completos, uno del lado izquierdo y otro del derecho. $\mathrm{MNE}=2$ para el TR4 y $\mathrm{MNE}=2$ para el TRC (en ambos corresponde uno al lado izquierdo y uno al lado derecho)

Tarso tercero (TRT)

Se identificaron 5 elementos, uno de ellos estaba fragmentado en dos especímenes. El MNE calculado es de 5 (3 izquierdos y 2 derechos)

\section{Metatarso (MT)}

Se construyó un MNE igual a 1 elemento para el lado izquierdo en base a los rasgos definidos para la porción posterior de la diáfisis. Para el elemento derecho se obtuvo un valor de MNE igual a 2 basándose en la presencia de la faceta articular entre el metacarpo y el tarso tercero y el foramen posterior de la epífisis proximal. El MNE total ascendió a 3 elementos.
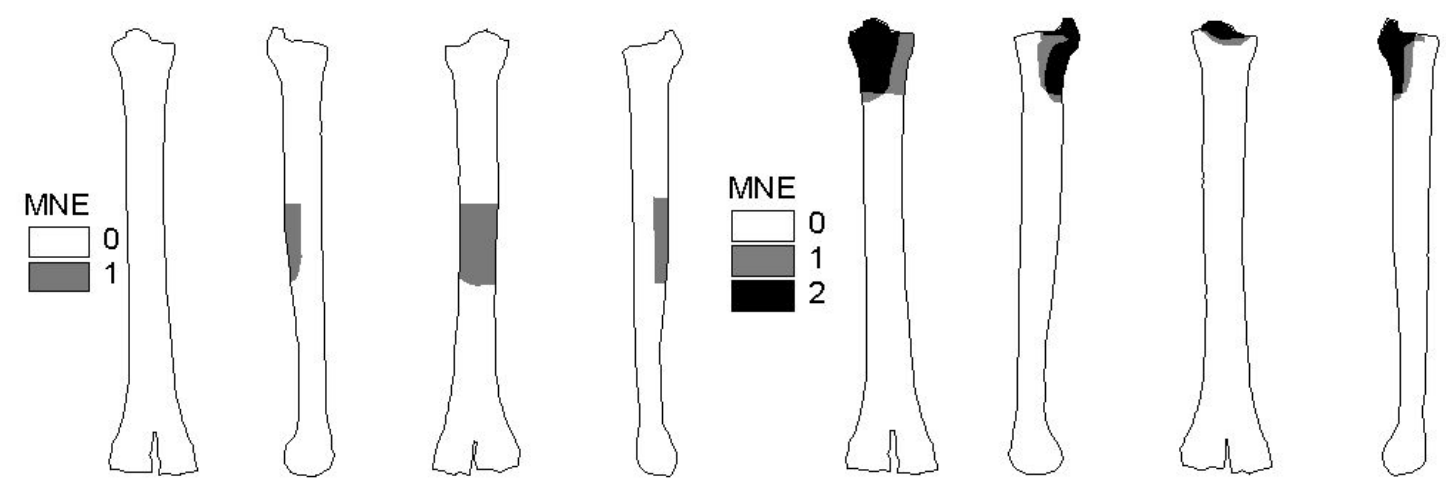

Figura 8.150. MNE Metatarso izquierdo y derecho

Metapodio (MP)

Se identificaron 4 elementos basados en la caracterización de diáfisis distales y cóndilos. $\mathrm{MNE}=4$.
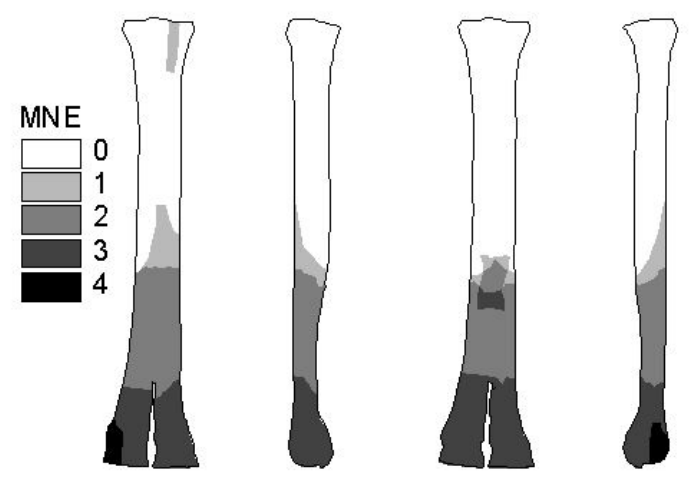

Figura 8.151. MNE Metapodio general 
Falange proximal (PHF)

Se obtuvo un MNE igual a 5 para este elemento. Zonas diagnósticas: epífisis proximal, epífisis distal y diáfisis.
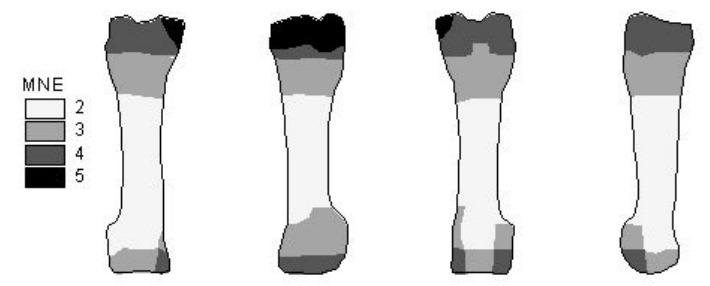

Figura 8.152 MNE Falange proximal general

Falange medial (PHS)

Sobre la base de la identificación de epífisis proximales sin fisionar y diáfisis con epífisis distales fusionadas se construyó un MNE igual a 2 elementos.

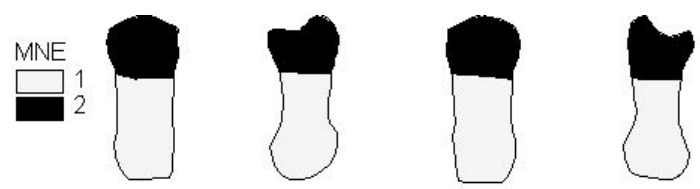

Figura 8.153. MNE Falange medial

Falange distal (PHT)

Se identificaron tres elementos completos. $\mathrm{MNE}=3$.
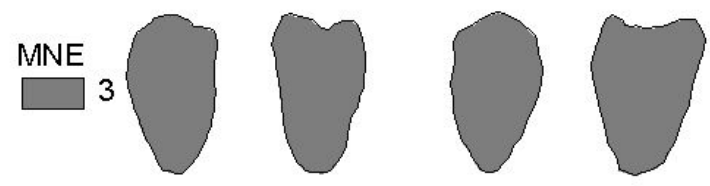

Figura 8.154. MNE Falange distal

Sesamoideos (SEP)

Se identificaron seis elementos completos. $\mathrm{MNE}=6$.

En base a los cálculos de MNE realizados precedentemente se determinaron el MNI, MAU y \%MAU para este subconjunto. Los resultados de estos índices se presentan en la Tabla 8.77. 
Tabla 8.77. Abundancia relativa de partes esqueletarias expresadas como NISP, MNE comprehensivo, MAU y \%MAU.

\begin{tabular}{|c|c|c|c|c|c|c|c|c|}
\hline Elemento & NISP & I & $\mathrm{D}$ & $\mathrm{S} / \mathrm{D}$ & MNE & MNI & MAU & $\% \mathrm{MAU}$ \\
\hline CRN & 1 & - & - & 1 & 1 & 1 & 1.00 & 40.00 \\
\hline IC & 5 & - & - & 4 & 4 & 1 & 0.67 & 26.67 \\
\hline CAN & 2 & - & 1 & 1 & 2 & 1 & 0.33 & 13.33 \\
\hline MMR & 2 & 2 & - & - & 2 & 1 & 0.33 & 13.33 \\
\hline PMR & 1 & 1 & - & - & 1 & 1 & 0.50 & 20.00 \\
\hline MMX & 1 & 1 & - & - & 1 & 1 & 0.17 & 6.67 \\
\hline MUN & 12 & - & - & 2 & 2 & 1 & 0.17 & 6.67 \\
\hline MR & 39 & - & - & 2 & 2 & 2 & 2.00 & 80.00 \\
\hline HY & 1 & - & - & 1 & 1 & 1 & 1.00 & 40.00 \\
\hline HM & 6 & 2 & 1 & - & 3 & 2 & 1.50 & 60.00 \\
\hline RDU & 8 & 3 & 1 & - & 4 & 3 & 2.00 & 80.00 \\
\hline $\mathrm{CPF}$ & 1 & - & 1 & - & 1 & 1 & 0.50 & 20.00 \\
\hline CPR & 1 & 1 & - & - & 1 & 1 & 0.50 & 20.00 \\
\hline CPS & 1 & - & 1 & - & 1 & 1 & 0.50 & 20.00 \\
\hline CPT & 3 & 2 & - & - & 2 & 2 & 1.00 & 40.00 \\
\hline CPU & 3 & 2 & 1 & - & 3 & 2 & 1.50 & 60.00 \\
\hline $\mathrm{MC}$ & 4 & - & 3 & - & 3 & 3 & 1.50 & 60.00 \\
\hline IM & 2 & - & 1 & - & 1 & 1 & 0.50 & 20.00 \\
\hline FM & 2 & 1 & 1 & - & 2 & 1 & 1.00 & 40.00 \\
\hline TA & 1 & - & 1 & - & 1 & 1 & 0.50 & 20.00 \\
\hline AS & 1 & 1 & - & - & 1 & 1 & 0.50 & 20.00 \\
\hline CL & 2 & 1 & 1 & - & 2 & 1 & 1.00 & 40.00 \\
\hline TR4 & 2 & 1 & 1 & - & 2 & 1 & 1.00 & 40.00 \\
\hline TRC & 2 & 1 & 1 & - & 2 & 1 & 1.00 & 40.00 \\
\hline TRT & 6 & 3 & 2 & - & 5 & 3 & 2.50 & 100.00 \\
\hline MT & 3 & 1 & 2 & - & 3 & 2 & 1.50 & 60.00 \\
\hline MP & 7 & - & - & 4 & 4 & 1 & 1.00 & 40.00 \\
\hline PHF & 7 & - & - & 5 & 5 & 1 & 0.63 & 25.00 \\
\hline PHS & 2 & - & - & 2 & 2 & 1 & 0.25 & 10.00 \\
\hline PHT & 3 & - & - & 3 & 3 & 1 & 0.38 & 15.00 \\
\hline SEP & 6 & - & - & 6 & 6 & 1 & 0.75 & 30.00 \\
\hline Total general & 137 & & & & & & & \\
\hline
\end{tabular}

\subsubsection{1.c. Número Mínimo de Individuos (MNI)}

Sobre la base de la radioulna izquierda, el metacarpo derecho y el tarso tercero izquierdo se calculó un MNI igual a tres individuos adultos. Dos de ellos corresponden a los determinados como llama y guanaco según el resultado de la aplicación de técnicas estadísticas multivariadas a partir de datos osteométricos.

\subsubsection{1.d. Unidades anatómicas representadas (MAU)}

Para el esqueleto axial las unidades anatómicas representadas corresponden al cráneo, la mandíbula y el hioides, todos elementos que conforman la cabeza. Los 
elementos de la columna vertebral están ausentes del conjunto. Para el esqueleto apendicular, están representados casi todos los elementos. Para la pata delantera se puede observar que la porción proximal esta más representada que la distal y que la frecuencia de elementos del carpo, si bien es alta, no es la que predomina en este conjunto (Figura 8.155). Para el miembro posterior los elementos del tarso, al contrario de su contraparte del miembro anterior, están más representados que el resto de los elementos.

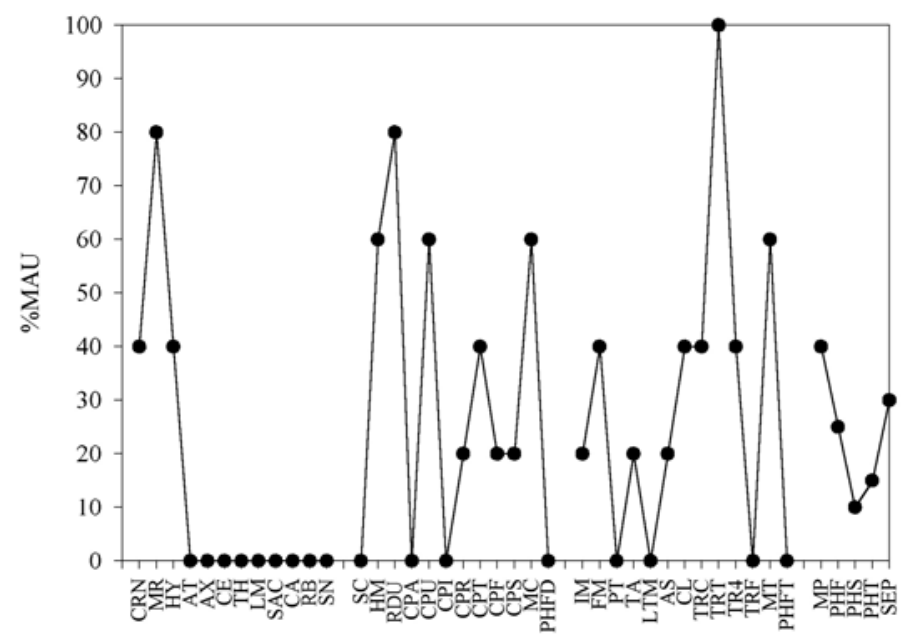

Figura 8.155. Abundancia relativa de elementos esqueletarios.

Esta misma relación se pude observar al comparar el comportamiento de las unidades anatómicas representadas en relación al índice de utilidad de carne y el volumen de la cavidad medular.

Para el primer caso y respecto de los elementos "no largos" se observa que solo están representados los elementos de la cabeza, los que en términos de rendimiento económico serían los de menor valor dentro de este conjunto. Esto queda claro al ver el valor de rho de Spearman obtenido mediante la correlación $r_{s}-.5891$ p.037 (significativa estadísticamente $\mathrm{p}<.05)$. Para los "huesos largos" la correlación arrojó un valor de $r_{s}$ .6375 p.087, lo que significa que se ha preservado en mayor medida aquellas partes que tienen menor utilidad económica en términos del índice de carne. Este resultado se vuelve a repetir para la relación del \%MAU y el volumen de la cavidad medular $r_{s}$ .3143 p.272. 
Estos resultados nos llevan a plantear que en este conjunto hay una representación alta de elementos de bajo rendimiento respecto de los elementos de mayor utilidad económica.
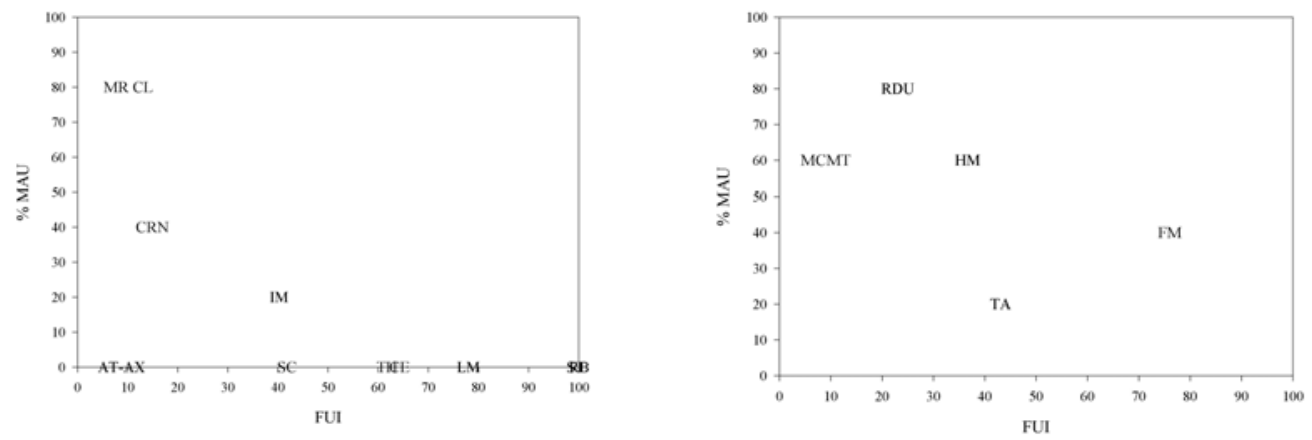

a

$\mathrm{b}$

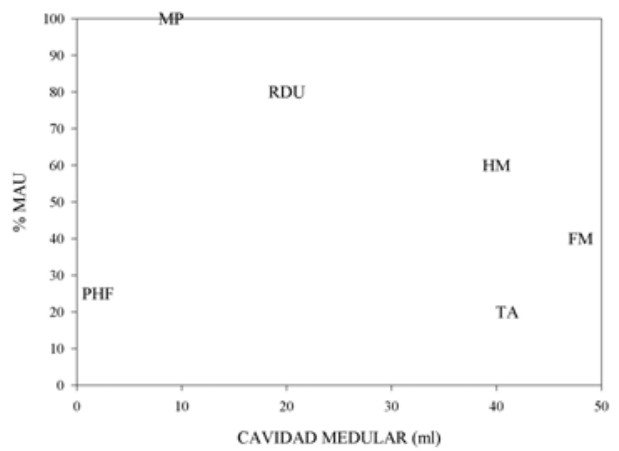

C

Figura 8.156. a) Relación \%MAU VS FUI huesos "no-largos"; b) Relación \%MAU VS FUI huesos "largos”; c) Relación \%MAU VS Cavidad Medular.

\subsubsection{1.e. Fragmentación del subconjunto}

La fragmentación global del conjunto presenta algunas diferencias con lo se venía advirtiendo hasta el momento en las distintas muestras de camélidos y de tamaño corporal 4 en general. Por lo que se observa existe una gran frecuencia de especímenes presentes en el módulo 50-60 mm y elementos completos. Los demás módulos están representados en frecuencias similares aunque se mantiene la mayor proporción de elementos menores a los $50 \mathrm{~mm}$ en relación a los mayores a $60 \mathrm{~mm}$. 


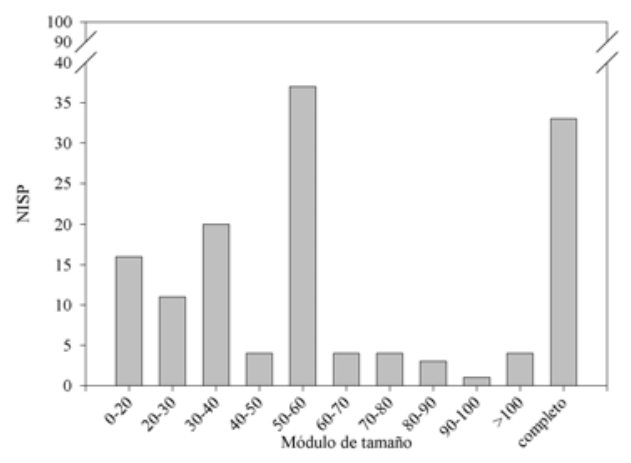

Figura 8.157. Módulos de tamaño expresado en NISP para especímenes y elementos del subconjunto adulto de camélidos

\section{Esqueleto axial}

En cuanto a los tamaños relativos de las superficies preservadas para los elementos del esqueleto axial se puede observar en la Figura 8.158 que para el cráneo los valores obtenidos no superan el 2\% (largo máximo $15 \mathrm{~mm}$ ), para la mandíbula varían entre el 2\% y el 10\% (30-69 mm) y para el hioideo alrededor del 35\% (36 mm)

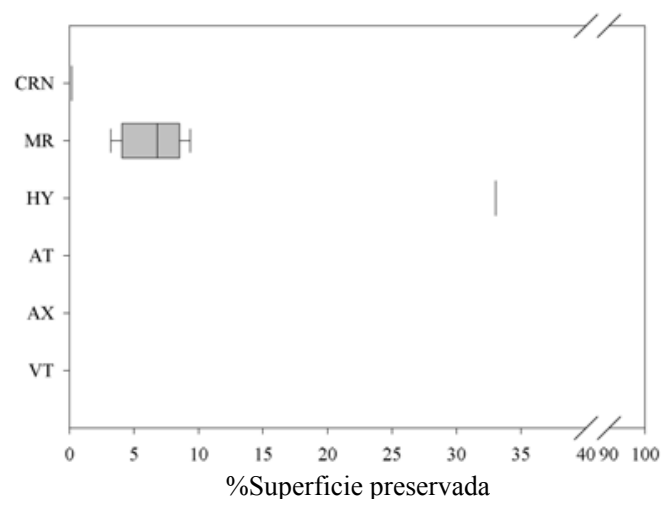

Figura 8.158. Fragmentación de elementos del esqueleto axial.

Esqueleto apendicular delantero

Para esta parte esqueletal se observa el perfil de fragmentación que se detalla a continuación.

Para el lado izquierdo el húmero presenta superficies cuyos tamaños van desde el 3,29\% al 13,49\% (49-71 mm). En tanto para la radioulna la superficie conservada varía entre el 2,77\% y el 25,74\% (20-104 mm). Los carpianos se preservaron completos. 
Por otra parte, en el caso del lado derecho el húmero presenta valores comprendidos entre el 1,63\% y el 31,98\% (34-111 mm). Para el Radioulna, por su parte, se calculó una superficie preservada que varía entre 2,93\% y 38,14\% (43-124 mm). Los carpianos de este miembro también se hallaron completos. Por último para el metacarpo se calculó un área que varía entre $1,74 \%$ y 25,27\% (31-89 mm)
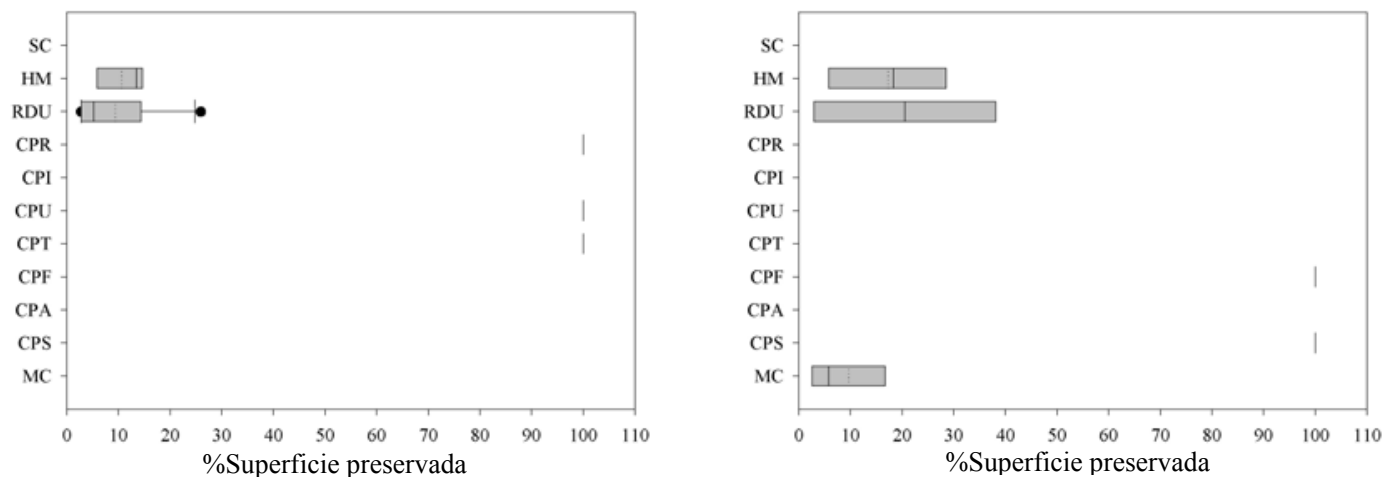

Figura 8.159. Fragmentación esqueleto apendicular delantero (izquierdo y derecho)

\section{Esqueleto apendicular trasero}

Para el lado izquierdo, el fémur presenta una preservación del 23,28\% con un largo máximo del espécimen de $127 \mathrm{~mm}$; el calcáneo a su vez presenta un 3,23\% (26 $\mathrm{mm})$ y el metatarso un 7,33\% (53 $\mathrm{mm})$.

En el lado derecho ninguno de los elementos supera el 11\% de la superficie preservada. En términos de largo máximo de los elementos para el fémur es de $20 \mathrm{~mm}$, para la tibia $56 \mathrm{~mm}$, para el calcáneo $25 \mathrm{~mm}$ y para el metatarso $53 \mathrm{~mm}$. En cuanto a los tarsianos se los halló completos en todos los casos.
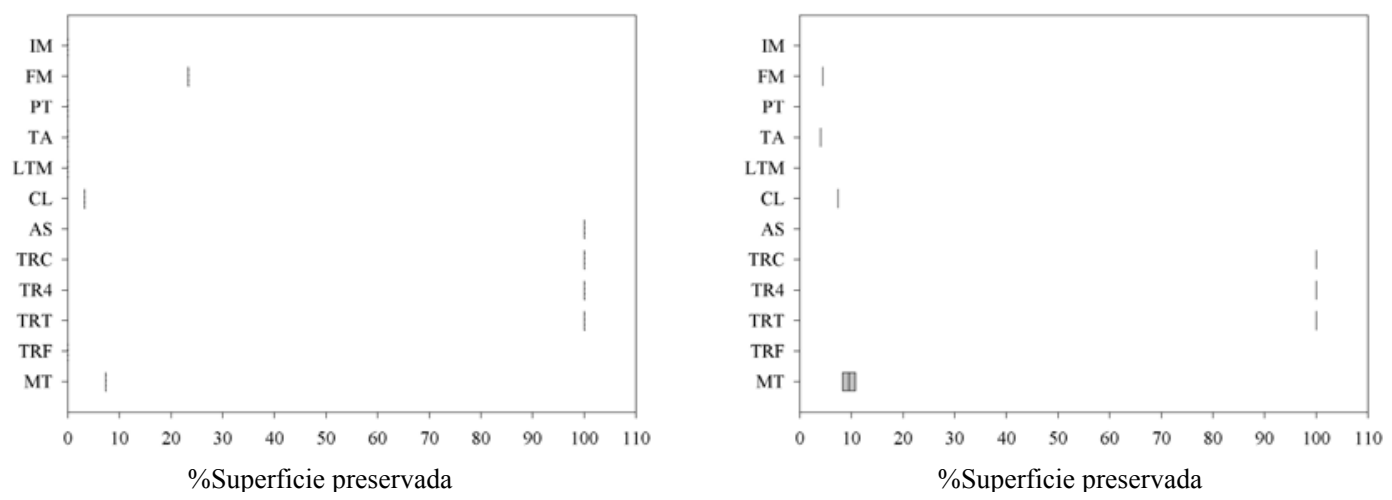

Figura 8.160. Fragmentación esqueleto apendicular trasero (izquierdo y derecho) 
Respecto al estado de los huesos al producirse la fractura se observa que se registró en mayor frecuencia la presencia de especímenes con fractura tipo fresco.

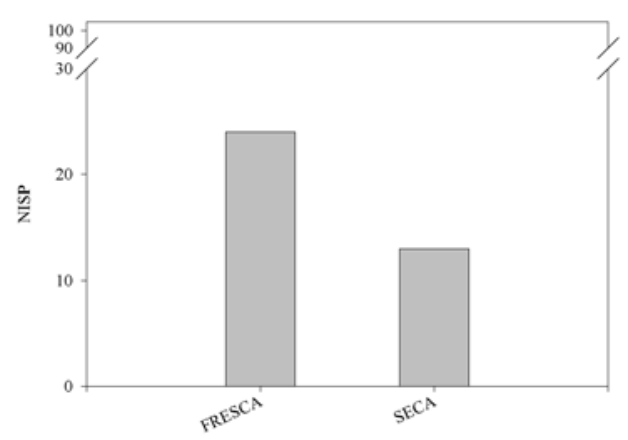

Figura 8.161. Cantidad (NISP) de especímenes y elementos del subconjunto adulto de camélidos según tipo de fractura.

\subsubsection{1.f. Utilización de las carcasas}

Se registraron en el conjunto distintos tipos de marcas que fueron asignadas a acción de origen antrópico. Para el esqueleto axial se identificaron marcas de corte en un espécimen de hioideo. El resto de las marcas se observaron en los elementos correspondientes al elemento anterior. Sobre estos se identificaron un fragmento de húmero con marcas de aserrado, otro fragmento de húmero con presencia de marcas de corte y de impacto. El resto de los elementos (RDU y MC) presentan marcas de impacto en las porciones proximales y las diáfisis.

Tabla 8.78. Marcas en hueso de camélidos adultos expresado en NISP

\begin{tabular}{cccccc}
\hline Elemento & Porción & Aserrado & Marcas de corte & Impactos & Total general \\
HY & BL & - & 1 & - & 1 \\
HM & DF & 1 & - & - & 1 \\
HM & DSS & - & 1 & 1 & 2 \\
RDU & FK & - & - & 1 & 1 \\
MC & FK & - & - & 1 & 1 \\
MC & PRS & - & - & 1 & 1 \\
Total general & & 1 & 2 & 4 & 7 \\
\hline
\end{tabular}

\subsubsection{1.g. Termoalteraciones}

La mayor frecuencia fue observada en los elementos que no presentan alteración térmica. Dentro de los que muestran rasgos asignables a alteración térmica se pudo advertir que estos se asocian con las categorías 1 y 4 las que se forman en temperaturas 
relativamente bajas. La categoría 2 presenta elementos pertenecientes a la porción distal del miembro trasero (AS, PHF, CL, TRT)

Tabla 8.79. Termoalteración del conjunto de camélidos adultos.

\begin{tabular}{cccccc}
\hline Descripción & Sin alteración & $\begin{array}{c}\text { Oxidación } \\
\text { incompleta/carbonización } \\
\text { marrón claro-negro } \\
\text { (moteado) }\end{array}$ & Carbonizado & Calcinado & \\
Color & - & $200{ }^{\circ} \mathrm{C}-300^{\circ} \mathrm{C}$ & $300{ }^{\circ} \mathrm{C}$ & $>500{ }^{\circ} \mathrm{C}$ & \\
Temperatura & $<200{ }^{\circ} \mathrm{C}$ & 1 & 13 & 5 & 137 \\
NISP & 118 & & gris-blanco & \\
\hline
\end{tabular}

Respecto de la relación tipo de fractura (estado en el cual se conformó) y tipo de alteración térmica se observa en la Tabla 8.80 que el tipo fresco solo se asocia con los no alterados y la mayor parte de los que tiene fractura seca si están asociados a alteración térmica.

Tabla 8.80. Relación entre tipo de termoalteración y tipo de fractura del conjunto de camélidos adultos.

\begin{tabular}{lccr}
\hline \multicolumn{1}{c}{ Tipo de alteración } & Fresca & Seca & Total \\
Sin alteración & 24 & 5 & 29 \\
Oxidación incompleta & - & 1 & 5 \\
Carbonizado & - & 6 & 7 \\
Calcinado & - & 1 & 3 \\
$\quad$ Total & 24 & 13 & 37 \\
\hline
\end{tabular}

\subsubsection{Camélidos subadultos}

\subsubsection{2.a. Supervivencia del material óseo mediada por la densidad ósea}

Se puede observar para este conjunto la presencia de una sola correlación positiva y cinco correlaciones negativas. Estos resultados no permiten apreciar que el conjunto ha conservado en general zonas diagnósticas con valores de densidad ósea relativamente bajos. Este patrón quizás se este dando por la imposibilidad en la mayoría de los casos de identificar zonas con densidades más altas correspondientes en general a la diáfisis de los huesos largos. No obstante ello y teniendo en cuenta características como la meteorización, la baja frecuencia de acción de carnívoros y roedores y la buena conservación observada en el conjunto, la cual se dedujo de la baja incidencia de la densidad ósea, es que creemos que esta no habría sido uno de los factores principales en la conformación de este conjunto. 
Tabla 8.81. \%MAU vs. VD.

\begin{tabular}{lccc}
\hline Elemento & Rank & $r_{s}$ & $p$ \\
Mandíbula & 8 &,- 577 &, 067 \\
Húmero & 5 &,- 707 &, 091 \\
Radioulna & 6 &, 207 &, 347 \\
Metacarpo & 4 &,- 258 &, 371 \\
Tibia & 5 &,- 707 &, 091 \\
Arqueofauna & 29 &,- 017 &, 437 \\
\hline
\end{tabular}

8.7.1.2.b. Número Mínimo de Elementos (MNE)

Mandibula (MR)

En base a la identificación de la sínfisis se pudo calcular un $\mathrm{MNE}=1$.

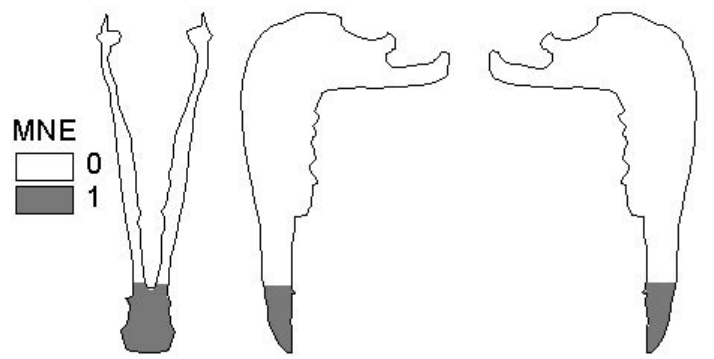

Figura 8.162. MNE Mandíbula

Húmero (HM)

Se identificó la cabeza de un húmero izquierdo $(\mathrm{MNE}=1)$.
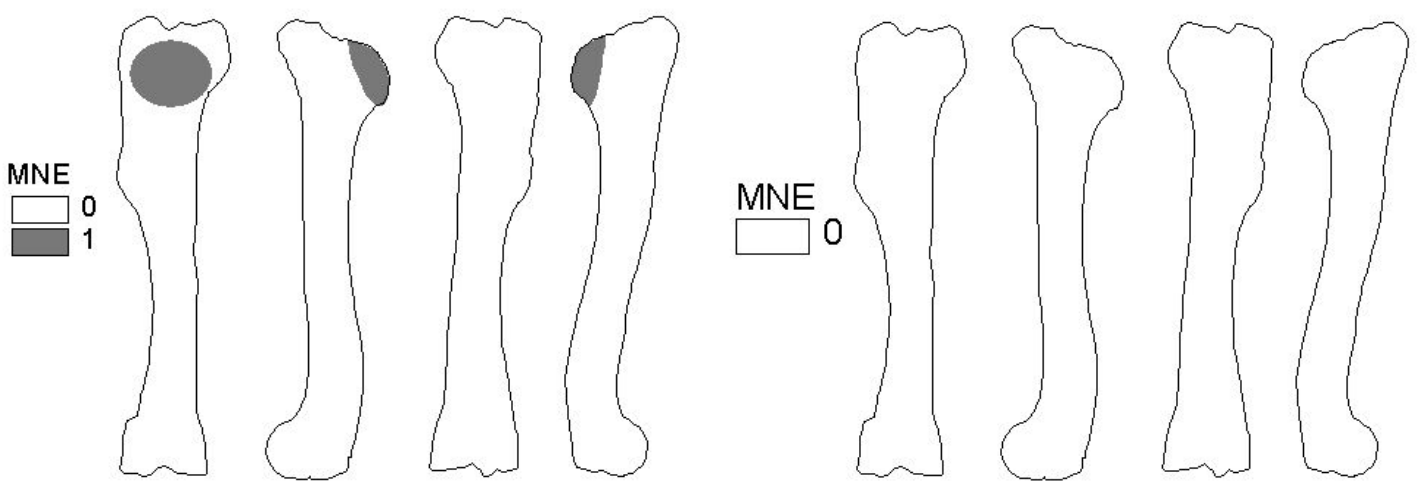

Figura 8.163. MNE Húmero izquierdo y derecho

Radioulna (RDU)

Como en los elementos anteriores solo un espécimen fue asignado al elemento izquierdo $(\mathrm{MNI}=1)$ 

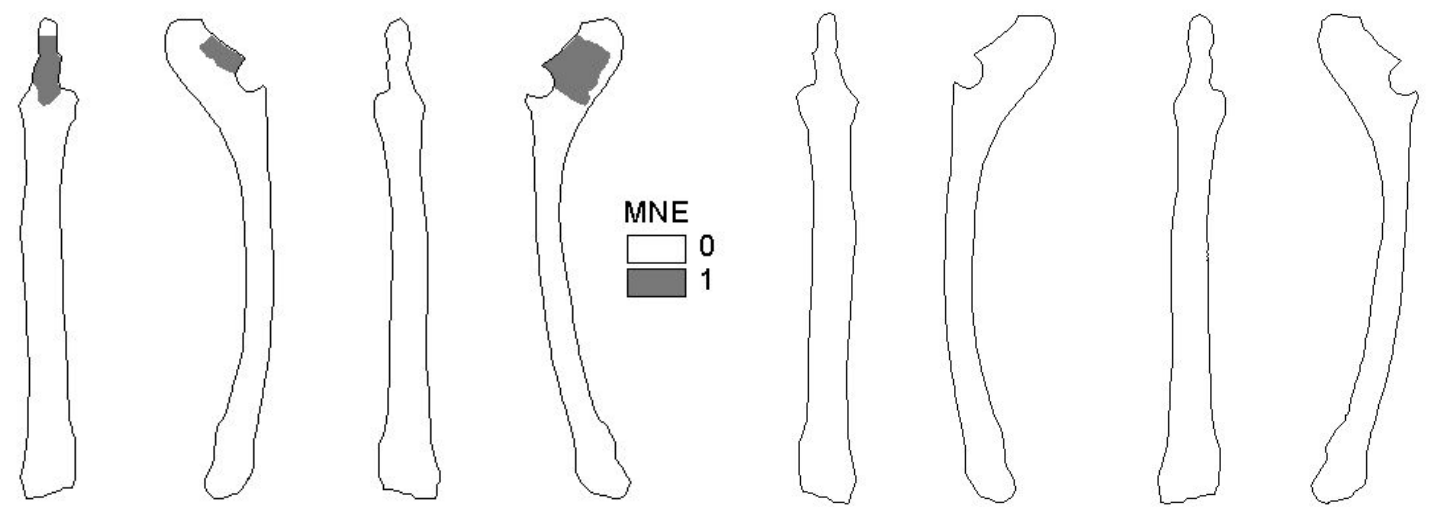

Figura 8.164. MNE Radioulna izquierda y derecha

\section{Metacarpo (MC)}

De este elemento se realizó la identificación de las siguientes zonas diagnósticas: segmento distal de la diáfisis, y porción craneal del elemento completo. Sobre estos especímenes asignados al lado izquierdo se calculó un MNE=2.
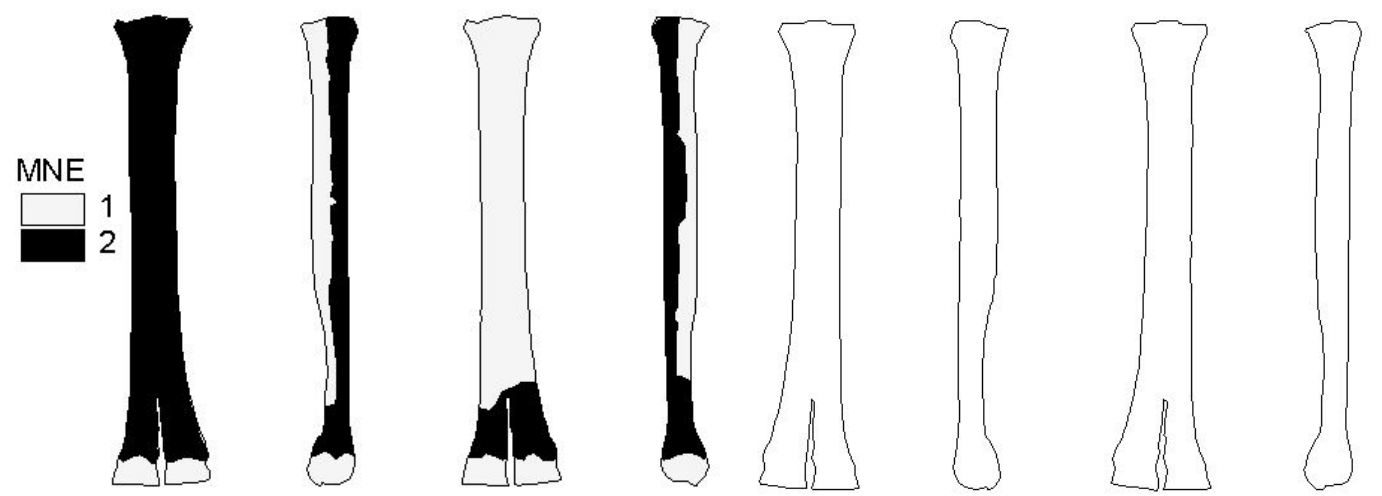

Figura 8.165. MNE Metacarpo izquierdo y derecho

Tibia (TA)

Se pudo identificar un fragmento de epífisis proximal del elemento izquierdo. $\mathrm{MNE}=1$
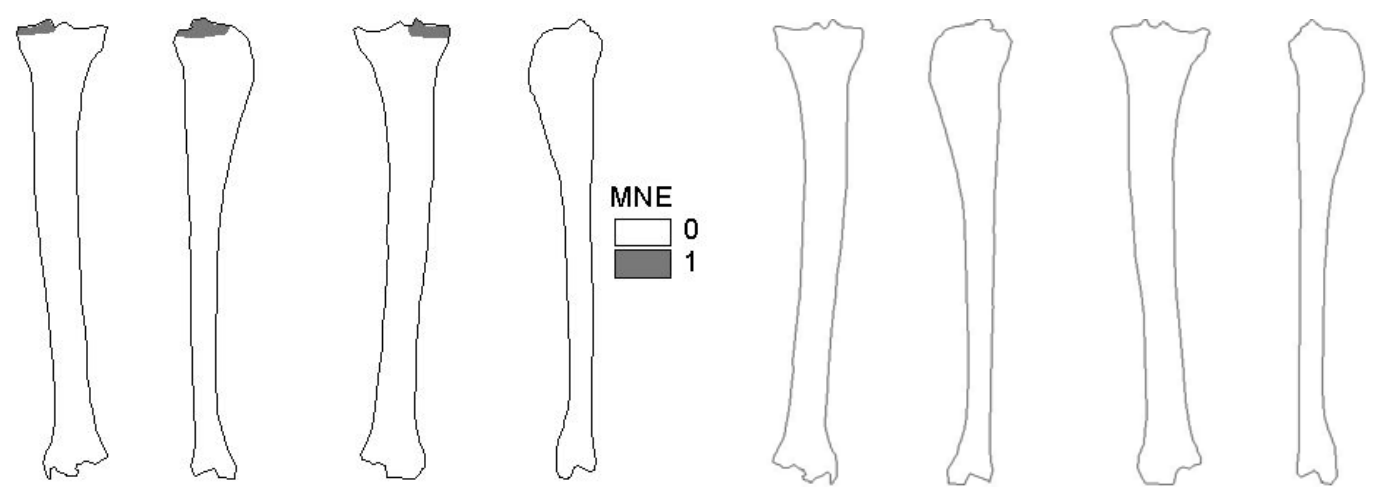

Figura 8.166. MNE Tibia izquierda y derecha 
Metapodio (MP)

Sobre la presencia de un cóndilo sin fusionar se contabilizó un MNE=1.
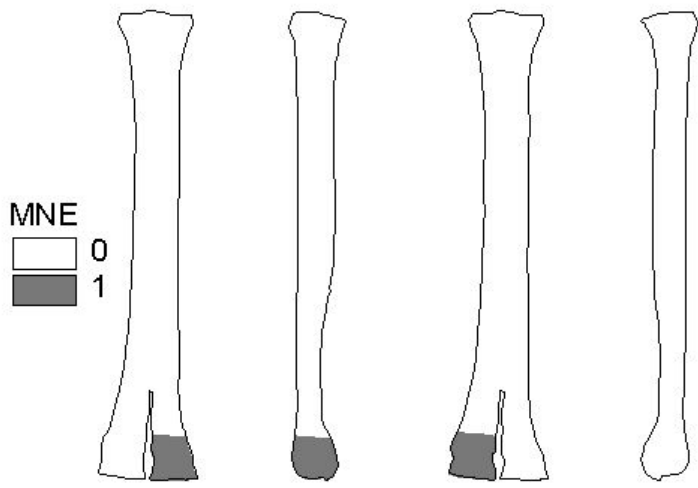

Figura 8.167. MNE Metatarso izquierdo y derecho

Falange proximal (PHF)

Se identificaron tres elementos en base a la epífisis proximal $(\mathrm{MNE}=3)$
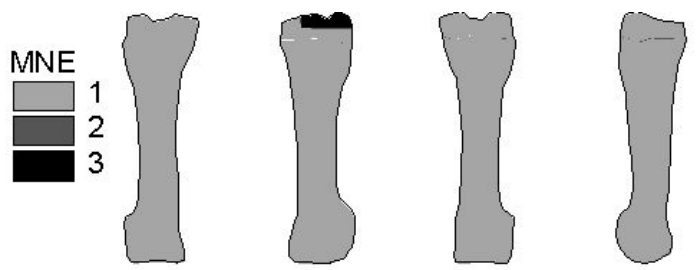

Figura 8.168. MNE Falange proximal general

Falange medial (PHS)

En este caso tres elementos fueron determinados en base a la epífisis proximal $(\mathrm{MNE}=3)$
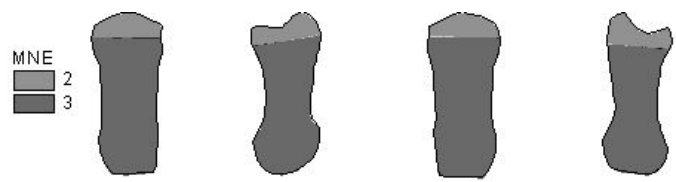

Figura 8.169. MNE Falange medial

A continuación se resumen los resultados obtenidos para el MNE. Asimismo se presentan los valores obtenidos para el MNI, MAU y \%MAU. 
Tabla 8.82. Abundancia relativa de partes esqueletarias expresadas como NISP, MNE comprehensivo, MAU y \%MAU.

\begin{tabular}{cccccccrr}
\hline Elemento & NISP & I & D & S/D & MNE & MNI & MAU & \%MAU \\
MR & 1 & - & - & 1 & 1 & 1 & 1.00 & 100.00 \\
HM & 1 & 1 & - & - & 1 & 1 & 0.50 & 50.00 \\
RDU & 1 & 1 & - & - & 1 & 1 & 0.50 & 50.00 \\
MC & 2 & 2 & - & 2 & 2 & 2 & 1.00 & 100.00 \\
TA & 1 & 1 & - & - & 1 & 1 & 0.50 & 50.00 \\
MP & 1 & - & - & 1 & 1 & 1 & 0.25 & 25.00 \\
PHF & 4 & - & - & 3 & 3 & 1 & 0.12 & 12.50 \\
PHS & 5 & - & - & 3 & 3 & 1 & 0.12 & 12.50 \\
Total general & 16 & & & & & & \\
\hline \multicolumn{7}{c}{$\mathrm{D}=$ derecho, I = izquierdo, S/D = axial o sin datos }
\end{tabular}

\subsubsection{2.c. Número Mínimo de Individuos (MNI)}

El número mínimo de individuos calculado para este conjunto es de dos individuos. Este número es resultado de la presencia de dos metacarpos izquierdos. El resto de los elementos solo permite identificar un solo individuo.

Uno de los individuos correspondería a una vicuña. La identificación se habría basado en la presencia de incisivos con características asignables a esta especie en un fragmento de mandíbula juvenil.

\subsubsection{2.d. Unidades anatómicas representadas (MAU)}

Si bien el conjunto es pequeño se observa que están representadas todas la partes esqueletales básicas. La mandíbula y el metacarpo son los que están más representados dentro de este conjunto.

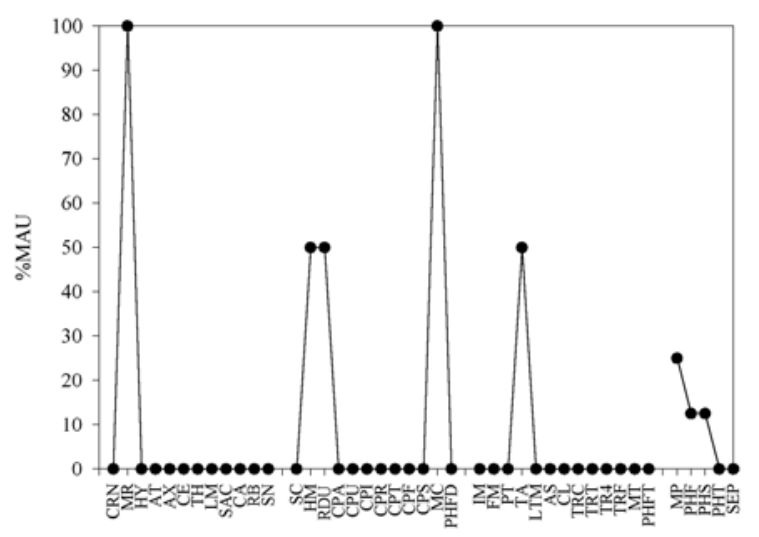

Figura 8.170. Abundancia relativa de elementos esqueletarios. 


\subsubsection{2.e. Fragmentación del subconjunto}

Como se puede observar en la Figura 8.171.a el conjunto presenta una casi exclusividad de fragmentos menores a los $60 \mathrm{~mm}$. Un solo fragmento supero los 100 $\mathrm{mm}$ y un solo hueso se halló completo. Respecto del tipo de fractura (según su estado) únicamente se pudieron identificar del tipo fresca.

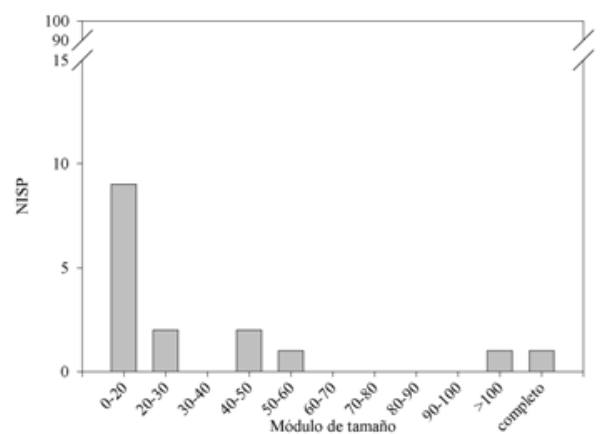

a

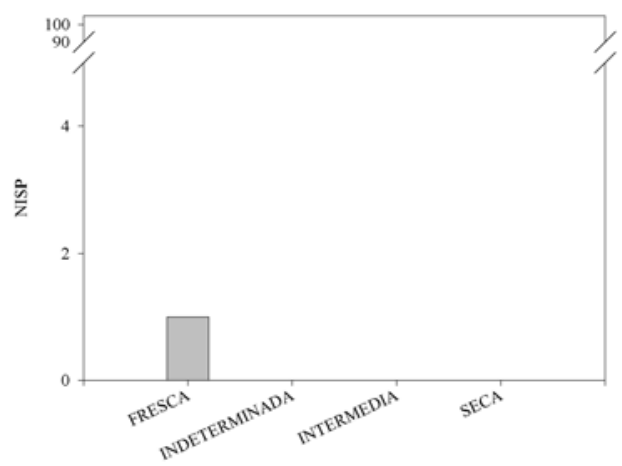

Figura 8.171.a) Módulos de tamaño expresado en NISP para especímenes y elementos del subconjunto subadulto de camélidos, b) Cantidad (NISP) de especímenes y elementos del subconjunto subadulto de camélidos según tipo de fractura.

\subsubsection{2.f. Utilización de las carcasas}

En uno de los metacarpos se identificó un impacto ubicado en la diáfisis.

Tabla 8.83. Marcas en hueso de camélidos subadultos expresado en NISP

\begin{tabular}{ccrr}
\hline Elemento & Porción & Impacto & NISP \\
MC & CO & 1 & 1 \\
Total & & & 1 \\
\hline
\end{tabular}

\subsubsection{2.g. Termoalteraciones}

Solo cuatro especímenes presentaron signos de carbonización (Tipo de alteración 1). Estos corresponden a la cabeza del húmero, dos especímenes de dos falanges proximales distintas y un fragmento de falange medial.

Tabla 8.84. Termoalteración del conjunto de camélidos subadultos.

\begin{tabular}{|c|c|c|c|c|c|}
\hline Descripción & Sin alteración & Oxidación & Carbonizado & Calcinado & \\
\hline & & incompleta/carbonización & & & \\
\hline Color & - & marrón claro-negro (moteado) & negro & gris-blanco & \\
\hline Temperatura & $<200{ }^{\circ} \mathrm{C}$ & $200{ }^{\circ} \mathrm{C}-300{ }^{\circ} \mathrm{C}$ & $300{ }^{\circ} \mathrm{C}$ & $>500{ }^{\circ} \mathrm{C}$ & \\
\hline NISP & 12 & - & 4 & - & 16 \\
\hline
\end{tabular}


Respecto del tipo de alteración relacionado con el tipo de fractura se registró un solo espécimen con fractura fresca y sin signos de acción de calor

\subsubsection{Subconjunto no camélido}

Este subconjunto está representado por siete taxones que representan todas las clases de tamaño corporal definidos. Sobre este grupo se harán consideraciones acerca de la presencia de marcas, la relación con signos de alteración por calor y patrón de fragmentación.

\subsubsection{Marcas de procesamiento}

Se identificaron distintos tipos de marcas en el conjunto. Estos corresponden a signos de machacado, aserrado e impacto. También fueron identificadas sobre una tibia de ave de tamaño corporal 2 marcas que posiblemente hayan sido realizada por acción antrópica pero que no ha podido ser identificada con certeza. Sobre un fragmento de mandíbula de carnívoro se identificaron signos de aserrado. Por último y sobre fragmentos de hueso largo y costillas asignadas a artiodáctilos se identificaron marcas de impactos. Por lo anteriormente nombrado se aprecia en este conjunto un número de marcas que permiten identificar tanto huellas asociadas con el procesamiento primario o secundario así como con el uso de elementos óseos de especies distintas a los camélidos para la posible manufactura de artefactos o adornos.

Tabla 8.85. Marcas en huesos del conjunto no camélido expresado en NISP.

\begin{tabular}{ccccccccr}
\hline Taxón & T. & Elemento & Porción & Marcas & Machacado & Aserrado & Impacto & Total \\
BD & 2 & TA & DSH & 1 & - & - & - & 1 \\
CN & 2 & MR & PRS & - & - & 1 & - & 1 \\
UL & 4 & LB & FK & - & 1 & - & 1 & 2 \\
UL & 4 & RB & BL & - & - & - & 1 & 1 \\
Total & & & & 1 & 1 & 1 & 2 & 5 \\
\hline
\end{tabular}

\subsubsection{Termoalteración}

Especímenes con este tipo de atributos se han hallado en restos de cuatro taxones distintos. Lagidium sp, Chaetophractus vellerosus y Rodentia presentan alteraciones asociadas a los tipos 1 y 4 que son los que se habrían producido a menor temperatura. Para artiodáctilos de tamaño corporal 4 se identificaron los mismos tipos que para los taxones anteriores y se le agrega el tipo 2 (el de mayor temperatura). En todos los casos 
los elementos sin alteración térmica o con valores bajos son los que se presentan en mayor frecuencia.

Dentro de los especímenes "no identificable"s a nivel taxonómico también se registró la presencia de signos de alteración por calor, correspondiendo a las categorías 1 y 2 .

Tabla 8.86. Termoalteración del conjunto de no camélido.

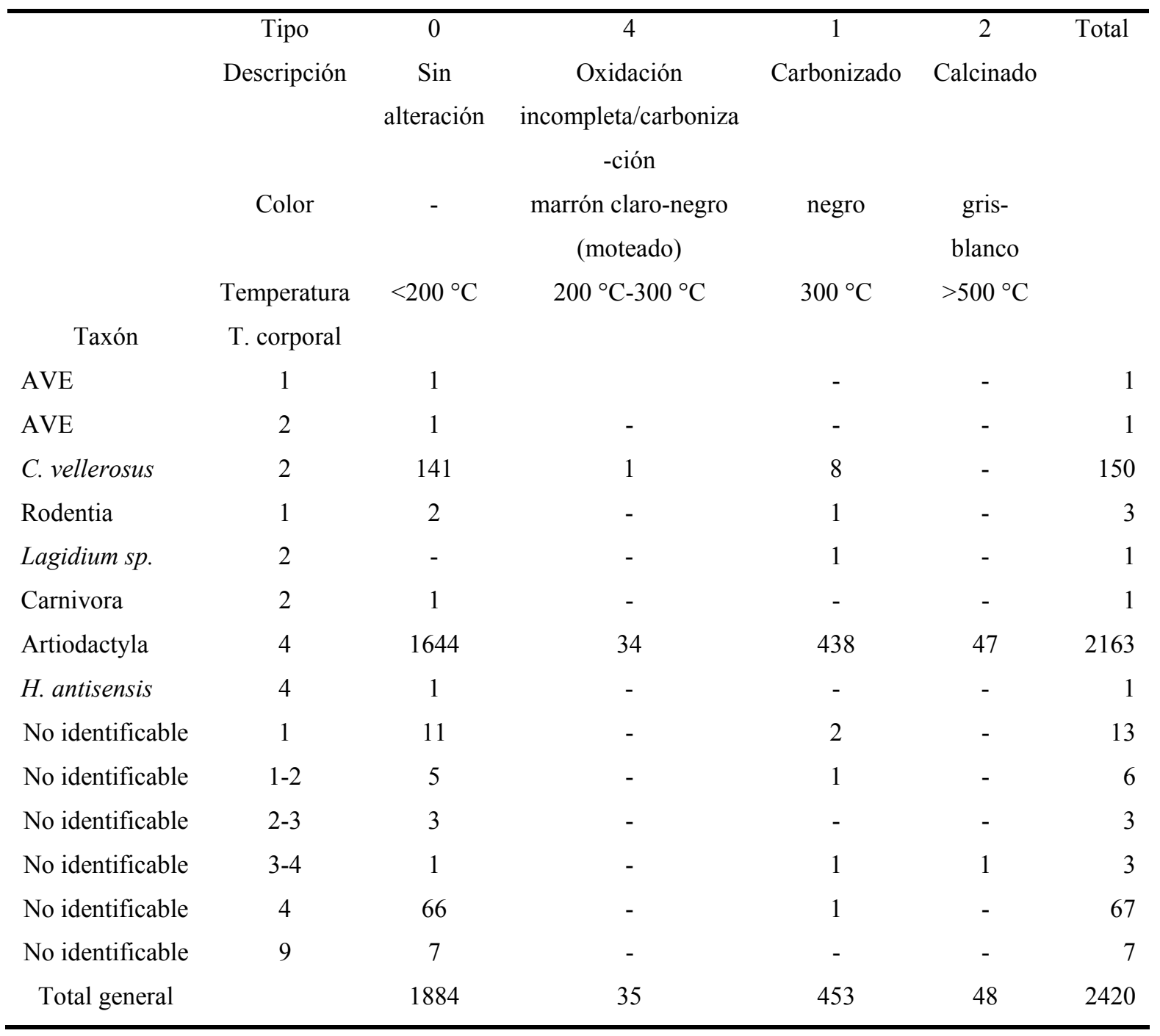

\subsubsection{Fragmentación del conjunto no camélido}

Por último, y en cuanto a la fragmentación del conjunto se observa que tanto en el tamaño corporal 1 como en el 2 la presencia de elementos completos es alta. En cuanto al tamaño corporal 4, éste presenta la misma disposición hallada para la mayoría de los conjuntos de este tamaño corporal, presentando una alta frecuencia de especímenes con tamaños pequeños y pocos con tamaños superiores a los $60 \mathrm{~mm}$. 


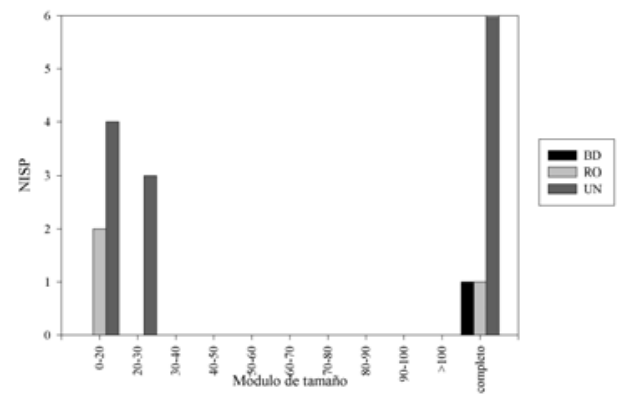

a

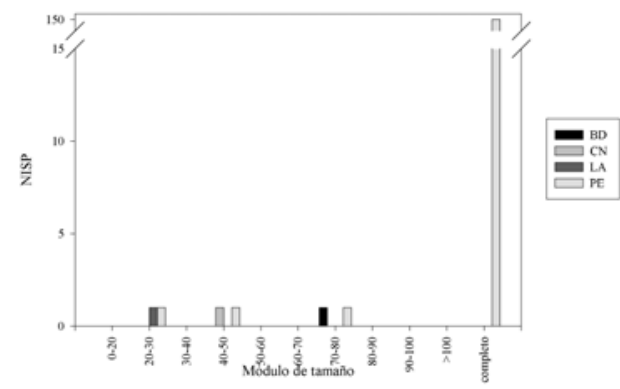

b

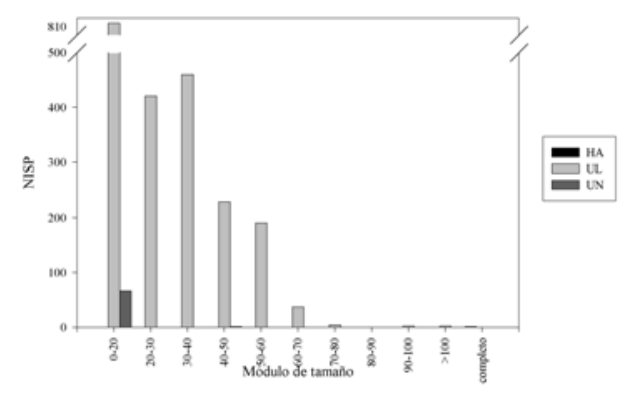

c

Figura 8.172. Fragmentación del conjunto no camélido expresado en NSP. a) Tamaño corporal 1, b) Tamaño corporal 2 y c) Tamaño corporal 4. 


\subsection{Bañado Viejo - Análisis faunístico}

Este sitio posee en la actualidad dos cuadrículas abiertas. De una de ellas (Cuadrícula 1) se han producido dos informes que dan cuenta de la composición faunística del sitio (Izeta y Scattolin 2001, Scattolin et al. 2001) En la presente tesis solo se trabajará con los datos de esta cuadrícula ya que la Cuadrícula 2 no ha sido excavada en toda su profundidad con lo cual la secuencia está incompleta.

\subsubsection{Composición de la muestra.}

La muestra está compuesta por 1527 huesos completos o fragmentos, de los cuales fueron identificados el 53,56\%. En la Tabla 9.1 se presenta el resultado de esta determinación según su correspondencia a alguno de los seis depósitos definidos para el sitio (Izeta y Scattolin 2001, Scattolin et al 2001)

Tabla 9.1. Composición de la muestra. Bañado Viejo.

\begin{tabular}{lcccccccr}
\hline \multicolumn{1}{c}{ Taxón } & T. corporal & I & II & III & IV & V & VI & Total general \\
Gastropoda & 9 & 2 & 3 & 2 & - & - & - & 7 \\
AVES & 1 & - & 1 & - & 1 & - & - & 2 \\
AVES & 2 & - & - & 1 & 1 & - & - & 2 \\
AVES & 3 & - & 1 & - & - & - & - & 1 \\
C. vellerosus & 2 & 2 & 4 & 5 & 4 & - & 1 & 16 \\
Rodentia & 1 & - & 3 & - & - & - & - & 3 \\
Rodentia & 2 & 27 & 23 & 1 & 10 & - & - & 61 \\
Canidae & 2 & - & 1 & - & - & - & - & 1 \\
Artiodactyla & 4 & 5 & 141 & 128 & 108 & 8 & 5 & 395 \\
Lama sp. & 4 & 5 & 106 & 53 & 72 & 48 & 14 & 298 \\
L. (V.) vicugna & 4 & - & 1 & 1 & 1 & - & - & 3 \\
Lama glama & 4 & - & 8 & 6 & 2 & - & - & 16 \\
Lama guanicoe & 4 & 4 & 3 & 5 & - & - & - & 12 \\
H. antisensis & 4 & - & - & 1 & - & - & - & 1 \\
$\quad$ Identificados & & & & & & & & 818 \\
& & & & & & & & 1 \\
No identificable & 1 & - & - & - & 1 & - & - & 44 \\
No identificable & 2 & 1 & - & 25 & 16 & - & 2 & 21 \\
No identificable & 4 & - & 1 & - & 11 & - & 9 & 643 \\
No identificable & 9 & 13 & 213 & 54 & 236 & 21 & 106 & \\
& & & & & & & & \\
No identificados & & & & & & & & 1527 \\
$\quad$ Total general & & 59 & 509 & 282 & 463 & 77 & 137 & \\
\hline
\end{tabular}


Ya en otros trabajos hicimos notar que "la composición de los conjuntos es en general homogéneo. No existe una gran variabilidad con respecto a taxones representadas, y salvo en el depósito 1 el resto está mayormente compuesto por elementos y especímenes asignados a Camelidae” (Izeta y Scattolin 2001: 391).

Para el Depósito II se determinó la presencia de Lama glama y de L. (V.) vicugna. En tanto para el Depósito III pudo identificarse la presencia $L$. (V.) vicugna. Todas las identificaciones se basaron en las medidas obtenidas sobre falanges proximales (\#1, \#2, \#3, \#4 y \#5 de Kent 1982).

\subsubsection{Aspectos tafonómicos por Depósito}

Aquí se analiza a cada conjunto en particular para poder luego evaluar las similitudes y diferencias de las respectivas historias tafonómicas.

Con respecto a los estadios de meteorización observados en los distintos depósitos se ve que los conjuntos no muestran alteraciones significativas, como se observa en las siguientes Figuras.

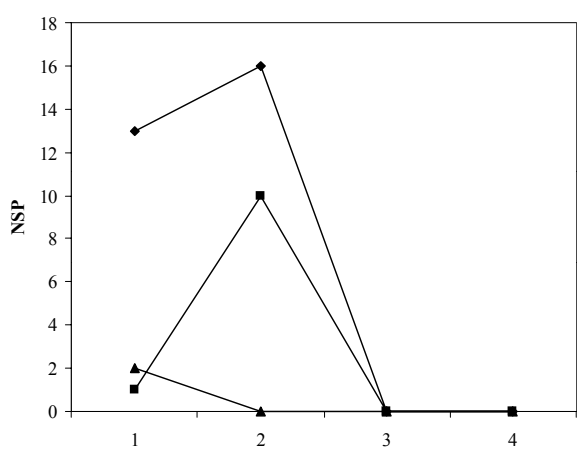

a

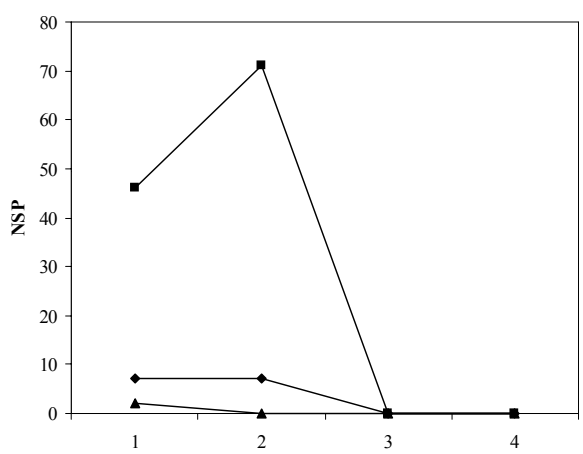

$\mathrm{C}$

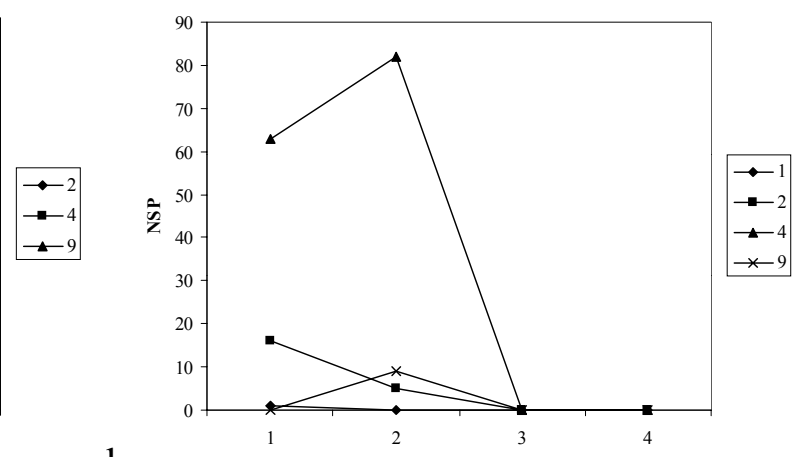



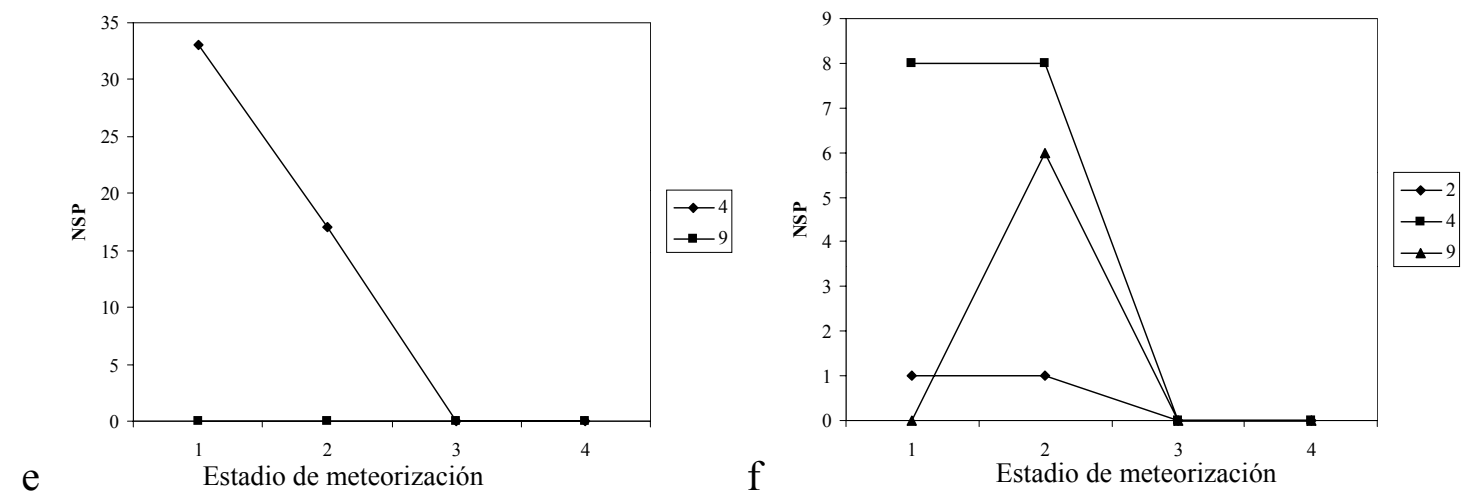

Figura 9.2. Meteorización de los conjuntos. a) Depósito I, b) Depósito II, c) Depósito III, d) Depósito IV, e) Depósito V, f) Depósito VI. Bañado Viejo.

La modificación de especímenes óseos por agentes tales como roedores y carnívoros ha sido registrada en muy baja frecuencia en el sitio. Estas modificaciones han sido reconocidas sólo en el Depósito II y corresponden a un fragmento de innominado sujeto a la acción de carnívoros (Figura 9.3) y tres especímenes de hueso largo que evidencian el mordisqueo por incisivos de roedor. Como se hizo notar anteriormente (Izeta y Scattolin 2001: 392) "Estas características sugieren una exposición a factores de meteorización aérea y subaérea poco prolongada en el tiempo de los subconjuntos analizados".

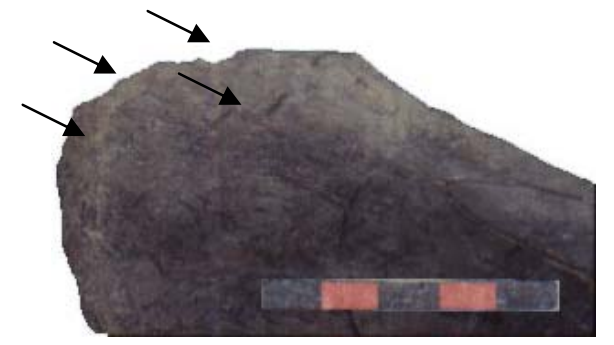

Figura 9.3. Acción de carnívoros en hoja del Ileon (LS).

\subsubsection{Marcas de corte, impacto e instrumentos}

La muestra contiene especímenes con huellas de acción humana relacionados con el procesamiento primario, secundario y formatización.

Con respecto a las huellas relacionadas con actividades de procesamiento primario y secundario se evidenció la presencia de marcas de corte, raspado, machacado e impacto. Estas serían en su gran mayoría producto de marcas causadas por eventos relacionados con el corte y procesamiento de animales con fines diversos como pueden 
ser la desarticulación de la carcasa, la obtención de la carne, tendones, etc. (Mengoni Goñalons 1999: 65).

Las marcas de corte aparecen en pocos especímenes correspondientes al Depósito 4 y fueron registradas en huesos de ave, camélidos y "no identificables" de tamaño corporal 2. Todos los rastros se ubican en las diáfisis de los elementos. Huellas de raspado se identificaron en un espécimen de artiodáctilo de tamaño corporal 4 del Depósito II. Por otro lado signos de machacado se registraron en fragmentos de hueso de camélidos y artiodáctilos de tamaño corporal 4 del Depósito 4. Por último los impactos fueron verificados en camélidos y artiodáctilos de tamaño corporal 4 de los Depósitos 2 y 4.

Tabla 9.2. Modificaciones observadas en el material de Bañado Viejo.

\begin{tabular}{rccccccccc}
\hline DEPOSITO & Taxón & T.corporal & $\begin{array}{c}\text { Marcas } \\
\text { de corte }\end{array}$ & $\begin{array}{c}\text { Marcas } \\
\text { anómalas }\end{array}$ & Raspado & Machacado & Aserrado & Impacto & Total \\
\multirow{6}{*}{ II } & LS & 4 & - & 1 & - & - & 2 & 1 & 4 \\
& UL & 4 & - & - & 1 & - & - & 1 & 2 \\
\multirow{2}{*}{ III } & BD & 2 & - & - & - & - & 1 & - & 1 \\
& UL & 4 & - & - & - & - & 1 & - & 1 \\
& BD & 2 & 1 & - & - & - & - & - & 1 \\
\multirow{2}{*}{ IV } & LS & 4 & 2 & - & - & 1 & - & 1 & 4 \\
& UL & 4 & - & - & - & 1 & - & - & 1 \\
\multirow{2}{*}{ Total } & UN & 2 & 3 & - & - & - & - & - & 3 \\
\hline
\end{tabular}

$\mathrm{LS}=$ Camelidae $; \mathrm{UL}=$ Artiodáctilo grande $; \mathrm{BD}=$ Ave; $\mathrm{UN}=$ no identificable

Para los depósitos 2, 3 y 4 se registró la presencia de elementos formatizados completamente terminados. En este caso se clasificaron de acuerdo a su morfología como instrumentos y adornos (Casiraghi 1985).

Respecto de los instrumentos se halló un metapodio cuya diáfisis distal se encuentra formatizada de modo que este extremo conforma una punta roma (Figura 9.4.b). Asimismo se halló otro metapodio que presenta las mismas marcas de aserrado que en el caso anterior pero por el contrario no presenta la formatización en uno de sus extremos (Figura 9.4.a). Por otro lado uno de los especímenes óseos formatizados es un fragmento de diáfisis de hueso largo cuya punta es de forma ahusada y presenta pulido.

En cuanto a la segunda categoría analizada se pudo advertir que "los adornos están representados por solo dos especímenes, siendo uno de ellos una diáfisis de hueso largo de ave del cual fueron extraídas ambas epífisis dando el aspecto de cuenta. El otro 
elemento es un fragmento de tubo realizado en diáfisis de hueso largo" (Izeta y Scattolin 2001: 393).

a)

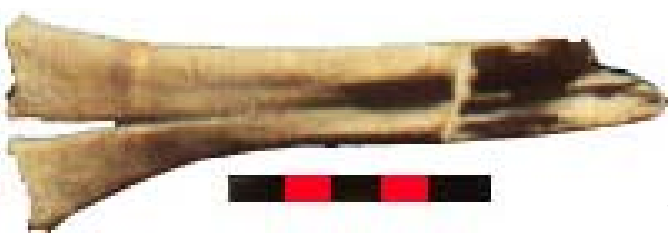

b)

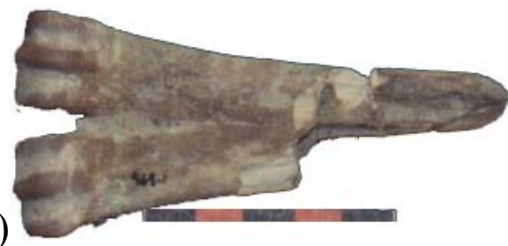

Figura 9.4.a) Metapodio de camélido subadulto con diáfisis aserrada, b) Metapodio de camélido adulto con extremo formatizado.

\subsubsection{Termoalteración}

La proporción de material con signos de alteración térmica presente en cada nivel varía desde el 0\% (nivel 4, D. II y nivel 21, D. VI) hasta el $50 \%$ (niveles 19 y 27 del D. 6). Los porcentajes más altos registrados de material quemado se registraron en el nivel $1(32 \%)$, parte superior del depósito II (38\%) y los niveles inferiores del depósito III (32\% a 45\%) (Izeta y Scattolin 2001). 


\subsection{Morro de las Espinillas - Análisis faunístico}

Como se describió en el Capítulo 5, este sitio presenta los restos faunísticos provenientes de tres sondeos. La muestra recuperada es pequeña por ello se realizarán solo algunas consideraciones.

El número de especímenes total recuperado durante la excavación fue de 18 . Tomando en cuenta el volumen excavado $\left(4,62 \mathrm{~m}^{3}\right)$ la relación NSP/Volumen es de 3,89 fragmentos por $\mathrm{m}^{3}$, siendo la más baja de todos los conjuntos estudiados en esta tesis.

Tabla 9.3. Composición de la muestra. Morro de las Espinillas

\begin{tabular}{lccccr}
\hline Taxón & T. corporal & S3 & S4 & S5 & Total general \\
AVES & 3 & 1 & - & - & 1 \\
Chaetophractus vellerosus & 2 & - & 1 & - & 1 \\
Rodentia & 1 & - & - & 1 & 1 \\
Cricetidae & 1 & - & 1 & - & 1 \\
Artiodactyla & 4 & - & 10 & 1 & 11 \\
Lama $s p$ & 4 & 2 & - & - & 2 \\
No identificable & 2 & - & 1 & - & 1 \\
Total general & & 3 & 13 & 2 & 18 \\
\hline
\end{tabular}

Como puede observarse en la Tabla 9.3 se identificó la presencia de seis taxones y una categoría de tamaños corporales de "no identificables". La frecuencia de elementos o especímenes más representada son los que se asignaron al tamaño corporal 4 (incluyen Lama sp y Artiodactyla).

La meteorización general del conjunto presentó 17 especímenes con estadio $1 \mathrm{y}$ 1 con estadio 2. En cuanto a las modificaciones producidas por agentes tafonómicos no se registró la acción de roedores ni de carnívoros.

\subsubsection{Subconjunto de tamaño corporal 4}

Debido a lo escaso del material asignado a camélido se realizará solo una breve descripción de algunos atributos de la muestra. A lo identificado como camélido se le han anexado los once especímenes correspondientes al tamaño corporal 4.

Tabla 9.4. Tamaño corporal 4, huesos del esqueleto axial y apendicular.

\begin{tabular}{cccc}
\hline Elemento & LS & UL & Total general \\
TFR & - & 3 & 3 \\
TA & 1 & - & 1 \\
CL & 1 & - & 1 \\
LB & - & 8 & 8 \\
Total general & 2 & 11 & 13 \\
\hline
\end{tabular}


Como se muestra en la Tabla 9.4 el número de especímenes identificados como camélidos o artiodáctilos de tamaño corporal 4 en este conjunto es extremadamente bajo. En cuanto a clases de edad representadas se determinó la presencia de un juvenil y un individuo adulto. Respecto de los elementos que representados en cada clase de edad tenemos que para los subadultos se identificó un fragmento de tibia. Por el contrario para los adultos tenemos representado un calcáneo.

\subsubsection{Fragmentación del subconjunto}

En este conjunto sólo se encontró completo el calcáneo. Los tamaños de los fragmentos están representados dentro del rango que va desde los $13 \mathrm{~mm}$ hasta los 66 $\mathrm{mm}$. Esto nos da una idea de la fragmentación y posiblemente de la selección de tamaños aunque no es posible aun determinar si esto se debe efectivamente a ello o es una cuestión referida al tamaño de la muestra.

En cuanto a los estados iniciales de los huesos al ser fracturados la frecuencia de la categoría seca es la mayor (siete especímenes). Las fracturas realizadas en estado fresco han sido halladas en muy baja frecuencia dentro de este conjunto (dos especímenes).

\subsubsection{Utilización de las carcasas y termoalteraciones}

En cuanto a la utilización de las carcasas no fue posible hallar indicadores de marcas producto de la acción humana.

Respecto de la termoalteración en tres especímenes se identificaron signos de acción del calor, presentándose todos los tipos de termo alteración.

Tabla 9.5. Termoalteración del conjunto de tamaño corporal 4. Morro de las Espinillas

\begin{tabular}{cccccc}
\hline Descripción & Sin alteración & $\begin{array}{c}\text { Oxidación } \\
\text { incompleta/carbonización } \\
\text { marrón claro-negro } \\
\text { (moteado) }\end{array}$ & Carbonizado & Calcinado & \\
Color & - & $200^{\circ} \mathrm{C}-300^{\circ} \mathrm{C}$ & $300{ }^{\circ} \mathrm{C}$ & $>500{ }^{\circ} \mathrm{C}$ & \\
Temperatura & $<200{ }^{\circ} \mathrm{C}$ & 1 & 1 & 1 & 13 \\
NISP & 10 & & & gris-blanco & \\
\hline
\end{tabular}

\subsubsection{Subconjunto no camélido (otros tamaños corporales)}

Para los otros tamaños corporales presentes en la muestra se pudo observar que una placa de Chaetophractus vellerosus muestra signos de termoalteración (tipo 4). No se hallaron otras marcas en este subconjunto. 
Parte 4-Discusión y conclusiones 
En los capítulos 6, 7 ,8 y 9 se presentaron los datos obtenidos mediante el análisis de los conjuntos faunísticos del sur de los Valles Calchaquíes. Como se pudo observar el grado de definición de cada uno de los sitios es distinto, no solo en términos de la variabilidad interna de los conjuntos sino también en cuanto al tipo de información que cada sitio nos permite extraer.

La primera variable observada para definir el nivel de resolución de cada conjunto fue el tamaño de la muestra. Para ello se tomó como valor de referencia la relación NISP/Volumen excavado con el fin de poder comparar las cantidades de huesos representadas en cada conjunto. Esto nos permitió observar que los conjuntos procedentes de Bañado Viejo Depósito $6\left(52\right.$ especímenes $\left./ \mathrm{m}^{3}\right)$, Yutopián Estructura 4 Ocupación Inferior $\left(17,5\right.$ especímenes $\left./ \mathrm{m}^{3}\right)$, Estructura 5 (42 especímenes $\left./ \mathrm{m}^{3}\right)$, Estructura Patio del Núcleo 1 (57,2 especímenes $\left./ \mathrm{m}^{3}\right)$, Tesoro 1 (20,74 especímenes $\left./ \mathrm{m}^{3}\right)$, y Morro de las Espinillas (3,89 especímenes $\left./ \mathrm{m}^{3}\right)$, son las muestras que presentan menor densidad de huesos en relación al volumen excavado. Salvo la ocupación inferior de la estructura 4 de Yutopián estos conjuntos corresponden a muestras parciales del total de los sitios, siendo en general sondeos exploratorios. Entonces, cuestiones relacionadas con el tamaño de la muestra pueden asumirse para estas faunas. Por ello han sido utilizadas con el fin de aportar datos acerca de la composición faunística tanto en términos de abundancia taxonómica relativa como de disposición por clases de edad o huellas dejadas por acción humana y/o agentes tafonómicos y se dejaron de lado las posibles implicancias respecto del uso de los animales en términos de su economía económica.

El resto de los conjuntos provienen de estructuras que han sido excavadas casi en su totalidad o totalmente como Loma Alta Núcleo E, F y G, Yutopián Estructura 1, Estructura 3, Estructura 4 Superior, Estructura 5 y Estructura 11. Es en estos casos que se pudo avanzar un poco más y además de evaluar los indicadores nombrados más arriba, se procedió a realizar un análisis en términos económicos de la utilización de la fauna y principalmente de los camélidos. Cuestiones como el transporte, reparto, distribución, acumulación y consumo pueden ser explorados en ellos con menos riesgos en las inferencias. 
A los datos ya obtenidos para los conjuntos se le agregará en este capítulo la dimensión temporal, por lo cual se realizará la discusión de los sitios según su adscripción a uno de los cuatro bloques temporales (BT) definidos en el Capítulo 3. Estos se presentan en orden correlativo comenzando por los sitios con fechados radiocarbónicos más antiguos (BT1) hasta los más modernos (BT4)

\subsection{Bloque Temporal 1}

Este bloque temporal está definido para las ocupaciones datadas en el primer tramo del primer milenio AD entre los 2000 y 1700 RCYBP. Está compuesto por los depósitos inferiores del sitio Bañado Viejo y las Estructuras 3 y 11 de Yutopián. Por lo que contamos con muestras de dos ambientes distintos: fondo de valle a una altura de 1200 msnm y piedemonte, ubicado a $3000 \mathrm{msnm}$. Asimismo los contextos arqueológicos de los que provienen los conjuntos se diferencian ya que Bañado Viejo proviene de un sitio sin arquitectura remanente en tanto que para las estructuras de Yutopián los conjuntos provienen de pisos de ocupación bien definidos dentro de recintos con paredes de piedra.

\subsubsection{Yutopián Estructura 11}

Esta estructura presenta la ocupación más antigua de todos los conjuntos tratados en esta Tesis. Por lo observado en el capítulo 7, este conjunto muestra una alta integridad ya sea expresada en términos de meteorización $(95,57 \%$ de la muestra presenta estadio de meteorización 1$)$, acción de carnívoros y roedores $(0,23 \%$ afectada) o preservación del conjunto de camélidos mediada por la densidad ósea $\left(r_{s}-, 640 \mathrm{p}\right.$ ,277). Entonces, es posible advertir que es un conjunto que posee una alta resolución arqueológica y cuya conformación podría atribuirse en gran parte a procesos que tendrían que ver con el ser humano como agente acumulador y responsable de la configuración del registro. En cuanto a la composición taxonómica de este conjunto se observó con anterioridad que se identificaron once taxones, con AVES presentando dos tamaños corporales distintos.

De estos once taxones Rodentia, Canidae y AVES son aquellos que podrían haber sido incluidos en el conjunto en algún momento post-abandono del recinto. Por ello se verificó en estos especímenes en particular la presencia de algún indicador que permitiera integrarlos junto a los depositados por acción humana. Salvo la marca de aserrado en el hueso de cánido ninguno de los atributos permitió arribar a una 
conclusión definitiva, pero la presencia de una mandíbula de roedor quemada y un fragmento de tibio-tarso de ave con posibles marcas de formatización sugieren que la incorporación al conjunto podría deberse más a factores culturales que a naturales. Asimismo los especímenes asignados a tamaños corporales 1 y 2 presentan en distinto grado evidencias de acción de calor sobre ellos. De todos modos este último indicador puede ser producto de superponer un fogón sobre los restos depositados naturalmente con anterioridad (Bennett 1999). Otra línea de evidencia independiente la aporta la no selección en cuanto a los tamaños y la fragmentación de los especímenes y elementos de los tamaños corporales pequeños. Por otro lado en estos elementos no se ha observado rastros de acción de ácidos gástricos por lo que se podría descartar su ingreso por causa de agentes tafonómicos como carnívoros o aves rapaces. La disposición espacial de los especímenes, los que se hallan desarticulados podría apoyar la idea de la inclusión de estos restos como parte de la actividad humana en el recinto en el pasado. Resumiendo, se puede advertir que tanto el cánido como las aves poseen rasgos asignables a la utilización directa de los humanos, en tanto que para los roedores, si bien presentan elementos quemados, no puede establecerse con certeza que hayan sido ingresados en el registro como producto de alguna acción humana aunque presumiblemente lo hayan hecho.

En cuanto al conjunto de camélidos se observó la presencia de al menos 3 individuos adultos y 2 subadultos.

Entre los adultos, a su vez, se identificó la presencia de las especies Lama guanicoe y Lama glama. Registrándose la presencia de al menos una llama y un guanaco, quedando el tercer individuo sin poder ser asignado a ninguna especie en particular.

En cuanto a la utilización de estos animales se realizó un análisis global que arrojó como resultado que se habrían preservado fragmentos de especímenes correspondientes a unidades anatómicas de bajo rendimiento económico tanto en lo que respecta a carne como a médula ósea. Los elementos mayormente representados son la cabeza (cráneo, mandíbula y hioideo) y los elementos del esqueleto apendicular. El perfil anatómico que conforma esta muestra presenta un patrón de procesamiento similar a los registrados en contextos actuales del noroeste argentino (Yacobaccio et al. 1998) por lo que interpretamos que los animales no entraban completos a la unidad doméstica, sino que lo realizaban siguiendo un patrón de trozamiento en unidades menores. 
Analizando el perfil por especie según los elementos que permiten realizar esta separación es interesante notar que en lo que respecta al guanaco se puede observar que se ha identificado una porción distal del húmero izquierdo y una proximal del húmero derecho. Además para los especímenes asignados a guanaco se observa que estos no están quemados, que presentan fractura helicoidal realizada en estado fresco y marcas de corte e impacto. Posiblemente estos elementos hayan sido sometidos a un proceso de extracción de medula ósea y sus restos habrían sido descartados sin haber sido utilizados en una segunda instancia lo que podría evidenciar que este es un desecho de procesamiento secundario según fuera definido por O’Connor (1993). Para los otros especímenes asignados a este taxón se observa que el resto de metatarso ha sido fragmentado en estado fresco en tanto que la falange proximal se encuentra entera. Este patrón nos sugiere que partes del animal ingresaron al recinto con el fin de procesarse y que estos una vez fragmentados fueron descartados.

Por otro lado en el caso de la llama los elementos identificados corresponden a radioulna, falange medial y distal. El patrón observado repite en algún modo el definido para guanaco, con elementos fragmentados con fractura fresca y sin estar quemados y descartados sin un procesamiento posterior.

Un dato a tener en cuanta es la disposición espacial de estos especímenes. Los que corresponden a guanaco fueron recuperados en las unidades que corresponden a la porción norte de la estructura. En este sector se encontraron asociados gran cantidad de lascas con bordes activos y "cuchillos de piedra". En cambio las identificadas como llama fueron descartadas más asiduamente en las unidades del sur de la estructura. Esto podría estar indicando que los elementos pueden haber sido descartados en distintos eventos formando dos grupos distintos de desechos.

En cuanto al conjunto de subadultos se identificaron dos individuos correspondiendo uno a vicuña. La determinación se efectuó en base a las características de los incisivos inferiores. El patrón de elementos repite el de los camélidos adultos, en donde se presentan la cabeza y el esqueleto apendicular. En base a la edad estimada para la fusión de la sínfisis de la mandíbula se estimó que la vicuña se trata de un ejemplar menor a 5 meses, por lo que su consumo podría haberse producido en algún momento de fines del invierno, ya que la edad de parición para esta especie varía entre febrero y abril (Franklin 1982).

Respecto de la utilización del resto de las carcasas que no pudieron ser identificadas a nivel taxonómico se identificaron ciertos patrones que sugieren una 
estandarización del procesamiento de los animales. La fragmentación del conjunto es alta tanto para adultos como para subadultos. Los módulos de tamaño más representados corresponden en ambos caso a los especímenes de menos de $60 \mathrm{~mm}$, estando los elementos completos representados por los huesos cortos del carpo y el tarso. La presencia de elementos con largos máximos mayores permitiría suponer que no hubo fragmentación postdepositacional La mayor frecuencia de los tamaños mas pequeños junto al tipo de estado en que se encontraba el hueso cuando se produjo la fractura nos hace pensar en un patrón ya observado para otros autores (Outram 2001, Church y Lyman 2003, y trabajos allí citados) típico del proceso de extracción de grasa ósea. Estos restos quizás indicarían la presencia de "desechos de mesa" en términos de O’Connor (1993).

\subsubsection{Yutopián Estructura 3}

Por lo observado en el capítulo 7, este conjunto al igual que el de la Estructura 11 presenta una alta integridad ya sea expresada en términos de meteorización $(93,27 \%$ de la muestra sobre la que pudo identificar meteorización presenta estadio de meteorización 1$)$, acción de carnívoros y roedores $(0,08 \%$ afectada) o preservación del conjunto de camélidos mediada por la densidad ósea $\left(r_{s}-, 233 \mathrm{p}, 416\right)$. Entonces, volveríamos a enfrentarnos a un conjunto cuya conformación posiblemente podría atribuirse a procesos relacionados con el ser humano como agente acumulador y encargado de la configuración del registro.

En cuanto a la composición taxonómica de este conjunto se identificaron nueve taxones, con Rodentia y Artiodactyla presentando tres y dos tamaños corporales distintos respectivamente.

En el caso de los animales de porte pequeño se registró la asociación de dos cráneos de roedor tamaño corporal 1 en un pozo (denominado Rasgo o Feature 2). Esto coincide con la presencia de un espécimen de artiodáctilo de tamaño corporal 4 con marcas de acción de roedor, lo que podría llevarnos a suponer un evento de depositación posterior de al menos estos dos individuos. Esto podría estar expresando el ingreso de estos animales de modo natural al conjunto

El resto de AVE corresponde a una uña y el de Ctenomys a un cráneo completo. Ninguno de los dos posee alguna característica que permita afirmar que su asociación en el conjunto se deba a la acción humana. 
La acción del calor sobre elementos o especímenes de animales de tamaño pequeño solo se registró en un espécimen de roedor tamaño corporal 1. En cuanto a la fragmentación de este conjunto se vió que la proporción elementos rotos versus completos es similar para los roedores.

Por lo expresado no existirían evidencias claras de la utilización de estos animales no obstante la relativamente elevada cantidad de especímenes asignados a roedor tamaño corporal 1 y Ctenomys sp. Es por esta razón que no se incluyó al tamaño corporal 1 dentro del grupo sobre el que se realizaron análisis de tipo económico.

No obstante la presencia de estos animales del tamaño corporal 1 creemos que el conjunto total recuperado de la estructura no ha sido modificado sustancialmente por este agente tafonómico ya que la muestra parece tener una alta integridad expresada por el resto de los indicadores tafonómicos analizados.

En cuanto al conjunto de camélidos se observó la presencia de individuos adultos y subadultos. Dentro de la primera categoría se identificó un $\mathrm{MNI}=3$ y de la segunda un $\mathrm{MNI}=2$.

Para los adultos se identificó la presencia de la especie Lama glama. El resto de los individuos no se pudieron asignar a ninguna especie en particular.

La utilización de las carcasas para el conjunto de camélidos adultos presenta un patrón un poco distinto al observado para la Estructura 11. En este caso los elementos más representados corresponden al esqueleto axial. No obstante ello los valores obtenidos mediante la correlación entre las unidades anatómicas representadas y los elementos "no largos" dan como resultado un $r_{s}-, 4815 \mathrm{p}, 079$, lo que significa que en realidad estarían representadas las partes con menor valor económico. De todos modos creemos que esto puede ser una limitación producto de lo poco diagnóstico en términos de identificación taxonómica que son elementos tales como las costillas (Berwick 1975), las que en el conjunto de artiodáctilos están representados por 290 especímenes. La misma situación ocurre con las vértebras cuyo NSP asciende a 29 solo para el tamaño corporal 4. Si bien no es totalmente seguro que estos especímenes correspondan a Lama sp (también podrían pertenecer a taruca) existe una gran probabilidad de que sí lo sean. Con esto los valores obtenidos serían distintos ya que se estaría aumentando la proporción de elementos del esqueleto axial con mayor rendimiento económico. No obstante ello, se puede apreciar para este conjunto que estarían ingresando a la unidad doméstica más partes esqueletales que para la estructura 11. En este caso se identificó la presencia de la cabeza (el axis podría haber entrado junto con el cráneo), el cuello y 
parte de las vértebras torácicas. Además tenemos costillas y por último elementos del esqueleto apendicular delantero (sin la escápula) y trasero (completo). El esqueleto apendicular trasero presenta la secuencia innominado - fémur - tibia para el lado izquierdo en tanto que el lado derecho posee astrágalo - metatarso. Este patrón es interesante ya que podemos observar que el lado izquierdo está sobrerrepresentado respecto del derecho para la porción proximal de esta pata, en tanto que para la porción distal la relación es inversa. Esto puede ser interpretado como el ingreso de distintas partes esqueletales en distintos eventos (principalmente de una parte de gran valor económico como el fémur).

En cuanto a la intensidad del procesamiento se observó que todos los elementos (salvo el astrágalo y otros huesos cortos) se hallan fragmentados y presentan largos máximos menores a $60 \mathrm{~mm}$ en su gran mayoría. Los perfiles de fragmentación repiten el mismo patrón que en la Estructura 11, por lo que posiblemente los especímenes hayan sido sometidos a algún proceso térmico. La presencia de especímenes calcinados, carbonizados y con oxidación incompleta se identificaron en todas las partes esqueletales. Como se hizo notar más arriba los elementos más distales suelen ser los que presentan en mayor frecuencia los estados de carbonización y calcinación.

En cuanto a los individuos juveniles están representadas costillas, húmero y tibia, además de falanges y metapodios. Esto implica la preservación de elementos con alto valor económico. En cuanto a la utilización de las carcasas se observó la presencia de impacto en un húmero. La acción del calor es casi nula (solo tres especímenes con alteración de tipo 1). En tanto que el estado del hueso mientras se efectuó la fractura es en general fresco. El área de dispersión de estos especímenes se restringe a las cuadrículas 320, 321 y 322, las que corresponden al sector norte de la unidad doméstica (Figura 10.2.b).

Para la llama adulta el elemento que permitió la identificación específica se extrajo del Pozo B.

Como se puede ver el comportamiento de la muestra de camélidos adultos respecto de los subadultos difiere en la disposición espacial de los especímenes. Mientras que los elementos de subadultos se ubican en la porción centro-norte, los que corresponden al conjunto de adultos están dispersos por toda la estructura sin formar un grupo como el anterior. 

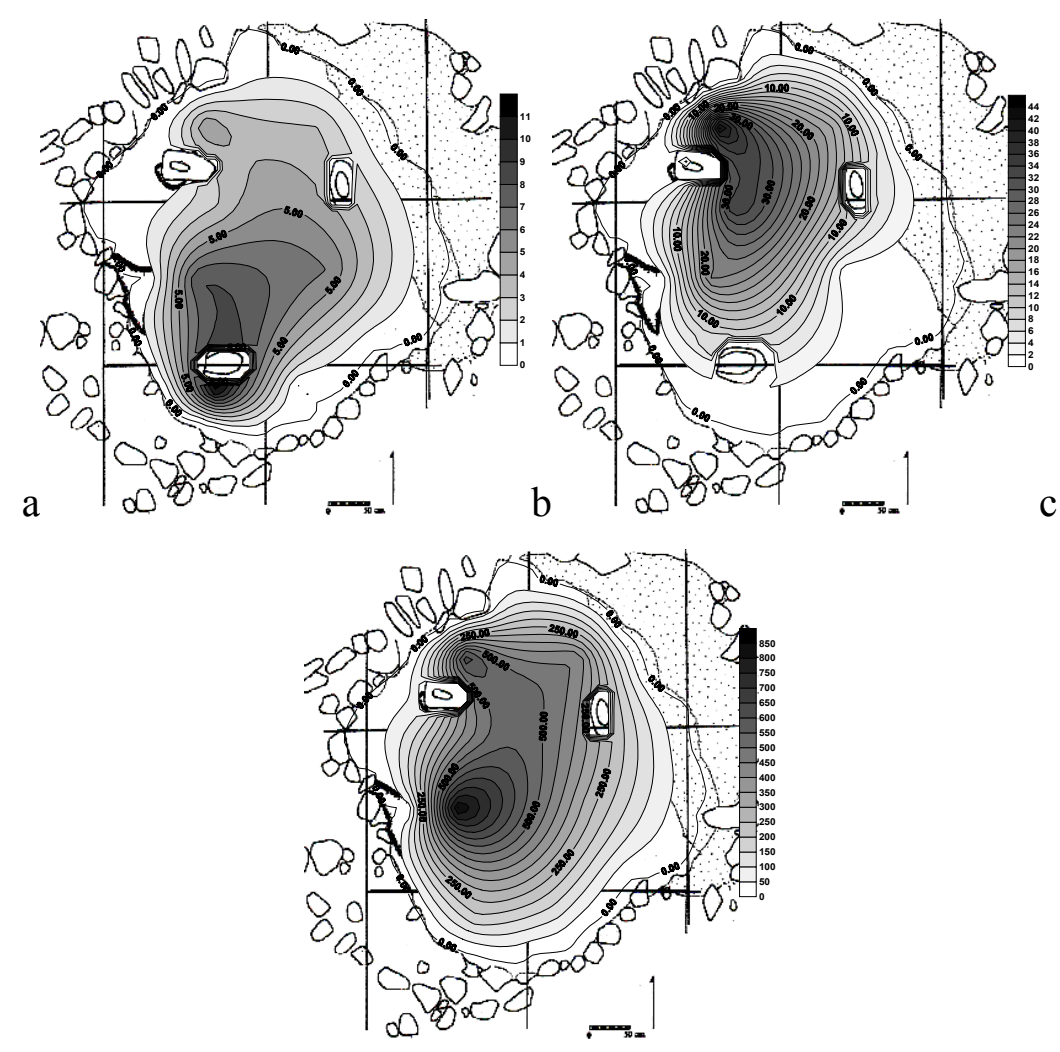

Figura 10.1. Distribución de especímenes en la Estructura 3. a) Tamaño corporal 1, b) Tamaño corporal 2, c) Tamaño corporal 4.
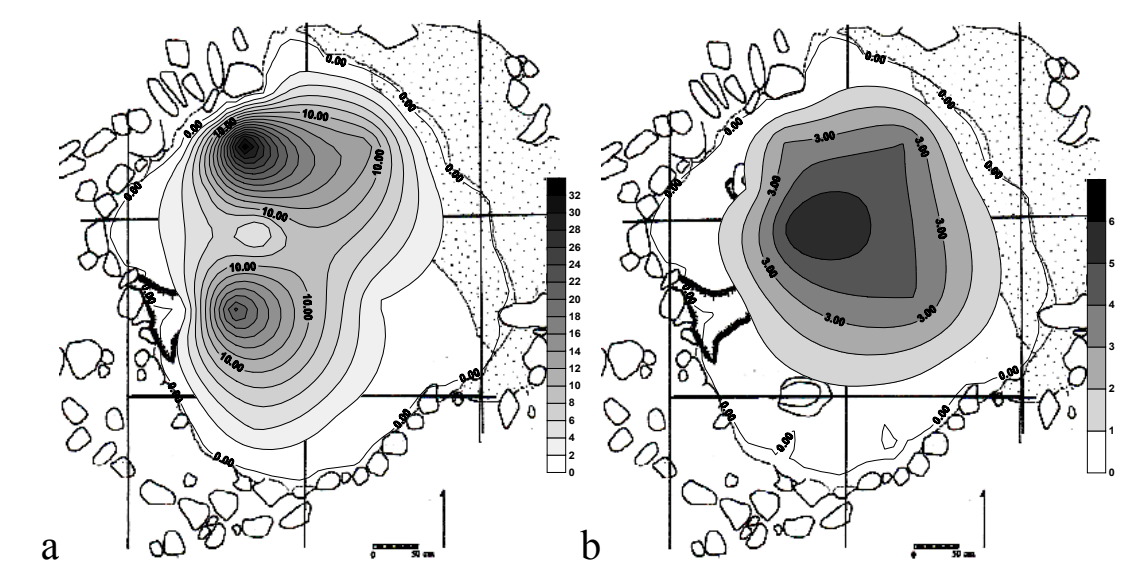

Figura 10.2. Distribución de camélidos en la Estructura 3. a) Adultos, b) Subadultos.

\subsubsection{Bañado Viejo Depósito VI}

Este depósito es el más profundo y se definió entre los niveles 19 a 30 (1,90 a $3,20 \mathrm{~m}$ ) lo que resulta en una potencia de $1,30 \mathrm{~m}$.

Como se vio anteriormente la resolución del conjunto no es la óptima pero nos permitió al menos identificar los siguientes taxones: Chaetophractus vellerosus, Lama $s p$., Artiodactyla y "no identificables" de tamaño corporal 2 y 4. 
En este conjunto no se reconocieron marcas de acción antrópica o huellas de agentes tafonómicos. Los estadios de meteorización presentes van desde el 1 al 3.

Dentro de los elementos asignado a Lama sp se identificó la presencia de al menos un individuo adulto y uno subadulto.

\subsection{Bloque Temporal 2}

Este BT está definido para las ocupaciones datadas en el tramo que va desde los 1700 hasta los 1500 A. P. Está compuesto por el Núcleo E de Loma Alta, las Estructuras 1, Patio Núcleo 1 y 4 de Yutopián y Antigal de Tesoro R19. Las muestras de Loma Alta y Yutopián pertenecen a ambientes similares: piedemonte, ubicado a 3000 msnm. Antigal de Tesoro se ubica un poco más alto, a los $3200 \mathrm{msnm}$. Asimismo los contextos arqueológicos de los que provienen los conjuntos proceden de sitios con arquitectura remanente y específicamente de pisos de ocupación bien definidos de unidades domésticas.

\subsubsection{Antigal de Tesoro}

Se vio que el conjunto mostró una meteorización homogénea para todos los tamaños corporales encontrándose solo un espécimen con estadio de meteorización 4 , lo que implica un $0,50 \%$ de la muestra (sobre un total de 199 con meteorización asignada). La acción de carnívoros y roedores no ha sido registrada en el conjunto. En cuanto a la densidad ósea como factor determinante de la conformación del conjunto se advirtió para el subconjunto de camélidos adultos que la relación era positiva y estadísticamente significativa $\left(r_{s}, 210 \mathrm{p}, 026\right)$, en tanto que para los subadultos también resultó positiva pero sin significación estadística $\left(r_{s}, 429 \mathrm{p}, 348\right)$. Sin embargo, como se discutió cuando se presentaron los datos, hay que tener en cuenta algunas variables como el tamaño de la muestra, la conservación diferencial de los distintos elementos (hay elementos que conservan las zonas menos densas), la alta proporción de elementos del carpo y la integridad del conjunto medida por la meteorización y la acción de carnívoros y roedores. Tomando en cuenta estas consideraciones creemos que el resultado de las correlaciones entre densidad ósea y unidades anatómicas representadas podría no necesariamente indicar una conservación diferencial causada por la destrucción de algunas zonas de los elementos.

La composición taxonómica de la muestra presenta cuatro taxones y tres categorías de tamaños corporales para los "no identificables" (el tamaño corporal 9 no 
es considerado). En cuanto a las características de este conjunto no se pudo asignar la asociación entre los tamaños corporales pequeños (1) y los grandes (4) respecto de la contemporaneidad de la asociación. Es decir si ingresaron en el mismo evento o posteriormente al abandono de la unidad doméstica. Un espécimen de tamaño corporal 1 carbonizado no bastaría para poder incluirlo dentro del conjunto ingresado por acción humana.

En cuanto a los camélidos se pudo calcular la presencia de un individuo adulto y uno subadulto. La utilización del individuo adulto parecería haber estado centrada en la adquisición de los nutrientes internos de los huesos largos más que en la utilidad de carne, en tanto que para el esqueleto axial solo se habría conservado un elemento de baja utilidad económica. La fragmentación para ambos conjuntos muestra la presencia de especímenes menores a $50 \mathrm{~mm}$ en ambos casos.

Como conclusión de esta ocupación podemos decir que las partes ingresadas a la unidad (o las descartadas allí) nos muestran la utilización de elementos de baja utilidad económica para el esqueleto axial y de alta utilidad en medula para el esqueleto apendicular anterior y nuevamente baja utilidad para el esqueleto apendicular trasero.

\subsubsection{Yutopián Estructura 4 - Ocupación inferior}

Esta ocupación fue definida a partir del hallazgo de un fogón que se encontró debajo de la ocupación principal de esta estructura. En general la asociación de material a este nivel de ocupación parece haberse restringido a los sectores en los que fue posible ubicar el piso de ocupación inferior. En determinadas zonas esto parecería no haber sido posible quizás por la alteración producida por la ocupación posterior. Por ello el número de especímenes recuperados es muy bajo. La meteorización es homogénea y no se registraron marcas de roedor y carnívoro por lo que estimamos una buena integridad del conjunto recuperado.

Quizás la característica más importante de esta ocupación y que se vuelve a repetir en la estructura 5 es el hallazgo de dientes humanos mezclados con la fauna. La presencia de estos restos se ubica en el extremo oeste de la estructura. El rasgo que define la ocupación (el fogón) en este caso se ubica en el extremo opuesto a donde se hallaron los dos dientes. En tanto los restos de fauna fueron extraídos de las unidades ubicadas en el cuadrante sur oeste. 


\subsubsection{Yutopián Estructura 4 - Ocupación superior}

Esta muestra es más grande que la anterior (NSP = 1897). La integridad del registro es buena como en los casos anteriores observándose una meteorización que presenta los estadios 1 y 2 para el 100\% del conjunto. La acción de roedores se observó en el $0,68 \%$ de la muestra concentrándose en su mayor parte en la unidad 331 y en dos especímenes en las unidades 332 y 334 respectivamente (Figura 10.3). La acción de carnívoros no fue registrada en el conjunto.

Con respecto a las partes representadas de camélidos y la densidad ósea vemos que para el conjunto adulto esta arrojó un resultado positivo y para juveniles negativo, lo que nos está sugiriendo nuevamente y por otra vía de análisis que la densidad ósea no ha sido un factor determinante en la conformación del conjunto, y que por otro lado las correlaciones estarían reflejando un patrón asociado a prácticas de descarte más que de destrucción por agentes naturales.

Los taxones registrados en la estructura son seis, de los cuales Rodentia y Artiodactyla presentan dos tamaños corporales distintos. Los "no identificables" presentan cuatro tamaños corporales.

Los camélidos están representados por las dos clases de edad. Para los adultos se calculó la presencia de tres individuos, en tanto que para los juveniles se pudieron identificar al menos dos.

En cuanto al perfil anatómico del conjunto adultos se puede observar que no hubo una selectividad respecto de las partes esqueletales registradas ya que en general se encuentran todas. Para el esqueleto axial el elemento más representado es el cráneo, el cual permitió calcular un número mínimo de tres individuos a partir de la identificación de los petrosos del lado derecho. Este elemento es el único de este conjunto que permite el cálculo de un individuo más a diferencia de la tibia derecha y el astrágalo izquierdo que permiten el cálculo de un MNI de dos. Es por esta sobrerrepresentación del cráneo que para el esqueleto axial se ha propuesto una mayor presencia de elementos de baja utilidad económica.

Los huesos largos del esqueleto apendicular representados sugieren una alta utilidad económica en tanto a su índice de carne como al volumen de la cavidad medular. Esto se ve expresado en las huellas encontradas en el conjunto que refiere a marcas de corte, impactos y raspado entre otros indicadores de actividades de procesamiento primario y secundario. 
El conjunto de camélidos subadultos también está caracterizado por elementos de alta utilidad económica para el esqueleto apendicular, en tanto que para el esqueleto axial no se identificó ningún elemento.

La distribución espacial de la fauna muestra que en el sector norte de la unidad doméstica es donde se halla la mayor diversidad taxonómica y al sur solo se observa la presencia de restos de camélidos. Analizando la disposición espacial de los camélidos adultos se pudo observar que estos se presentan por todo el recinto. En tanto para los subadultos se pudo determinar que solo se ubican en la porción este del recinto. Esto a grandes rasgos nos permite observar una segmentación en pequeñas áreas internas de descarte de los especímenes óseos.

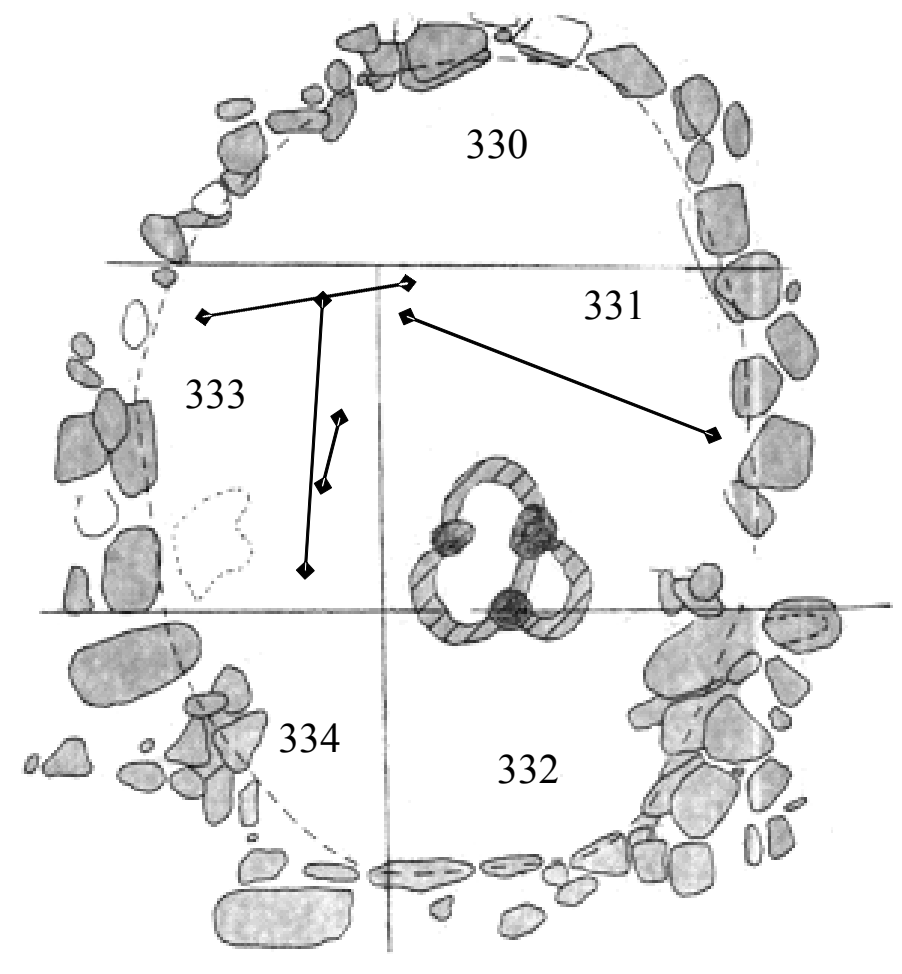

Figura 10.3. Remontajes de elementos. Estructura 4

En cuanto a las partes esqueletales se advirtió que en la unidad 334 solo se han recuperado elementos pertenecientes al extremo distal del esqueleto apendicular. Para el cráneo se han reconocido fragmentos que permiten el calculo de un MNI de tres, de los cuales dos de ellos están ubicado al norte en tanto que el tercero esta al sur. Algunos remontajes entre elementos se han realizado para esta unidad doméstica demostrando para los camélidos adultos y subadultos una gran desarticulación de las partes esqueletales (Figura 10.3). 

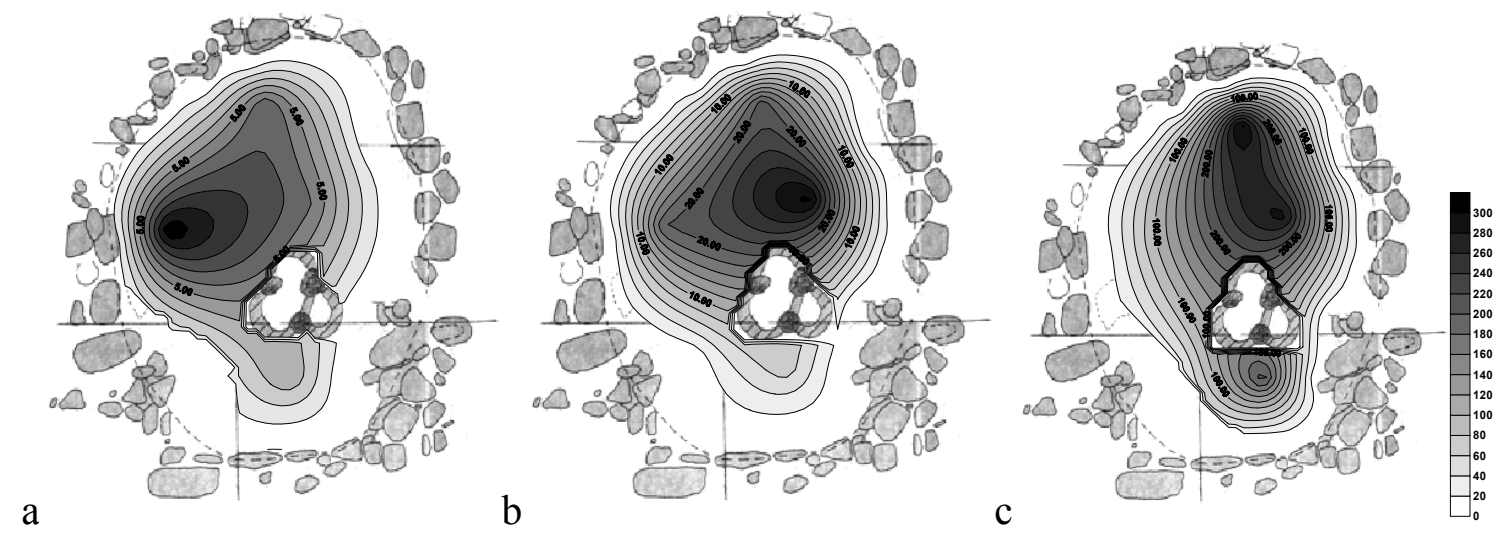

Figura 10.4. Distribución de especímenes en la Estructura 4 Ocupación Superior. a) Tamaño corporal 1, b) Tamaño corporal 2, c) Tamaño corporal 4.
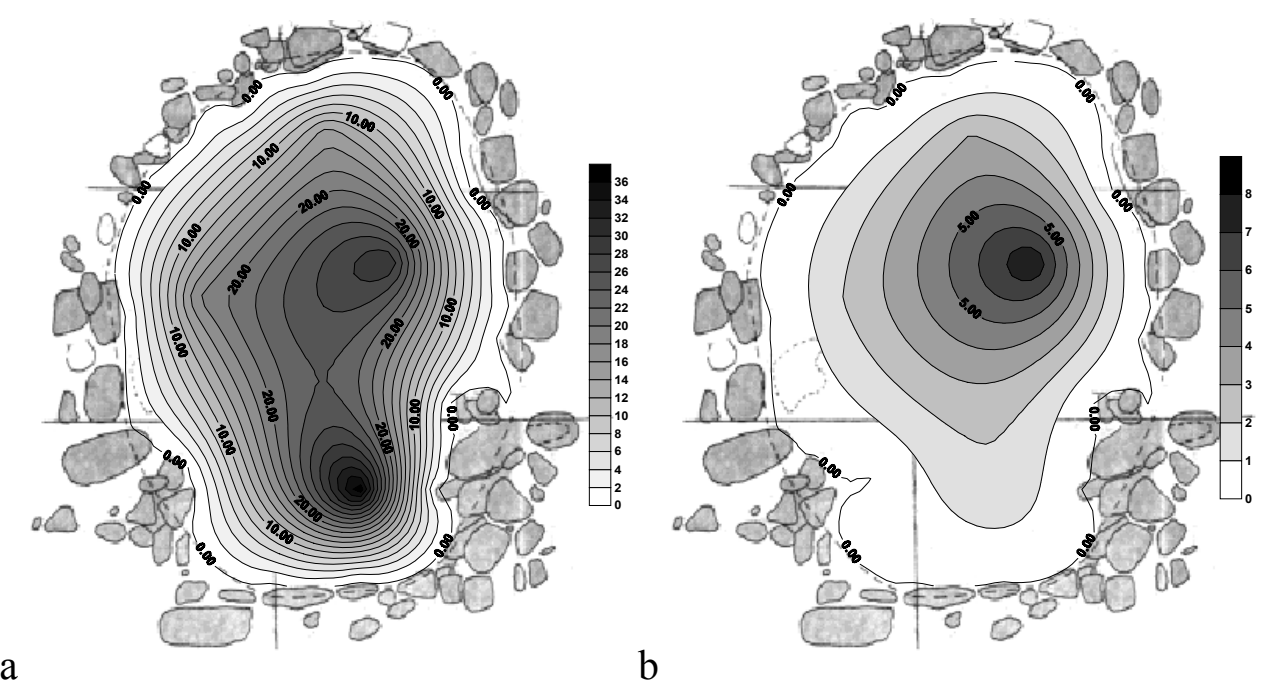

Figura 10.5. Distribución de camélidos en la Estructura 4 Ocupación Superior. a) Adultos, b) Subadultos.

La disposición espacial de los elementos y especímenes junto con el análisis de la anatomía económica nos sugeriría que las partes esqueletales podrían haber ingresado al conjunto como producto del procesamiento primario. En el interior de la estructura se procedería a su reducción y la desarticulación de las partes básicas por medio del procesamiento secundario y a la fragmentación de los elementos. Todo ello se habría producido en distintos eventos como lo sugiere la disposición de los grupos de huesos identificados en la Figura 10.5.

\subsubsection{Yutopián Estructura 5}

Está estructura se encuentra íntimamente ligada a la estructura 4 con la que forma un núcleo. La estructura 4 posee dos ocupaciones por ello se intentó establecer 
con cual de ellas era contemporánea. El único rasgo interesante para poder lograr esto fue la presencia de dientes humanos en la estructura 5 al igual de lo que sucede en la ocupación inferior de la 4. Salvo esta presencia que no deja de ser ambigua no se ha identificado con seguridad la contemporaneidad con alguna de las dos ocupaciones de la estructura 4.

En cuanto a la historia tafonómica de esta estructura se pudo establecer que en los primeros $40 \mathrm{~cm}$ de excavación la acción de los roedores había sido intensa ya que 143 especímenes presentaban rastros de la acción de este agente tafonómico. Desde los $40 \mathrm{~cm}$ de profundidad hasta la roca de base no se registró la acción de roedores razón por la cual se optó por trabajar solo con esta parte de la muestra. La meteorización del conjunto fue de $73,20 \%$ para los estadios 1 y 2 . Mientras que los valores de rho para la correlación entre la densidad ósea y las unidades anatómicas preservadas dieron un resultado positivo para el conjunto adulto y uno negativo para el subadulto. La interpretación de este patrón es la misma que para otros conjuntos: el ser humano como posible acumulador/distribuidor de partes anatómicas.

Los taxones presentes en el sitio son siete. De ellos los roedores presentan dos tamaños corporales. Además se asignaron especímenes "no identificables" a tres tamaños corporales.

En cuanto a los camélidos se identificó la presencia de una llama y una vicuña adultas y tres camélidos subadultos. En cuanto a aspectos de la anatomía económica se registró para el esqueleto apendicular la presencia de elementos de alta utilidad económica en términos de carne y médula ósea. El esqueleto axial presenta partes de baja utilidad.

\subsubsection{Yutopián Estructura 1}

Esta estructura presentó una alta integridad en términos del registro arqueológico en general. En cuanto a la arqueofauna se pudo establecer que el 94,85\% de la muestra presentó valores bajos de meteorización y que solo el $0,26 \%$ había sido afectada por agentes tafonómicos tales como carnívoros y roedores. El conjunto de camélidos presentó un problema de equifinalidad en relación a los valores de densidad ósea y las partes anatómicas representadas ya que el resultado de la correlación dio positiva y significante estadísticamente, lo que debería ser interpretado como la conformación del conjunto mediada por la densidad ósea. A partir de este resultado se trató de establecer cual pudo haber sido el agente causante de ello. Lo que se observó es que si no se 
integraba al análisis los elementos de valores de densidad altos y poca utilidad económica como los elementos del carpo y del tarso ("riders") el resultado cambiaba notablemente. Si bien el valor siguió siendo positivo se asemeja más a los presentes en otros conjuntos del área. Por ello creemos en este caso en particular que si bien hay una cierta tendencia a preservar las partes más densas esta no necesariamente debería estar asociada a factores naturales. Líneas independientes de análisis como la meteorización y la acción de carnívoros y roedores por un lado y el resultado del $r_{s}-.371 \mathrm{p} .000$ para el conjunto de subadultos permite observar la incongruencia del valor obtenido para el conjunto de camélidos adultos.

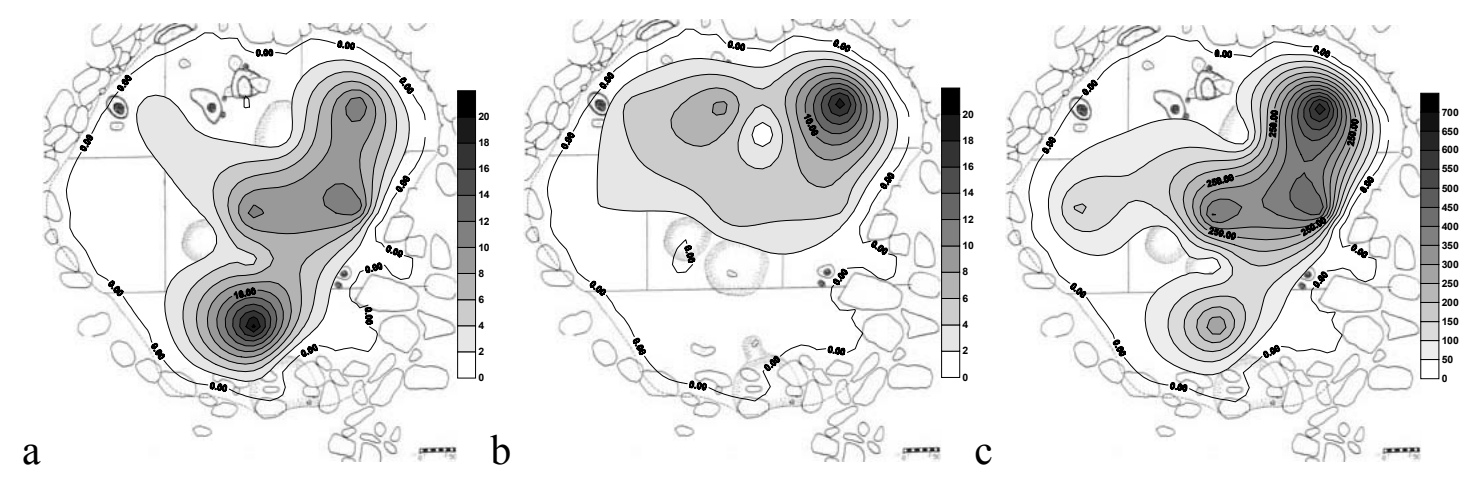

Figura 10.5 Distribución de especímenes en la Estructura 1. a) Tamaño corporal 1, b) Tamaño corporal 2, c) Tamaño corporal 4.

Una vez establecida la integridad del conjunto se estableció la presencia de 12 taxones. El taxón AVES se dividió en tres tamaños corporales, Rodentia en dos y Artiodactyla en dos. A esto hay que agregarle cinco categorías de tamaño corporal de especímenes no identificables. De estos doce taxones al menos siete poseen marcas y huellas de acción humana directa (marcas de corte, impactos, alteración térmica, etc).

En cuanto a dispersión de los taxones dentro de la estructura se puede apreciar en la Figura 10.5 que el grueso de los especímenes correspondientes al tamaño corporal 1 se ubica al sur de la estructura y los de tamaño corporal 2 en el norte junto con los de tamaño corporal 4.

Los elementos y especímenes de camélidos adultos y subadultos se ubican en concentraciones ubicadas diferencialmente en el espacio. Como se puede observar en la Figura 10.6.a y b, la disposición de los camélidos adultos es más amplia que la de subadultos aunque las mayores frecuencias recaen para los dos conjuntos en la zona más próxima al fogón (sector este de la estructura). La diferencia en las frecuencias de especímenes está dada por la mayor presencia de los asignados a la categoría adultos 
que a la de subadultos. Esto expresado en términos de mxMNI nos da un número de tres adultos y dos subadultos de los cuales al menos uno sería menor a tres meses. Este último dato ubicaría el consumo de este animal aproximadamente en invierno.

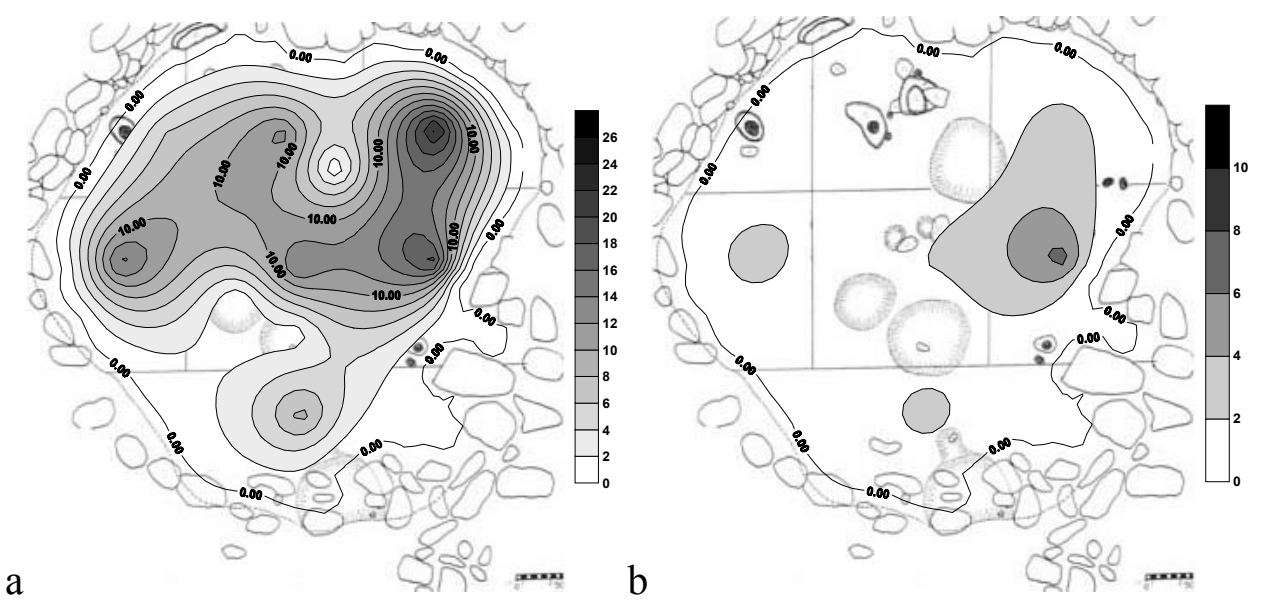

Figura 10.6. Distribución de camélidos en la Estructura 1. a) Adultos, b) Subadultos.

En cuanto a la representación de las partes esqueletales tenemos que para el conjunto adulto el esqueleto apendicular se presenta completo para el lado izquierdo (delantero y trasero) en tanto que el lado derecho está más representado para la pata delantera que para la trasera. El esqueleto axial está representado por todas sus partes. En el caso del subconjunto de subadultos tenemos representada más la parte derecha que la izquierda del esqueleto apendicular (delantero y trasero).

Debido a esta representación diferencial de las partes esqueletales básicas pensamos que el reparto y la distribución de camélidos deben haber jugado un rol importante dentro de la economía de esta unidad doméstica.

\subsubsection{Yutopián Estructura Patio Núcleo1}

La muestra de esta unidad es pequeña, aunque fueron identificados cinco taxones y dos categorías de tamaño corporal. La meteorización es baja así como la frecuencia de la acción de carnívoros y roedores. En cuanto a los camélidos se identificó la presencia de un subadulto. Los restos se hallan diseminados por todas la unidades excavadas (350, 352, 354 y 357). La densidad de especímenes para este caso es de 26,25 especímenes por m3, lo cual es una densidad baja comparada con otros conjuntos. 


\subsubsection{Loma Alta Núcleo E}

El conjunto recuperado presenta estadios de meteorización 1, 2 y 3. El 99,82\% de la muestra presenta estadios de meteorización 1 y 2 . El estadio 3 fue asignado a cuatro especímenes los cuales fueron localizados en un sector acotado de la excavación (Cuadrícula A). La acción de roedores y carnívoros ha sido identificada en el 4\% de la muestra.

En cuanto a los camélidos tenemos que la correlación entre los valores de densidad ósea y las unidades anatómicas representadas presentan un resultado positivo para el conjunto adulto y negativo para el subadulto. Nuevamente estos resultados nos hacen plantear el rol de la densidad ósea en la conformación de estos conjuntos. Si partimos de la base que la destrucción de los elementos óseos están ligados a la resistencia mecánica que tienen diversas zonas a la destrucción por factores naturales (físicos o químicos), entonces tendríamos una secuencia de destrucción que empezaría por las porciones más débiles y finalizaría por las más duras. En este caso la secuencia de desaparición podría ser: porciones menos densas de juveniles - porciones menos densas de adultos - porciones más densas de juveniles - porciones más densas de adultos. Teniendo en cuenta este modelo la muestra se ubicaría en los dos extremos de esta sucesión, por lo que creemos que la densidad ósea no habría sido un factor determinante en la conformación del conjunto de camélidos.

El nivel de ocupación está compuesto por la presencia de quince taxones de los cuales ocho presentan indicios de utilización humana claros.

Los conjuntos de camélidos al igual que lo observado en otras unidades domésticas se ubican en concentraciones ubicadas diferencialmente en el espacio. Como se puede observar en la Figura 10.7.a y b la distribución del conjunto de camélidos adultos es más amplia que la de subadultos. Para los dos casos el volumen mayor de especímenes se aglutina alrededor de uno de los fogones principales que se encuentra en el centro del R47. La segunda concentración se ubica también en un área asociada a actividades de combustión y en la que se halló el fondo de una vasija in situ quizás utilizada como refractario en un fogón (Scattolin 1990). La diferencia en las frecuencias de especímenes está dada además por la mayor presencia de adultos que de subadultos. Esto expresado en términos de mxMNI nos da un número de ocho adultos y seis subadultos de los cuales al menos dos serían menores a seis meses. Este último dato ubicaría el consumo de estos animales aproximadamente a fines de invierno o mediados de primavera. 


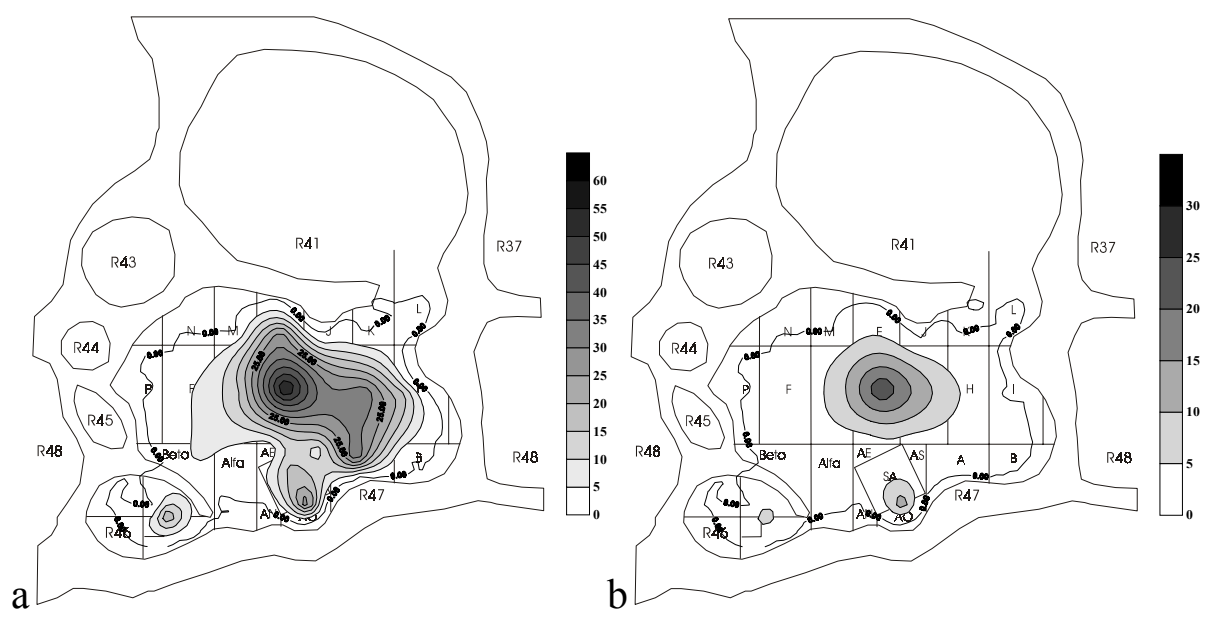

Figura 10.7. Distribución de camélidos en LANE. a) Adultos, b) Subadultos.

En cuanto a la disposición de los especímenes de acuerdo a su asignación a nivel de especie se pudo observar que los restos de las llamas han sido recuperados principalmente de la porción sur del recinto, en tanto que el guanaco se ubicó en la porción norte y la vicuña fue hallada en el centro del patio en asociación con el fogón principal (Figura 10.8). Evidentemente esta disposición espacial de las especies es diferencial lo que podría interpretarse como el producto del descarte de restos óseos producto de distintos eventos. En otros contextos del Período Formativo se han encontrado que el descarte de elementos de distintas especies se ha realizado en distintos espacios, sean estos internos o externos a la unidad doméstica (Haber 1999, 2002)

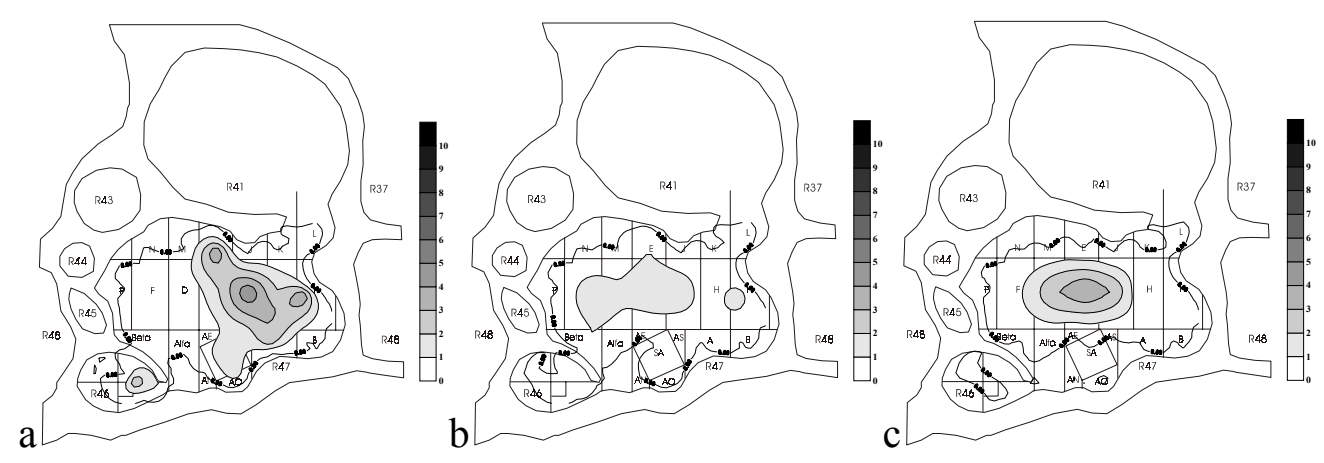

Figura 10.8. Distribución de especímenes en LANE. a) Llama 1, b) Guanaco, c) Vicuña. 
En cuanto a las partes esqueletales presentes para los distintos conjuntos tenemos para los adultos la representación de todas las partes en tanto que el subconjunto de los subadultos presenta en mayor parte elementos del esqueleto apendicular. Una cuestión interesante planteada en este conjunto es el análisis de la lateralidad de los elementos hallados. Para el esqueleto axial delantero se pudo observar que los elementos del lado derecho estaban sobrerrepresentados respecto de sus pares del lado izquierdo en todos los casos, variando la diferencia desde un elemento hasta tres como en el caso del radioulna. Para el esqueleto apendicular trasero la relación es la misma, con mayor cantidad de elementos del lado derecho respecto de los del lado izquierdo. Para el caso del conjunto subadulto se vuelve a repetir un esquema similar. Esta vez para el esqueleto apendicular delantero la sobre representación pasa por el lado izquierdo, en tanto que para el posterior vuelve a repetirse el lado derecho.

Esta situación nos permite abordar varios aspectos de la economía de los habitantes de la unidad doméstica. Por un lado el descarte diferencial de los elementos respecto de su asociación con determinada especie nos permite estimar que los eventos de procesamiento ocurrirían diacrónicamente permitiendo de este modo preservar de algún modo la unidad de cada individuo. Por otro lado la sobrerrepresentación de determinados elementos de un lado en particular respecto de su homólogo podría indicar la presencia de redistribución de las partes y que el individuo completo no sería consumido en su totalidad dentro de la unidad doméstica. En cuanto al rol de esta unidad como consumidora de partes esqueletales podemos ver que las encontradas corresponden en general a las que poseen más cantidad de carne respecto de nutrientes internos.

Marshall (1994) propone para casos etnoarqueológicos de África que las unidades domésticas en las que viven los cazadores más exitosos poseen un mayor número de partes esqueletales representadas a la vez que la biodiversidad hallada en esos contextos sería la más elevada respecto de otras unidades donde los cazadores hayan tenido menos éxito en sus actividades cinegéticas. Para este nivel de ocupación quizás podría interpretarse que estamos en una situación similar a la propuesta para un cazador exitoso. La alta proporción de animales silvestres y la diferencia en cuanto a partes esqueletales básicas presentes permitirían entonces inferir que las actividades de caza asociadas estarían relacionadas quizás a un comportamiento de reparto. Este, a su vez, podría estar conectado con el consumo inmediato de las partes de mayor utilidad en término de carne. 


\subsection{Bloque Temporal 3}

Este Bloque Temporal está definido para las ocupaciones datadas en el tramo comprendido entre los 1500 y 1200 A. P. Está compuesto por los depósitos III y IV del sitio Bañado Viejo y el Núcleo G de Loma Alta. Por lo que tenemos muestras de dos ambientes distintos: fondo de valle a una altura de $1200 \mathrm{msnm}$ y piedemonte, ubicado a $3000 \mathrm{msnm}$. Asimismo los contextos arqueológicos de los que proviene los conjuntos se diferencian ya que Bañado Viejo proviene de un sitio sin arquitectura remanente en tanto que para el Núcleo $G$ de Loma Alta los conjuntos provienen de niveles de ocupación dentro de recintos con arquitectura remanente en piedra.

\subsubsection{Bañado Viejo Depósito 3-4}

Estos depósitos son los que presentan una mayor integridad del conjunto, no solo en términos del conjunto faunístico, sino también en cuanto a la asociación con restos cerámicos y líticos (Izeta y Scattolin 2001, Scattolin et al. 2001).

La meteorización para ambos depósitos se comporta de manera similar presentados solo los estadios 1 y 2. La acción de otros agentes tafonómicos como carnívoros y roedores no ha sido registrado en estos depósitos.

En cuanto a la composición de la muestra se registró la presencia de diez taxones distintos. Dentro de AVES se identificaron dos tamaños corporales. Para los "no identificables" se determinaron tres tamaños corporales. La mayor frecuencia fue establecida para el tamaño corporal 4 y dentro de este se identificó Hippocamelus antisensis, Lama (Vicugna) vicugna, Lama glama y Lama guanicoe. Para L. glama se reconoció al menos un individuo juvenil determinado a partir de un fragmento de fémur cuyas medidas son superiores a los estándares actuales de llama y guanaco andino. $L$. (V.) vicugna presentó un individuo adulto. Por último L. guanicoe presenta elementos pertenecientes a un individuo adulto y otro juvenil.

\subsubsection{Loma Alta Núcleo G(LANG)}

Al igual que las arqueofaunas analizadas hasta el momento la integridad de esta respecto a la acción de agentes tafonómicos es alta. La meteorización baja (estadios 1 y 2) suma el $95,20 \%$ de la muestra, en tanto que la acción de roedores afectó a siete especímenes $(1,15 \%)$ y la acción de carnívoros no ha sido detectada.

La densidad ósea no habría sido un factor determinante en la conformación del conjunto ya que para los camélidos adultos el resultado de la correlación entre los 
valores de densidad ósea y las unidades anatómicas representadas es negativo. Por otro lado para el los camélidos subadultos el resultado es positivo. Esta incongruencia en los resultados permitió advertir que la tendencia negativa y positiva de cada grupo etario representaría tendencias moderadas ya que los valores se encuentran extremadamente cercanos al valor 0 (no correlación). Esto volvería a confirmar la buena preservación de la muestra ósea y la relativamente baja acción de agentes tafonómicos.

En cuanto a la composición de la muestra se pudo observar que para la totalidad de los recintos se identificaron cinco taxones y cinco tamaños corporales distintos. Respecto de la distribución de estos según su procedencia se registraron cinco taxones en el R88 y en el R87 y dos en el R89.

El conjunto de camélidos está compuesto por especímenes que provienen de todas la estructuras. La mayor parte de los especímenes asignados a este taxón fueron extraídos del R87 el cual es notable por su gran cantidad de especímenes óseos la cual expresada en densidad de especímenes por dm3 de sedimento excavada da un valor de 19,1 especímenes/dm3, en tanto que los valores obtenidos para el R88 es de 0,65 especímenes/dm3 y para el R89 de 1,43 especímenes/dm3.

El tamaño pequeño del R87 y la gran diferencia en la cantidad de restos hallados respecto de las otras estructuras quizás pueda estar mostrando un uso diferencial de este espacio como basurero

Se identificó la presencia de un individuo adulto y un juvenil. Para los elementos asignados a la categoría adulto se registraron elementos del esqueleto axial y apendicular. De este último para los miembros anteriores solo se identificó un carpiano (derecho), en tanto que para los traseros se reconoció la presencia de fragmentos de innominado, tibia y un maléolo lateral (todos del lado izquierdo). Para el subadulto los elementos identificados corresponden al esqueleto apendicular tanto delantero como trasero.

Las fracturas asociadas son en su mayoría secas y los tamaños de los fragmentos (para las dos clases de edad) son menores a $60 \mathrm{~mm}$. En cuanto a la alteración térmica fue identificada en especímenes asignados al conjunto adulto.

El ingreso de partes esqueletales se habría efectuado en general completo para los camélidos adultos. Esto podría verificarse para el esqueleto axial y la pata trasera izquierda (Figura 10.9.a) En el caso de los subadultos esto no pudo establecerse ya que si bien se presentan elementos del esqueleto axial tanto delantero como trasero, en general no coinciden la lateralidad de los elementos (Figura 10.9.b) 


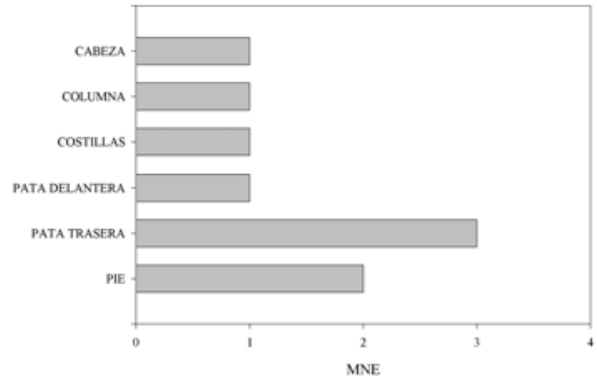

a

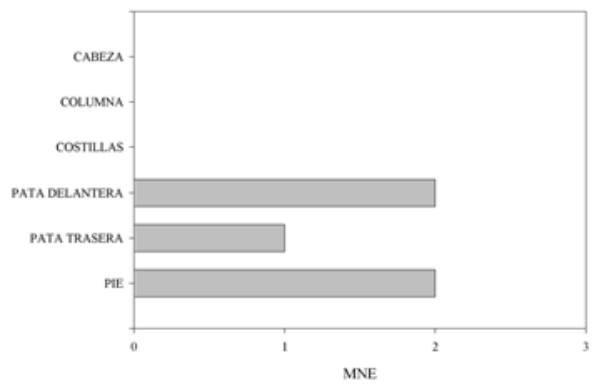

b

Figura 10.9. Representación diferencial de partes esqueletales básicas de camélidos. a) Adultos y b) Subadultos

\subsection{Bloque Temporal 4}

\subsubsection{Bañado Viejo Depósito 1-2}

Estos depósitos son los más superficiales del sitio y los que poseen un mayor volumen de restos faunísticos (Izeta y Scattolin 2001, Scattolin et al. 2001).

La meteorización para ambos depósitos se comporta de manera similar presentados solo los estadios 1 y 2. La acción de roedores ha sido registrada en cinco especímenes de estos depósitos ( $0,88 \%)$.

En cuanto a la composición de la muestra se registró la presencia de diez taxones distintos. Dentro de AVES y Rodentia se identificaron dos tamaños corporales. Para los no identificables se determinaron dos tamaños corporales. La mayor frecuencia fue establecida para el tamaño corporal 4 y dentro de este se identificó la presencia de Lama (Vicugna) vicugna, Lama glama y Lama guanicoe. Para L. glama se identificó la presencia de al menos un individuo adulto. $L$. (V.) vicugna presentó un individuo adulto. Por último $L$ guanicoe presenta elementos pertenecientes a un individuo adulto. Además se encontraron elementos asignados a un individuo juvenil.

\subsubsection{Morro de las Espinillas}

Durante el desarrollo de esta tesis la inclusión de este conjunto faunístico en la muestra fue un motivo de discusión. Varias veces fue añadido y otras tantas separado. Todo ello producto de la escasa frecuencia en que habían sido hallados los restos arqueofaunísticos.

No obstante ello se decidió integrarlo al estudio por varias causas: a) su ubicación en el final de la secuencia tal como lo atestigua el resultado del fechado 
radiocarbónico; b) el diseño arquitectónico del asentamiento cuya forma se asimila a los de períodos más tardíos; y, c) el volumen apreciable de sedimento excavado.

Todo ello nos hizo pensar en que quizás el pequeño tamaño del conjunto pueda deberse no a una cuestión de muestreo si no a un patrón de descarte distinto al observado para otros asentamientos. Asimismo la presencia de restos de cáscara de huevo que posiblemente pertenezcan a "suri" ( $P$. pennata) fue otro de los factores claves para el estudio y comparación de lo hallado en este sitio arqueológico.

Otra característica notable es la relativamente alta frecuencia de taxones identificados ya que de solo 18 especímenes identificados se pudo establecer la presencia de al menos seis taxones y una clase de tamaño corporal para el espécimen no identificable.

La meteorización es baja y los tamaños de los fragmentos varían entre 13 y 66 mm encontrándose entre ellos un calcáneo casi completo.

En cuanto a los especímenes de tamaño corporal 4 las partes representadas refieren tanto al esqueleto axial como al apendicular.

La alteración térmica se registró en especímenes del tamaño corporal 4 y 2 (Chaetophractus vellerosus).

A partir de estos indicadores se sugiere que la presencia de especímenes óseos en los sondeos corresponde a indicios de la utilización de la fauna en el sitio por parte de agentes humanos y que su escasa frecuencia no estaría relacionada con el tamaño de la muestra excavada. Si bien para confirmar esta hipótesis deberíamos ampliar las superficies excavadas, creemos que esta disposición de los desechos en áreas restringidas (quizás basurales) sería más afín a lo establecido para poblados del Periodo de Desarrollos Regionales. Este sitio ha sido planteado como Scattolin (2002) como uno de los exponentes de la transición entre el Período Formativo y los períodos posteriores, por lo cual creemos que lo dicho más arriba puede ser una manifestación más de los cambios observados en otros aspectos de los restos materiales preservados de esta ocupación.

\subsubsection{Tesoro 1}

Este sitio presentó una de las muestras más pequeñas de la colección. Sus 14 especímenes permitieron identificar la presencia de cuatro taxones, tres de los cuales son de utilidad económica. 


\subsubsection{Loma Alta Núcleo F}

Este núcleo es el que posee el fechado más moderno de la ocupación de Loma Alta y contemporánea con la de Potrero Antigal.

La información tafonómica relevada en el conjunto nos permitió observar que los estadios 1 y 2 son los que se presentan en mayor frecuencia para todos los tamaños corporales $(95,36 \%)$. La modificación por roedores y carnívoros ha sido detectada en dos especímenes $(0,39 \%)$. Por último para la correlación entre los valores de densidad ósea y las unidades anatómicas preservadas se observó para el conjunto adulto una no correlación y para el de juveniles una correlación positiva débil. De nuevo ante este indicador se obtuvo un resultado ambiguo, el que creemos deberá ser explicado por otros factores que no estén relacionados con agentes tafonómicos naturales.

El conjunto presenta ocho taxones en el R63A y nueve para el R67. En ambos recintos el tamaño corporal más abundante es el 4 , dentro de los que se determinó la presencia de llama y guanaco.

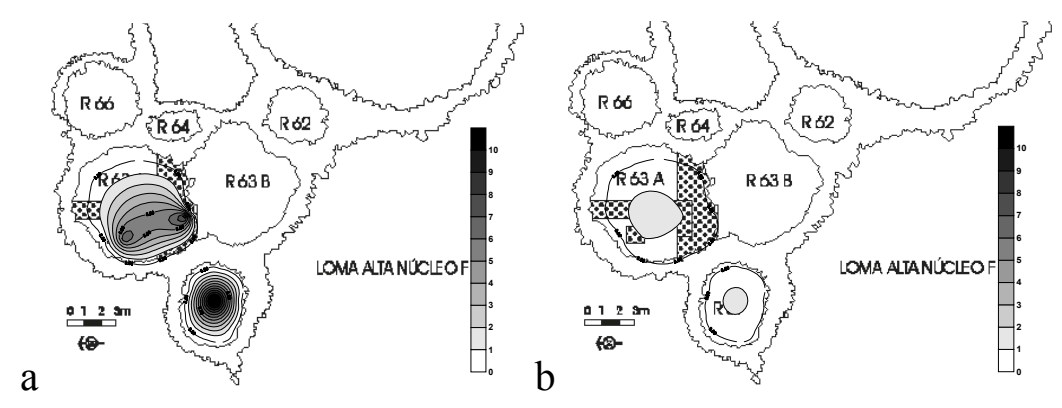

Figura 10.10. Distribución de especímenes de camélidos. LANF. a) Adultos, b) Subadultos.

La llama se encuentra en el S1 del R67 y el S5 y Trinchera de R63A en tanto que los restos de guanaco han sido hallados en las unidades S1 y AS5. Debido a esto es que se observa en el R67 una mayor frecuencia de especímenes y que en el R63A se noten dos acumulaciones, las que de un modo genérico pueden estar representando la depositación en distintos espacios de los elementos de llama y guanaco (Figura 10.10.a).

En cuanto a las clases de edad representadas las determinadas específicamente corresponden a adultos. Además se estableció la presencia de un animal subadulto.

Las partes anatómicas representadas en este conjunto corresponden a tanto al esqueleto axial como al apendicular para los adultos y solo los elementos más distales del esqueleto axial para los subadultos (pies). Esto puede observarse en la Figura 10.11. 


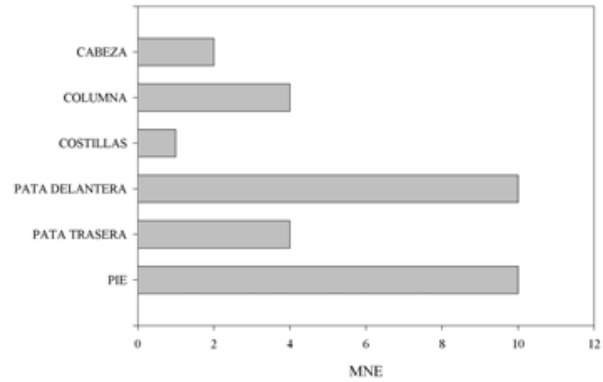

a

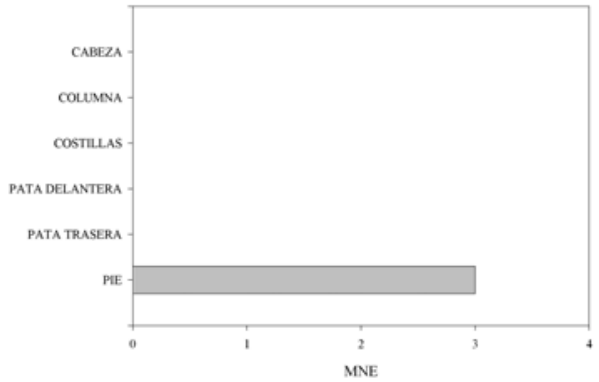

b

Figura 10.11. Representación diferencial de partes esqueletales básicas de camélidos. a) Adultos y b) Subadultos

En cuanto a la utilización de los camélidos se pudo observar que el conjunto estaría representado por unidades anatómicas de bajo rendimiento económico.

Esto puede ser interpretado de distintos puntos de vista, ya sea como una cuestión basada en el transporte de partes anatómicas o como un producto de la distribución de estas entre distintas unidades domésticas.

\subsubsection{Potrero Antigal}

Como se vio con anterioridad este sitio presenta los restos provenientes de un sondeo de un recinto habitacional. Por ello la discusión de la fauna recuperada solo va a ser referida a unos pocos aspectos.

En cuanto a la información tafonómica registrada en el conjunto se pudo observar que la muestra se comporta de manera similar independientemente del tamaño corporal tratado, presentando el grueso del material un estadio 2 (91,91\%) mientras que los estadios 1 y 3 están representados en baja frecuencia. La acción de roedores se registró en un solo espécimen de toda la muestra. Estos datos en conjunto muestran que el grueso del material habría sido depositado contemporáneamente y que la acción de distintos agentes tafonómicos no habrían afectado severamente al conjunto.

En cuanto a la composición taxonómica del sitio, se ha registrado la presencia de al menos cuatro taxones y dos tamaños corporales distintos de especímenes no identificables, siendo el más abundante Lama sp.

En cuanto a la composición interna de esta última categoría taxonómica se identificaron camélidos adultos y subadultos. Los primeros están representados por más especímenes que el segundo por lo que se estima la presencia de más elementos 
correspondientes a animales adultos que a subadultos ya que el MNI calculado para cada categoría es de al menos un individuo.

Para el individuo adulto los elementos representados son: vértebra, escápula, radioulna, tibia, calcáneo y metapodio. Para el individuo subadulto las partes representadas corresponden a su vez a un fragmento de cráneo y otro de vértebra. En vista de esto se observa que para el conjunto adulto la mayor parte de los elementos representados pertenecen a el esqueleto apendicular (la excepción es la vértebra) y para el conjunto subadulto la representación corre por parte de elementos del esqueleto axial.

Por lo que se pude observar el conjunto de adultos presentan partes esqueletales con mayor valor económico que los del conjunto subadulto.

En cuanto a la fragmentación se vio que los especímenes no sobrepasaban el límite de los $60 \mathrm{~mm}$, que las fracturas asociadas correspondían en la gran mayoría al tipo seco y en general no han sido asociadas a alteración térmica. Las huellas registradas correspondieron a marcas de corte (vértebra) e impactos (lascas de hueso largo) y la acción térmica se registró en cinco especímenes (tipo 1, carbonizado).

Respecto a huellas de acción humana en el resto de los especímenes asignados a otros taxones se registró un fragmento de costilla asignado al tamaño corporal 2 (¿Lagidium sp?).

En síntesis, el registro arqueofaunístico de esta unidad doméstica parecería haber sido depositado contemporáneamente, así como lo habría sido el uso de la fauna. 
Antes de proceder a discutir las conclusiones a las que hemos llegado pensamos útil realizar ciertas consideraciones. Por lo que se pudo observar en los capítulos precedentes los objetivos generales de esta tesis eran los de:

- Determinar la composición de los conjuntos arqueofaunísticos de los sistemas aldeanos del Período Formativo (Primer milenio A. D.), que sirvieron de base al desarrollo de los sistemas socioeconómicos más complejos de las sociedades semi-urbanas del Período de Desarrollos Regionales en los valles del Noroeste argentino a través del análisis de sitios arqueológicos del Sur de los Valles Calchaquíes (Diversidad taxonómica y etaria)

- Generar un modelo relacionado con el sistema de subsistencia (caza-pastoreo) de los habitantes de estas aldeas, a la vez que se intenta contribuir al conocimiento de la variabilidad general de recursos animales.

En el análisis y discusión de los datos obtenidos de los conjuntos arqueofaunísticos estudiados se encontraron ciertas regularidades a la vez que cada conjunto proporcionó información acerca de distintos aspectos de la economía doméstica del Período Formativo.

Con ello se generó información acerca de prácticas de apropiación de los recursos, la distribución/acumulación y el consumo de la fauna.

En vista de que se abordaron distintos aspectos en el estudio de cada uno de los conjuntos se procederá a su evaluación final según dos aspectos generales: el metodológico y los resultados obtenidos en cuanto al uso de la fauna en el pasado y su tendencia a lo largo del tiempo.

\subsection{Resultados obtenidos en relación con aspectos metodológicos}

En esta parte se tratará acerca de la evaluación de cuatro objetivos específicos planteados en esta tesis. Estos son; la evaluación del componente caza versus el pastoreo; observar los patrones de fracturas; registrar marcas de procesamiento; visualizar patrones en el material óseo formatizado; aplicar y evaluar nuevos métodos de cuantificación. 
11.1.1. Reevaluación comparativa de las muestras disponibles para establecer la relación componente de caza vs. pastoreo con el objeto de establecer las diferencias y similitudes entre ambos.

Esto se llevó a cabo mediante la aplicación de técnicas estadísticas multivariadas en las cuales se utilizaron medidas correspondientes a elementos arqueológicos y elementos comparativos actuales de camélidos del noroeste argentino con el fin de avanzar en la identificación taxonómica de los camélidos sudamericanos a partir de la discriminación por medio de análisis morfológico-comparativos de los elementos postcraneales pertenecientes a las distintas especies que componen esta familia.

A lo ya elaborado anteriormente para las falanges proximales se le sumó el análisis de otros elementos postcraneales. Se efectuaron análisis en todos los huesos largos del esqueleto apendicular siguiendo los parámetros dados por otros autores (Kent 1982 y Von den Driesch 1976). Para los elementos de la región tarsal y la región carpal de camélidos al no haber antecedentes en este tipo de estudios se adaptó la metodología propuesta por Morlan (1991) para Bison sp. Por ello se procedió a la confección de una guía en la que se detalla como fueron tomadas las medidas para estos elementos óseos (ve Anexo 4). Las medidas obtenidas de los huesos actuales fueron analizadas estadísticamente junto a 169 elementos óseos arqueológicos.

Debido a que las muestras de referencia actuales son escasas y aún no se ha confeccionado un estándar para las medidas de elementos óseos para ninguna de las especies de camélidos presentes en el noroeste argentino se procedió a utilizar los siguientes tipos de análisis estadísticos: a) Diagramas de dispersión bivariados, b) aplicación del Coeficiente de similitud "Manhattan Distance" o "City Block"; c) análisis de agrupamiento UPGMA (Unweighted Pair Group using Arithmetical Averages); d) análisis de los componentes principales. Las técnicas b) y c) se efectuaron con el fin de poder expresar gráficamente las relaciones de similitud entre los elementos.

\subsubsection{Profundización en el conocimiento de los patrones de fracturas.}

El estudio de los patrones de fracturas es un indicador que ha sido utilizado en arqueología para inferir distintos tipos de acciones, sean estas naturales o culturales (Bonnichsen y Sorg 1989, Johnson 1989, Marean 1991, Miotti 1990/92, Outram 2001). Para determinar esta primera cuestión (natural vs. cultural) se han empleado indicadores tales como la forma de la fractura (Sadek-Kooros 1975) o las características de la superficie de fractura (Johnson 1989). 
En nuestro caso hemos tomado los criterios nombrados mas arriba con el fin de aproximarnos a la identificación de patrones de fractura en los conjuntos sumándole un criterio propuesto por Outram (2001) que es el largo máximo de las astillas y uno propuesto por el autor basado en la cantidad de superficie relativa preservada en cada espécimen óseo determinada mediante el calculo de superficie efectuado por el programa ArcView (GIS software). Esta última aproximación es novedosa y su empleo en el conjunto servirá en el futuro como ejemplo de aplicación de la metodología. Con ello se ha logrado profundizar en el uso alternativo de nuevos procedimientos en el estudio de conjuntos arquofaunísticos.

\subsubsection{Características de los cortes y marcas, con especial interés en la determinación} de patrones.

Este aspecto de los conjuntos fue abordado básicamente siguiendo los criterios sintetizados en Mengoni Goñalons (1999). El material se procesó de dos maneras: la primera se realizó a ojo desnudo y la segunda con lupa binocular de bajos aumentos.

Las interpretaciones se han realizado de acuerdo a los rasgos hallados con la implementación de las primeras estrategias de observación, las cuales tienen en cuenta criterios de forma, ubicación y contexto de las huellas de origen antrópico. A partir de ello se han identificado principalmente marcas de corte y huellas de impacto. Otros tipos de marcas también han sido identificadas, pero en menor proporción.

\subsubsection{Resultados de la aplicación del software de GIS para la cuantificación de} elementos óseos versus métodos tradicionales.

Desde hace relativamente poco tiempo se ha implementado dentro de los estudios arqueológicos el uso de sistemas de información geográfica. En general este estuvo dirigido hacia cuestiones relacionadas con el uso del espacio a nivel regional. Basado en el mismo concepto es que en los últimos años Marean y colaboradores (2001, Abe et al. 2002) adaptaron el uso de este tipo de software a la problemática zooarqueológica cambiando la escala en la que se focalizaban anteriormente los estudios. Esta vez, en lugar de analizar cuestiones espaciales territoriales la entidad a estudiar fueron unidades espaciales de elementos óseos. Al igual que en otras áreas la aplicación de este tipo de tecnología es escasa, pero hasta el momento ha demostrado ser eficiente en cuestiones relacionadas con cuantificación como el cálculo del MNE o marcas de corte. 
Todos los procedimientos explicados en el Capítulo 3 permitieron crear las plantillas para Camelidae en general. Sobre estas plantillas se procedió a ingresar cada uno de los elementos o especímenes identificados tanto a nivel taxonómico como a nivel elemento. Los elementos (o especímenes) así dibujados son superpuestos uno sobre otro, lo que permite el cálculo de la cantidad de veces que un píxel (medida estándar) ocupa el mismo lugar en cada porción del elemento. Esta simple suma por superposición de especímenes es la que nos brindó el valor del MNE para cada elemento.

La ventaja de este método con respecto a la cuantificación tradicional es que permite ingresar fragmentos de diáfisis y con ello ajustar mejor el MNE a la realidad de la muestra. Asimismo la representación gráfica, unida a las bases de datos, permite observar patrones de fractura y procesamiento de manera más rápida.

Este método, también permite el análisis de marcas de corte (Abe et al. 2002). Por último existe un enorme campo de potencialidades para trabajar con este tipo de metodología ya que permitiría cuantificar casi cualquier rasgo que se quiera de las distintas sub-muestras a ser analizadas (por ejemplo superficies con meteorización diferencial en el mismo elemento, superficie quemada $v s$. no quemada, etc.)

La aplicación de esta técnica en los conjuntos analizados para la Tesis Doctoral permitió realizar las siguientes observaciones en cuanto a la performance del programa:

1- El programa ArcView demostró ser muy versátil a la hora de realizar el cálculo de MNE ya que permite corregir errores con suma rapidez.

2- Es posible realizar con confianza el cálculo de MNE a partir de fragmentos de diáfisis.

3- Al basarse en una lógica intuitiva permite interpretaciones sumamente rápidas de la configuración del conjunto.

4- Permite realizar un inventario digital de los elementos diagnósticos del conjunto arqueofaunístico.

En cuanto a las potencialidades desarrolladas y aplicadas en la Tesis Doctoral se observó:

1- Debido a su interfaz gráfica permite observar patrones respecto a la presencia o ausencia de elementos óseos o partes de estos elementos.

2- Por la característica nombrada anteriormente es posible además cuantificar la superficie preservada. 
Por último y en cuanto a la diferencia entre la utilización de esta metodología y otras utilizadas para el cálculo de MNE no se pudo observar una diferencia significativa ya que el enfoque que se le dio a la base de datos fue el mismo criterio que utilizó Marean para ubicar los especímenes en la plantillas digitales, es decir la identificación mediante zonas diagnósticas

\subsection{Resultados obtenidos en relación con el análisis de la arqueofauna.}

En los capítulos anteriores se han tratado varios tópicos referentes tanto a cuestiones tafonómicas y formación del registro arqueofaunísticos así como a asuntos relativos a la economía de las sociedades formativas y su evolución a lo largo del primer milenio A. D.

En cuanto a los controles tafonómicos aplicados a las muestras se pudo observar una tendencia general a presentar estadios de meteorización bajos en frecuencias que van desde el $91,5 \%$ al $100 \%$ de la muestra. Esto es congruente con lo planteado para la depositación en ambientes áridos por Nasti (1991) y es análogo al caso de Casa Chávez Montículos en el que las mayores frecuencias de estadio de meteorización se ubicaban en las categorías 1 y 2 . Además y aunque no pretendemos proponer que una unidad doméstica abandonada sea una buena madriguera para carnívoros (como si lo serían los aleros y cuevas) se efectuó el control del daño de carnívoros en la muestra con el fín de determinar si este agente habría modificado sustancialmente a alguno de los conjuntos. El resultado muestra para todas las ocupaciones una mayor semejanza de la configuración de los conjuntos al modelo humano que al modelo de carnívoro tal cual fuera planteado por Mondini (2002). Los criterios tomados basándonos en Mondini nos permitieron observar que la frecuencia de marcas de acción de carnívoros nunca superan el $1 \%$ de la muestra (la expectativa del modelo es de un máximo de $25 \%$ aunque los casos arqueológicos comparados no presentan mas del 3\%); el porcentaje de corrosión por ácidos gástricos es $0 \%$; el daño producido por la utilización de artefactos sobre elementos óseos es de un promedio de $0,79 \%$; el porcentaje de huesos quemados varia entre $0 \%$ y $25 \%$; la asociación con copros de carnívoro es nula y la asociación con artefactos es variable pero supera el valor mínimo del 50\%. Todo ello nos permitió descartar la conformación por este agente tafonómico.

En cuanto a la acción de roedores sobre el conjunto, si bien este fue variable, el valor máximo registrado fue el del 3\% de la muestra para un sector acotado de LANE. 
Por último, y por si los demás indicadores arqueológicos como arquitectura remanente, infinidad de tiestos cerámicos, puntas de proyectil e instrumentos líticos, metales trabajados, etc., etc., no fueran suficientes, se procedió a realizar un análisis con el fin de observar si la densidad ósea habría afectado la conformación de los perfiles anatómicos de los conjuntos de camélidos observados en cada sitio. En general los resultados fueron disímiles pero se llegó a la conclusión de que en el caso de que los resultados ofrecieran correlaciones positivas se debería interpretar no como la expresión de la destrucción de las partes mas blandas por agentes naturales si no que reflejarían la conformación del conjunto por su alta fragmentación asociadas tanto a técnicas culinarias como a prácticas de distribución o acumulación de distintas partes esqueletarias. Por ello creemos que el análisis de la correlación entre la densidad ósea y las unidades anatómicas representadas debe realizarse sobre cada "scan site" de cada uno de los elementos presentes en el conjunto, así como sobre el total de elementos. Todo ello sobre la base de haber separado el conjunto según clases de edad. De este modo se podrá tener un mayor control sobre los valores obtenidos evitando caer en interpretaciones erróneas o distorsionadas de la historia tafonómica de los conjuntos.

Tomando en cuenta estas consideraciones es que se procederá a interpretar la composición y estructura de cada uno de los conjuntos en términos económicos y de tendencias temporales.

La cantidad de individuos calculados en total para el conjunto ascendió a 62 de los cuales $22(35,48 \%)$ fueron asignados a alguna de las especies de camélidos sudamericanos (Figura 11.1). La proporción general de la presencia de llama es del 50\% en tanto que el resto se distribuye entre guanaco y vicuña. Esto implicaría que para el conjunto el uso de los camélidos silvestres y domésticos mantendría la misma proporción durante todo el período. Esto permitiría estimar que la caza sería un componente importante en la economía de estas aldeas tempranas y que si bien la cría de ganado doméstico habría sido un factor importante dentro de estos sistemas, su utilización como alimento no sería el principal factor por lo cual se habría criado, al contrario de, por ejemplo, la planteado por Miller y Burger (1995) para Chavín de Huantar en Perú. 


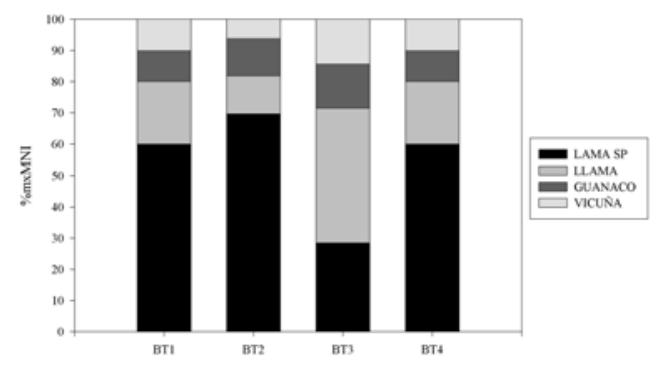

Figura 11.1. Proporción de camélidos no identificados e identificados a nivel de especie.

En términos de utilidad económica en casi todos los conjuntos están representados camélidos, cérvidos, vizcachas y peludos. Estas especies son los que se han hallado en general en otros sitios arqueológicos del noroeste argentino cubriendo todo el rango temporal de ocupación humana y el Período Formativo no es una excepción (Aschero et al 1991, Elkin 1996, Olivera 1998, Yacobaccio 1991). Estos animales son los de más porte por lo cual es comprensible que hayan sido los más explotados, pero son los camélidos en última instancia los que componen en su gran mayoría los conjuntos arqueofaunísticos.

Por ello se realizaron análisis en los conjuntos de camélidos con el fin de obtener información del manejo de los animales domésticos, los silvestres y la clase de edad a que correspondían. Todo ello fue realizado mediante análisis sincrónicos y diacrónicos. Lo que se pudo observar en primer lugar es la composición de los conjuntos en cada sitio. El primer resultado de esta aproximación nos permitió observar que los patrones de presencia o ausencia de distintos elementos nos dejaban, junto con el análisis espacial de la dispersión de esos huesos, discriminar distintos eventos de utilización de las partes esqueletales. A partir de ello se puede establecer una estructuración de los espacios y una redundancia temporal. Estas partes a su vez estarían entrando a los conjuntos como unidades separadas, es decir, que la unidad no sería el individuo sino la parte esqueletal básica tal cual como fue planteada para casos etnoarqueológicos del área andina (Haber et al. 1991, Miller 1977, Yacobaccio et al. 1998). Esto se desprende de la configuración de los perfiles anatómicos a la vez que de las cantidades de individuos calculados.

Las partes anatómicas representadas en cada conjunto varían. En general se observó que para el esqueleto axial o elementos "no largos" los elementos mayormente 
representados son los de baja utilidad como el cráneo o la mandíbula. En el caso de los huesos largos los patrones son más variados.

En cuanto al registro del consumo se advirtió que los conjuntos arqueofaunísticos presentan un alto grado de fragmentación, el cual es independiente tanto del elemento anatómico en el que se presenta como de la porción de cada elemento. Es decir, que la densidad ósea diferencial de los distintos rasgos que componen un elemento óseo no ha jugado un papel importante en la conformación de los patrones de fractura. Los tamaños de los fragmentos, a su vez, son consistentes en todas la muestras por lo cual se ha interpretado que las fracturas en general estarían asociadas a practicas relacionadas a actividades de procesamiento primario $\mathrm{y}$ secundario. Asimismo el tamaño de los fragmentos y otras características como la baja frecuencia de marcas preservadas son consistentes con los modelos planteados para la extracción de componentes tales como la grasa ósea (Church y Lyman 2003, De Nigris 1999, Outram 2001).

En cuanto a los patrones identificados, se ha observado una consistencia de las marcas relacionadas con el procesamiento primario y secundario en relación a las zonas más propensas a presentar este tipo de huellas. Esto es: los impactos se han registrado recurrentemente en diáfisis de huesos largos y las marcas de corte en las zonas de articulación tanto de huesos largos como de vértebras y costillas. La ubicación de este tipo de marcas coincide en términos generales con los modelos de procesamiento de camélidos propuestos para el área andina (Haber et al. 1991, Miller 1977, Yacobaccio et al. 1998)

De todos modos el material que presentó este tipo de características es relativamente escaso en el conjunto total de la muestra analizada.

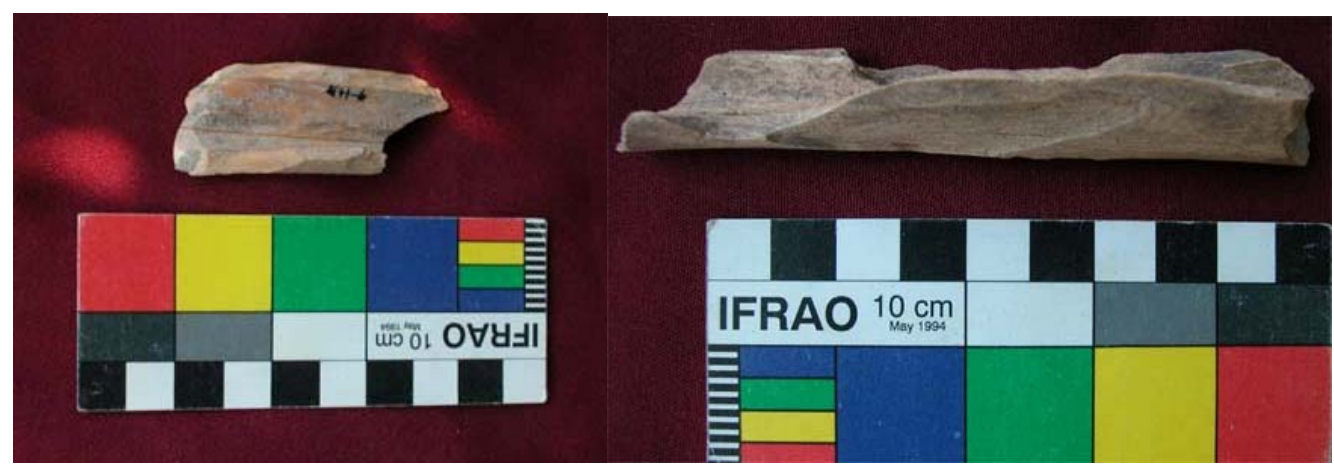




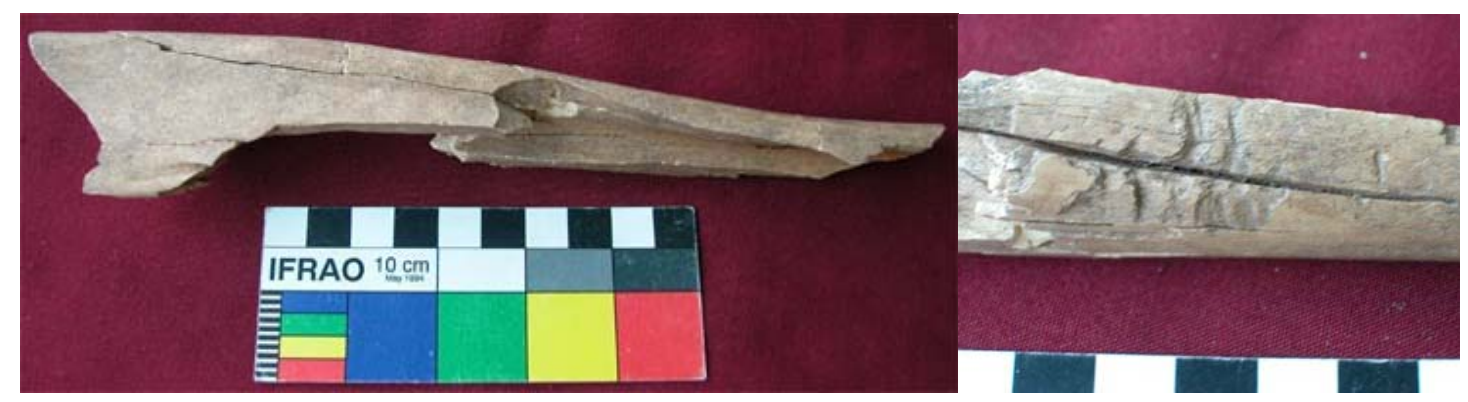

Figura 11.2. Impactos en diáfisis de huesos largos y lascas óseas.

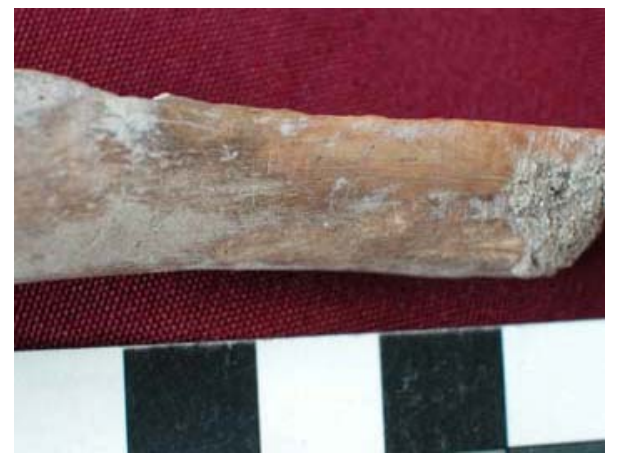

Figura 11.3. Marcas de corte en metapodio de camélido

El material óseo formatizado extraído en excavación es poco abundante. En general se reconocieron dos grupos de materiales los cuales pueden clasificarse de acuerdo a su morfología como instrumentos y adornos (Casiraghi 1985). El primero está compuesto por dos formas altamente estandarizadas que corresponden a los que poseen una punta roma pero punzante de longitud variable y poco espesor y que pueden ser asignados a la categoría punzones. La segunda forma lo integra una forma altamente estandarizada y que se repite en varios de los sitios trabajados. Esta corresponde a metapodios que presentan la diáfisis posterior aserrada y la anterior conserva una porción mayor cuya punta se encuentra pulida. Por último, en cuanto al segundo grupo se hallaron diáfisis principalmente de ave con signos de corte en ambos extremos y que conformarían cuentas de collar las cuales se presentan con y sin decoración.

El total de elementos formatizados en la muestra ascendió a 35 (sobre un total de 18.048) lo que significa un $0,19 \%$ de la muestra.
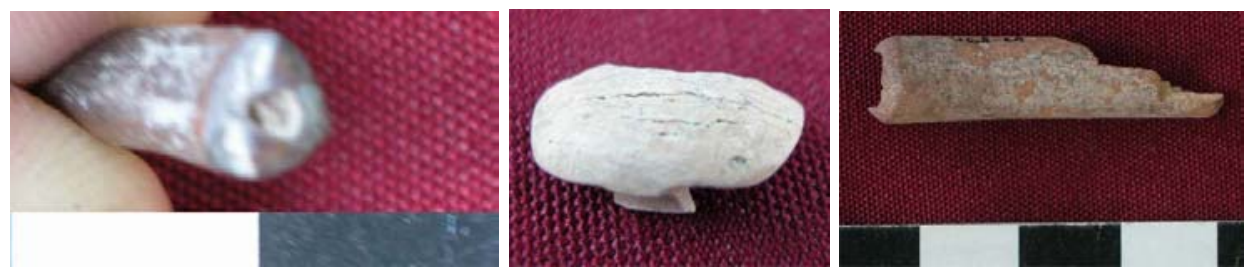

Figura 11.4. Fragmentos óseos formatizados (Adornos). 

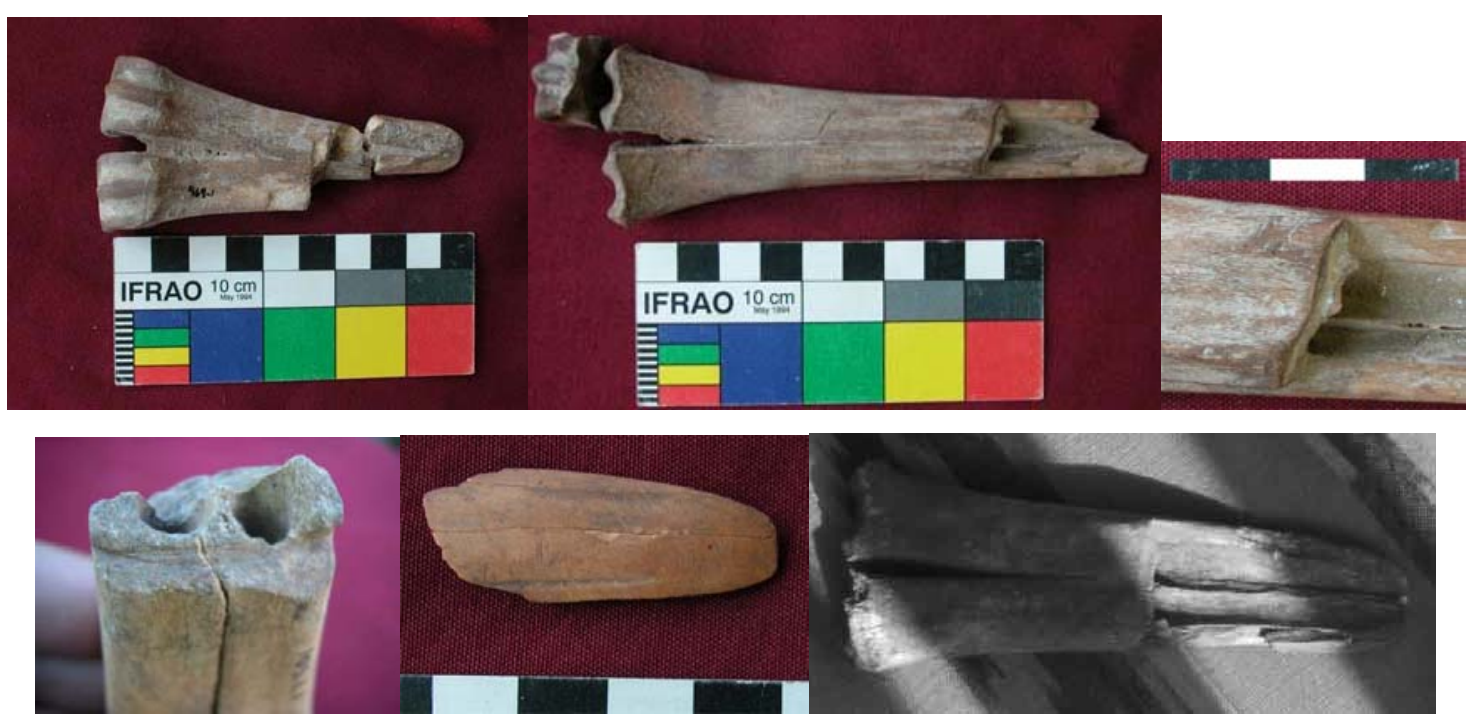

Figura 11.5. Metapodios formatizados (artefactos)

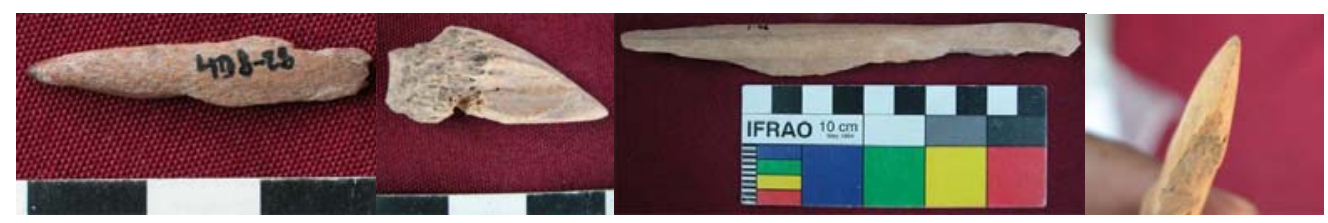

Figura 11.6. Punzones

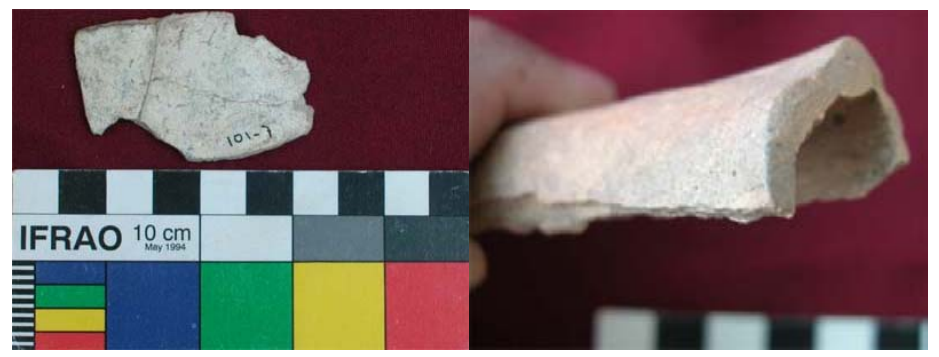

Figura 11.7. Fragmento de hueso plano pintado y húmero aserrado.

En cuanto a las clases de edad representadas se pudo observar que hay una utilización levemente superior de individuos adultos (Figura 11.8) 


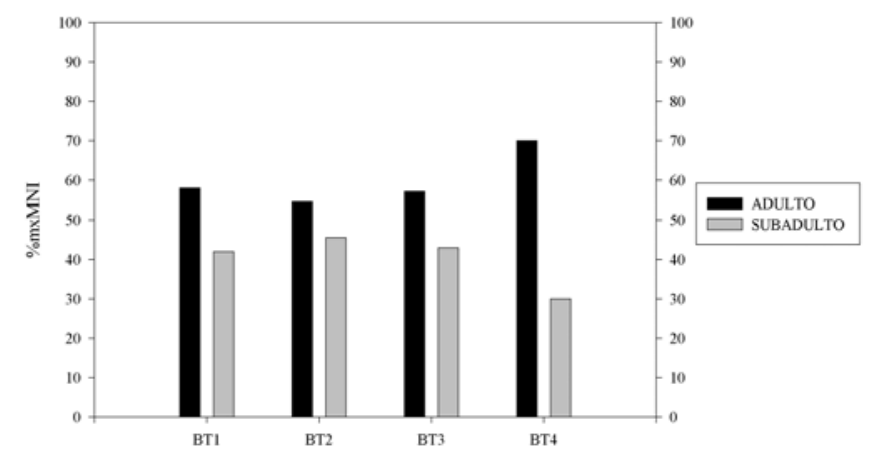

Figura 11.8. Proporción de camélidos adultos y subadultos.

Respecto de la tendencia temporal en el uso de las distintas clases de edades se pudo observar que la proporción de adultos versus subadultos es básicamente similar en los primeros tres bloques temporales cambiando su patrón en el último. En el bloque temporal 4 la proporción de adultos es de $70 \%$ en tanto que los subadultos sólo representan el $30 \%$ del conjunto.

La presencia de neonatos en los conjuntos de subadultos permitieron realizar una aproximación a la economía de algunos grupos domésticos ya que en uno de los casos la presencia de un animal menor a los tres meses de edad se encontró asociado a un patrón de consumo de animales adultos compuesto mayormente por elementos del pie. Según Haber et al. (1991) estos elementos son los menos apetecibles para el consumo y en muchas oportunidades son descartados en el lugar dónde se produce el procesamiento primario del animal. No obstante en otras regiones se ha observado que el uso de los elementos del pie, si bien no poseen gran cantidad de carne adosada o el contenido de médula ósea es relativamente bajo, serían consumidos en épocas de escasez como puede ser inviernos extremadamente duros (Hill 2001). En este caso estaríamos frente a una estrategia basada en la optimización de los recursos disponibles, los cuales pueden haber sido captados en uno de dos escenarios posibles: la caza de un neonato silvestre o la utilización de un neonato doméstico (faenado intencionalmente o producto de una muerte natural por stress ambiental). Dentro de la segunda de estas opciones creemos más plausible la utilización del animal luego de la muerte natural ya que los neonatos son bastante proclives a sucumbir ante stress ambiental severo. Además esta es una práctica registrada en contextos pastoriles actuales del noroeste argentino. 
En cuanto a la utilización de los camélidos a lo largo del período estudiado se enfatizó en el análisis de las tendencias temporales mediante la aplicación del denominado Índice de Artiodáctilos propuesto por Broughton (1994) para el estudio de la utilización de la fauna en contextos de complejización social creciente. Este es un índice cuantitativo simple de abundancias relativas de vertebrados y se calcula mediante la siguiente ecuación:

\section{Índice de Artiodáctilos $=\sum$ Artiodáctilos $/(\Sigma$ Artiodáctilos $+\Sigma$ Vertebrados pequeños $)$}

El índice de artiodáctilos permite conocer la contribución de este tipo de animales dentro de un conjunto faunístico. Los valores que pueden obtenerse se encuentran entre 1.0 (representa frecuencias altas de artiodáctilos) y 0.0 (representa frecuencias de artiodáctilos bajas en relación con vertebrados más pequeños).

Esto nos permitió observar que si bien existe variabilidad en los conjuntos arqueofaunísticos de cada ocupación este presenta una tendencia general a la incorporación de animales de porte más pequeño en los momentos más tardíos (BT4) (Figura 11.9)

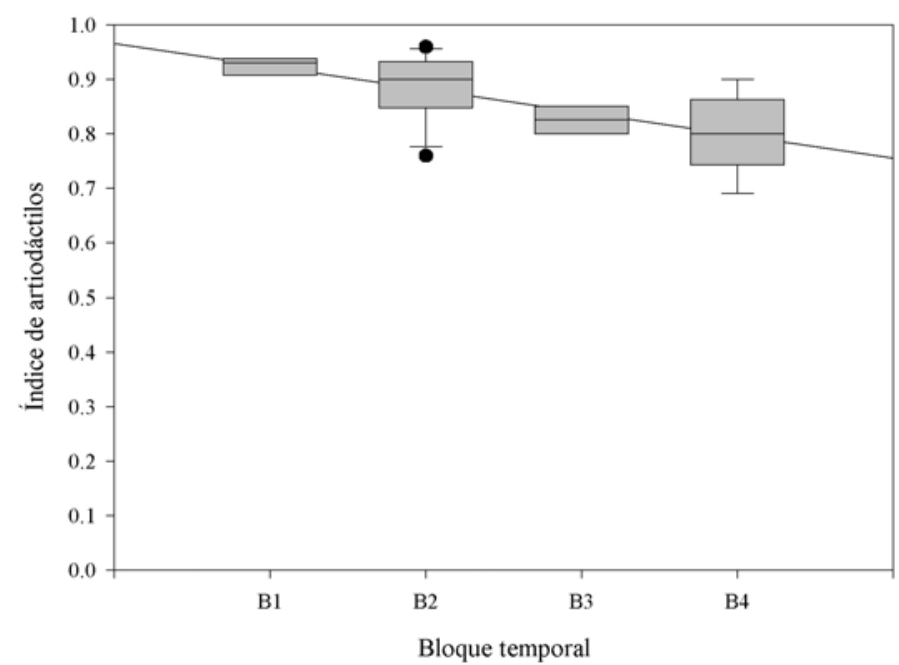

Figura 11.9. Índice de Artiodáctilos según Bloque Temporal.

Por ultimo nos resta advertir la utilización de las distintas especies de camélidos. Por lo que se puede observar en la Figura 11.10 durante los cuatro bloques 
temporales se mantiene aproximadamente la misma proporción: 50\% camélidos domésticos y 50\% camélidos silvestres (variando la relación entre guanaco y vicuña)

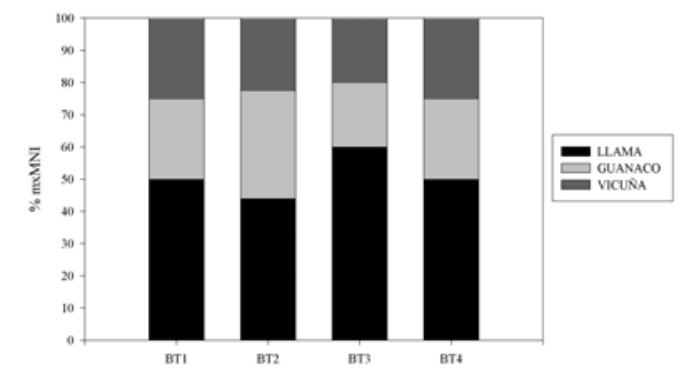

Figura 11.10.Proporción de especies de camélidos.

Para los sitios del sur de lo valles Calchaquíes podemos observar en líneas generales que las tendencias que muestran los restos de fauna pueden interpretarse en una disminución de la presencia de camélidos así como un aumento de la proporción de individuos adultos de este mismo taxón.

Integrando estas dos variables se propone que durante el primer milenio de la era cristiana en el sur de los Valles Calchaquíes se privilegiaría la conservación del ganado doméstico hasta edad adulta (posiblemente para la utilización de productos secundarios como lana o para transporte). Quizás la gran presencia de elementos formatizados (metapodios) asociados a las prácticas de la fabricación de textiles apoye esta idea general.

Para concluir se compararán los patrones encontrados en esta región con los datos disponibles para áreas cercanas, principalmente de Puna. Para ello tomaremos datos de los sitios Quebrada Seca 3 Nivel 2a (Elkin 1996), Casa Chávez Montículos 1, Casa Chávez Montículos 4, Real Grande NI y NII (Olivera 1997, 1998) para la zona de Antofagasta de la Sierra y Tebenquiche Chico 1 (Haber 1999) en la región de Antofalla. Si bien la información es dispar el conjunto de los sitios nos permitirá tener una idea global de lo que estaría sucediendo en un ambiente ecológico distinto al de los valles mesotermales.

Del sitio Quebrada Seca 3 (QS3 N2a) solo tomamos la ocupación formativa. Según los datos presentados por Elkin para este sitio se pudo calcular la presencia de al 
menos seis animales adultos y dos subadultos. Las especies presentes en el sitio fueron identificadas por características osteométricas y mediante el análisis de fibras. El primer indicador aportó datos acerca de la presencia de vicuñas y guanacos, en tanto que las fibras permitieron asignar a las muestras a las especies vicuña, guanaco y llama. La proporción computada de animales silvestres es superior a la que se pudo calcular para los animales domésticos.

Por otro lado en los sitios Real Grande NI y NII y Casa Chávez Montículos 1 y 4 las proporciones respecto a las clases de edad cambiarían drásticamente ya que en todos los casos registrados más del $78 \%$ de las muestras corresponderían a subadultos. Cabe mencionar que para este cálculo se utiliza el \%NISP asignado a cada clase edad. Por lo visto en los conjuntos del formativo la fragmentación suele ser muy alta por lo que creemos que el cálculo de frecuencias basadas en este estimador de abundancia taxonómica no sería el mejor. Por ello planteamos la necesidad de realizar el cálculo de los MNE y los mxMNI con el fin de confirmar si esas tendencias registradas mediante el \%NISP se mantienen. Proponemos esto ya que los primeros indicadores suprimirían el problema que introduce la alta fragmentación de los conjuntos.

Para el sector de Antofalla en el sitio TBCh1 Haber (1999) plantea la presencia de un $30 \%$ de llama y un $70 \%$ de vicuña.

Lo que se puede observar entonces en la Puna es que la mayor parte de los conjuntos están representados por animales silvestres, principalmente vicuña, lo cual es razonable ya que es un recurso típico del área. En cuanto a las clases de edad existiría una incongruencia que podría explicarse tanto como por una cuestión del método o simplemente por las distintas características de los sitios tratados (QS3 y MCCh). No obstante esta consideración tendríamos entonces una mayor abundancia de animales subadultos respecto de los adultos.

Esto resultados contrastan con lo obtenidos para el sur de los valles Calchaquíes por lo que estaríamos presenciando dos tendencias o modelos económicos de aprovechamiento de la fauna distintos. Para los sitios el sur de los valles Calchaquíes podemos observar en líneas generales que las tendencias que muestran los restos de fauna pueden interpretarse en una disminución de camélidos a lo largo del tiempo, un aumento de la proporción de adultos de los restos y un mantenimiento de las proporciones de especies utilizadas respecto de su condición de doméstico o silvestre. Por el contrario para la Puna podemos ver que la utilización del recurso camélido 
(principalmente silvestres) permanece estable en tanto que las edades de los restos tienden a presentar mayor cantidad de restos de subadultos.

De por sí estas tendencias parecerían ser significativas razón por la cual solo restaría en un contexto regional indagar cuales han sido las causas (fuera de condicionantes ecológico) que hicieron que durante el Período Formativo se pusieran en práctica distintos modelos económicos.

Otros indicadores arqueológicos nos permiten identificar grandes redes de intercambio para la época (Núñez y Dillehay 1995, Núñez 1994, Scattolin y Lazzari 1997) con circulación de distintos bienes como la cerámica o la obsidiana. Quizás nos resta preguntarnos si las diferencias notadas más arriba en cuento al uso del recurso camélido en estos dos distintos ambientes corresponden simplemente a la adaptación de las economías al recurso disponible o se trata de algún aspecto de complementariedad aún no discutido a nivel zooarqueológico. Creemos que este es un de los grandes interrogantes a contestar y que con los datos aquí presentados pueda comenzar a ser parte de la discusión en el área sur de los Andes.

Con esto podemos ver como la fauna de sitios arqueológicos puede ayudar a comprender distintos aspectos de la vida y las relaciones sociales y económicas de los sistemas aldeanos del Formativo durante el primer milenio A. D. tanto a nivel local como a nivel regional. Por último pretendemos que esto sea el comienzo de una discusión mas profunda respecto del potencial de información que este tipo de estudios nos puede brindar utilizando metodologías que si bien parecen sofisticadas, hoy en día están al alcance de todos.

La Plata - Buenos Aires, Noviembre de 2003.- 
Abe, Y., Marean, C.W., Nilssen, P., Assefa, Z., y E. Stone.

2002. "The analysis of cutmarks from archaeological sites: a review and a new GIS image-analysis approach". American Antiquity 66(3): 333-348.

Altamirano E., A. J.

1983. Guía Osteológica de Cérvidos Andinos. Serie Investigaciones 6. Departamento Académico de Ciencias Histórico-Sociales, Universidad Mayor de San Marcos, Lima, Perú.

Aschero, C., D. Elkin y E. Pintar.

1991. Aprovechamiento de recursos faunísticos y producción lítica en el precerámico tardío. Un caso de estudio: Quebrada Seca 3 (Puna Meridional Argentina). Actas del XI Congreso de Arqueología Chilena. Tomo II: 101-114. Museo Nacional de Historia Natural, Santiago de Chile.

Behrensmeyer, A. K.

1978. Taphonomic and ecological information from bone weathering. Palaeobiology 4: $150-162$.

Bennett, J.

1999. Thermal Alteration of Buried Bone. Journal of Archaeological Science (1999) 26, 1-8. jasc 1998.0283

Berwick, D.

1975. Valoración del análisis sistemático de los restos de fauna en sitios arqueológicos. Chungara 5: 125-140. Arica.

Biddick, K. A. y J. Tomenchuck

1975. Quantifying lesions and fractures on long bones. Journal of Field Archaeology 2, 339-249.

Binford, L.R.

1978. Nunamiut Ethnoarchaeology. Academic Press. New York

Binford, L.R.

1981. Bones: Ancient men and Modern Myths. Academic Press. New York

Binford, L.R.

1984. Faunal Remains from Klasies River Mouth, Academic Press, Orlando, FL.

Blumenschine, R.J.

1988. An experimental model of the timing of hominid and carnivore influence on archaeological bone assemblages. Journal of Archaeological Science, 15: 483-502.

Bonnichsen, R. y M. H. Sorg

1989. Bone Modification. Orono: University of Maine Centre for the Study of the First Americans

Bonnin, M.

1997. Zooarqueología del Valle de Ambato, Catamarca. Resúmenes del XII

Congreso Nacional de Arqueología Argentina. p. 90.UNLP. La Plata.

Bolsi, A. S.

1967. Estudio Antropogeográfico del Valle de Santa María - Catamarca. Publicaciones del Departamento de Extensión Universitaria y Ampliación de estudios de la Universidad Nacional del Nordeste, Resistencia, Chaco.

Borrero, L. A.

2003. Taphonomy of the Tres Arroyos 1 Rockshelter, Tierra del Fuego, Chile. Quaternary International 109-110: 87-93 
Brain, C.K.

1981. The Hunters or the Hunted? The University of Chicago Press, Chicago.

Braun, J. K. y M. Díaz

1999. Key to the Native Mammals of Catamarca Province, Argentina. Occasional

Papers of the Oklahoma Museum of Natural History. 4: 1-16. University of

Oklahoma, Norman, Oklahoma

Broughton, J.M.

1994. Late Holocene Resource Intensification in the Sacramento Valley, California:

The Vertebrate Evidence. Journal of Archaeological Science 24: 501-514.

Bugliani, M. F. y L. Pereyra Domingorena

2001. Conjuntos cerámicos en el sitio formativo "Bañado Viejo" (Tucumán). Actas del XIII Congreso Nacional de Arqueología Argentina, 1999. Tomo II: 347-358. Córdoba, Argentina.

Bunn, H.T.

1986. Patterns of skeletal part representation and hominid subsistence activities at

Olduvai Gorge, Tanzania, and Koobi Fora, Kenya, Journal of Human Evolution 15: 673-690.

Bunn, H.T. y E. M. Kroll

1986. Systematic butchery by Plio-Pleistocene hominids at Olduvai Gorge, Tanzania, Current Anthropology 27: 431-452.

Cabrera, A

1953. Los roedores argentinos de la familia Caviidae. Publicaciones de la Escuela de Veterinaria 6: 1-93. Buenos Aires.

Cardich, A. y A. Laguens.

1984. Fractura intencional y posterior utilización del material óseo arqueológico de

la Cueva 3 de Los Toldos, Pcia. de Santa Cruz, Argentina (Contribución metodológica al estudio del material óseo fracturado recuperado en excavación arqueológica). Revista del Museo de La Plata. Nueva Serie. Tomo VIII, Antropología 63: 329-384. La Plata

Cardich, A. y A. D. Izeta.

1999-2000. Revisitando Huargo (Perú). Análisis cuantitativos aplicados a restos de Camelidae del Pleistoceno Tardío. Anales de Arqueología y Etnología 54-55: 2940. U N Cuyo. Mendoza.

Cardich, A., E. Tonni y N. Kriscautzky

1977. Presencia de Canis familiaris en Los Toldos (Santa Cruz). Relaciones de la Sociedad Argentina de Antropología. Tomo XI N.S.: 115-120.

Cartajena, I e I. Concha

1997. Una contribución a la determinación taxonómica de la familia Camelidae en sitios formativos del Loa medio. Estudios Atacameños 14: 71-83. San Pedro de Atacama.

Casiraghi, M.

1985. Análisis de los artefactos óseos de Huachichocana III (Provincia de Jujuy, Rep. Argentina). Paleoetnobotánica IX: 19-33. Buenos Aires.

Casteel, R. W. y D. K. Grayson

1977. Terminological problems in quantitative faunal analysis. World Archaeology 9

(2): $235-242$.

Church, R.R. y R. L. Lyman

2003. Small fragments make small differences in efficiency when rendering grease from fractured artiodactyl bones by boiling. Journal of Archaeological Science 30: 1077-1084. doi:10.1016/S0305-4403(03)00010-4 
Cigliano, E. M. (editor)

1973. Tastil, una ciudad preincaica argentina. Editorial Cabargón. Buenos Aires. $694 \mathrm{pp}$.

Cigliano, E. M., B. Carnevali, M. T. Carrara y S. Renard.

1960. Molino del Puesto. En: Investigaciones arqueológicas en el Valle de Santa María. E. M: Cigliano (Ed.). Publicación $N^{\circ}$ 4. Instituto de Antropología. Facultad de Filosofía y Letras. Universidad Nacional del Litoral. Rosario.

Cruz, I y D. Elkin

2003. Structural Bone Density of the Lesser Rhea (Pterocnemia pennata) (Aves: Rheidae). Taphonomic and Archaeological Implications. Journal of Archaeological Science 30: 37-44

De Nigris, $M$.

1999. Lo crudo y lo cocido: Sobre los efectos de la cocción en la modificación ósea. Arqueología 9: 239-264.

Díaz, M., J. K. Braun, M. A. Mares y R. M. Bárquez.

1997. Key to Mammals of Salta Province, Argentina. Occasional Papers of the Oklahoma Museum of Natural History. 2: 1-10. University of Oklahoma, Norman, Oklahoma

Elkin, D. C.

1995. Volume density of South American camelid skeletal parts. International Journal of Osteoarchaeology 5: 29-37.

Elkin, D. C.

1996. Arqueozoología de Quebrada Seca 3: indicadores de subsistencia humana temprana en la Puna Meridional Argentina. Tesis para otra al grado de Doctor de la UBA. F. F. y L. UBA. Buenos Aires, Argentina. MS

Elkin, D. y J. R. Zanchetta

1991. Densitometría ósea de camélidos. Aplicaciones arqueológicas. Shincal 3: 195204.

Elkin, D. C., C. M. Madero, G. L. Mengoni Goñalons, $\quad$ D. E. Olivera y H. D. Yacobaccio.

1991. Avances en el estudio arqueológico de los camélidos en el noroeste argentino. Actas de la VII Convención Internacional de Especialistas en Camélidos Sudamericanos.

Fauque, L. E. y M. R. Strecker

1987. Rasgos de Neotectónica y avalanchas de roca producidas por terremotos en la vertiente occidental de los Nevados del Aconquija, Provincia de Catamarca, Argentina. Décimo Congreso Geológico Argentino, Actas (1) 219-222. San Miguel de Tucumán, Argentina.

Fernández, P. M.

2001. Procesamiento del guanaco en el sitio Campo Cerda 1 (Piedra Parada, Chubut, Argentina) En: El uso de los camélidos a través del tiempo. 65-90. G. L. Mengoni Goñalons, D. E. Olivera y H. D. Yacobaccio(ed). Grupo Zooarqueología de Camélidos. Buenos Aires.

Fraga, C.

1999. Cerámica: un estudio morfológico funcional en el Valle de Santa María. Tesis de Licenciatura inédita. FFyL. Universidad de Buenos Aires.

Franklin, W. L.

1982. Biology, Ecology, and Relationship to Man of the South American Camelids.

En: Mammalian Biology in South America. Mares, M. A. y H. H. Genoways (ed). 
Pymatuning Laboratory of Ecology, Special Publications Series, Volume 6: 457489. University of Pittsburgh.

Galván, A. F.

1981. Descripción Geológica de la Hoja 10e, Cafayate. Boletín N 177, Ministerio de Economía, Subsecretaría de Estado de Minería, Servicio Geológico Nacional. Buenos Aires.

Gero, J. y M. C. Scattolin

1994. Hacia la comprensión de la jerarquización: un estudio desde Yutopián, Valle del Cajón. En prensa: Actas del XI Congreso Nacional de Arqueología Argentina. San Rafael. Mendoza.

Gero, J. y M. C. Scattolin

1999. Household chronology at Yutopián, Valle del Cajón, Northwest Argentina.

Trabajo presentado en el Northeast Andean Archaeology and Ethnohistory Conference. Amherst Massachussetts. Octubre de 1999.

Gero, J. y M. C. Scattolin

2002. Beyond Complementarity and Hierarchy: New Definitions for Archaeological

Gender Relations. En: In Pursuit of Gender. Worldwide Archaeological Approaches. S. M. Nelson y M Rosen-Ayalon (Ed). Altamira Press.155-171.

Gifford Gonzalez, D. P.

1989. Ethnographic analogues for interpreting modified bones: some cases from East

Africa. En: Bonnichsen, R. y M. H. Sorg (Eds) Bone Modification. Orono:

University of Maine Centre for the Study of the First Americans. 179-246.

Gifford Gonzalez, D. P.

1991. Bones are not enough: analogues, knowledge, and interpretive strategies in zooarchaeology. Journal of Anthropological Archaeology 10: 215-54.

Gifford Gonzalez, D. P. y D. C. Crader.

1977. A Computer Coding System for Archaeological Faunal Remains. American Antiquity 42: 225-238.

González, A. R.

1998. Arte Precolombino. Cultura La Aguada, Arqueología y Diseños. Filmediciones Valero. Buenos Aires.

González Bonorino, F.

1951. Descripción geológica de la Hoja 12e "Aconquija", Catamarca, Tucumán. Boletín $\mathrm{N}^{\mathrm{o}}$ 75. Ministerio de Industria y Comercio. Dirección Nacional de Minería. Bs. As.

Grayson, D.

1984. Quantitative Zooarchaeology. Academic Press. Orlando.

Grayson, D. K.

1991. Alpine faunas from the White Mountains, California: adaptive change in the

Late Prehistoric Great Basin? Journal of Archaeological Science, 18: 483-506.

Greegor, D. H.

1980a. Diet of the little hairy armadillo, Chaetophractus vellerosus, of northwestern

Argentina. Journal of Mammology 61:331-334.

Greegor, D. H.

1980b. Preliminary studies and home range of the armadillo, Chaetophractus vellerosus. Journal of Mammology 61:334-335.

Grosjean, M., I. Cartajena, M.A. Geyh, L. Nuñez

2003. From proxy data to paleoclimate interpretation: the mid-Holocene paradox of the Atacama Desert, northern Chile. Palaeogeography, Palaeoclimatology, Palaeoecology 194: 247-258. 
Haber, A.

1999. Una arqueología de los oasis puneños. Domesticidad, interacción e identidad en Antofalla, primer y segundo milenios $d$. C. Tesis Doctoral inédita. Facultad de Filosofía y Letras, Universidad de Buenos Aires.

Haber, A.

2002. Hunting after domestication. Trabajo presentado en el Ninth International Conference on Hunting and Gathering Societies. Heriot-Watt University, Edinburgh, Escocia. http://www.abdn.ac.uk/chags9/1Haber2.htm

Haber, A., S. Ahumada, J. Ferreira y M. Jiménez

1991. De la carnicería al almacén. Hacia la identificación arqueológica del charqueo: un caso de estudio. Shincal 3(1): 219-233

Heredia, Osvaldo, M. Palacios, A. Luzzi y L. Naudeau

1974. Ensayo de un cuadro cronológico del sector meridional del Valle Calchaquí. Ponencia presentada al III Congreso Nacional de Arqueología Argentina. Salta.

Hill, M. G.

1994. Subsistence Strategies by Folsom Hunters at Agate Basin, Wyoming: A Taphonomic Analysis of the Bison and Pronghorn Assemblages. Unpublished M.A. thesis, Department of Anthropology, University of Wyoming, Laramie, WY.

Hill. M. G.

1996. Appendix 3: Size Comparison of the Mill Iron Site bison Calcanea. En: The Mill Iron Site, G. C. Frison (Ed), 231-237. New Mexico University Press, New Mexico, USA.

Hill, M. G.

2001. Paleoindian Subsistence Strategies on the Northwestern Great Plains of North America. Unpublished Ph. D. dissertation, Department of Anthropology, University of Wisconsin, Madison.

Hockett, B.

1998. Sociopolitical meaning of faunal remains from Baker Village. American Antiquity 63(2): 289-302.

Hudson, J.

1990 Identifying food sharing archaeologically: an ethnoarchaeological study among the Aka. Precirculated Papers \& Abstracts, II: 616-631. Sixth International Conference on Hunting and Gathering Societies, Fairbanks.

Izeta, A. D.

2002. Interespecific Differentiation of South American Camelids on Archaeofaunal Assemblages from Calchaquies Valleys (Argentina). Tafonomía y Zooarqueología Argentina. (ed) María Gutiérrez, Gustavo Barrientos, Guillermo Mengoni Goñalons, Laura Miotti y Mónica Salemme. BAR (British Archaeological Reports, International Series, Oxford, UK). En prensa

Izeta, A. D.

2003. Bone fragmentation profile: A GIS image-analysis based approach. Manuscrito en posesión del autor.

Izeta, A. D. y M. C. Scattolin

2001. Bañado Viejo: Análisis faunístico de un sitio formativo en el fondo del Valle de Santa María. Actas del XIII Congreso Nacional de Arqueología Argentina, 1999. Tomo II: 385-397. Córdoba.

Jackson H. E. y S. L. Scott

2003. Patterns of Elite Faunal Utilization at Moundville, Alabama. American Antiquity 68(3)

Johansson, $\mathrm{N}$. 
1996. Burials and Society. A Study of Social Differentiation at the Site of El Pichao, Northwestern Argentina, and the Cemeteries dated to the Spanish-Native Period. GOTARC series B. Gothenburg Archaeological Theses, N 5. Göteborg University.

Johnson, E.

1985. Current developments in bone technology. En: M. B. Schiffer (Ed.) Advances in Archaeological Method and Theory Vol. 8_ 157-235. Academic Press, New York.

Johnson, E.

1989. Human-modified Bones from Early Southern Plains Sites. In (R. Bonnichsen \& M. H. Sorg, Eds) Bone Modification. Orono: University of Maine Centre for the Study of the First Americans, pp. 431-471.

Kauffman C.

2002. La fusión ósea como indicador de edad y estacionalidad en guanaco (Lama guanicoe). Trabajo presentado en las $V$ Jornadas de Arqueología de la Patagonia. Buenos Aires.

Kent, J. D.

1982. The Domestication and exploitation of the South American camelids: methods of analysis and their application to circum-lacustrine archaeological sites in Bolivia and Peru. Unpublished Ph. D. Dissertation. Washington University. St. Louis, Missouri, USA.

Klein, R.G. y K. Cruz-Uribe,

1984. The Analysis of Animal Bones from Archaeological Sites, University of Chicago Press, Chicago.

Lam, Y.M., O.M. Pearson, Curtis W. Marean y Xingbin Chen

2003. Bone density studies in zooarchaeology. Journal of Archaeological Science 00. 1-8. doi:10.1016/S0305-4403(03)00065-. En prensa.

Lavallée, D.

1990. La domestication animale en Amérique du Sud. Le point des connaissance.

Bulletin Institut Française d'études Andines 19(1) : 25-44.

Lazzari, M.

1989. Materias primas líticas en la falda occidental del Aconquija. Hacia un modelo regional de intercambio. Tesis de Licenciatura inédita. FFyL. UBA.

López Campeny, S. M. L.

1999. Actividades domésticas y organización del espacio intrasitio. El sitio Punta de la Peña 9 (Antofagasta de la Sierra, Prov. de Catamarca). Tesis de Licenciatura inédita. Facultad de Ciencias Naturales e Instituto Miguel Lillo, Universidad Nacional de Tucumán.

Lozano, $\mathrm{P}$.

[1989 (1773)]. Descripción Corográfica del Gran Chaco Gualamba. Universidad Nacional de Tucumán.

Lucherini, M.

1995. Group size, spatial segregation and activity of wild sympatric vicuñas Vicugna vicugna and guanacos Lama guanicoe. En: Valutazione quantitativa del differenziamneto eto-ecologico in un ecosistema andino. Working Paper 95.10. Istituto di Biologia Generale e Biostatistica. Universitá di Siena. Italia.

Lupo, K. y J. O'Connell

2002. Cut and tooth mark distributions on large animal bones: ethnoarchaeological data from Hadza and their implications for current Ideas about early human carnivory. Journal of Archaeological Science 29:85-109.

Lyman, R. L. 
1984. Bone density and differential survivorship in fossil classes. Journal of Anthropological Archaeology 3: 259-299.

Lyman, R. L.

1994a. Quantitative units and terminology in zooarchaeology. American Antiquity 59: 36-71.

Lyman, R. L.

1994b. Vertebrate Taphonomy. Cambridge Manuals in Archaeology, Cambridge University Press.

Madero, C.

1992. Análisis faunístico de Huachichocana III (Jujuy): Identificación arqueológica de la caza y el pastoreo. Palimpsesto Revista de Arqueología 2: 107-122. Buenos Aires.

Marean, C.W.

1991. Measuring the postdepositional destruction of bone in archaeological assemblages. Journal of Archaeological Science, 18: 677-694.

Marean, C.W.

1995. Of taphonomy and zooarchaeology. Evolutionary Anthropology 4(2) 64-72.

Marean, C.W. y L.M. Spencer

1991. Impact of carnivore ravaging on zooarchaeological measures of element abundance. American Antiquity 56: 645-658.

Marean, C.W. y C.J. Frey

1997. The animal bones from caves to cities: reverse utility curves as methodological artifacts, American Antiquity 62: 698-711.

Marean, C.W., Spencer, L.M., Blumenschine, R.J. \& Capaldo, R. J.

1992. Captive hyena bone choice and destruction, the schlepp effect, and Olduvai archaeofaunas. Journal of Archaeological Science 19: 101-121.

Marean, C.W., Abe, Y., Nilssen, P., y E. Stone.

2001. "Estimating the Minimum Number of Skeletal Elements (MNE) in Zooarchaeology: a Review and a New Image-analysis GIS Approach." American Antiquity 66(2): 333-348.

Mares, M. A., Ojeda, R. A., y Barquez R. M.

1989. Guide to the mammals of Salta Province, Argentina. Norman: University of Oklahoma Press.

Mares, M. A., Ojeda, R. A., Braun, J. K. y Barquez, R. M.

1997. Systematics, distribution, and ecology of the mammals of Catamarca Province, Argentina. En: Life among the muses: papers in honor of James S. Findley. Yates, T. L. Gannon, W. L., and Wilson, D. E. (ed), pp. 89-141. Albuquerque: The Museum of Southwestern Biology, The University of New Mexico.

Marshall, F.

1994. Food sharing and body part representation in Okiek faunal assemblages. Journal of Archaeological Science 21: 65-77.

Martínez, L. 1999. Diversidad Cerámica en la Falda del Aconquija.Tesis de Licenciatura inédita. FFyL. Universidad de Buenos Aires.

Menegaz, A., M. Salemme y E. Ortiz Jaureguizar.

1988. Una propuesta de sistematización de los caracteres morfométricos de los metapodios y las falanges de Camelidae. En: De procesos, contextos y otros huesos. N. Ratto y A. Haber (Eds). UBA, ICA. Buenos Aires, Argentina.

Menegaz, A., F. J. Goin, y E. Ortiz Jaureguizar. 
1989. Análisis morfológico y morfométrico multivariado de los representantes fósiles y vivientes del género Lama (Artiodactyla, Camelidae). Sus implicancias sistemáticas, biogeográficas, ecológicas y biocronólogicas. Ameghiniana 26(3-4): 153-172. Buenos Aires, Argentina.

Mengoni Goñalons, G. L.

1988. Análisis de materiales faunísticos de sitios arqueológicos. Xama (1):78-120. Mendoza, Argentina.

Mengoni Goñalons, G. L.

1991. La llama y sus productos primarios. Arqueología 1: 179-196, Revista de la Sección Prehistoria, Instituto de Ciencias Antropológicas, Facultad de Filosofía y Letras, UBA.

Mengoni Goñalons, G. L.

1996. La domesticación de los camélidos sudamericanos y su anatomía económica.

En: Zooarqueología de Camélidos 2: 33-45. Elkin, D. C., C. M. Madero, G. L. Mengoni Goñalons, D. E. Olivera, M. C. Reigadas y H. D. Yacobaccio (ed). Grupo Zooarqueología de Camélidos. Buenos Aires.

Mengoni Goñalons, G. L.

1999. Cazadores de Guanacos de la estepa patagónica. Sociedad Argentina de Antropología, Colección Tesis Doctorales, Buenos Aires.

Mengoni Goñalons, G. L.

2001. Variabilidad de la anatomía económica en la llama. En: El uso de los camélidos a través del tiempo. 145-154. G. L. Mengoni Goñalons, D. E. Olivera y H. D. Yacobaccio (ed). Grupo Zooarqueología de Camélidos. Buenos Aires.

Mengoni Goñalons, G. L. y D. Elkin

1990. Camelid Zooarchaeological research in Argentina: Present status and perspectives. MS

Miller, G.

1979. An introduction to the ethnoarchaeology of andean camelids. $\mathrm{PhD}$ Dissertation. University of California, Berkeley.

Miller, G. y R. Burger

1995. Our father the caiman, our dinner the llama: Animal utilization at Chavín de Huantar, Peru. American Antiquity 60(3): 421-458.

Miotti, L. L.

1989. Zooarqueología de la Meseta Central y Costa de la Prov. de Santa Cruz: Un enfoque de las estrategias adaptativas aborígenes y los paleoambientes. Tesis Doctoral inédita. Fac.Cs.Nat. y Museo UNLP.

Miotti, L. L.

1990/92. La experimentación simulativa de fracturas y marcas óseas y sus implicancias arqueológicas. Arqueología Contemporánea 3(1): 39-64.

Miotti, L. L.

1998. Zooarqueología de la Meseta Central y Costa de Santa Cruz: Un enfoque de las estrategias adaptativas aborígenes y los paleoambientes. Museo Municipal de Historia Natural, San Rafael, Mendoza.

Mondini, $\mathrm{M}$.

2002. Carnivore Taphonomy and the Early Human Occupations in the Andes. Journal of Archaeological Science 29, 791-801. doi:10.1006/jasc.2001.0780

Morlan, R.E.

1991. Bison Carpal and Tarsal Measurements: Bulls versus Cows and Calves. Plains Anthropologist 36 (136): 215-227.

Morlan, R.E. 
1994. Bison Bone Fragmentation and Survivorship: a Comparative Method. Journal of Archaeological Science 21: 797-807.

Nasif, N. y C. Gómez Cardozo

1999. El material olvidado: Análisis de los instrumentos de hueso del sitio arqueológico del El Mollar (Tafí del Valle, Tucumán). Actas del XII Congreso Nacional de Arqueología Argentina. La Plata. Tomo I: 102-106. La Plata.

Nasti, A.

1991. Tafonomía de vertebrados en contextos sedimentarios modernos de la Puna Sur: Chances de enterramiento y formación del registro arqueológico. Shincal 3: 243-251. Catamarca, Argentina.

Nasti, A.

1994-1995. Desarticulación natural y supervivencia de partes anatómicas: Tafonomía de vertebrados modernos en medioambientes puneños. Palimpsesto. Revista de Arqueología 4: 70-89. Buenos Aires.

Nicholson, R.

1993. A morphological investigation of burnt animal bone and an evaluation of its utility in archaeology. Journal of Archaeological Science 20: 411-428.

Nuñez Atencio, L

1994. Cruzando la cordillera por el Norte: Señoríos, caravanas y alianzas. En: $L a$ Cordillera de los Andes. Ruta de encuentros. Museo Chileno de Arte Precolombino. Santiago.

Nuñez Atencio, L y T. Dillehay.

[1995 (1979)]. Movilidad giratoria, armonía social y desarrollo en los Andes Meridionales: Patrones de tráfico e interacción económica. Ensayo. Universidad Católica del Norte, Antofagasta. Segunda Edición.

O'Connor, $\mathrm{T}$.

1993. Process and terminology in Mammal Carcass Reduction. International Journal of Osteoarchaeology 3: 63-67.

Olivera, D. E.

1992. Tecnología y estrategias de adaptación en el Formativo (Agroalfarero Temprano) de la Puna Meridional Argentina. Un caso de estudio: Antofagasta de la Sierra (Pcia. de Catamarca, R. A.). Tesis para optar al grado de Doctor en Ciencias Naturales. Universidad Nacional de La Plata. La Plata. MS.

Olivera, D. E.

1997. La importancia del recurso Camelidae en la Puna de Atacama entre los 10.000 y 500 años ap. Estudios Atacameños 14: 29-41. San Pedro de Atacama, Chile.

Olivera, D. E.

1998. Cazadores y pastores tempranos de la Puna Argentina. Etnologiska Studier 42:153-180. Goteborg, Suecia

Olivera, D. E.

2001. Perfil etario y rendimiento económico de Lama Glama. En: El uso de los camélidos a través del tiempo. 179-202. G. L. Mengoni Goñalons, D. E. Olivera y H. D. Yacobaccio (ed). Grupo Zooarqueología de Camélidos. Buenos Aires.

Outram A. K.

2001. A New Approach to Identifying Bone Marrow and Grease Exploitation: Why the "Indeterminate"' Fragments should not be Ignored. Journal of Archaeological Science 28, 401-410. doi:10.1006/jasc.2000.0619

Pacheco Torres, V. R., A. Altamirano Enciso y E. Guerra Porras 
1979. Guía Osteológica para camélidos sudamericanos. Serie Investigaciones 4, Departamento Académico de Ciencias Histórico-Sociales, Universidad Mayor de San Marcos, Lima, Perú.

Palermo, M. A.

1983. Los Tuco-tuco. Fauna Argentina 41. Centro Editor de América Latina, Buenos Aires.

Pelissero N. y H. A. Difrieri.

1981. Quilmes. Ed. Gobierno de la Provincia de Tucumán. Tucumán, Argentina.

Pérez Gollán, J. A.

1991. La cultura de La Aguada vista desde el valle de Ambato. Publicaciones del CIFFyH 46:157-173. Facultad de Filosofía y Humanidades. Universidad Nacional de Córdoba.

Perkins, D. y P. Daly

1968. A hunters' village in Neolithic Turkey. Scientific American 219(11): 97-106.

Pochettino, M. L. y M. C. Scattolin.

1991. Identificación y significado de frutos y semillas carbonizados de sitios arqueológicos formativos de la ladera occidental del Aconquija (Prov. de Catamarca, Argentina). Revista del Museo de La Plata (NS) Sección Antropología, IX(71):169-181. La Plata.

Raffino, R. A.

1977. Las aldeas del Formativo Inferior de la Quebrada del Toro (Salta, Argentina). Estudios Atacameños 5: 64-100

Raffino, R. A., E. P. Tonni y A. L. Cione.

1977. Recursos alimentarios y economía en la Región de la Quebrada del Toro, Provincia de Salta, Argentina. Relaciones de la SAA. Tomo XI NS Buenos Aires, Argentina.

Ramenofsky, A. F. y A. Steffen

1998. Units as tools of measurement. En: Unit issues in Archaeology, editado por A.F. Ramenofsky y A. Steffen, pp. 3-17. The University of Utah Press, Salt Lake City.

Rapson D.J. y L.C. Todd

1999. Linking Trajectories of Intrasite Faunal use with food management strategies at the Bugas-Holding Site. Atributte-Based Spatial Analysis of a High Altitude Winter Habitation, Wyoming, USA. En: Bison Subsistence trough time: From Paleolithic to Paleo-Indian times.

Reigadas, M. C.

1994. Incidencia de los factores de variación en las especies de camélidos y tipos domésticos especializados en el NOA. Un paso más allá de la taxonomía en el proceso de explicación de la domesticación. Estudios Atacameños 11: 53-72. San Pedro de Atacama, Chile.

Reigadas, M. C.

2001. Variabilidad y cambio cultural en el NOA desde los comienzos de la domesticación animal hasta la consolidación de las adaptaciones pastoriles. Tesis para optar al grado de Doctor de la UBA. F. F. y L. UBA. Buenos Aires. MS.

Reitz, E. J. y E.S. Wing 1999. Zooarchaeology. Cambridge University Press, Cambridge.

Ruiz Huidobro, O. J.

1972. Descripción Geológica de la Hoja 11e, Santa María. Boletín № 134 , Ministerio de Industria y Minería, Subsecretaría de Minería, Servicio Nacional Geológico Minero. Buenos Aires, Argentina 
Saba, S. L.

1987. Biología Reproductiva del guanaco (Lama guanicoe Müller). Tesis Doctoral. Facultad de Ciencias Naturales y Museo. Universidad Nacional de La Plata. MS.

Sadek-Kooros, H.

1975. Intentional fracturing of bone: description and criteria. En: A: T. Clason (Ed). Archaeozoological Studies 139-150. Amsterdam. North Holland Publishing Company.

Salemme, M. y L. Miotti

1998. The status of Rheids in Patagonia: Environmental approach and economic interpretation during the Late Pleistocene/Early Holocene transition. Poster presentado en el 8th International Congress of the International Council for Archaeozoology, Victoria (Canadá), August 23-29.

Salemme, M., L. Miotti y E. Tonni

1988. La determinación sistemática de los mamíferos en el análisis faunístico. En: N.

Ratto y A. Haber (eds) De procesos, contextos y otros huesos. ICA-FFyL-UBA, Buenos Aires.

Scattolin, M. C.

1982. Una prospección arqueológica en la Falda Occidental del Aconquija. Novedades del Museo de La Plata, I(3):27. La Plata.

Scattolin, M. C.

1986. Informe a CONICET. Manuscrito en posesión del autor.

Scattolin, M. C.

1990. Dos asentamientos formativos al pie del Aconquija. El sitio Loma Alta.

(Catamarca, Argentina). Gaceta Arqueológica Andina V(17):85-100. Lima.

Scattolin, M. C.

1994a. Espacio doméstico y agrario en el Aconquija. En prensa: Actas del XI

Congreso Nacional de Arqueología Argentina. San Rafael. Mendoza.

Scattolin, M. C.

1994b. Posibilidades y restricciones al crecimiento en comunidades aldeanas formativas del Aconquija. En prensa: Actas del XI Congreso Nacional de Arqueología Argentina. San Rafael. Mendoza.

Scattolin, M. C.

2000. Santa María durante el Primer Milenio A. D. ¿Tierra baldía?. Arstryck 19951998: 63-83. Etnografiska Museet i Göteborg.

Scattolin, M. C.

2002. Recursos arquitectónicos y estilos cerámicos en los siglos IX y X d. C. en el valle de Santa María (Catamarca, Argentina).Ms.

Scattolin, M. C. y M. E. Albeck.

1994. El asentamiento humano en la falda occidental del Aconquija (Catamarca, Argentina). Shincal 4:35-65. Catamarca.

Scattolin M. C. y A. Korstanje.

1994. Tránsito y Frontera en los Nevados del Aconquija. Arqueología 4:165-195.

Scattolin, M. C. y M. Lazzari,

1993. Informe de actividades y observaciones en la Falda Occidental del Aconquija. Palimpsesto 3:150-154. Bs. As.

Scattolin, M. C., M. F. Bugliani, A. D. Izeta, L. Pereyra Domingorena, M. Lazzari y L.

A. Martínez.

2001. Conjuntos materiales en dimensión temporal. El sitio Formativo "Bañado Viejo" (Valle de Santa María, Tucumán). Relaciones de la Sociedad Argentina de Antropología. 26: 167 - 192. Buenos Aires. 
Scillato Yané, G.

1982. Los Dasypodidae (Mammalia, Edentata) del Plioceno y el Pleistoceno de Argentina. Tesis Doctoral. Facultad de Ciencias Naturales y Museo. UNLP. MS

Scott, S. y H. Jackson.

1989. Aspects of Mississippian Subsistence Organization: Contrasts in Large Mammals Remains from Homestead and Village in the Tombigbee Valley. MS.

Sielfeld, W., C. Carrasco, G. Gonzalez y J. Torres.

1999. La Taruca (Hippocamelus antisensis D'Orbigni, 1834), CERVIDAE, ARTYODACTILA) en la Provincia de Parinacota, Región de Tarpacá, Chile: Población, hábitat y alimentación. An. Mus. Hist. Nat. Valparaíso, 24: 95-108.

Stahl, P.W.

1999. Structural density of domesticated South American camelid skeletal elements and the archaeological investigation of prehistoric andean ch'arki. Journal of Archaeological Science 26: 1347-1368.

Tarragó, M. N.

1978. Paleoecology of the Calchaquí Valley, Salta Province, Argentina. En: D. L.

Browman (ed) Advances in Andean Archaeology. 485 - 512.

Tarragó, M. N.

1984. La historia de los pueblos circumpuneños en relación con el altiplano y los andes meridionales. Estudios Atacameños 7: 116-132. San Pedro de Atacama.

Tarragó, M. N.

1994, El Formativo en el Noroeste argentino y el alto Valle Calchaquí. Actas del XI

Congreso Nacional de Arqueología Argentina. San Rafael.

Tarragó, M. N., L. González y J. Nastri

1997. Las interacciones prehispánicas a través del estilo: el caso de la iconografía santamariana. Estudios Atacameños 14: 223-242. San Pedro de Atacama.

Tarragó M. N. y M. C. Scattolin

1999. La Problemática del Período Formativo en el Valle de Santa María. Actas del XII Congreso Nacional de Arqueología Argentina. Tomo I: 142-153. La Plata.

Tartusi, M. y V.A. Nuñez Regueiro.

1993. Los centros ceremoniales del NOA. Publicaciones 5. Instituto de Arqueología. UNT.

Thomas, D. H. y D. Mayer

1983. Behavioral faunal analysis of selected horizons. En: D.H. Thomas (ed). The Archaeology of Monitor Valley 2: Gatecliff Shelter, pp. 353-391. American Museum of Natural History, New York.

Todd, L. C.

1987. Taphonomy of the Horner II Bonebed. In The Horner Site: The Type Site of the Cody Cultural Complex, edited by G.C. Frison and L.C. Todd, pp. 107-198. Academic Press, Orlando.

Todd, L.C. y D.J. Rapson

1988. Long bone fragmentation and interpretation of faunal assemblages: approaches to comparative analysis. Journal of Archaeological Science 15: 307-25.

Tonni, E.P y J.H Laza.

1977. Paleoetonozoología del área de la Quebrada del Toro, provincia de Salta.

Estudios Atacameños 5: 101-108. San Pedro de Atacama.

Turner, J. C. M.

1973. Descripción Geológica de la Hoja 11d, Laguna Blanca. Boletín No 142 , Ministerio de Industria y Minería, Subsecretaría de Minería, Servicio Nacional Geológico Minero. Buenos Aires, Argentina 
Ubilla, M.

1996. Paleozoología del Cuaternario continental de la cuenca norte de Uruguay: Biogeografia, cronología y aspectos climático-ambientales. Tesis Doctoral. Universidad de la República, Uruguay. MS.

Valdez, L. M.

2000.On Ch'arki Consumption in the Ancient Central Andes: A Cautionary Note. American Antiquity 65(3): 567-572.

Von den Driesch, A.

1976. A Guide to the Measurement of Animal Bones from Archaeological Sites.

Bulletin N. 1, Peabody Museum of Archaeology and Ethnology. Cambridge, USA.

Wheeler, J., E. Pires Ferreira y P. Kaulicke

1976. Preceramic animal utilization in the Central Peruvian Andes. Science 194.

Wheeler, J.

1982. Ageing Llamas and Alpacas by their teeth. Llama World 1: 12-17

Yacobaccio, H. D.

1988. Camélidos, domesticación y tamaño de la muestra. Reflexiones sobre la utilización animal prehistórica en los Andes. En: De procesos, contextos y otros huesos. N. Ratto y A. Haber (Eds). UBA, ICA. Buenos Aires, Argentina.

Yacobaccio, H. D.

1991. Sistemas de asentamiento de cazadores-recolectores tempranos de los Andes Centro-Sur. Tesis para otra al grado de Doctor de la UBA. F. F. y L. UBA. Buenos Aires, Argentina. MS

Yacobaccio, H. D. y C. Madero.

1992. Zooarqueología de Huachichocana III (Jujuy, Argentina). Arqueología 4: 43-

71. ICA. UBA. Buenos Aires, Argentina.

Yacobaccio, H. D. y C. Madero

1994. Etnoarqueología de pastores surandinos: una herramienta para conocer el registro arqueológico. Actas de las Jornadas de Arqueología e Interdisciplinas. CONICET-PREP. Buenos Aires, Argentina.

Yacobaccio, H.D., C.M. Madero y M.P. Malmierca

1998. Etnoarqueología de pastores surandinos. Grupo de Zooarqueología de Camélidos, Buenos Aires.

Yacobaccio, H.D., C.M. Madero, M.P. Malmierca, M. C. Reigadas

1997/98. Caza, domesticación y pastoreo de camélidos en la Puna Argentina. Relaciones de la Sociedad Argentina de Antropología. Tomo XXII-XXIII: 389418. Buenos Aires

Zeder, M.

1991. Feeding Cities. Specialized Animal Economy in the Ancient Near East. Smithsonian Institution Press.

Zeder, M. y S. Arter

1996. Meat Consumption and Bone Use in a Mississippian Village. En: Case Studies in Environmental Archaeology. 319-337. E. Reitz y, L Newsom y S. Scudder (ed) Plenum Press, New York. 


\begin{tabular}{llllll}
\hline \multicolumn{5}{c|}{ CODIGOS DE TAXONES (CLASE) } \\
\hline BD & Ave & FC & Felis concolor, puma & LS & Lama sp. \\
CA & Cavia sp., cuis & GP & Gastropoda & MU & Mustelido, zorrino \\
CF & Canis familiaris, perro & HA & Hippocamelus antisensis, taruca & PE & Chaetophractus vellerosus, peludo \\
CH & Chinchilla sp. & LA & Lagidium sp., vizcacha de la sierra & RO & Rodentia \\
CN & Canidae & LG & Lama guanicoe & UL & artiodáctilo grande (Camelidae, Bovidae) \\
CT & Ctenomys sp. Ocultos & LL & Lama glama & UN & especie no identificable \\
CV & Carnivora & LP & Lama pacos & VV & Lama (Vicugna) vicugna
\end{tabular}

\section{ELEMENTOS ESQUELETALES (EL)}

\begin{tabular}{|llllll|}
\hline \multicolumn{5}{c|}{ CRANEO/DIENTES } \\
\hline ANT & asta & IC & incisivo & PMR & premolar mandibular \\
CAN & canino & MMR & molar mandibular & PMX & premolar maxilar \\
CRN & cráneo & MMX & molar del maxilar & PUN & premolar no identificado \\
DIC & incisivo deciduo & MR & mandíbula & TFR & fragmento de diente \\
HS & cubierta del cuerno & MUN & molar no identificado & TTH & diente no identificado \\
HY & hiodeo & MX & maxilar & &
\end{tabular}

\begin{tabular}{|llllll|}
\hline & & \multicolumn{3}{c|}{ ESQUELETO AXIAL } \\
AT & atlas & CS & cartílago costal & SAC & sacro completo \\
AX & axis & LM & vértebra lumbar & SN & elemento esternal \\
CA & vértebra caudal & MN & manubrio & TH & vértebra torácica \\
CE & vértebra cervical & RB & costilla & VT & vértebra no identificada frag. \\
CLA & clavícula & SA & vértebra sacra & XY & xifoide
\end{tabular}

\begin{tabular}{llllll|}
\hline & & \multicolumn{3}{c|}{ ESQUELETO APENDICULAR (APENDICES ANTERIORES) } \\
\hline COR & coracoides & CPR & carpo radial & RD & radio \\
CP & carpo no identificado & CPS & carpos 2do. & RDU & radioulna \\
CP23 & carpo 2do y 3ro fusio. & CPT & carpo tercero & SC & escápula \\
CPA & carpo accesorio & CPU & carpo ulnar & UL & ulna \\
CPF & carpo cuarto & HM & & \\
CPI & carpo interme & &
\end{tabular}

CPI carpo intermedio MC metacarpo

\begin{tabular}{|llllll|}
\hline & & \multicolumn{2}{l|}{ ESQUELETO APENDICULAR (APENDICES POSTERIORES) } \\
\hline AS & astrágalo & MT & metetarso & TR & tarso no identificado \\
CL & calcáneo & MTS & segundo metatarso & TR4 & tarso 4to. \\
FM & fémur & PT & patella & TRC & tarso central \\
IM & innominado & PV & pelvis completa & TRF & primer tarso \\
LTM & maleolo lateral & TA & tibia & TRT tarso 3ro.
\end{tabular}

\begin{tabular}{|llllll|}
\hline \multicolumn{5}{c|}{ ESQUELETO APENDICULAR (OTROS) } \\
\hline DC & falange accesoria & PHF & primera falange & SED & sesamoideo distal \\
HF & pezuña & PHS & segunda falange & SEP & sesamoideo proximal \\
MP & metapodio & PHT & tercera falange & \\
PH & falange no identificada & SE & sesamoideo no identificado \\
\hline \multicolumn{2}{c}{ FRAGMENTOS (GENERAL) } \\
\hline BL & hueso largo & FB & hueso plano & fragmento de hueso no identificado \\
BZ & bezoarto & HV & huevo & \\
CB & tejido esponjoso indet & PL & placa & \\
\hline
\end{tabular}




\begin{tabular}{|c|c|c|c|c|c|}
\hline \multicolumn{6}{|c|}{ HUESOS LARGOS Y CODIGOS GENERALES } \\
\hline $\mathrm{CO}$ & completo & PRE & epífisis pr & $\mathrm{SH}$ & diáfisis de hueso largo \\
\hline PR & proximal & $\mathrm{CDL}$ & cóndilo & FK & lasca ósea \\
\hline PRD & $\begin{array}{l}\text { extremo pr }+ \text { menos de la } \\
\text { mitad de la df }\end{array}$ & EP & epífisis & $\mathrm{BL}$ & hoja de costilla o de la escápula \\
\hline PSH & $\begin{array}{l}\text { extremo pr }+ \text { mas de la } \\
\text { mitad de la df }\end{array}$ & DSE & epífisis ds & $\mathrm{HE}$ & cabeza \\
\hline DFP & $\mathrm{df}+\mathrm{ep} \mathrm{pr}$ & $\mathrm{DF}$ & diáfisis & US & no identificado \\
\hline DS & extremo ds & DDS & diáfisis ds & IFK & lasca de impacto en hueso \\
\hline DSS & $\begin{array}{l}\text { extremo ds }+ \text { menos de la } \\
\text { mitad de la df }\end{array}$ & DPR & diáfisis pr & ESH & epifisis + diafisis \\
\hline DSH & $\begin{array}{l}\text { extremo ds }+ \text { mas de la } \\
\text { mitad de la df }\end{array}$ & DFD & diáfisis + epífisis ds & AST & astilla de $\mathrm{df}$ \\
\hline \multicolumn{6}{|c|}{ ESCAPULA } \\
\hline BDR & borde & GN & porción glenoidea & GS & glenoide + espina \\
\hline CBD & porción del borde caudal & GNB & glenoide + fragmento de hoja & TOT & porción del tubérculo teres mayor \\
\hline CRB & porción del borde cranial & & & & \\
\hline
\end{tabular}

\begin{tabular}{|c|c|c|c|c|c|}
\hline \multicolumn{6}{|c|}{ ULNA } \\
\hline ANC & porción troclear & OLC & porción del olecranon & & \\
\hline \multicolumn{6}{|c|}{ CRANEO } \\
\hline $\mathrm{BRC}$ & caja craneana $(\mathrm{FN}+\mathrm{OCC})$ & MAL & malar & PMX & premolar del maxilar \\
\hline EN & esmalte dental & MMX & molar del maxilar & SKO & otra combinación de fragmentos \\
\hline ESF & esfenoides & MX & maxilar & SR & techo del cráneo $(\mathrm{FN}+\mathrm{HC})$ \\
\hline $\mathrm{FN}$ & frontal & NSL & nasal & TMP & temporal \\
\hline $\mathrm{HC}$ & cuerno (horn core) & OCC & occipital & TW & hilera de dientes \\
\hline INV & incisivo & PAL & palatino & ZGO & arco zigomático \\
\hline JUG & yugal & PAR & parietal & & \\
\hline $\mathrm{LC}$ & lacrimal & PET & petroso & & \\
\hline
\end{tabular}

\begin{tabular}{|llllll|}
\hline \multicolumn{5}{c|}{ HIODEO/DIENTES } \\
\hline ANG & ANG-angular & DP4 & cuarto premolar deciduo & MMX & molar del maxilar \\
BOD & BOD-cuerpo & EN & fragmento de esmalte & P2 & segundo premolar \\
CU & cuspide & IC & incisivo & P3 & tercer premolar \\
CW & corona & M1 & primer molar & P4 & cuarto premolar \\
DP & premolar deciduo & M2 & segundo molar & PM & premolar (MR) \\
DP2 & segundo premolar deciduo & M3 & tercer molar & PMX & premolar del maxilar \\
DP3 & tercer premolar deciduo & MMR & molar mandibular & RT & fragmento de raíz
\end{tabular}

\begin{tabular}{|lllll|}
\hline & & \multicolumn{3}{c|}{ MANDIBULA } \\
\hline ANG & angular & DAM & DRM + RAM & MMR molar mandibular \\
BDR & borde distal & DRM & rama dentaria & RAM rama ascendente \\
CON & proceso condilar & EN & esmalte dentario & SYM sínfisis \\
COR coronoide & HRM & rama horizontal & TW &
\end{tabular}

\begin{tabular}{|llllll|}
\hline \multicolumn{7}{c|}{ INNOMINADO } \\
\hline AC & acetábulo & IL & ilium & ISD & porción caudal del ischium \\
ACL & acetábulo + ilium & ILC & porción craneal del ilium & PB & pubis \\
ACP & acetábulo + pubis & ILD & porción caudal del ilium & PBS & porción sínfisis púbica \\
ACS & acetábulo + ischium & IS & ischium & VT & tubérculo ventral púbico (IS) \\
ASP & ac + is + pb & ISC & porción craneal del ischium & &
\end{tabular}




$\begin{array}{llllll}\text { AN } & \text { arco neural } & \text { CNS } & \text { CN + fragmento de la espina dorsal } & \text { PEP } & \text { epífisis posterior } \\ \text { AP } & \text { proceso articular } & \text { CNT } & \text { CN menos TSP } & \text { SP } & \text { proceso de la espina dorsal } \\ \text { CN } & \text { centro } & \text { CNW } & \text { atlas: CN + alas } & \text { TSP } & \text { proceso espinoso transverso } \\ \text { CNA } & \text { CN + AP } & \text { DRE } & \text { espina dorsal } & & \end{array}$

\section{SEGMENTOS ESQUELETALES (SG)}

\#(1- especificar la

14) vertebra/costilla/diente DT tuberosidad deltoidea (HM)

$\mathrm{AB}$ abaxial

EG borde

ACR cresta anterior (TA)

EN esmalte dental

PLF nutriente posterolateral (HM-RD-TA)

ACT porción acetabular

ECT epicondilo lateral (HM)

AL anterolateral ECM epicondilo medial (HM)

AM anteromedial

EX exterior

PL posterolateral

ANF foramen nutriente ant(FM)

FO anterior

AOD apofisis odontoides

FR fragmento

AX axial

HB hoja de RB quebrada

PM

posteromedial

\section{cavidades articulares}

CAC craneales

HD posterior

POF fosa olecraniana proximal (HM)

$\mathrm{CD}$ caudal (posterior)

HE cabeza

CDL cóndilo

IN interior

CDL cóndilo

L izquierdo

PR proximal

$\mathrm{CO}$ completo

LT lateral

$\mathrm{R}$ derecho

CDT condilo lateral (TA)

MAE meato acustico externo

RT tuber. Radial (RD)

SF fosa suprocondila (FM)

SP espina

CPLF cresta sobre PLF

ME medial

$\mathrm{CR}$ craneal (anterior)

MOA trocanter mayor

MO trocanter menor (FM)

tuberosidad supracondila medial (FM)

DS distal

MST (ME hasta la LT SF)

TM tubérculo teres mayor (HM)

TR tróclea

CXT tuberculo coxal del ilium

IST tuberculo isquial

OLT tuberculo olecraniano

RDT tuberosidad radial

TTU tuberosidad tibial

TW hilera de dientes

US no identificado

$\mathrm{VN}$ ventral

\begin{tabular}{llll}
\hline & & & \\
\hline $\mathrm{A}$ & axial & $\mathrm{R}$ & derecho \\
$\mathrm{L}$ & izquierdo & $\mathrm{N}$ & no identificado
\end{tabular}

\begin{tabular}{|c|c|c|}
\hline \multicolumn{3}{|c|}{ FUSION EPIFISAL (PFUS = FUSION EPIFISIS PROXIMAL; DFUS = FUSION EPIFISIS DISTAL) } \\
\hline 0 sin fusionar & 2 fusionado, línea aun visible & 4 hueso roto, no se puede decir \\
\hline 1 parcialmente fusionado & 3 completamente fusionado & 5 no aplicable \\
\hline \multicolumn{3}{|c|}{ ALTERACION TERMICA (BURN) } \\
\hline 0 no & 3 carbonizado y calcinado & 8 indeterminado \\
\hline 1 carbonizado & 4 oxidación incompleta/carbonización & 9 no aplicable \\
\hline 2 calcinado & & \\
\hline
\end{tabular}

\begin{tabular}{llllll|}
\hline \multicolumn{5}{c|}{ FRACTURA (BREAK) } \\
\hline 0 & no & 6 & longitudinal & $\# .2$ & intermedia \\
1 & espiral & 7 & aplastado & $\# .3$ & seca \\
2 & escalonada & 8 & indeterminada & $\# .4$ & indeterminada \\
3 & chipped & 9 & oblicua & $\# .5$ & removida por mordisqueo \\
4 & cono de impacto & 10 & por recolección/curation & \\
5 & transversa & $\# .1$ & fresca \\
\hline & & \multicolumn{5}{c}{ MORDISQUEO (CARMOD) } \\
\hline 0 & no & 12.1 & daño moderado/grave por roedor & 40 & posible mordisqueo de carnívoro
\end{tabular}




\section{PROCESAMIENTO/MODIFICACIONES ANTROPICAS (BUTCH; CUTNO; IMPAC)}

$0 \quad$ sin evidencia de proces.

marcas de corte

raspado (estrías paralelas)

groove

chopping

aserrado

6

7 marca perimetral

8

9

10

11

cortes e impactos

marcas anómalas

posible impacto

marca perimetral 13

posibles cortes y marcas de chop
12 morfologia de raspado y fractura

13 marcas anómalas y morfología de fractura

14 morfologia de fractura por procesamiento

15 formatizacion

\begin{tabular}{|lllllll}
\hline \multicolumn{7}{c|}{ TRATAMIENTO } \\
\hline A & acrysol & E & cola plástica & $\mathrm{M}$ & tratamientos múltiples \\
C & molde de yeso & F & aluminio & V & barniz
\end{tabular}




\section{METEORIZACIÓN}

\begin{tabular}{|c|c|c|}
\hline Estadio & Hueso Compacto* & Superficie cortical (Modificado de Beherensmeyer 1978)** \\
\hline 1 & $\begin{array}{l}\text { No meteorizado, superficies articulares sin craquelado } \\
\text { superficial }\end{array}$ & No meteorizado \\
\hline 2 & $\begin{array}{l}\text { Superficies articulares intactas con algún craquelado } \\
\text { superficial }\end{array}$ & Meteorización superficial limitada, algunas grietas longitudinales \\
\hline 3 & $\begin{array}{l}\text { Superficies articulares exhiben algún deterioro, pero más del } \\
50 \% \text { de la superficie permanece intacto }\end{array}$ & $\begin{array}{l}\text { Astillamiento ligero de la superficie, grietas longitudinales más } \\
\text { profundas }\end{array}$ \\
\hline 4 & $\begin{array}{l}\text { Superficies articulares intactas restringidas a pequeñas } \\
\text { "islas", menos del } 50 \% \text { de las superficies articulares } \\
\text { permanecen intactas }\end{array}$ & Trozos de tejido esponjoso con astillamiento moderado y craquelado \\
\hline 5 & Ninguna área de la superficie articular permanece intacta & Agrietamiento profundo y astillamiento superficial extenso \\
\hline 6 & $\begin{array}{l}\text { Hueso severamente deteriorado, grandes áreas de tejido } \\
\text { esponjoso expuestas }\end{array}$ & Hueso desmenuzándose in situ \\
\hline 7 & Fragmento, no aplicable & Fragmento, no aplicable \\
\hline 8 & Químicamente alterado, o superficie original no visible & Químicamente alterado, o superficie original no visible \\
\hline 9 & Sin datos & Sin datos \\
\hline
\end{tabular}

* tomado de Todd 1987 Tabla 3.3

** modificado de Beherensmeyer (1978) con el estadio 0 representando una muerte reciente (hueso todavía grasoso). Estadio 1 representa el Estadio 0 de Beherensmeyer, el estadio 2 corresponde al estadio 1 de Beherensmeyer y así sucesivamente. 
Astrágalo (AS)

$\begin{array}{rrrrrrr}\text { SPECNUMBER } & 201 & 202 & 206 & 207 & 212 & 213 \\ 148 & 26.9 & 27.2 & 43 & 39.8 & 24.4 & 24.1 \\ 149 & 27.1 & 24.5 & 41.3 & 38 & 21.6 & 22.6 \\ 1412 & 26 & 24.8 & 37.8 & 34.7 & 19.4 & 19.8 \\ 18617 & 27.8 & 26.9 & 44.9 & 40.2 & 22.5 & 23.3 \\ 80129 & 22.8 & 20.1 & 35.9 & 33.2 & 15.5 & 19.1 \\ 135132 & 23.8 & 21.2 & 36.1 & 34.1 & 19.9 & 20.5 \\ 9992072 & 27.7 & 27.3 & 45.5 & 42.3 & 20 & 0\end{array}$
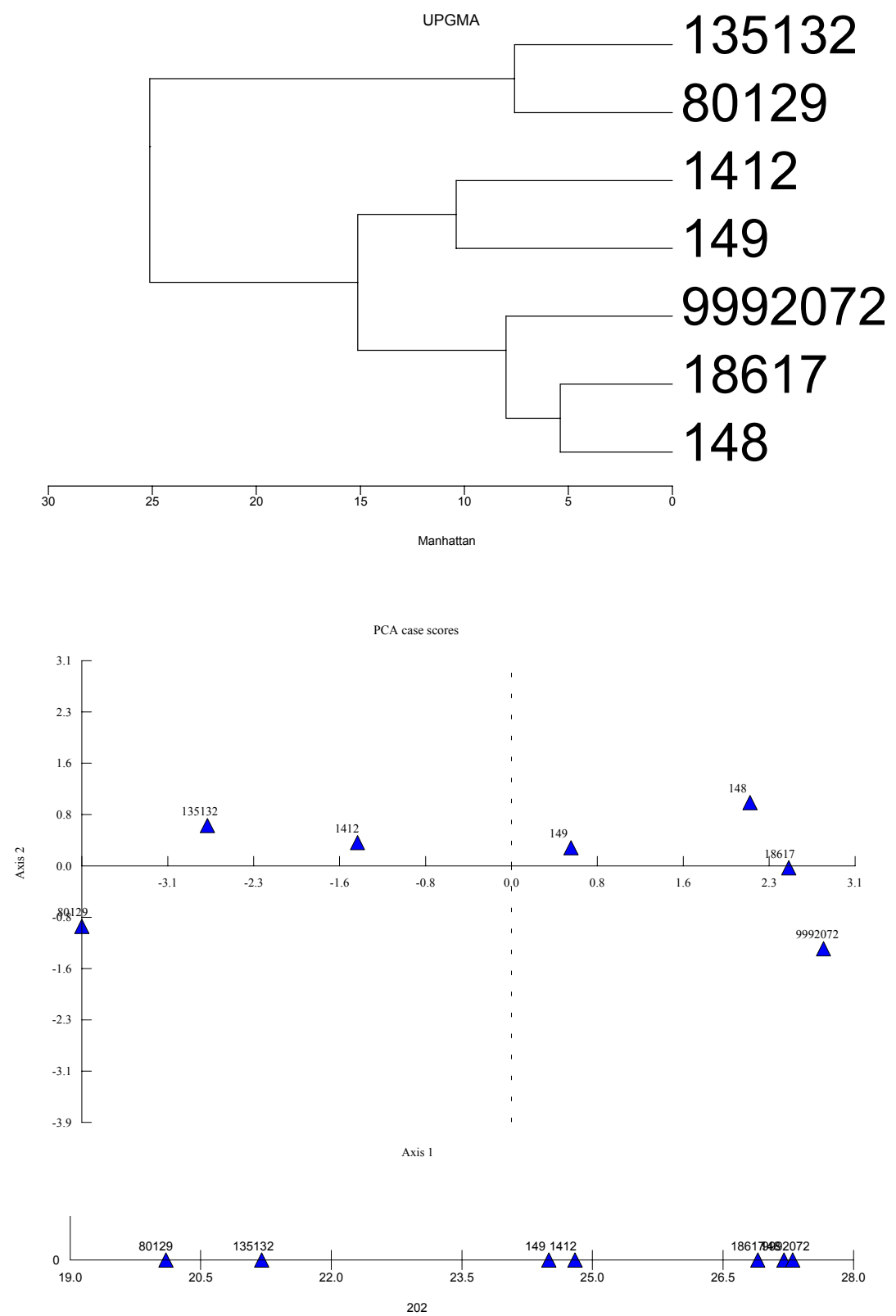
Calcáneo (CL)

$\begin{array}{rrrrrrr}\text { SPECNUMBER } & 201 & 202 & 203 & 204 & 209 & 214 \\ 10016 & 31.6 & 23.9 & 100.0 & 25.9 & 25.9 & 30.4 \\ 148 & 25.0 & 22.2 & 89.0 & 23.8 & 23.6 & 26.8 \\ 149 & 26.5 & 21.4 & 85.3 & 23 & 24.7 & 26.6 \\ 149 & 26.1 & 21.2 & 85 & 23.1 & 24.5 & 26.3 \\ 5911 & 31.4 & 22.6 & 95.8 & 24.8 & 25.7 & 30.5 \\ 18511 & 24.9 & 20.4 & 82.4 & 21 & 23.5 & 27.2 \\ 21211 & 29.7 & 20.2 & 84.1 & 21.8 & 23.5 & 27 \\ 40414 & 25.3 & 19.5 & 79.1 & 20.8 & 22.6 & 23\end{array}$
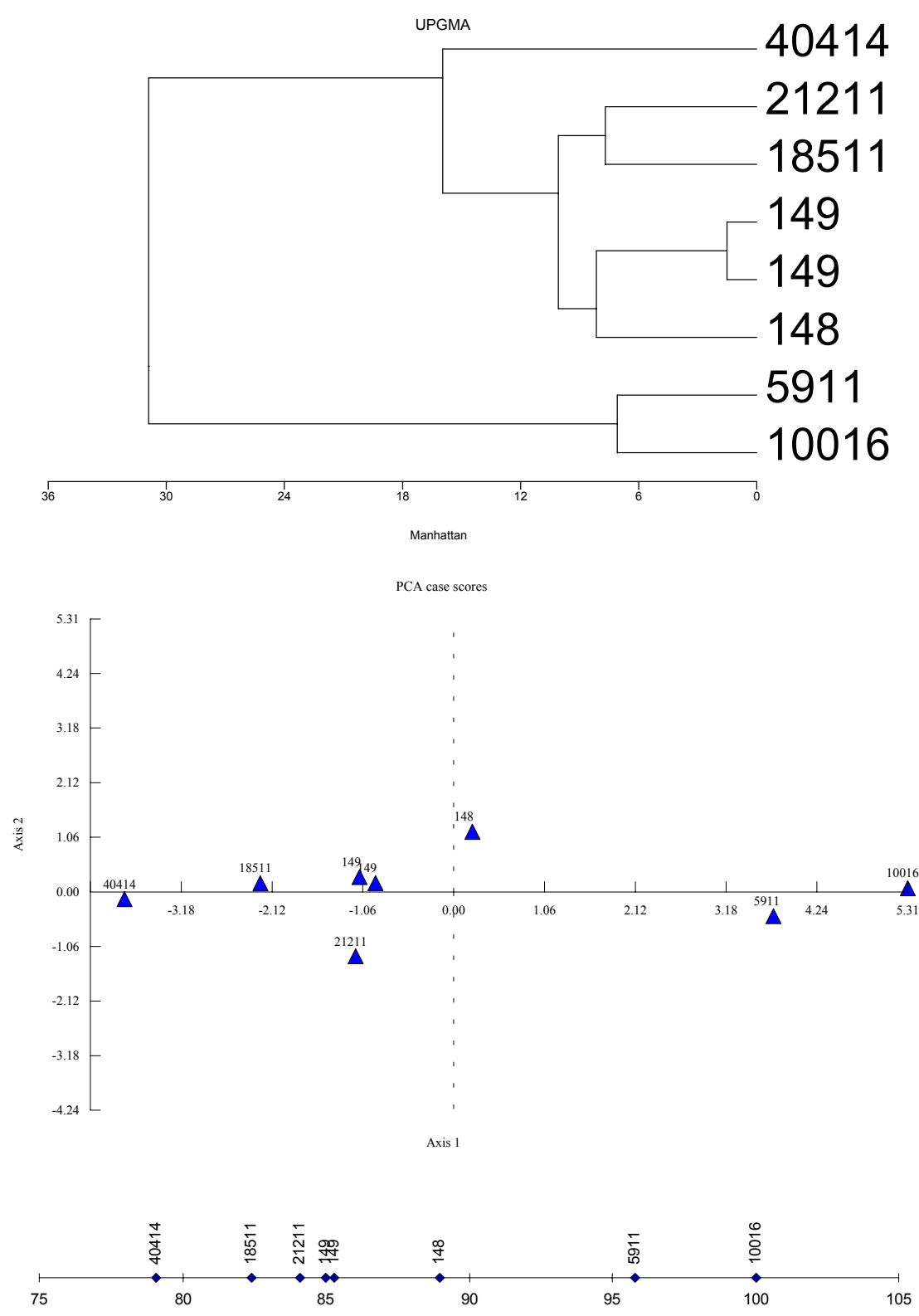
Carpo Accesorio (CPA)

$\begin{array}{rrrr}\text { SPECNUMBER } & 202 & 205 & 208 \\ 148 & 11.8 & 25.1 & 17.2 \\ 149 & 11.8 & 28.3 & 16.3 \\ 40216 & 14.4 & 25.7 & 19.8 \\ 54313 & 13 & 29.1 & 17.7 \\ 9992074 & 10.7 & 23.1 & 13.4\end{array}$

9992074

148

149

54313

40216

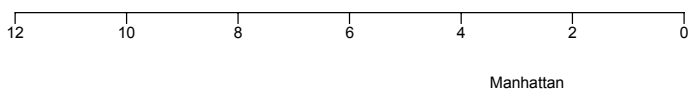

PCA case scores

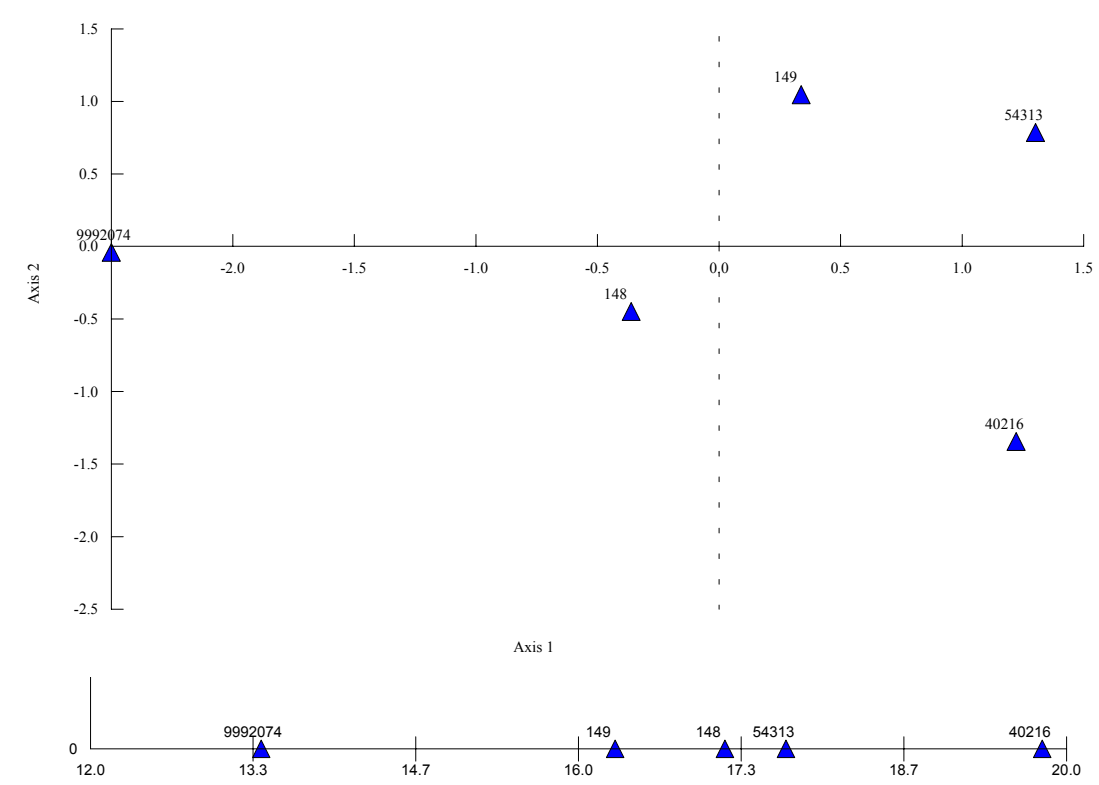




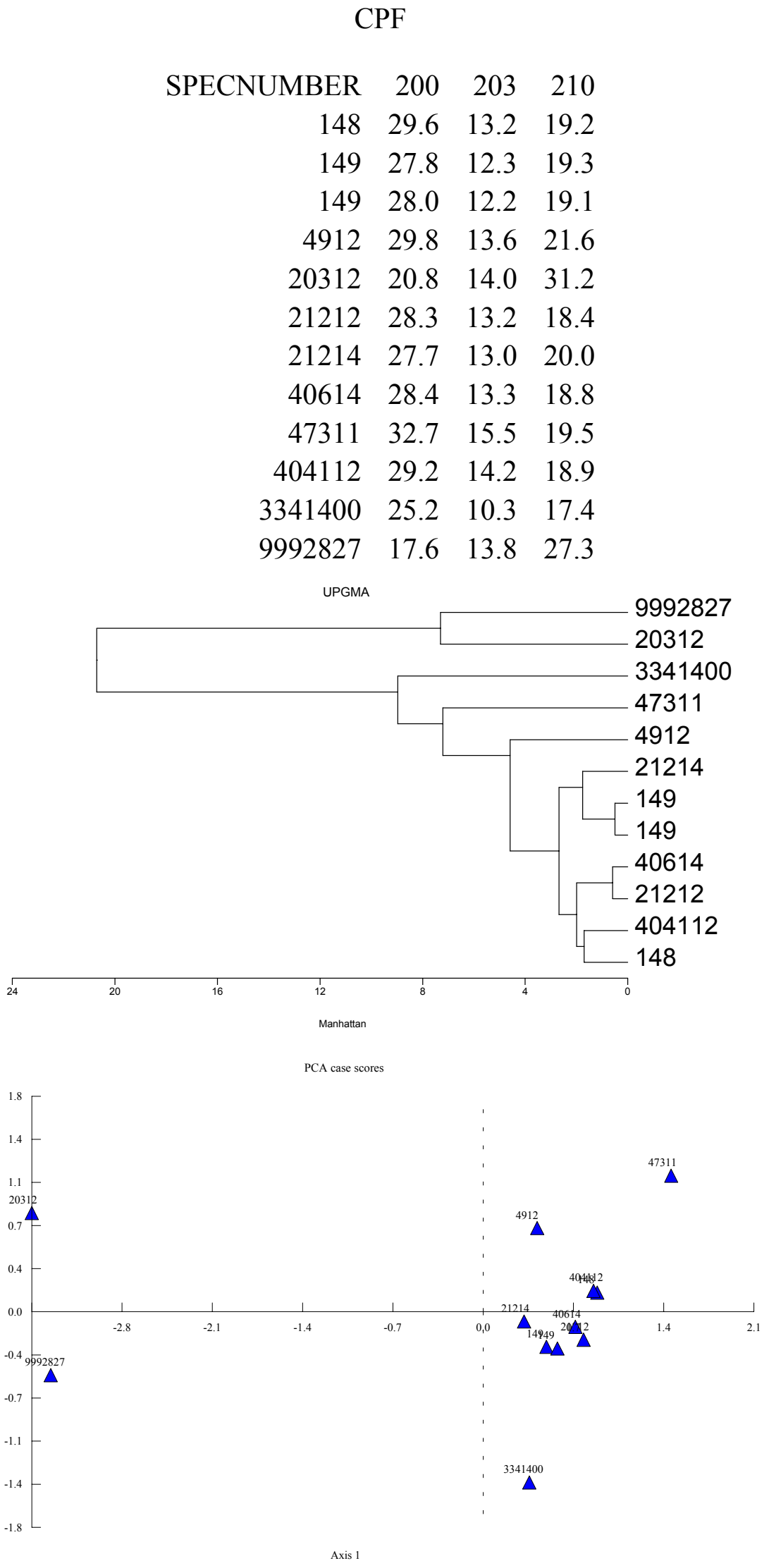




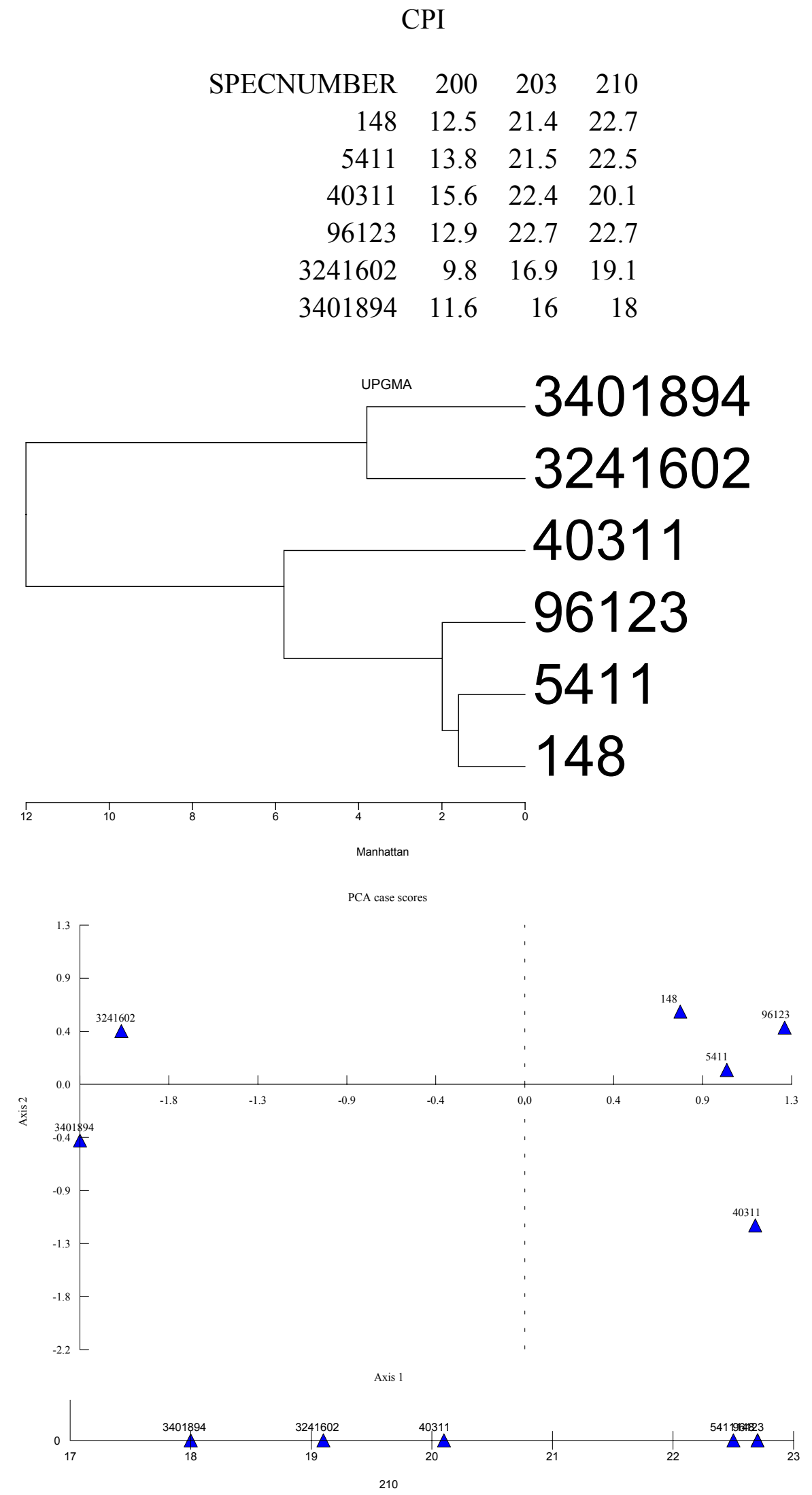




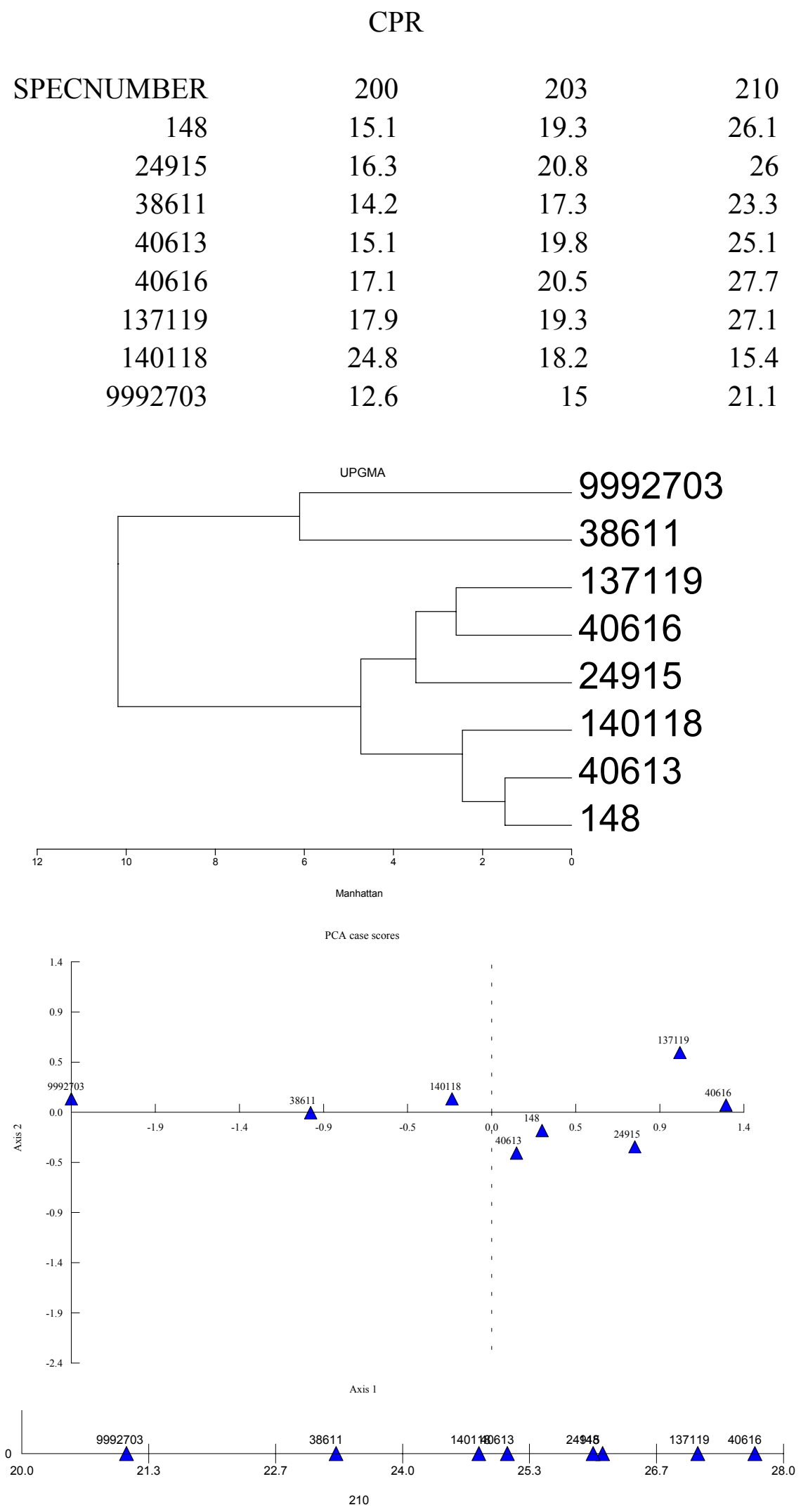




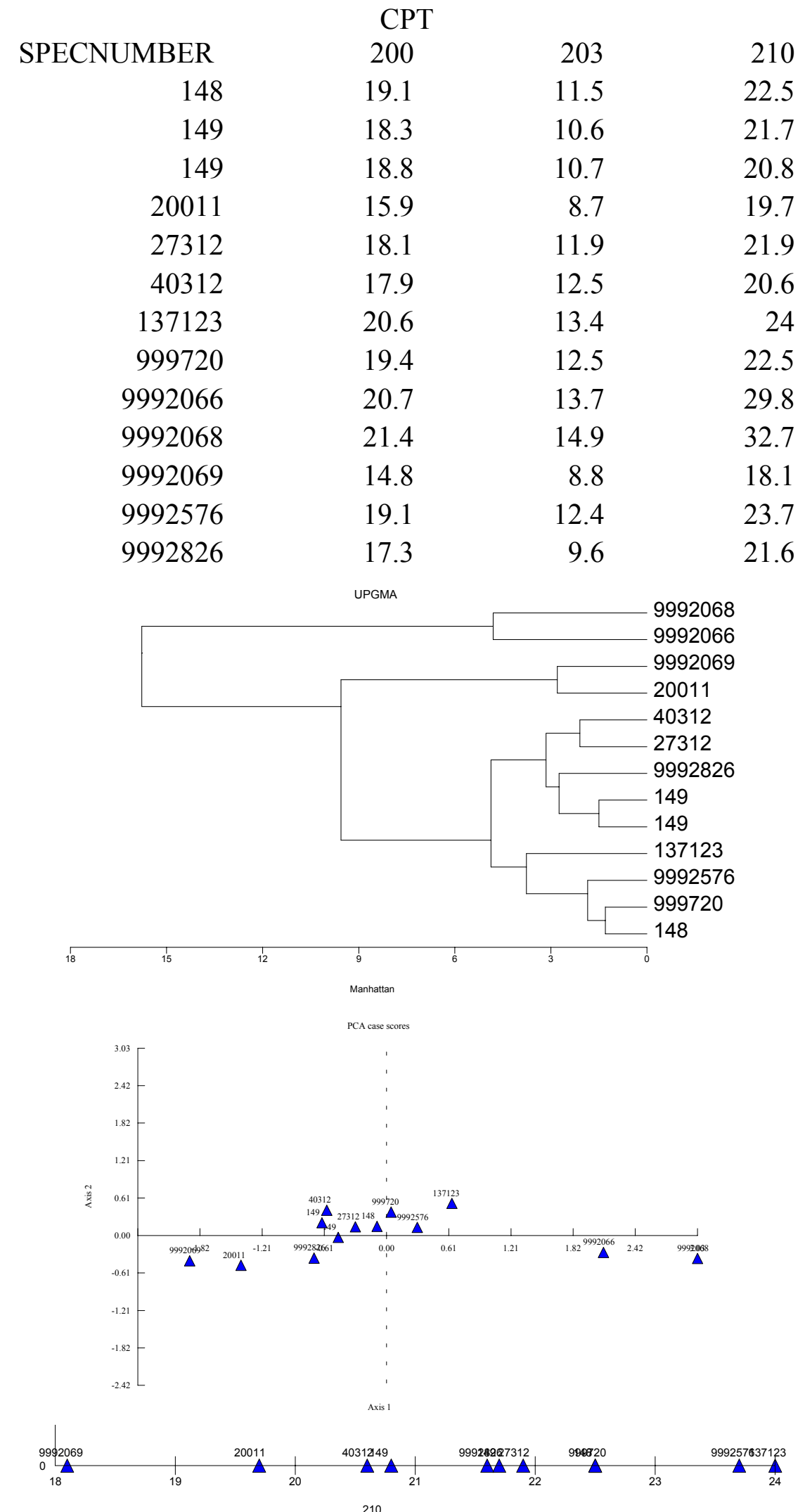

210 


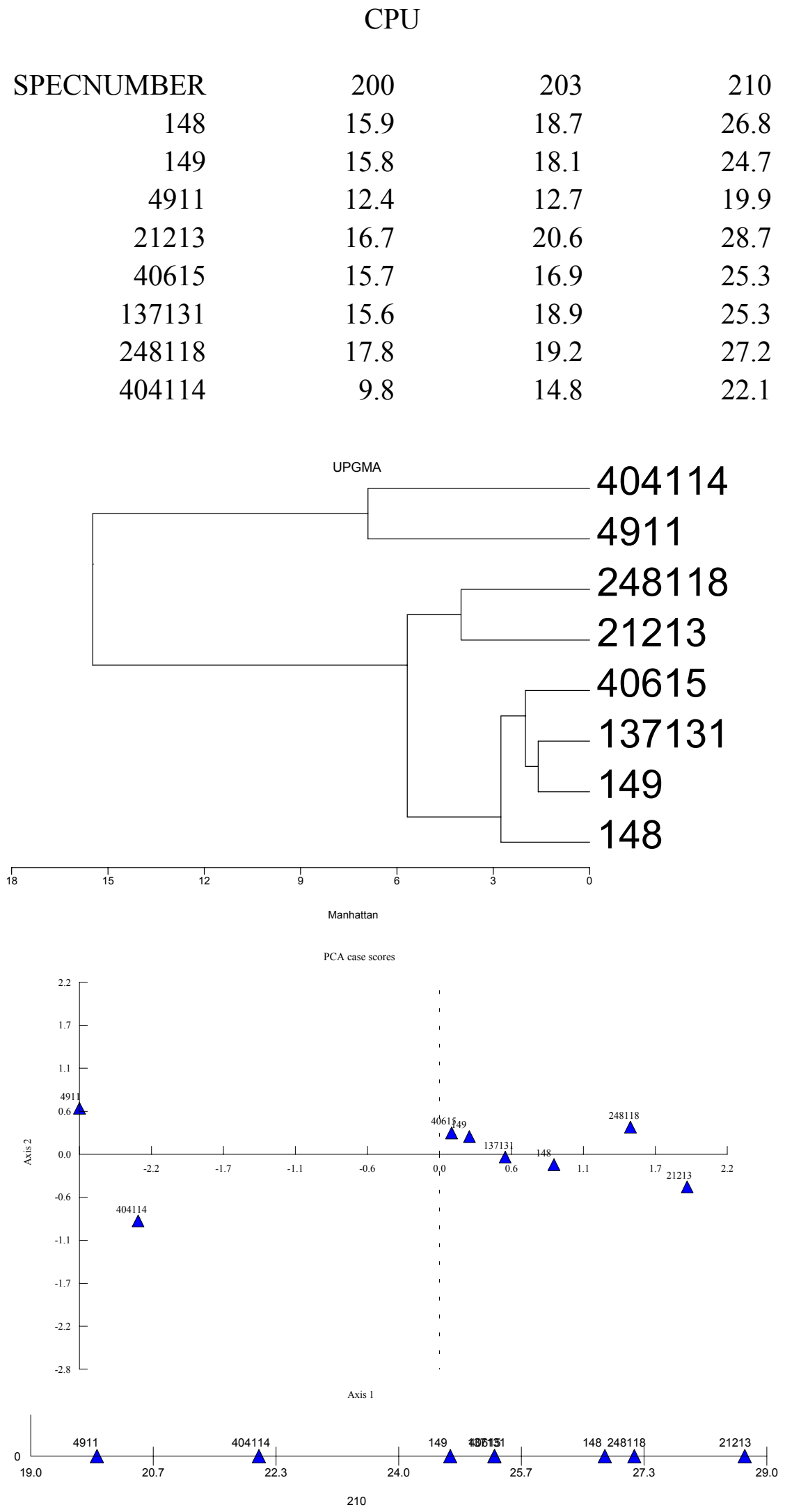


Fémur Proximal (FM PR)

$\begin{array}{rrrr}\text { SPECNUMBER } & 115 & 116 & 117 \\ 148 & 73.1 & 71.3 & 53 \\ 149 & 67.8 & 67.3 & 29.6 \\ 149 & 67.9 & 67.4 & 30.1 \\ 20311 & 74.3 & 60 & 31.3 \\ 40411 & 68.7 & 53.9 & 26.7\end{array}$

UPGMA
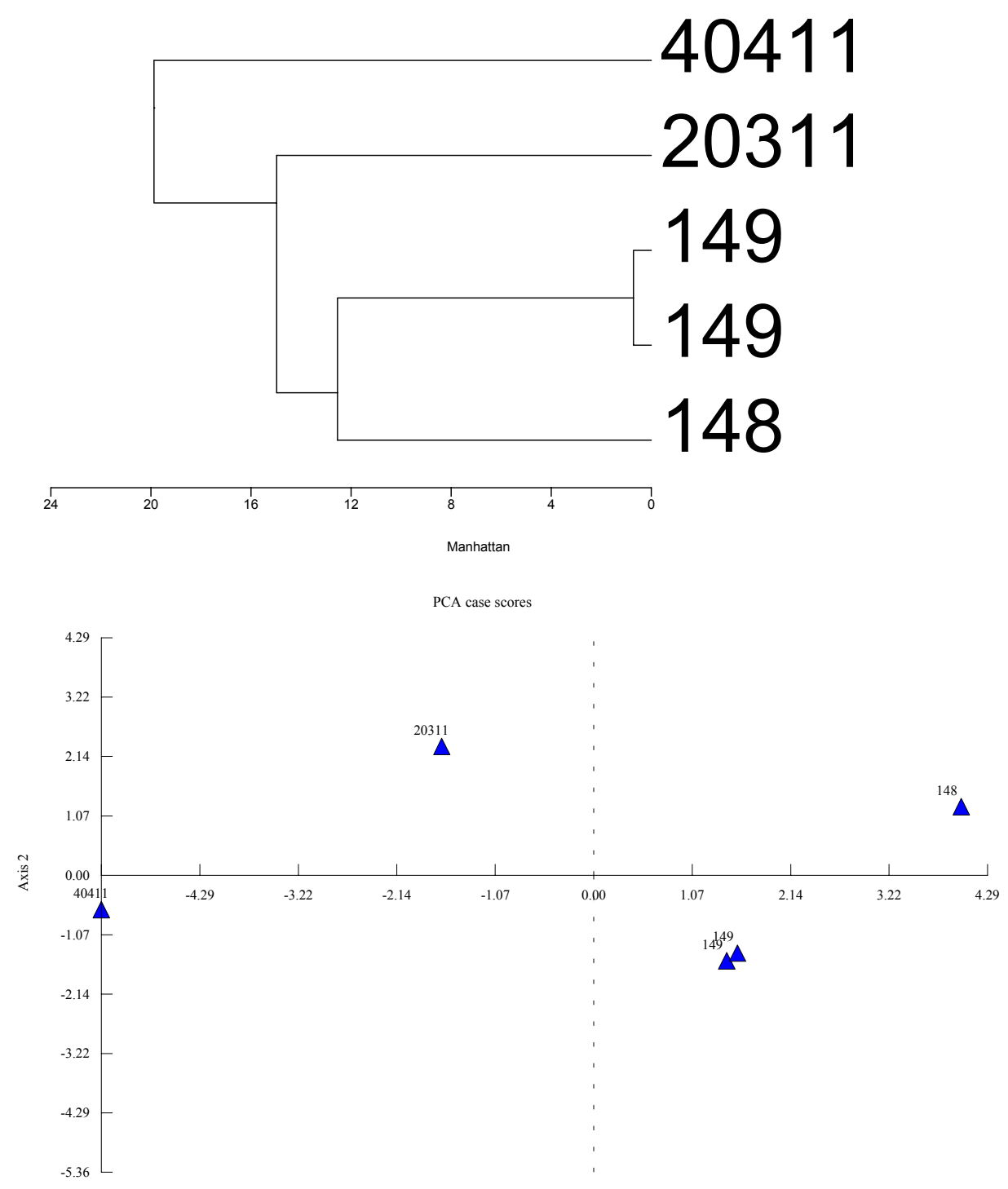
Fémur Distal (FM DS)

$\begin{array}{rrrrrrr}\text { SPECNUMBER } & 121 & 122 & 123 & 124 & 125 & 129 \\ 148 & 59.5 & 28.5 & 67.5 & 25.8 & 22 & 50.7 \\ 149 & 56.5 & 25.6 & 60.4 & 17.8 & 20.8 & 44.8 \\ 149 & 45.5 & 25.6 & 61.3 & 18.4 & 20.6 & 41.8 \\ 40111 & 55 & 26.7 & 62 & 19.3 & 20.3 & 41.6\end{array}$

UPGMA
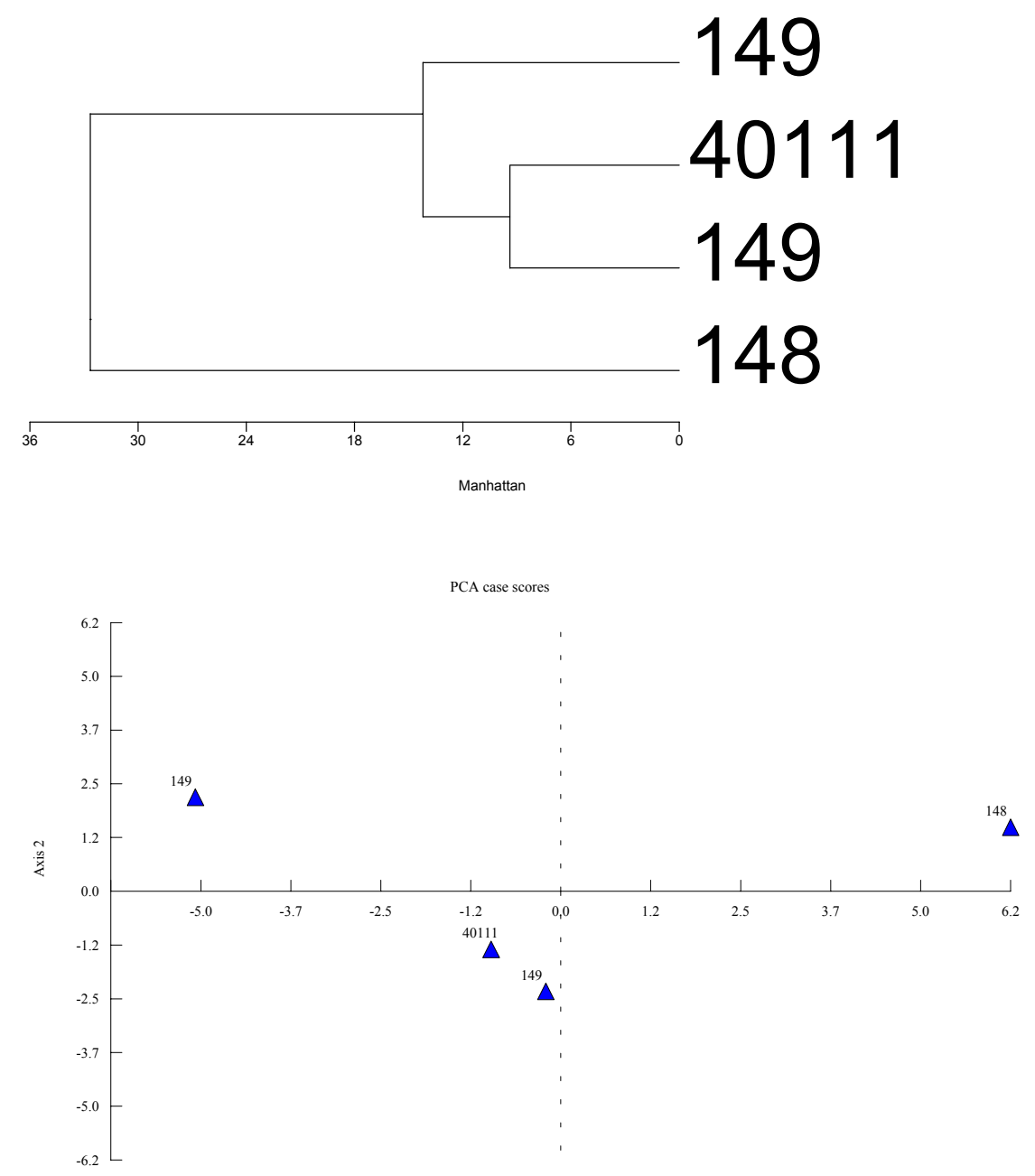
Fémur Distal (FM DS)

$\begin{array}{rrrrrr}\text { SPECNUMBER } & 120 & 121 & 123 & 125 & 129 \\ 148 & 47.4 & 59.5 & 67.5 & 22 & 50.7 \\ 149 & 44.9 & 56.5 & 60.4 & 20.8 & 44.8 \\ 149 & 46.4 & 45.5 & 61.3 & 20.6 & 41.8 \\ 40511 & 47.2 & 60.1 & 68.3 & 22.3 & 44.7 \\ & & & & & \\ & \text { UPGMA } & & & & \end{array}$

149

149

40511

148

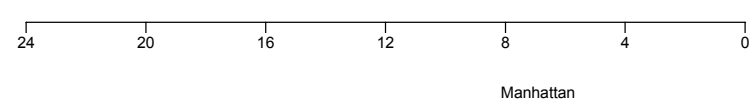

PCA case scores

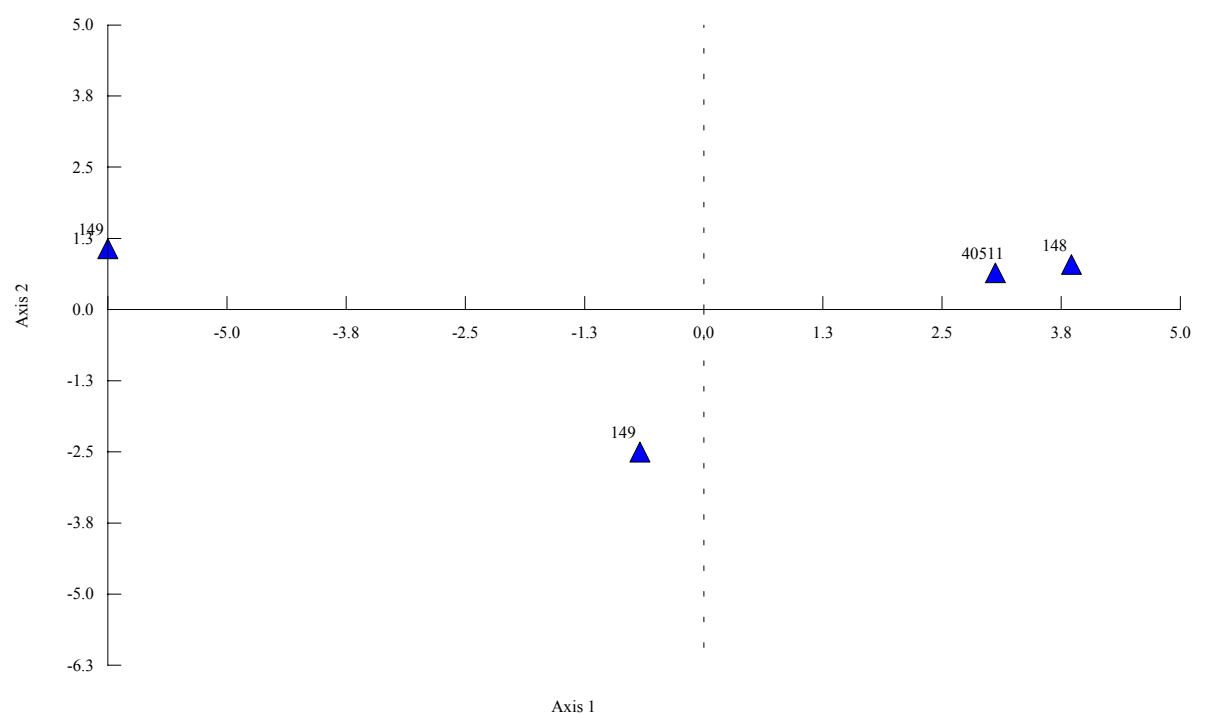


Humero (HM)
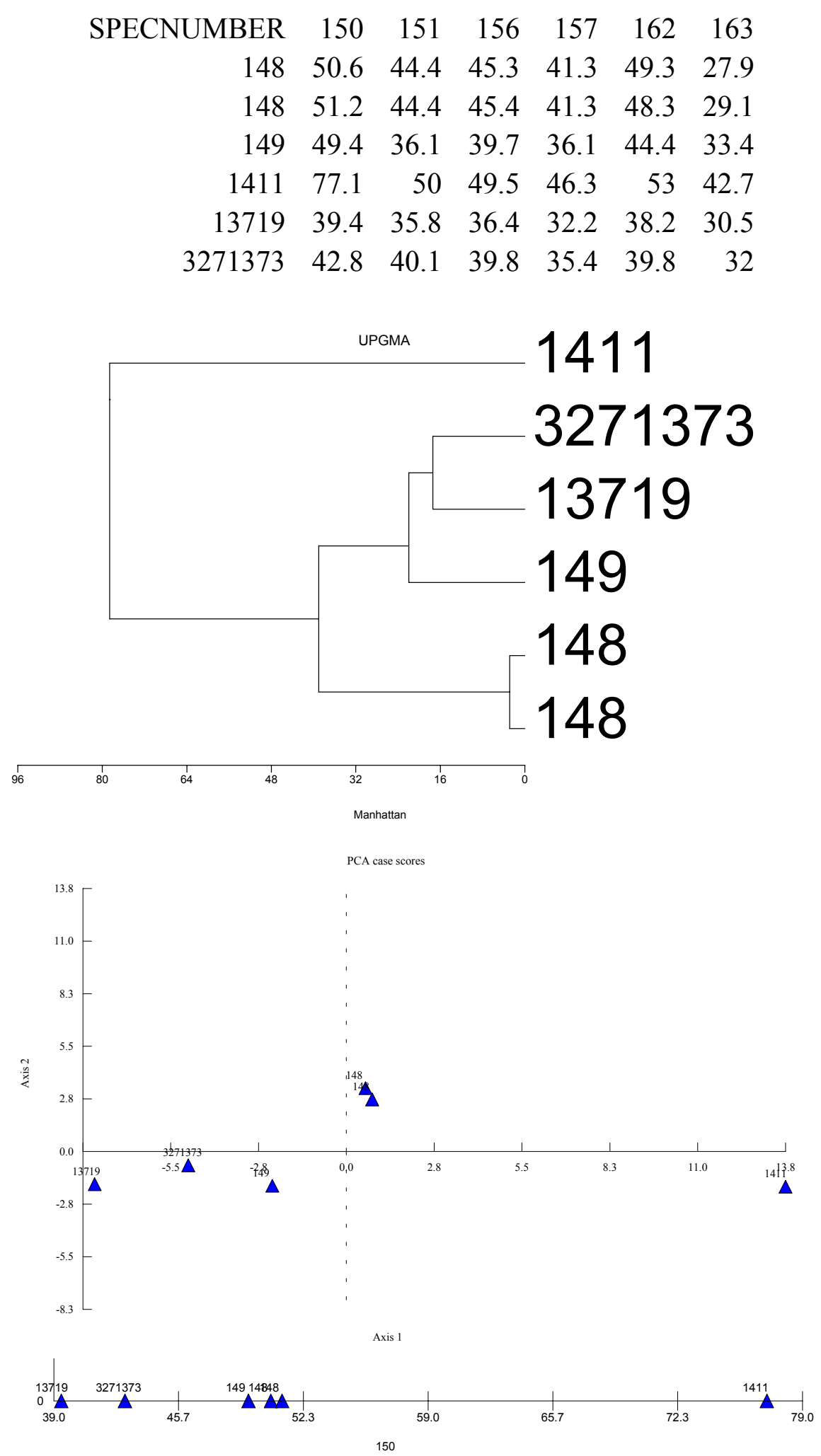
Humero (HM)

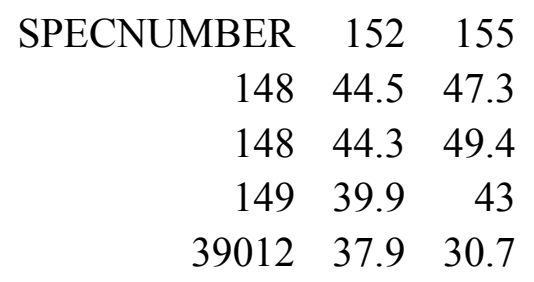

UPGMA
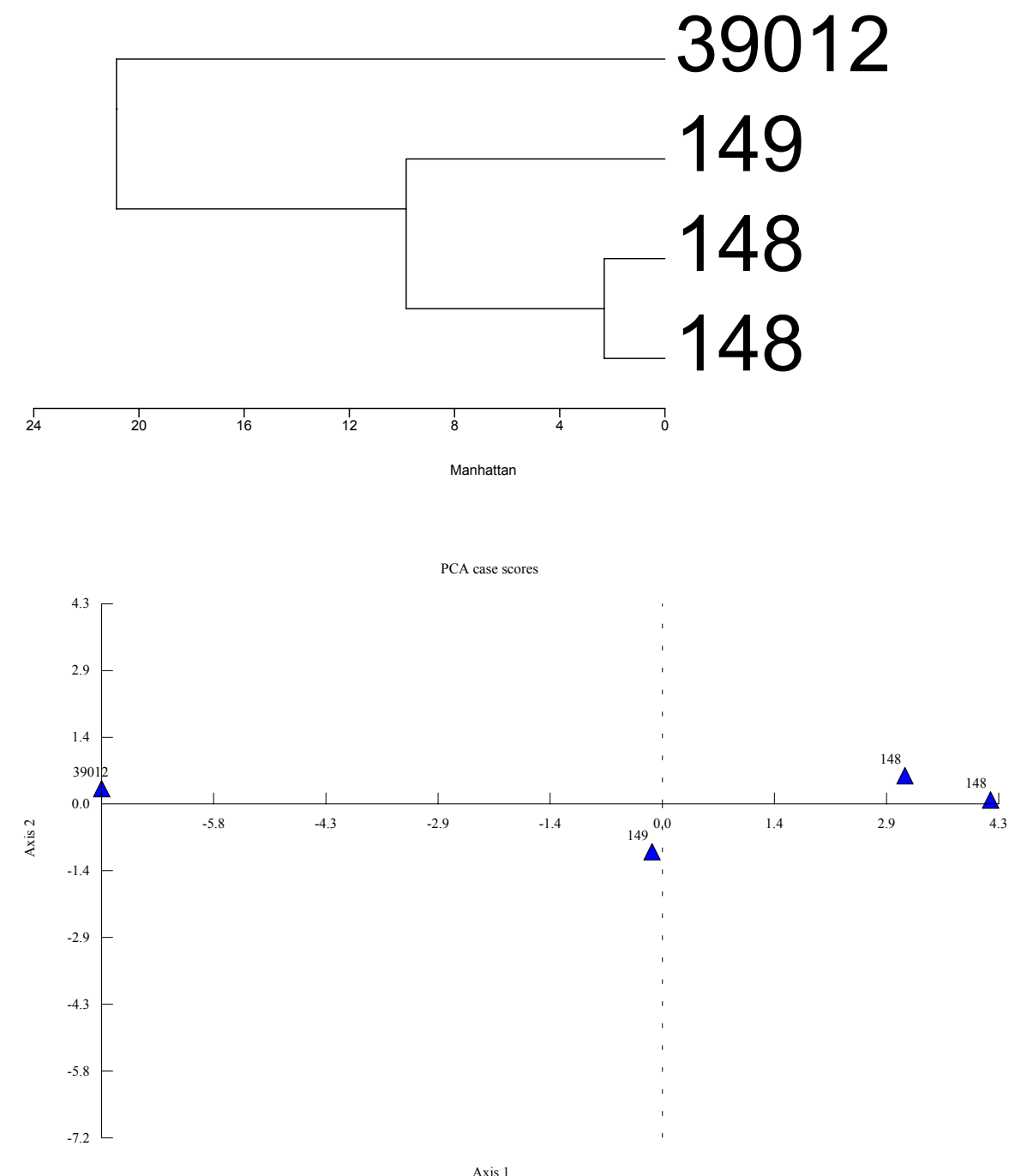
Humero (HM)

$\begin{array}{rrrr}\text { SPECNUMBER } & 152 & 153 & 155 \\ 148 & 44.5 & 65.1 & 47.3 \\ 148 & 44.3 & 65.6 & 49.4 \\ 149 & 39.9 & 67.4 & 43 \\ 9992629 & 42.3 & 73.2 & 44\end{array}$

UPGMA
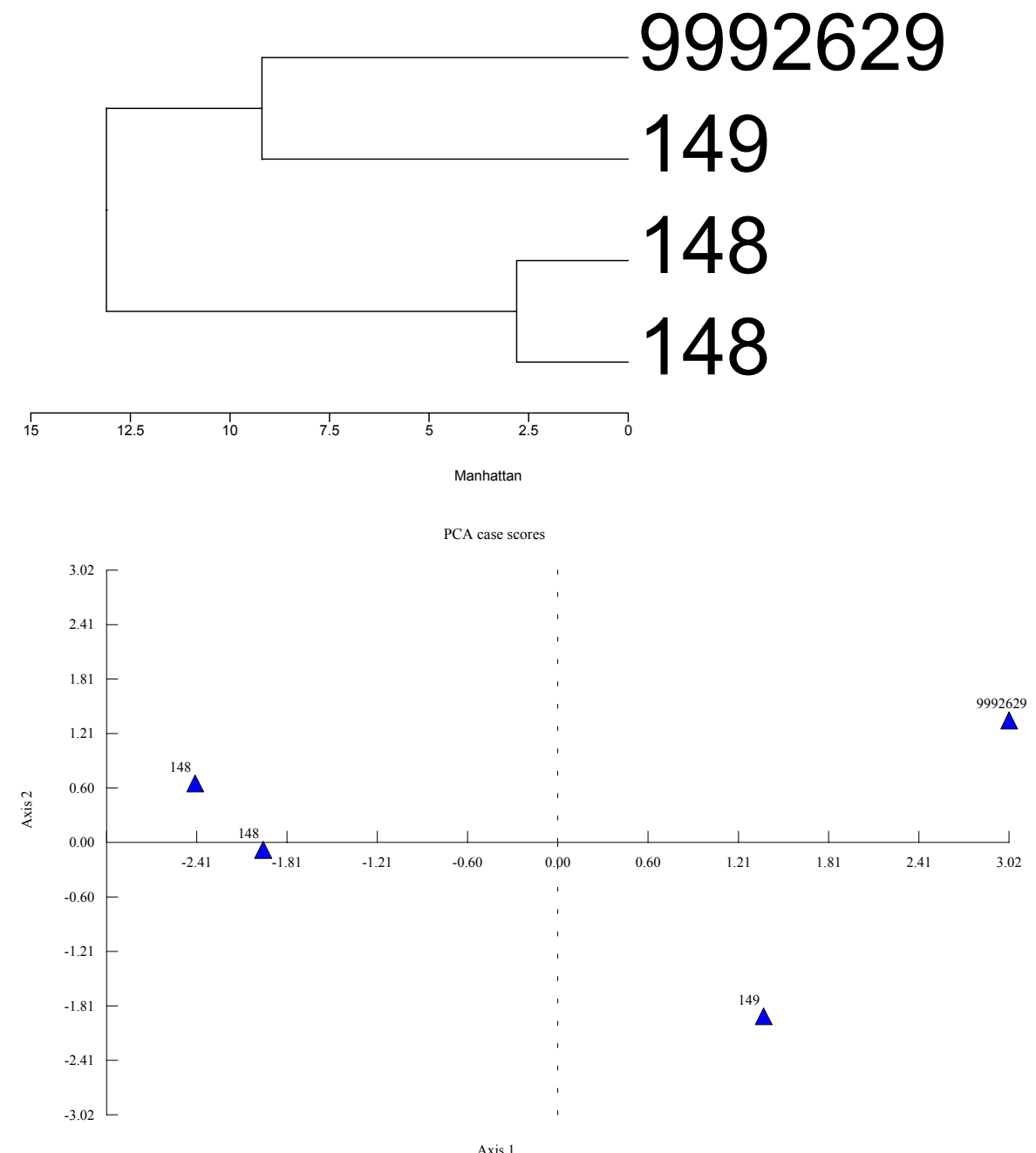
Maleolo Lateral (LTM)

$\begin{array}{rrrr}\text { SPECNUMBER } & 200 & 203 & 210 \\ 148 & 12.6 & 25.7 & 21.8 \\ 149 & 12.5 & 41.7 & 21.4 \\ 13314 & 13.6 & 20.5 & 22.4 \\ 36611 & 15.3 & 23.2 & 24.7 \\ 3481503 & 12.9 & 19.9 & 21.1\end{array}$

UPGMA
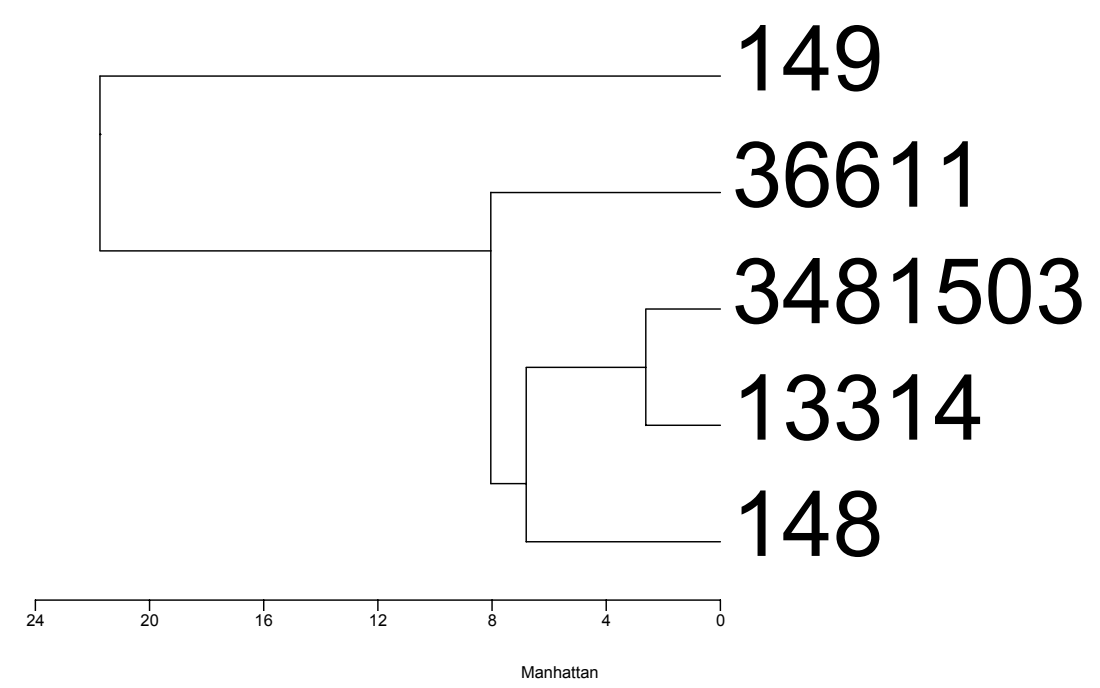

PCA case scores

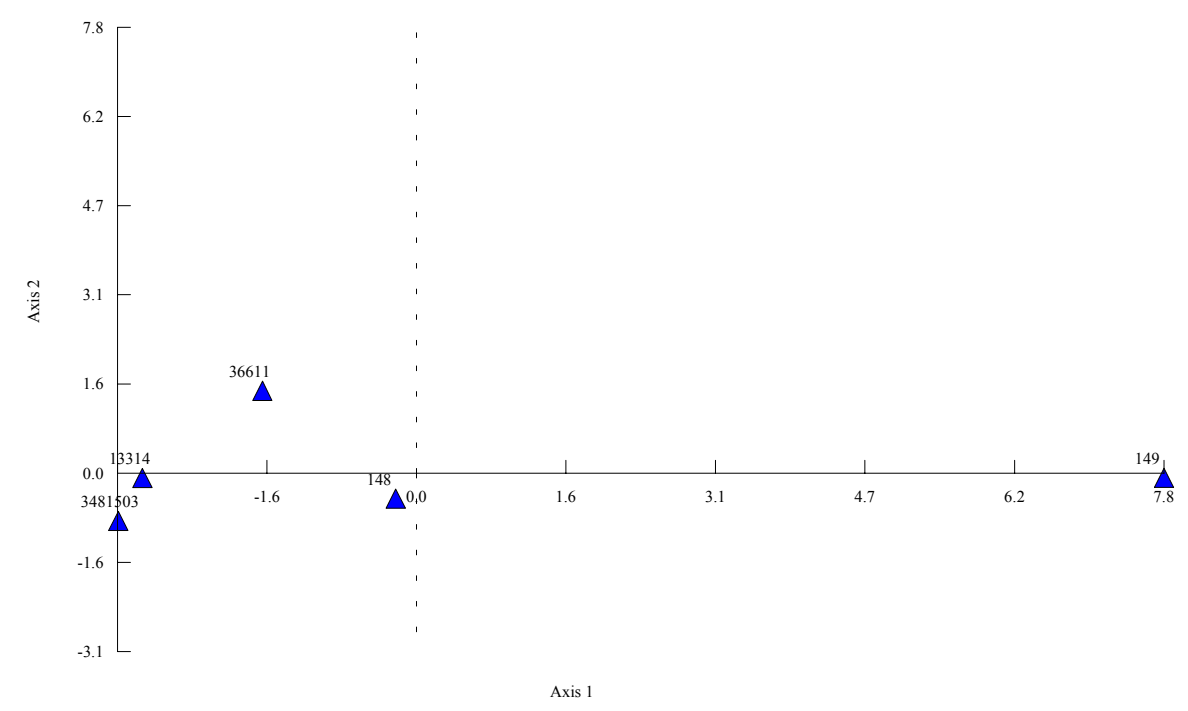


Metacarpo Proximal (MC PR)

$\begin{array}{rrrrrrrrrrr}\text { SPECNUMBER } & 59 & 60 & 61 & 62 & 63 & 64 & 65 & 66 & 67 & 68 \\ 148 & 35.6 & 24.5 & 25 & 13.1 & 22.8 & 21.1 & 14.8 & 11.4 & 16 & 9.4 \\ 149 & 36 & 24.9 & 26.2 & 15.5 & 22 & 14.9 & 14.4 & 11.4 & 14.9 & 8.9 \\ 149 & 35.5 & 25.1 & 26.9 & 16 & 22.5 & 15.7 & 14.9 & 11.1 & 13.8 & 10.5 \\ 40317 & 35.2 & 25.6 & 24.1 & 15.6 & 21.6 & 14.2 & 14.9 & 11.7 & 16.9 & 8.9 \\ 40611 & 34.7 & 24.4 & 24.4 & 15.2 & 24.3 & 15.4 & 18 & 14 & 15.1 & 7 \\ 101142 & 30.4 & 22.3 & 22.2 & 13.2 & 21.4 & 12.3 & 12.7 & 11.3 & 14.6 & 4.7\end{array}$
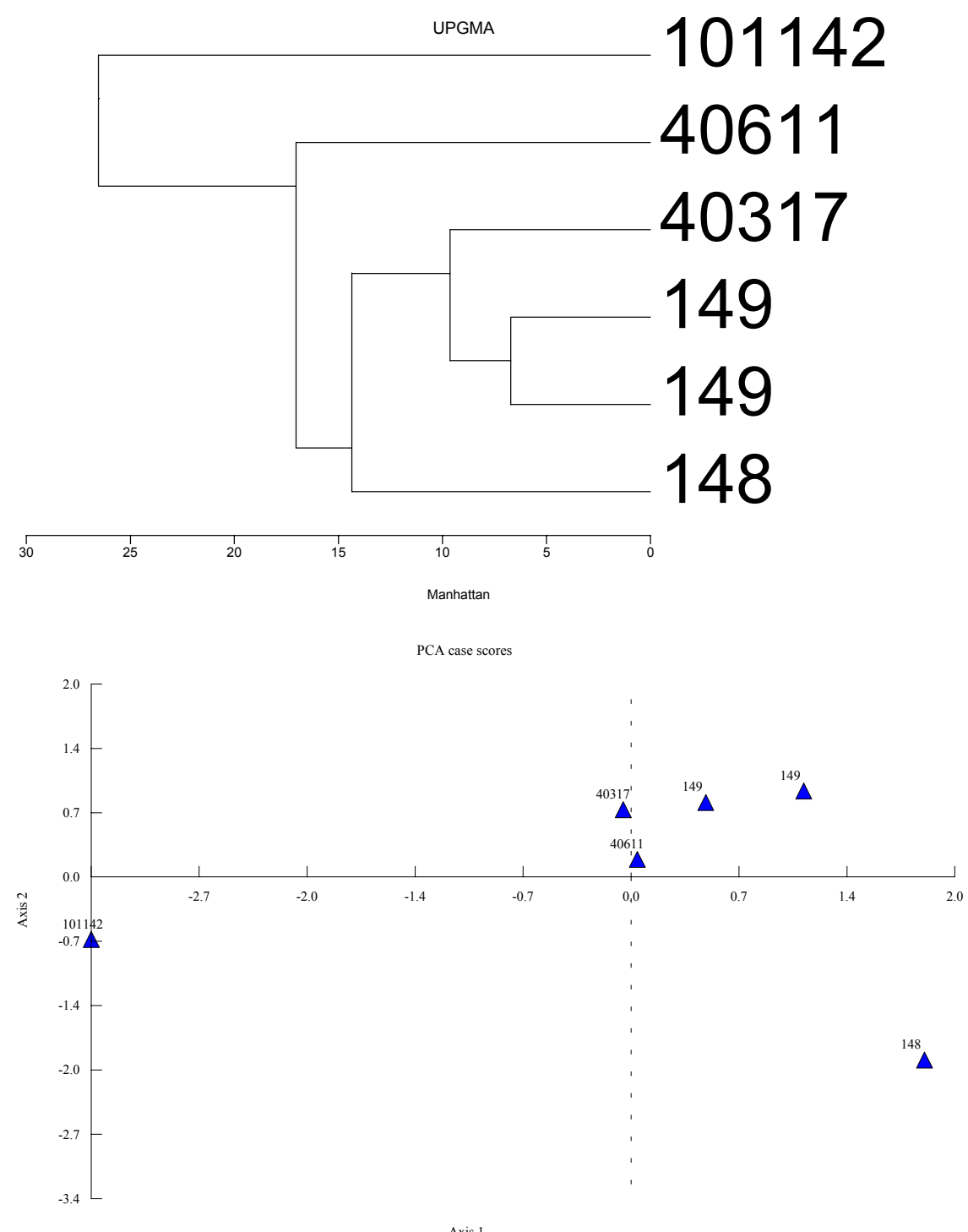


\section{Metacarpo Distal (MC DS)}

\begin{tabular}{|c|c|c|c|c|c|c|c|c|c|c|}
\hline SPECNUMBER & 72 & 73 & 74 & 75 & 76 & 77 & 78 & 79 & 80 & 81 \\
\hline 148 & 29.7 & 12.4 & 17.4 & 39.5 & 18.7 & 45.8 & 21.3 & 21.3 & 21.3 & 21.5 \\
\hline 149 & 26 & 13.8 & 34 & 42.5 & 20.6 & 44.8 & 20.8 & 21.3 & 21.8 & 21. \\
\hline 40419 & 32 & 12.4 & 26.3 & 41.2 & 21.4 & 47.5 & 21.9 & 21.8 & 22.5 & 22 \\
\hline
\end{tabular}

\section{9}

40419

148

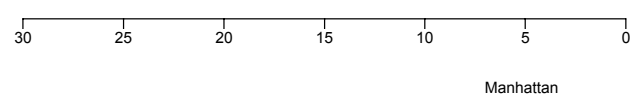

PCA case scores

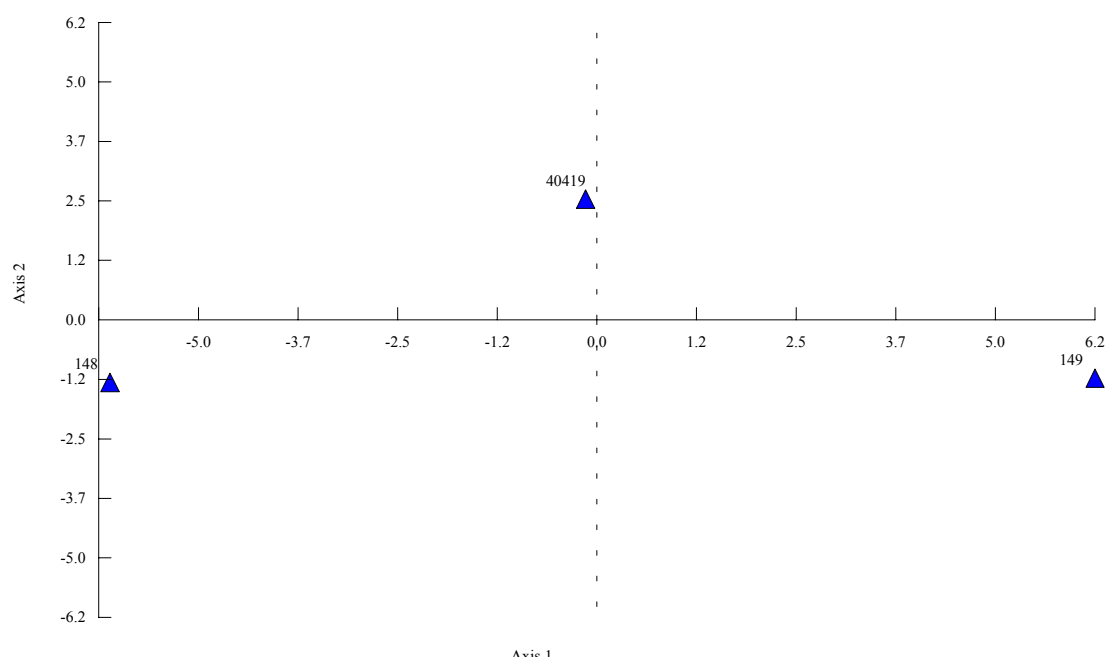




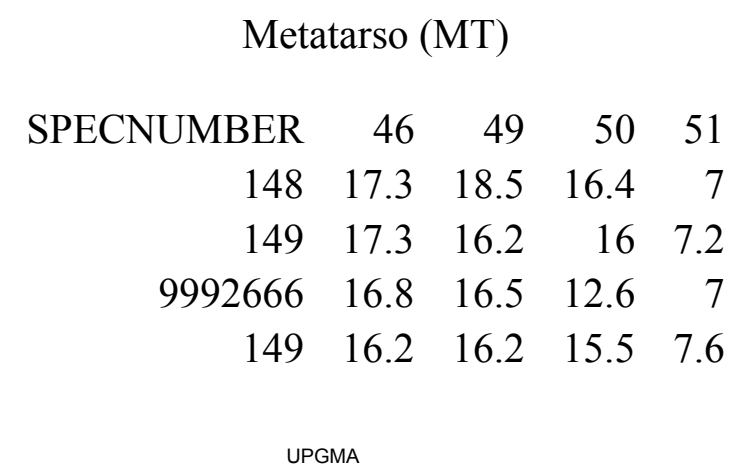

9992666

149

149

148

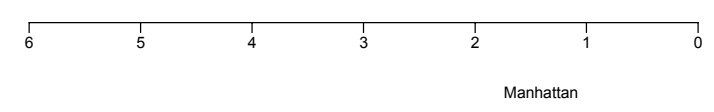

PCA case scores

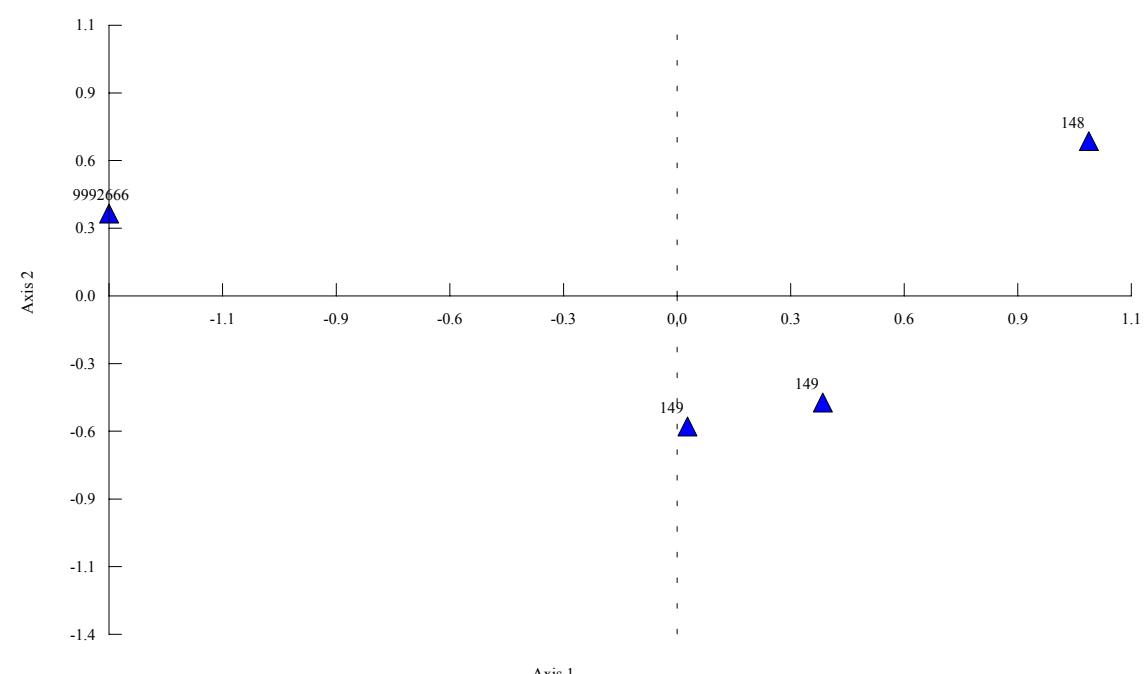

Axis 1 


\section{Falange Proximal (PHF)}

$\begin{array}{rrrrrr}\text { SPECNUMBER } & 1 & 2 & 3 & 4 & 5 \\ 10212 & 63.2 & 20.4 & 18.8 & 16.4 & 15.2 \\ 13015 & 83.6 & 24.1 & 22.5 & 19.5 & 18.2 \\ 13713 & 71.8 & 21.4 & 21.3 & 18.1 & 16.6 \\ 36511 & 67.0 & 21.1 & 18.0 & 17.6 & 16.4 \\ 39011 & 71.5 & 21.4 & 20.6 & 18.7 & 16.7 \\ 100120 & 63.0 & 20.0 & 17.1 & 15.6 & 14.5 \\ 102110 & 59.8 & 19.1 & 16.4 & 15.1 & 13.1 \\ 108110 & 61.8 & 19.8 & 17.0 & 17.1 & 15.5 \\ 999996 & 18.7 & 21.5 & 19.3 & 18.1 & 17.8 \\ 9992902 & 64.1 & 20.2 & 19.2 & 17.2 & 15.6 \\ 999 & 51.0 & 14.0 & 13.0 & 13.0 & 11.0 \\ 999 & 49.0 & 15.0 & 13.0 & 13.0 & 11.0 \\ 999 & 49.0 & 15.0 & 13.0 & 13.0 & 11.0 \\ 999 & 50.0 & 14.0 & 13.0 & 13.0 & 11.0 \\ 999 & 53.0 & 16.0 & 14.0 & 14.0 & 11.0 \\ 149 & 62.9 & 20.1 & 17.1 & 16.6 & 15.1 \\ 149 & 63.0 & 20.2 & 17.2 & 16.6 & 14.9 \\ 149 & 64.3 & 20.1 & 17.0 & 16.7 & 14.7 \\ 148 & 67.8 & 20.0 & 16.7 & 16.3 & 14.8 \\ 148 & 66.6 & 21.0 & 17.1 & 16.2 & 14.8 \\ 148 & 75.4 & 21.8 & 19.4 & 17.9 & 18.0 \\ 148 & 76.3 & 21.9 & 18.3 & 17.7 & 15.7 \\ 149 & 72.8 & 21.5 & 18.1 & 17.8 & 16.7 \\ 149 & 71.9 & 21.5 & 18.4 & 18.7 & 16.3 \\ 149 & 71.7 & 22.2 & 18.5 & 18.7 & 16.7 \\ 149 & 72.8 & 21.8 & 18.4 & 18.2 & 16.9 \\ 999 & 54.0 & 15.0 & 14.0 & 14.0 & 11.0 \\ 999 & 55.0 & 15.0 & 14.0 & 14.0 & 11.0 \\ 999 & 56.0 & 17.0 & 14.0 & 13.0 & 13.0 \\ 999 & 56.0 & 17.0 & 15.0 & 14.0 & 13.0 \\ 999 & 62.0 & 18.0 & 16.0 & 14.0 & 13.0 \\ 999 & 56.0 & 17.0 & 15.0 & 13.0 & 13.0 \\ 999 & 61.0 & 18.0 & 16.0 & 15.0 & 14.0 \\ 999 & 61.0 & 18.0 & 16.0 & 15.0 & 15.0 \\ 999 & 62.0 & 18.0 & 16.0 & 14.0 & 13.0 \\ 40219 & 69.7 & 20.5 & 19.0 & 18.2 & 17.4 \\ 40319 & 59.6 & 18.2 & 15.5 & 14.7 & 13.4 \\ 40811 & 55.6 & 17.5 & 15.4 & 14.0 & 12.9 \\ 37811 & 60.6 & 20.0 & 17.2 & 16.2 & 13.7\end{array}$



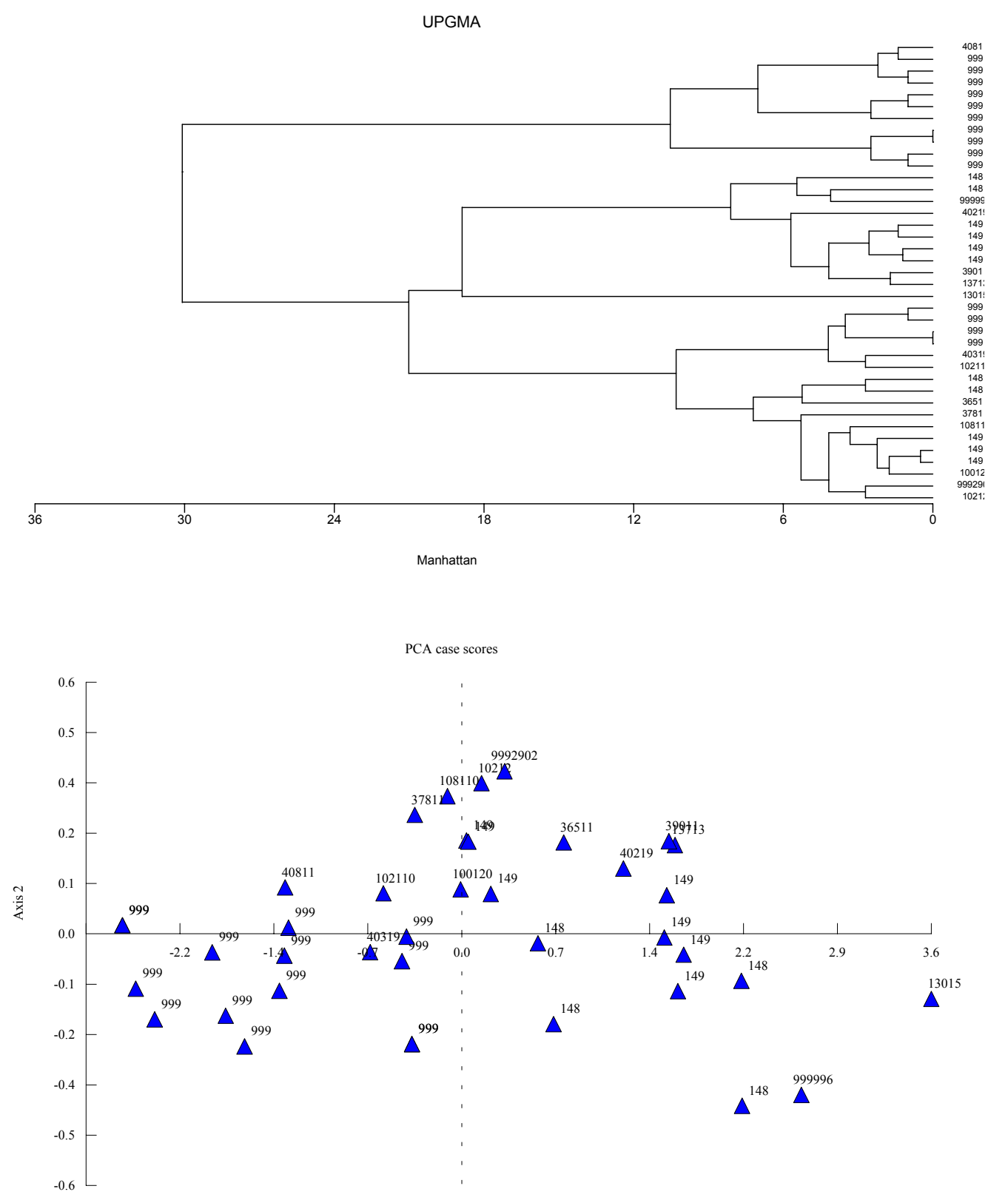

Axis 1 
Falange Medial (PHS)

$\begin{array}{rrrr}\text { SPECNUMBER } & 1 & 2 & 3 \\ 11412 & 77.3 & 22.9 & 20.9 \\ 3481502 & 66.8 & 20.6 & 18.5 \\ 999 & 51.0 & 14.0 & 13.0 \\ 999 & 49.0 & 15.0 & 13.0 \\ 999 & 49.0 & 15.0 & 13.0 \\ 999 & 50.0 & 14.0 & 13.0 \\ 999 & 53.0 & 16.0 & 14.0 \\ 149 & 62.9 & 20.1 & 17.1 \\ 149 & 63.0 & 20.2 & 17.2 \\ 149 & 64.3 & 20.1 & 17.0 \\ 148 & 67.8 & 20.0 & 16.7 \\ 148 & 66.6 & 21.0 & 17.1 \\ 148 & 75.4 & 21.8 & 19.4 \\ 148 & 76.3 & 21.9 & 18.3 \\ 149 & 72.8 & 21.5 & 18.1 \\ 149 & 71.9 & 21.5 & 18.4 \\ 149 & 71.7 & 22.2 & 18.5 \\ 149 & 72.8 & 21.8 & 18.4 \\ 999 & 54.0 & 15.0 & 14.0 \\ 999 & 55.0 & 15.0 & 14.0 \\ 999 & 56.0 & 17.0 & 14.0 \\ 999 & 56.0 & 17.0 & 15.0 \\ 999 & 62.0 & 18.0 & 16.0 \\ 999 & 56.0 & 17.0 & 15.0 \\ 999 & 61.0 & 18.0 & 16.0 \\ 999 & 61.0 & 18.0 & 16.0 \\ 999 & 62.0 & 18.0 & 16.0\end{array}$



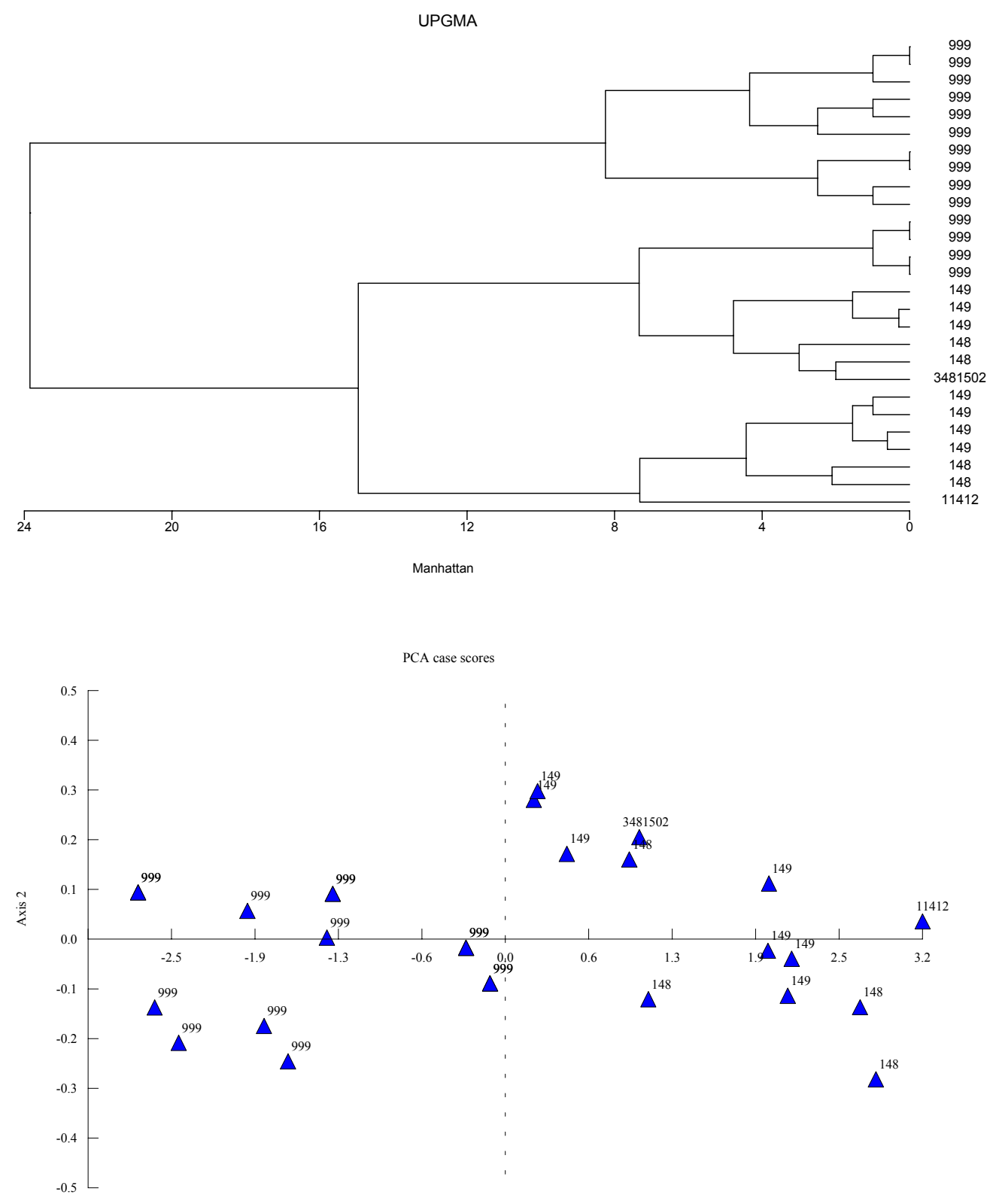

Axis 1 
Falange Medial (PHS)
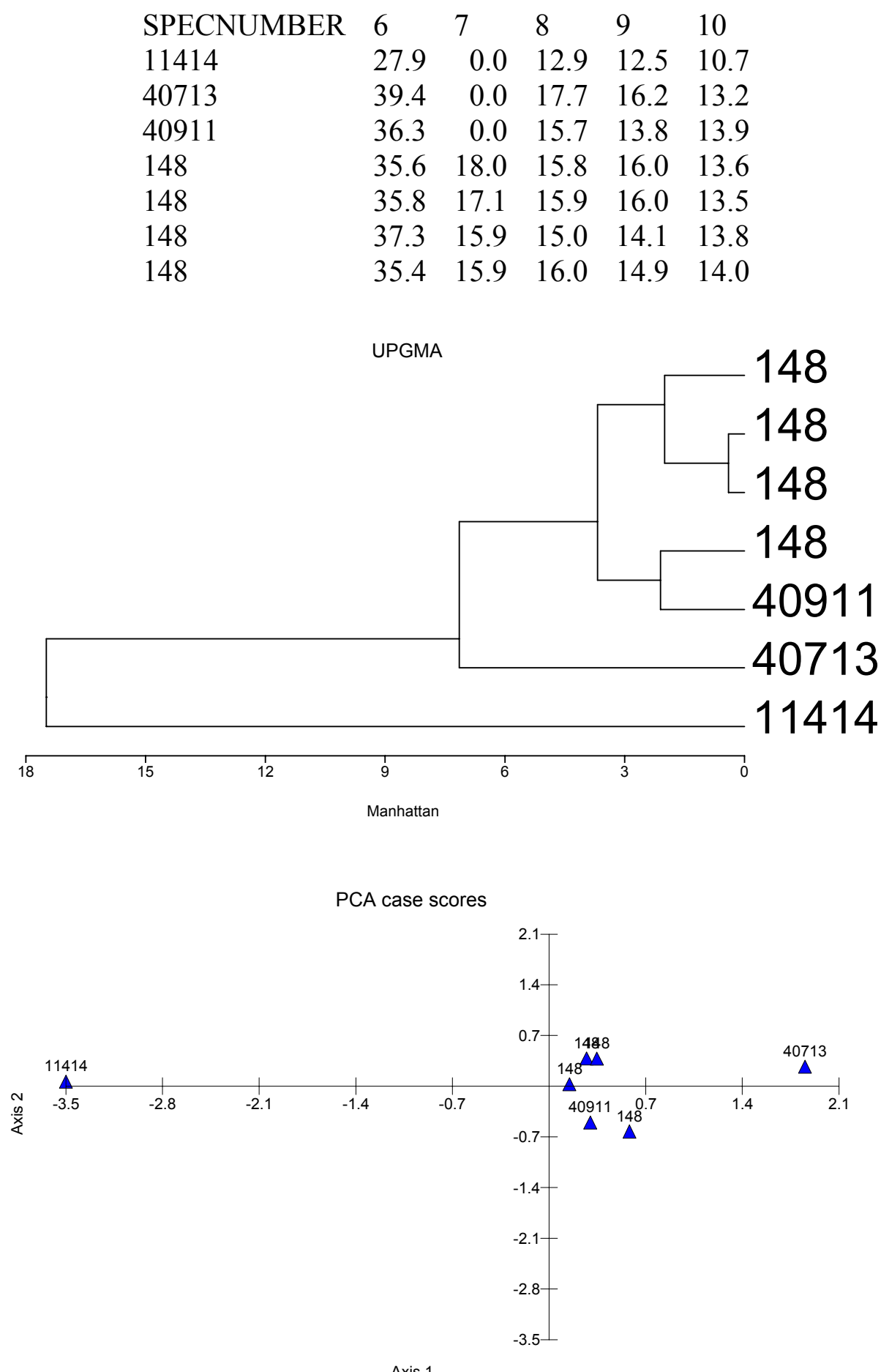
Falange Medial (PHS)

\begin{tabular}{lllllr} 
SPECNUMBER & 6 & 7 & \multicolumn{1}{l}{9} & \multicolumn{1}{l}{10} \\
139123 & 28.9 & 14.7 & 12.2 & 0.0 & 0.0 \\
18612 & 31.1 & 18.7 & 15.6 & 0.0 & 0.0 \\
27313 & 39.2 & 19.5 & 16.7 & 0.0 & 14.4 \\
38311 & 37.8 & 17.5 & 16.4 & 0.0 & 0.0 \\
148 & 35.6 & 18.0 & 15.8 & 16.0 & 13.6 \\
148 & 35.8 & 17.1 & 15.9 & 16.0 & 13.5 \\
148 & 37.3 & 15.9 & 15.0 & 14.1 & 13.8 \\
148 & 35.4 & 15.9 & 16.0 & 14.9 & 14.0 \\
6113 & 31.8 & 17.5 & 15.5 & 15.3 & 0.0 \\
& & & & &
\end{tabular}
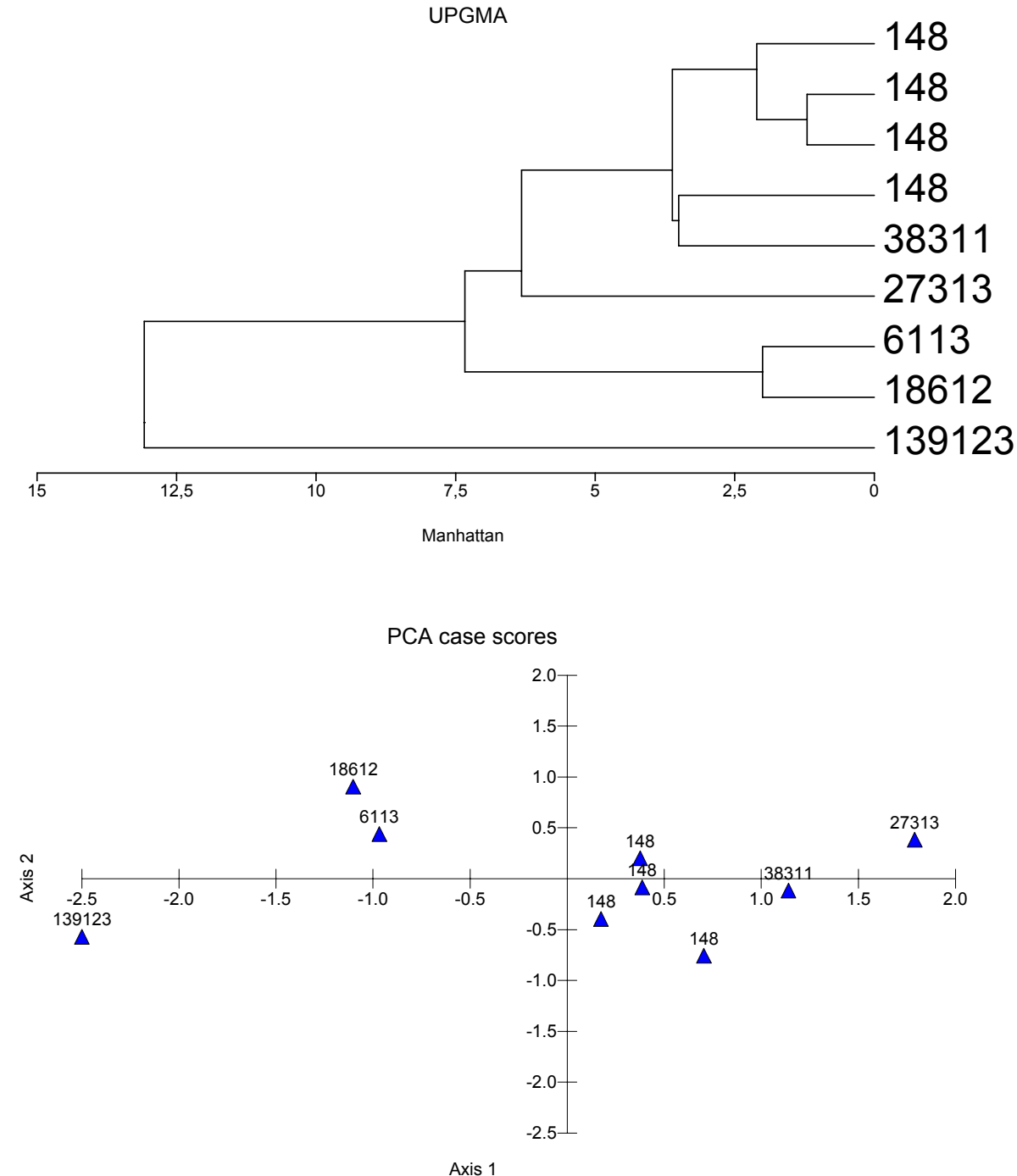
Falange Medial (PHS)

\begin{tabular}{lrrlll} 
SPECNUMBER & \multicolumn{1}{l}{6} & \multicolumn{1}{l}{7} & 8 & 9 & 10 \\
9991972 & 0.0 & 0.0 & 15.6 & 33.9 & 14.3 \\
148 & 35.6 & 18.0 & 15.8 & 16.0 & 13.6 \\
148 & 35.8 & 17.1 & 15.9 & 16.0 & 13.5 \\
148 & 37.3 & 15.9 & 15.0 & 14.1 & 13.8 \\
148 & 35.4 & 15.9 & 16.0 & 14.9 & 14.0
\end{tabular}

UPGMA
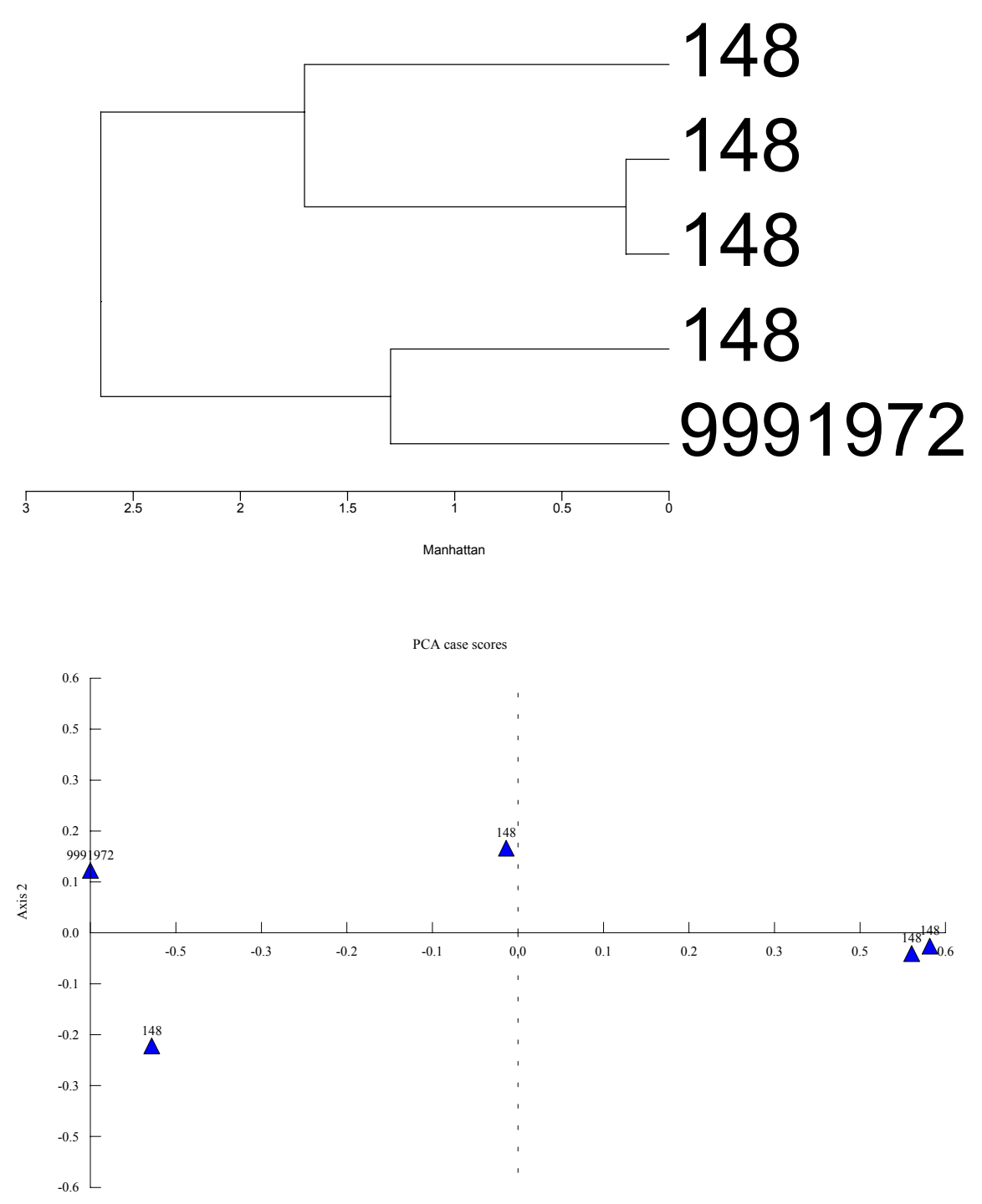
Falange Medial (PHS)

\begin{tabular}{lllrrr} 
SPECNUMBER & 6 & \multicolumn{1}{l}{7} & \multicolumn{1}{l}{9} & \multicolumn{1}{l}{10} \\
137116 & 45.1 & 20.5 & 0.0 & 0.0 & 0.0 \\
148 & 35.6 & 18.0 & 15.8 & 16.0 & 13.6 \\
148 & 35.8 & 17.1 & 15.9 & 16.0 & 13.5 \\
148 & 37.3 & 15.9 & 15.0 & 14.1 & 13.8 \\
148 & 35.4 & 15.9 & 16.0 & 14.9 & 14.0 \\
25111 & 33.1 & 17.6 & 0.0 & 15.8 & 12.2
\end{tabular}

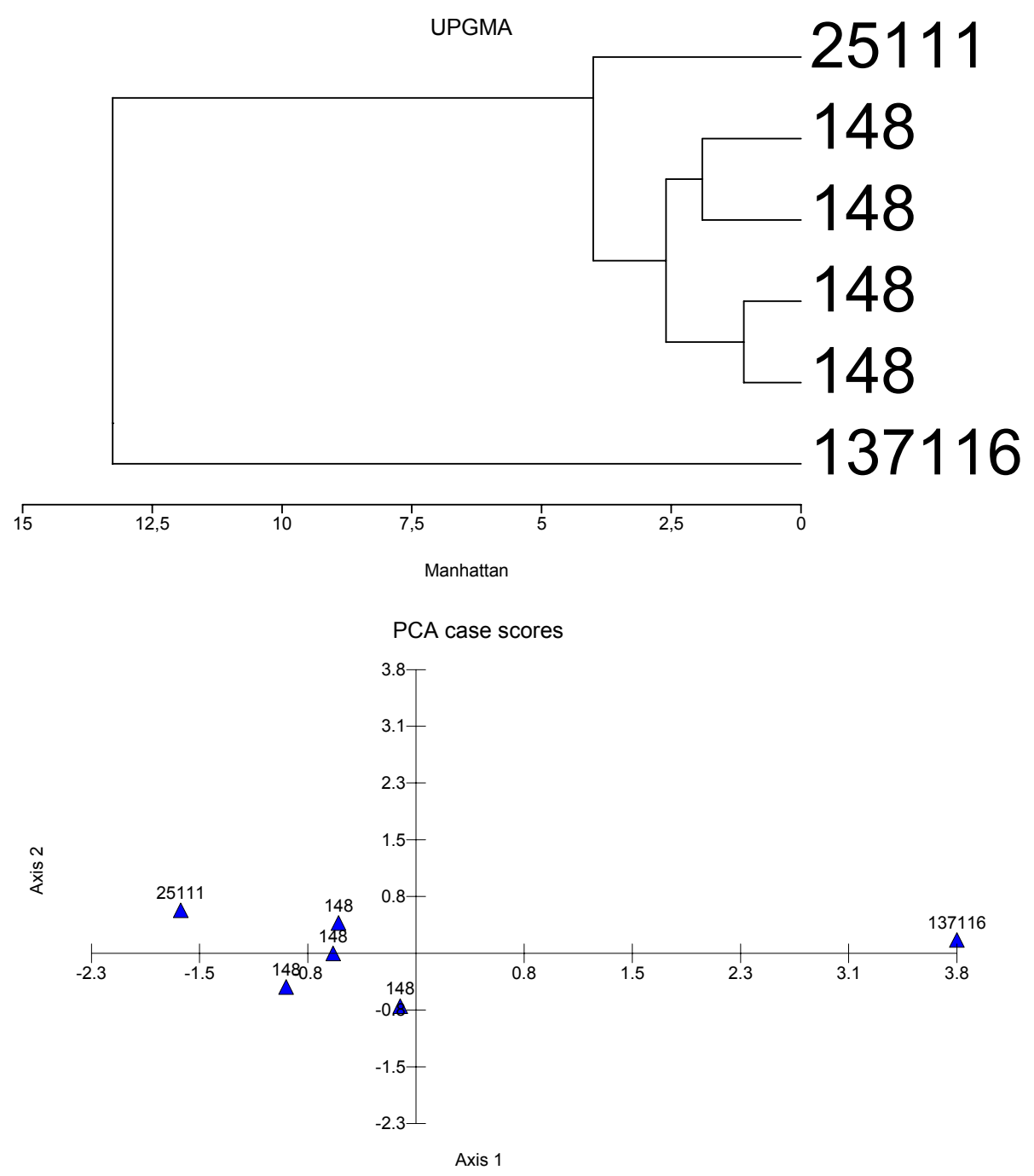


Falange Distal (PHT)

$\begin{array}{rrlll}\text { SPECNUMBER } & 11 & 12 & 13 & 14 \\ 148 & 10.4 & 14.4 & 11.7 & 21.9 \\ 148 & 11.3 & 14.9 & 12.1 & 22.5 \\ 148 & 12.4 & 14.9 & 13.2 & 23.1 \\ 148 & 12.4 & 14.9 & 13.0 & 22.5 \\ 1011 & 10.8 & 13.7 & 11.6 & 20.0 \\ 3911 & 13.7 & 15.8 & 15.4 & 22.1 \\ 8218 & 11.6 & 17.7 & 13.0 & 23.1 \\ 11213 & 13.4 & 14.2 & 11.9 & 22.9 \\ 18611 & 9.0 & 11.9 & 9.1 & 16.9 \\ 24819 & 9.7 & 10.9 & 9.8 & 16.0 \\ 24914 & 11.4 & 14.4 & 11.7 & 20.7 \\ 25112 & 11.5 & 13.3 & 11.9 & 19.2 \\ 36512 & 10.4 & 14.4 & 11.6 & 20.2 \\ 40519 & 12.4 & 12.8 & 13.0 & 22.4 \\ 75117 & 11.9 & 13.8 & 14.2 & 23.8 \\ 96118 & 12.3 & 14.7 & 14.6 & 22.7 \\ 96152 & 12.2 & 14.4 & 13.4 & 21.9 \\ 101127 & 10.8 & 11.9 & 11.2 & 17.8 \\ 248110 & 9.0 & 12.5 & 9.0 & 17.8 \\ 403111 & 13.0 & 14.2 & 13.2 & 20.3 \\ 405110 & 11.3 & 13.3 & 11.6 & 20.6 \\ 3271348 & 6.9 & 11.4 & 8.7 & 15.8 \\ 3401893 & 12.3 & 16.0 & 13.6 & 23.1 \\ 9992117 & 13.3 & 15.9 & 20.6 & 22.2 \\ 9992569 & 13.1 & 15.2 & 13.2 & 22.4 \\ 9992828 & 8.8 & 11.4 & 8.6 & 16.7 \\ 9992846 & 10.3 & 12.6 & 10.5 & 18.5\end{array}$

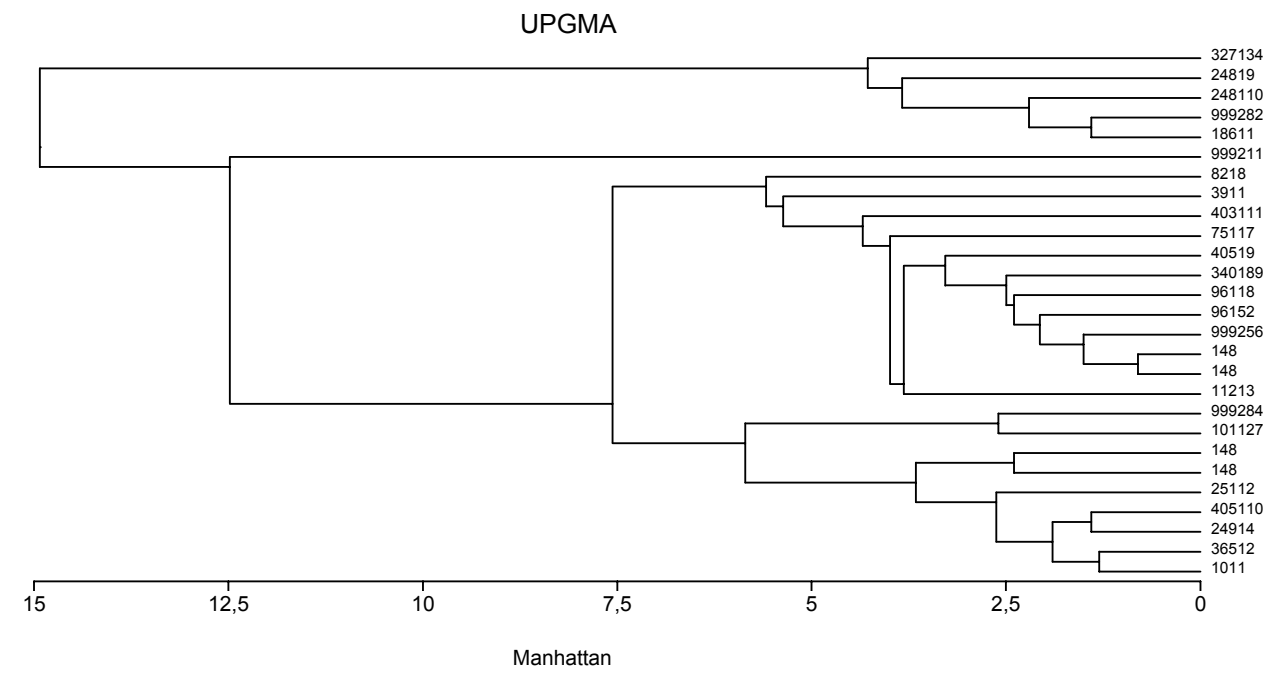




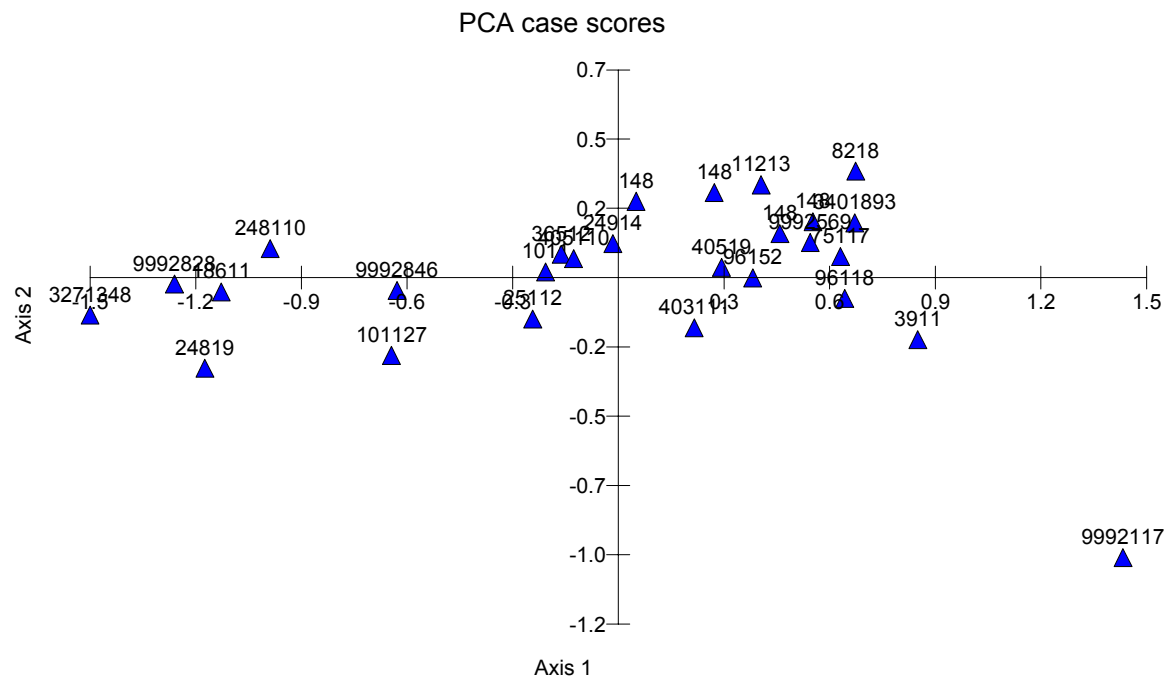



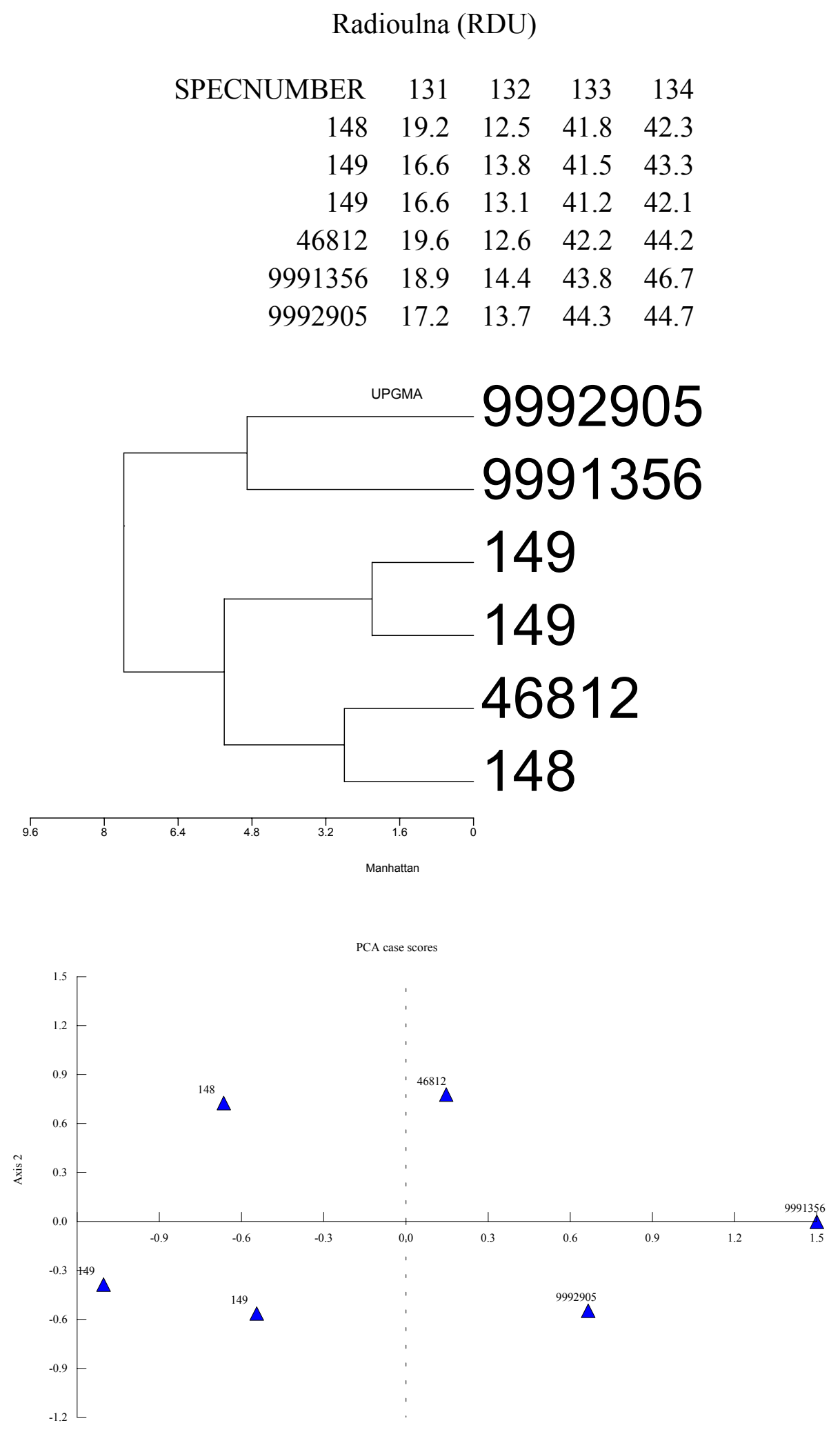


\section{Radioulna (RDU)}

$\begin{array}{rrrr}\text { SPECNUMBER } & 131 & 132 & 133 \\ 148 & 19.2 & 12.5 & 41.8 \\ 149 & 16.6 & 13.8 & 41.5 \\ 149 & 16.6 & 13.1 & 41.2 \\ 110120 & 12.1 & 11.2 & 35.4 \\ 9992067 & 17.9 & 11.9 & 38.2\end{array}$

UPGMA

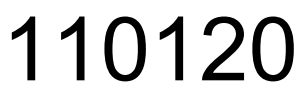

9992067

149

149

148
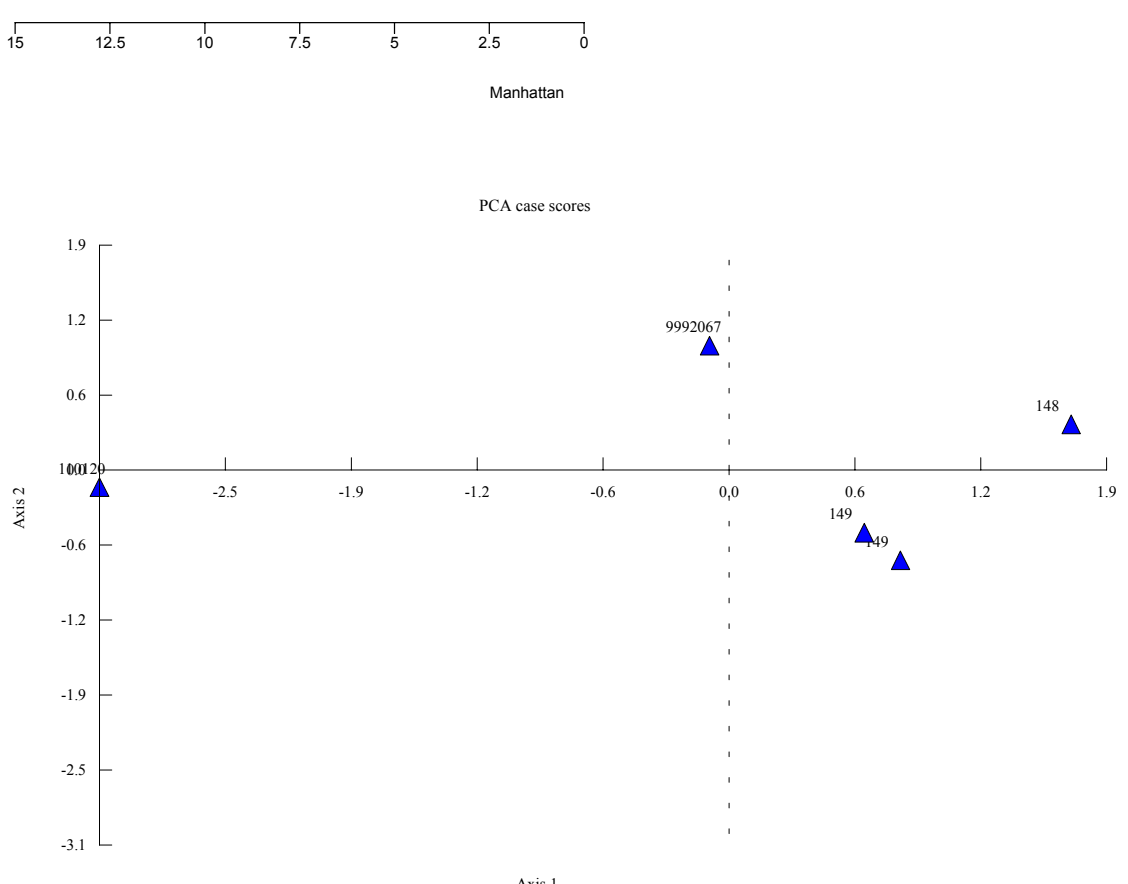


\begin{tabular}{|rrrrr}
\multicolumn{6}{c}{ Radioulna (RDU) } \\
SPECNUMBER & 141 & 142 & 143 & 144 \\
148 & 44.9 & 28.6 & 27.2 & 37.9 \\
149 & 45.1 & 27.1 & 29.1 & 37.2 \\
149 & 45.1 & 34 & 24.7 & 37.6 \\
40612 & 41.8 & 26.9 & 25.1 & 36.7 \\
134123 & 49.3 & 30.9 & 33.1 & 39.8
\end{tabular}

UPGMA
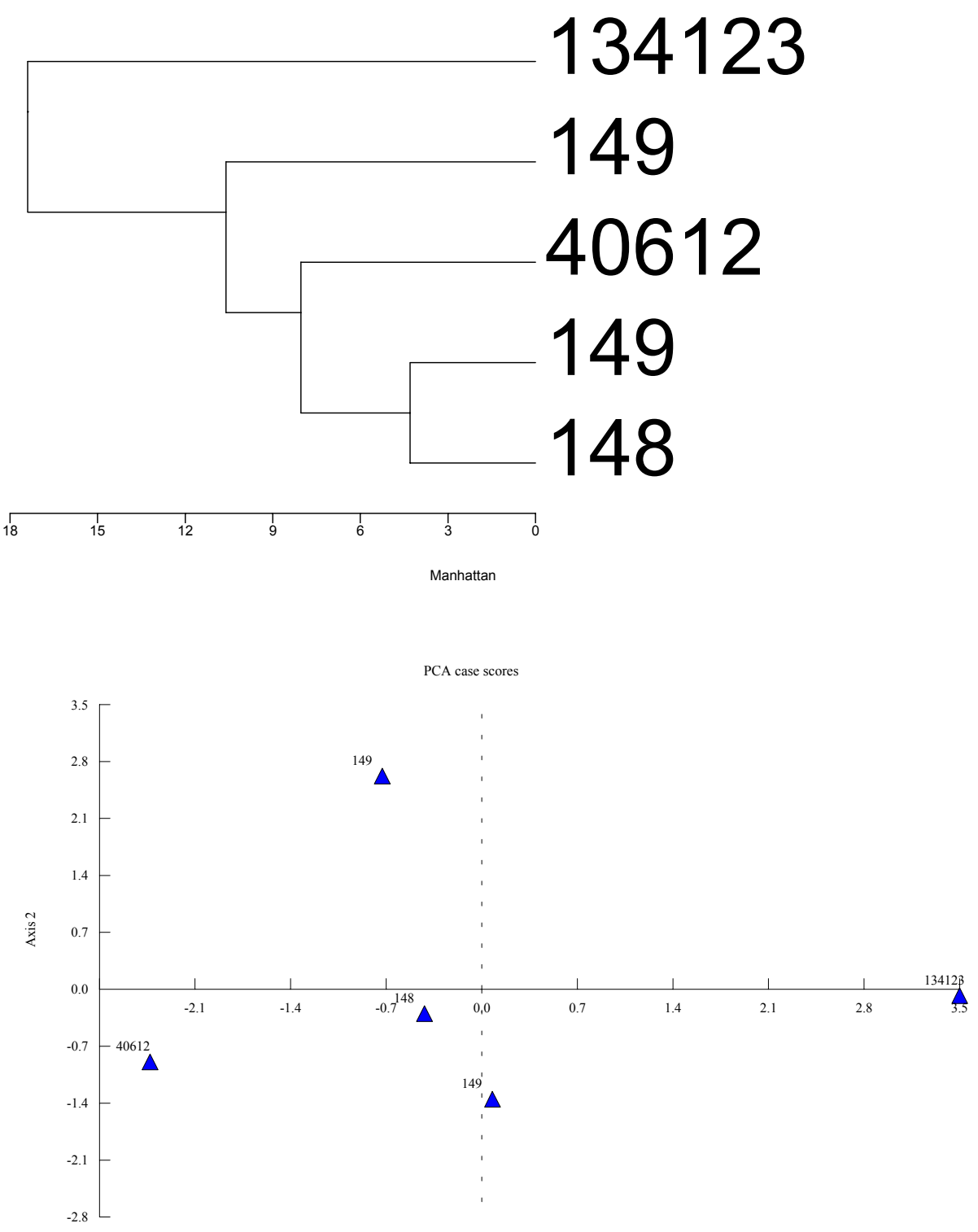

Axis 1 


\section{Radioulna (RDU)}

$\begin{array}{rrrr}\text { SPECNUMBER } & 140 & 142 & 144 \\ 148 & 28.1 & 28.6 & 37.9 \\ 149 & 31 & 27.1 & 37.2 \\ 149 & 30.8 & 34 & 37.6 \\ 107129 & 20.3 & 24.2 & 31.2 \\ 9992904 & 28.4 & 27.1 & 37.2\end{array}$

UPGMA

107129

149

149

9992904

148

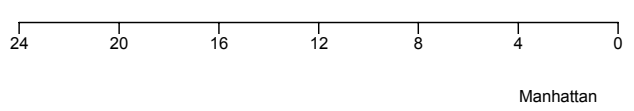

PCA case scores

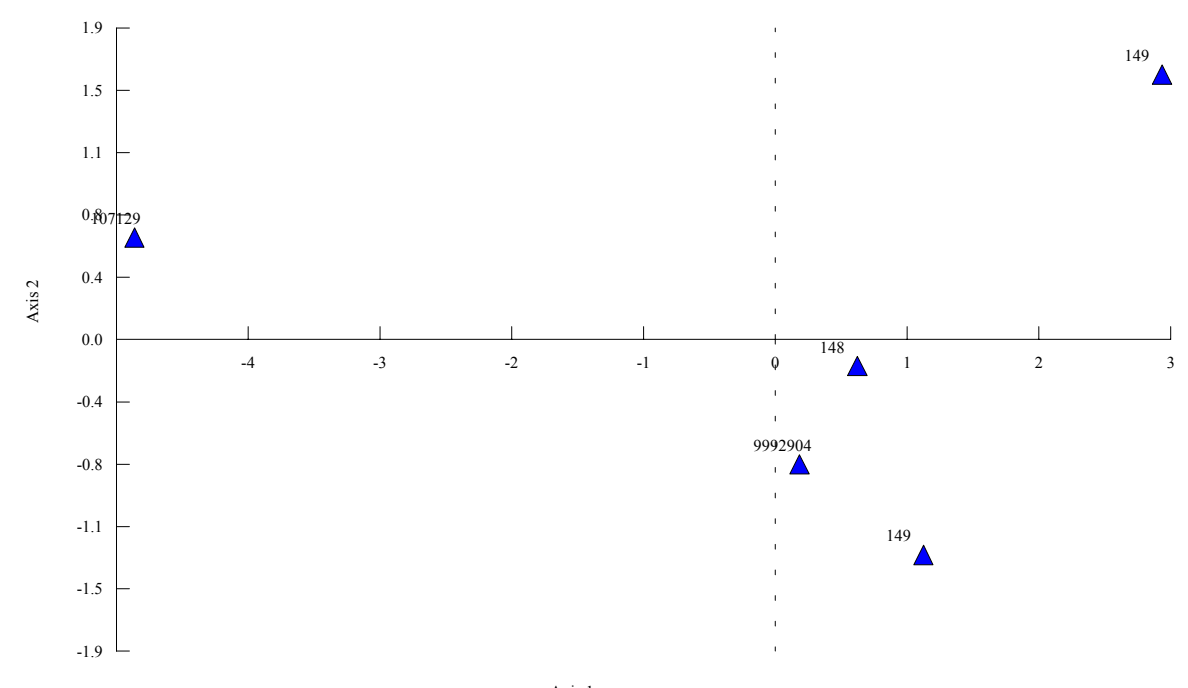




\begin{tabular}{rrrrr}
\multicolumn{6}{c}{ Escápula (SC) } & & \\
& & & & \\
SPECNUMBER & 164 & 165 & 166 & 169 \\
148 & 19.7 & 57 & 34.8 & 27.2 \\
148 & 19.5 & 56.1 & 35.1 & 23.1 \\
46711 & 19.2 & 48.4 & 30.9 & 15.4 \\
403122 & 20.5 & 53.6 & 34.7 & 20.9
\end{tabular}

UPGMA

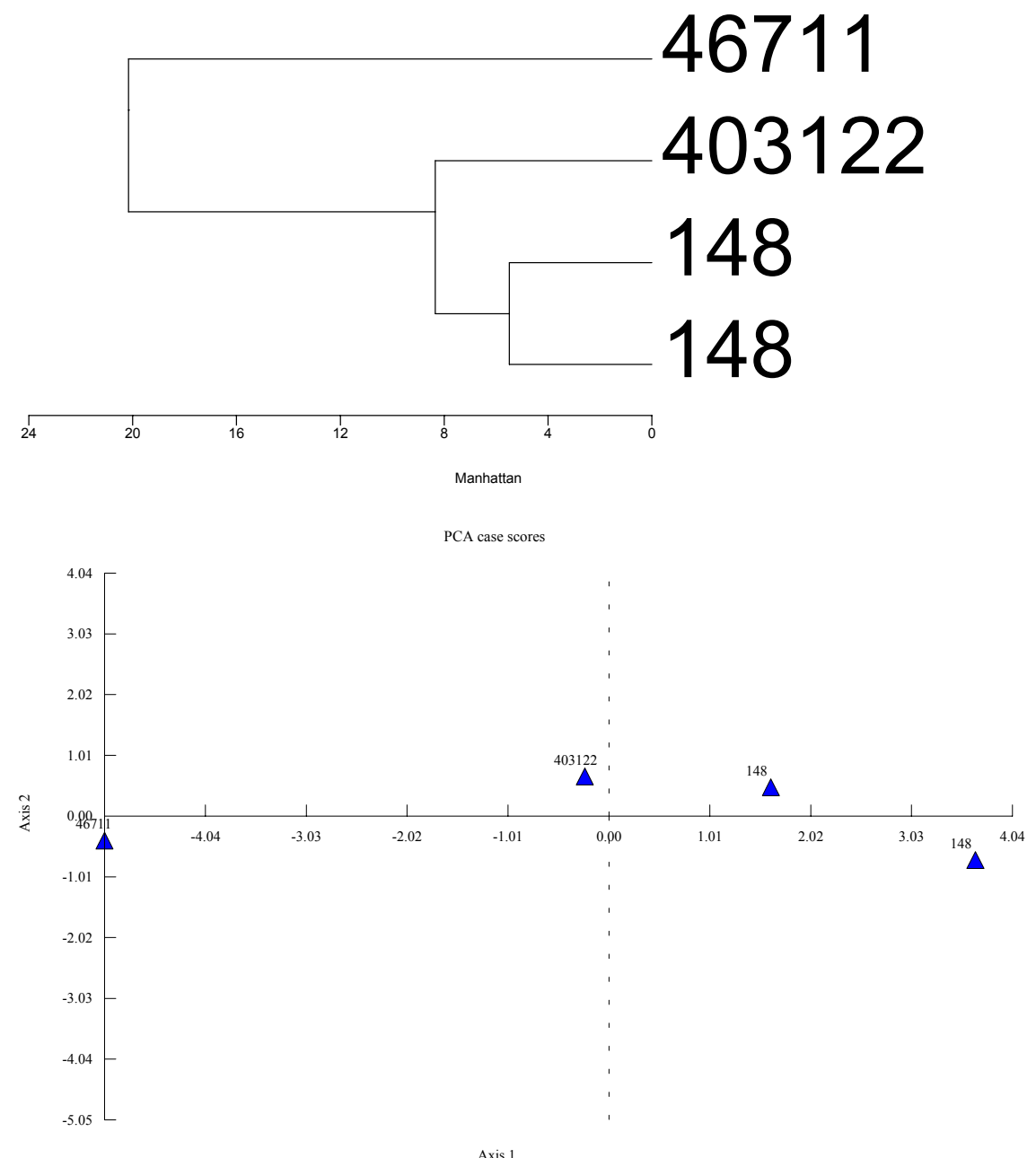


Tibia (TA)

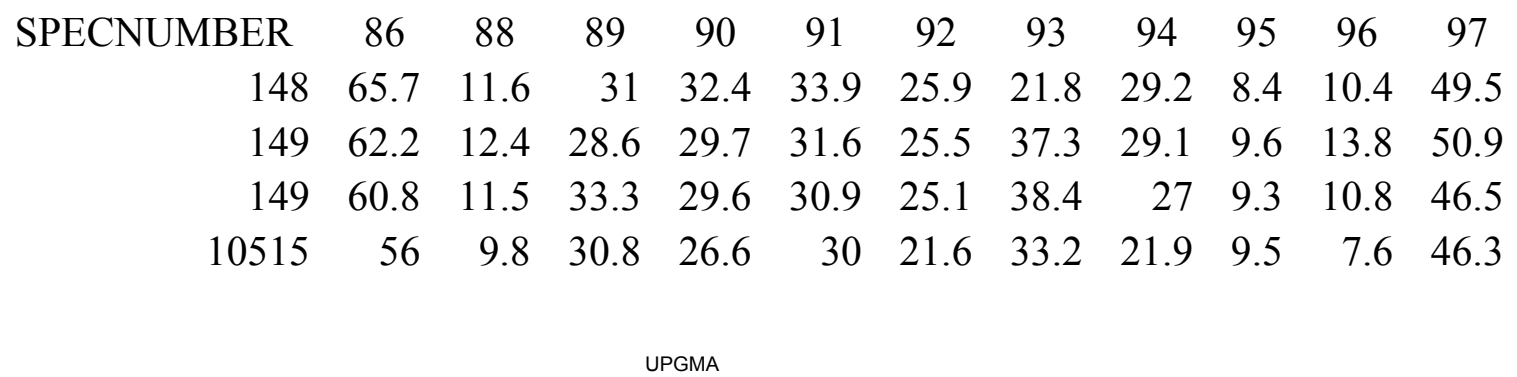

10515
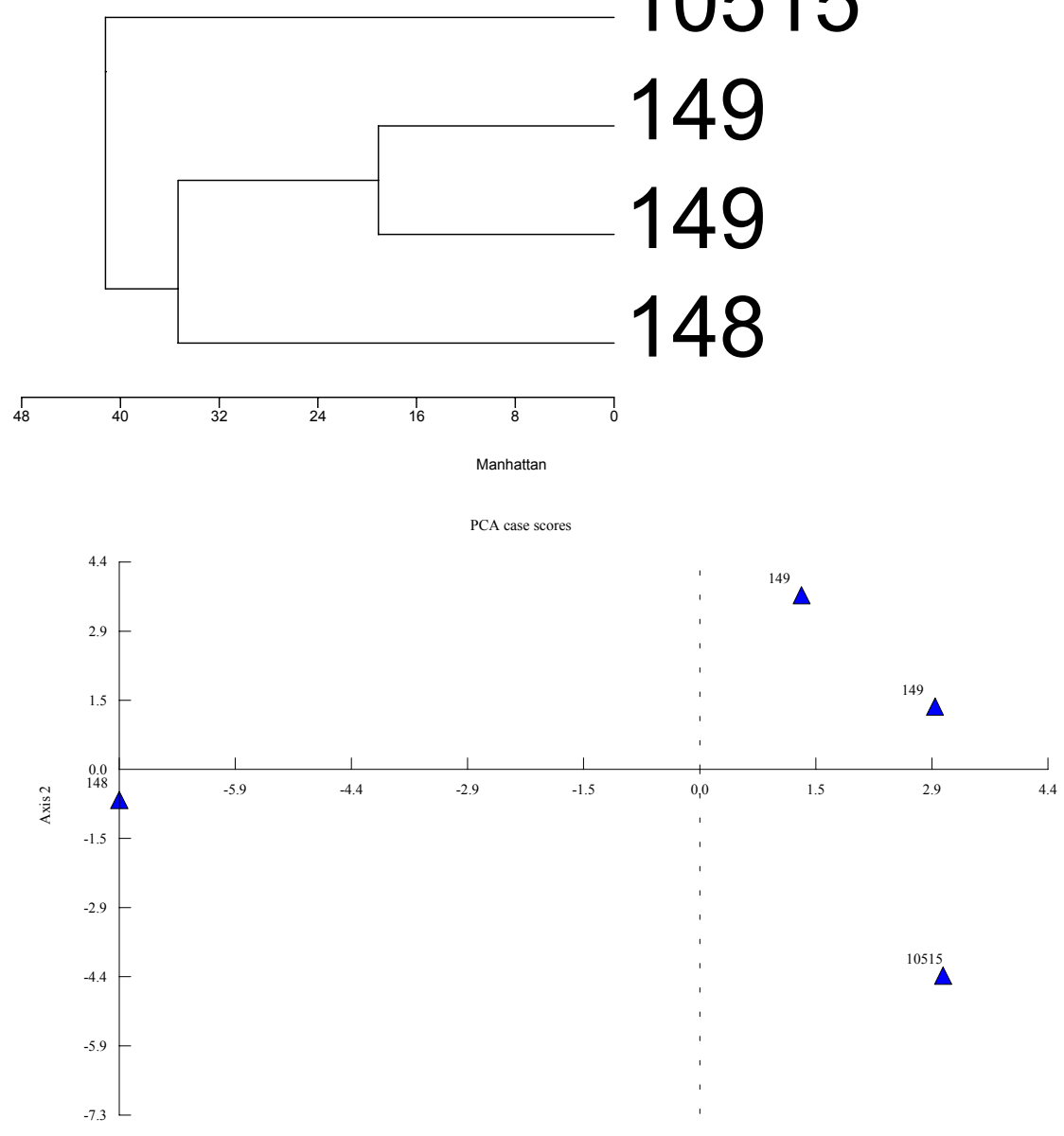
Tibia (TA)

$\begin{array}{rrrrrrrr}\text { SPECNUMBER } & 104 & 105 & 106 & 107 & 108 & 109 & 110 \\ 148 & 28.8 & 10.2 & 7.9 & 9.3 & 8.3 & 22.1 & 7.8 \\ 149 & 35.4 & 9.9 & 8.2 & 8.2 & 7.9 & 19.5 & 6.7 \\ 149 & 36.5 & 10.3 & 7.8 & 6.8 & 7 & 19.4 & 4.8 \\ 13016 & 36.1 & 9.7 & 10.7 & 9.3 & 6.9 & 13.2 & 4.5 \\ 18711 & 37.8 & 7.5 & 11.3 & 8.8 & 6.3 & 12.8 & 3.7 \\ 9992070 & 41.5 & 11.1 & 10.5 & 9.3 & 8.5 & 17.4 & 5.2\end{array}$
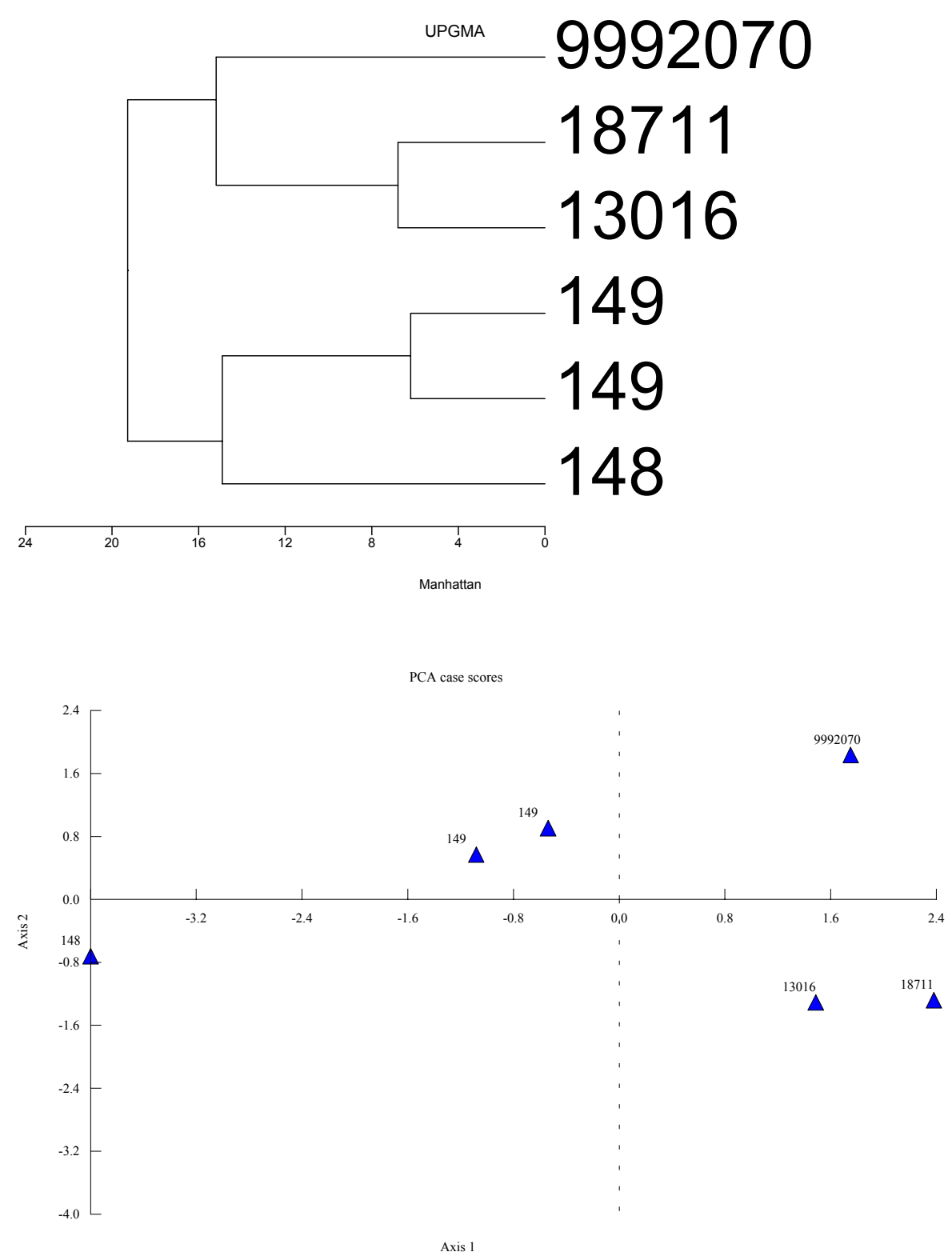
(TRC)

$\begin{array}{rrrr}\text { SPECNUMBER } & 200 & 203 & 210 \\ 148 & 26.8 & 17.8 & 19.2 \\ 149 & 25.7 & 17.8 & 20.2 \\ 6111 & 27.8 & 18 & 20.5 \\ 6112 & 29.1 & 19.4 & 19.1 \\ 9818 & 22.4 & 15.1 & 15.5 \\ 18613 & 25.1 & 18.3 & 22.1 \\ 40313 & 27 & 17.2 & 20.1 \\ 248119 & 23.4 & 13.8 & 17.4 \\ 404111 & 24.3 & 17 & 17 \\ 9992071 & 25 & 16.1 & 16.9\end{array}$
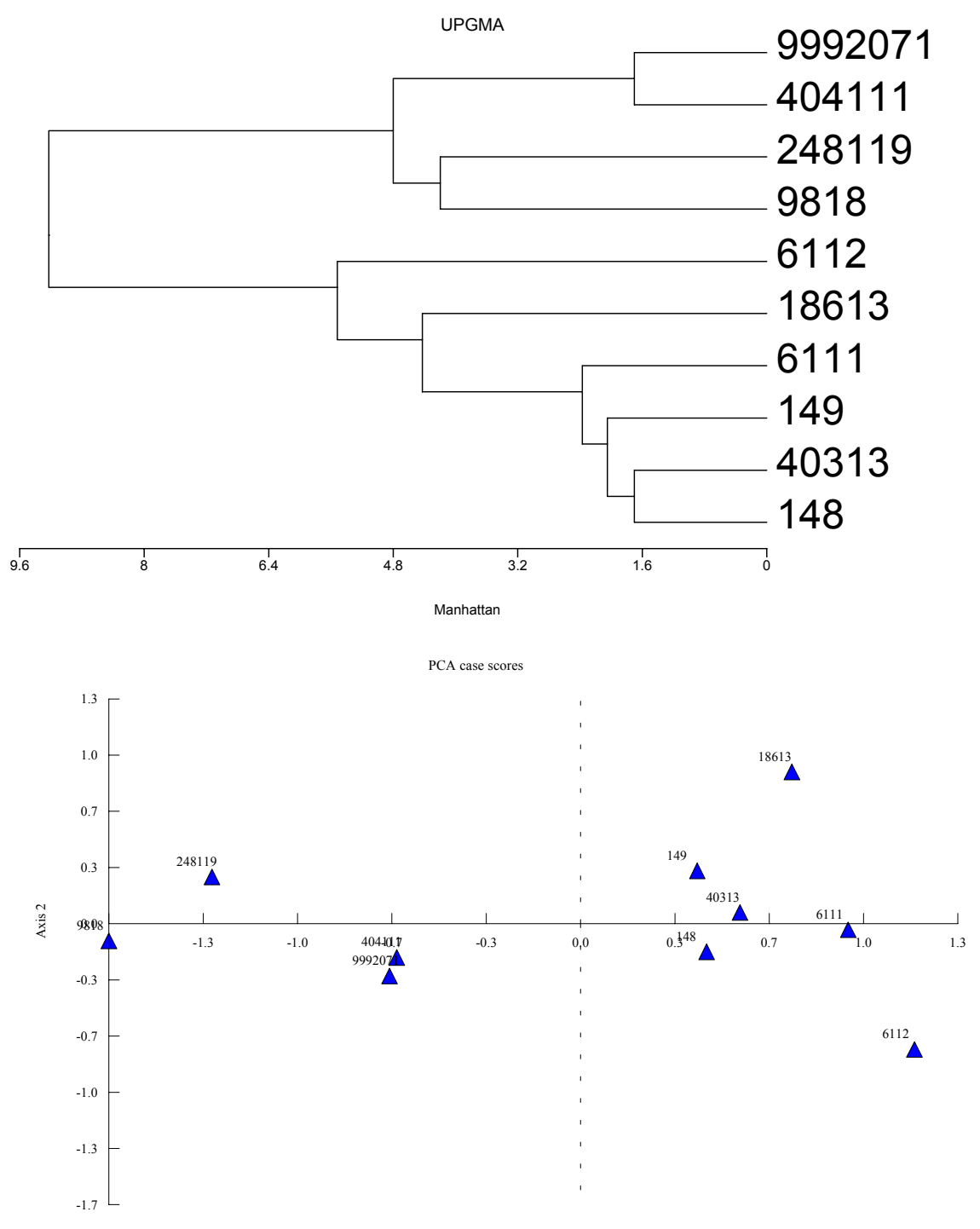
Descripción osteometría de carpales:

\section{Carpo Radial:}

(Código 210) P: Profundidad. Se coloca al elemento en su posición anatómica normal y se mide el máximo valor desde la cara anterior hasta la parte mas posterior del elemento.

(Código 203) L: Largo, medido en la región anterior. Desde la parte mas proximal de la faceta articular del radioulna hasta la parte mas distal de la faceta articular con el carpo 3.

(Código 200) A: Ancho, medido en la región distal. Ancho máximo de las facetas articulares con el carpo 3 .

Carpo Intermedio:

(Código 210) P: Profundidad. Se coloca al elemento en su posición anatómica normal y se mide el máximo valor desde la cara anterior hasta la parte posterior del elemento.

(Código 203) L: Largo, medido en la cara anterior del elemento. Desde la faceta articular con el radioulna hasta la arista de las facetas articulares con el carpo 3 y el carpo 4.

(Código 200) A: Ancho, medido en la porción anterior. Ancho máximo de la faceta articular con el radioulna.

\section{Carpo Ulnar}

(Código 210) P: Profundidad. Se coloca al elemento en su posición anatómica normal y se mide el máximo valor desde la cara anterior hasta la parte mas posterior del elemento.

(Código 203) L: Largo, medido en la porción anterior. Largo máximo entre la faceta articular con el radioulna y la faceta articular con el carpo 4.

(Código 200) A: Ancho, medido en la porción distal. Valor máximo desde la cara externa del elemento y la cara interna.

\section{Carpo 3}

(Código 210) P: Profundidad. Valor máximo entre la cara anterior y la porción mas caudal del elemento. 
(Código 203) L: Largo, medido en la región anterior. Valor máximo entre las facetas articulares con el carpo radial y el carpo intermedio y la faceta articular con el metacarpo.

(Código 200) A: Ancho, medido en la región anterior. Desde la cara externa hasta las facetas articulares con el carpo 4.

\section{Carpo 4}

(Código 210) P: Profundidad. Valor máximo entre la cara anterior y la porción mas caudal del elemento.

(Código 203) L: Largo, medido en la región anterior. Valor máximo entre las facetas articulares con el carpo intermedio y el carpo lunar y la faceta articular con el metacarpo.

(Código 200) A: Ancho. Valor máximo entre la cara externa y las facetas articulares con el carpo 3 .

\section{Carpo Accesorio}

(Código 210) P: Profundidad. Se coloca al elemento en su posición anatómica normal y se mide el máximo valor desde las facetas articulares con el carpo lunar hasta la porción mas caudal del elemento.

(Código 208) Lp: Largo proximal. Desde el borde proximal hasta el borde distal de las facetas articulares con el carpo lunar.

(Código 202) Ap: Ancho proximal. Desde el borde externo hasta el borde interno de las facetas articulares con el carpo lunar.

\section{Carpo 2}

(Código 210) P: Profundidad. Medido en la faceta articular con el metacarpo. Desde el borde anterior hasta el borde posterior.

(Código 203) L: Largo. Valor máximo entre la faceta articular con el carpo radial y la faceta articular con el metacarpo.

(Código 200) A: ancho. Desde la cara externa hasta las facetas articulares con el carpo 3 
Códigos utilizados en el análisis osteométrico

148: Lama glama comparativa

149: Lama guanicoe comparativo

999: Lama (Vicugna) vicugna comparativa

1??? Falda del Aconquija

10??? Falda del Aconquija

100??? Falda del Aconquija

200??? Falda del Aconquija

300??? Falda del Aconquija

350??? Bañado Viejo

400??? Morro de las Espinillas

999???? Yutopián 